INEL-95/0112 .

\title{
Lessons Learned from the EG\&G Consolidated Hazardous Waste Subcontract and ESH\&Q Liability Assessment Process
}

\author{
N. J. Fix \\ Published March 1995

\section{Idaho National Engineering Laboratory Lockheed Idaho Technology Company, Inc. Idaho Falls, Idaho 83415}

\author{
DISCLAIMER
}

This report was prepared as an account of work sponsored by an agency of the United States Government. Neither the United States Government nor any agency thereof, nor any of their employees, makes any warranty, express or implied, or assumes any legal liability or responsibility for the accuracy, completeness, or usefulness of any information, apparatus, product, or process disclosed, or represents that its use would not infringe privately owned rights. Reference herein to any specific commercial product, process, or service by trade name, trademark, manufacturer, or otherwise does not necessarily constitute or imply its endorsement, recommendation, or favoring by the United States Government or any agency thereof. The views and opinions of authors expressed herein do not necessarily state or reflect those of the United States Government or any agency thereof.

Prepared for the

U.S. Department of Energy

Office of Environmental Management

Under DOE Idaho Operations Office

Contract No. DE-AC07-94ID13223

DISTRIBUTION OF THIS DOCURAENT IS UNLMITED 


\section{DISCLAIMER}

Portions of this document may be illegible in electronic image products. Images are produced from the best available original document. 


\section{ABSTRACT}

Hazardous waste transportation, treatment, recycling, and disposal contracts were first consolidated at the Idaho National Engineering Laboratory (INEL) in 1992 by the previous INEL management and operating (M\&O) prime contractor, EG\&G Idaho, Inc. (EG\&G Idaho). At that time, disposition of Resource, Conservation and Recovery Act hazardous. waste, Toxic Substance Control Act waste, Comprehensive Environmental Response, Compensation, and Liability Aet hazardous substances and contaminated media, and recyclable hazardous materials (all of which will hereafter be referred to as "hazardous waste") was consolidated under five subcontracts. The wastes were generated by five different INEL M\&O contractors, which were under the direction of three different Department of Energy (DOE) field offices. The consolidated contract reduced the number of facilities that handled INEL waste from 27 to eight qualified treatment, storage, and disposal facilities, with brokers specifically prohibited. This reduced the associated transportation costs, amount and cost of contractual paperwork, and the environmental liability exposure to the INEL M\&O contractors and the DOE.

EG\&G, Inc. (EG\&G), the corporate parent of EG\&G Idaho, reviewed this new approach to subcontracting and liability reduction, and proposed that a consolidated hazardous waste subcontract be formed for the major EG\&G managed DOE sites: INEL, Mound, Rocky Flats, Nevada Test Site, and 10 satellite facilities. After obtaining concurrence from DOE Headquarters, this effort began in March 1992 and was completed with the award of two master task subcontracts in October and November 1993. In addition, the effort included a team to evaluate the apparent awardee's facilities for environment, safety, health, and quality (ESH\&Q) and financial liability status. The assessment team was composed of qualified inspectors from each of the EG\&G-operated DOE sites and under the leadership of the INEL group. The evaluation criteria were defined and personnel were trained to ensure that the assessments were consistent.

The consolidated subcontract and assessment process has generated much interest from the United States Department of Energy Headquarters and other DOE sites. EG\&G Idaho has received numerous requests for information regarding the process and copies of the bid package.

This report documents the evaluation of the process used to prepare, bid, and award the EG\&G consolidated hazardous waste transportation, treatment, recycling, and/or disposal subcontracts and associated ESH\&Q and financial liability assessments; document the strengths and weaknesses of the process; and propose improvements that would expedite and enhance the process for other DOE installations that used the process and for the re-bid of the consolidated subcontract, scheduled for fiscal year 1997. 


\section{EXECUTIVE SUMMARY}

Before October 1994, EG\&G, Inc. (EG\&G) was the management and operating (M\&O) contractor at four major and ten satellite United States Department of Energy (DOE) sites through its wholly owned subsidiaries: EG\&G Idaho, Inc. (EG\&G Idaho); EG\&G Rocky Flats, Inc.; EG\&G Mound Applied Technologies, Inc.; EG\&G Energy Measurements, Inc.; and Reynolds Electrical and Engineering Company, Inc. EG\&G established a group, called the DOE Support Group, within the corporation to oversee these M\&O contractor sites and evaluate ways to conduct business "better, faster, and cheaper" at the DOE sites. One of the initiatives proposed by the EG\&G DOE Support Group was to consolidate the hazardous waste transportation, treatment, recycling, and disposal options at the sites. This initiative was based upon a successful program at the Idaho National Engineering Laboratory (INEL) in which EG\&G Idaho consolidated all of the hazardous waste disposal activities in one master subcontract for the DOE contractors at the INEL.

EG\&G obtained concurrence from the United States Department of Energy-Headquarters (DOE-HQ) Office to proceed. The EG\&G M\&O contractors obtained concurrence from their respective DOE operations offices, defined funding sources, and assigned personnel to work on the subcontract standardization and personnel to work on the assessments. EG\&G Idaho, as the prime contractor of the lead laboratory, INEL, established one master task subcontract for all five EG\&G M\&O contractors and one environment, safety, health, and quality (ESH\&Q) Liability Assessment Team, with representatives from the five affected M\&O contractors. The benefits included one standardized request for proposal (RFP) instead of five RFPs, coordinated statements of work (SOWs), uniform subcontract language, consistent and thorough ESH\&Q and financial liability assessments, insurance of treatment, storage, and disposal facility (TSDF) ESH\&Q compliance, and cost savings.

In October 1994, EG\&G Idaho was replaced by Lockheed Idaho Technologies Company (Lockheed Idaho) as the prime M\&O contractor for the INEL. Lockheed Idaho has assumed the lead laboratory responsibility for the consolidated hazardous waste subcontract and continues to support this effort with the remaining EG\&G M\&O contractors.

The consolidated subcontract process has generated much interest from DOE-HQ and other DOE sites. EG\&G Idaho has received numerous requests for information regarding the process and for copies of the bid package. Although the effort was successful and the subcontracts are now in place, a number of weaknesses in the process have been identified which participants in the various tasks wanted to document and correct in order to prevent other DOE installations from repeating them.

The purpose of this report is to document the evaluation of the process that was used to: prepare, bid, and award the EG\&G consolidated hazardous waste transportation, treatment, recycling, and/or disposal subcontract and associated ESH\&Q and financial liability assessments; document the strengths and weaknesses of the process; and propose improvements that would expedite and enhance the process for other DOE installations that use the process and for the Lockheed Idaho sponsored re-bid of the consolidated subcontract, scheduled for fiscal year (FY) 1998.

As previously stated, EG\&G was searching for long-term solutions to the hazardous waste disposal issues encountered by DOE sites. Two main issues were (a) the potential ES\&H liability and (b) the cost for hazardous waste disposal. The company planned to address these issues with the consolidated hazardous waste subcontract project. The project involved the 14 DOE facilities operated by EG\&G 
subsidiaries. EG\&G believed that this project could be used as a model for other DOE facilities across the country.

DOE sites generally had individual subcontracts with numerous vendors for hazardous waste disposal. More than 200 commercial facilities were identified as part of a DOE study conducted in 1992. The subcontracts generally were costly, with no price breaks for the DOE sites because individual sites did not generate enough volume. The subcontracts generally did not contain adequate operational controls. For example, there were no "hard hammers" in place to ensure ES\&H compliance. Therefore, the DOE was being exposed to potential ES\&H liability at many TSDFs across the U.S. This was especially significant where brokers were used to collect the hazardous waste for disposal. Brokers did not assume any contractual ES\&H liability for their actions.

EG\&G also noted that ES\&H liability assessments (frequently called audits), if conducted at all, were inadequate for determining the potential liability risks associated with using a particular vendor company or facility. In general, there were no standards of excellence for either the subcontracting or ES\&H liability assessment processes.

The objective of this procurement was to standardize the method of procurement and ESH\&Q assessments of haulers and disposers which would result in the following benefits and cost savings:

- Reduce procurement costs, and benefit from economies of scale (i.e., lower prices for higher waste volumes)

- Reduce risk of Resource, Conservation and Recovery Act (RCRA) wastes becoming Comprehensive Environmental Response, Compensation, and Liability Act (CERCLA) cleanups by contracting with approved subcontractors

- Reduce liability assessment costs and eliminate redundant compliance audits.

The proposal had two advantages that resulted in substantial savings:

- Consolidating the volume of waste to be disposed of allowed DOE sites to negotiate volume discounts and take advantage of economies of scale. Estimates based on preliminary information gathered by EG\&G Idaho indicated that approximately $\$ 1.8$ million could be saved within the first three years from the consolidation of the hazardous waste disposal contracts.

- Limiting the number of disposal locations and using consistent environmental liability assessment standards to evaluate disposal sites, significantly reduced contractor and DOE potential environmental liability for fines and penalties, cleanup costs, legal defense costs, and remedial public relations efforts.

- . Using fewer disposal sites meant fewer potential CERCLA cleanup sites for DOE and its contractors. This reduced DOE complex-wide and DOE operations offices exposure.

- A subcontract could be awarded with higher quality sites. 
- Increased assessments and oversight meant that the best run facilities would be used, decreasing the likelihood that a site would become a CERCLA cleanup site.

- Having consistent environmental liability assessment standards reduced the likelihood of bid protests from offerors accepted or rejected by one DOE site and not by another.

- Having consistent site evaluation standards helped to prevent allegations of negligence if one DOE site awarded a contract to a facility that another DOE site had found unacceptable and problems developed subsequently.

- A unified subcontract prevents uneven acceptance/rejection criteria among DOE sites, thereby reducing procurement challenges.

Volume gives DOE leverage in subcontracts because, if it is a lucrative subcontract, facilities would be more willing to modify operations to address DOE's environmental compliance concerns; expedite waste acceptance to alleviate compliance problems; or give volume discounts.

One of the issues that arose during preliminary discussions concerning the workability of the consolidated hazardous waste subcontract and assessment program, was how to issue and administer the subcontract. The options discussed included control through DOE-HQ, EG\&G, one M\&O contractor, and/or one DOE operations office. It was determined that, because this was the first time a subcontract consolidating several M\&O contractors and DOE operations offices had been proposed, neither DOE-HQ nor EG\&G should "own" the process. The lead laboratory concept allowed DOE-HQ and the operations offices to be participants in the overall process while assigning the implementation and management activities to one of the DOE national laboratories.

EG\&G Idaho as the contractor at the lead laboratory, INEL, developed the RFP and subcontract language with input from the other M\&O contractors. They issued the RFP and provided oversight of the procurement process. The lead laboratory was also responsible for leading and conducting of the ESH\&Q liability assessments. Final decisions regarding the qualification of the TSDFs and award of the subcontracts were assigned to the lead laboratory with concurrence from DOE.

A number of different types of subcontracts were reviewed before the master task subcontract (MTS) with implementing task orders was chosen. The MTS allows separate M\&O contractors to enter into a basic agreement with two subcontractors who provide for hazardous waste disposal services and have the flexibility to incorporate terms and conditions specific to each M\&O contractor site. Control of subcontract modifications by the lead laboratory ensures that the subcontracts remain consistent, competitive, and available for all of the $M \& O$ contractors involved.

The MTS replaced the need for awarding multiple individual subcontracts at each DOE site, yet allowed the use of TSDFs via task orders generated by the individual sites on an "as needed" basis. Only one liability assessment was performed on a TSDF, rather than the total number of site users each performing separate assessments, or in some cases, no assessments at all, to whatever criteria they felt were appropriate. Therefore, the MTS approach can significantly reduce the resources required complexwide to ensure that the M\&O contractor's subcontracts meet applicable ESH\&Q requirements. Additionally, as a result of the combined effort, price breaks for treatment/disposal options were received that significantly reduced the costs for each DOE site. 
EG\&G Idaho Procurement prepared the RFP. The RFP contained a description of the purpose of the request, instructions for proposal submission, conditions for award of the subcontract, and applicable conditions.

The following advantages were noted as a result of the consolidated RFP process:

- Consolidating the RFP process prevented or reduced redundant procurement, legal, and ESH\&Q liability assessment resource requirements for the five $M \& O$ contractors.

- Communication, cooperation, and technical experience among M\&O contractors was improved.

The following advantages were realized through construction of the RFP package and the award process for the subcontracts:

- Comprehensive SOWs that follow regulations were developed.

- The waste stream exhibits were developed with vendor input, which ensured good characterization for treatment/disposal options and pricing.

- Overall, the number of destination TSDFs was reduced. In addition, the certification of these TSDFs was ensured.

- The subcontracts were awarded to the "biggest and best" TSDFs for the greatest potential liability reductions.

- The consolidated approach supported Total Quality Management principles. The subcontracts were awarded based on quality factors rather than lowest price, because technical excellence was rated before price. Total cost was not a primary criterion for award. "Go/no-go" requirements established minimum compliance and service requirements.

- The awareness and compliance postures of both successful subcontractors were improved significantly.

- Overall significant reductions in line item costs, resulting from volume discounts, were realized.

- M\&O contractors were forced to better identify and define their waste streams.

DOE regulatory guidelines exist in the form of both orders and policy statements. Summarized, they require that the selection of subcontractors by M\&O contractors be performed such that the ability of offerors to meet environment, safety, and health (ES\&H) requirements is assured. Therefore, it becomes necessary to perform assessments in order to ensure compliance.

The prime M\&O contractor at the INEL does not perform compliance audits of the commercial facilities. The INEL program, developed by EG\&G Idaho and adopted by Lockheed Idaho, is designed to perform ESH\&Q and financial liability assessments of the potential and subcontracted vendors. The 
reason assessments are conducted rather than audits is that the M\&O contractors do not have the legal or regulatory authority to conduct compliance audits. In addition, audits are designed to identify specific violations of requirements. This assessment process examines specific problems but extrapolates from those items the potential long-term liability issues that may arise and estimates the probability that they will arise. These functions are reserved for regulatory agencies such as the EPA. Therefore, Lockheed Idaho performs assessments designed to identify and manage potential liability issues arising from operations at the commercial TSDFs subcontracted to treat and/or dispose of INEL-generated regulated wastes.

The ESH\&Q and liability assessment program is driven by the following federal regulations, DOE orders, and policies: 10 CFR $\S 830,48$ CFR $\S 970$, DOE-HQ Order 5480.1B and DOE-ID Order 5480.1B-ID, DOE-HQ Order 5482.1B, and DOE-HQ EM-332 Policy.

In order to conduct the ESH\&Q liability assessments for this initiative, each EG\&G M\&O contractor supplied personnel to the INEL to form one assessment team. The consolidated team composed of qualified ESH\&Q professionals from each M\&O contractor had the following advantages:

- The consolidated team could be composed of specialists from each site, thereby relieving one site of losing all of its specialists for the duration of the assessment period.

- Strong environmental assessments with a good mix of specialist team members eliminates "high risk" locations.

- Ensured that all major areas of expertise are adequately represented (not every site has experts in all areas).

- It was the opinion of the legal departments that the use of a strong team could reduce the basis for negligence suits for the following reasons:

- The consolidated team would eliminate the regulator's argument that, if one DOE site rejected a facility as unacceptable, other DOE sites "should have known better" and not approved the facility.

- The use of a consolidated team ensures that consistent and quality criteria are used to evaluate the TSDFs:

The main disadvantage for the M\&O contractors was the loss of prime staff members for the duration of the assessment process.

After the award of the MTS, EG\&G Idaho re-evaluated the costs incurred in the process and predicted potential cost savings for future consolidated competitions. Significant cost savings (about $\$ 200,000$ ) could be realized in a worst-case scenario re-competition if the only significant expense were the necessity to evaluate a different set of vendors. If the same vendors passed the initial bid evaluation, a potential of more than $\$ 300,000$ could be realized.

Cost avoidance is a more difficult metric to calculate than direct cost savings because, unless the system fails, the costs are avoided. That is, if facilities with potential regulatory problems are eliminated 
during the pre-award assessment, then if these facilities are targeted by the regulatory agencies, the program would have protected the contractors and DOE from being named a participant in the cleanup of the failed facility, thus avoiding cleanup costs.

As stated in the introduction to this study, the purpose of analyzing the MTS and ESH\&Q liability assessment processes was to determine the strengths and weaknesses of the process and propose changes to correct deficiencies. The identified strengths and weaknesses and the suggested changes are the lessons the participants learned. The participants agreed that, taken in total, the project was an outstanding success and is worth repeating for the next subcontract competition. However, the following lessons were the most significant from a management perspective.

- All agreements and policy statements among the participants in the process, i.e., the M\&O contractors, DOE-HQ, and DOE operations offices must be written and maintained in the official program record. Each participant must keep a copy of the program record.

- A formal approved program management plan that controls the entire life cycle activities and budgets must be developed. The contents of the plan must be agreed upon by all participating companies and agencies.

- Work packages and task baseline agreements must be developed by the lead laboratory and approved by all M\&O contractors in order to control the flow of work and acceptance criteria for deliverables.

- The players assigned to all aspects of the process must be dedicated both personally and by management to ensure that consistency is maintained. Dedicated performers include procurement, ES\&H, legal, waste management, and successful vendor personnel. Each of these performers must, through the process, learn not only how to prepare the RFP and conduct liability assessments, but also how to operate under the subcontract.

- The process must remain task and schedule driven. If any milestone is permitted to slip, then the whole schedule will slip. The end point, i.e., award of the subcontract, must rely on completion of all critical path tasks and not a critical subcontract expiration date.

The program, as defined, can be used for both regional subcontracts or a consolidated national effort, which includes all of the DOE sites. The determination of whether one national effort or regional subcontracts, based upon M\&O contractor cooperative efforts, should be made at the DOE-HQ and operations office levels. Financial benefits, particularly subcontract award and liability assessment cost reductions, can be derived from each.

The most significant recommendation regarding the expansion of the program is that DOE-HQ must be intimately involved in the preliminary planning stages. It is crucial that DOE-HQ provide guidance, either through policy statements or directives, to the operations offices and the M\&O contractors regarding the conduct of the program. If the INEL retains its position as the lead laboratory in the effort, then DOE-HQ must ensure that the INEL receives management, programmatic, and funding support.

Whether DOE-HQ proposes this process as an example of an efficient, cost-effective means for reducing hazardous waste treatment/disposal and liability, or requires this technique for future hazardous 
waste treatment/disposal procurements, the following recommendation is crucial. It is critical that adequate scheduling be maintained. That is, if this method is used by either a consortium of DOE regional sites or to propose a national MTS, scheduling of planning activities and site agreements must occur well before the preparation of SOWs and the RFP.

The INEL lead MTS will expire in October 1998. If the same DOE sites choose to join in the rebid, the effort must begin in late calendar year 1996 in order to ensure that the RFP is issued in calendar year 1997 and the subcontract award made before October 1998. If other DOE sites, under other M\&O contractors wish to join the INEL and its partners, planning must begin in early 1996 in order to complete M\&O contractors Memoranda of Understanding, the Project Management Plan, and schedules before preparation of the SOWs and RFP. 


\section{CONTENTS}

ABSTRACT $\ldots \ldots \ldots \ldots \ldots \ldots \ldots \ldots \ldots \ldots \ldots \ldots \ldots \ldots \ldots \ldots \ldots$

EXECUTIVE SUMMARY $\ldots \ldots \ldots \ldots \ldots \ldots \ldots \ldots \ldots \ldots \ldots \ldots \ldots$

1. INTRODUCTION $\ldots \ldots \ldots \ldots \ldots \ldots \ldots \ldots \ldots \ldots \ldots \ldots \ldots \ldots \ldots$

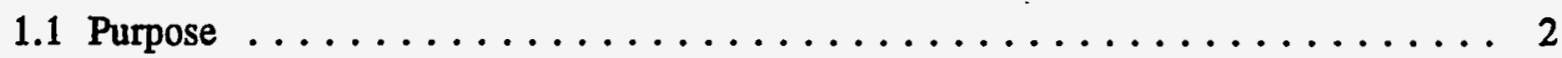

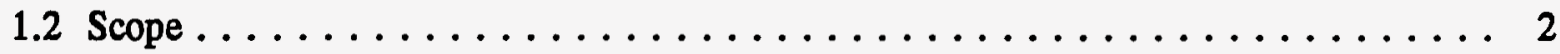

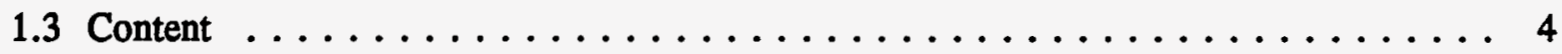

1.4 Disclaimer $\ldots \ldots \ldots \ldots \ldots \ldots \ldots \ldots \ldots \ldots \ldots \ldots \ldots \ldots \ldots \ldots \ldots \ldots$

2. BACKGROUND AND HISTORY $\ldots \ldots \ldots \ldots \ldots \ldots \ldots \ldots \ldots \ldots \ldots \ldots \ldots \ldots$

2.1 INEL Consolidated Hazardous Waste Subcontract Process . . . . . . . . . . . 5

2.2 INEL ESH\&Q Liability Assessment Process $\ldots \ldots \ldots \ldots \ldots \ldots \ldots$

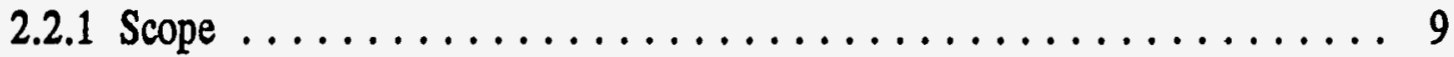

2.2.2 Pre-Assessment Review Procedures ................. 10

2.2 .3 On-site Assessment Procedures . . . . . . . . . . . . . . . . 12

2.2.4 Post-Assessment Procedures . . . . . . . . . . . . . . . . 14

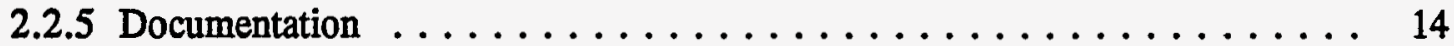

2.3 EG\&G Corporate Initiatives $\ldots \ldots \ldots \ldots \ldots \ldots \ldots \ldots \ldots \ldots \ldots \ldots$

3. DESCRIPTION OF THE CONSOLIDATED SUBCONTRACT PROCESS $\ldots \ldots \ldots$

3.1 Development of the Initiative $\ldots \ldots \ldots \ldots \ldots \ldots \ldots \ldots \ldots \ldots \ldots$

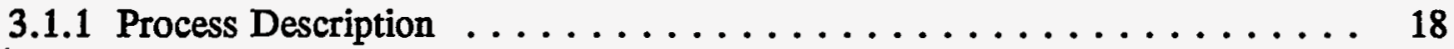

3.1 .2 Advantages . . . . . . . . . . . . . . . . . . 22

3.1 .3 Disadvantages . . . . . . . . . . . . . . . . . 23

3.1.4 Issues and Resolutions and Recommendations $\ldots \ldots \ldots \ldots \ldots$

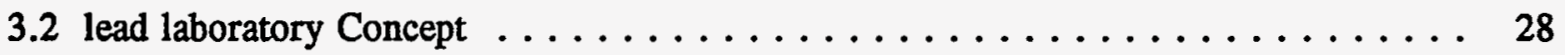

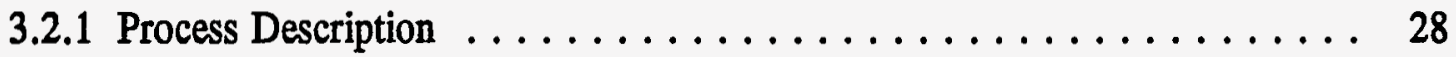

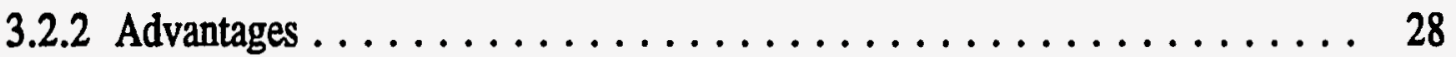

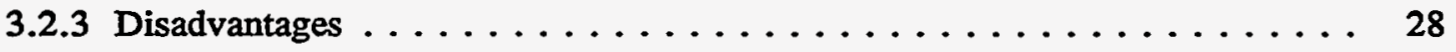


3.3 Master Task Subcontract Concept . . . . . . . . . . . . . . . . . . . 29

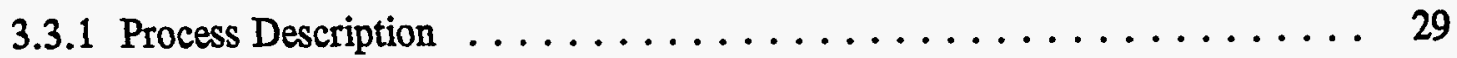

3.3 .2 Advantages . . . . . . . . . . . . . . . . . . . 30

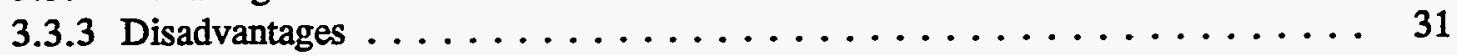

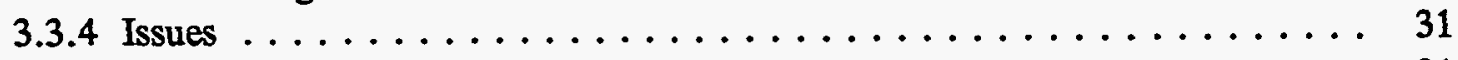

3.3.5 Resolutions and Recommendations ................. 31

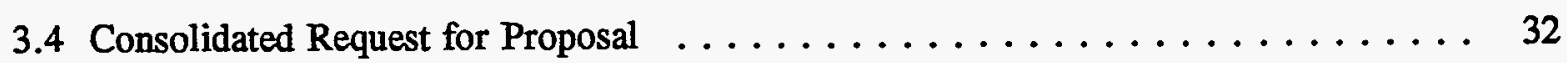

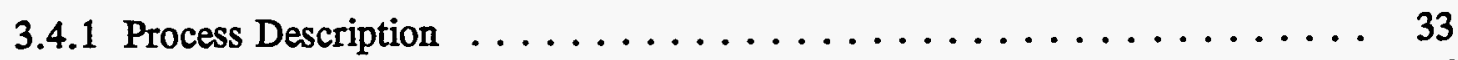

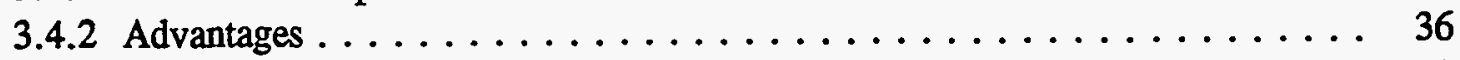

3.4 .3 Disadvantages $\ldots \ldots \ldots \ldots \ldots \ldots \ldots \ldots \ldots \ldots \ldots \ldots$

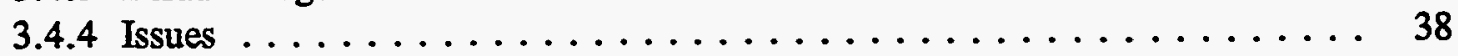

3.4.5 Resolutions and Recommendations . . . . . . . . . . . . . . 39

3.4 .6 Vendor Perspective $\ldots \ldots \ldots \ldots \ldots \ldots \ldots \ldots \ldots \ldots \ldots$

3.5 Bid Evaluation $\ldots \ldots \ldots \ldots \ldots \ldots \ldots \ldots \ldots \ldots \ldots \ldots \ldots \ldots \ldots \ldots$

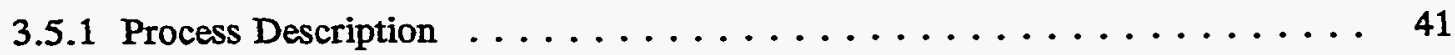

3.5 .2 Advantages . . . . . . . . . . . . . . . . . . 42

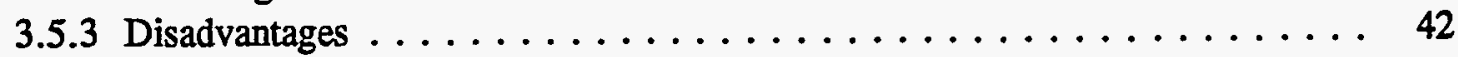

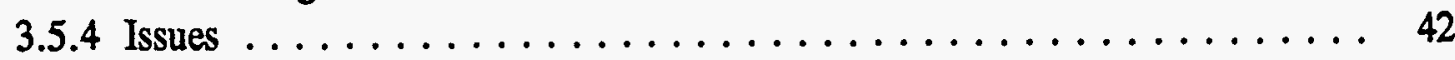

3.5.5 Resolutions and Recommendations . . . . . . . . . . . . . . 43

3.5.6 Vendor Perspective $\ldots \ldots \ldots \ldots \ldots \ldots \ldots \ldots \ldots \ldots \ldots$

3.6 Subcontract Award $\ldots \ldots \ldots \ldots \ldots \ldots \ldots \ldots \ldots \ldots \ldots \ldots \ldots \ldots \ldots$

3.6 .1 Process Description $\ldots \ldots \ldots \ldots \ldots \ldots \ldots \ldots \ldots \ldots \ldots \ldots$

3.6 .2 Advantages . . . . . . . . . . . . . . . . . . . 43

3.6 .3 Disadvantages . . . . . . . . . . . . . . . . . . . 44

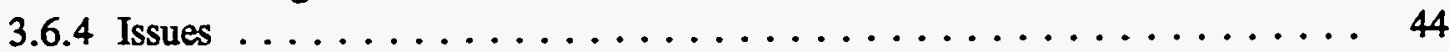

3.6 .5 Resolutions and Recommendations . . . . . . . . . . . . . . . 44

3.6.6 Vendor Perspective $\ldots \ldots \ldots \ldots \ldots \ldots \ldots \ldots \ldots \ldots \ldots . \ldots \ldots$

4. DESCRIPTION OF THE CONSOLIDATED ESH\&Q LIABILITY ASSESSMENT PROCESS ............................. 45

4.1 Team Composition and Qualifications $\ldots \ldots \ldots \ldots \ldots \ldots$

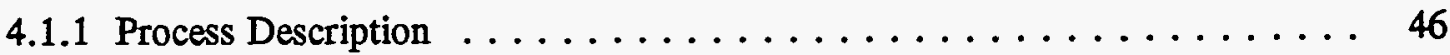

4.1 .2 Advantages . . . . . . . . . . . . . . . . . . . . 49

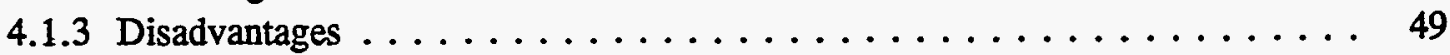

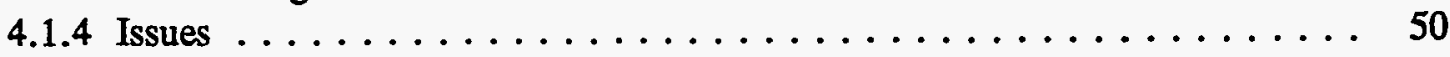

4.1 .5 Resolutions and Recommendations ................ 50 
4.2 Assessment Criteria $\ldots \ldots \ldots \ldots \ldots \ldots \ldots \ldots \ldots \ldots \ldots \ldots \ldots \ldots \ldots$

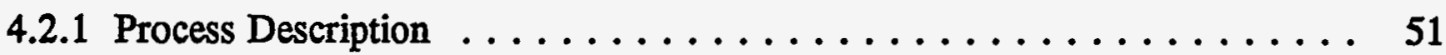

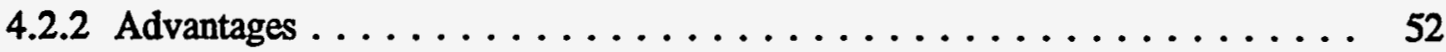

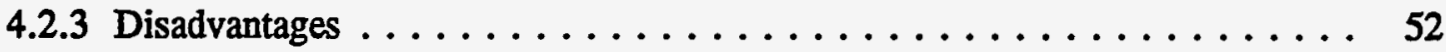

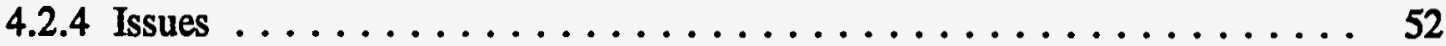

4.2.5 Resolutions and Recommendations $\ldots \ldots \ldots \ldots \ldots \ldots \ldots \ldots \ldots 2$

4.3 Pre-Award Assessment Process $\ldots \ldots \ldots \ldots \ldots \ldots \ldots \ldots \ldots \ldots \ldots \ldots$

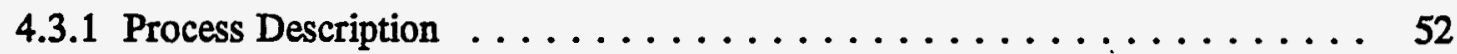

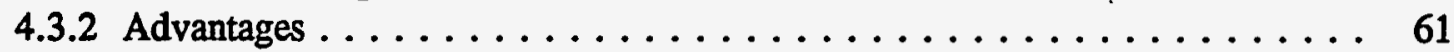

4.3.3 Disadvantages . ...................... 61

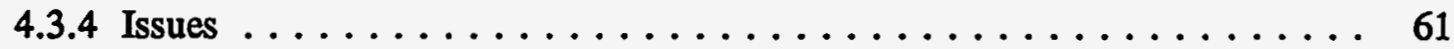

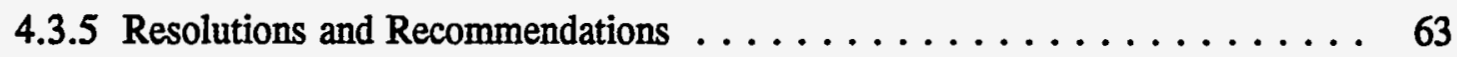

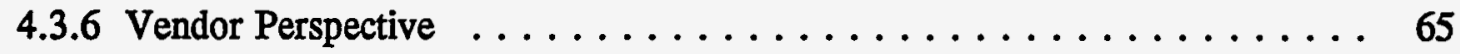

4.4 Annual Review Assessment Process . . . . . . . . . . . . . . . 66

4.4.1 Process Description $\ldots \ldots \ldots \ldots \ldots \ldots \ldots \ldots \ldots \ldots \ldots 6$

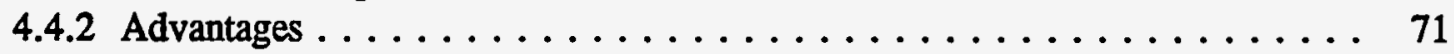

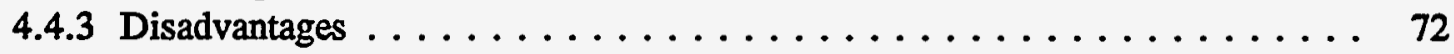

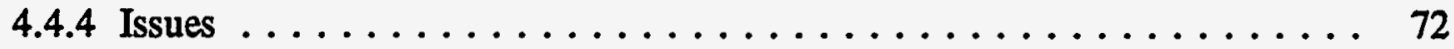

4.4.5 Resolutions and Recommendations $\ldots \ldots \ldots \ldots \ldots \ldots \ldots \ldots \ldots 72$

5. OPERATIONS UNDER THE CONSOLIDATED SUBCONTRACTS $\ldots \ldots \ldots \ldots \ldots 73$

5.1 Activation of Task Orders $\ldots \ldots \ldots \ldots \ldots \ldots \ldots \ldots \ldots \ldots \ldots \ldots$

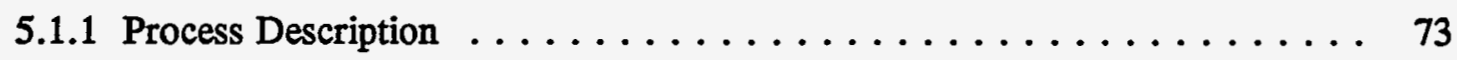

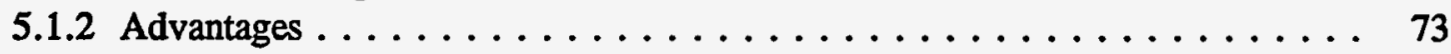

5.1 .3 Disadvantages ...................... 74

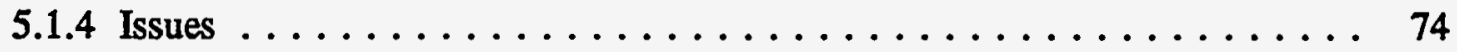

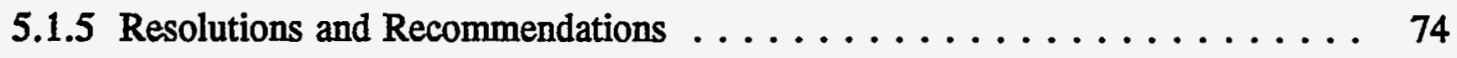

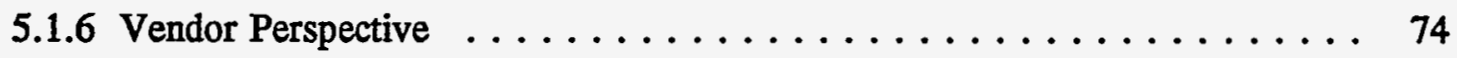

5.2 Subcontract Modifications $\ldots \ldots \ldots \ldots \ldots \ldots \ldots \ldots \ldots \ldots \ldots$

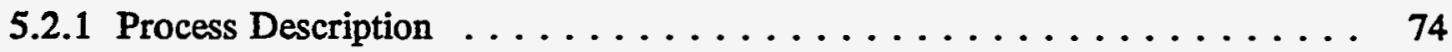

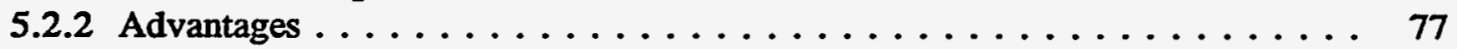

5.2.3 Disadvantages .................... 77

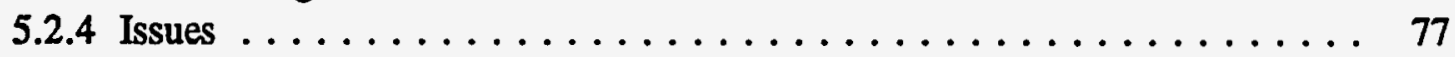

5.2.5 Resolutions and Recommendations ............... 77

5.2.6 Vendor Perspective $\ldots \ldots \ldots \ldots \ldots \ldots \ldots \ldots \ldots \ldots \ldots \ldots \ldots$ 
5.3 M\&O Contractor Waste Management Operations $\ldots \ldots \ldots \ldots \ldots \ldots \ldots .78$

5.3.1 INEL Waste Management Operations Process Description ......... 79

5.3.2 Rocky Flats Plant Waste Management Operations Process Description . . . 94

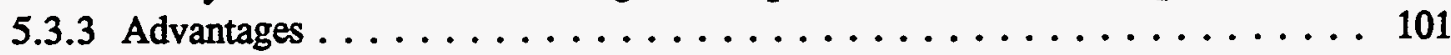

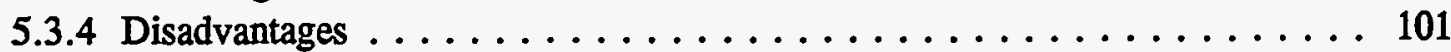

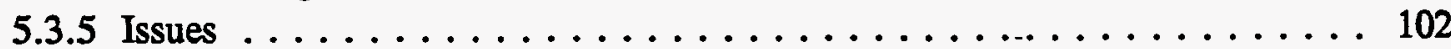

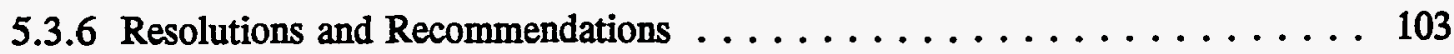

5.3.7 Vendor Perspective $\ldots \ldots \ldots \ldots \ldots \ldots \ldots \ldots \ldots \ldots \ldots \ldots \ldots$

6. COSTS OF THE INITIATIVE $\ldots \ldots \ldots \ldots \ldots \ldots \ldots \ldots \ldots \ldots \ldots$

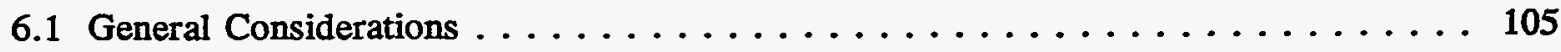

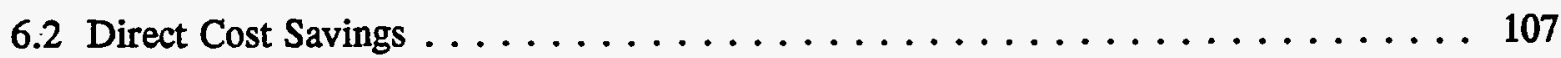

6.2.1 Consolidated Master Task Subcontract $\ldots \ldots \ldots \ldots \ldots \ldots \ldots \ldots 107$

6.2.2 Consolidated ESH\&Q Liability Assessments . . . . . . . . . . . 109

6.2.3 Post-Award Operations $\ldots \ldots \ldots \ldots \ldots \ldots \ldots \ldots \ldots \ldots \ldots$

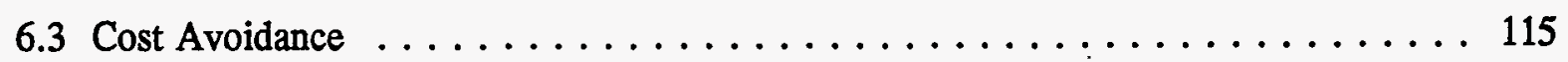

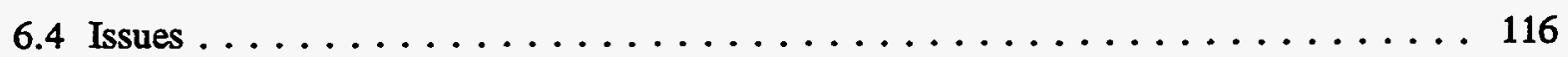

6.5.1 Accurate Calculations and Justifications $\ldots \ldots \ldots \ldots \ldots \ldots \ldots \ldots$

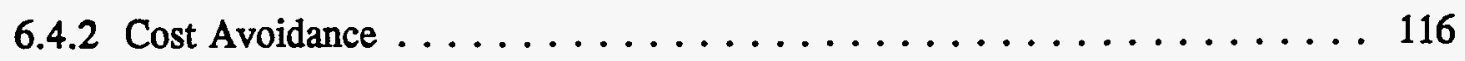

6.5 Resolutions and Recommendations $\ldots \ldots \ldots \ldots \ldots \ldots \ldots \ldots \ldots \ldots$

6.5.1 Accurate Calculations and Justifications $\ldots \ldots \ldots \ldots \ldots \ldots \ldots \ldots$

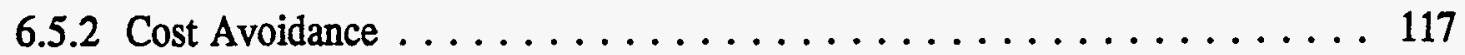

7. LESSONS LEARNED $\ldots \ldots \ldots \ldots \ldots \ldots \ldots \ldots \ldots \ldots \ldots \ldots \ldots \ldots$

7.1 General Process $\ldots \ldots \ldots \ldots \ldots \ldots \ldots \ldots \ldots \ldots \ldots \ldots \ldots \ldots$

7.2 Consolidated Master Task Subcontract . . . . . . . . . . . . 119

7.3 Consolidated ESH\&Q Liability Assessments $\ldots \ldots \ldots \ldots \ldots \ldots \ldots \ldots$

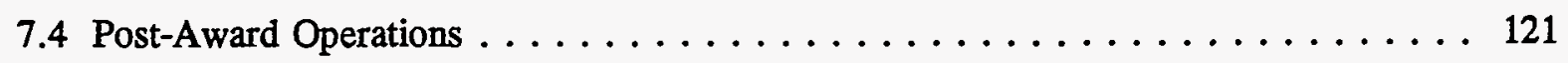

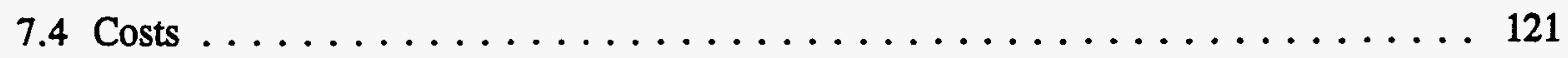

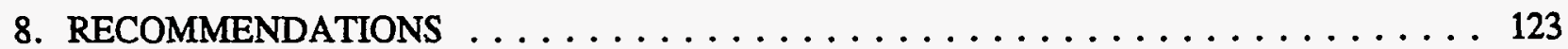




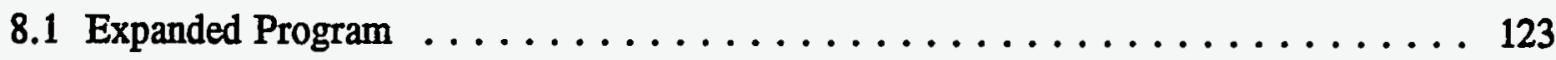

8.1.1 Programmatic Recommendations . . . . . . . . . . . . . 123

8.1.2 Schedule Recommendations . . . . . . . . . . . . . . . 123

8.1.3 Funding Sources and Costs . . . . . . . . . . . . . . . . 127

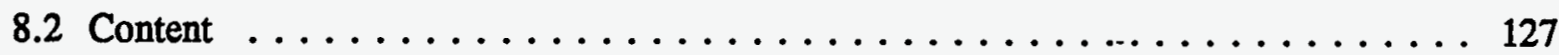

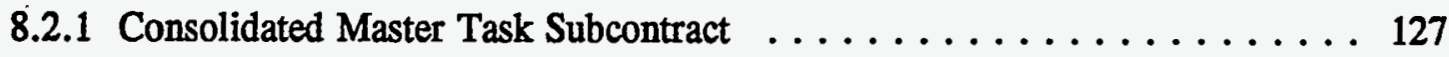

8.2.2 Consolidated ESH\&Q Liability Assessments . . . . . . . . . 127

8.3 Post-Award Operations $\ldots \ldots \ldots \ldots \ldots \ldots \ldots \ldots \ldots \ldots \ldots \ldots \ldots \ldots \ldots$

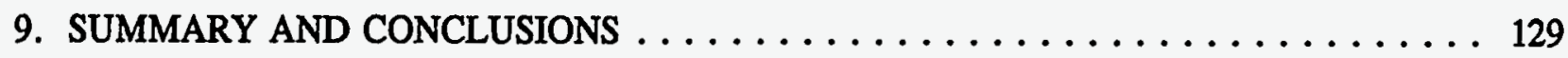

10. REFERENCES $\ldots \ldots \ldots \ldots \ldots \ldots \ldots \ldots \ldots \ldots \ldots \ldots \ldots \ldots \ldots \ldots \ldots$

10.1 Federal Statutes $\ldots \ldots \ldots \ldots \ldots \ldots \ldots \ldots \ldots \ldots \ldots \ldots \ldots \ldots \ldots \ldots \ldots \ldots$

10.2 Code of Federal Regulations $\ldots \ldots \ldots \ldots \ldots \ldots \ldots \ldots \ldots \ldots \ldots \ldots$

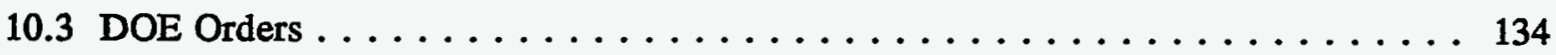

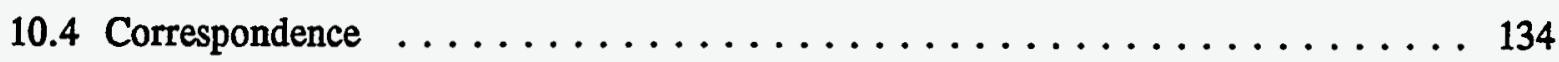

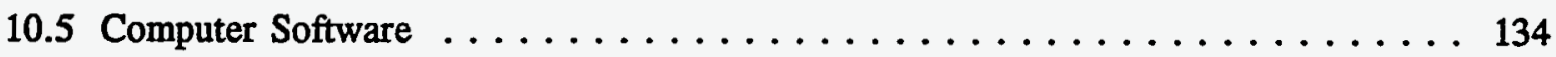

10.6 Publications $\ldots \ldots \ldots \ldots \ldots \ldots \ldots \ldots \ldots \ldots \ldots \ldots \ldots \ldots \ldots \ldots \ldots$

Appendix A-Abbreviations and Acronyms $\ldots \ldots \ldots \ldots \ldots \ldots \ldots \ldots \ldots \ldots \ldots$

Appendix B-Consolidated Request for Proposal $\ldots \ldots \ldots \ldots \ldots \ldots \ldots \ldots \ldots$ B-1

Appendix C-ESH\&Q Liability Assessment Team Training Program Contents . . . . . . . C-1

Appendix D-ESH\&Q and Financial Liability Assessment Report Contents . . . . . . . . D D-1

\section{FIGURES}

1. Example of a Task Order . . . . . . . . . . . . . 75

2. INEL Form EG\&G 669 (Identification of the Hazardous Component) . . . . . . . 81

3. INEL Form EG\&G 669A (Shipment Request and Certification) $\ldots \ldots \ldots \ldots \ldots \ldots .85$

4. Rollins LDR notification/certification form used by the INEL . . . . . . . . . . 89

5. EG\&G Rocky Flats confirmation of a shipment . . . . . . . . . . . . 95

6. EG\&G Rocky Flats invoice with associated assigned profiles $\ldots \ldots \ldots \ldots \ldots \ldots . . \ldots 7$

7. EG\&G Rocky Flats waste disposal expense accrual using assigned profiles . . . . . . . 99 
8. Work package activity sheet for a pre-award assessment $\ldots \ldots \ldots \ldots \ldots \ldots \ldots \ldots \ldots$

9. Work package activity sheet for an annual review assessment $\ldots \ldots \ldots \ldots \ldots \ldots$

10. Locations of the participating DOE sites and TSDFs under the MTS . . . . . . . . 125

\section{TABLES}

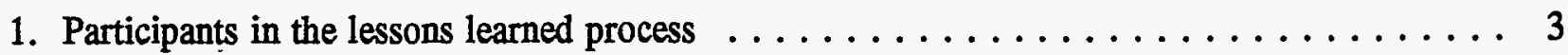

2. Participants subcontract life cycle ...................... 8

3. Sites managed by EG\&G M\&O contractor and owned by DOE. . . . . . . . . 18

4. ESH\&Q areas of expertise and checklists, based on Audit Master" module titles . . . . . 48

5. EG\&G ESH\&Q liability assessment program participants . . . . . . . . . . 49

6. Documents and information reviewed concerning the subject facilities .......... 59

7. EG\&G M\&O contractor hazardous waste disposal initiative-consolidated subcontract estimated

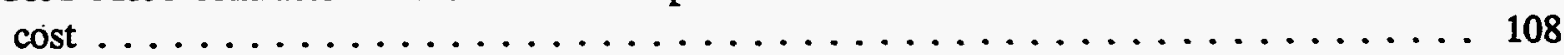

8. EG\&G M\&O contractor hazardous waste disposal initiative-analysis of administrative costs . 109

9. CWM and Rollins subcontracted TSDFs, locations, and associated treatment capabilities . . 124 


\section{Lessons Learned from the EG\&G Consolidated Hazardous Waste Subcontract and ESH\&Q Assessment Process}

\section{INTRODUCTION}

Before October 1994, EG\&G, Inc. (EG\&G) was the management and operating (M\&O) contractor at four major and ten satellite United States Department of Energy (DOE) sites through its wholly owned subsidiaries, EG\&G Idaho, Inc. (EG\&G Idaho); EG\&G Rocky Flats, Inc. (EG\&G Rocky Flats); EG\&G Mound Applied Technologies, Inc. (EG\&G Mound); EG\&G Energy Measurements, Inc. (EG\&G - EMI); and Reynolds Electrical and Engineering Company, Inc (REECo). EG\&G established a group, called the DOE Support Group, within the corporation to oversee these M\&O Contractor sites and evaluate ways to conduct business "better, faster, and cheaper" at the DOE sites.

One of the initiatives proposed by the EG\&G DOE Support Group was to consolidate the hazardous waste transportation, treatment, recycling, and disposal options at the sites. This initiative was based upon a successful program at the Idaho National Engineering Laboratory (INEL) in which EG\&G Idaho consolidated all of the hazardous waste disposal activities in one master subcontract for the DOE contractors at the INEL. EG\&G Idaho managed the disposal activities and the subcontract for the INEL. Included in the initiative was disposition of Resource, Conservation and Recovery Act (RCRA) hazardous waste, Toxic Substance Control Act (TSCA) waste, Comprehensive Environmental Response, Compensation, and Liability Act (CERCLA) hazardous substances and contaminated media, and recyclable hazardous materials, all of which will hereafter be referred to as "hazardous waste".

In March 1992, the DOE Support Group proposed to standardize the method of procurement and monitoring of hazardous waste transporters and disposers including an evaluation of the use of regional or national subcontracts. The previous practices at the EG\&G M\&O contractor DOE sites included individual subcontracts with numerous transporters and treatment, storage, and disposal facility (TSDF) vendors; inadequate operational controls in the contacts; inadequate environmental, safety, health, and quality (ESH\&Q) liability assessments of the vendors; and no standards of excellence. The purpose and scope of the EG\&G effort was to cut costs and reduce the potential liability for both DOE and EG\&G. EG\&G Idaho was assigned the lead in this effort.

EG\&G obtained concurrence from the United States Department of Energy-Headquarters (DOE-HQ) Office to proceed. The EG\&G M\&O contractors obtained concurrence from their respective DOE operations offices, defined funding sources, and assigned personnel to work on the subcontract standardization, and personnel to work on the assessments. EG\&G Idaho as the prime contractor of the lead laboratory, INEL, established one master task subcontract for all five EG\&G M\&O contractors and one ESH\&Q Liability Assessment Team with representatives from the five M\&O contractors. The benefits included one standardized request for proposal (RFP) instead of five RFPs, coordinated statements of work (SOWs), uniform subcontract language, consistent and thorough ESH\&Q and financial liability assessments, insurance of TSDF ESH\&Q compliance, and cost savings.

In October 1994, EG\&G Idaho was replaced by Lockheed Idaho Technologies Company (Lockheed Idaho) as the prime M\&O contractor for the INEL. Lockheed Idaho has assumed the lead laboratory 
responsibility for the consolidated hazardous waste subcontract and continues to support this effort with the remaining EG\&G M\&O contractors.

\subsection{Purpose}

The consolidated subcontract process has generated much interest from DOE-HQ and other DOE sites. EG\&G Idaho has received numerous requests for information regarding the process and for copies of the bid package. Although the effort was successful and the subcontracts are now in place, a number of weaknesses in the process have been identified which participants in the various tasks wanted to document and correct in order to prevent other DOE installations from repeating them.

The purpose of this report is to document the evaluation of the process used to prepare, bid, and award the EG\&G consolidated hazardous waste transportation, treatment, recycling, and/or disposal subcontract (C93-170250/C93-170251) and associated ESH\&Q and financial liability assessments; document the strengths and weaknesses of the process; and propose improvements that would expedite and enhance the process for other DOE installations that use the process and the Lockheed Idaho sponsored re-bid of the consolidated subcontract, scheduled for fiscal year (FY) 1998.

\subsection{Scope}

The scope of this study is limited to (a) evaluating the process used to prepare, bid, and award the EG\&G consolidated hazardous waste transportation, treatment, recycling, and/or disposal subcontract, and (b) evaluating the process used to assess the facilities proposed under the subcontract.

The lessons learned evaluation was conducted as part of the environmental oversight function of the Lockheed Idaho Environmental Protection Department (EPD) to support the United States Department of Energy - Idaho Operations Office (DOE-ID) and DOE-HQ, Office of Environmental Restoration and Waste Management. Evaluation assistance was also provided by EG\&G, EG\&G - EMI, EG\&G Environmental, Inc., EG\&G Rocky Flats, EG\&G Mound, and REECo. Members of the evaluation team were chosen based on their participation in and experience with the entire process. A number of other representatives of the various contractor departments were consulted during the process. The M\&O contractor and corporate departments involved included procurement, legal, quality assurance, environmental programs, waste operations, and traffic control.

Representatives from the two successful hazardous waste vendors: [Rollins Environmental Services, Inc. (Rollins) and Chemical Waste Management, Inc. (CWM)]; were also given the opportunity to provide comments regarding the processes. It was determined that the vendor's perspective of this process would provide valuable insight into how the process was perceived within the commercial sector. The vendors could also provide comments on the strengths and weaknesses from a commercial perspective which would be useful in the future. The vendor representatives chosen for this task were also those who had participated in preparing the bid responses and assessment processes. Table 1 lists the participants and their affiliations.

The result of this evaluation is a report describing

- The steps required to put a consolidated subcontract in place 
- The advantages and disadvantages of the process

- Process improvements that would alleviate rework required in the original task

- Proposed methods to streamline the process.

Table 1. Participants in the lessons learned process.

\begin{tabular}{|c|c|c|}
\hline Name of participant & Area of expertise & Company affiliation \\
\hline T. D. Christensen & $\begin{array}{l}\text { Subcontracts Administration } \\
\text { and Procurement }\end{array}$ & Lockheed Idaho Technology Company, Inc. \\
\hline J. A. Ciucci & $\begin{array}{l}\text { Waste Management } \\
\text { Operations }\end{array}$ & EG\&G Rocky Flats, Inc. \\
\hline C. L. Dutro & $\begin{array}{l}\text { Waste Minimization } \\
\text { Coordinator }\end{array}$ & $\begin{array}{l}\text { Reynolds Electrical and Engineering } \\
\text { Company, Inc. }\end{array}$ \\
\hline L. E. Ewing & $\begin{array}{l}\text { Waste Management } \\
\text { Operations }\end{array}$ & Lockheed Idaho Technology Company, Inc. \\
\hline N. J. Fix & $\begin{array}{l}\text { Regulatory Compliance and } \\
\text { Assessments }\end{array}$ & Lockheed Idaho Technology Company, Inc. \\
\hline L. A. Guinn & Legal/Regulatory & EG\&G Environmental, Inc. \\
\hline J. D. Hops & Legal & Lockheed Idaho Technology Company, Inc. \\
\hline A. M. Jacobs & $\begin{array}{l}\text { Waste Management Program } \\
\text { Manager }\end{array}$ & Lockheed Idaho Technology Company, Inc. \\
\hline $\begin{array}{c}\text { K. McNeel } \\
\quad:\end{array}$ & $\begin{array}{l}\text { Waste Management } \\
\text { Operations }\end{array}$ & Lockheed Idaho Technology Company, Inc. \\
\hline R. J. Molter & $\begin{array}{l}\text { Waste Management } \\
\text { Operations }\end{array}$ & EG\&G Rocky Flats, Inc. \\
\hline K. K. Mullins & Regional Proposal Manager & Chemical Waste Management, Inc. \\
\hline R. Orr & Account Executive & Rollins Environmental Services(Sales), Inc. \\
\hline B. D. Reyes & Regulatory Compliance & Lockheed Idaho Technology Company, Inc. \\
\hline A. R. Thomas & Contract Administration & $\begin{array}{l}\text { Reynolds Electrical and Engineering } \\
\text { Company, Inc. }\end{array}$ \\
\hline D. E. Trump & $\begin{array}{l}\text { Waste Management } \\
\text { Operations }\end{array}$ & $\begin{array}{l}\text { Reynolds Electrical and Engineering } \\
\text { Company, Inc. }\end{array}$ \\
\hline G. D. White & $\begin{array}{l}\text { Waste Management } \\
\text { Operations }\end{array}$ & EG\&G Energy Measurements, Inc. \\
\hline
\end{tabular}




\subsection{Content}

Section 1 contains the introduction and a description of the scope of this report. Section 2 presents the background and history of the proposed consolidated hazardous waste subcontract process. Section 3 describes the consolidated subcontract process. Section 4 describes the consolidated ESH\&Q and financial liability assessment process. Section 5 discusses waste management operations during the first year under the consolidated subcontract. Section 6 presents cost data representing actual direct cost savings and cost avoidances. Section 7 presents lessons learned from the process. Section 8 contains recommendations for future implementations of the process. Section 9 contains the summary and conclusions of the report. Section 10 contains a list of references used in this report. Appendix A is a list of abbreviations and acronyms used in this report. Appendix B contains a sample of a portion the RFP. Appendix C contains an outline of the ESH\&Q liability assessment training program. Appendix D contains an outline of the contents of the ESH\&Q liability assessment report.

\subsection{Disclaimer}

The conclusions and recommendations contained in this report are based on background information, evaluations of information and documents from participating contractors and subcontractors, and interviews with corporate, contractor, and subcontractor personnel. The purpose of this report was to identify potential ESH\&Q and financial risks associated with the prospect of the EG\&G-managed DOE facilities using the consolidated subcontract process for the treatment/disposal of hazardous wastes and combining efforts for conducting ESH\&Q and financial liability assessments. Nothing in this report should be construed as a statement on a facility's compliance status with regard to any law, regulation, or requirement. 


\section{BACKGROUND AND HISTORY}

\subsection{INEL Consolidated Hazardous Waste Subcontract Process}

The INEL consolidated hazardous waste subcontract process was used as a case study for evaluating the multi-site consolidation effort. EG\&G Idaho was a prime M\&O contractor and designated the coordinating contractor for the INEL. As the coordinating contractor, the company was responsible for waste management activities, including, hazardous waste treatment and/or disposal, subcontracting hazardous waste treatment/disposal companies, ensuring that the wastes were properly characterized, treated, and disposed of and that all resulting documentation was properly maintained and archived. EG\&G Idaho performed these tasks for its own operations, as well as for Westinghouse Idaho Nuclear Company (WINCO), operator of the Idaho Chemical Processing Plant (ICPP); Babcock and Wilcox, Inc. $(B \& W)$, operator of the Special Manufacturing Complex (SMC); Westinghouse Electric Company, operator of the Naval Reactor Facility (NRF); Morrison-Knudsen, Inc. (M-K), site construction contractor; Argonne National Laboratory-West (ANL-W); and the DOE-ID direct operations, although each of the other organizations retained the right to subcontract for their own waste disposal.

RCRA/TSCA hazardous wastes and recyclable materials were generated as a result of daily operations at the INEL. All wastes carry the DOE-ID hazardous waste generator numbers, of which there are three for the Idaho operations: one as a large quantity generator, for the 980 square mile INEL site located 50 miles west of Idaho Falls; one as a small quantity generator, for the 35-acre INEL Research Center (IRC) located within Idaho Falls; and one for the Willow Creek Building (WCB), a conditionally exempt small quantity generator located in Idaho Falls, but not on property contiguous with the IRC. The INEL site includes the ICPP, NRF, SMC, ANL-W, and a number of other operations.

In late 1990, oversight personnel from the EG\&G Idaho Environmental Programs Group, Environmental Technical Support (ETS) Unit, began noticing deficiencies in the way EG\&G Idaho was subcontracting for hazardous waste disposal services and subsequent environment, safety, and health (ES\&H) oversight of the operations. For example, a subcontract was awarded to a vendor to provide recycling of spent activated carbon filters. However, upon investigation by the ETS oversight personnel, it was discovered that the vendor could not fulfill the requirements of the subcontract because it could not accept CERCLA remediation wastes, and the carbon filters were generated as a result of a CERCLA remediation effort. This point was overlooked by an INEL assessment team. The subcontract had to be canceled and a new proposal issued.

Another example of inadequate controls was that it appeared that several purchase order subcontracts had been awarded for treatment and disposal of the same, or similar, waste streams. This occurred because different groups or departments had requested the subcontracts from different company procurement agents. In 1991, problems with the primary hazardous waste vendor began to appear, and an evaluation of the subcontract and operations identified the following:

- The subcontract with a large permitted treatment/disposal company did not contain adequate language ensuring regulatory compliance, i.e., no "hard hammers"

- The vendor was allowed to "broker" wastes to other facilities without consent of the INEL 
- The vendor became unresponsive to INEL requests for ES\&H compliance assurance

- The vendor's facilities were closed by the United States Environmental Protection Agency (EPA) and the state regulators for several months because of violations of environmental regulations

- The INEL had no options for waste treatment/disposal during theperiod of regulatory closure of the vendor's facilities.

Although the INEL generators were able to hold waste shipments in less than 90 day accumulation areas and interim status storage areas until the vendor's facilities were re-opened, the risk of noncompliance with storage regulations at the INEL was a significant concern.

At about the same time, the generators at the INEL were investigating recycling opportunities for both RCRA-regulated and unregulated materials generated at the site. The materials identified included clean lead and lead acid batteries, silver and silver compounds, RCRA scrap metal (circuit boards, solder, cadmium, etc.), other materials (nickel-cadmium batteries, mercury and mercury contaminated debris). Some of these materials were being accumulated at the INEL with no landfill disposal options. EG\&G Idaho attempted to obtain subcontracts with legitimate recyclers, primarily smelters, for these materials; however, because of the relatively small quantities generated by the INEL, the recycling industry claimed no interest in the materials. The primary reason cited was that it cost the recycler more money to bid on, and operate under, a government subcontract than the materials were worth.

Based on these, and several other issues, identified by the oversight personnel, a team was formed to address the entire INEL subcontracting and assessment processes. The team was composed of personnel from the Procurement; Waste Management; and Environment, Safety, and Quality Departments. The results of the evaluation were that, if possible, it would be in the best interest of the INEL contractors and DOE to consolidate the RCRA-regulated hazardous, CERCLA, and TSCAregulated wastes into a single full-service system subcontract and to re-evaluate the recycling opportunities and system subcontract forms.

As a result of the evaluation, the following solutions were proposed and implemented for the RCRA/TSCA treatment/disposal process:

- New style of RFP and SOW bid and subcontract package with ESH\&Q "hard hammers" specifically stated was developed. The new format still met applicable Federal Acquisition Requirements (FARS) and DOE Acquisition Requirements (DEARS), and anticipated the promulgation of 48 CFR $\S 970$ (additional DEARS environmental requirements) by two and one-half years.

- Limits were placed on the number of treatment/disposal facilities used to perform the work in the subcontract; no more than five were allowed. The limits were based on the composition of INEL generator's waste streams, which were evaluated against the treatment technologies and vendors available within the Continental United States in order to treat all wastes at the fewest possible sites. 
- Incorporated a potential for two subcontracts to be awarded: a primary and a contingency. The purpose of the contingency subcontract was to provide a vendor capable of fulfilling the subcontract should the primary vendor and/or any of its facilities fail.

- The term "broker" was specifically defined and such firms banned from participating in the proposed subcontract. A broker was defined as a firm that acts as an agent in securing the services of other firms for performing any portion of the subcontract.

- Go/no-go criteria were used to evaluate the vendor proposals, rather than convening a selection board. This resulted in the subcontract award being based primarily on technical merit, rather than lowest price and selection board evaluation. It should be noted that the primary subcontract was awarded to the vendor with the lowest priced bid, as well as highest technical merit.

- The new format made all interested parties at the INEL contributors and owners of the subcontracts as can be seen in Table 3.

As a result of the evaluation, the following solutions were proposed and implemented for the RCRA regulated recyclable materials process:

- $\quad$ Recycling opportunities were identified

- A new style of RFP designed to encourage vendors to bid, but which still met the FARS and DEARS was developed. This RFP was a somewhat abbreviated version of that developed for the RCRA/TSCA treatment/disposal format allowing the hazardous waste vendor to obtain recycling subtier facilities.

- Recyclable materials with economically insignificant returns versus cost to treat were rolled into the hazardous waste treatment/disposal RFP within the 325 identified waste streams.

The results of the efforts for the hazardous waste treatment/disposal evaluation and implementation were:

- A primary hazardous waste transportation/treatment/disposal subcontract was awarded to Rollins Environmental Services, Inc. The company proposed five treatment/disposal facilities and recycling options.

- A contingency subcontract was awarded to Burlington Environmental, Inc.

- Vendor services offered and responsiveness to requests by the vendors under the new subcontract were rated excellent by INEL contractors and waste operations. The services required by the INEL as delineated in the RFP and subcontract SOWs were clearly and concisely described. The SOWs helped both the vendor and the INEL generators evaluate performance. 
Table 2. Participants subcontract life cycle.

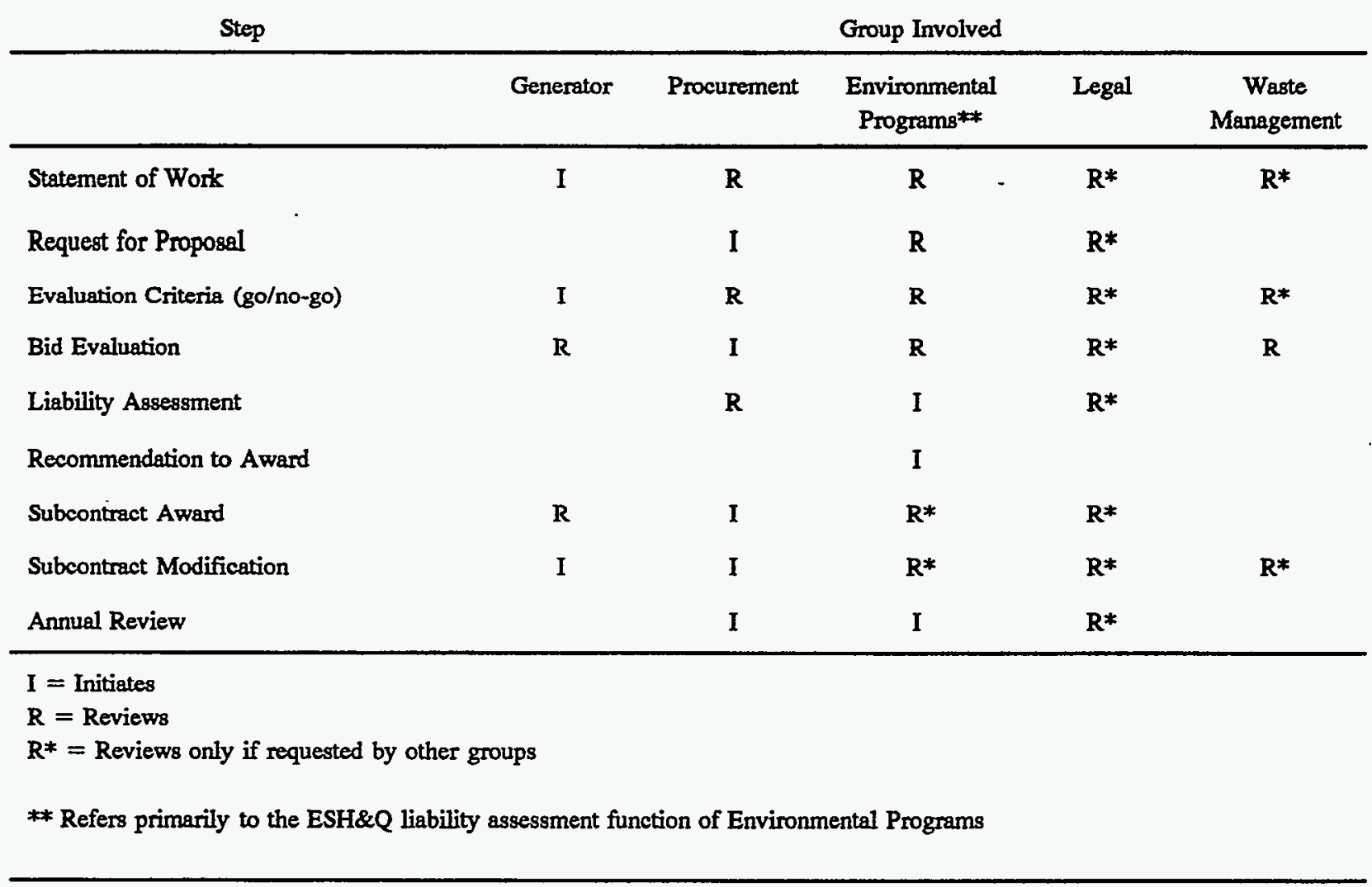

The results of the efforts for the RCRA-regulated recyclable materials evaluation and implementation were:

- The INEL contractors received responsive, acceptable bids from vendors on the new RFP

- Recycling contracts were awarded for clean lead, RCRA-regulated scrap metal, and silver

- Successful shipments of materials were made

- The value of materials offset the cost of processing, e.g., in 1992 EG\&G Idaho received a check for $\$ 1,200.00$ from the silver recycler after the deduction of transportation and processing charges. EG\&G Idaho recovered costs associated with the material versus incurring treatment/disposal cost.

The structure and content of the initial INEL RFP and associated SOWs are not discussed in this section because they will be described in Section 3.4 (Consolidated Request for Proposal) of this report. The RFP and SOWs were modified, improved, and used for the consolidated subcontract effort, which is the subject of this study. 


\subsection{INEL ESH\&Q Liability Assessment Process}

It is known that ES\&H assessments of commercial TSDFs were conducted by INEL assessment teams as early as 1985 . However, there was no systematic approach or program control of either the criteria or decisions on which facilities would be assessed. By 1990, it had become clear that the program had to be formalized through program management plans and procedures. The first formal assessment procedures were developed in October 1990. The first pre-award assessment that was required to be performed and where award of the subcontract was made contingent upon the apparent awardee's success occurred in 1991 . The assessment program was officially assigned to the Environmental Programs, ETS unit at that time and has been active ever since that time. The following sections briefly described the original 1990 program which was substantially modified and improved. The program, as it appeared in 1993, was the basis for the consolidated assessment effort and is described in Section 4 of this report.

\subsubsection{Scope}

A complete external assessment of the off-site facility consists of pre-assessment, on-site assessment, post-assessment, risk assessment, and financial evaluations. The comprehensiveness of an external assessment may be modified and adjusted by the External Assessment team leader with concurrence from the ETS Manager. Factors that influence the scope of the assessment include: type of hazardous waste or hazardous material to be sent, amount of waste or material to be sent, time period under which the INEL will be doing business with the offsite facility, etc. The scope of the assessment can be adjusted at any point during the evaluation, based on information gathered during the procedure.

The external assessment examines compliance with regulations promulgated by the Clean Air Act (CAA), Clean Water Act (CWA), CERCLA, RCRA, Safe Drinking Water Act (SDWA), Superfund Amendment and Reauthorization Act (SARA), TSCA, and any applicable regulations promulgated by state and local legislation.

An external assessment includes the following:

- On-site review of the TSDF or recycling facility operation

- Examination of facility plans and construction

- Examination of all applicable permits and facility records

- Review of where the wastes or recyclable materials go, cradle to grave

- EPA, state, and local regulatory observations of the facility

- Opinions of other businesses that use the facility

- Review of other parties that take title of the waste or materials

- Review of transporters 
- Review of certificates of destruction or disposal

- Review of INEL contract for adequacy, e.g., environmental compliance

- Opinion of the community in which the facility is located

- Financial condition of the facility/parent and ability to pay for potential cleanup and lawsuits

\subsubsection{Pre-Assessment Review Procedures}

The pre-assessment review consists of information gathering and is conducted using the telephone, mail, or electronic data base systems. The purpose of the pre-assessment review is to determine if:

- In the case of a TSDF, that the TSDF waste management processes are compatible with wastes generated

- In the case of a recycler, that the hazardous materials are being recycled in accordance with the regulations, and that the facility properly disposes of any waste it generates

- The facility has had serious environmental, regulatory, financial, or legal problems that can be identified using the sources described as follows.

If a complete assessment had been conducted recently and a report was available, it is requested and evaluated before proceeding with the pre-assessment. If the report information is inadequate or unavailable, the pre-assessment continues. The External Assessment Team makes this decision with the concurrence of the ETS manager.

Many sources are evaluated to obtain an impression of potential problem areas and general environmental compliance. Although none are used as decision criteria, they are useful in formulating questions for the facility operators and pinpointing areas requiring additional investigation.

A LEXIS/NEXIS database search is conducted to identify any situations such as adverse publicity, criminal proceedings, and/or major environmental problems that could have a detrimental impact on any arrangements that the INEL subcontract might make with the facility.

A Dun and Bradstreet (D\&B) search is conducted to collect the following information about a company: the financial condition, company rating and trends, net assets, and balance sheet information. The financial condition of the facility of interest may be collected and evaluated by the EG\&G Financial Services or Procurement Groups.

Regulatory contacts include, but are not limited to: the EPA; state regulators (e.g., the state water commission); and local regulators (e.g., city or county sanitation districts). Each regulatory agency should be contacted in order to obtain or verify the following information: 
Permit status

CERCLA involvement

Existing contamination

Compliance problems
Inspection results

Financial compliance

Recommendations

Written Freedom of Information Act requests may also be needed.

In addition to the regulatory agencies, the assessor contacts city and/or county officials, the local Chamber of Commerce and the Better Business Bureau in order to obtain opinions they might have concerning the conduct of operations and community opinions of the facility of interest.

The TSDF or recycler is contacted directly in order to collect the following information:

Site history and CERCLA involvement

Existing contamination

Ownership

Services and operations

Waste streams, or recyclable materials, accepted and not accepted

Permit status, including RCRA, air, and water

Financial information
Insurance information

References

Other businesses that use and/or have assessed the TSDF

Regulatory compliance status

Assessment coordination procedures (only

if a decision has been made to conduct an assessment.)

Businesses that have conducted a risk assessment or compliance evaluation of the facility are contacted. Their opinions of the facility are discussed and they are asked to send a copy of the results of any risk assessments or evaluations they have conducted of the TSDF or recycler.

The INEL subcontract, RFP, or request for quotation (RFQ) with the TSDF or recycler are reviewed for adequacy. The following points are noted:

- Non-assignability clause (without prior consent)

- Return of completed manifest before payment

- Certificates of destruction/disposal returned before payment

- Hold harmless, indemnification, contribution clauses

- Review by company attorney

- Provisions to immediately terminate services if it appears that an environmental compliance problem has arisen.

After a review of all of the above information, a determination is made as to whether an on-site assessment is necessary or if sufficient information has been obtained in order to complete an assessment report. If a determination is made by the External Assessment Team Leader, with the concurrence of 
the ETS manager, or designee, that sufficient information has been acquired, a risk evaluation and . assessment report is completed using the instructions and format specified in the procedure.

\subsubsection{On-site Assessment Procedures}

The purpose of an on-site assessment is to examine the facility history, capabilities, operations, and general site acceptability.

2.2.3.1 Preparation for an On-site Assessment. The assessment date and assessment schedule is established with the TSDF contact and confirmed in writing.

Arrangements are made with TSDF contact to have the following information mailed ahead for review before the site visit and also available for on-site review:

- Information on site history, pre-RCRA/TSCA waste disposal

- Consent agreements and responses to Notices of Violations

- All permits and corrective action plans

- Surface water, air, and groundwater monitoring data for the last three years

- Closure/post-closure plans, cost estimates and basis, and financial mechanism documentation

- Current Certificate of Insurance for Sudden and Nonsudden Incident, and a copy of policy

- Independently audited financial statements for the past three years

- Documentation of involvement in any Superfund sites or related active or pending environmental litigation

- Information on assignees to which waste is transferred

- Certificates of destruction or disposal (CDs)

- Facility construction plans

- Emergency/contingency plans

- Manifests, bills of lading, records, reports, and notices

- Hazardous waste minimization plan

- Personnel training records

- Land use permits or documentation 
A determination is made of what wastes have been shipped from the INEL to this facility. Copies are made of shipping manifests. If a large number of manifests are involved, a random selection is made to be used during the on-site evaluation.

A determination of whether the state in which the facility of interest is located has authority to regulate federal environmental laws. If the state has authority in any area, the implementing regulations are reviewed and a checklist is prepared to address compliance with these regulations.

2.2.3.2 Conduct of the On-site Assessment. Checklists are used during the conduct of the on-site assessment. These checklists include all applicable federal and state regulations. The checklists can be prepared ahead of time, or if a computer program such as Audit Master ${ }^{2 x}$ is used, during the onsite inspection. If the Audit Master ${ }^{\mathrm{Tn}}$ is not used, commercially available or specially developed checklists may be used. However, these checklists must be reviewed and approved by the External Assessment team leader before the on-site inspection.

The facility and operations are inspected in the sequence specified below using checklists for the specific type of facility:

- Waste arrival

- Waste storage

- Waste analysis and verification procedures

- Manifest verification

- Inspection of each unit

- Residues management

- Transportation into and out of facility.

Facility representatives are interviewed to assess management's understanding of the facility, regulations, and company's risk assessment procedures. Management personnel to be interviewed include the laboratory manager, facility manager, and environmental coordinator.

The following documents, in addition to those listed in Section 2.2.3.1, are reviewed and compared to conditions observed during the inspection:

- RCRA Part A or B permit application, air emissions permits, water permits, and any other permit required by the state and local regulatory agencies

- Other assignees to which the waste is transferred, final disposition of waste, and certificates of disposal or destruction documents

- Plans for hazardous waste minimization and statements on manifests 
- Inspection records, including storage areas, loading and unloading areas, and equipment.

The tracking system is evaluated by following the processing on one of the shipments, preferably from the INEL, from arrival to final disposition at the facility. All internal records are checked.

\subsubsection{Post-Assessment Procedures}

A TSDF risk evaluation following the instructions found in the EG\&G Idaho procedure is followed. An assessment report using format described in this procedure is also prepared. The facility file is completed.

\subsubsection{Documentation}

The following documentation is generated and/or maintained for each external assessment or risk analysis performed:

2.2.5.1 Formal Assessment or Risk Analysis Report. A formal assessment or risk analysis report is written for each facility evaluated. This document is prepared in accordance with EG\&G Idaho document preparation procedures, using the format described in the procedure and is controlled through the EG\&G Idaho Document Management System.

Because the material contained in the report is sensitive, dissemination of this document is strictly limited to a distribution list that has been approved by the ETS manager. Any deviation from the distribution list, or additional requests for copies of the document, must be submitted to the External Assessment Team leader in writing and must be approved by the team leader and ETS manager.

2.2.5.2 Telephone Conversations. All telephone conversations regarding the facility under evaluation must be documented using the EG\&G Idaho memo of conversation form or memo to file form. The forms must be typed or written in black indelible ink. These memos must be kept as a record in the facility file.

2.2.5.2 Facility Files. A formal file is created and maintained for each facility being evaluated. The files are retained in the ETS unit. These files contain all correspondence, notes, completed assessment checklists, copies of permits and contracts, completed external assessment chronology log, regulatory contact checklist, risk assessment, external assessment report, and any other information that was collected and used during the facility evaluation. The contents of the files must be able to withstand a regulatory and/or quality assessment.

\subsection{EG\&:G Corporate Initiatives}

EG\&G formalized a Corporate Environmental Policy in October 1991. The company stated that EG\&G was committed to conducting its business in an environmentally responsible manner in all aspects of its operations. The objectives of the company's environmental policy were: 
- Comply with all applicable environmental laws, regulations, and standards

- Evaluate compliance on a routine basis throughout all company operations through the use of a self-assessment and audit program

- Train and educate employees in identifying and implementing the requirements of environmental compliance

- Encourage the use of environmentally benign techniques and waste minimization methodologies in (a) designing products and processes, and (b) managing and operating facilities

- Develop programs for conserving resources and protecting the environment through recycling and reusing materials

- Develop programs to incorporate environmental considerations among internal management's criteria by which projects, products, processes, and purchases are evaluated

- Develop in our employees an awareness of their environmental responsibilities and encourage adherence to sound environmental practices

- Ensure the integration of environmental considerations in business planning.

EG\&G implemented the policy through its Corporate Director of Environmental Programs. The company initiated a program in which each operation was evaluated by a Corporate team to determine where environmental strengths and weaknesses existed. The result of the survey was a series of recommendations that the company believed would result in enhanced environmental compliance, quality products and services, and significant cost savings for its customers, including DOE.

A GOCO [Government-Owned, Contractor-Operated] Environmental Committee was established. This committee was composed of delegates from each of the EG\&G operated government installations, particularly those owned by DOE. In March 1992, this committee selected three environmental initiatives that the members believed could be started quickly and in which the cost savings could be quantified for the customer, i.e., DOE. The initiatives were:

- Standardize the approach for selecting and monitoring environmental laboratories

- Initiate corporate procurement of waste haulers and disposers through national and/or regional contracts

- Review and select existing environmental training modules for EG\&G-wide standardization as the first step in optimizing the standardization of environmental training.

The second initiative became the consolidated hazardous waste transportation/treatment/disposal master task subcontract and assessment program, which is the subject of this study. 
This page intentionally left blank 


\section{DESCRIPTION OF THE CONSOLIDATED SUBCONTRACT PROCESS}

\subsection{Development of the Initiative}

As previously stated, EG\&G was searching for long-term solutions to the hazardous waste disposal issues encountered by DOE sites. Two main issues were potential ES\&H liability and costs associated with hazardous waste disposal. The company planned to address these issues with the consolidated hazardous waste subcontract project. The project involved four major and ten satellite DOE facilities operated by EG\&G subsidiaries. The facilities and their associated M\&O contractors are shown in Table 3. EG\&G believed that this project could be used as a model for other DOE facilities across the country.

DOE sites generally had individual subcontracts for hazardous waste disposal with numerous vendors. More than 200 commercial facilities were identified as part of a DOE study conducted in 1992. The subcontracts generally were costly, with no price breaks for the DOE sites because individual sites did not generate enough volume. The subcontracts generally did not contain adequate operational controls. For example, there were no "hard hammers" in place to ensure ES\&H compliance. Therefore, DOE was being exposed to potential ES\&H liability at many TSDFs across the United States. This was especially significant where brokers were used to collect the hazardous waste for disposal, because brokers did not assume any contractual ES\&H liability for their actions.

ES\&H liability arises under several of the federal environmental laws. RCRA holds the generator responsible for ensuring proper treatment and ultimate disposal of the waste, no matter how many intervening companies handle the waste. CERCLA imposes joint and several liability on the owner of the waste, the person "arranging for disposal," and the owner or operator of the disposal location. Therefore, EG\&G and DOE remain legally responsible for the waste. Without strong contractual controls in place, neither EG\&G nor DOE could exercise any control over how and where the waste was managed and disposed of even if they had notice of improprieties. Currently, EPA estimates that the average CERCLA (Superfund) site cleanup costs around $\$ 1$ million. The entire cost can be collected from any single potentially responsible party.

EG\&G also noted that ES\&H liability assessments (frequently called audits), if conducted at all, were inadequate for determining the potential liability risks with using a particular company and/or facility. In general, there were no standards of excellence for either the subcontracting or ES\&H liability assessment processes.

During the July 6, 1992 EG\&G corporate meeting, the general managers from the five EG\&G M\&O contractor subsidiaries endorsed the concept of consolidating the hazardous waste shipping and disposal function. As planned, all of the EG\&G M\&O contractors would use the services of the same hazardous waste disposal companies, a unified contractual arrangement would be established, and a single EG\&G assessment team would assess the acceptability of the facilities. It was intended that eventually the entire DOE complex could be included. This activity by EG\&G was planned to be a model effort to demonstrate the feasibility and cost savings. Acceptance and approval by DOE was needed before final implementation: 
Table 3. Sites managed by EG\&G M\&O contractor and owned by DOE.

\begin{tabular}{|c|c|c|}
\hline EG\&G M\&O Contractor & DOE-Owned Facility & Facility Location \\
\hline EG\&G Idaho, Inc. & $\begin{array}{l}\text { Idaho National Engineering } \\
\text { Laboratory }\end{array}$ & Idaho Falls, ID \\
\hline $\begin{array}{l}\text { EG\&G Mound Applied } \\
\text { Technologies, Inc. }\end{array}$ & Mound Site & Miamisburg, $\mathrm{OH}$ \\
\hline \multirow[t]{2}{*}{ EG\&G Rocky Flats, Inc. } & $\begin{array}{l}\text { Rocky Flats Environmental } \\
\text { Technology Site }\end{array}$ & Denver, CO \\
\hline & Oxnard Facility & Oxnard, CA \\
\hline \multirow[t]{6}{*}{ EG\&G Energy Measurements, Inc. } & North Las Vegas Operations & Las Vegas, NV \\
\hline & $\begin{array}{l}\text { Woburn Cathode Ray Tube } \\
\text { Operations }\end{array}$ & Woburn, MA \\
\hline & Santa Barbara Operations & Santa Barbara, CA \\
\hline & Special Technologies Laboratory & Goleta, CA \\
\hline & Amador Valley Operations & Pleasanton, CA \\
\hline & Kirtland Operations & Albuquerque, NM \\
\hline $\begin{array}{l}\text { Reynold Electrical and Engineering } \\
\text { Company, Inc. }\end{array}$ & Nevada Test Site & Las Vegas, NV \\
\hline
\end{tabular}

\subsubsection{Process Description}

Although consolidated hazardous waste disposal contracts were known to be used by private industry, e.g, the Boeing Company, which consolidated 28 aircraft manufacturing facilities on one disposal contract, the concept had not yet been used by DOE facilities. The U. S. Department of Defense, through the Defense Reutilization and Marketing Office (DRMO), was attempting to consolidate the disposal options for some of its operations. However, none of the companies or agencies investigated had proposed a hazardous waste subcontract or maintained an ES\&H assessment program such as that used at the INEL. Therefore, EG\&G Idaho had to research the federal regulations, DOE requirements, and $\mathrm{M} \& \mathrm{O}$ contractual obligations in order to ensure that the program would not conflict with any of the regulations and requirements. It was quickly determined that the program could not proceed without considerable assistance from legal, procurement, environmental protection, waste management, and quality organizations at each of the sites managed by an M\&O contractor and at EG\&G Corporate. In order to expedite the process, each organization was assigned specific tasks as part of the process, and conference calls were used to discuss issues.

3.1.1. Procurement. Procuring an individual site contractor or participating in regional or Corporate contracts would be necessary. The contracts should provide EG\&G with the best possible financial savings, while still reducing liability to the maximum extent possible. (In other words, reduced 
potential liability, and the quality of TSDF performance, should outweigh minor cost savings achieved through going with the low bidder.)

The financial solidity of a potential TSDF was also considered. Reducing risk of increased regulatory problems and increased financial liability are of the utmost importance in this task; while still trying to improve our product or affect cost savings.

The EG\&G Idaho Procurement Group prepared a strategy plan to define and control the RFP process. The EG\&G Idaho "INEL Specific" SOW was used as a model. The objective of this procurement was to standardize the method of procurement and ESH\&Q assessments of haulers and disposers which would result in the following benefits and cost savings:

- Reduce procurement costs, and benefit from economies of scale (i.e., lower prices for higher waste volumes)

- $\quad$ Reduce risk that RCRA wastes could become CERCLA cleanups by contracting with approved subcontractors

- $\quad$ Reduce liability assessment costs and eliminate redundant compliance audits.

The Procurement Group proposed awarding two fixed price per unit master task subcontracts (MTS). Each subcontract would have an initial three-year term with two one-year options. Procurement proposed the following approach.

A draft RFP. was provided by EG\&G Idaho Procurement. The RFP included each M\&O contractor's site-specific waste streams and estimated volumes. The price proposals were also site specific based on each M\&O contractor's waste streams, including transportation costs from the site. A total of five price proposals would be required. All participating M\&O contractors reviewed the draft RFP before it was finalized.

A notice of the solicitation was published in the Commerce Business Daily (CBD) to ensure that all potential vendors were reached. Responses to the CBD notice provided the source for the bid list.

Subcontractor site assessments were performed as part of the process. The team included representatives from each of the participating M\&O contractors.

The result of the process was two competitive awards. The pricing was fixed annual pricing for each of the five years. The awards were made to the two responsive and responsible offerors proposing the lowest and second lowest total pricing for the five-year term.

Each M\&O contractor would award individual task orders to implement the subcontract. Selection of which of the two MTSs to use for a task order would be based on lowest price, best treatment method for the waste streams being shipped, and availability of the subcontractor. Each M\&O contractor determined which subcontract to use. Additional waste streams could be incorporated into task orders by M\&O contractors. The prices for these new waste streams would be negotiated by the M\&O contractor and would be provided to EG\&G Idaho for information and record. Each M\&O contractor would seek.DOE Operations Office approvals independently, if necessary, for task orders. 
The key elements in the approach were:

- DOE operations office buy-in of the master task subcontract

- M\&O contractor support.

3.1.1.2 Legal. Attorneys must ensure that the contractual relationships or shared assessment capabilities that are selected reduce the potential liability as much as possible and still meet regulatory or contractual requirements.

The legal departments of each of the participating EG\&G M\&O contractors and EG\&G Corporate were retained to address issues and resolve conflicts as a result of the analyses being performed by the other department participants. The legal representatives were assigned the task of reviewing existing M\&O contracts to ensure that the consolidated approach would not violate negotiated conditions or "Cost Plus Award Fee" (CPAF) evaluation criteria. Legal review was also conducted of the RFP to ensure that appropriate environmental and other requirements were included.

A continuing concern of the legal offices was the potential for "piercing the corporate veil". Generally, one of the main reasons for setting up separately incorporated, independent subsidiary companies is to enjoy the legal protection of incorporation. If a corporation is found liable, only the corporate assets for that corporation are at risk. If the subsidiaries act as a whole, or if the parent company directs actions, then the entire assets of the parent company and subsidiaries are at risk. The court would use a balancing test for determining the necessary extent of involvement, to decide if the "corporate veil" should be pierced to reach all assets. It was determined by the EG\&G M\&O legal offices that, although this was a corporate initiative, the final decision for any site to participate and the extent of that participation rested with DOE. Therefore, this was more of an EG\&G corporate suggestion than direction, which would tip the balance against piercing the veil. The legal offices also believed that the benefits of the liability protection of the consolidated contract outweighed the risk of veil piercing, given other related circumstances.

3.1.1.3 Environmental Protection Tasks. The ES\&H staff must develop TSDF assessment criteria, participate in the assessments, develop selection criteria and weighing systems, help resolve DOE hazardous waste treatment/disposal moratorium issues, consider waste minimization goals, and work with the waste generators to identify waste types and anticipated volumes.

The EG\&G Idaho ETS Unit had the lead in this area. This group reviewed copies of the hazardous waste treatmient/disposal subcontracts that each of the M\&O contractors had in place to date. The review focused on identifying strengths and weaknesses in each of the subcontracts. The strengths were incorporated into the SOWs being prepared for the new competition.

The ETS members also reviewed copies of the most recent RCRA biennial or annual hazardous waste reports supplied by the M\&O contractors. This review was designed to determine if the waste streams reported by the other M\&O contractors were comparable to those generated by the INEL. If major differences existed, then the waste stream exhibits from the INEL subcontract would have to undergo major revisions before they could be used as boiler plate for the other contractors. The results of the review were that no waste streams were identified in the reports that were not accounted for on the INEL exhibits. 
The assigned members of the ETS unit were ultimately responsible for ensuring that the SOWs were complete and accurate. Environmental protection staff at the other $\mathrm{M} \& \mathrm{O}$ contractors were responsible for ensuring that their portions of the SOWs were correct and accurate.

As a note for the record, the DOE hazardous waste treatment/disposal moratorium resulted from an order from DOE to all of the DOE sites directing them to cease the shipment of any RCRA-hazardous or TSCA-regulated waste originating in a radiologically controlled area to commercial facilities not licensed by the NRC or Agreement State until further notice (See letter from J. E. Lytle, DOE-HQ EM30, to Distribution, dated May 17, 1991). The order was issued after a Baton Rouge, Louisiana newspaper reported that the Rollins incinerator in Baton Rouge had burned radioactive waste received from the DOE nuclear weapons complex at Oak Ridge, Tennessee (See Oversight Hearing before the Committee on Interior and Insular Affairs, House of Representatives, dated February 20,1992). As a result of the newspaper report, the DOE issued the ban on shipments of the RCRA/TSCA-regulated wastes to non-nuclear commercial TSDFs until the DOE sites could provide information to DOE-HQ that described the criteria and the methods used for measuring a waste to the criteria which would ensure that the wastes were not radioactively contaminated. DOE-HQ would review the information to determine its regulatory and technical validity before it would allow the site to release the wastes. DOE-HQ subsequently provided clarification on what wastes were subject to the moratorium and defined the term "radiological area" (See letter from J. E. Lytle, DOE-HQ EM-30, to Distribution, dated June 7, 1991). The greatest effect of the moratorium on the DOE sites was that the volumes of regulated wastes available for treatment/disposal were significantly decreased while the DOE operations offices and M\&O contractors 'worked to prepare acceptable justifications for declaring the wastes radioactively uncontaminated.

3.1. 1.4 Quality Participation. Quality assurance people should verify that the assessment criteria and contracts meet all quality requirements. They may also need to be included in the assessments and/or contract selection process.

The quality assurance groups from each of the $M \& O$ contractors were requested to join the effort, but the groups declined to become active participants because the program addressed only hazardous wastes and not nuclear waste and operations.

Conduct of operations and performance assurance personnel were also contacted. These were relatively new considerations for some sites, but these people were consulted to ascertain if this task was consistent with their criteria and planning goals.

3.1.1.5 Waste Management. Waste management groups who directly controlled the management and disposition of RCRA/TSCA/CERCLA-regulated wastes were active participants in the process. It was their task to ensure that all site operational requirements and special services requested from the vendors were addressed in the SOWs. These people were also critical for the technical review of proposals.

The field people who generate the waste were consulted if waste management operations personnel were not present. They were asked to verify that all waste types were identified and that volume estimates for proper TSDF selection were accurate. 
3.1.1.6 Project Management. An administrative project manager was selected to control the flow of administrative tasks required to implement the project. The project manager was responsible for ensuring that activities remained on schedule, notifying management of potential roadblocks, and ensuring that proper distribution of funds was maintained.

3.1.1.7 EG\&G Senior Management Strategy. The Director of EG\&G DOE Support Services tasked each of the M\&O contractor general managers with obtaining DOE operations office concurrence with the proposed project. The general managers discussed the project with, and obtained concurrence from, the DOE operations office managers. In addition, each M\&O contractor department, i.e., procurement, legal, ES\&H, and waste management, was tasked with discussing and obtaining concurrence from their respective DOE operations office counterparts.

EG\&G Corporate representatives discussed the project with, and obtained concurrence from, the associated DOE-HQ departments.

\subsubsection{Advantages}

The proposal had two advantages that resulted in substantial savings:

- Consolidating the volume of waste to be disposed of allowed DOE sites to negotiate volume discounts and take advantage of economies of scale.

- Economy-of-scale costs included: reducing the number of assessment teams that had to visit the facilities; providing higher quality assessments because the assessment team could draw on expertise from several DOE sites; receiving volume discounts; and the possibility of coordinated waste transportation, thereby reducing the number of trips required. Only one or two assessment members from any one DOE site were required, thus minimizing the burden on each DOE site.

- Specific cost savings were unknown at the time of initiation because many of the DOE sites had not kept records sufficiently accurate to calculate exact potential saving. However, estimates based on preliminary information gathered by EG\&G Idaho indicated approximately $\$ 1.8$ million could be saved within the first three years from the consolidation of the hazardous waste disposal contracts.

- Limiting the number of disposal locations and using consistent environmental liability assessment standards to evaluate disposal sites, significantly reduced contractor and DOE potential environmental liability for fines and penalties, cleanup costs, legal defense costs, and remedial public relations efforts.

- Using fewer disposal sites meant fewer potential CERCLA cleanup sites for DOE and contractors. This reduced exposures both DOE complex-wide and for DOE operations offices.

- A subcontract could be awarded with higher quality sites. 
- Increased assessments and oversight meant that the best run facilities would continue to be used, decreasing the likelihood that the site would become a CERCLA cleanup site.

- Having consistent environmental liability assessment standards reduced the likelihood of bid protests from offerors that were accepted or rejected by one DOE site and not by another.

- Having consistent site evaluation standards helped to prevent allegations of negligence if one DOE site awarded a contract to a facility that another DOE site had found unacceptable and problems developed subsequently.

- A unified subcontract prevents uneven acceptance/rejection criteria among DOE sites, thereby reducing procurement challenges.

Volume gives DOE leverage in subcontracts because, if it is a lucrative subcontract, facilities would be more willing to modify operations to address our environmental compliance concerns, expedite waste acceptance to alleviate compliance problems, or give volume discounts.

For example, EG\&G Idaho did not have any challenges to the tough criteria of the INEL hazardous waste transportation/treatment/disposal subcontract. Brokers were not permitted to submit offers on that subcontract and were not allowed on this one either.

\subsubsection{Disadvantages}

The major disadvantage identified was that the prohibition of brokers could result in higher initial treatment/disposal costs for some of the small sites. The DOE operations offices and EG\&G M\&O contractors agreed that the potential increase was more acceptable than the increased risk posed by the use of brokers transferring waste to unknown and unassessed TSDFs.

Another potential disadvantage was that extremely small local disposal sites were disadvantaged in the procurement because of the desire to keep the number of facilities that were used to a minimum. This is inconsistent with the DOE policy of trying to optimize opportunities for small, local businesses.

\subsubsection{Issues and Resolutions and Recommendations}

3.1.4.1 Preliminary Issues Identified. The issues and concerns described in this section were identified during discussions held with procurement, legal, technical, and regulatory personnel from each of the M\&O contractors and EG\&G corporate staff and addressed before the initiative was launched. Each of the issues was identified and described. The issue statement is followed by the resolutions and recommendations reached at the time by careful research and consensus.

1. The first question that must be answered is related to capacity to handle the corporate loading, and the capability to handle the varied waste streams.

The majority of the vendors that replied to the 1992 EG\&G Idaho RFP had the capacity, and were able, to handle the varied wastes streams. These streams are generally treated and/or disposed of at the prime subcontractor's facility or at a subtier contractor approved by EG\&G Idaho. The waste streams 
generated at the INEL are generally the same as those generated at other EG\&G-managed facilities, e.g., . laboratory wastes and contaminated soils. Waste minimization efforts have been successful at the INEL and have resulted in significant reductions in waste streams and volumes. Corporate loading would not be a significant issue.

2. The question of whether the vendor has several facilities across the country, lending itself to a regional approach, must also be examined.

The majority of the vendors who bid on government contracts have several facilities across the country, e.g., Rollins Environmental Services, Inc. (Rollins); Chemical Waste Management, Inc. (CWM); United States Pollution Control, Inc. (USPCI); Laidlaw Environmental, Inc.; and Environmental Services Company (ENSCO). The standard government bidding procedures and requirements generally result in excluding the smaller companies from consideration. During past recycling and disposal contract efforts, EG\&G Idaho received comments such as "Too much paperwork for too little profit".

3. Selection criteria must be carefully determined. If a national or regional approach is not feasible, common selection criteria should still be used by each division for their individual selections.

EG\&G Idaho is continually upgrading and enhancing its selection criteria to ensure that the best facility is chosen for the task. For example, in the 12 months before this consolidated subcontract, criteria were added to ensure that CERCLA remediation wastes could be accepted by treatment/disposal facilities. Requirements for CERCLA-generated wastes were significantly different than those for RCRA wastes.

4. The financial capability of the vendor is critical in the event of Superfund liability and must therefore be examined.

EG\&G Idaho conducts a financial liability assessment of potential vendors as part of a full ES\&H liability assessment. Financial analysts in the Procurement Group conduct this analysis. Dun and Bradstreet, Security and Exchange Commission (SEC) Form-10K, company annual reports, and proof of necessary insurance are required for the analysis. This information becomes a part of the vendor's record.

5. A backup contract for waste handling must be considered in the event of a sudden closure of one facility by a regulatory agency order, natural disaster, or other unforeseen circumstances. Even if the closure is only temporary, a contingency plan is necessary to avoid violations of storage times.

EG\&G Idaho was pursuing the award of two subcontracts, a primary and a backup, for hazardous waste disposal services in 1992 (when the corporate analysis was done). This action was necessitated by the loss of the hazardous waste TSDF for three months earlier in 1992. EG\&G Idaho preferred the use of "escape clauses" in other EG\&G contracts rather than maintaining two contracts onsite.

6. Unless prohibited, the vendors may broker, which could increase both liability and the number of facilities that may need to be assessed. This must be examined for savings/decreased liability concern. 
EG\&G Idaho specifically excluded brokers from consideration in its hazardous waste and recycling contracts. Liability issues were carefully considered as part of this decision. EG\&G Idaho permits a subcontractor to subcontract specific services only with prior approval. ES\&H assessments are performed on those subcontractors before approval is given.

7. At a minimum; the use of one procedure, and perhaps one team, to complete the assessments could significantly cut costs and allow sharing of information. Standard contract language could also decrease liability.

EG\&G Idaho was working to standardize the language within its own Procurement system. Standard clauses were added to RFPs and SOWs and subcontracts in order to ensure ES\&H compliance and give EG\&G Idaho the right to assess (inspect) the subcontractor at any time during the term of the subcontract.

EG\&G Idaho had concerns regarding the use of one assessment team. Who would direct and/or fund this team? DOE budgetary constraints must be considered. The "corporate veil" should also be considered, although EG\&G subsidiaries represent DOE and act on behalf of DOE as part of the M\&O daily operations.

8. The use of a separate cell for disposal of EG\&G Corporate and M\&O contractor waste, in order to avoid combining with other wastes, should be considered.

The wastes that were generated at sites operated by EG\&G Idaho are owned by DOE and shipped as DOE waste. EG\&G does not generate wastes in its own name.

It was the opinion of EG\&G Idaho that this option would be prohibitively expensive. A TSDF would not build a cell specifically for EG\&G wastes. TSDFs generally permit one disposal cell at a time. The cells are designed to accumulate wastes for several years. Wastes are mapped in the cells using a grid system. If a cell leaks and results in the TSDF being named a Superfund site, regulatory agencies will pursue all entities that have sent wastes to the site for cleanup costs no matter whose drum leaked. However, accurate records of the amounts and types of wastes disposed of and the locations (cells) where the wastes were disposed of in may greatly mitigate potential liability.

9. Forecasting waste volumes must be carefully considered with emphasis on potentially decreasing volumes via waste minimization efforts and goals. The DOE moratorium on offsite shipments of hazardous waste that may have had "rad added" could also impact forecasting. If the subcontract is a requirement-type contract, adequate estimates are also needed to minimize the risk of liability from overstated estimates.

EG\&G Idaho presently forecasts waste volume based on historical trends. The company inserts a statement into the RFP and SOW stating that volumes are in no way guaranteed or implied. EG\&G Idaho also has clauses stating that new waste streams may be added with prior subcontractor approval.

10. The question of "sitewide" approaches to offsite waste management, under the auspices of the DOE Operations Office controller, must be examined. In other words, a corporate-led consolidated approach may not currently be acceptable to DOE or other site contractors. 
EG\&G Corporate should be aware that, where an EG\&G subsidiary is the prime M\&O contractor, it may frequently handle waste operations for other M\&O contractors at the DOE site. For example, the waste generated at the INEL is not specifically EG\&G, WINCO, Westinghouse Electric Company, etc. waste but is identified as DOE-generated waste. The Corporate parent would probably not want to assume the liability for other contractors' waste, or for the DOE in general.

11. The existing hazardous waste treatment/disposal contracts at each site managed by an EG\&G subsidiary M\&O contractor site must be considered for expiration or "termination."

The present contractual language used by Lockheed Idaho, formerly EG\&G Idaho, specifies oneyear subcontracts with up to five one-year renewal options. The subcontracts also specifically state that funds are not presently available under the subcontract beyond the end of the current fiscal year. This clause notifies the subcontractor that the contractor is under no obligation for the performance of the subcontract beyond the end of the current fiscal year if no funding is forthcoming.

The subcontract language states that waste streams identified in the exhibits may not be shipped and allows for additional waste streams to be added. This clause may facilitate phasing-out or termination of the subcontract.

12. Each site must consider DOE's concerns at each site including:

- Is waste staying on or leaving the site an issue?

- What is the potential impact of the DOE hazardous waste moratorium?

- Does DOE want to participate in assessments or treatment/storage/disposal selection?

- Would the customer prefer increased costs, if necessary, in order to decrease liability, e.g., prohibition of brokers and/or preference given to treatment by incineration?

These issues were assigned to the $M \& O$ contractor general managers for discussions with their respective DOE operations office representatives. The answers were as follows:

- Waste staying on site when it could be shipped off site was an issue.

- The impact of the DOE hazardous waste moratorium was that, if the generators could certify a waste as "clean," it could be sent to a commercial TSDF. If not, then it remained on site and was managed as a mixed waste.

- The DOE -operations offices did not want their personnel to actively participate in the assessments or vendor selection because these were M\&O contractor functions. The DOE operations offices retained the right to audit and approve or disapprove the criteria and selections made by the $M \& O$ contractors.

- The DOE operations offices considered the decrease in long-term liability to outweigh shortterm cost savings, as long as these costs could be quantified and justified. The majority of 
the operations offices also expressed a desire for incineration as the preferred treatment method to be used whenever appropriate.

3.1.4.2 Coordination Among Sites. The participating M\&O contractor groups involved, i.e., waste management, procurement, etc., reported that they never received written direction from their respective managements to proceed with implementation of the initiative. Verbal direction was received at some levels of management.

The participating M\&O contractor groups never received written explanations or assignments of responsibilities under the initiative. In particular, the procurement and legal counterparts did not receive directives relieving them of their responsibilities with respect to the master task subcontract (MTS) because the INEL was assigned to act on their behalf. This oversight resulted in problems with implementation of site-specific requirements at the task order level after the award of the MTS.

Written agreements, assignments of responsibilities, and definition of requirements, before commencement of a project of this magnitude, are crucial to preventing a recurrence of these types of issues.

How to coordinate activities among five separate companies was an issue.

A project manager was assigned to manage the coordination among the sites. This individual reported directly to the project's technical and program managers and interfaced with the M\&O contractor general managers and EG\&G corporate management.

3.1.4.3 Schedule. The proposed schedule required the entire process to be completed within one year of initiation. This was determined to be unreasonable and unfeasible.

The schedule was re-negotiated to make the award of the subcontracts occur before the issuance of the DOE-HQ RFP for an M\&O contractor to consolidate and operate the INEL. This added only about six months to the entire process.

3. 1.4.4 Scope. No issues regarding the scope of the proposed project were recorded.

3. 1.4.5 Budget. Sources of money to finance the project were a major concern because the annual site budgets had been approved months before the project was proposed. In addition, budget requests for the next fiscal year had also been submitted.

The M\&O contractors discussed the budget issues with their respective DOE operations office counterparts. It was agreed that no additional funding would be forthcoming; however, the general managers were allowed to reset priorities within their existing budgets to finance the project. The general managers assured the DOE Operations Offices that the cost savings would offset the initial expenses. 


\section{2 lead laboratory Concept}

\subsubsection{Process Description}

One of the issues that arose during the preliminary discussions concerning the workability of the consolidated hazardous waste subcontract and assessment program, was how to issue and administer the subcontract. The options discussed included control through DOE-HQ, EG\&G, one M\&O contractor, and/or one DOE operations office. It was determined that, because this was the first time a subcontract consolidating several M\&O contractors and DOE operations offices had been proposed, neither DOE-HQ nor EG\&G should "own" the process. The lead laboratory concept allowed DOE-HQ and the operations offices to be a participant in the overall process while assigning the implementation and management activities to one of the DOE national laboratories.

EG\&G Idaho as the contractor at the lead laboratory, INEL, developed the RFP and subcontract language with input from the other M\&O contractors. They issued the RFP and provided oversight of the procurement process. The lead laboratory was also responsible for the leadership and conduct of the ESH\&Q liability assessments. Final decisions regarding the qualification of the TSDFs and award of the subcontracts were assigned to the lead laboratory with concurrence from the DOE.

\subsubsection{Advantages}

A number of advantages for both DOE and the M\&O contractors were identified through the lead laboratory concept.

The site coordination issues identified in Section 3.1.4 were more easily resolved because the use of personnel from one DOE site to assist another DOE site was not considered novel or unusual. It had been the practice within the DOE system to share expertise on specific processes for years.

The distribution of financial requests was more easily accomplished. Because the DOE sites were working as DOE sites, memoranda of understanding (MOUs) among DOE contractors were the mechanisms used to commit and allocate resources. The use of the MOU allowed charges to be billed to the various participants using purchase orders.

DOE was kept informed of the progress of the initiative throughout the process because it was considered an active participant. This allowed DOE to take credit for process improvements and cost savings as they occurred.

The perception of the initiative as an EG\&G Corporate project was diminished. EG\&G commercial interests were not involved in the process. .

\subsubsection{Disadvantages}

The only disadvantage identified was the perceived loss of site autonomy with respect to control of the content and use of the subcontracts. This was not considered to be significant when compared with the advantages. 


\subsection{Master Task Subcontract Concept}

A number of different types of subcontracts were reviewed before the MTS, with implementing task orders, was chosen. One of the options that was reviewed and rejected was a consortium that negotiates a model terms and guidelines. In this scenario, each of the M\&O contractors would negotiate an individual subcontract based on the terms and guidelines. Another option that was reviewed and rejected was negotiation of a single subcontract by one of the M\&O contractors with each of the other M\&O contractors, subcontracting the lead to run the subcontract. The MTS provided the best control of the process, was most cost effective, and was preferred by the Secretary of Energy.

\subsubsection{Process Description}

3.3.1.1 Master Task Subcontract. The MTS is a basic agreement entered into with two subcontractors to procure multiple hazardous waste disposal services for five M\&O contractors for DOE. The MTS establishes a basic contractual agreement (including firm-fixed-unit pricing for each service) among the parties with no initial work assignments or monetary commitments, for a period of three years with two one-year options; it is maintained and administered by one of the five M\&O contractors. The basic agreement with both subcontractors provides each of the M\&O contractors the ability to determine which subcontractor can provide disposal services in a most cost-effective manner, specific to their own site, and based on firm-fixed prices received under the MTS. Each M\&O contractor issues a task order against the MTS to each subcontractor for a specific period of time; this establishes a ceiling price and additional terms and conditions applicable to their site. Task rder releases generated to the subcontractor who is deemed most cost effective authorizes funding for the specific disposal service required.

3.3. 1.2 Task Order. Each M\&O subcontractor issues a task order to each of the subcontractors; this task order incorporates the basic contractual agreement established under the MTS and provides a price ceiling and any additional terms and conditions applicable to the M\&O contractor's specific site. Task orders are generally issued for a one-year and may be issued for a longer period of time to meet the needs of each M\&O contractor. Releases are issued against each task order for specific work performed. Generally a release or shipment request/authorization is issued each time an M\&O contractor determines that enough waste exists to direct the subcontractor to provide transport and disposal services. A release is issued each time the subcontractor is directed by an M\&O contractor to perform services (transport, lab pack, disposal and etc.) on a specific day. All services specifically performed on that day become part of the release and are tracked by a designated release number for invoice and internal tracking purposes.

3.3.1.3 Subcontract Modifications. All modifications to the MTS are issued through the single $\mathrm{M} \& \mathrm{O}$ contractor, who maintains and administers the agreement as awarded.

Examples of potential modifications are changes in M\&O contractor shipment sites, scope of work changes, and regulatory changes affecting the basic contractual agreement established under the original award of the MTS. All such changes affecting the basic contractual agreement must be forwarded to the single M\&O contractor responsible for administering the MTS. The designated M\&O contractor is responsible for incorporating the applicable changes to the MTS by issuing a formal modification to the subcontract. The written modification is then distributed to all M\&O contractors as required. 
Changes specific to each M\&O contractor task order that have no effect on the basic contractual agreement established under the MTS are issued by each applicable M\&O contractor.

3.3. 1.4. Invoicing. Invoices are submitted to the applicable M\&O contractor for work performed at their site. The process for invoice approval is as follows:

1. The M\&O contractor technical representative, who directs the subcontractor to provide the services to perform a shipment or release, provides procurement personnel with a detailed breakdown of the transport/disposal services and applicable pricing established under the MTS for each release immediately after a shipment has occurred. The detailed breakdown identifies each drum of waste, the applicable generator, and a specific charge number for each drum that provides authorization to make payment.

2. After the subcontractor has provided the transport/disposal services, the subcontractor provides a work copy to the $M \& O$ contractor, which designates the specific shipment release, types of waste and drum sizes, transport services, all other services, and applicable fixed prices that correspond to each, including a total proposed price for the release.

3. The M\&O contractor technical representative who is responsible for directing the subcontractor to perform the shipment or release then reviews the work copy to determine if the work copy information is correct. After any discrepancies are addressed and resolved with the subcontractor, the work copy is provided to the appropriate procurement representative, with technical concurrence that the work copy is correct.

4. The procurement representative issues a formal written release to the subcontractor that obligates funds for that shipment.

5. The subcontractor issues an invoice for the release.

6. A copy of the release, the contractor's detailed breakdown showing charge numbers etc., and the reconciled subcontractor work copy provided and concurred with by the technical representative are provided to the Payables Department for payment of invoice.

\subsubsection{Advantages}

The MTS allows separate M\&O contractors to enter into a basic agreement with two subcontractors that provide for hazardous waste disposal services, with the flexibility to incorporate terms and conditions specific to each M\&O contractor site.

Control of subcontract modifications by the lead laboratory ensures that the subcontracts remain consistent, competitive, and available for all of the M\&O contractors involved.

The issuance of releases provides a mechanism to track the services as they occur under each shipment. The releases can be tracked with manifests and CDs to ensure that all services required are performed before payment of the invoices. The use of releases also provides a mechanism to ensure that duplicate invoices are not received and inadvertently paid. 


\subsubsection{Disadvantages}

A perception persists among some staff at several of the participating M\&O contractors that local control of their hazardous waste services is diminished by the lead laboratory. This is a misconception, because the lead laboratory controls actions concerning the MTS only and is available to assist the other participants with resolutions to problems when they requested it.

Some procurement representatives believe that a task order approach works better for a finite task or service but not as well for an indefinite volume, type, and timing of waste to be treated/disposed of. One of the participants found that, as their site activities changed from production to site cleanup, the generation of more nonrecurring, bulk wastes was becoming an issue.

EG\&G Rocky Flats noted that probably the most inconvenient and unrefined aspect of the subcontract was their line item price schedule. Each time they amend a profile (even a minor administrative change to add a waste code) they must also do a corresponding change to the appropriate subcontract line item. The solution that they proposed to this problem is to develop line items that are more generic and flexible in nature, while maintaining the restrictions necessary to obtain the best treatment/disposal pricing.

\subsubsection{Issues}

3.3.4:1 Coordination Among Sites. Some procurement groups did not appear to understand the MTS and task order concepts. Confusion regarding what the jurisdictional limits were became apparent. Some M\&O contractor procurement and technical personnel continued to have difficulty understanding their responsibilities with respect to the MTS and task orders and the responsibility of the lead laboratory for the MTS.

3.3.4.2 Schedule. No schedule issues related to the description of the MTS, task orders, or invoicing procedures were identified.

3.3.4.3 Scope. Scope issues regarding the MTS and task orders were the same as those identified in Section 3.3.4.1. M\&O contractor procurement personnel appeared to be confused as to the scope of their control of their various SOWs within the MTS and what they could incorporate into their specific task orders.

3.3.4.4 Budget. Budget issues regarding the MTS and task orders related to the misunderstanding of the amount of local control the M\&O contractors had over their SOWs and task orders.

\subsubsection{Resolutions and Recommendations}

3.3.5.1 Coordination Among Sites. Once the MTS is established (terms and conditions, scope of work, pricing, etc.) each individual M\&O contractor has the flexibility to issue a specific task order within the contractual agreement of the MTS that best meets the needs of their site by adding services or terms and conditions not identified under the basic agreement. 
Although the MTS allows each M\&O contractor the flexibility to procure site-specific services, the required disposal services change as new waste streams are developed and subcontractors performances change at individual M\&O contractor sites. Following are recommendations that would enhance the ability of all M\&O contractors to monitor pricing received for new waste streams, track subcontractor's performance and ensure that basic contractual elements of the MTS are adhered to by each subcontractor.

- Conduct an initial training/briefing session so that participants are clear on their roles and responsibilities

- Meet periodically to discuss and resolve issues

- All pricing for new waste streams should be consistent for all M\&O contractors

- Evaluate subcontractor's performance quarterly

- Meet with subcontractors quarterly to discuss performance.

Since award of the MTS, major modifications of the MTS have not been required. There appears to be no need for modifications on an ongoing basis for anything except deletion or addition of M\&O contractor sites or regulatory changes. To date, only one such modification has occurred and that was the addition of one site and the deletion of a second site. The two sites in question were located within 60 miles of each other; therefore, the waste stream and transportation pricing sheets were unaffected. The same subcontractor service center supplied both locations.

3.3.5.2 Schedule. No schedule resolutions or recommendations related to the description of the MTS, task orders, or invoicing procedures were identified.

3.3.5.3 Scope. The initial confusion over the scope of local control that the M\&O contractors had as a result of the award of the MTS, and what they could control with task orders could be removed by providing a class or meeting for discussing the operation of the MTS and Task Orders. This instruction should be provided immediately following the award of the MTS and before the M\&O contractors issue Task Orders.

3.3.5.4 Budget. The same resolution and recommendation regarding the clarification of the scope of local control can be applied to budget issues.

\subsection{Consolidated Request for Proposal}

The request for proposal (RFP) is one method by which a government agency notifies interested parties that it has a requirement for services to be provided on a specific project. The RFP also provides a mechanism for interested parties to inform the government agency of their capabilities and commitment to provide the requested services. 


\subsubsection{Process Description}

The RFP was prepared by the EG\&G Idaho Procurement Group, with input provided by the ETS Unit and Waste Management Operations. This document package was provided to each of the participating M\&O contractors for review and comment. Once the document package was declared complete and accurate it was issued to the vendors and interested parties who responded to the CBD advertisement, and to any others who expressed interest through other channels. The potential offerors are provided a window of time in which to provide a response to the RFP. In addition, the RFP specifically requires all interested vendors to attend a pre-bid conference before submitting their proposals.

The purpose of the pre-bid conference is to provide the potential offerors with a forum in which to ask questions or request clarification of issues arising from the RFP package. The result of the conference is a set of meeting minutes (and if necessary, an addendum to the RFP), which are provided to each of the participating potential offerors before the proposals are due to the government. If necessary, the due date for the proposals may be extended if the clarifications warrant it. After the closure of the proposal period, the proposal evaluation process begins. Any proposals not meeting the closure date and time are automatically excluded from consideration, unless, under special circumstances, it is in the interest of the government to consider them.

Although the RFP is considered one document, it actually contains a number of freestanding documents that are added or deleted depending upon the nature of the services requested. Each section of the RFP package is discussed in the following sections.

3.4.1.1 Request for Proposal. The RFP was prepared by EG\&G Idaho Procurement. The RFP contained a description of the purpose of the request, instructions for proposal submission, conditions for award of the subcontract, and applicable conditions. The RFP incorporated, by reference, the following documents:

- $\quad$ Pricing requirements applicable to all EG\&G M\&O price proposal attachments (Attachment 0).

- M\&O services and hazardous waste treatment/disposal SOWs and pricing submittal forms (Attachments 1-25)

- Representations and certifications (Enclosure 1)

- A sample small business and small disadvantage business subcontracting plan (Enclosure 2)

- EG\&G Idaho Standard Terms and Conditions for Purchase Orders and Subcontracts (Enclosure 3)

- A copy of the Service Contract Act of 1965, as amended (Enclosure 4)

- Wage determination No. 86-0889 (Revision 12) dated August 7, 1992 (Enclosure 5)

- Sample fixed price per unit master task requirement subcontract (Enclosure 6) 
- Proposal submittal form (Enclosure 7) also called the mandatory go/no-go form

- Draft - Rocky Flats Plant Health and Safety Plan (Enclosure 8)

- EG\&G Mound Service Contract Safety Provisions (Enclosure 9)

- EG\&G Idaho Environmental, Safety, and Health Requirements for subcontractors (Enclosure 10)

- EG\&G Rocky Flats - Oxnard Facility General Safety and Security Rules for contractors and subcontractors (Enclosure 11).

EG\&G EMI and REECo did not have site health and safety plans and required the vendors to prepare such a document for their approval upon award of the subcontract.

The vendors were required to provide the following documents as part of their proposals:

- Six complete sets of their technical and price proposals.

- A technical proposal consisting of a completed "Proposal Submittal Form" (Enclosure 7) Mandatory Go/No-Go Requirements.

- A price proposal containing annual firm-fixed-price-per-unit prices quoted for each year for the initial three-year period, and the two one-year optional periods for all five EG\&G M\&O contractors. These submittal forms were the pricing sheets contained in Attachments 2 - 5, $7-10,12-15,17-20$, and $22-25$.

- A completed "Representations and Certifications" form (Enclosure 1)

- A completed Subcontracting Plan in accordance with the "Sample Small Business and Small Disadvantaged Business Subcontracting Plan" (Enclosure 2). Completion and submission of this plan is required if the total price quoted for five years exceeds $\$ 5,000,000.00$ and the offeror is a large business.

- Accurate listing of all labor categories required to perform the Subcontract for submittal to the Department of Labor for current wage determinations in accordance with the Service Contract Act. A list of counties and states where the work would be performed was also required.

- In order to determine that the offeror, i.e., vendors, and any lower tier subcontractors had adequate financial capability to fulfill the capital requirements of the subject procurement, SEC $10 \mathrm{~K}$ reports or income statements and balance sheets (if the $10 \mathrm{~K}$ reports were not applicable to the firm) for the last three years were required from the offeror and its lower-tier subcontractors as part of the proposal package. 
The RFP stated that the award of the procurement would be to the responsive, responsible offeror(s) meeting the mandatory go/no-go criteria requirements, submitting the lowest total price, and passing the site verification assessment. These three conditions were defined in the RFP as follows:

- Mandatory Go/No-Go Criteria: The offeror's proposal must meet all of the mandatory go/nogo criteria. The proposal must address each of the mandatory requirements on a point-bypoint basis and be very clear and precise. A proposal that does not meet all of the mandatory go/no-go criteria was considered nonresponsive.

- Price: Prices proposed for all five EG\&G M\&O contractors for the anticipated five-year period, Attachments, 2 - 5, $7-10,12-15,17-20$, and $22-25$ are required. The five-year grand total price of each offeror will be used for the price evaluation. Failure to submit a completed price proposal will result in disqualification.

- Site Verification Assessment: Site verification assessments will be conducted on the two technically responsive, lowest priced offerors, and any lower-tier subcontractors. The site verification assessment includes a thorough review of the offeror, including verification of all the requirements of the RFP. Failure to pass the assessments will result in disqualification and the next lowest offeror(s) will then be assessed. This process is used until two offeror(s) are completely acceptable.

3.4.1.2 Statements of Work. SOWs were developed to describe each of the tasks required under the proposed subcontract. Each of the M\&O contractors modified the EG\&G Idaho SOWs in order to incorporate site-specific requirements. The purpose of these SOWs was to clarify the specific requirements for each site and provide a requirements source for the bid evaluations. The SOWs addressed the following subjects: hazardous waste treatment/disposal, waste disposal (specifically waste stream definitions, volumes, and pricing), sample evaluation, lab pack, transportation, and gondola boxes. Each of the SOWs contained pricing sheets, which were completed by the vendors as part of the bid proposals. The go/no-go criteria used to evaluate the technical completeness and capabilities of the vendors were derived from the site-specific requirement identified in the SOWs. The total number of SOWs prepared by the M\&O contractors for the proposal was 25 . This large number was required because each M\&O contractor had at least five SOWs that described its requirements and EG\&G EMI had six sites that were located in five different states and had to be considered separately. An example of the SOWs is contained in Appendix B of this report. The only SOW set that deviated from the example was the EG\&G Rocky Flats hazardous waste disposal SOW. (A copy of this SOW is also reproduced in Appendix B for comparison purposes.) EG\&G Rocky Flats waste operations personnel had very specific waste streams that they believed would not change during the five year duration of the subcontract and submitted their own waste stream exhibit, using the prescribed format, in lieu of using the EG\&G Idaho model. One additional attachment (Attachment 0 ) was added to the package to provide instructions to the vendors regarding the completion of the price proposal attachments.

At the pre-bid conference, it was determined through discussions with the vendors and M\&O contractors, that the SOWs did not adequately address transportation. Subsequent to that meeting an Addendum, called Addendum 1, was issued to all of the vendors requesting that transportation charges be specifically defined and priced. An example of this SOW is contained in Appendix B. 
3.4.1.3 Pricing Sheets. As previously stated, the pricing sheets were contained as attachments . to the SOWs (See Appendix B). The pricing sheets were prepared as tables printed on 8-1/2-in. by 14-in. pages in landscape format. The forms were reduced to 8-1/2 in. by $11 \mathrm{in}$. for this report. The waste descriptions and EPA code columns were originally prepared as part of the 1992 EG\&G Idaho hazardous waste treatment/disposal SOWs. EG\&G Idaho incorporated comments from the vendors regarding the content of the descriptions, which assisted both EG\&G Idaho and the vendors in understanding what each of the waste streams contained. Information in these descriptions is based on information required by the vendors for waste characterization. The waste characterization information is a component of the vendor's pricing schedules as well.

The EG\&G M\&Os contractors required the vendors to complete all of the rows and columns on the sheets whether or not a quantity of waste was specified by the M\&O. The vendors were specifically required to identify the methods of treatment and/or disposal to be used, as well as the TSDFs that would perform the treatment/disposal. The TSDFs proposed for each waste stream were locked into the subcontracts, i.e., if the Rollins Deer Park, TX incineration facility was proposed for the treatment/disposal of an EG\&G Idaho specific waste stream, no other facility, e.g., the Rollins Baton Rouge, LA TSDF, could be used for the treatment/disposal of this waste stream for EG\&G Idaho. If one TSDF was used for treatment and another proposed for disposal of a waste stream, both the treatment and disposal methods and each of the TSDFs were recorded on the sheets. The purpose for the detail was to permit the EG\&G M\&O contractors to track their waste streams from cradle to grave and to ensure that the vendors were honoring the conditions of the subcontracts and not brokering or substituting TSDFs for their own convenience.

As is noted in the example pricing sheets, quantities of wastes were not specified for all of the items. The vendors were required to price all of the items; however, only those items for which quantities were specified were evaluated during the bid evaluation in order to determine which vendor provided the lowest cost. The purpose for requiring pricing for all items was to provide the EG\&G M\&O contractors with a method to be used for forecasting treatment/disposal budgets. It also reduced the number of phone calls to vendor representatives to request pricing, which probably would not have been in line with the subcontract requirements.

3.4.1.4 Terms and Conditions. The EG\&G Idaho Standard Terms and Conditions for Purchase Orders and Subcontracts (issued June 1991), called T\&Cs, was included in the RFP. The document was revised in August 1993, and this version became part of the MTS. The purpose of the T\&Cs is to specifically identify the contractual obligations of the purchase order or subcontract. The term, subcontract, as used in the T\&Cs includes by reference all related plans, drawings, specifications, standards, and other documents. The T\&Cs specifically prohibit modifications unless supplied to, and accepted by, the contractor. Vendors attending the pre-bid conference were told that the M\&O contractors would not negotiate any of the T\&Cs. A copy of the EG\&G Idaho T\&Cs is located in Appendix B of this document. It is important to note that any section in the T\&Cs highlighted with bold type also applies to any subtier subcontractor used by the prime subcontractor.

\subsubsection{Advantages}

The following advantages were noted as a result of the consolidated RFP process: 
- Consolidating the RFP process prevented and/or reduced redundant procurement, legal, and ESH\&Q liability assessment resource requirements for the five $M \& O$ contractors.

- The communication and cooperation, as well as technical experience, among M\&O contractors were improved.

The following advantages were realized through the construction of the RFP package and the award process for the subcontracts:

- Comprehensive SOWs that complied with regulations were developed.

- The waste stream exhibits were developed with vendor input, which ensured good characterization for treatment/disposal options and pricing.

- Overall, the number of destination TSDFs was reduced. In addition, the certification of these TSDFs was ensured.

- The subcontracts were awarded to the "biggest and best" TSDFs for the greatest potential liability reductions.

- The subcontracts were awarded based on quality factors rather than lowest price, because technical excellence was rated before price. Total cost was not a primary criterion for award. Go/no-go requirements established minimum compliance and service requirements.

- The awareness and compliance postures of both successful subcontractors were improved significantly.

- Overall significant reductions in line item costs, resulting from volume discounts, were realized.

- Forced M\&O contractors to better identify and define their wastestreams. That information was consolidated in a single document.

The pre-bid conference provided a forum at which the following issues were clarified:

- Exportation of government-generated hazardous waste was explicitly forbidden. Exportation of U. S. Government generated hazardous wastes is prohibited under the Basil Convention, which, although not yet ratified by the United States, is being observed by Government agencies (See 57 FR 20602). The Buy American Act, as amended, also encouraged the retention of waste treatment/disposal procurements to United States companies operating within the continental United States.

- Waste streams for which no treatment technologies existed were eliminated from the pricing schedules before the proposal due dates. If a proposer was unable to bid treatment or disposal for a particular item, such as mercuric chloride and dioxins, the proposer would be disqualified; therefore, these items had to be removed because of the absence of available treatment technology. 
- The transportation statement of work and subsequent pricing sheet were modified to more clearly represent actual transportation charges for the proposers.

\subsubsection{Disadvantages}

The RFP required five addenda before the evaluation and award could be made; this caused a major delay in the schedule. Each addendum was required in order to clarify more questions and issues posed by the vendors.

\subsubsection{Issues}

3.4.4.1 Coordination Among Sites. The M\&O contractors were not prompt with respect to returning reviewed documents with written comments to the lead laboratory on schedule.

The M\&O contractors did not retain the same personnel for the entire review cycle of the documents and subsequent bidding process.

3.4.4.2 Schedule. The front-end schedule slip was not reflected in the total life cycle. The final award dates were not allowed to slip, resulting in a significant compression of the ESH\&Q liability assessment process.

3.4.4.3 Scope. No scope of the RFP process issues was identified.

3.4.4.4 Budget. No budget of the RFP process issues was identified.

3.4.4.5 Content. The content of the RFP package can be a dynamic metric. The contents must define all of the contractor's requirements for the requested services. Therefore, it must be carefully constructed and must represent an analysis of the entire M\&O contractor waste management life cycle. The analytical weakness in some $\mathrm{M} \& \mathrm{O}$ contractor waste management programs became apparent during the bidding process.

3.4.4.5.1 Request for Proposal-Based on an evaluation of actual services received, more detailed service requirements as go/no-go requirements should have been established.

Liquidated damages for regulatory violations and costs should have been clarified. Penalties for performance problems, such as Certificate of Destruction/Disposal (CD) returns and lab packing services, should have been clarified.

3.4.4.5.2 Statements of Work-The SOWs generated for some of the M\&O contractor site requirements were not accurate representations of actual site needs.

3.4.4.5.3 Pricing Sheets-Some waste stream descriptions, such as mercury contaminated debris, were not accurate representations of the wastes actually generated. In the case of mercury contaminated debris, line items listing fluorescent tubes, mercury switches, waste mercury liquids, etc., should have been added for clarification for proper treatment and pricing. 
Waste stream pricing should have been consistent from one M\&O contractor's pricing exhibit to another. The same treatment/disposal options should have been priced consistently throughout the schedules. During the review of the vendor's completed price proposals, pricing inconsistencies were identified. Some of the line item price variations were significant.

As previously stated, EG\&G Rocky Flats noted that probably the most inconvenient and unrefined aspect of the subcontract was their line item price schedule. Each time they amend a profile, even a minor administrative change to add a waste code, they mast also do a corresponding change to the appropriate subcontract line item.

3.4.4.5.4 Terms and Conditions-The T\&Cs provided in the bid process were not current.

\subsubsection{Resolutions and Recommendations}

3:4.5.1 Coordination Among Sites. The M\&O contractors should commit through MOUs to retain the same personnel, if possible, for the entire review cycle of the documents and subsequent bidding and subcontract award processes. This should aid in ensuring that consistency is retained throughout the development evaluation periods. If personnel must be reassigned, the replacement staff must be trained to the same rigor as the personnel replaced.

All agreements and policy decisions regarding any aspect of the RFP packages and bid requirements must be written and formally issued through formal letter transmittals. These documents must become part of the quality records documenting the subcontract process. The record retention of these documents should assist personnel in understanding the decisions regarding the content and award of the subcontract should personnel change during the life cycle of the subcontract.

3.4.5.2 Schedule. The RFP process should be scheduled properly. Enough time should be allowed to compensate for actual process analysis and documentation development. Time slots should be built into the process to allow addenda to be issued, as needed, without compromising the remainder of the process. The schedule should permit the early award of the subcontracts, with actual activation dependent upon the completion of prior subcontract performance periods.

3.4.5.3 Scope. No scope of the RFP process issues was identified; therefore, no recommendations or resolutions are presented.

3.4.5.4 Budget. No RFP process budget issues were identified; therefore, no recommendations or resolutions are presented.

3.4.5.5 Content. The main recommendation regarding the content of the RFP package is that the policies, such as the decisions concerning preferred treatment technologies and selection of the consolidated standard terms and conditions regarding the process, must be documented. Each M\&O contractor must understand and agree, in writing, to the policies before the documents are developed.

3.4.5.5.1 Request for Proposal-Actual service performance indicators should be defined in the RFP. Examples of criteria include vendor responsiveness to scheduled and emergency requests, such as time limits for waste shipment profile approvals and the return of completed manifests and CDs. Requirements for tracking manifests from the point of origin to the ultimate disposal site should be 
clarified as a performance indicator. The quality of vendor staff, such as chemists and technicians should be quantified in the RFP as a performance indicator. Penalty clauses for nonperformance to specifications should be established.

3.4.5.5.2 Statements of Work-The participating M\&O contractor staff assigned to prepare the SOWs should be instructed in the purpose and scope of an SOW before developing or modifying an existing SOW. The M\&O contractors should have a program in place to evaluate the waste management life cycle requirements for each site in order to define the actual requirements requested from the vendors.

3.4.5.5.3 Pricing Sheets-As with the SOWs, the participating M\&O contractor staff assigned to prepare the pricing sheets should be instructed in the purpose and scope of the pricing sheets before developing or modifying the existing exhibits. The M\&O contractors should have a program in place to evaluate the waste management life cycle requirements for each site in order to define the actual waste streams generated by the site.

Before the next competition, the pricing sheets should be evaluated, with the assistance of the successful vendors, to determine which waste stream descriptions should be combined and which should be further divided for clarification.

The solution that EG\&G Rocky Flats proposed to their particular problem was to develop line items that are more generic and flexible in nature, while maintaining the restrictions necessary to obtain the best treatment/disposal pricing. For example:

- They could have one line item for destructive incineration of organic debris, with all common waste codes for spent solvent contamination, all common toxicity characteristic leaching procedure (TCLP) metals, all RCRA "P" and "U" listed hazardous waste codes, etc. However, they note that vendors typically provide better pricing for "soft wastes" with these same waste codes, because this physical description presents a lesser burden for them to treat, i.e., easier on the kiln than other organic debris is.

- EG\&G Rocky Flats noted that they had numerous line items for lab packs, each with a different combination of waste codes. The only distinctions either subcontractor made in pricing these items or in their treatment/disposal destination was based solely on whether the waste stream was an aerosol, solid, or liquid. Therefore, and assuming other proposing vendors agree, the next solicitation could have fewer, more generic line items for lab packs destined for incineration, with a broad range of waste codes allowed for each, differentiated only by characterization as solids, liquids, or aerosols.

- EG\&G Rocky Flats noted that they solicited pricing for "bulk waste shipments," which they now consider to be a very broad request. One vendor bid a price for solids, a per-ton price; the other bid a price for liquids. Therefore, if EG\&G Rocky Flats has a bulk quantity of either liquids or solids to ship, they do not have a "competitive" comparison available and must solicit at least one bid. They may then have to modify one of the task orders, depending upon who receives the waste. They believe that they can improve the pricing solicitation by requesting bulk prices for solids, liquids, sludges, debris, etc., and further break these out by treatment type (i.e., direct landfill, solidification/landfill, liquids incineration, solids 
incineration, etc.) This solution could result in fewer task order modifications because more descriptions and treatments would be provided.

3.4.5.5.4 Terms and Conditions-A uniform set of T\&Cs should be established. These should specifically include ESH\&Q requirements. They should also reflect the 48 CFR $\$ 970$ regulations and the 10 CFR $\$ 830.120$ requirements.

In addition, regulatory changes, e.g., the promulgation of 48 CFR $\$ 970$, which affect the T\&Cs should be incorporated immediately into the T\&Cs, and a method for incorporating these changes into the subcontract should be established.

\subsubsection{Vendor Perspective}

3.4.6.1 Chemical Waste Management, Inc. Limiting the number of acceptable outlets caused several challenges for CWM's system. CWM strongly encourages and supports strict oversight of all subcontractors; however, in a rapidly changing hazardous waste environment, multiple new niche service providers are now available, e.g., fluorescent tube recylers. CWM audits its subcontractors and maintains a broad diverse spectrum of waste treatment, recycling, and disposal outlets. Limiting the use of this national network increases costs and complicates CWM's normal internal processing of wastes.

CWM, as one of the largest hazardous waste companies, supports the strong indemnification of our clients. Through this indemnification, CWM routinely incorporates management of waste through nonCWM facilities. Virtually all of CWM's major clients use the entire network of CWM and non-CWM facilities without reservation.

As a large DRMS contractor, CWM is accustomed to submitting a list of disposal facilities to be used for the contract. Additional facilities, may be used pending DRMS approval before use. All waste must be tracked to its ultimate disposal or treatment point with each final invoice. The system works very well.

3.4.6.2 Rollins Environmental Services, Inc. No comments were submitted regarding the content of the RFP.

\subsection{Bid Evaluation}

\subsubsection{Process Description}

The consolidated RFP contained an attachment called the Proposal Submittal Form (Enclosure 7) which the potential vendors were required to complete. The Proposal Submittal Form provided the basis for the technical response to the RFP. This form contained 26 go/no-go criteria which the vendors had to complete in order to be considered responsive to the RFP. The go/no-go criteria were conditions specifically identified in the SOWs which the various M\&Os considered crucial to the successful administration of the subcontracts.

The bid evaluation was conducted by reviewing the technical responses from the vendors and determining whether or not the vendors had met the go/no-go criteria. No selection board was convened 
for this effort. Each of the M\&Os was required to send a representative to the lead laboratory to review the bids with respect to their respective SOWs. Price per unit volume was not considered during this phase of the evaluation, only the technical merit of the proposals.

Once the technical response evaluation was complete, those vendors meeting all of the go/no-go criteria were evaluated by the assigned EG\&G Idaho subcontract administrator to determine which two proposals provided the lowest overall five-year cost. These two vendors were selected for the next phase of the evaluation which was the ESH\&Q and Financial Liability Assessment.

Each facility, both vendor-owned and subcontractor-owned, was assessed in order to verify the compliance status, capacity, and capabilities described in the bid proposals. Failure of any facility to pass the assessments would result in disqualification of the vendor, and the next lowest vendor who passed the technical evaluation would then be assessed. This process is used until such time as two vendors are completely acceptable. The details of the content and conduct of the ESH\&Q and Financial Liability Assessments are discussed in Section 4 of this report. Once the assessments were complete, the recommendations to award, or not award, the subcontracts were made.

\subsubsection{Advantages}

The use of go/no-go criteria for a technical response versus using a selection board evaluation removed the tendency of members of a selection board to favor one vendor over another. The members of the evaluation team were required to review the technical merit of the proposal only; no consideration was afforded to previous use of vendors and special arrangements that may have developed among the vendors and the $M \& O$ contractors.

The vendors were apprised during the bidding process of which criteria were crucial to a successful bid proposal.

The go/no-go criteria were clearly defined for each M\&O contractor's operation.

Go/no-go criteria ensured that one vendor would not undercut another on price thereby winning the subcontract without providing a clear definition of services provided for the price. This subcontract emphasized service and proper treatment/disposal versus lowest price-per-unit volume.

\subsubsection{Disadvantages}

The potential for a site to lose a long-term hazardous waste treatment/disposal vendor because of technical inadequacy for this subcontract was possible.

\subsubsection{Issues}

Original plans called for all $\mathrm{M} \& O$ contractors to perform a technical review of the proposals at their own sites in a 10-day period, followed by a meeting in Las Vegas, NV to determine the two finalists. The history of this project indicated that the $M \& O$ contractors were not good at meeting review response deadlines of this type. 
Attempts to get the vendors who passed the initial evaluation to pass subsequent steps of the evaluation, such as the ESH\&Q Liability Assessments, was difficult.

\subsubsection{Resolutions and Recommendations}

Because of schedule constraints and past $M \& O$ contractor response times, the INEL required that each M\&O contractor send one representative, who was familiar with the technical specifications in their own SOWs in the RFP, to Idaho Falls for three to five days. The representatives were required to spend this time at the INEL reviewing the technical proposals. This allowed the people to concentrate on the evaluation without the interruptions of day-to-day operations.

The requirements for a successful response to each of the go/no-go criteria should be defined in such a way that confusion is eliminated. In addition, the scope and acceptance criteria required in the ESH\&Q liability assessments should be defined better at the pre-bid conference.

\subsubsection{Vendor Perspective}

3.5.6.1 Chemical Waste Management, Inc. Using a consistent format to evaluate each facility was very helpful. Once CWM understood the process, the program advanced much more quickly.

3.5.6.2 Rollins Environmental Services, Inc. No comments were submitted regarding the bid evaluation.

\subsection{Subcontract Award}

\subsubsection{Process Description}

After two subcontractors have met the mandatory requirements (including the ESH\&Q Liability Assessments), are deemed responsive, and have submitted the low priced proposal, MTS award is accomplished by issuing a revised copy of the MTS Sample Subcontract referenced in the RFP documents, which provided a framework for the actual MTS document. Several areas of the MTS Sample Subcontract that were left blank (supplier name, actual period of performance, and etc.) during the procurement process are completed based on the competitive award of the MTS. The actual MTS document is provided to the successful subcontractors with a required signature blank. The subcontractor acknowledges the signature blank and returns the MTS, signed by the supplier, to the single M\&O contractor responsible for administering the MTS for the remainder of the M\&O contractors. The single $M \& O$ contractor then distributes the signed agreement to the remainder of the M\&O contractors.

\subsubsection{Advantages}

The advantage of providing all of the subcontract documents in the RFP is that the vendors are notified at the outset of the proposal what the requestor's administrative and operational requirements are. This reduces the likelihood of protests or protracted negotiations upon award of the subcontract. 


\subsubsection{Disadvantages}

No disadvantages regarding the subcontract process were identified.

\subsubsection{Issues}

No issues regarding the subcontract process were identified.

\subsubsection{Resolutions and Recommendations}

No resolutions and recommendations regarding the subcontract award process are presented.

\subsubsection{Vendor Perspective}

3.6.6.1 Chemical Waste Management, Inc. No comments were submitted regarding the subcontract award process.

3.6.6.2 Rollins Environmental Services, Inc. No comments were submitted regarding the subcontract award process. 


\section{DESCRIPTION OF THE CONSOLIDATED ESH\&O LIABILITY ASSESSMENT PROCESS}

The Superfund Amendments and Reauthorization Act (SARA) and CERCLA assign joint and several liability to all responsible parties for releases of hazardous substances into the environment. Responsible parties can include TSDF owners and operators, past owners and operators, transporters, and persons contracting or arranging for disposal. Therefore, the DOE and its M\&O contractors that generate and contract for the disposal of hazardous waste could be liable for all or part of the cost of remedial cleanup if the offsite TSDF lacks the capacity to pay for cleanup. In addition, the DOE M\&O contractors are considered sophisticated in their knowledge of environmental, health, and safety requirements. Contracting with a vendor who is obviously deficient in these areas could give rise to a negligence claim for failing to adequately investigate the vendor's abilities. In order to reduce the potential liability inherent in dealing with an offsite contractor who is not under the direct control of a DOE M\&O contractor an ESH\&Q liability assessment program with the purpose of evaluating potential and current offsite contractors with respect to environmental compliance was established. This program has been adopted by EG\&G DOE Support Services corporate division, for all of its other DOE M\&O contracts. It is believed that this evaluation process provides a clearer picture of the risks associated with a contractor who aids the EG\&G M\&O contractors in making the best decisions with regard to selection of offsite subcontractors.

The concept of environmental auditing developed as a means of providing assurance to management that its ES\&H responsibilities were being adequately discharged and that no significant noncompliances existed. According to Ann C. Smith writing in Environmental TQM "the concept and application were taken virtually wholesale from the financial audit field, where

audits evolved as a means of verifying compliance with bookkeeping practices. They were created basically to uncover cheating-which, of course, is still a prime audit application. The intent of compliance auditing is to identify operations where standards aren't being adhered to and to then force changes in practices-or people-to make sure that standards are met. A standard might be a specification, law, policy, procedure, contractual agreement, or the auditee's own documents" (Smith, 1994:214 and quoting Aquino, 1990).

The prime M\&O contractor at the INEL does not perform compliance audits of the commercial facilities. The INEL program, developed by EG\&G Idaho and adopted by Lockheed Idaho, is designed to perform ESH\&Q and financial liability assessments of the potential and subcontracted vendors. The reason assessments are conducted rather than audits is that the M\&O contractors do not have the legal and/or regulatory authority to conduct compliance audits. In addition, audits are designed to identify specific violations of requirements. This assessment process examines specific problems but extrapolates from those items the potential long-term liability issues that may arise and estimates the probability that they will arise. These functions are reserved for regulatory agencies such as the EPA. Therefore, Lockheed Idaho performs assessments designed to identify and manage potential liability issues arising from operations at the commercial TSDFs who are subcontracted to treat and/or dispose of INELgenerated regulated wastes.

The ESH\&Q and liability assessment program is driven by the following federal regulations, DOE Orders, and policies: 
DOE regulations - 10 CFR $\S 830$ requires that procured items and services meet established requirements and perform as specified. Prospective suppliers must be evaluated and selected on the basis of specified criteria.

DEARS - 48 CFR $\S 970$ - requires compliance with regulations promulgated by EPA, DOE, United States Department of Transportation (DOT), executive orders, etc.

DOE-HQ Order 5480.1B and DOE-ID Order 5480.1B-ID - require that contractors ensure that proposed subcontractors operate in compliance with ES\&H regulations and requirements.

DOE Order 5480.1B Change 4, "Environment, Safety, and Health Program for Department of Energy Operations," requires the liability assessments. Section 8, 20d, Responsibilities and Authorities, states: "Heads of Field Organizations are responsible for assuring that all operations under their jurisdiction are carried out consistent with sound ES\&H practices and in accordance with ES\&H Orders. In carrying out this responsibility the Heads of Filed Organizations shall: In the selection of contractors, ensure the ability of offerors to meet ES\&H requirements. Assure the applicable environment, safety, health, and quality assurance requirements are included in contracts." In addition, the order states that Heads of Field Organizations shall: "Execute programs and assure that contractors and their subcontractors execute programs and policies in a manner that complies with mandatory requirements relating to ES\&H," and, "Appraise the programs, projects, and facilities of subordinate filed activities in accordance with DOE 5482.1B and other DOE 5480 series Orders." These subcontractors' site liability assessments are the only reliable method to reduce the probability of future cleanup actions and associated costs.

DOE-HQ Order 5482.1B - requires that M\&O contractors ensure that all subcontractors operating under the M\&O Subcontract do so in compliance with ES\&H regulations and requirements. This would include subcontractors to the prime $\mathrm{M} \& \mathrm{O}$ contractor.

DOE-HQ EM-332 Policy - requires ES\&H audits of hazardous waste subcontractors

The protocol generally employed to meet the requirements is the use of the EPA multimedia inspection, which addresses: Atomic Energy Act (AEA), CAA, CWA, CERCLA, Hazardous Materials Transportation Act (HMTA), Hazardous and Solid Waste Act (HSWA), Mine Safety and Health Act (MSHA), Occupational Safety and Health Act (OSHA), RCRA, SDWA, SARA, TSCA, NRC requirements, and applicable regulations promulgated by the states and local legislation.

\subsection{Team Composition and Qualifications}

\subsubsection{Process Description}

In order to meet these requirements, it is essential that the assessment teams be trained to the same level and rigor as that described in DOE Order 5480.1B. Therefore, the project schedule included defining a training plan and implementing training for personnel from all of the sites. The assessment team areas of expertise are environmental regulations, transportation, quality assurance and quality control, and OSHA compliance. 
Personnel attending the training were required to have the following minimum qualification and . prerequisite skills:

- Certified ESH\&Q auditor, lead preferable.

- Must have conducted at least two ESH\&Q audits or assessments within the last year (on-site surveillances were acceptable).

- Must have expertise in at least six of the "areas of expertise" shown in Table 4.

- Must have attended 40-hour OSHA (also known as hazardous waste operations and emergency response (HAZWOPER)) class and a current 8-hour OSHA refresher.

- Must be respirator qualified-[half-face, full-face, and self-contained breathing apparatus (SCBA)].

- Must have attended hazard communication training.

- Must know the difference between commercial ESH\&Q requirements and those specific to DOE and nuclear facilities.

- Must own basic safety equipment--steel-toed boots or shoes and safety glasses. If wearing prescription glasses, they must have safety frames/lenses with side shields. If wearing contact lenses, safety glasses must also be worn

- Must be proficient in the use of WordPerfect ${ }^{\mathrm{nx}}$ software.

Personnel from REECo and EG\&G Rocky Flats participated on the INEL Assessment Team conducting the pre-award liability assessments for the INEL subcontract. The participants received first hand experience regarding the rigorous detail and demanding schedule associated with these assessments.

Each of the EG\&G M\&O contractors was required to provide at least two qualified individuals to participate in the assessment process. A training class was held in Idaho Falls, Idaho in January 1993 the purpose of which was to provide training specific to the procedures that would be used to assess the proposed facilities. The training was particularly important, because although traditional audit practices were used to conduct the assessment, the final product of the assessment is radically different from the product of an audit. Audits identify specific cases of noncompliance, and target them for correction. The assessment process identifies noncompliances only to the extent that they may indicate larger liability issues, such as the vendor's overall ability to stay in compliance. The training program was formalized in order to ensure that the participants would be certified to conduct the ESH\&Q liability assessments upon completing the course. The following topics were addressed during the training: scope of the assessment (i.e., pre-award assessment as opposed to an annual review or surveillance); required documentation, forms, and checklists; an overview of the content and requirements for the final reports; preparation for an on-site assessment; conduct of the on-site assessment; post-assessment procedures; and an introduction to the use of the Audit Master ${ }^{\text {nt }}$ software package. A copy of the training program is provided in Appendix $\mathrm{C}$ of this report. 
Table 4. ESH\&Q areas of expertise and checklists, based on Audit Master" module titles.

\begin{tabular}{|c|c|c|}
\hline ESH\&Q Area & Legislation & Regulations \\
\hline Air Quality & CAA & 40 CFR $8850-52,60,61,124$ \\
\hline $\begin{array}{l}\text { Solid and Hazardous Waste especially } \\
\text { the following requirements: generator, } \\
\text { interim status, and permitted TSDF, } \\
\text { recycling, permit applications, land } \\
\text { disposal restrictions (LDR), boiler and } \\
\text { industrial fumace (BIF) }\end{array}$ & RCRA, HSWA, CERCLA & $\begin{array}{l}40 \text { CFR } 88824,124,148,257-258 \text {, } \\
260-272,280-281\end{array}$ \\
\hline Spill Prevention and Control & $\begin{array}{l}\text { CWA, RCRA, CERCLA, SARA, } \\
\text { TSCA }\end{array}$ & $\begin{array}{l}40 \text { CFR } 88110,112,117,300,302 \text {, } \\
761\end{array}$ \\
\hline $\begin{array}{l}\text { Storage Tanks (above and } \\
\text { underground) }\end{array}$ & RCRA, HSWA & 40 CFR $\$ \S 280-281$ \\
\hline Toxic Substances Control & TSCA & 40 CFR $8717,761-762,796-798$ \\
\hline Water Quality & CWA, SDWA, RCRA & $\begin{array}{l}40 \text { CFR } \$ 8110,112,116-117,121- \\
125,130-131,136,141-148,260,264- \\
265,311,400-699,43 \text { CFR } \& 11\end{array}$ \\
\hline $\begin{array}{l}\text { Community Right-to-Know/ Chemical } \\
\text { Risk }\end{array}$ & SARA II, SARA III & $\begin{array}{l}40 \text { CFR } \$ 8302,350,355,370,372 \text {, } \\
373\end{array}$ \\
\hline Remedial Actions & RCRA, CERCLA, CWA & $\begin{array}{l}40 \text { CFR } \$ \& 24,300,302,373 \\
43 \text { CFR } \& 11\end{array}$ \\
\hline Hazardous Materials Transportation & $\begin{array}{l}\text { Transportation Safety Act (TSA), } \\
\text { HMTA }\end{array}$ & $\begin{array}{l}10 \text { CFR } \$ \$ 30,50,71,110 \\
49 \text { CFR } \$ 8101,171-180,300,340, \\
390\end{array}$ \\
\hline $\begin{array}{l}\text { Hazard Communication and Hazardous } \\
\text { Worker }\end{array}$ & OSHA, MSHA & 29 CFR \& 1910 \\
\hline Occupational Medicine & OSHA, MSHA & 29 CFR \& 1910 \\
\hline Quality Assurance & $\begin{array}{l}\text { CWA, CAA, RCRA, CERCLA, } \\
\text { TSCA }\end{array}$ & $\begin{array}{l}40 \text { CFR } 8850,53,61,122,129,130 \text {, } \\
136,143,240-241,260-280,300,402 \text {, } \\
710,717,792 \\
\text { EPA, QAMS-005/80, EPA, QAMS- } \\
\text { 001/80, EPA-SW-846, EPQ-600/2-80- } \\
\text { 018, EPA Contract Lab Program. }\end{array}$ \\
\hline Nuclear Regulatory Compliance & AEA & $\begin{array}{l}10 \text { CFR } 8 \& 20,21,30,40,51,61,71 \text {, } \\
40 \text { CFR } \& 61, \text { NQA-1 }\end{array}$ \\
\hline
\end{tabular}

Table 5 lists the final assessment team composition. Several individuals who attended the training course were not able to participate in the actual assessments because they had individual site program obligations or personal obligations. The loss of those participants resulted in a unreasonable demands being placed upon the remaining members as a result of the schedule, scope, and budget considerations. The issues are discussed below. 
Table 5. EG\&G ESH\&Q liability assessment program participants.

Name of participant

Company affiliation

E. H. Baker

J. A. Ciucci

N. J. Fix (Lead)

R. J. Kieffer (Contract)

R. J. Molter

D. E. Trump

G. D. White
EG\&G Energy Measurements, Inc.

EG\&G Rocky Flats, Inc.

EG\&G Idaho, Inc.

EG\&G Mound Applied Technologies, Inc.

EG\&G Rocky Flats, Inc.

Reynolds Electrical and Engineering

Company, Inc.

EG\&G Energy Measurements, Inc.

\subsubsection{Advantages}

A consolidated team composed of qualified ESH\&Q professionals from each M\&O contractor had the following advantages:

- The consolidated team could be composed of specialists from each site, thereby relieving one site of losing all of its specialists for the duration of the assessment period.

- Strong environmental assessments with a good mix of specialist team members eliminates "high-risk" locations.

- Ensures that all major areas of expertise are adequately represented. (Not every site has experts in all areas.)

- It was the opinion of the Legal Departments that the use of a strong team could reduce the basis for negligence suits for the following reasons:

- The consolidated team would eliminate the regulator's argument that, if one DOE site rejected a facility as unacceptable, other DOE sites "should have known better" and not approved the facility.

- The use of a consolidated team ensures that consistent and quality criteria are used to evaluate the TSDFs.

\subsubsection{Disadvantages}

The main disadvantage for the M\&O contractors was the loss of prime staff members for the duration of the assessment process. 
It became apparent during the process that there was a shortage of well-trained and experienced . ESH\&Q professionals who could conduct audits or assessments in the DOE system. This deficiency has also been documented in the private sector.

\subsubsection{Issues}

4.1.4.1 Coordination Among Sites. EG\&G Idaho issued the request for training course participation in December 1992. The M\&O contractors were requested to provide at least two individuals with qualifications as described above. Several managers responded that personnel would not, or could not, be provided. Written direction from EG\&G was required in order to ensure that the M\&O contractors would honor the request to provide personnel.

4.1.4.2 Schedule. The training course was presented in January 1993; however, the actual assessments did not begin until April 1993. This delay between the course and the conduct of the assessments allowed toomuch time so that some personnel were removed from the project by their respective $\mathrm{M} \& \mathrm{O}$ contractor managers and assigned to other projects. The delay also contributed to participants forgetting program-specific requirements and details.

4. 1.4.3 Scope. The scope of the training course initially appeared to be sufficient; however, in retrospect, based upon the actual qualifications of the personnel, several areas of instruction should have been expanded.

4. 1.4.4 Budget. No specific budget issues were identified regarding the team composition and qualification.

4. 1.4.5 Content. As with the scope of the training course, the content initially appeared to be sufficient; however, in retrospect, several areas were not sufficiently addressed and stressed.

One participant stated that, upon completing the training session, he misunderstood the emphasis that were to assume. An accurate picture of the task sequence or scope of the process was not well defined.

\subsubsection{Resolutions and Recommendations}

4.1.5.1 Coordination Among Sites. Based upon experience, written commitments from each of the direct and indirect managers should be obtained in order to ensure that necessary personnel are provided. The commitments should be obtained at the outset of the project, and not as a last resort during the period of activity. If an M\&O contractor is absolutely unable to supply personnel, then that $\mathrm{M} \& \mathrm{O}$ contractor has the obligation to negotiate and fund a participant who has qualifications acceptable to the lead laboratory program manager and the $\mathrm{M} \& \mathrm{O}$ contractor. A written agreement, in the form of a memorandum of agreement, should be obtained documenting this assignment.

Once personnel are committed for the assessment program and the training class, they cannot be removed. If an $M \& O$ contractor believes that it cannot support the program with two individuals and still maintain its own operations, that contractor must notify the program manager of the lead laboratory and negotiate either the addition of one or two more qualified individuals or directly fund the addition 
of qualified personnel chosen by the lead laboratory to represent the M\&O contractor for the duration of the project.

4. 1.5.2 Schedule. The training class should be held within a month of the scheduled assessments in order to ensure that personnel are ready to conduct the assessments without requiring a refresher course. If the schedule for the assessments is slipped as a result of procurement or scheduling issues, a one-day refresher course should be conducted before the actual conduct of the first assessment.

4.1.5.3 Scope. The scope of the actual training program should not require changes, as long as the personnel meet the minimum mandatory qualifications. However, a written response from the M\&O contractors to the program manager of the lead laboratory as to the actual qualifications of their proposed participants should be obtained at least one month before the training class is conducted in order to ensure that the scope of the training is adequate and appropriate.

4:1.5.4 Budget. No budget recommendations required.

4.1.5.5 Content. The content of the training program resolution should reflect the scope resolution. In addition, those areas of weakness identified in the original program should be modified before this training course is used again for a pre-award assessment program.

Training should address scope, sequence of the process, and the schedule. The pre-assessment coordination should be emphasized, along with assessment criteria, report format, and personnel responsibilities. Each participant should be particularly instructed as to preparation work required before arrival at the site for the inspection, and what to do upon arrival at the site.

\subsection{Assessment Criteria}

The criteria used for all vendor assessments consist of checklists generated by the commercial software package Federal Audit Master ${ }^{\mathrm{Ix}}$, with additional checklists developed inhouse or from published sources. The Audit Masterri addresses all of the areas described in Table 4, including NRC requirements. Additional checklists were developed for quality assurance and corrective actions.

The Audit Master ${ }^{\mathrm{Tx}}$ was chosen because it was a complete management tool containing complete regulatory citations, questions addressing compliance with the regulations, and cross references to other modules with the same or similar requirements. The Audit Master ${ }^{\text {Tr }}$ provided consistent results and complete coverage for the assessments. Results of assessments and the qualifications of the facilities could be compared directly.

\subsubsection{Process Description}

Environmental audit checklists were used for part of the facility appraisal. These checklists tested compliance with regulations promulgated by the EPA. The checklists used were generated by the Audit Master ${ }^{\text {tx }}$ environmental audit checklist, which is a commercially available computer software program that generates facility specific audit checklists. (See Section 10.5 for references.) The Audit Master ${ }^{\text {rx }}$ checklists concerning solid and hazardous waste (RCRA, HSWA, CERCLA), water quality (CWA, SDWA), air quality (CAA), and EPCRA [Emergency Planning and Community Right-to-Know Act] 
(SARA II, III), Industrial Hygiene, Hazardous Materials Transportation (HMTA), Occupational Medicine, Personnel Safety (OSHA), PCB management (TSCA), storage tank programs (RCRA, HSWA), and spill prevention (CWA, RCRA, SARA, CERCLA) were generated on site during the interviews with facility representatives. These checklists are kept as part of the assessment record. Additional checklists were used to address quality assurance and remedial actions.

\subsubsection{Advantages}

The Audit Master ${ }^{\mathrm{Tx}}$ software is updated at least twice a year. The updates include regulatory updates and associated audit questions, as well as software enhancements; these updates ensure that the checklists are current.

The software ensures that evaluations of each facility are consistent.

The software runs on portable computers. This allows the team to carry less paper and to work on the assessments while traveling.

\subsubsection{Disadvantages}

The Audit Master ${ }^{\text {ix }}$ contained federal regulations only. Additional review of state promulgated regulations was required for accuracy.

\subsubsection{Issues}

At the time of the 1993 assessments, the Audit Master ${ }^{\text {Ix }}$ did not adequately address boiler and industrial furnace (BIF) requirements (40 CFR $\S 266$, Subpart H) and requirements for recyclers.

The quality assurance checklists used for the assessments were not generally available. Therefore, consistency of quality assurance criteria was not maintained if personnel changed.

\subsubsection{Resolutions and Recommendations}

Discussions have been held with regulatory and systems analysts employed by Utilicom, the developer and marketer of the Audit Master ${ }^{\mathrm{TW}}$ regarding the BIF and recycling deficiencies noted in the Audit Master modules. The Utilicom representatives have stated that these deficiencies will be addressed in a subsequent release of the software. The company is considered exceptionally receptive to users' comments regarding the content and use of the software package.

The quality assurance checklists should be formalized and copies made available to all team members before the next annual review or pre-award assessment program.

\subsection{Pre-Award Assessment Process}

\subsubsection{Process Description}

The ESH\&Q and financial liability assessment consisted of pre-assessment, on-site inspection, post-assessment, financial evaluations, a risk assessment of the facilities, and a final report. The liability 
assessment process uses observations of the facility at a single point in time. Based on these observations, the probability of future environmental problems is projected. In addition, the risk of DOE or EG\&G M\&O contractor liability, should a problem occur, is included in the risk assessment. The liability assessment is not intended to evaluate whether a facility is, or is not, in actual compliance with environmental, safety, and/or health laws or regulations. These assessments become a benchmark of the facility and/or company operations in question.

The ESH\&Q liability assessment examines compliance with regulations promulgated under the CAA, CWA, CERCLA, HMTA, HSWA, MSHA, OSHA, RCRA, SDWA, SARA, TSCA, and applicable regulations promulgated by the NRC and the state in which the facility is located, and with local legislation.

The ESH\&Q and financial liability assessment includes the following:

- On-site review of the RCRA and PCB TSD facilities operations

- Examination of facility plans and construction

- Examination of all applicable permits and facility records, including manifests and certificates of disposal/destruction

- Review of where the waste materials went (cradle to grave)

- EPA, state, and local regulatory observations of the facilities and opinions of the communities near which the facilities are located

- Opinions of other businesses that use the facilities

- Review of other parties that take title of the waste or materials

$\therefore \quad$ Review of transporters

- Review of the EG\&G master task subcontract for adequacy

- Financial condition of the facilities/parent and ability to pay for potential cleanup and lawsuits.

Financial analyses consist of review of insurance policies, closure and post-closure cost estimates, financial assurances and capacity and capital of the company.

Federal, state, and local regulatory agencies are contacted for observations of the facility. Local agencies, such as the Chamber of Commerce, are contacted for public relations comments.

The liability assessment process uses observations of the facility at a single point in time. Based on these observations, the probability of future environmental problems is projected. In addition, the risk of DOE or M\&O contractor liability, should a problem occur, is included in the risk assessment. The liability assessment is not intended to evaluate whether a facility is, or is not, in actual compliance with environmental, safety, and/or health laws or regulations. 
Facilities proposed for new contract awards also undergo pathway analyses of potential groundwater, surface water, and air contamination, and a receptor analysis of potential populations and environments that could be at risk from activities conducted at the facility. The purpose of a pathway analysis is to determine potential paths that pollutants could take that would significantly degrade the quality of a natural resource. The receptor analysis uses information from the pathway analysis and determines the potential risk to neighboring populations from a release of pollutants at the facility in question.

The final assessment task is to compile all of the information gathered and conduct a liability risk assessment of the facility. This risk assessment determines whether the facility is acceptable, is acceptable with conditions, or is not acceptable for use by the M\&O contractors. Nothing in the report should be construed to be a statement on the facility's actual compliance or lack of compliance with any law, regulation, or requirement.

4.3.1.1 Coordination among Sites. Once a facility is selected to undergo a pre-award assessment, each participating M\&O contractor is contacted in order to obtain the services of a specified qualified member of the assessment team with specific expertise as defined in Table 4 . The team members are provided with copies of relevant information regarding the TSDF and given assignments that must be completed before the site inspection. The coordination requests are documented by letters and agreements among the M\&O contractors.

The size of the assessment team used for the pre-award assessment is based on the size and complexity of the TSDF to be evaluated. For example, a facility such as the Rollins Deer Park, TX facility which has two RCRA/TSCA incinerator trains, RCRA and TSCA container storage, tank storage, wastewater treatment plant, RCRA stabilization unit and landfill cell, on-site verification laboratory, and captive transportation unit, requires a team of at least six individuals in order to adequately address all of the ESH\&Q requirements in a timely fashion (i.e., two days onsite or less). On the other hand, a smaller facility such as the CWM OSCO facility, which is a bulking facility with a verification laboratory, RCRA/TSCA container storage, tank storage, and a transportation unit, can be evaluated affectively in one day on site by four qualified team members.

4.3.1.2 Schedule. A pre-award assessment is generally scheduled to take about six weeks of effort by each member of the assessment team. This effort includes time scheduled for preparation for the assessment, time at the facility, and report preparation. Preparation for the assessment includes tasks such as review of information requested from the TSDF, applicable federal, state and local regulations, and regulatory contacts.

4.3.1.3 Scope. The scope of the pre-award assessment is designed to ensure that a full characterization of the TSDF or recycler is obtained. The report resulting from the assessment is considered a benchmark of the facility, which becomes the basis for further evaluations such as the annual review and surveillances. The pre-award assessment contains historical information regarding the facility, as well as current permit and operational information.

4.3.1.4 - Budget. Memoranda of understanding between EG\&G Idaho and each of the M\&O contractors were established as a mechanism to share the costs of the assessments. Upon completion of the tasks, the charges accrued to the project are calculated and invoices are issued to each participant for payment of their portions. 
4.3.1.5 Content. This section describes the pre-award assessment process as it is designed to be conducted. Members of the EG\&G Assessment Team which evaluated the potential subcontractors and facilities as part of the 1993 consolidated effort did not have the luxury of the time necessary to complete the assessments properly in accordance with this process.

4.3. 1.5.1 Pre-Assessment Process-The pre-assessment process consists of information gathering and is conducted using the telephone, mail, or electronic data base systems. The purpose of the pre-assessment review is to determine

- If, in the case of a TSDF, the TSDF waste management processes are compatible with wastes generated

- If, in the case of a recycler, the hazardous materials are being recycled in accordance with the regulations, and the facility properly disposes of any waste it generates

- The facility has had serious environmental, regulatory, financial, or legal problems that can be identified using the sources described as follows.

If a complete assessment had been conducted recently and a report was available, the report was requested and evaluated before proceeding with the pre-assessment. If the report information was inadequate or unavailable, the pre-assessment continued. The Assessment Team makes this decision with the concurrence of the program manager.

A LEXIS/NEXIS database search is conducted to identify any situations such as adverse publicity, criminal proceedings, and/or major environmental problems that could have a detrimental impact on any arrangements that the INEL or other M\&O contractors might make with the facility.

A Dun and Bradstreet search is conducted to collect the following information about a company: the financial condition, company rating and trends, net assets, and balance sheet information. The financial condition of the facility of interest may be collected and evaluated by the EG\&G Financial Services or Procurement Groups.

Regulatory contacts include, but are not limited to: the EPA; state regulators (e.g., the state water commission); and local regulators (e.g., city or county sanitation districts). Each regulatory agency should be contacted in order to obtain or verify the following information:

Permit status

CERCLA involvement

Existing contamination

Compliance problems
Inspection results

Financial compliance

Recommendations

In addition to the regulatory agencies, the assessor contacts city and/or county officials, the local chamber of commerce, and the Better Business Bureau in order to obtain opinions they might have concerning the conduct of operations and community opinions of the facility of interest. 
The TSDF or recycler was contacted through the vendor who bid the prime subcontract in order to collect the following information:

Site history and CERCLA involvement

Existing contamination

Ownership

Services and operations

Waste streams, or recyclable materials, accepted and not accepted

Permit status, including RCRA, air, and water
Insurance information

References

Other businesses that use and/or have assessed the TSDF

Regulatory compliance status

Assessment coordination procedures, only if a decision has been made to conduct an assessment.

Financial information

Businesses that have conducted a risk assessment or compliance evaluation of the facility are contacted. Their opinions of the facility are discussed, and they are asked to send a copy the results of any risk assessments or evaluations they have conducted of the TSDF or recycler.

The INEL subcontract, RFP, or RFQ with the TSDF or recycler are reviewed for adequacy. The following points are noted:

- Non-assignability clause

- Return of completed manifest before payment

- Certificates of destruction/disposal returned before payment

- Hold harmless, indemnification, contribution clauses

- Review by company attorney.

After a review of all of the above information, a determination is made as to whether an on-site assessment is necessary or if sufficient information has been obtained in order to complete an assessment report. If a determination is made by the Assessment Team leader, with the concurrence of the program manager (or designee), that sufficient information has been acquired, a risk evaluation and assessment report is completed using the instructions and format specified in the procedure.

4.3 1.5.2 On-Site Assessment-The Assessment Team conducts a site inspection of each of the facilities listed on the proposals. The purpose of the inspection is to observe and compare the operations of the facilities with their documentation and permit conditions. The site inspection consists of documentation reviews, process flows, and operational observations. Photographs are taken of various operations, and copies of relevant photographs are included in the assessment report. All of the photographs are kept as part of the assessment record.

4.3.1.5.2.1 Preparation for an On-site Assessment-The assessment date and assessment schedule are established with the TSDF contact and confirmed in writing. 
Arrangements are made with TSDF contact to have the following information mailed ahead for review before the site visit. This information should also be available for onsite review:

- Information on site history, pre-RCRA/TSCA waste disposal

- Consent agreements and responses to Notices of Violations

- All permits and corrective action plans

- Surface water, air, and groundwater monitoring data for the last three years

- Closure/post-closure plans, cost estimates and basis, and financial mechanism documentation

- Current Certificate of Insurance for Sudden and Nonsudden Incident, and a copy of policy

- Independently audited financial statements for the past three years

- Involvement in any Superfund sites or related active or pending environmental litigation

- Information on assignees to which waste is transferred

- Certificates of destruction or disposal

- Facility construction plans

- Emergency/contingency plans

- Manifests, bills of lading, records, reports, and notices

- Hazardous waste minimization plan

- Personnel training records

- Land use permits or documentation

A determination is made as to what wastes have been shipped from the M\&O contractors to the particular facility. Copies are made of shipping manifests. If a large number of.manifests are involved, a random selection is made to be used during the on-site evaluation.

A determination of whether the state in which the facility of interest is located has primacy in any areas of environmental protection. If the state has primacy in any area, the implementing regulations are reviewed and a checklist is prepared to address compliance with these regulations.

4.3 1.5.2.2 Conduct of the On-site Assessment-Checklists are used during the on-site assessment. These checklists include all applicable federal regulations and, where the state has primacy, applicable state regulations. The checklists can be prepared ahead of time, or if a computer program such as Audit Master ${ }^{\text {Tx }}$ is used, during the on-site inspection. If the Audit Master ${ }^{\text {Ix }}$ is not used, commercially 
available, or specially developed checklists may be used. However, these checklists must be reviewed and approved by the Assessment Team leader before the on-site inspection.

The on-site portion of the assessment begins with an introductory meeting with all applicable facility representatives and management. The purpose of this meeting is to discuss the conduct of the site inspection, document reviews, and facility representative interviews. The assessment team generally requests that the vendor's corporate proposal technical contact, or a proposed subcontract technical contact, accompany the team on the site inspection. The vendor's corporate representatives are a resource for both the assessment team and the company in that they can clarify issues and provide immediate feedback to the corporation regarding the status of the assessed facility.

The facility and operations are inspected in the sequence specified below using checklists for the specific type of facility:

- Waste arrival

- Waste storage

- Waste analysis and verification procedures

- Manifest verification

- Inspection of each unit

- Residues management

- Transportation into and out of facility.

Facility representatives are interviewed to assess management's understanding of the facility, regulations, and company's risk assessment procedures. The laboratory manager, facility manager, and environmental coordinator are included among those managers to be interviewed.

The documents and information listed in Table 6 were reviewed before and/or during the site inspection of the subject facility. The table is used in the report to summarize the status of the information requirements.

At the end of each day at the facility, a closeout meeting is held with all the TSDF management to discuss issues that may have arisen during the inspection. This is also the point at which potential regulatory noncompliances are identified. The facility management response to the closeout meetings is a critical measure as to the responsiveness of management and their commitment to maintaining regulatory compliance at the facility. Potential regulatory noncompliances are generally not specifically described in the facility assessment report because of the concern regarding the availability of the assessment reports under the Freedom of Information Act (FOIA). It is also not the intention of the assessment team to trigger a regulatory inspection of the facility by the EPA or the state. In addition, any identified potential noncompliances are important to the assessment only as they indicate the quality of the vendor's compliance program or the possibility of future liability problems for the M\&O contractors or DOE. 
Table 6. Documents and information reviewed concerning the subject facilities.

DOCUMENT/INFORMATION REVIEWED (R), DISCUSSED (D) OR NOT APPLICABLE (N/A)

Air Monitoring Data

Air Permits

Annual Hazardous Waste/Biennial Report

Bills of Lading

Bureau of Land Management (BLM) Right-of-Way Grant

CERCLA Off-Site Policy Approval

Certificates of Insurance for Sudden and Non-Sudden Incidents

Chain-of-Custody Procedures

Closure/Post Closure Plan

Conditional Use Permit

Emergency Response/Contingency Plan, including Spill Response and Cleanup Procedures

Facility Construction Plans

Final Environmental Impact Statement

Groundwater Monitoring Data

Groundwater Monitoring Plan

Hazardous Waste Manifests

Information concerning OSHA compliance

Information on assignees to which waste is transferred and final disposition of the waste

Inspection Records

Medical Surveillance Program

Notices of Violation and Consent Orders

Notification of Hazardous Waste Activities

Operations Record

Part A Permit Application

Part B Permit Application

Part B Permit

PCB Annual Documents Log

PCB Annual Report

PCB Exception Reports

Pending Environmental Litigation

Personnel Training Records

Provisions for transport of recyclable materials/hazardous waste to and from this facility 
Table 6. Continued.

\author{
Quality Assurance Plan \\ Safety Program Plan \\ Sample Aralysis Plans \\ SARA Reports \\ Sewage Permit \\ Solid Weste Disposal Permit \\ Spill Prevention Control and Countermeasures Plan \\ Standard Operating/Divisional Practices \\ TSCA Storage/Disposal Approval/Permit \\ Visitor's Log \\ Waste Analysis Plan \\ Water Discharge Data \\ Wastewater Permit
}

DOCUMENT/INFORMATION REVIEWED (R), DISCUSSED (D) OR NOT APPLICABLE (N/A)

By this point in the process, the experienced members of the assessment team generally have a good idea as to whether the specific TSDF and company are acceptable for inclusion in the proposed subcontract. A preliminary verbal decision can be returned to the subcontract administrator for status purposes. However, no firm decision is made until the assessment process is complete. If major risks are identified at this point, a decision may be made to cancel the procurement or issue further addenda allowing the proposers to correct deficiencies or substitute facilities. These decisions are made in concert with the subcontract administrator, assessment program manager, and assessment team members.

4.3.1.5.2.3 Post-Assessment Process-A TSDF Risk Evaluation following the instructions found in the EG\&G Idaho procedure is followed. An assessment report using format described in this procedure is also prepared. The facility file is completed.

4.3.1.5.3 Reports and Supporting Documentation-The following documentation is generated and/or maintained for each external assessment or risk analysis performed:

4.3.1.5.3.1 Formal Assessment or Risk Analysis Report-A formal assessment or risk analysis report is written for each facility evaluated. This document is prepared in accordance with EG\&G Idaho document preparation procedures, using the format described in the procedure and is controlled through the EG\&G Idaho Document Management System. An example of the boiler plate used for the pre-award assessment report can be found in Appendix D.

Because the material contained in the report is sensitive, dissemination of this document is strictly limited to a distribution list that the program manager has approved. Any deviation from the distribution 
list or additional requests for copies of the document must be submitted to the Assessment Team leader in writing and must be approved by the Team leader and program manager.

4.3 1.5.3.2 Telephone Conversations-All telephone conversations regarding the facility under evaluation must be documented using the EG\&G Idaho memo of conversation form or memo to file form. The forms must be typed or written in black indelible ink. These memos must be kept as a record in the facility file.

4.3. 1.5.3.3 Facility Files-A formal file is created and maintained for each facility being evaluated. The files are retained in the Environmental Protection Department of the lead laboratory. These files contain all correspondence, notes, completed assessment checklists, field notes, copies of permits and contracts, completed external assessment chronology log, regulatory contact checklist, risk assessment, external assessment report, and any other information that was collected and used during the facility evaluation. The contents of the files must be able to withstand a regulatory and/or quality assessment.

\subsubsection{Advantages}

The pre-assessment report contains a complete description of the facility in question. The report is designed to provide enough information that non-participants in the process can be assured that the correct decisions were made.

The pre-assessment report, when used as a benchmark, provides a means for comparing the operations in future years. Operational trends can be projected, thus providing a means for risk calculations.

WordPerfect ${ }^{\mathrm{Tn}}$ word processing software was readily available for each participant. The participants were required to use Wordperfect $t^{\mathrm{nx}}$ version 5.1 for DOS [disk operating system] in order to complete their assignments. Therefore, all team members were using compatible software.

Use of WordPerfect ${ }^{\mathrm{Tx}}$ ensured that each team member could complete assigned portions of the assessment report, using the assigned boiler plate, and transfer the information to the team leader for incorporation while on travel.

\subsubsection{Disadvantages}

The pre-assessment reports are lengthy, requiring large expenditures of time for completion.

\subsubsection{Issues}

4.3.4.1 Coordination among Sites. Personnel assigned to conduct the regulatory contacts did not complete the work before the on-site portion of the assessment began. In addition, personnel assigned to the assessment team were not allowed to complete assignments because of being assigned additional requirements by their own management. The participating $M \& O$ contractors did not want to release their few qualified personnel for the time required to properly complete the task. Constant pressure by corporate management was required to keep personnel from being reassigned and on the project. 
Adequate administrative support, such as technical editors, was not supplied.

M\&O contractor-specific quality requirements were not specifically defined or excluded. These must be defined and approved in the project management plan (PMP).

4.3.4.2 Schedule. As the project progressed, milestones and deadlines for RFP and SOW development and review were repeatedly slipped. However, because of the importance EG\&G placed upon the successful award of the subcontracts, the portions of the schedule allotted to the conduct of the assessment process became compressed. The deadlines and milestones associated with this critical facet of the program were not renegotiated because EG\&G wanted the program to be successful and complete within one year.

The schedule was compressed as a result of slippage during the preparation and approval of the RFP. The assessment schedule was not allowed to slip accordingly. The original schedule required six months to complete the entire process proposed for 20 possible facilities. The schedule was compressed to three months for the entire process. It was not possible to complete the process in this time period.

There was constant complaining by M\&O contractor management about the time required to perform the site liability assessments. $M \& O$ contractor managers indicated that they had great difficulty "freeing up" personnel for the time indicated on the schedule. The schedule was agreed to when the project was originally presented.

4.3.4.3 Scope. The scope of the pre-award assessment was not well understood by team members before site inspections began.

4.3.4.4 Budget. MOUs among all of the participating M\&O contractors were not in place before the assessments began.

\subsubsection{Content.}

4.3.4.5. 1 Pre-Assessment Process-The time allotted for the pre-assessment process was compressed to the point that the information could not be received and adequately reviewed before the on-site portion of the assessments began.

Documentation requested from the vendors was not complete or received from some of the proposed subtier subcontractors.

Regulatory contact assignments were not completed before the on-site portion of the assessments began.

4.3.4.1.2 On-site Assessment-The on-site assessments were conducted sequentially covering two facilities each week. No work time was allotted among facility inspections for report generation. One team covered all of the 16 proposed facilities.

The assessment team did not have time to review permits and state regulations before arriving at the facilities. 
Management from several of the vendor-proposed TSDFs apparently did not understand the importance of the pre-award site inspections. In these cases, the EG\&G Assessment Team did not receive full cooperation from the TSDF personnel without having a representative from the proposing vendor present. In several instances, cooperation was achieved only after the vendor company corporate vicepresident level or regional representatives accompanied the EG\&G Assessment Team and introduced the team to the TSDF managers.

4.3.4.1.3 Post-Assessment Process-Completion of the reports was difficult for personnel from the other M\&O contractors, because all of the documentation from the facilities was sent to the lead laboratory. Personnel had to return to the INEL to review the documentation and complete the reports.

4.3.4.1.4 Reports and Supporting Documentation-Regulatory contact assignments were not completed before the on-site portion of the assessments commenced.

The schedule required drafts of reports to be completed at night in the field during the on-site portion of the assessment. However, personnel waited until the on-site portions of all of the assessments were completed to begin writing any portions of the reports.

Personnel did not complete their portions of the assessment reports. Supporting documentation, particularly field notes, were not supplied to the lead laboratory.

The WordPerfect ${ }^{\mathrm{nx}}$ software package contained a "block-copy" feature, the use of which introduced errors into the completion of the reports. The "block-copy" feature was used by some members of the assessment team to copy large sections of one report and insert these sections into another report. The problem with this technique was that these authors frequently neglected to proof read the inserted sections to ensure that they actually addressed operations at the site. For example, Rollins facility process descriptions were found repeated verbatim within CWM facility process descriptions. These two companies do not use the same processes or operate the same way.

\subsubsection{Resolutions and Recommendations}

4.3.5.1 Coordination among Sites. Personnel assigned to the project should be assigned to the lead laboratory on an "out plant" assignment for the duration of the scheduled assessment period.

Memoranda of understanding should be used as inter-site contractual agreements to ensure that personnel are committed to the project. Work packages containing SOWs and budget estimates can be used to define the scope and expectations of the project. The use of task baseline agreements (TBAs), which are contractual agreements between the performing individuals and project managers, should clarify any issues surrounding expectations and deliverables for each task. These documents also provide a quantifiable performance indicator.

Before each assessment or series of assessment site inspections, all participants should meet, physically or via telecom, to address the following issues:

- Discuss and negotiate how many participants are required and who will perform the assessment tasks, including the regulatory background checks; obtain, collect, reproduce, and 
distribute TSDF-supplied audit documents and permits before the site inspection; and write the post-inspection report. These tasks should also be specified in the TBA.

- Negotiate the schedule of the assessment tasks:

- Perform regulatory background checks and distribute the results to the other team members

- Collect and distribute documents and permits

- Determine dates of the site inspection and schedule of tasks during the inspection

- Determine report writing schedule and location.

- Responsibilities of each team member before, during, and after the actual site inspection must be set. This includes assigning activities and due dates for activities that are prerequisite to the next step in the process, and determining, before arriving at the site, who is responsible for each task of the assessment.

Immediately preceding the actual site inspection, participating team members should have a preassessment strategy session to discuss the pending inspection: the major points of the regulatory background check, document and permit reviews, management and operating issues on which to concentrate, assigned areas of responsibilities for each team member, sequence of activities, etc.

After completion of the site inspection, the observations of the TSDF and its operations should be evaluated against specific, measurable go/no-go criteria. This activity should occur out of contact with TSDF or vendor personnel. The decision to approve/disapprove a facility should be made by the committee based on the pre-determined criteria which should be specific, defensible, and measurable.

It has also been suggested that in order to ensure that each team member understands the responsibilities inherent in the process, a lead be assigned to each facility. This individual would have the following responsibilities for the conduct of the particular assessment:

- Arrive at the facility a day early to ensure that documents are ready

- $\quad$ Perform regulatory contacts

- Take responsibility for the content of the report

- Schedule visit after all preparations are complete

- Coordinate the followup meeting of the team, within one week of completion of the site inspection, to finalize the report.

This facility lead would report directly to the program manager who would oversee all aspects of the assessment and have the final word with respect to conflicts that might arise. The facility lead would receive the responsibility and lead training through this process. 
M\&O contractor specific quality requirements must be defined and approved by all participating M\&O contractors in the project management plan (PMP).

4.3.5.2 Schedule. All of the portions of the subcontracting process must be held to a tight schedule. However, if problems occur at the front end of the process, it must be realized that time cannot be recovered by compressing the assessment schedule. Therefore, it is recommended that controls be placed upon the front-end of the life-cycle (i.e., procurement development and waste management review) to ensure that the integrity of the schedule is maintained. If the schedule must be slipped, then the schedule required for the assessments and subcontract awards must also be slipped. This could place a tremendous burden upon any particular $M \& O$ contractor whose previous hazardous waste subcontract expires during the interim. However, quality cannot be compromised for expediency.

4.3.5.3 Scope. The scope of the pre-award assessment should be emphasized in the assessment team training class. The scope of the pre-award assessment should be evaluated in terms of potential risk from assigning priorities to specific items in cases where a modified pre-award assessment may be warranted. Modification clauses should be specified in the program management plan.

4.3.5.4 Budget. MOUs must be completed and in place before the assessment program begins. If it appears that the assessment schedule will overrun the fiscal year, then an MOU for the subsequent year must be negotiated before the end of the current fiscal year.

4.3.5.5 Content. The majority of the issues identified with the content of the assessment process can be resolved through

- Scheduling properly and controlling the schedule

- Assigning out-plant assessment team members to the lead laboratory for the duration of their specific assignments

- Assigning facility leads to absorb the responsibilities for each site assessment process, rather than leaving all of the tasks to the program manager.

The issue regarding the assessed facility manager's perceptions of the process can be resolved by defining the assessment criteria in the RFP and making compliance with the process one of the go/no-go criteria. The issue may also be resolved within a prime subcontractor by having the company direct the facilities to comply with the requests of the assessment team.

The "block-copy" feature of WordPerfect $t^{\text {nt }}$ should be disabled, unless specifically permitted by the lead laboratory program manager for limited precise use. The limits on the use of the feature will be addressed in all future training courses.

\subsubsection{Vendor Perspective}

4.3.6.1 Chemical Waste Management, Inc. CWM received many incidental benefits as a result of this procurements. Having trained, experienced personnel inspect/review our facilities provided excellent insight into areas for improvement. The level of detail and thoroughness heightened CWM's 
awareness to the customer's perspective. Based upon this process, CWM has expanded its customer audit support system and routinely reports observations from auditors to management and all facility personnel.

4.3.6.2 Rollins Environmental Services, Inc. No comments were submitted regarding the preaward ESH\&Q liability assessment process.

\subsection{Annual Review Assessment Process}

As of the date of this report, the annual review assessment process for the consolidated hazardous waste subcontracts had not been conducted. A management decision was made in FY 1994 to postpone the annual review until FY 1995 for the following reasons:

- The 1993 ESH\&Q liability assessments for each of the facilities proposed for the MTS were not completed until October 1993 as a result of various issues identified during the initial assessment period, which ended in June 1993. Therefore, it was decided that the time lapse between approval of the facilities and the annual review was not significant in terms of incurring risks if the annual reviews were postponed.

- The compliance and operational statuses of the facilities assessed suggested that significant changes to either would probably not occur within one year of the EG\&G assessments.

- The ESH\&Q liability assessment reports for a number of the facilities were not complete at the end of FY 1993, and it was decided that the completion was a prerequisite for the annual review.

- The MTSs were not awarded until October and November 1993 (beginning of FY 1994) and most of the M\&O contractors were placing their task orders in 1994 because their prior subcontracts expired. Therefore, the subcontracted facilities would not have been extensively used by the participating M\&O contractors in FY 1994.

- The costs associated with the annual reviews were not budgeted by the majority of the M\&O contractors for FY 1994. It was determined that, because DOE funding was decreasing, it would not be cost effective to request additional funding at that date; planning for FY 1995 annual reviews would be more effective.

This section will discuss the ESH\&Q and financial liability annual review process, as proposed for FY 1995. It will be assumed that the recommendations and resolutions proposed for correcting deficiencies in the pre-award assessment process will be incorporated into the annual review process. If these recommendations are not incorporated, it is assumed that many of issues identified in the preaward process will recur, which will result in a far less effective program.

\subsubsection{Process Description}

The annual review process is the same as that used for the pre-award assessment, except that the annual review focuses on changes to a facility's permit status, operations, and/or compliance that have occurred since the last assessment, either pre-award or annual review. Emphasis is placed upon 
regulatory opinions and daily operations. The report resulting from the annual review builds upon the information contained in the pre-award assessment benchmark reports. The benchmark pre-award assessment report is referenced throughout the annual review document.

4.4.1.1 Coordination among Sites. Once the annual review schedule is established by the program manager at the lead laboratory, each participating M\&O contractor is contacted in order to obtain the services of specified qualified members of the assessment team with specific expertise as defined in Table 4. A work package describing the schedule, scope, and budget requirements is sent to each participating M\&O contractor. A TBA will be negotiated between the team members, their respective management, and the program manager. The TBA defines the schedule, scope, and budget requirements for the project and defines the deliverables expected from the participating team member. The TBA is signed by the team member, M\&O contractor manager, and lead laboratory program manager. The team members are provided with copies of relevant information regarding the TSDF and given assignments that must be completed before the site inspection. The coordination requests are documented by letters and agreements among the M\&O contractors.

As with the pre-award assessment, the size of the annual review assessment team is based on the size and complexity of the TSDF to be evaluated. Team sizes are expected to range from two to six people.

4.4.1.2 Schedule. An annual review assessment is generally scheduled to take about three weeks of effort by each member of the assessment team. This effort includes time scheduled for preparing for the assessment, time at the facility, and time for preparing the report. Preparation for the assessment includes tasks such as reviewing the pre-award assessment benchmark report, requesting information from the TSDF, and making applicable federal, state, and local regulatory contacts.

4.4.1.3 Scope. As previously described, the scope of the annual review is the same as that used for the pre-award assessment, except that the annual review focuses on the changes to a facility's permit status, operations, and/or compliance that have occurred since the last assessment, either pre-award or annual review. Emphasis is placed upon regulatory opinions of the facility and daily operations. The report resulting from the annual review builds upon the information contained in the pre-award assessment benchmark reports. The report focuses on impressions and observations of the operations, as well as on reviewing regulatory inspections and observations. The annual review report is not designed to be a "stand alone" document.

4.4.1.4 Budget. MOUs between Lockheed Idaho and each of the M\&O contractors are established as a mechanism to share the costs of the assessments. All MOUs will be in place before the start of the activity. As tasks are completed, the charges accrued to the project are calculated and invoices are issued to each participant for payment of their portions. Participating M\&O contractors who decline to provide staff for the effort are charged an even split of the costs to fund a participant from the lead laboratory or another M\&O contractor to participate in their place. All participants receive copies of the reports. 


\subsubsection{Content.}

4.4. 1.5.1 Pre-Assessment Process-The pre-assessment process consists of gathering information and is conducted using the telephone, mail, or electronic data base systems. The purpose of the pre-assessment review is to determine:

- In the case of a TSDF or recycler, what changes have occurred to the facility since the last assessment

- Whether the facility has, since the last assessment, had serious environmental, regulatory, financial, or legal problems that can be identified using the sources described as follows.

A LEXIS/NEXIS database search is conducted to identify any situations such as adverse publicity, criminal proceedings, and/or major environmental problems that could have a detrimental impact on any arrangements that the INEL or other $\mathrm{M} \& \mathrm{Z} \mathrm{O}$ contractors might make with the facility.

The Dun and Bradstreet search is conducted to collect the following information about a company: the financial condition, company rating and trends, net assets, and balance sheet information. The financial condition of the facility of interest may be evaluated by the EG\&G Financial Services or Procurement Groups.

Regulatory contacts include, but are not limited to: the EPA; state regulators (e.g., the state water commission); and local regulators (e.g., city or county sanitation districts). Each regulatory agency should be contacted in order to obtain or verify the following information:

Permit status

CERCLA involvement

Existing contamination

Compliance problems
Inspection results

Financial compliance

In addition to the regulatory agencies, the assessor contacts city and county officials, the local chamber of commerce and the Better Business Bureau in order to obtain opinions they might have concerning the conduct of operations and community opinions of the facility of interest.

The TSDF or recycler was contacted through the vendor who bid the prime subcontract, in order to collect any changes to the following information:

Site history and CERCLA involvement

Existing contamination

Ownership

Services and operations

Waste streams, or recyclable materials, accepted and not accepted

Permit status, including RCRA, air, and water
Financial information

Insurance information

References of other businesses that use and/or have assessed the TSDF

Regulatory compliance status

Assessment coordination procedures, only if a decision has been made to conduct an assessment. 
After a review of all of the above information, a determination is made as to whether an on-site assessment is necessary or if sufficient information has been obtained in order to complete an assessment report. If a determination is made by the facility team leader, with the concurrence of the program manager (or designee) that sufficient information has been acquired, a risk evaluation and assessment report is completed using the instructions and format specified in the procedure.

4.4.1.5.2 On-site Assessment-The assessment team conducts a site inspection of each of the facilities listed on the subcontracts. The purpose of the inspection is to observe and compare the operations of the facilities with their documentation and permit conditions. The site inspection focuses on changes in the operations since the last inspection, documentation reviews, process flows, and operational observations. Photographs are taken of various operations. Copies of relevant photographs are included in this report. All of the photographs are kept as part of the assessment record.

4.4.1.5.2.1 Preparation for an On-site Assessment-The assessment date and assessment schedule are established with the TSDF contact and confirmed in writing.

Arrangements are made with TSDF contact to have the information listed in Section 4.3.1.5.2.1, which have undergone changes since the last assessment, mailed ahead for review before the site inspection. This information should also be available for on-site review.

A determination is made as to what wastes have been shipped from the M\&O contractors to the particular facility. Copies are made of shipping manifests. If a large number of manifests are involved, a random selection is made to be used during the on-site evaluation.

A determination of whether the state in which the facility of interest is located has primacy in any areas of environmental protection. If the state has primacy in any area, the implementing regulations are reviewed and a checklist is prepared to address compliance with these regulations.

4.4. 1.5.2.2 Conduct of the On-site Assessment-The same checklists used for the preaward assessment are used during the annual review on-site assessment. The checklists can be prepared ahead of time, or if a computer program such as Audit Master ${ }^{\text {rn }}$ is used, during the on-site inspection. If the Audit Master ${ }^{\mathrm{nx}}$ is not used, commercially available, or specially developed checklists may be used. However, these checklists must be reviewed and approved by the Program Manager before the on-site inspection.

The on-site portion of the assessment begins with an introductory meeting with all applicable facility representatives and management. The purpose of this meeting is to discuss the conduct of the site inspection, document reviews, and facility representative interviews. The assessment team generally requests that the vendor's corporate proposal technical contact, or a proposed subcontract technical contact, accompany the team on the site inspection. The vendor's corporate representatives are a resource for both the assessment team and the company in that they can clarify issues and provide immediate feedback to the corporation regarding the status of the assessed facility.

The facility and operations are inspected in the sequence specified below using checklists for the specific type of facility: 
- Waste arrival

- Waste storage

- Waste analysis and verification procedures

- Manifest verification

- Inspection of each unit

- Residues management

- Transportation into and out of facility.

Facility representatives are interviewed to assess management's understanding of the facility, regulations, and company's risk assessment procedures. The laboratory manager, facility manager, and environmental coordinator are among those managers to be interviewed.

The documents and information listed in Table 5, which have undergone changes since the last assessment, are reviewed before and/or during the site inspection of the subject facility. The table is used in the report to summarize the status of the information requirements.

At the end of each day at the facility, a closeout meeting is held with all the TSDF management to discuss issues that may have arisen during the inspection. This is also the point at which potential regulatory noncompliances are identified. The facility management response to the closeout meetings is a critical measure as to the responsiveness of management and their commitment to maintaining regulatory compliance at the facility. Potential regulatory noncompliances are generally not specifically described in the facility assessment report because of the concern regarding the availability of the assessment reports under the FOIA. It is also not the intention of the annual review assessment team to trigger a regulatory inspection of the facility by the EPA or the state.

By this point in the process, the experienced members of the assessment team generally have a good idea as to whether the specific TSDF and company are acceptable for continued use under the subcontract. A preliminary verbal decision can be returned to the subcontract administrator for status purposes. At this point, if the site inspection team leader is not the assessment team leader, this individual should report the TSDF conditions to the assessment team leader and program manager. This report would allow the program manager to resolve any potential concerns or issues identified by the team members. However, no firm decision is made until the assessment process is complete. If major risks are identified at this point, a decision may be made to allow the vendors to correct deficiencies or substitute facilities; this decision must be approved by the ESH\&Q Assessment Team. The vendor is liable for the assessment costs of replacing a facility. These decisions are made in concert with the subcontract administrator, assessment program manager, and assessment team members.

4.4. 1.5.3 Post-Assessment Process-The post-assessment process is the same for the annual review as for the pre-award assessment process. 
4.4.1.5.4 Reports and Supporting Documentation-The following documentation is . generated and/or maintained for each annual review assessment performed:

4.4.1.5.4.1 Formal Assessment Report-A formal assessment report is written for each facility that is evaluated. As previously stated, this document focuses on changes to a facility's permit status, operations, and/or compliance, which may have occurred since the last assessment, either preaward or annual review. Emphasis is placed upon regulatory opinions of the facility and daily operations. The report resulting from the annual review builds upon the information contained in the pre-award assessment benchmark reports. The report focuses on impressions and observations of the operations, as well as on reviewing regulatory inspections and observations. The annual review report is not designed to be a "stand-alone" document. This document is prepared in accordance with INEL document preparation procedures, using the format described in the procedure, and is controlled through the INEL Document Management System.

Because the material contained in the report is sensitive, dissemination of this document is strictly limited to a distribution list that has been approved by the program manager. Any deviation from the distribution list or additional requests for copies of the document must be submitted to the Assessment Team leader in writing and must be approved by the team leader and program manager.

4.4. 1.5.4.2 Telephone Conversations-All telephone conversations regarding the facility under evaluation must be documented using the EG\&G Idaho memo of conversation form or memo to file form. The forms must be typed or written in black indelible ink. These memos must be kept as a record in the annual review facility file.

4.4. 1.5.4.3 Facility Files-An annual review formal file is created and maintained for each facility being evaluated. The files are retained in the Environmental Protection Department of the lead laboratory. These files contain all correspondence, notes, completed assessment checklists, field notes, copies of permits and contracts, completed external assessment chronology log, regulatory contact checklist, risk assessment, external assessment report, and any other information that was collected and used during the facility evaluation. The contents of the files must be able to withstand a regulatory and/or quality assessment.

\subsubsection{Advantages}

Several advantages resulting from this process have been identified, although they have not yet qualified or quantified:

- The fact that the annual review builds upon the work completed in the pre-award assessment provides a method for assessing the continued compliance of a facility based upon a benchmark

- The use of assessment team members who were participants in the pre-award assessment process provides a continuum of expertise

- The use of the same team skill mixes ensures that consistent and quality criteria are used for evaluation of disposal facilities. 


\subsubsection{Disadvantages}

No disadvantages regarding the process have been identified to date, because the consolidated annual review process has not yet been implemented in the field.

\subsubsection{Issues}

No issues relating to the annual reviews have been recorded to date, as the consolidated process has not yet been used.

\subsubsection{Resolutions and Recommendations}

The only recommendation recorded is that all of the issue resolutions and recommendations recorded in the pre-award assessment process be incorporated into the annual review process. 


\section{OPERATIONS UNDER THE CONSOLIDATED SUBCONTRACTS}

This section addresses the actual implementation of the consolidated hazardous waste subcontract. The important points of this section concern waste management operations under this new approach to waste treatment/disposal. The process of how the task orders were activated by each of the M\&Os upon expiration of the previous hazardous waste subcontracts is addressed. Modification of the waste stream exhibits and additional scope of work are discussed.

\subsection{Activation of Task Orders}

\subsubsection{Process Description}

After the MTS is established, all M\&O contractors issue task orders for their individual sites that establish or incorporate the following:

- The task orders are issued in accordance with the terms and conditions of the master task agreement

- The task orders reference and incorporate the original scope of work, pricing sheets, and pickup locations specific to their locations

- The task orders specify the period of performance, generally one year

- The task orders' ceiling prices and reference to payment for actual services in accordance with the firm-fixed-unit-prices are established under the MTS award

- Actual work is ordered and authorized by issuance of written subcontract releases

- Contractor and subcontractor administration is established.

An example of a task order is provided in Figure 1. The task order is designed to become effective upon expiration of the current term of any pre-existing applicable subcontracts. Task order modifications issued to add waste streams, and additional funding to increase the price ceiling, etc., are issued by the M\&O contractor who issued the original task order.

\subsubsection{Advantages}

One of the most important advantages of the task order is that it allows an M\&O contractor to incorporate any site-specific requirements that were not inherent in the MTS into its operating agreement with the subcontractor. These site-specific requirements must not, however, conflict with the terms and conditions of the MTS.

The MTS reduces the amount of paperwork required to activate the subcontract. Only the task order, in letter format, is required for implementation. 
The task order "turns on" the MTS for a particular M\&O contractor site, based on the expiration . of pre-existing subcontracts. Therefore, subcontract negotiations are not required.

\subsubsection{Disadvantages}

No disadvantages to the activation of task orders were identified.

\subsubsection{Issues}

It became apparent that, as a result of personnel changes during the implementation of the consolidated MTS, some of the procurement personnel assigned by various M\&O contractors were not aware of how a task order was to be implemented or how it worked.

\subsubsection{Resolutions and Recommendations}

Upon award of the MTS, a team composed of technical, waste management, and procurement personnel from the lead laboratory should meet with the comparable personnel from each of the M\&O contractors to explain how the MTS, task orders, and invoicing procedures are implemented at the M\&O contractor level.

It may also be an advantage to have the associated vendor representatives present at this working meeting in order to ensure that personnel from each vendor area support office are also aware of the terms and conditions of the MTS, task orders, and invoicing procedures. This would provide an opportunity for the M\&O contractor staff to meet and work with the vendors' assigned staffs under the watchful eye of the lead laboratory.

\subsubsection{Vendor Perspective}

5.1.6.1 Chemical Waste Management, Inc. CWM would recommend a kick-off meeting with each location using the subcontract. The meeting could assist in clarifying both subcontract interpretations and operational expectations. Developing and maintaining clear open communication is critical to overall performance.

5.1.6.2 Rollins Environmental Services, Inc. No comments were submitted regarding activation of the task orders.

\subsection{Subcontract Modifications}

\subsubsection{Process Description}

Modifications affecting the MTS are issued by the single M\&O contractor, lead laboratory, responsible for administering the MTS. All modifications are issued at the direction and concurrence of the lead laboratory technical representative who is responsible for providing technical support to the subcontract administrator. Requests from other M\&O contractors technical personnel to add shipment sites or change SOWs are submitted to the subcontract administrator at the M\&O contractor who is 


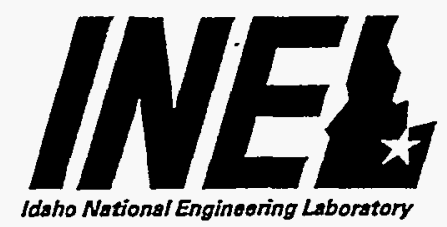

October 25, 1994

Mr. Bob Orr

Roilins Chempak, Inc (RCI)

7835 S. H. Hunsiker St.

Tigard, OR 97223

TASK ORDER NO. 2 UNDER MASTER TASK REQUIREMENTS SUBCONTRACT NO. C93-170250 TDC-214-94

Dear Mr. Orr:

1. This Task Order No. 2, effective November 1, 1994, is issued in accordance with the terms and conditions of Fixed-Price-Per-Unit Master Task Requirements Subcontract No. C93-170250.

2. As a result of this Task Order No. 2, RCI will provide Hazardous Waste Transport/Treatment/Disposal Services in accordance with the Master Task Requirements Subcontract No. C93-170250 and Scope of Work No.'s $0,21,22,23,24$, and 25 , including Lockheed Idaho Technologies Co. (LITCO) pickup location and transportation price sheets.

3. The period of performance for this Task Order No. 2 is from its effective date, November 1, 1994, through September 30, 1995.

4. The total price ceiling for performance of this Task Order No. 2 is $\$ 400,000.00$ and shall not be exceeded without written approval from LITCO.

Payment will be made for actual services performed and in accordance with the firm-fixed-unit-prices established under the Master Task Requirements Subcontract No. C93-170250.

Actual work will be ordered and authorized by the issuance of written subcontract releases by LITCO. All releases will be subject to the Terms and Conditions of Subcontract No. C93-170250.

5. LITCO Administration:

A. Subcontractual responsibilities under this Task Order No. 2 shall be administered by Mr. Scott Drewes.

B. Ail work to be performed, and occurrence reporting, under this Task Order No. 2 shall be under the technical jurisdiction and direction of Mr. Leroy Ewing.

$\overline{\text { \#Llockheed }}$

Idaho Technologies Company

P. O. Box 1625 Idaho Falls, ID 83415

Figure 1. Example of a Task Order. 
Mr. Bob Orr

October 25, 1994

TDC-214-94

Page 2

6. Subcontractor Administration:

A. RCI, subcontractual responsibilities under this Task Order No. 2, shail be administered by Mr. Bob Orr.

B. All work to be performed under Task Order No. 2 shall be under the technical jurisdiction and direction of Mr. Bob Orr.

Two copies of this Task Order No. 2, executed by LITCO, are forwarded.

Please execute one copy and return it to LITCO. One copy may be retained for your records.

ROLLINS CHEMPAK INC.

LITCO

By

Title

By

Ted D. Christensen

Title Subcontract Administrator

Date

Date

Figure 1. Continued. 
responsible for administering the MTS. Such requests are reviewed by the subcontract administrator and the lead laboratory technical representative. The subcontract administrator, at the direction of the technical lead, incorporates the requested change or addition into a modification, which is issued to the subcontractor. The subcontractor acknowledges acceptance of the modification by signing it and returning it to the subcontract administrator, who then distributes the modification to all M\&O contractors.

Another modification that must be made at the MTS level is the replacement of a facility approved under the MTS. This modification request must come from the subcontractor and must have a significant amount of justification, not including convenience for the subcontractor. An example of this would be the failure of a facility approved under the MTS to perform under the terms and conditions of the MTS.

\subsubsection{Advantages}

The control of modification requests of the MTS by the lead laboratory ensures that the integrity of the MTS is maintained.

Modifications regarding the MTS are available for all of the M\&O contractors.

M\&O contractors and subcontractors are unable to change the facilities approved under the MTS without the concurrence of the lead laboratory. Justifications for facility changes must be significant (i.e., failure of a facility to perform under the MTS) before the lead laboratory will consider a modification.

\subsubsection{Disadvantages}

M\&O contractors and subcontractors are unable to change the facilities approved under the MTS without the concurrence of the lead laboratory. Although this is an advantage, it may also be considered a disadvantage by some M\&O contractor participants.

The length of time between an M\&O contractor's request for an MTS modification appears to be too long. This might be attributable to M\&O contractor lack of understanding regarding the MTS modification process.

\subsubsection{Issues}

M\&O contractor procurement personnel appeared to be confused as to what constituted an MTS modification.

\subsubsection{Resolutions and Recommendations}

The resolution to the issue identified is the same as that identified in Section 5.1.5 regarding task orders. That is, upon award of the MTS, a team composed of technical, waste management, and procurement personnel from the lead laboratory should meet with the comparable personnel from each of the M\&O contractors to explain how the MTS, task orders, and invoicing procedures are implemented at the $\mathrm{M} \& \mathrm{O}$ contractor level.

It may also be an advantage to have the associated vendor representatives present at this meeting in order to ensure that personnel from each vendor area support office are also aware of the terms and 
conditions of the MTS, task orders, and invoicing procedures. This would provide an opportunity for the $\mathrm{M} \& \mathrm{O}$ contractor staff to meet and work with the vendors' assigned staffs under the watchful eye of the lead laboratory.

\subsubsection{Vendor Perspective}

5.2.6.1 Chemical Waste Management, Inc. No comments were submitted regarding subcontract modifications.

5.2.6.2 Rollins Environmental Services, Inc. The hazardous waste business in the mid 1990s is changing rapidly. As a result of waste minimization and the general expansion of technology-based treatment options (e.g., chemical industry recycling) in North America, the "waste pie" has decreased. At the same time competition in the hazardous waste treatment/disposal industry has increased. The players that have dominated the industry to date are responding to this economic environment either by selling assets or acquiring new assets (e.g., other company's waste facilities). The big are getting bigger and the small are going out of business. Tighter profit margins resulting from expansions and the higher competitive environment are requiring those companies to move waste to the most effective facilities within their own systems to remain economically viable. The high degree of environmental compliance required is also adding to the operating expense under these changing conditions. As waste treatment professionals we need flexibility to add and subtract facilities from this subcontract without unduly restrictive procedures. The need for liability protection of DOE interests would not be compromised by re-evaluating current procedures.

It is recommended that the $\mathrm{M} \& \mathrm{O}$ contractors review new requests for modifications and additions of new vendor facilities. If the reason for the proposed change makes logistical sense and/or there is a demonstratable savings in cost for the DOE, let the private sector manage its business and accept the economic benefits as they are presented to the DOE.

The private waste management companies developed the systems and the processes that enable the DOE to dispose of the toxic byproducts made while carrying out their mission. It only makes sense to encourage these companies to refine their systems and processes to the extent that the interests of the DOE can be maintained.

\subsection{M\&O Contractor Waste Management Operations}

This section provides two examples of how a waste management group uses the MTS and associated task orders to facilitate the proper treatment and disposal of site-generated hazardous wastes. The first example is from the INEL waste management operation because this style of subcontract was first tried at the INEL and it has the most experience with it. The second example is from Rocky Flats, for whom this was a new way of conducting business. EG\&G Rocky Flats did not use the same waste stream exhibits as the rest of the participants. They compiled their own, based on waste streams they had generated in the past. Therefore, their waste stream exhibit was not nearly as comprehensive as that used by the other $\mathrm{M} \& \mathrm{O}$ contractors. 


\subsubsection{INEL Waste Management Operations Process Description}

In order to properly manage and dispose of wastes generated at a facility, several organizations must complete a number of steps; these include the generator of the waste, the waste management operations, Traffic, and Procurement. The Waste Reduction Operations Complex (WROC) and Traffic personnel at the INEL are the primary contacts with the hazardous waste subcontractors. At the INEL the waste generator is responsible for hazardous and mixed waste until its final disposition. The process is documented in several INEL internal procedures, including EG\&G Idaho Company Procedures, EG\&G Idaho Hazardous Materials Transportation Manual, and WROC Standard Operating; the process is described in the following sections.

5.3.1.1 Hazardous Waste Determination and Profiling. The process required to properly dispose of a waste begins with the generator of the waste, who is required to characterize and profile the waste in the following manner:

- Complete a hazardous waste determination per 40 CFR § 262.11. All supporting information and process knowledge statements must be documented as part of the written characterization, per 40 CFR $\$ 268.7$ and DOE Order 5700.6C (DOE-ID Supplemental Order 5700.6C).

- If the waste is determined to be hazardous, the generator must comply with 40 CFR $\S 268$. If the hazardous wastes are to be sent to an onsite TSDF, the Waste Acceptance Criteria (WAC) for that TSDF must also be met.

- Sampling, if required, must be done in accordance with SW-846 or other equivalent methods designed to supplement process knowledge. Determinations must be documented.

- Review analytical data and/or process knowledge statements, and identify the appropriate RCRA and LDR codes and constituents. Once the proper classification and profile are completed, this information is submitted on a Form EG\&G 669 (Identification of the Hazardous Component) and 669A (Shipment Request and Certification), in addition to the appropriate LDR notification/certification form, to the WROC Document Control (See Figures 2,3 , and 4). The forms 669, 669A, and LDR must be completed by the generator and then reviewed by WROC Technical Programs (WROC-TP) before transportation of hazardous or mixed waste.

At this point, when the forms are submitted to WROC, the generator also generally provides WROC with a charge number to cover the cost of WROC-TP's document review and profiling, and the waste transportation and disposal cost.

- WROC reviews the forms $669,669 \mathrm{~A}$, and LDR for container/labeling/shipping information to be used for that waste. The information provided on the EG\&G 669 forms is evaluated against the WAC for the specific TSDF, and any deficiencies are noted. In addition, WROC verifies the list of required shipping papers to accompany the shipment submitted by the generator. After reviewing the 669, the WROC-TP Waste Generator Interface (WGI) notifies the generator of inconsistencies or data gaps that must be resolved before acceptance approval. 
5.3.1.2 Acceptability Review of Waste for Storage or Offsite Treatment. WROC-TP reviews new waste streams and existing waste streams before accepting waste at the Hazardous Waste Storage Facility (HWSF) or offsite shipment as follows:

- New waste streams destined for HWSF storage: The WGI completes and initials the Waste Profile Checklist for each new waste stream destined for storage in the HWSF and attaches the checklist to the applicable form EG\&G-669.

- Existing waste streams: The WGI evaluates the updated waste stream file data for any changes that may have impacted acceptability of the waste for shipment, storage, or treatment.

At a minimum, generators must either recharacterize their existing waste streams or certify by letter that the most recent profile has remained current. Annual characterization is generally considered adequate when the generating process is highly controlled and waste composition remains consistent for the duration of the year. More frequent waste characterization is required under the following circumstances:

- A new waste stream is generated

- The process generating the waste changes

- The waste characteristics are highly variable from shipment to shipment

- WROC personnel have reason to suspect a change in the waste based on inconsistencies in the manifest, packaging, or labeling of the wastes

- The off-site receiving facility rejects the waste because its fingerprint samples are inconsistent with the waste profile provided by the INEL.

- As previously stated, the WGI notifies the generator of any observed data inconsistencies or data gaps that must be resolved before approval, as well as any situations that preclude acceptance of the generator's waste (e.g., HWSF or off-site TSDF WAC restrictions). Such notifications, and resultant actions, are documented by the WGI and included in the waste stream file.

- When the data package is complete, and the waste is determined to be acceptable for storage at the HWSF or direct shipment to an offsite TSDF, the WGI reviews the submitted form EG\&G-669A. This form identifies DOT shipping information such as packaging, marking, and labeling requirements; DOT proper shipping name; DOT hazard class; and DOT identification number. The WGI assists the generator with necessary corrections to this form.

5.3.1.3 Process for Off-site Treatment/Disposal. Once the INEL-specific paperwork is complete, the following process is followed to complete the treatment/disposal of the waste.

- WROC-TP compares the waste descriptions to the waste description exhibits in the MTS and profiles the waste with the technical representative from the appropriate subcontractor to an off-site TSDF as identified in the MTS. 


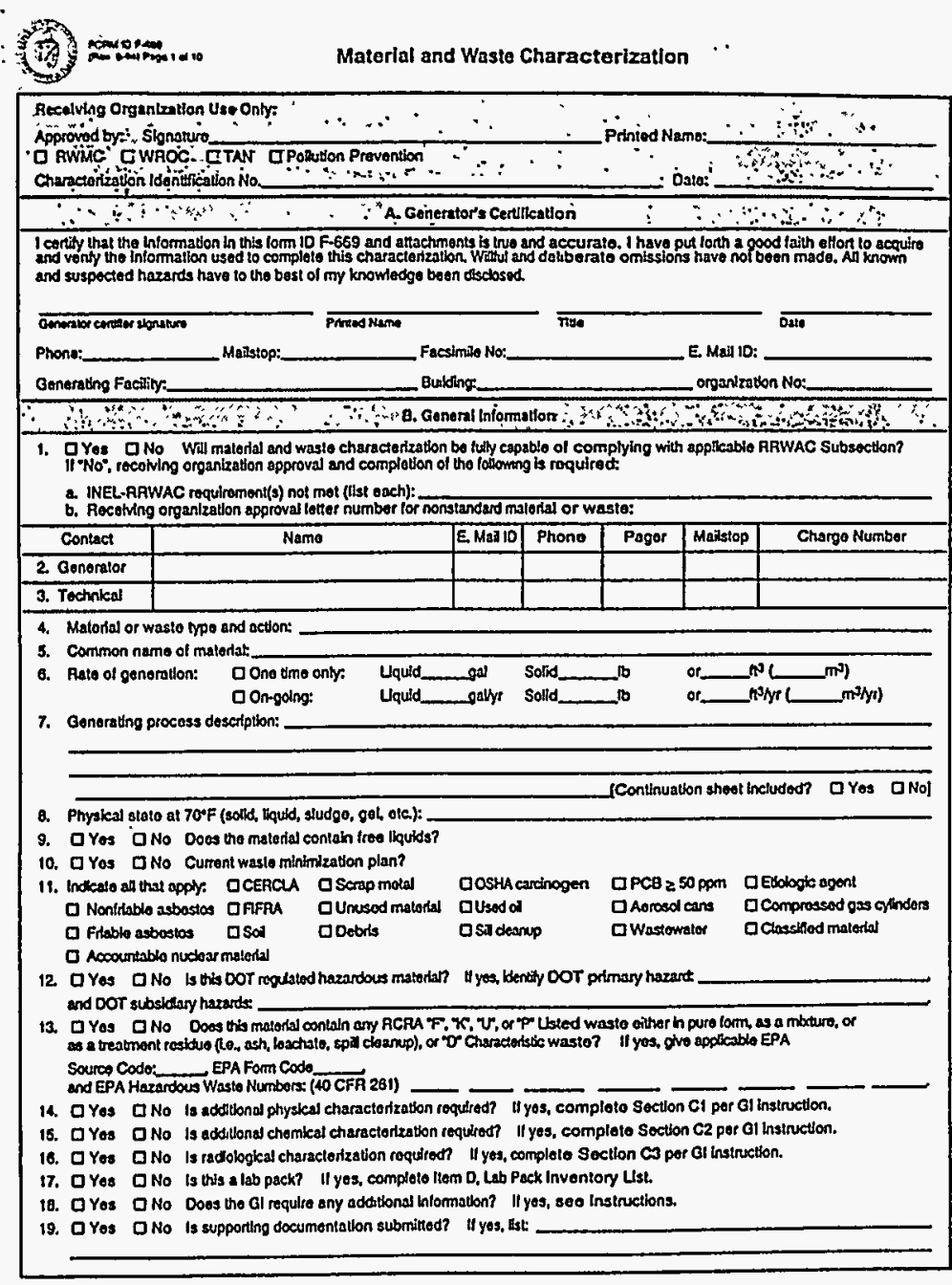

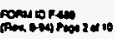

Characterization Lentilication Na:

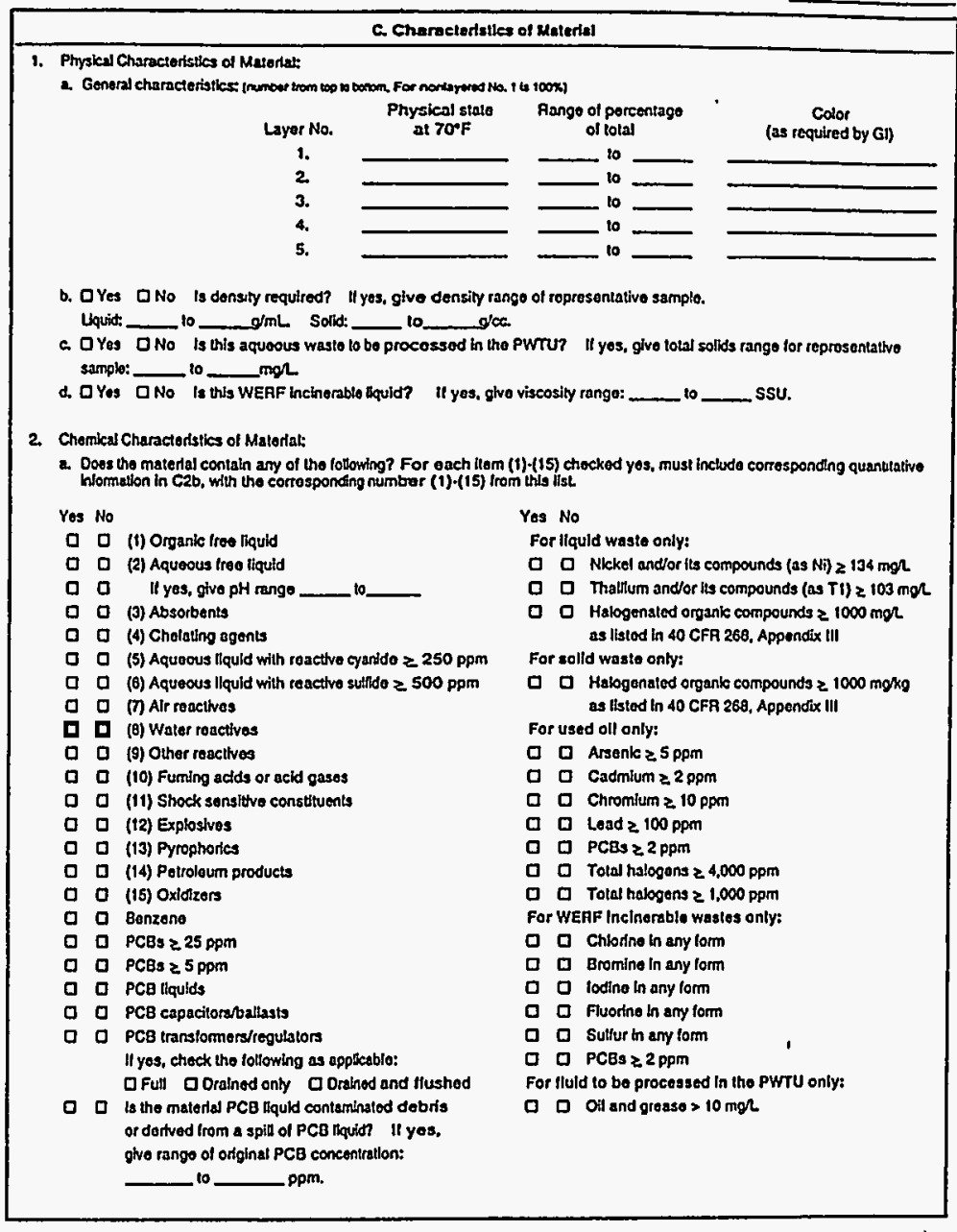

Figure 2. INEL Form EG\&G 669 (Identification of the Hazardous Component) at $50 \%$ size reduction. 

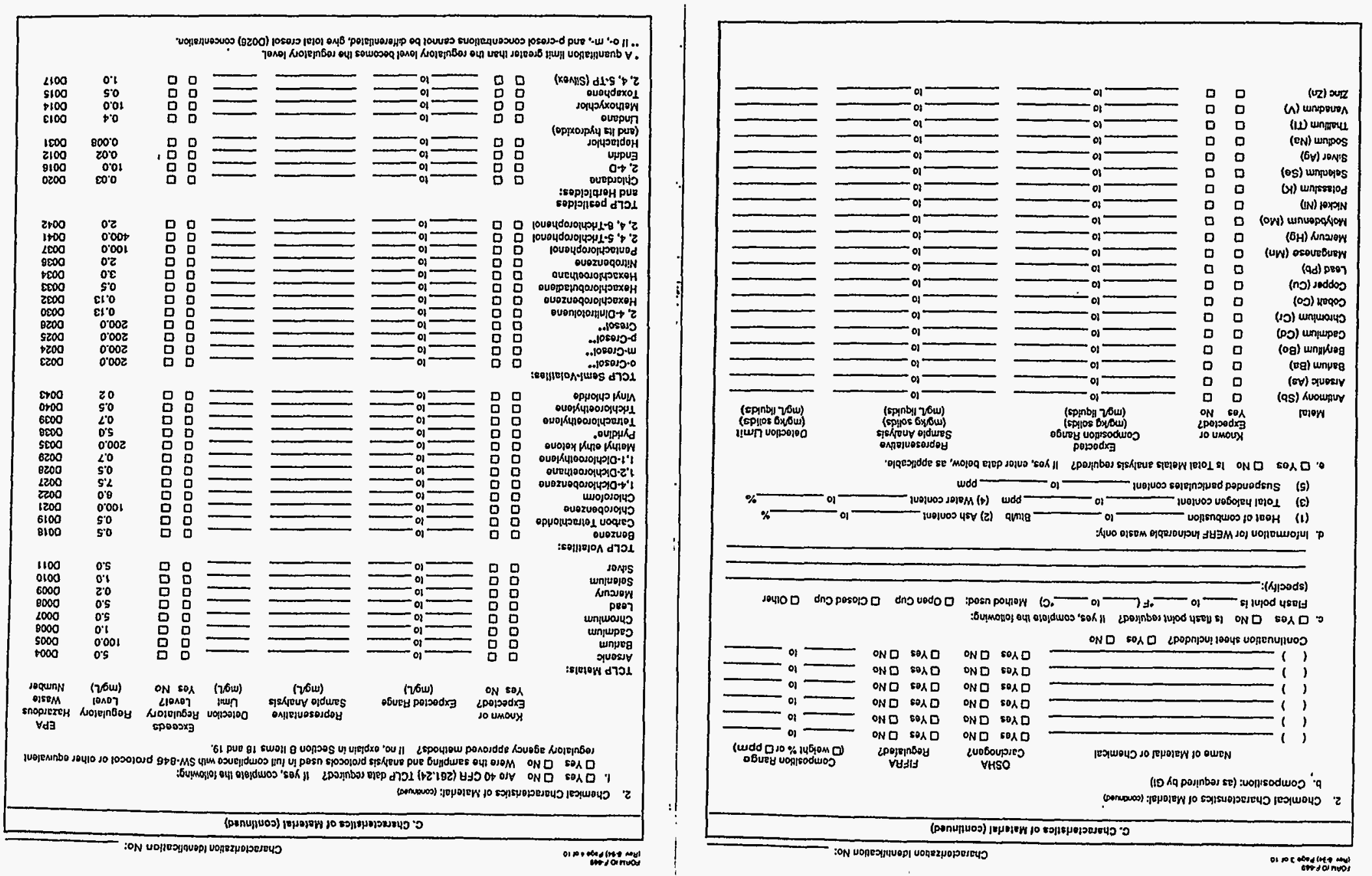

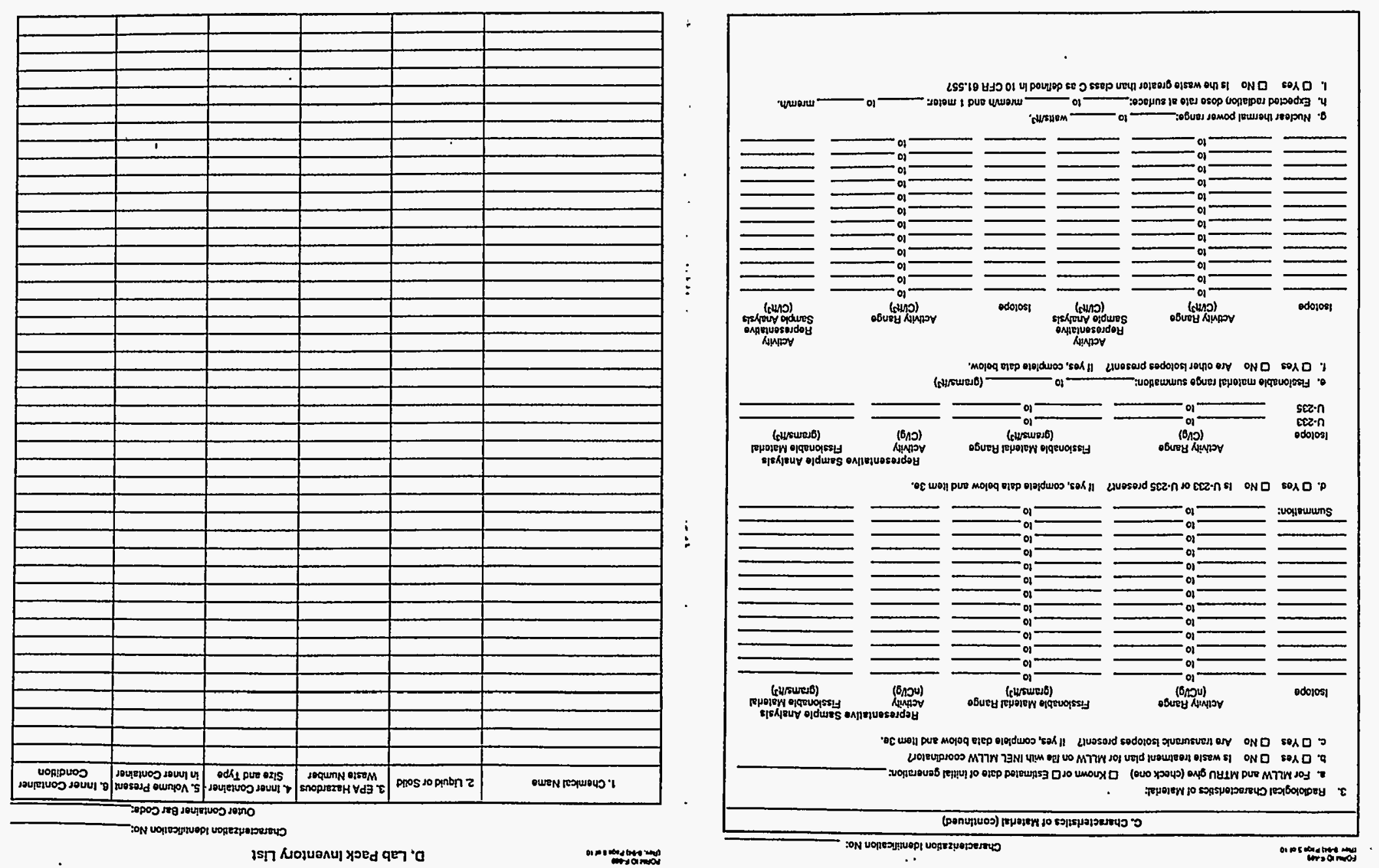
This page intentionally left blank 


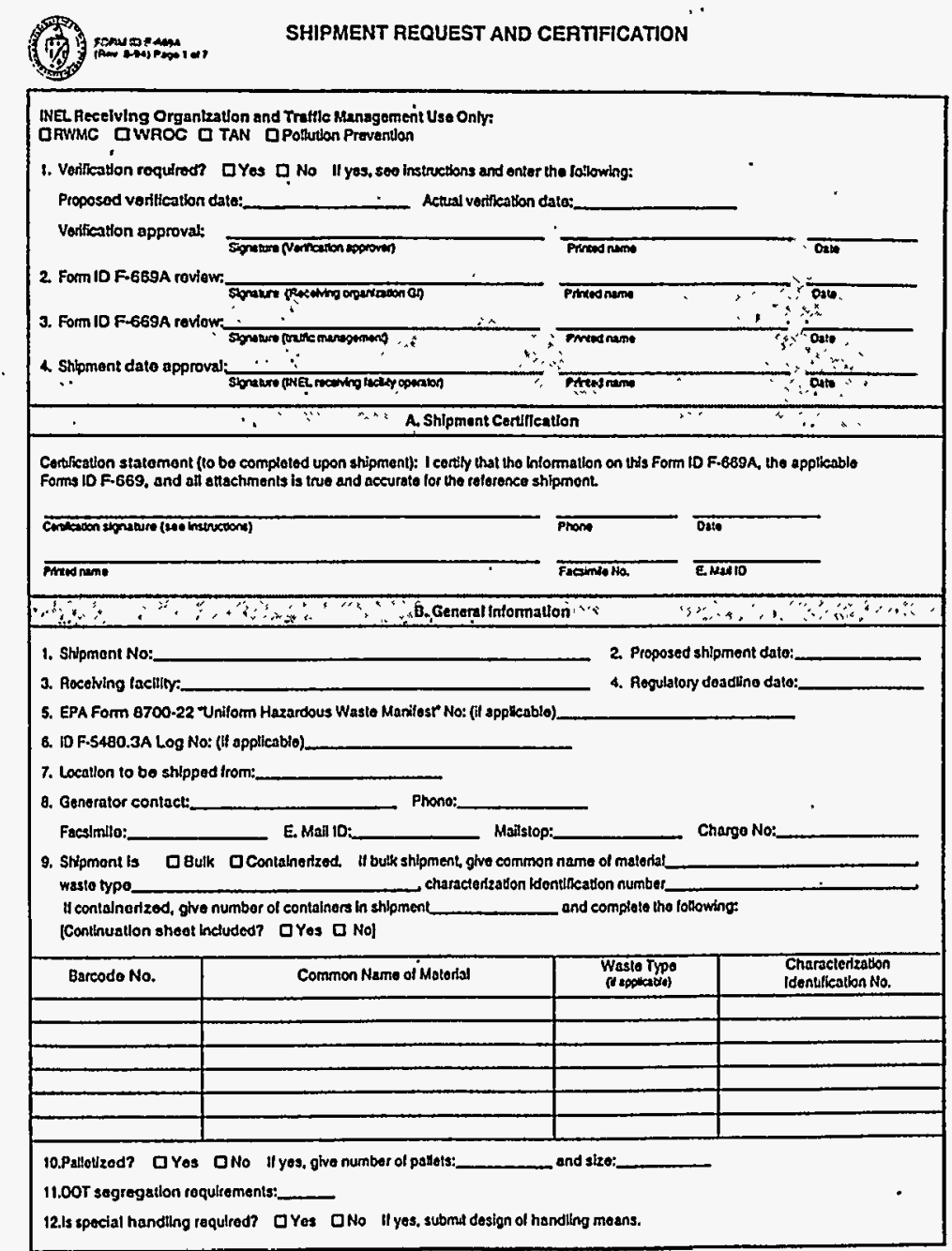

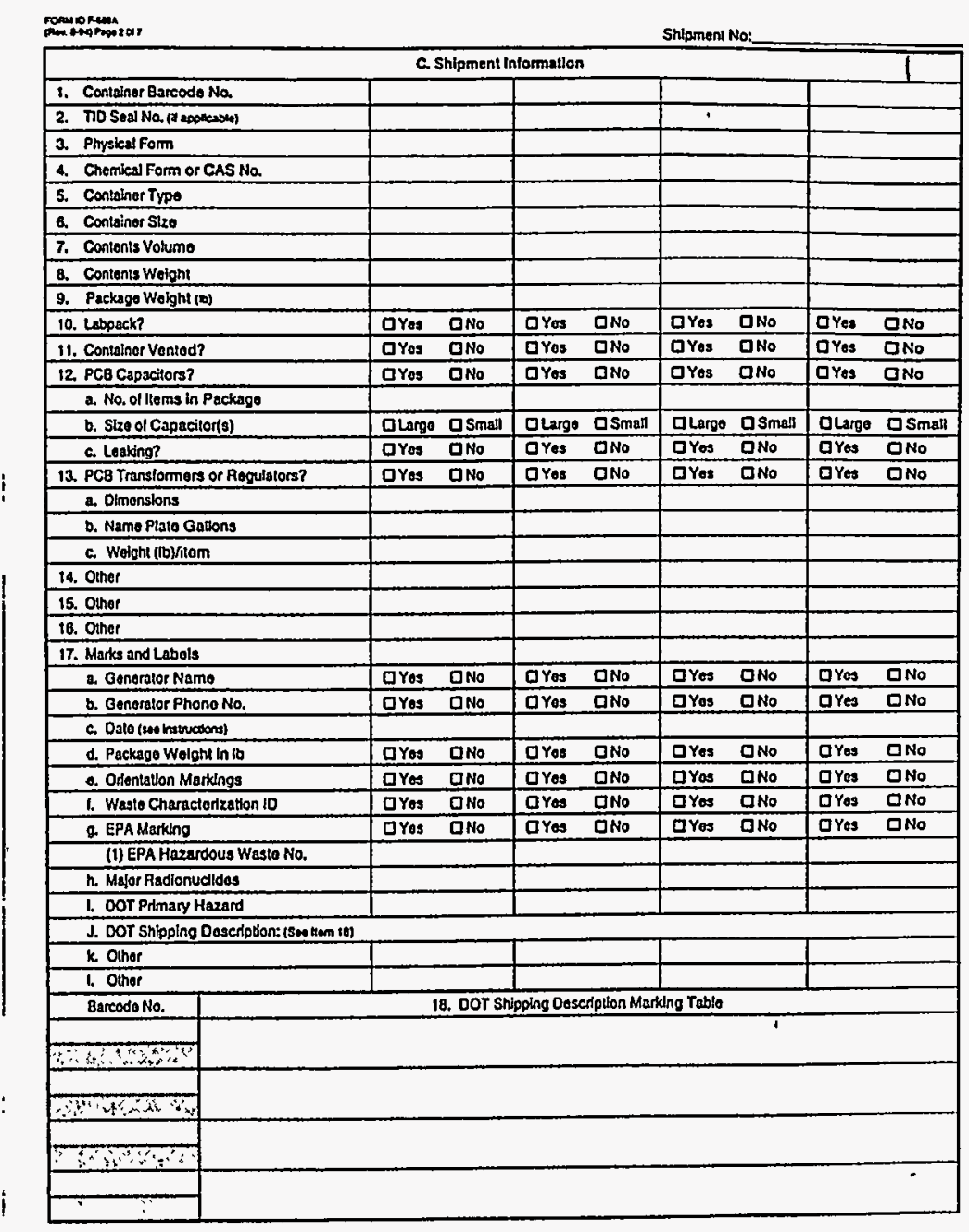

Figure 3. INEL Form EG\&G 669A (Shipment Request and Certification) at 50\% size reduction. 

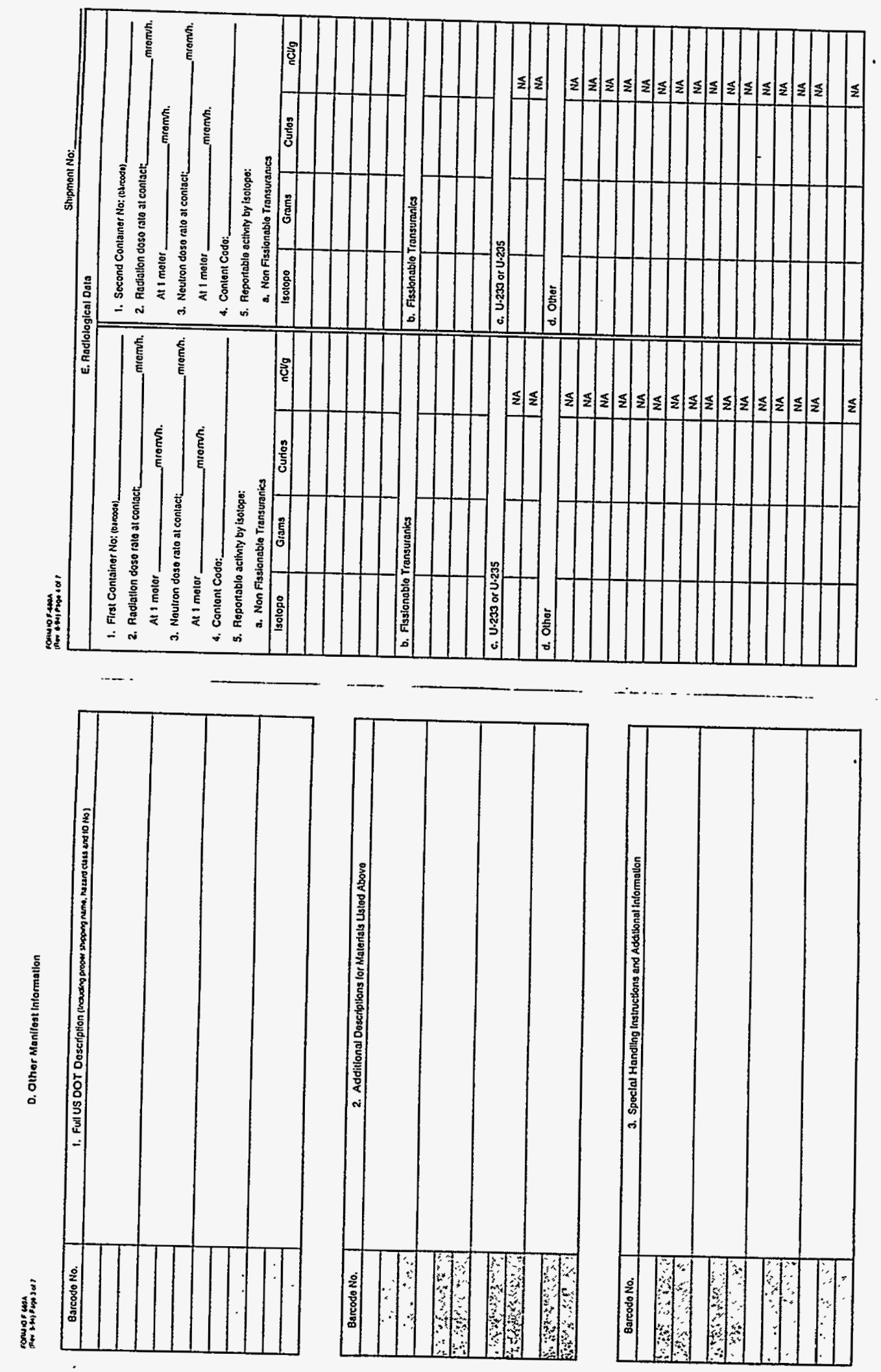

ن 


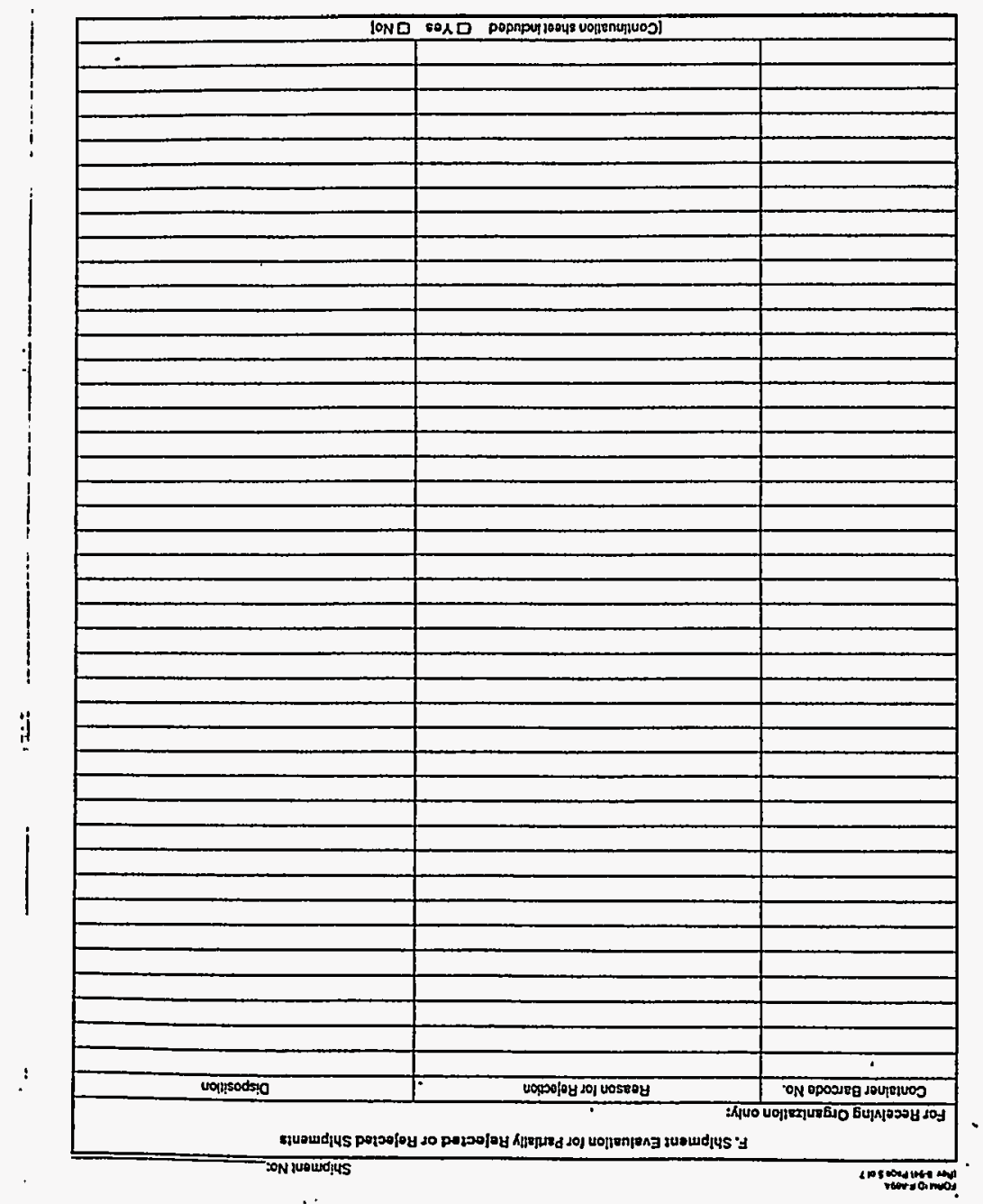


This page intentionally left blank 
123 PE2 DEC $12 \cdot 94 \quad 141$

RoIDNS

CUSTOMER INSTRUCTIONS

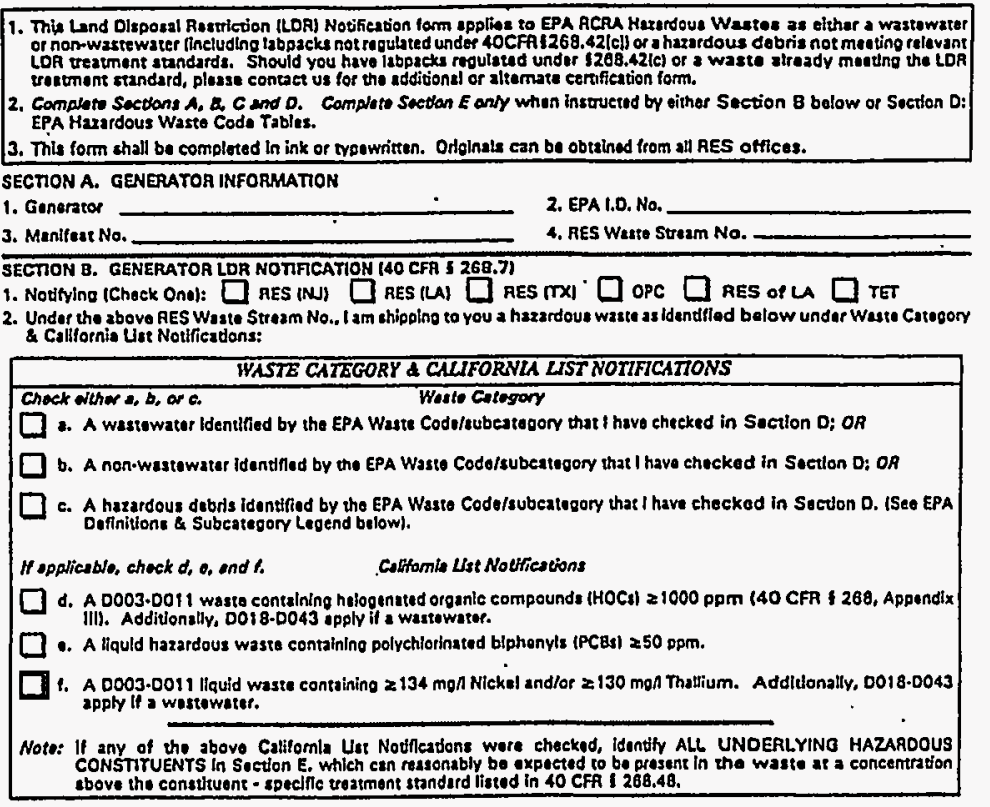

SECTION C. GENERATOR CERTIFICATION (Aucherizod Reprosentoalvos)

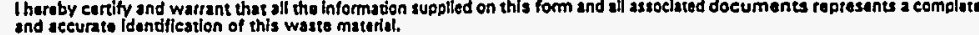

1. Print or Type Name:

2. Dara: _-' - -

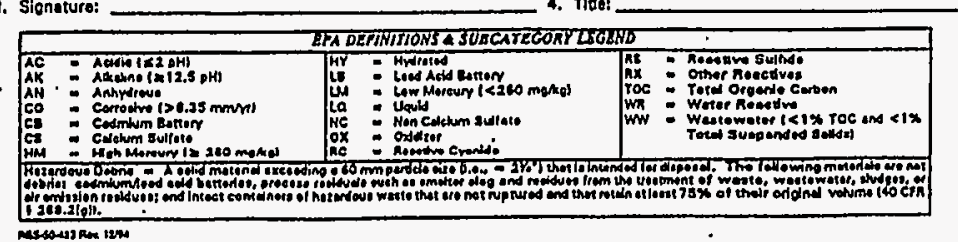

206- Tha oenes

123 PQs

$2512 \cdot 94$

SECTION D: EPA HAZARDOUS WASTE CODE TABLES

\begin{tabular}{|c|c|c|c|c|c|c|}
\hline \multicolumn{2}{|c|}{ 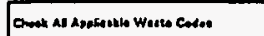 } & \multicolumn{3}{|c|}{ "D" CHARACTERISTIC CODES } & \multicolumn{2}{|c|}{ 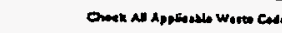 } \\
\hline 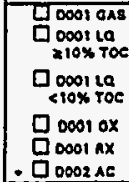 & 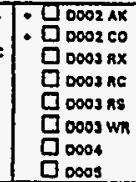 & 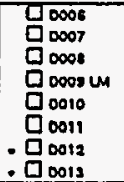 & 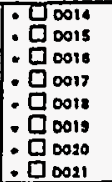 & 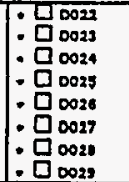 & 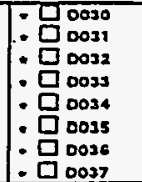 & \\
\hline \multicolumn{7}{|c|}{ 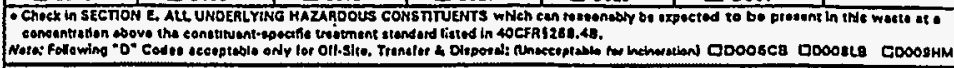 } \\
\hline \multicolumn{2}{|c|}{ 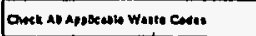 } & \multicolumn{3}{|c|}{ "F" LISTED CODBS } & \multicolumn{2}{|c|}{ 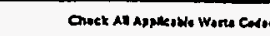 } \\
\hline 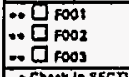 & 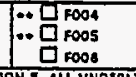 & 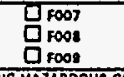 & 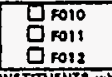 & 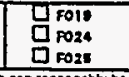 & 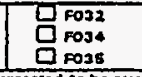 & \\
\hline \multicolumn{7}{|c|}{ 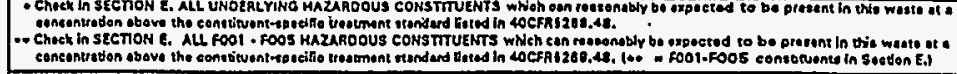 } \\
\hline \multicolumn{2}{|c|}{ 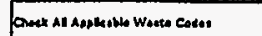 } & \multicolumn{3}{|c|}{ " $K$ " LISTED CODES } & \multicolumn{2}{|c|}{ 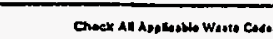 } \\
\hline 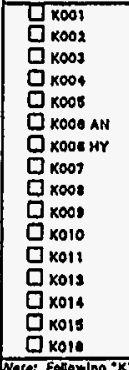 & 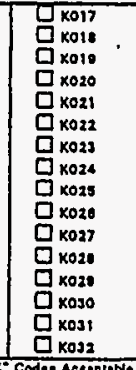 & 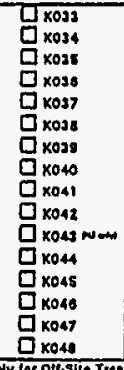 & 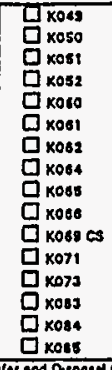 & 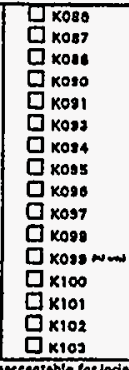 & 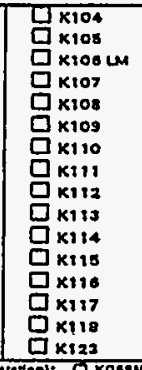 & ㅁ \\
\hline & & & & & & a \\
\hline \multicolumn{2}{|c|}{ 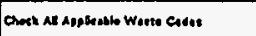 } & \multicolumn{3}{|c|}{ "P" LISTED CODES } & \multicolumn{2}{|c|}{ 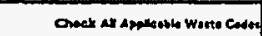 } \\
\hline 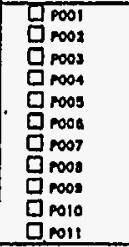 & 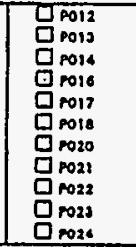 & 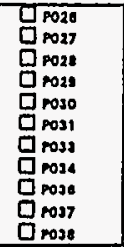 & 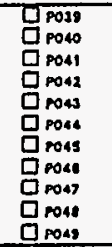 & 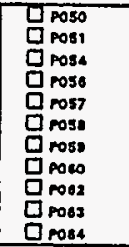 & 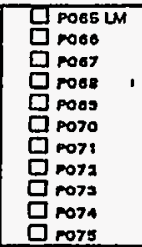 & 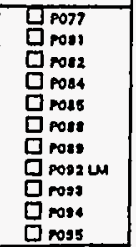 \\
\hline
\end{tabular}

Figure 4. Rollins LDR notification/certification form used by the INEL at 50\% size reduction. 


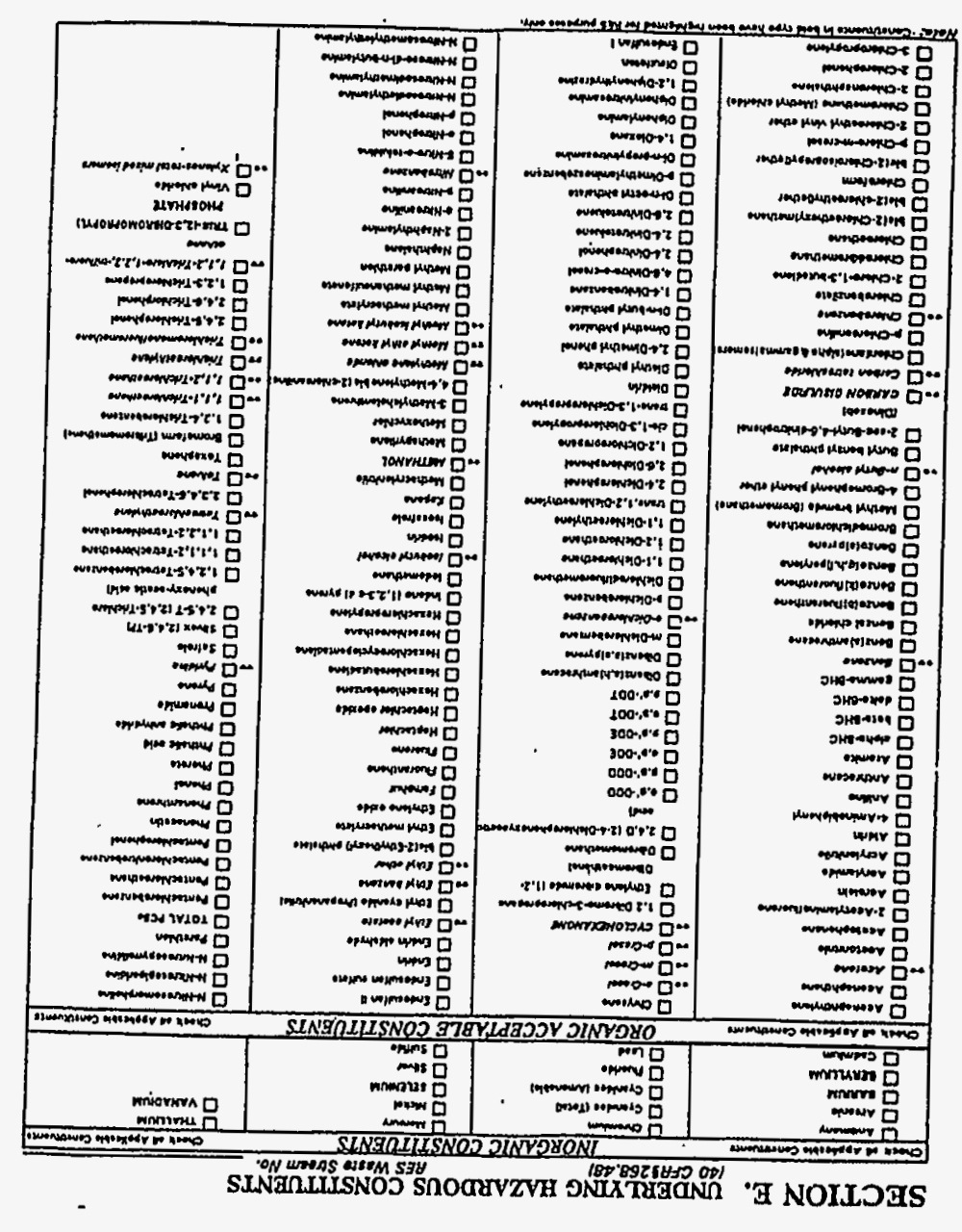

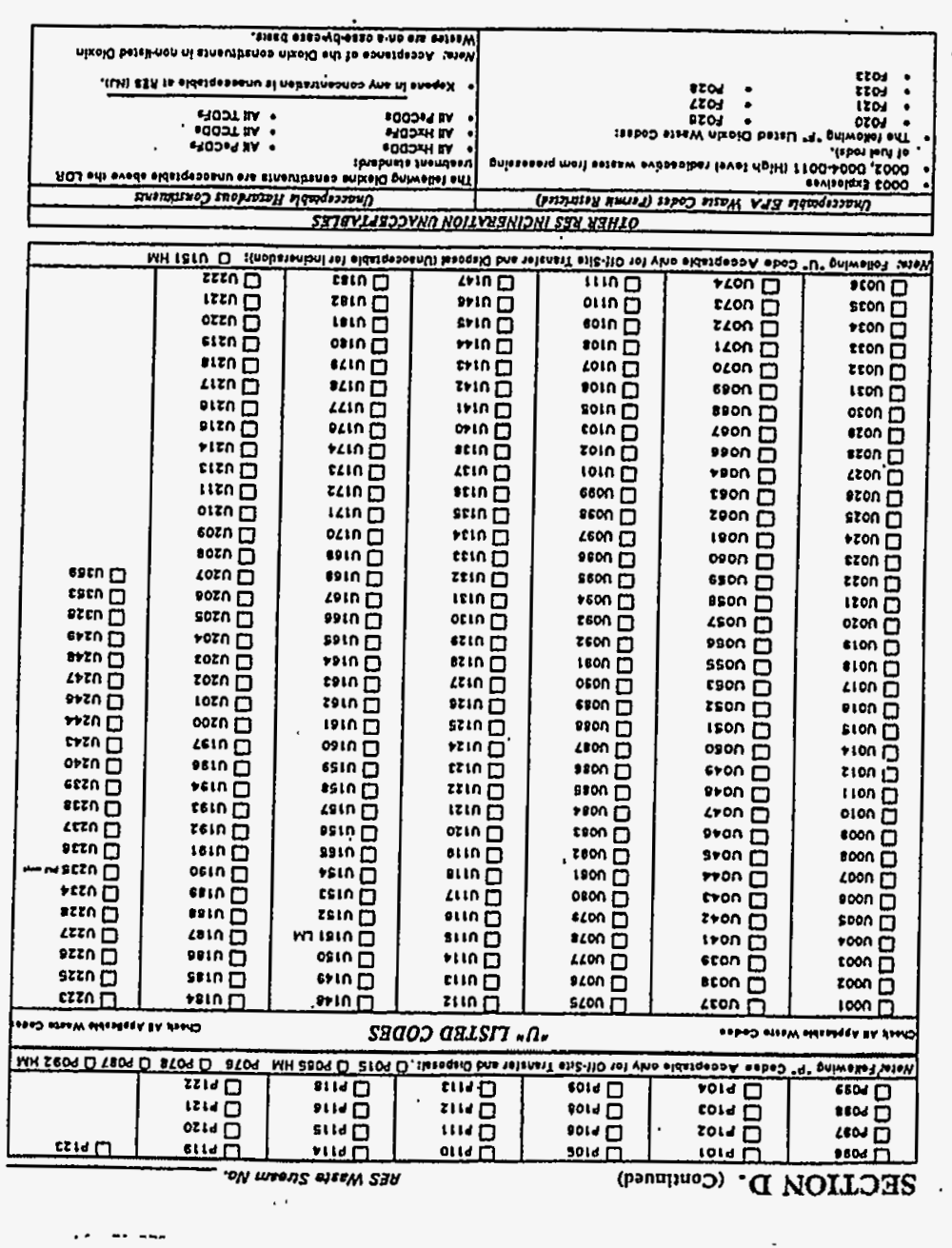




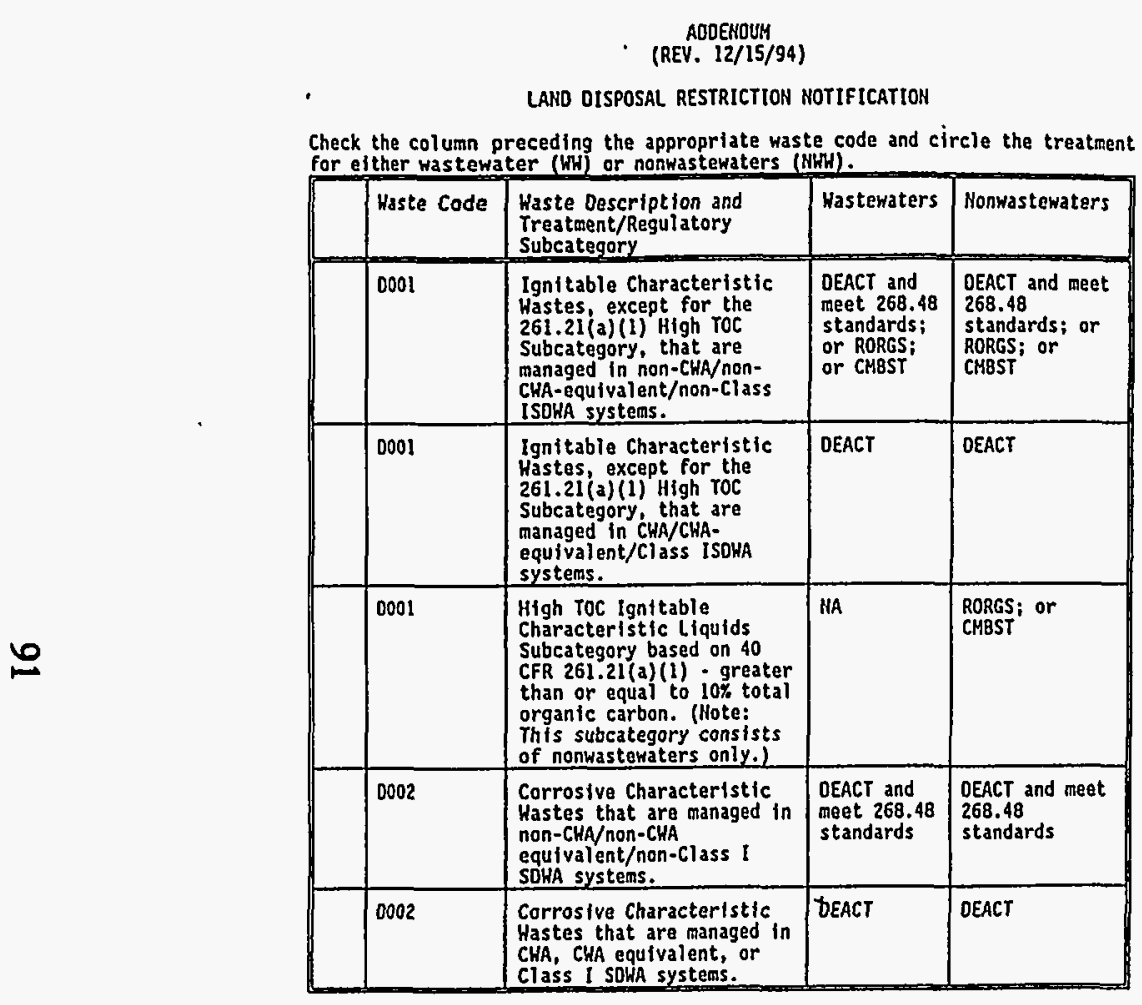
If the treatment standard in the above table requires meeting the 40 CFR
268.48 standards, tdent ffy the appropriate underly ing hazardous constituents notification 268.48 table.

Figure 4. Continued. 
This page intentionally left blank 
- The subcontractor technical representative provides WROC-TP with the approval number for the waste materials.

- WROC-TP or the WROC Waste Operations facility operator notifies the INEL Traffic group of the material to be shipped on the next monthly scheduled shipment. The notification is required, in writing, at least 14 days in advance. The notification descriptions consists of a complete description and quantity of waste to be shipped and any additional documentation required to accompany the shipment.

- Traffic personnel verify that the material is:

- $\quad$ Packaged in accordance with 49 CFR $\$ \S 173,178$, and 179

- $\quad$ Marked in accordance with 49 CFR $\S \S 172.300-338$

- $\quad$ Labeled in accordance with 49 CFR $\$ \S 172.400-448$

and that the vehicle used for transporting the shipment is properly placarded in accordance with 49 CFR $\S 172$, Subpart F.

- Traffic notifies the subcontractor which of the approved drums are tentatively planned for shipment.

- Traffic and WROC-TP schedule a time with the generator to review the waste's packaging, marking, and labeling, and applicable LDR notifications before the scheduled shipment.

- WROC packaging and transportation representatives accompany the subcontractor when the wastes are being picked up at the INEL sites. The packaging and transportation representatives ensure that the approvals and manifests accurately reflect the drums being loaded. Traffic signs the manifest for the INEL.

- After the shipment of approved drums occurs, WROC-TP sends a list of shipped drums and respective charge numbers applicable for the transportation and disposal costs to the Procurement subcontract administrator.

- The subcontractor submits an invoice work sheet to the INEL subcontract administrator for the shipment of waste containers. The subcontract administrator sends a copy of the invoice to WROC-TP for concurrence on the number of containers identified and to determine that the related charges are correct.

- WROC-TP reviews the invoice worksheet and signs it stating that the charges are acceptable, or identifies any discrepancies requiring negotiations between the INEL and the subcontractor.

- The subcontract administrator uses the invoice worksheet and the shipment list provided by WROC-TP to transform the generator's charge numbers into funds to pay for the offsite transportation and disposal charges. 


\subsubsection{Rocky Flats Plant Waste Management Operations Process Description}

Before the implementation of the Rocky Flats Environmental Technology Site (RFETS) task order under the MTS, the EG\&G Rocky Flats Regulated Waste Operations (RWO) had numerous waste stream profiles in use with their disposal vendors, who provided for the disposal of the majority of their routinely generated wastes. Upon task order implementation, the RWO staff matched their existing profiles to specific line items in the MTS price schedule exhibit. Waste profiling, shipment preparations and executions, etc., did not change as a result of the new subcontract.

Currently RFETS generators need only to characterize, document, and package their wastes to meet RCRA LDR, TSCA, and/or nonradioactive certification criteria (i.e., meet the permitted storage WAC), and RWO initiates commercial treatment/disposal of the waste from permitted storage. RWO addresses any additional criteria needed to meet the commercial TSDF's WAC. The EG\&G Rocky Flats RWO is currently developing a waste form-specific WAC for use by waste generators plantwide. This WAC will permit the generators to "target" their waste generation for ultimate treatment/disposal, not just permitted storage. This enhancement should expedite actual disposal from the RFETS storage area by reducing the additional characterization, preparation, etc., required in order to profile, prepare, and ship waste to the subcontracted TSDFs.

Under the MTS, every item that is shipped for treatment/disposal has a specific line item, specific treatment/disposal technology, and a destination TSDF. Before the implementation of the MTS, the RFETS profiles allowed for variable treatment technology options and facilities, and therefore billing variations. Under the MTS, the EG\&G Rocky Flats RWO and Procurement staff negotiated amendments to profiles to ensure that, for each item (drum) of waste they shipped, the EG\&G Rocky Flats staff and the destination TSDF would know precisely which subcontract line item the drum would be treated and billed under.

This way of doing business also facilitated accurate disposal service accrual management. For example: RFETS had in use a profile for waste "machine coolants," which consist of oil, water, "trimsol," and ethylene glycol in varying ratios depending upon the contents of each drum. Before the MTS, EG\&G Rocky Flats would send a load of this waste to the vendor's TSDF, and, based upon their acceptance sampling, the TSDF staff would determine which drums met their minimum BTU (British Thermal Unit) and maximum water content limits for fuel blending, at one facility and one price, versus which drums had to be sent to another facility for destructive incineration at a different price.

Although both treatments and facilities were included in the MTS price schedule and list of approved facilities, this created a potential accrual, billing, and subcontract technical compliance problem. Therefore, EG\&G Rocky Flats negotiated restrictions on some of their profiles to remove the variable treatment options. EG\&G Rocky Flats restricted the profile parameters to a tracking system, the appropriate destination TSDF and treatment technology, and subcontract line item number for each active profile. The CWM representative administering the RFETS account set up a tracking system within the CWM billing system, which assigned each active profile to the correct treatment, TSDF, and line item information. Figures 5, 6, and 7 show how the profile assignments are used for confirmation of shipments, invoicing, and accrual records. Anyone at any CWM facility can query a RFETS profile, associated subcontract line item number, and determine where and how the waste must be treated/disposed. This vendor billing modification forces both parties to ensure that an item is on the subcontract before they request or render service. 


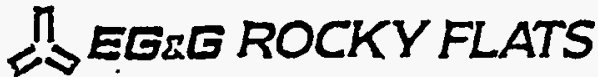

EG\&G ROCKY FLATS, INC.

ROCKY FLATS PLANT. P.O. BOX 464, GOLDEN, COLORADO 80402-0464 - (303) 966-7000

September 21, 1994

C. L. Elliott

Chemical Waste Management, Inc.

Rocky Mountain Desert Region

9131 E. 96th Avenue

Henderson, Colorado 80640

\section{SCHEDULED SHIPMENT - MANIFEST NUMBER 26217 - JSVM-12-94}

This letter is to confirm the shipment of 51 hazardous waste containers scheduled for Thursday, September 22, 1994. The attached "draft" manifest details the items to be shipped. Please review and make comments to the proposed proper shipping names.

The following table identifies the CWM Profile and the treatmentdisposal method line item specified for the wastes included in the referenced shipment. This table can also be used to identify the associated pricing and appropriate treatment, storage, and disposal facility.

\begin{tabular}{|c|c|c|}
\hline Iteris & CWM'Profile Number - Description & Line Item Number- \\
\hline 25 & AL8137 - Soft Waste & 1 \\
\hline 7 & B86408 - Oils/Grease & 30 \\
\hline 2 & BF2208 - Mercury Equipment >260 ppm & 6 \\
\hline 3 & BF2211 - Ni-Cd Batteries (Wet) & 11 \\
\hline 4 & BJ2218 - Debris for Incineration & 1 \\
\hline 3 & H06402 - Machine Coolants/Antifreeze & 3 \\
\hline 4 & H19620 - Garage Solvents & 27 \\
\hline 3 & H19623 - Paints/Thinners & 9 \\
\hline
\end{tabular}

Upon your review of the inciuded information, please fax your comments and/or approval of all pages to me at 966-3029. EG\&G Rocky Flats . Inc. regrets any inconvenjence that this rescheduling may have caused. If you have any questions, 1 can be reached at 966-5810. Thank you for your cooperation.

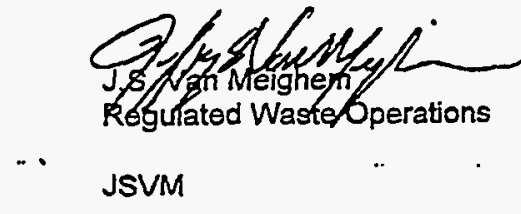

Attachments: As Stated bec:

D. R. Lobdell ORL

D. A. Parker

R. J. Molter g 2

Figure 5. EG\&G Rocky Flats confirmation of a shipment. 
This page intentionally left blank 


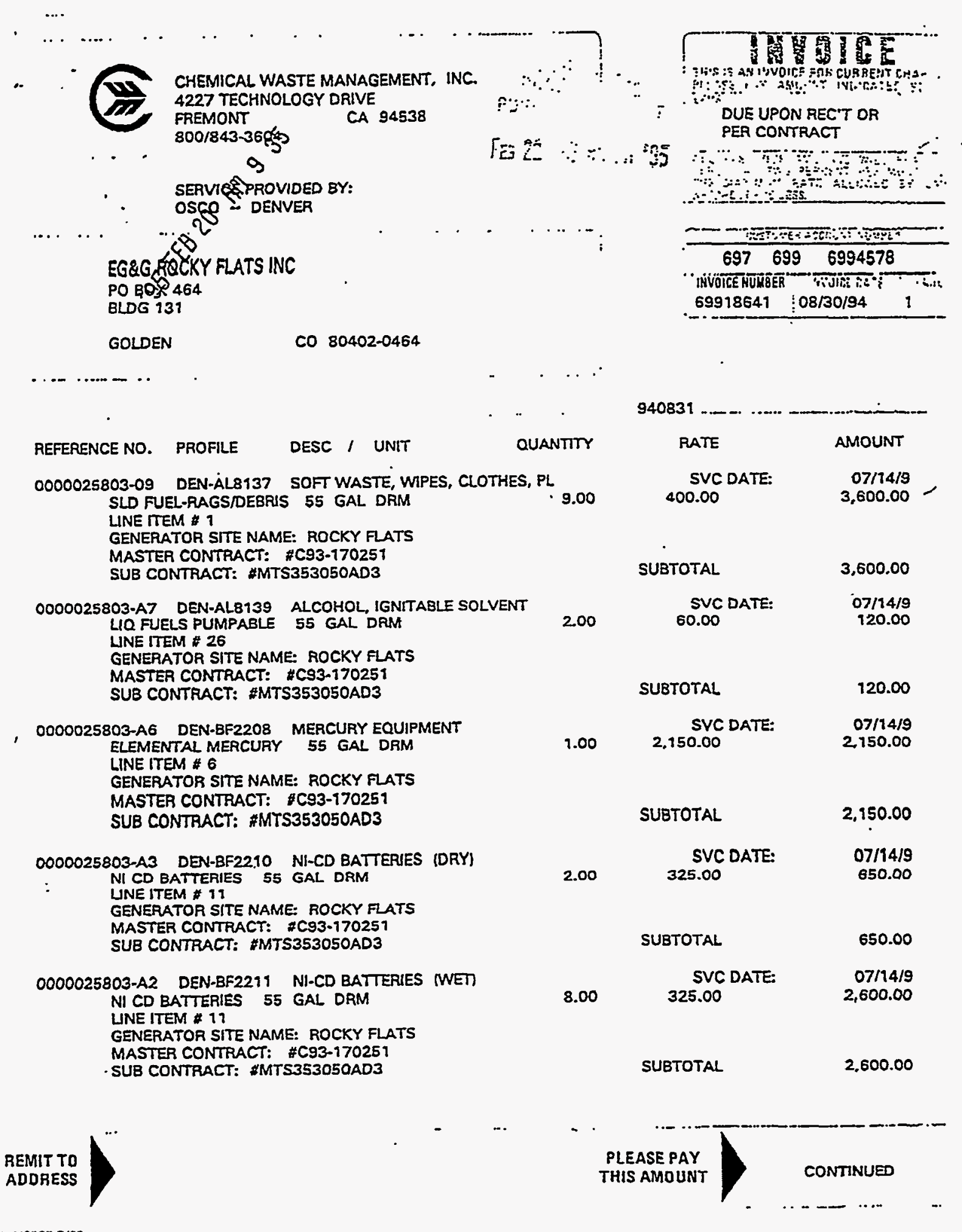

:WM0067 8/82

ORIGINAL INVOICE

Figure 6. EG\&G Rocky Flats invoice with associated assigned profiles. 
This page intentionally left blank 
RWS FY95 WASTE DISPOSAL EXPENSE ACCRUAL

\begin{tabular}{|c|c|c|c|c|c|c|c|}
\hline SERVICE, DATE & $\begin{array}{l}\text { PROFILE } \\
\text { \# }\end{array}$ & $\begin{array}{c}\text { MTS line } \\
\text { item \# }\end{array}$ & $\begin{array}{l}\text { DISP } \\
\text { COST } \\
\text { \$NNIT }\end{array}$ & \begin{tabular}{|c|} 
UNITS \\
SHIPPED
\end{tabular} & $\begin{array}{l}\text { EXPENSE } \\
\text { ACCRUED }\end{array}$ & $\begin{array}{l}\text { TOTAL FOR } \\
\text { SHIPMENT }\end{array}$ & INVOICE INFO \\
\hline SHIP 11///94 & AL8137 & 1 & $\$ 400$ & 8 & $\$ 3,200$ & & Inv\# 69919489 \\
\hline Manifests \# & AK6659 & 18 & $\$ 600$ & 1 & $\$ 600$ & & \\
\hline 26581,30386 & BB6408 & 30 & 560 & 6 & $\$ 180$ & & \\
\hline \multirow[t]{8}{*}{26 Loadlists } & BF2208 & 6 & $\$ 2,150$ & 1 & $\$ 2,150$ & & \\
\hline & $B \sqrt{22} 18$ & 1 & 5400 & 2 & 5800 & & \\
\hline & B. 13098 & A4 & $\$ 600$ & 1 & 5600 & & \\
\hline & HO6402 & 3 & $\$ 285$ & 16 & $\$ 4,560$ & & \\
\hline & H19620 & 27 & $\$ 60$ & 3 & $\$ 180$ & & \\
\hline & H19623 & 9 & $\$ 145$ & 3 & $\$ 435$ & & \\
\hline & $B 04745$ & 210 & $\$ 44$ & 2 & 588 & & (<not billed yet) \\
\hline & Truck & & 51,085 & 40 & $\$ 1,085$ & $\$ 13,878$ & \\
\hline SHIP 11/21/94 & BO4729, & 210 & $44(5 G)$ & 10 & $\$ 440$ & & $\operatorname{lnv} \$ 68116967$ \\
\hline Manifest \# 31156, & AK6654 & 12 & $65(5 G)$ & 1 & $\$ 65$ & & OKD 2/17/95 \\
\hline \multirow[t]{3}{*}{3 Loadlists } & BF2208 & 6 & $500(5 \mathrm{G})$ & 1 & $\$ 500$ & & \\
\hline & $\mathrm{BO4744,5}$ & 210 & $67(10 \mathrm{~g})$ & 6 & $\$ 402$ & & \\
\hline & Truck & & $\$ 1,085$ & 18 & $\$ 1,085$ & $\$ 2,492$ & \\
\hline SHIP 12/1/94 & H75544 & A1 & $\$ 250$ & & 511500 & & \\
\hline Manifest \# 31222, & $A L 8139$ & 26 & $\$ 260$ & $\frac{40}{1}$ & $\frac{\$ 1,100}{\$ 60}$ & & \\
\hline \multirow[t]{14}{*}{29 Loadlists } & A 2239 & 28 & $\$ 285$ & 1 & $\$ 285$ & & \\
\hline & $\mathrm{B} \sqrt{2923}$ & $\overline{A 2}$ & $150(10 G)$ & 1 & $\$ 150$. & & \\
\hline & B $\sqrt{2923}$ & $A 2$ & $\$ 296$ & 2 & $\$ 592$ & & \\
\hline & $B \sqrt{3145}$ & $\overline{A 6}$ & $\$ 360$ & 9 & $\$ 3,240$ & & \\
\hline & BJ2920 & 28 & $\$ 285$ & 1 & $\$ 285$ & & \\
\hline & $B \sqrt{3098}$ & A4 & 5600 & 2 & $\$ 1,200$ & & \\
\hline & $8 \sqrt{3088}$ & A7 & $\$ 260$ & 1 & $\$ 260$ & & \\
\hline & BJ3081 & $\overline{A 3}$ & $\$ 285$ & 5 & $\$ 1,425$ & & \\
\hline & H06402 & 3 & $\$ 285$ & 3 & $\$ 855$ & & \\
\hline & BB6408 & 30 & $\$ 50$ & 4 & $\$ 240$ & & \\
\hline & H19620 & 27 & 560 & 4 & $\$ 240$ & & \\
\hline & AL8137 & 1 & $\$ 400$ & 6 & $\$ 2,400$ & & \\
\hline & Overpack & & $\$ 100$ & 1 & $\$ 100$ & & \\
\hline & Truck & & $\$ 2.420$ & 86 & $\$ 2,420$ & $\$ 25,252$ & \\
\hline SHIP $12 / 14 / 94$ & BJ2921 & 3 & 285 & 9 & $\overline{52} \overline{565}$ & & \\
\hline \begin{tabular}{|l|} 
Manifests \\
\end{tabular} & BJ3986 & 28 & 285 & 1 & $\$ 285$ & & \\
\hline$\# 31470,31479$ & AL8140 & 17 & 600 & 1 & $\$ 500$ & & \\
\hline \multirow{8}{*}{24 Loadlists } & BJ3089 & A3 & 140 & 1 & 5140 & & \\
\hline & $A \sqrt{2240}$ & 218 & 493 & 13 & $\$ 6,409$ & & \\
\hline & BJ3098 & $\mathrm{A4}$ & 600 & 1 & 5600 & & \\
\hline & 119619 & 28 & 285 & 3 & $\$ 855$ & & \\
\hline & H19623 & 9 & 145 & 2 & $\$ 290$ & & \\
\hline & H19620 & 27 & 60 & 6 & $\$ 360$ & & \\
\hline & AL8137 & 1 & 400 & 1 & $\$ 400$ & & \\
\hline & 1406402 & 3 & 285 & 2 & $\$ 570$ & & \\
\hline
\end{tabular}

Figure 7. EG\&G Rocky Flats waste disposal expense accrual using assigned profiles. 
This page intentionally left blank 


\subsubsection{Advantages}

The INEL waste management organizations have identified the following advantages from the MTS:

- The facility combination has allowed the INEL to schedule and direct ship waste at a cost that is not prohibitive, enabling the INEL to keep the inventory at the HWSF low.

- The generators are charged for actual transportation and treatment/disposal costs, rather than a "per gallon" charge. This tends to encourage waste minimization and reduce the amount of waste for which treatment/disposal is difficult and/or expensive.

- When a problem waste is identified or a storage time is about to elapse, the subcontractors have been very helpful in approving the waste stream quickly and arranging transportation for shipment of the waste.

- The INEL has been able to obtain several small emergency PCB cleanup activities from the subcontractors by preparing SOWs and negotiating pricing using the MTS lab pack services SOW and actual PCB waste stream pricing sheets as the basis for pricing. Response and service provided by the subcontractor have been excellent for these requests.

The EG\&G Mound facility reported that the line item pricing on the MTS was equivalent or less than what they had paid on their previous hazardous waste disposal subcontract. In addition, the majority of the line item pricing on the MTS had incineration specified as the treatment option, whereas, on their previous subcontract, the waste streams were generally land disposed. The reduction in longterm liability as a result of incineration as the treatment as opposed to direct landfill or stabilization/landfill was of considerable importance to EG\&G Mound management and their DOE operations office.

REECo identified the following advantages for their waste management operations at the MTS under the new MTS:

- A strong one-point localized control of the site-specific portions of the MTS package. This control limits the potential for confusion or misdirection of the vendors for a requested service.

- There is a wide range of waste stream descriptions in the pricing sheets; these are designed to cover most "normal" contingencies.

\subsubsection{Dișadvantages}

The INEL did not record any disadvantages to the systems as it presently operates.

EG\&G Rocky Flats identified the following disadvantages to the system they had implemented under the MTS:

- Profiles were not as flexible or customer friendly as they could be, or once were. 
- Occasionally a drum did not match the proposed profile parameters. Negotiating a new or revised profile to accommodate treatment of the waste required a concurrent negotiation and possible task order modification to match the new or revised profile.

REECo identified the following advantages for their waste management operations at the MTS under the new MTS:

- It was the opinion of some waste management personnel that no wide range "generic" waste streams existed on the MTS. These would need to be established under localized subcontract administration and approved for use by the MTS administrators at INEL.

- Waste management personnel noted that it was extremely difficult to add new disposal facilities to the MTS. There was a perceived difficulty for handling newly identified waste streams. That is, it requires an approval, grouped M\&O contractor review, and consolidated ESH\&Q liability assessment before any vendor facility can be added to the existing list. (Note from the lead laboratory: The MTS was designed to handle all waste streams generated by the participating M\&O contractors for which treatment technologies located within the Continental United States existed.)

\subsubsection{Issues}

The INEL WROC and Traffic personnel identified several issues relating to customer service with respect to the first year of operations under the MTS. For example,

- The customer service representative assigned by Rollins to the INEL has been required to spend large amounts of time on other customers and projects. If he is not in the office, no one else knows the status of the INEL shipments pending approval.

- The INEL has established scheduled shipment dates and made it known that they would like the approvals returned two weeks in advance of the shipping date. Before the October 1994 shipment, this was a problem. However, the vendor appears to have solved the problem.

- Returning completed manifests and CDs within required times has been a problem for Rollins. The INEL Traffic group has had to initiate a letter listing specific manifest numbers approaching the 45-day limit on a monthly basis. Some delinquent CDs are now more than two years late.

Representatives from REECo stated that bullets one and three applied to their interactions with Rollins as well.

An issue identified in waste management operations at one of the other M\&O contractor sites concerned the qualifications of the waste management staff assigned to manage wastes for offsite treatment/disposal. The MTS was designed to be administered by personnel with technical backgrounds, primarily in the chemical sciences. A thorough understanding of the chemistry, as well as regulatory requirements, for hazardous waste determinations is necessary in order to understand how the waste stream exhibits are designed. 
The MTS is also designed based on the understanding that the M\&O contractor's generators will retain their legal responsibility under RCRA for hazardous waste characterization, management, and transportation. That is, the M\&O contractor is not relieved of environmental liability if the subcontractor performs an activity that is the legal responsibility of the M\&O contractor's generator (such as hazardous waste characterization, preparation of manifests, and/or waste packaging).

\subsubsection{Resolutions and Recommendations}

A periodic feedback mechanism should be implemented by the M\&O contractors. This would provide a forum for discussing perceived customer/subcontractor problems before the problems become critical.

The Rollins representative stated that, as a subcontractor, the company totally concurs with the implementation and periodic meeting concept; however, as a private contractor, they believe is the responsibility of the $\mathrm{M} \& \mathrm{O}$ contractor to organize and conduct these meetings. The attempts made by Rollins representatives to implement these meetings has not been as productive as each party desired.

Meetings were held with the vendor representatives to try to correct the system deficiencies that resulted in the identified issues. The vendor representatives proposed solutions.

INEL will have to modify its tracking to ensure that $100 \%$ payment is not made until the vendor returns the completed manifests and CDs.

The ultimate resolution and recommendation proposed with regard to service issues is to switch subcontractors. This is a major advantage of having two subcontractors, if the service is unacceptable from one subcontractor, then the other vendor should be used.

With respect to $\mathrm{M} \& \mathrm{O}$ contractor staff qualifications, it is imperative that $\mathrm{M} \& \mathrm{O}$ contractors ensure that they have qualified staff. The waste management staff is the last safeguard that a site has to ensure that environmental compliance is maintained and potential liability reduced.

\subsubsection{Vendor Perspective}

5.3.7.1 Chemical Waste Management, Inc. No comments regarding the M\&O contractor's waste management process were received.

5.3.7.2 Rollins Environmental Services, Inc. Knowledge of the M\&O contractor's waste management process is in some ways blind to the subcontractor. The private waste disposal contractor, in general, does not have the staff resources to concern themselves with the details of the interworking of the M\&O contractors beyond a superficial level. The private waste disposal contractors' concerns are driven by their goal to remain in compliance, protect the health and safety of their employees, and protect their facility permits. As long as the waste stream data provided meet the permit requirements of the receiving plant; the private waste disposal contractor is in compliance and satisfied. Therefore, as long as the M\&O contractor provides all of the waste stream information required by the receiving plant's permit, and the waste is offered to the subcontractor in a safe and DOT legal package, Rollins has no issues with the DOE M\&O contractor. If these conditions are not met, the waste management subcontractor will not accept the shipment. 
This page intentionally left blank 


\section{COSTS OF THE INITIATIVE}

The actual and potential costs associated with developing and implementing the consolidated hazardous waste transportation/treatment/disposal subcontract and ESH\&Q liability assessment initiative are perhaps the most difficult to calculate. Several reasons for the difficulty can be cited, including failure to identify all costs associated with the process, lack of tracking mechanisms for support organizations, and initiation of the project after site budgets were approved and in place.

\subsection{General Considerations}

One of the most constructive methods for determining the effectiveness of the initiative is to examine the process in terms of environmental total quality management. This is particularly true for the ESH\&Q liability assessment program, which can be viewed in terms of the EPA Environmental Auditing Policy (See 51 FR 25004). EPA states in its auditing policy that it encourages the regulated entities (e.g., DOE and its contractors) to use environmental auditing to help achieve and maintain compliance with environmental laws and regulations, as well as to help identify and correct unregulated environmental hazards. One can view an auditing or assessment program as a method of maintaining environmental quality.

Another consideration is that, because management is generally driven largely by financial concerns, determining the cost of environmental quality (in this case the costs of the consolidated initiatives) is a critical step in developing an environmental total quality management (TQM) program for which management, both DOE and the M\&O contractors, will actively demonstrate commitment and support. Richard S. Greenberg and Cynthia A. Unger group costs of environmental quality into three categories: failure, prevention, and appraisal. They also stated that the total cost of environmental quality can be used as a benchmark to monitor the level of environmental quality and to justify the redirection of resources (Greenberg and Unger, 1994:177).

As previously stated, a company's total cost of environmental quality consists of all costs associated with maintaining the existing level of environmental quality, including not just those of the environmental department, but also, at a minimum, those of legal, procurement, and operations. Greenberg and Unger state that "in general, determining the total cost of environmental quality means identifying all direct environmental expenditures, accounting for all personnel time devoted to environmental activities, and estimating implied costs (for example, lost sales). After these costs are identified, they can be tracked to provide management with valuable data to evaluate the change in quality and identify areas for improvement, consequential cost reduction, and ultimate savings.

"The cost of environmental quality can serve as a benchmark against which improvements can be measured. Because a company's level of environmental quality is correlated to its environmental compliance record, management will find that as a company's level of environmental quality and regulatory compliance increase, the cost of environmental compliance will decrease over the long term" (Greenberg and Unger, 1994:179).

Richard P. Wells, et al., writing in Environmental TQM state that "Perhaps the single largest obstacle to effective corporate environmental management is the absence of cost accounting systems that accurately reflect the true costs of quality. If environmental costs of quality are not recognized by 
corporate accounting systems and allocated to the processes that give rise to the costs, process managers will have neither an incentive to minimize environmental impacts nor a reward for successful environmental management" (Wells, et al., 1994:153).

Wells, et al. warn that "Financial results must always be kept in mind as you measure the results of your environmental programs. Typically, corporate accounting systems recognize only direct cost savings as returns on environmental expenditures. Avoided costs are sometimes considered, but often very narrowly. For example, accounting systems may see avoided compliance costs as benefits of environmental expenditures, ignoring materials savings and dramatically increasing environmental costs. Or systems may subsidize some wasteful practices by not charging the operating unit the full cost that their wastes impose on the company" (Wells, et al., 1994:157-158).

These considerations can be applied to projecting and justifying the costs associated with the processes required to implement the consolidated hazardous waste transportation, treatment, and disposal subcontract and associated ESH\&Q liability assessment program.

In general, three basic types of financial sources, commonly referred to as colored money, are used to fund activities at M\&O contractor sites within the DOE system: burden or overhead, common support, programmatic, and service centers. Each of these sources is tagged for funding specific activities and cannot be used to fund others, nor can money from the various sources be mixed to fund an activity. For example, at the INEL, overhead accounts are used to fund management and direct report administrative support (e.g., unit managers and associated secretaries, training, sick leave).

The common support pool includes costs that are incurred for the benefit of the INEL site. Examples include legal offices, bus operations, and procurement activities. Common support costs are distributed to end-cost objectives.

Programmatic dollars fund program-specific activities such as environmental restoration. Each of the funding sources has different G\&A (general and administrative) adders and burdens associated. For example, for each programmatic dollar required to perform an activity, adders and burdens are added to compensate for the costs that relate to the overall management and operation of the company, such as finance, security, and human resources. Common support dollars and overhead dollars have the adders built in.

Costs in the service centers are included primarily in accounts referred to as direct recovery accounts. These accounts are designed to recover costs by distributing them to the requesters and those who benefit from their services. Costs include labor-related costs and material and other miscellaneous costs required to provide business computer operations, technical publications, and material handling. Costs for these services are distributed using various unit costs.

The INEL data cited in the following sections are predominantly common support dollars, unless otherwise specified. 


\subsection{Direct Cost Savings}

\subsubsection{Consolidated Master Task Subcontract}

EG\&G Idaho projected the potential costs associated with the tasks required to prepare, issue, and award the MTS. The total estimated costs for the process were allocated to each participating M\&O contractor on an equal basis. These tasks consisted of: preparing the RFP,-issuing the RFP, evaluating proposals, conducting liability assessments, and issuing the MTS. Each of the M\&O contractors was required to issue a purchase order to EG\&G Idaho for their portion of the shared cost before the tasks began for real-time reimbursement of the EG\&G Idaho cost. Each M\&O contractor received a detailed breakdown of the estimated costs, as shown in Table 7.

Based on the labor estimate, EG\&G Idaho calculated the procurement and liability costs for implementing the initiative as follows:

M\&O shared costs 7597 hours ( $\$ 85.00 /$ hour)

Cost for materials and supplies

Travel for site liability assessments

Travel for pre-bid conference

Travel for preliminary procurement assessment
$\$ 645,745$

$\$ 2,000$

$\$ 80,000$

$\$ 6,000$

$\$ 7,000$

$\$ 740,745$

$\$ 148,149$

Shared cost to each M\&O: $\$ 740 \mathrm{~K} / 5 \mathrm{M} \& O$ s

Additional costs in preparing the MTS and performing the liability assessments were not shared. These costs were calculated as follows:

Example: INEL: $\$ 148 \mathrm{~K}$ shared cost $+\$ 38 \mathrm{~K}(442 \mathrm{hrs}) \quad \$ 186 \mathrm{~K}$

Each M\&O: \$148K shared cost $+?=$ ?

EG\&G Idaho estimated that there could be new or additional operations costs once the subcontract was in place. For example:

- Profiling waste streams ( $\$ 300-\$ 3,000 /$ waste stream)

- New transportation rates.

After the award of the MTS EG\&G Idaho re-evaluated the costs incurred in the process and predicted potential cost savings for future consolidated competitions. Each of the participating M\&O contractors was asked to provide estimates of their actual expenses. The responses from the participating M\&O contractors was generally poor, because they apparently had not established methods (such as work packages) to track the expenses. Therefore, the analysis of administrative costs presented in Table 8 is a best estimate based on available data. As can be seen in that table, significant cost savings (about $\$ 200,000$ ) could be realized in a worst-case scenario re-competition if the only significant expense is the necessity to evaluate a different set of vendors. If the same vendors passed the initial bid evaluation, a potential of more than $\$ 300,000$ could be realized. Again, these numbers are very conservative best 
estimates based primarily on available INEL data. The weak links in the cost data are total actual costs associated with labor charges from the legal, waste management, and procurement departments, M\&O contractor managers' reviews, and costs expended by EG\&G corporate personnel.

Table 7. EG\&G M\&O contractor hazardous waste disposal initiative--consolidated subcontract estimated cost.

\begin{tabular}{lrrr} 
& M\&O Shared & $\begin{array}{c}\text { Additional } \\
\text { Costs to the }\end{array}$ & $\begin{array}{c}\text { Additional } \\
\text { Individual }\end{array}$ \\
Task Description & Costs (hrs) & INEL (hrs) & M\&O Cost \\
\hline
\end{tabular}

1. Commerce Business Daily Advertisement

\section{4}

2. Prepare Statement of Work

3. Prepare Waste Stream Pricing Exhibits - Individual M\&Os

4. Verify M\&O Waste Streams are new and not duplicates

5. Prepare RFP Waste Stream Exhibits - Draft M\&O RFP

6. Prepare Draft M\&O RFP

7. M\&Os Review and Make Final Comment3 on Draft RFP

8. Incorporate Final Comments to RFP

9. Finalize RFP and distribute to interested vendors

10. Pre-Bid Conference

11. Develop Assessment Criteria

12. Prepare Assessment Training Plan

13. Identify Assessment Team Members

14. Train Assessment Team Members

15. Conduct Preliminary Procurement Assessment

16. Conduct Pre-Bid Award Site Liability Assessments

17. Prepare Site Liability Assessment Final Report

18. Prepare Award Package for MTS

19. Prepare M\&O Specific Task Orders and Obtain DOE Operations Office Approval

20. Project Management

21. Yearly Administration of MTS

22. Yearly Administration of M\&O Specific Task Orders
120

$$
0
$$

60

160

80

0

40

8

12

200

80

0

320

30

3840

1800

80

0

613

150

0

7597 no

yes

yes

no

no

no

yes

no

no

yes

yes

no

yes

yes

yes

no

no

no

yes

no

no

yes 
Table 8. EG\&G M\&O contractor hazardous waste disposal initiative-analysis of administrative costs.

\begin{tabular}{llll}
\hline Task(s) & Implementation & Next Competition & Next Competition \\
\hline Assessment Criteria & $\$ 37,000$ & $\$ 5,000$ & $\$ 5,000$ \\
Request for Proposal & $\$ 56,000$ & $\$ 5,000$ & $\$ 5,000$ \\
Statement of Work & $\$ 79,000$ & $\$ 10,000^{-}$ & $\$ 10,000$ \\
Proposal Evaluation & $\$ 23,000$ & $\$ 23,000$ & $\$ 23,000$ \\
Assessment of Low Bidder Facilities & $\$ 375,000$ & $\$ 375,000 *$ & $\$ 210,000$ \\
Contract Award & $\$ 37,000$ & $\$ 37,000$ & $\$ 37,000$ \\
Subtotal & $\$ 607,000$ & $\$ 433,000$ & $\$ 268,000$ \\
Contingency (10\%) & $\$ 61,000$ & $\$ 43,000$ & $\$ 27,000$ \\
Total & $\$ 668,000$ & $\$ 476,000 *$ & $\$ 295,000 *$ \\
\hline
\end{tabular}

* Worst case if receive an undercut bid

** Comparison with status quo of $\$ 1$ million per year

\subsubsection{Consolidated ESH\&Q Liability Assessments}

As previously stated in this report, the ESH\&Q and financial liability assessment process is managed as a formal program at the INEL. The formalization of the program provided a mechanism for detailed planning and tracking of the costs associated with the scope of work because work packages were required for planning and budgeting purposes. At the INEL, both programmatic and common support funded programs require work packages for budget justifications. Work packages are the lowest level of planning, called level 40 , and the minimum requirement for work authorization.

"A work package (WP) is a definite task within a control account, which is used to define, schedule, budget, and measure work accomplishment. Every control account will have at least one WP. A WP has the following characteristics:

- It represents work at the level it is performed

- It has a resource value that is time-phased

- It is integrated with other detail WP schedules within the control account

- It has a scheduled start and completion date and, as applicable, interim milestones that represent accomplishment of actual work

- It has a duration limited to a relatively short time span, or is subdivided by interim milestones to enable periodic measurement of work accomplishment

- It is clearly distinguishable from other WP budgets" (Adams, et al, 1994:2-29). 
Work management and technical schedule, and cost performance measurement occur in the control account. The control accounts are levels within the contract work breakdown structure (WBS). The control account is a management control point representing the work, the plan, and the resources assigned to a single responsible organization in a single WBS element. The WBS is a hierarchical structure at the Lockheed Idaho level that organizes, displays, and defines the contractual (i.e., M\&O contract, products, or services) and the interrelationship of the elements of work which are ultimately authorized by DOE. Work packages may be developed for levels of effort below level 40 (such as level 50); in this case, the work packages provide a mechanism for tracking specific projects within a larger funded project.

6.2.2.1 Pre-award Assessment. Since the initial year of the consolidated initiative tasks has been completed, a WP has been developed in order to identify and estimate costs associated with a preaward ESH\&Q liability assessment. An example of an activity sheet for one of the tasks is shown in Figure 8. As can be seen in the figure, details regarding the budget estimate justifications can be delineated. All tasks associated with a subcontract pre-award assessment are described in this manner. This activity sheet also indicates which costs are to be divided among the participating M\&O contractors (line item called "Allocation to other DOE sites").

6.2.2.2 Annual Review Assessment. A work package was prepared in FY 1994 to address the need for the annual review of the facilities listed and used under the MTS. Figure 9 shows an example of an annual review work package activity sheet. This example uses the INEL programmatic charge rate for technical manpower in order to allow a direct comparison to be made with the pre-award activity sheet. The actual work package prepared by Lockheed Idaho for the annual reviews, used a common support charge rate $(\$ 45.16)$ because the entire package was being funded from the common support pool at the INEL rather than as a programmatic activity. It is apparent from a comparison of the activity sheets that the annual review costs about one-half what a pre-award assessment costs.

The budgeted total cost to the INEL for the annual reviews under the MTS is estimated at \$103K for FY 1995. This number also includes specific associated assessment team training.

\subsubsection{Post-Award Operations}

Costs associated with the post-award operations have, to date, been difficult to estimate for the following reasons:

- Work packages designed specifically to address the management of the MTS, task orders, and daily support operations were not established. It was not expected that managing the MTS and task orders would warrant the expenditure.

- The actual operations that use the MTS have different methods of charging costs (e.g., some facilities have a flat price-per-gallon charge for treatment/disposal of any waste streams, while other sites use an actual price based on waste composition and treatment/disposal cost). 
Rev. No.: $\mathbf{0}$

WBS No.: C29140000 Title:

External ESH\&Q and Financial Liability Assessments

\begin{tabular}{|c|c|c|c|c|c|}
\hline $\begin{array}{l}\text { Activity Title } \\
\text { or Description }\end{array}$ & $\begin{array}{c}\text { Org. } \\
\text { No. }\end{array}$ & $\begin{array}{c}\text { Cost } \\
\text { Element } \\
\end{array}$ & $\begin{array}{c}\text { Amount (Indicate } \\
\text { both Hours and } \\
\text { Dollars) }\end{array}$ & $\begin{array}{c}\text { Estimate } \\
\text { Justification/Basis } \\
\end{array}$ & $\begin{array}{c}\text { Performing Org, } \\
\text { Acknowl edgement } \\
\text { and Date } \\
\end{array}$ \\
\hline $\begin{array}{l}\text { Trip 1: RES(LA) Baton Rouge, LA } \\
\text { and RES(TX) Deer Park, TX }\end{array}$ & 1330 & & & Pre-Award Assessment & \\
\hline $\begin{array}{l}\text { Manpower - conduct of the } \\
\text { assessment and preparation of } \\
\text { report. This includes preparation } \\
\text { for assessment, time at the } \\
\text { facility, and report preparation. }\end{array}$ & 1330 & G & $\begin{array}{l}2880 \text { hours }= \\
\$ 216,000.00\end{array}$ & $\begin{array}{l}\text { Progrommotic Charge Rato } \theta \text { peoplo for } \theta \text { wooks } \\
\text { oflort of oach facility (2 fecilitioa) }=12 \times 120 \times \\
2 \times 875.00\end{array}$ & \\
\hline $\begin{array}{l}\text { Manpower - technical editing of the } \\
\text { final report }\end{array}$ & 6630 & G & $\begin{array}{l}40 \text { hours }= \\
\$ 1,806.00\end{array}$ & $\begin{array}{l}\text { Inal roport cloan up. Common eupport charco } \\
\text { out roto of } 845.18 \text {. }\end{array}$ & \\
\hline Trave1 expenses & 1330 & $\mathrm{J12}$ & $\$ 12,492.00$ & 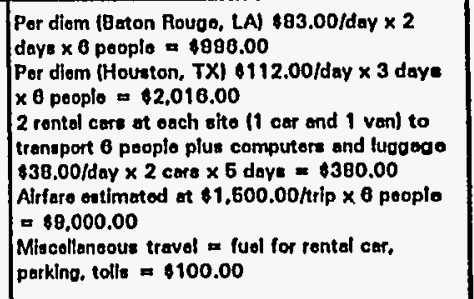 & \\
\hline $\begin{array}{l}\text { Travel expenses for assessment } \\
\text { preparation and report completion }\end{array}$ & & $\times 50$ & $\$ 15,400.00$ & 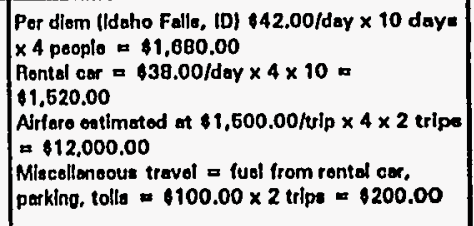 & \\
\hline
\end{tabular}

Figure 8. Work package activity sheet for a pre-award assessment. 


\begin{tabular}{|c|c|c|c|c|c|}
\hline $\begin{array}{l}\text { Activity Title } \\
\text { or Description } \\
\end{array}$ & $\begin{array}{l}\text { Org. } \\
\text { No. } \\
\end{array}$ & $\begin{array}{c}\text { Cost } \\
\text { Element } \\
\end{array}$ & \begin{tabular}{|c}
$\begin{array}{c}\text { Amount (Indicate } \\
\text { both Hours and } \\
\text { Dollars) }\end{array}$ \\
\end{tabular} & $\begin{array}{c}\text { Estimate } \\
\text { Justification/Basis } \\
\end{array}$ & $\begin{array}{l}\text { Performing Org } \\
\text { Acknowledgement } \\
\text { and Date }\end{array}$ \\
\hline Supplies - film & 1330 & MS & $\$ 100.00$ & 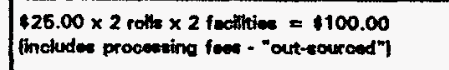 & \\
\hline Final report copies & 6630 & RA & $\$ 530.00$ & 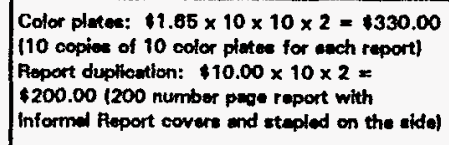 & \\
\hline Total for effort: & 1330 & & $\$ 246,328.00$ & & \\
\hline Allocation to other DOE sites & & $\times 50$ & $(\$ 197,062.00)$ & & \\
\hline Net Lockheed (INEL) & $1330 \mid$ & & $\$ 49,266.00$ & $\$ 24,633.00$ per site & \\
\hline
\end{tabular}

Figure 8. Continued. 
Rev. Mo.: 0

HBS No.: C29140000 Title:

External ESH\&Q and Financial Liability Assessments

\begin{tabular}{|c|c|c|c|c|c|}
\hline $\begin{array}{l}\text { Activity Title } \\
\text { or Description }\end{array}$ & $\begin{array}{l}\text { Org. } \\
\text { No. } \\
\end{array}$ & $\begin{array}{c}\text { Cost } \\
\text { Element }\end{array}$ & $\begin{array}{c}\text { Amount (Indicate } \\
\text { both Hours and } \\
\text { Dollars) }\end{array}$ & $\begin{array}{c}\text { Estimate } \\
\text { Justification/Basis }\end{array}$ & $\begin{array}{l}\text { Performing Org. } \\
\text { Acknowledgement } \\
\text { and Date }\end{array}$ \\
\hline $\begin{array}{l}\text { Trip 1: RES(LA) Baton Rouge, LA } \\
\text { and RES(TX) Deer Park, TX }\end{array}$ & 1330 & & & Annual Review & \\
\hline $\begin{array}{l}\text { Manpower - conduct of the } \\
\text { assessment and preparation of } \\
\text { report. This includes preparation } \\
\text { for assessment, time at the } \\
\text { facility, and report preparation. }\end{array}$ & 1330 & G & $\begin{array}{l}1440 \text { hours }= \\
\$ 108,000.00\end{array}$ & 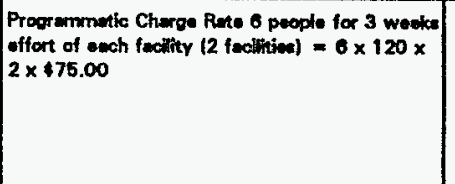 & \\
\hline $\begin{array}{l}\text { Manpower - technical editing of the } \\
\text { final report }\end{array}$ & 6630 & G & $\begin{array}{l}40 \text { hours }= \\
\$ 1,806.00\end{array}$ & 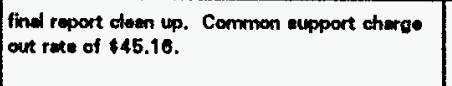 & \\
\hline Travel expenses & 1330 & $\mathrm{~J} 12$ & $\$ 12,492.00$ & 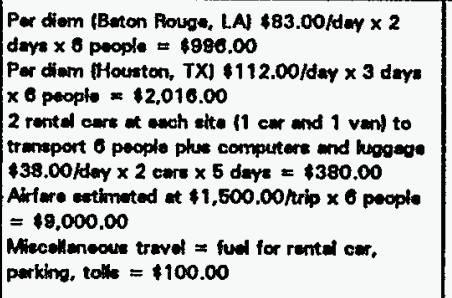 & \\
\hline $\begin{array}{l}\text { Travel expenses for assessment } \\
\text { preparation and report completion }\end{array}$ & & $\times 50$ & $\$ 15,400.00$ & 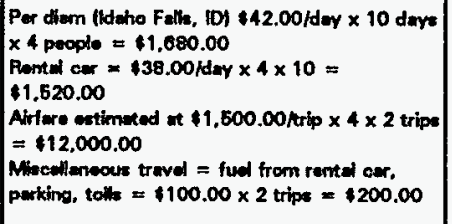 & \\
\hline
\end{tabular}

Figure 9. Work package activity sheet for an annual review assessment. 
Rev. No.:

0

WBS No.: C29140000

Title:

External ESH\&Q and Financial Liability Assessments

\begin{tabular}{|c|c|c|c|c|c|}
\hline $\begin{array}{l}\text { Activity Title } \\
\text { or Description }\end{array}$ & $\begin{array}{l}\text { Org. } \\
\text { No. }\end{array}$ & $\begin{array}{c}\text { Cost } \\
\text { Element }\end{array}$ & $\begin{array}{c}\text { Amount (Indicate } \\
\text { both Hours and } \\
\text { Dollars) }\end{array}$ & $\begin{array}{c}\text { Estimate } \\
\text { Justification/Basis } \\
\end{array}$ & $\begin{array}{l}\text { Performing Org. } \\
\text { Acknowledgement } \\
\text { and Date }\end{array}$ \\
\hline Supplies - film & 1330 & MS & $\$ 100.00$ & $\begin{array}{l}\text { \$25.00 } \times 2 \text { rolls } \times 2 \text { facilitios }=8100.00 \\
\text { (includes processing foos o "out =sourcod") }\end{array}$ & \\
\hline Final report copies & 6630 & RA & $\$ 530.00$ & $\begin{array}{l}\text { Color plates: } \$ 1.05 \times 10 \times 10 \times 2=\$ 330.00 \\
\text { (10 coplos of } 10 \text { color plotes for osch report) } \\
\text { loport duplication: } \$ 10.00 \times 10 \times 2=2 \\
\$ 200.00 \text { (200 number pego roport with } \\
\text { inlormol foport covers end stoplod on the sidol }\end{array}$ & \\
\hline Total for effort: & 1330 & & $\$ 138,328.00$ & & \\
\hline Allocation to other DOE sites & & $x 50$ & $(\$ 110,662.00)$ & & \\
\hline Net Lockheed (INEL) & 1330 & & $\$ 27,666.00$ & $\$ 13,833.00$ per site & \\
\hline
\end{tabular}

Figure 9. Continued. 


\subsection{Cost Avoidance}

Cost avoidance is a more difficult metric to calculate than direct cost savings because unless the system fails, the costs are avoided. That is, if facilities with potential regulatory problems are eliminated during the pre-award assessment, and these facilities are targeted by the regulatory agencies, the program would have protected the contractors and DOE from being named a participant in the cleanup of the failed facility, thus avoiding cleanup costs.

Cost avoidance is directly related to liability risks from hazardous waste disposal. The RCRA regulations make the "generator" responsible until final disposal. CERCLA assigns joint and several liability for cleanup costs. Joint liability means that anyone connected with the site is responsible. Several liability means that any single responsible person can be made to pay $100 \%$ of the costs. Person is defined as an individual, company, agency, etc. The persons that will be likely to be targeted for enforcement will generally include those with "deep pockets."

Liability costs are generally calculated as follows:

Under RCRA $=\$ 25,000 /$ violation/day (maximum fine)

For example: 100 drums $\times 10$ days $=\$ 25$ million

Under CERCLA the average remediation actions are over $\$ 30$ million, based on EPA data as of 1992. Using these numbers, EG\&G Idaho Legal calculated that the five M\&O contractors together could be liable for as much as $\$ 150,000,000$ in potential cleanup costs over five years, if each M\&O contractor subcontracted with different facilities.

A United States Department of Justice study determined that the average cost per potentially responsible party per Superfund site was \$10.5 million in 1993.

Another factor to be considered in cleanup risk and potential cost calculations is the legal fees versus total remedial costs. For private industrial companies, this ratio was $21 \%$ of which $\$ 6.3$ million were considered unallowable costs. Insurance companies reported a ratio of $88 \%$, of which $\$ 26.4$ million were unallowable costs.

An example of how an ESH\&Q liability assessment probably would have prevented or mitigated cleanup costs is the following, which is based on an actual situation:

Company A ("A") had a customer, Company B ("B"), who needed a specialty part manufactured for a process line. A knew that Company $C\left({ }^{\prime \prime} C^{\prime \prime}\right)$ could manufacture this part. A issued a contract to $C$ that included a requirement that $C$ undergo an ESH\&Q audit. $C$ refused to allow the audit to be conducted. A discussed the situation with $\mathrm{B}$, who believed that, because $\mathrm{C}$ was generally considered reputable and was also one of the very few companies that could manufacture the part that the risk associated with not conducting the audit was acceptable. B told A to issue the contract to $C$, which $A$ did. At the end of the manufacturing process, several years after the initial discussions, A sent a representative to $C$ to retrieve its specifications. The company representative discovered that $C$ had accumulated all of the wastes generated during the several years the special manufacturing process was active and was storing this material on the property, in an unpermitted location, and with A's name on the containers. The representative reported the findings to $A$, who then sent qualified audit and legal 
teams to $\mathrm{C}$ to determine what had actually transpired. They determined that the contents of the containers were uncharacterized hazardous waste. After legal negotiations, A and B agreed to pay for the proper characterization and disposal of the wastes that $\mathrm{C}$ had generated in their names. The cost associated with the cleanup exceeded $\$ 4$ million. These costs might have been avoided if $A$ and $B$ had conducted the audit at an estimated cost of $\$ 21,000$.

\subsection{Issues}

\subsubsection{Accurate Calculations and Justifications}

The use of different funding sources for individual activities and/or departments makes it difficult to track expenditures, because many are built in as general site support functions or the costs of doing business.

Each M\&O contractor has a different charge rate; for example, the fully burdened programmatic charge rate at the INEL is about $\$ 75.00 / \mathrm{hr}$, while the programmatic rate at Rocky Flats is $\$ 98.00 / \mathrm{hr}$.

The daily management requirements of the MTS, particularly for the lead laboratory, were underestimated. Management of the MTS by the technical lead can be defined as answering questions regarding the content of the MTS, resolving issues identified by the M\&O contractors with the vendors, and resolving issues identified by the vendors. These tasks have become nearly a one-half full-timeequivalent (FTE) task.

M\&O contractors have not maintained in their annual budgets line items regarding funding required for the ESH\&Q annual reviews.

M\&O contractors have not projected funding for the re-bid planning processes scheduled to begin in calendar year 1996.

\subsubsection{Cost Avoidance}

The importance of cost avoidance is underestimated by M\&O contractor management and the DOE.

\subsection{Resolutions and Recommendations}

\subsubsection{Accurate Calculations and Justifications}

Funding sources should be identified for a consolidated effort before work actually begins on the effort. Charge-out rates should be adjusted to reflect the actual costs of the initiative.

Work packages address funded activities directly tied to a project. However, they do not generally provide line items for common support funded activities, such as legal and procurement. Therefore, in order to obtain a more detailed breakdown of charges, either these common support functions should be identified and funded, or line items within the legal or procurement common support packages should address support of specific projects. 


\subsubsection{Cost Avoidance}

Cost avoidance should be explained to all levels of management, both at the M\&O contractor and DOE levels. The value of cost avoidance must be emphasized. 
This page intentionally left blank 


\section{LESSONS LEARNED}

As stated in the introduction to this study, the purpose of the analysis of the consolidated hazardous waste transportation, treatment, and disposal subcontract and ESH\&Q liability assessment processes was to determine the strengths and weaknesses of the process and propose changes to correct deficiencies. The identified strengths and weaknesses and the suggested changes are the lessons the participants learned. The participants agreed that, taken in total, the project was an outstanding success and is worth repeating for the next subcontract competition. However, this section lists the lessons learned, the incorporation of which the participants consider imperative for ensuring that the next iteration is also an outstanding success.

\subsection{General Process}

All agreements and policy statements among the participants in the process (i.e., the M\&O contractors, DOE-HQ, and DOE operations offices) must be written and maintained in the official program record. Each participant must keep a copy of the program record.

A formal approved program management plan, which controls the entire life cycle activities and budgets, must be developed. The contents of the plan must be agreed upon by all participating companies and agencies.

Work packages and task baseline agreements must be developed by the lead laboratory and approved by all M\&O contractors in order to control the flow of work and the acceptance criteria for deliverables.

The players assigned to all aspects of the process must be dedicated both personally and by management to ensure that consistency can be maintained. Dedicated performers include procurement, ES\&H, legal, waste management, and personnel from each successful vendor. Each of these performers must, through the process, learn not only how to prepare the RFP and conduct liability assessments, but also how to operate under the subcontract.

The process must remain task and schedule driven. If any milestone is permitted to slip, then the whole schedule must also slip. The end point (i.e., award of the subcontract) must rely on completion of all critical path tasks and not on a critical subcontract expiration date.

\subsection{Consolidated Master Task Subcontract}

M\&O contractor acceptance/buyoff of the DOE directives should be documented before preparing the RFP or awarding the MTS.

Five addenda caused a major delay in the schedule. Time should be factored into the bidding portion of the schedule in order to compensate for addenda. The RFP should be carefully constructed in order to ensure that only one or two addenda might be needed as a result of clarifications requested by the vendors at the pre-proposal conference. 
The use of the lab packing portion of the subcontract should be reassessed. The use of lab packing services should be specifically defined in order to ensure that M\&O contractors understand that this service is a special requirement and not a standard operating feature.

Subcontractor performance indicators should be defined more precisely. Periodic meetings should be held with the M\&O contractor and the vendors to address performance.

The following lessons learned were related directly to the content of the SOWs contained within the RFP:

- Waste stream treatment requirements should be documented before the RFP is issued. For example, if it is a policy decision of both the DOE and the M\&O contractors that incineration is to be the preferred treatment standard, then this should be written and approved.

- The SOW should be more refined, especially with respect to recyclable materials. For example, mercury-contaminated wastes should be more clearly defined (e.g., fluorescent tubes, elemental mercury, mercury compounds, and mercury-contaminated debris/dirt).

- Waste streams on the pricing sheets should be standardized as to treatment standards (e.g., if the treatment specified for a particular waste stream on one pricing sheet is incineration, the same should be noted for this same waste stream on all of the other pricing sheets.

- Waste stream pricing should be consistent (i.e., the treatment/disposal prices should not vary from exhibit to exhibit as long as the facility specified for the particular waste stream on each pricing sheet is the same). For example, if the specified treatment/disposal site for a particular waste stream is Rollins Deer Park on each exhibit, the prices for this site should be the same, as long as transportation is specified in a separate SOW.

\subsection{Consolidated ESH\&Q Liability Assessments}

Potential vendors should be educated as to the $M \& O$ contractors' expectations and requirements for performance of the proposed subcontract. These requirements should be passed on to the management of the proposed facilities before the ESH\&Q liability assessments.

M\&O contractor personnel participating in the ESH\&Q liability assessments should be provided to the lead laboratory on an "outplant" assignments in order to ensure that they are able to complete their assignments in a timely and efficient manner.

A larger pool of qualified liability assessment personnel should be developed in order to provide adequate coverage of the program.

Task baseline agreements negotiated among the liability assessment participants, M\&O contractor direct managers, and the lead laboratory program manager should be used to clearly define the individual tasks and deliverables. 
The liability assessment schedule should be given a concrete time period which is not compressed by problems occurring earlier in the process. If the front-end of the schedule slips, then the assessment completion date and subsequent subcontract awards should slip accordingly.

Re-assessments, or annual reviews, of facilities under subcontract should be risk-based.

\subsection{Post-Award Operations}

A final implementation meeting between the $M \& O$ contractors and vendors should be held in order to ensure that all parties understand the operations and requirements of the subcontracts.

The M\&O contractors should implement a periodic feedback mechanism. This mechanism would provide a forum for discussing perceived customer/subcontractor problems before the problems become critical.

\subsection{Costs}

Consistent funding sources for the initiative and follow-on work should be established and maintained from year to year.

In order to accurately calculate costs of the initiative, work packages should be developed. These work packages should address level-of-effort support groups, such as procurement and legal services.

Work packages and funding should be developed to address administrative costs associated with the MTS. The work packages should identify tasks associated with the lead laboratory technical lead and procurement subcontract administrator. Funding should also be provided for periodic meetings to review the conduct of the MTS, task orders, and vendor performance. 
This page intentionally left blank 


\section{RECOMMENDATIONS}

The consolidated subcontract process has generated much interest from DOE-HQ and other DOE sites. EG\&G Idaho and Lockheed Idaho have received numerous requests for information regarding the process and copies of the bid package and assessment documents. Although the effort was successful and the subcontracts are now in place, a number of weaknesses in the process have been identified and documented, and participants have proposed recommendations to correct or prevent the recurrence of the deficiencies.

This section of the report proposes improvements that would expedite and enhance the process for other DOE installations that use the process and the re-bid of the consolidated subcontract, scheduled for FY 1997. The major assumptions in this section are that DOE-HQ will consider this initiative to be the way it wants its operations offices and M\&O contractors to conduct business and that DOE-HQ will take the lead in proposing that the re-bid effort be expanded to include additional DOE sites.

\subsection{Expanded Program}

The program, as defined, can be used for both regional subcontracts or a consolidated national effort that would include all of the DOE sites. The determination must be made as to whether one national effort or regional subcontracts, based upon M\&O contractor cooperative efforts, should be made at the DOE-HQ and operations office levels. Financial benefits, particularly subcontract award and liability assessment cost reductions, can be derived from each. As can be seen in Table 9 and Figure 10, the two MTSs awarded in the EG\&G effort provided adequate service and treatment and disposal options for facilities located nationwide. An expanded program should not require any more facilities in order to be effective.

\subsubsection{Programmatic Recommendations}

The most significant recommendation regarding the expansion of the program is that DOE-HQ must be intimately involved in the preliminary planning stages. It is crucial that DOE-HQ provide guidance, either through policy statements or directives, to the operations offices and the M\&O contractors regarding the conduct of the program. If the INEL retains its position as the lead laboratory in the effort, then DOE-HQ must ensure that the INEL receives management, programmatic, and funding support.

An issue that will undoubtedly arise regarding the expansion will relate to the authority the prime M\&O contractor will have over other M\&O contractors. The issues of corporate parent concerns regarding ES\&H liability, corporate veils, and directions from one M\&O contractor to another must be addressed and resolved before the program begins. Each M\&O contractor should document its understanding that, while not a signatory to the MTS, it assumes all responsibilities for its performance under the MTS. These records should be retained in the file.

\subsubsection{Schedule Recommendations}

Whether DOE-HQ proposes this process as an example of an efficient, cost-effective means for hazardous waste treatment and disposal and liability reduction, or requires this technique for future 
Table 9. CWM and Rollins subcontracted TSDFs, locations, and associated treatment capabilities.

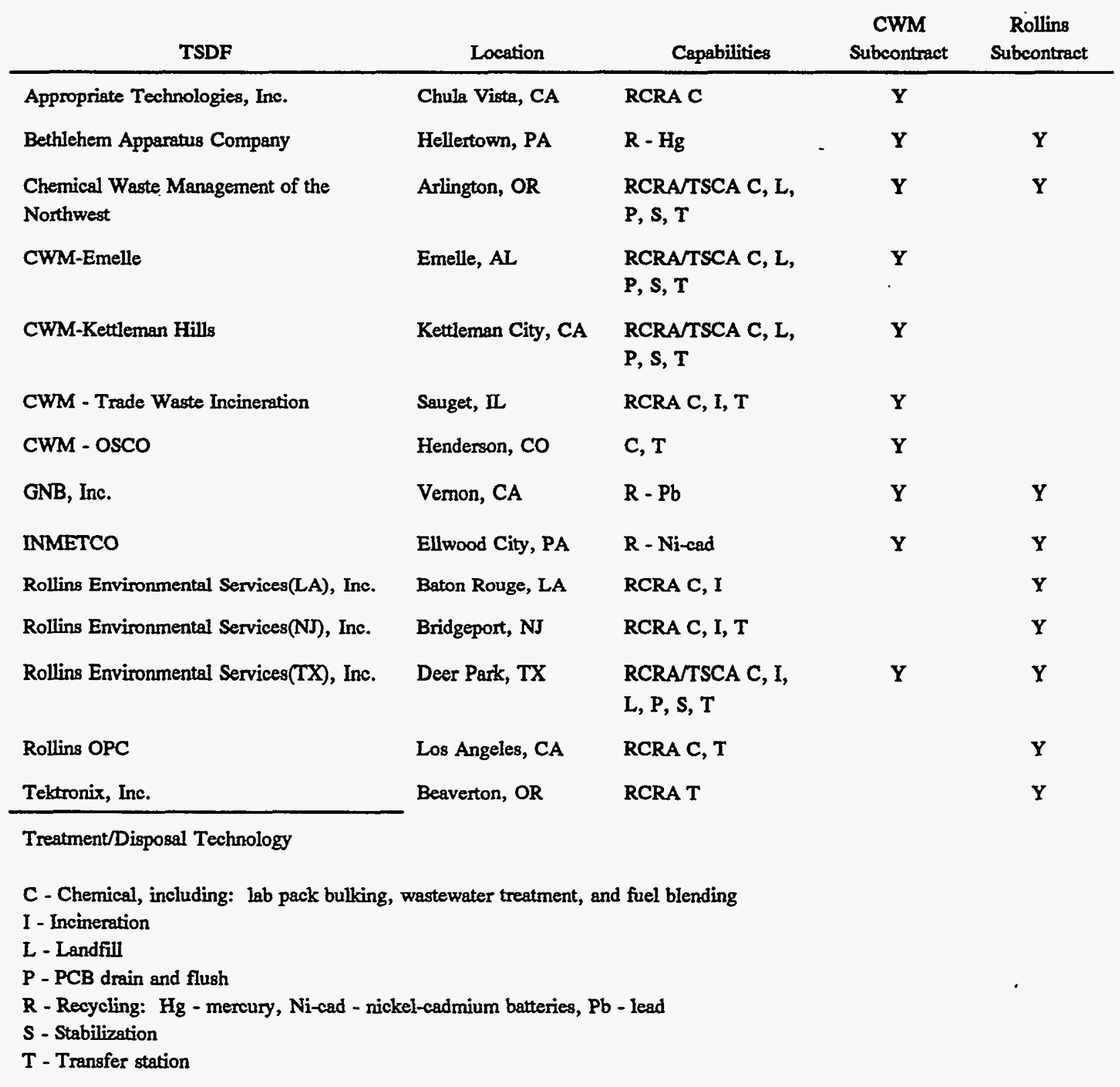

hazardous waste treatment and disposal procurements, the following recommendation is crucial. It is critical that adequate scheduling be maintained in order for the process to be successful. That is, if this method is used by either a consortium of DOE regional sites or to propose a national MTS, scheduling of planning activities and site agreements must occur well before SOWs and the RFP are prepared.

The INEL-led MTS will expire in October 1998. If the same DOE sites choose to join in the rebid, the effort must begin in late calendar year 1996 in order to ensure that the RFP is issued in calendar year 1997 and the subcontract award made before October 1998. If other DOE sites, under other M\&O 


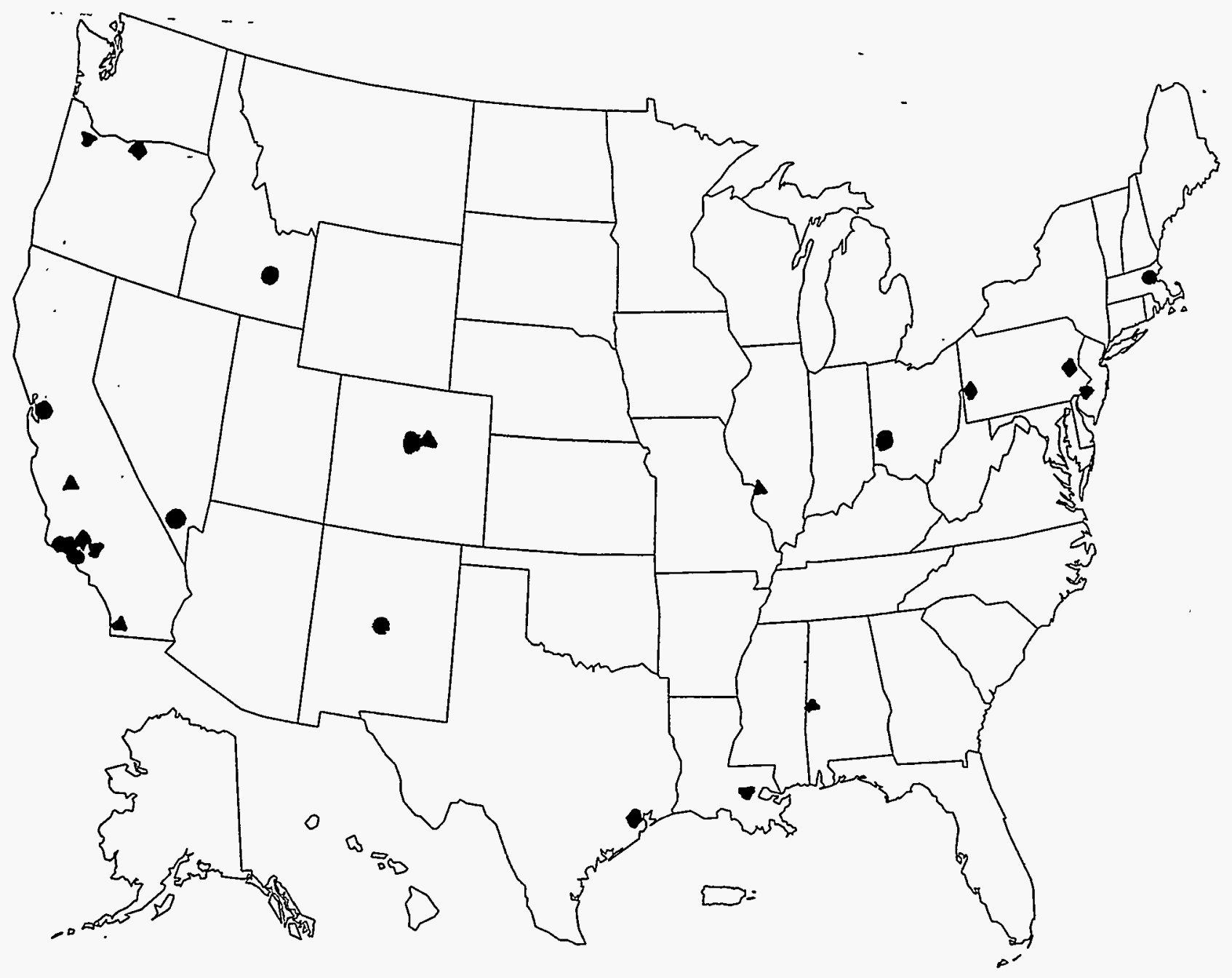

Legend

- - DOE sites managed by EG\&G M\&O contractors

4 - CWM subcontract TSDFs

$\checkmark \quad$ - Rollins subcontract TSDFs

- - TSDFs subcontracted by both CWM and Rollins

Figure 10. Locations of the participating DOE sites and TSDFs under the MTS. 
This page intentionally left blank 
contractors, wish to join the INEL and its partners, planning must begin in early 1996 in order to complete M\&O contractors' MOUs, the project management plan (PMP), and schedules before preparation of the SOWs and RFP.

\subsubsection{Funding Sources and Costs}

Funding sources and costs must be identified at the beginning of the planning cycles for the next competition. It is recommended that, if DOE-HQ sponsors or endorses this process, DOE-HQ should provide direct funding to the lead laboratory to cover the startup costs. Anticipated startup costs are those associated with establishing the MOUs, PMP, and schedules.

Funding sources for preparing the SOWs, preparing and issuing the RFP, and conducting the ESH\&Q Liability Assessments must be established before work begins. The actual cost distribution methods described in Section 6 of this report can be used for this work.

Funding sources for the follow-on administration of the MTS and ESH\&Q annual reviews must also be identified before work begins. These funding sources must be identified in the out-year plans.

\subsection{Content}

\subsubsection{Consolidated Master Task Subcontract}

The consolidated MTS should be based on the content of the RFP and SOWs described in this report. The process improvements, issue resolutions and recommendations, and vendor perspectives should be incorporated into the new process.

\subsubsection{Consolidated ESH\&Q Liability Assessments}

The consolidated liability assessments should be based on the content of the ESH\&Q liability assessment program as described in this report. The process improvements, issue resolutions and recommendations, personnel staffing, funding requests, and vendor perspectives should be incorporated into the new process.

\subsection{Post-Award Operations}

The recommendations concerning training of the participating M\&O contractor personnel and subcontractor representatives must be conducted by the lead laboratory upon award of the MTS.

It is expected that the lead laboratory will actively administer the MTS after the awards are made. Funding must be identified to support these functions.

In order to maintain continuity and prevent operational problems with the MTS, task orders, and operations, the participating M\&O contractors and subcontractors should plan to meet periodically to discuss the daily operations and expectations. It is suggested that these meetings be held at least quarterly. 
The Rollins representative stated that, as a subcontractor, the company totally concurs with the implementation and periodic meeting concept; however, as a private contractor, they believe that it is the responsibility of the $\mathrm{M} \& \mathrm{O}$ contractor to organize and conduct these meetings. The attempts made by Rollins representatives to implement these meetings have not been as productive as each party could have desired. 


\section{SUMMARY AND CONCLUSIONS}

The INEL, under its previous M\&O prime contractor, EG\&G Idaho, first consolidated hazardous waste transportation, treatment, recycling, and disposal contracts in 1992. At that time, RCRA/TSCA/CERCLA-regulated hazardous wastes and recyclable materials from all five INEL M\&O contractors were consolidated on five subcontracts, one of which was a contingency subcontract. This effort reduced the environmental liability exposure, transportation/disposal costs, and contractual paperwork for the site from about 27 different facilities, including brokers, to eight qualified TSDFs, with brokers specifically prohibited.

EG\&G, Inc., the corporate parent of EG\&G Idaho, reviewed this new approach to subcontracting and liability reduction, and proposed (with DOE-HQ and operations office concurrence) that a consolidated hazardous waste transportation/treatment/disposal subcontract be formed for the five major EG\&G-operated DOE sites: INEL, Mound, Rocky Flats, and the Nevada Test Site, and 10 satellite facilities. This effort began in March 1992 and was completed with the awarding of two MTSs in October and November 1993. The effort consisted of the preparation of a master RFP, with separate SOWs describing RCRA/TSCA/CERCLA regulated waste streams and services to be performed (e.g., lab packing, sample evaluation for each site). The Standard Terms and Conditions for the proposed subcontract were reviewed and edited by the various Procurement Departments and Legal Offices. The RFP contained go/no-go technical criteria by which the potential offerors would be evaluated, as opposed to a selection board. In addition, the effort included a consolidated effort for ESH\&Q and financial liability assessments. The assessment team that evaluated the potential vendors and facilities was composed of qualified inspectors from each of the EG\&G operated DOE sites and operated under the leadership of the INEL. The evaluation criteria were defined and personnel were trained to ensure that the assessments were consistent.

Although the effort was successful and the subcontracts are now in place, a number of weaknesses in the process were identified which $\mathrm{M} \& \mathrm{O}$ contractor participants in the various tasks and subcontractors wanted to document and correct in order to prevent their reoccurrence. This report documented the evaluation of the process used to prepare, bid, and award the EG\&G Idaho consolidated hazardous waste transportation, treatment, recycling, and/or disposal and associated ESH\&Q and financial liability assessments; the strengths and weaknesses of the process; and proposed improvements which would expedite and enhance the process for other DOE installations which used the process and the re-bid of the consolidated subcontract, scheduled for fiscal year 1997. 
This page intentionally left blank 


\section{REFERENCES}

\subsection{Federal Statutes}

Clean Air Act (as amended) 42 U.S.C. 7401 et seq.

Clean Water Act (Federal Water Pollution Control Act) (as amended) U.S.C. $\& 1251$ et seq.

Comprehensive Environmental Response, Compensation, and Liability Act (as Amended) Title I Hazardous Substances Releases, Liability, Compensation, 42 USC $\S 9601$ et seq.

Comprehensive Environmental Response, Compensation, and Liability Act (as Amended) Title III Miscellaneous Provisions, 42 USC \& 9651 et seq.

Hazardous Materials Safety Act of 1974, (P. L. 93-633).

Hazardous Materials Transportation Act of 1974, 49 USC $\S 1801$ et seq.

Mine Safety and Health Act of 1977, as Amended.

Occupational Safety and Health Act, as amended.

Safe Drinking Water Act as Amended, 42 USC $\S 300$ et seq.

Solid Waste Disposal Act, as Amended, 42 USC $§ 6901$ et seq.

Superfund Amendments and Reauthorization Act, 42 USC $\S 11001$ et seq.

Toxic Substances Control Act, as Amended, 42 USC $\S 2601$ et seq.

Water Quality Act of 1987 (P. L. 100-4).

\subsection{Codle of Federal Regulations}

10 CFR 830, "Nuclear Safety Management."

29 CFR 1910.120, "Hazardous Waste Operations and Emergency Response."

29 CFR 1910.1200, "Hazard Communication."

30 CFR 11, "Respiratory Protective Devices; Tests for Permissibility; Fees."

30 CFR 48, "Training and Retraining of Miners."

30 CFR 56, "Safety and Health Standards-Surface Metal and Nonmetal Mines." 
40 CFR 50, "National Primary and Secondary Ambient Air Quality Standards."

40 CFR 60, "Standards of Performance for New Stationary Sources."

40 CFR 61, "National Emissions Standards for Hazardous Air Pollutants (NESHAPs)."

40 CFR 110, "Discharge of Oil."

40 CFR 112, "Oil Pollution Prevention."

40 CFR 116, "Designation of Hazardous Substances."

40 CFR 117, "Determination of Reportable Quantities for Hazardous Substances."

40 CFR 122, "EPA Administered Permit Programs: The National Pollutant Discharge Elimination System."

40 CFR 125, "Criteria and Standards for the National Pollutant Discharge Elimination System."

40 CFR 136, "Guidelines Establishing Test Procedures for the Analysis of Pollutants."

40 CFR 141, "National Primary Drinking Water Regulations."

40 CFR 142, "National Primary Drinking Water Regulations Implementation."

40 CFR 143, "National Secondary Drinking Water Regulations."

40 CFR 144, "Underground Injection Control Program."

40 CFR 146, "Underground Injection Control Program: Criteria and Standards."

40 CFR 148, "Hazardous Waste Injection Restrictions."

40 CFR 257, "Criteria for Classification of Solid Waste Disposal Facilities and Practices."

40 CFR 260, "Hazardous Waste Management System - General."

40 CFR 261, "Identification and Listing of Hazardous Waste."

40 CFR 262, "Standards Applicable to Generators of Hazardous Waste."

40 CFR 263, "Standards Applicable to Transporters of Hazardous Waste."

40 CFR 264, "Standards for Owners and Operators of Hazardous Waste Treatment, Storage, and Disposal Facilities." 
40 CFR 265, "Standards for Owners and Operators of Interim Status Hazardous Waste Treatment, . Storage, and Disposal Facilities."

40 CFR 266, "Standards for Management of Specific Hazardous Wastes and Specific Types of Hazardous Waste Management Facilities."

40 CFR 268, "Land Disposal Restrictions."

40 CFR 270, "EPA Administered Permit Programs: The Hazardous Waste Permit Program."

40 CFR 271, "Requirements for Authorization of State Hazardous Waste Management Programs."

40 CFR 272, "Approved State Hazardous Waste Management Programs."

40 CFR 280, "Underground Storage Tanks."

40 CFR 281, "State Programs for Administering the Underground Storage Tank Programs."

40 CFR 761, "Polychlorinated Biphenyls (PCBs) Manufacturing, Processing, Distribution in Commerce, and Use Prohibition."

40 CFR 300, "National Oil and Hazardous Substances Pollution Contingency Plan."

40 CFR 302, "Designation, Reportable Quantities, and Notification."

40 CFR 355, "Emergency Planning and Notification."

40 CFR 370, "Hazardous Chemical Reporting: Community Right-To-Know."

40 CFR 372, "Toxic Chemical Release Reporting: Community Right-To-Know."

40 CFR 401, "General Provisions."

40 CFR 403, "General Pretreatment Regulations for Existing and New Sources of Pollution."

48 CFR 970, "Acquisition Regulation; Environmental Protection."

49 CFR 171, "General Information, Regulations, and Definitions."

49 CFR 172, "Hazardous Materials Table, Special Provisions, Hazardous Materials Communications Requirements and Emergency Response Information."

49 CFR 173, "Shippers - General Requirements for Shipments and Packagings."

49 CFR 177, "Carriage by Public Highway."

49 CFR 178, "Specifications for Packagings." 
49 CFR 180, "Continuing Qualification and Maintenance of Packagings."

OSWER/OER/HSCD, "CERCLA Off-Site Policy: Providing Notice to Facilities," 9330.2-05.

OSWER/OER/HSCD, "CERCLA Off-Site Policy: Eligibility of Facilities in Assessment Monitoring," 9330.2-06.

44 FR 75, "Interagency Agreement," U. S. Mine Safety and Health Administration and U. S. Occupational Safety and Health Administration, 22827-22830, April 17, 1979.

50 FR 214, "Procedure for Planning and Implementing Off-Site Response Actions, " U. S. Environmental Protection Agency, 45933-45937, November 5, 1985.

57 FR 93, "Hazardous Waste Management System; Notification Concerning the Basel Convention's Potential Implications for Hazardous Waste Exports and Imports," 20602-20624, May 13, 1992.

\subsection{DOE Orders}

DOE Order 5480.1B, "Environment, Safety, and Health Program for DOE Operations," 1989.

DOE Order 5480.1B-ID, "Environment, Safety, and Health Program for DOE Operations," 1989.

DOE Order 5482.1B, "Environment, Safety, and Health Appraisal Program," 1987.

DOE Order 5700.6C, "Quality Assurance," 1989.

DOE Order 5700.6C-ID, "Quality Assurance," 1989.

\subsection{Correspondence}

Letter from J. E. Lytle, DOE-HQ EM-30, to Distribution, Subject: "Shipment of Waste Originating in Radiation Control Areas," dated May 17, 1991.

Letter from J. E. Lytle, DOE-HQ EM-30, to Distribution, Subject: "Update to the Moratorium on Shipment of Hazardous Waste Originating in Radiologically Controlled Areas," dated June 7, 1991.

Letter from A. A. Pitrolo, DOE-ID, to Distribution, Subject: "Guidance Concerning Hazardous Waste Shipments, " dated June 27, 1991.

\subsection{Computer Software}

Air Quality, Federal Version, Audit Master, Version 4.8, Pittsford, New York: Utilicom, 1993. EPCRA, Federal Version, Audit Master, Version 4.8, Pittsford, New York: Utilicom, 1993. 
Hazardous Materials Transportation, Federal Version, Audit Master, Version 4.8, Pittsford, New York: Utilicom, 1993.

Industrial Hygiene, Federal Version, Audit Master, Version 4.8, Pittsford, New York: Utilicom, 1993.

Materials and Equipment Safety, Federal Version, Audit Master, Version 4.8, Pittsford, New York: Utilicom, 1993.

Occupational Medicine, Federal Version, Audit Master, Version 4.8, Pittsford, New York: Utilicom, 1993.

PCB Management, Federal Version, Audit Master, Version 4.8, Pittsford, New York: Utilicom, 1993.

Personnel Safety, Federal Version, Audit Master, Version 4.8, Pittsford, New York: Utilicom, 1993.

Solid and Hazardous Waste, Federal Version, Audit Master, Version 4.8, Pittsford, New York: Utilicom, 1993.

Spill Prevention, Federal Version, Audit Master, Version 4.8, Pittsford, New York: Utilicom, 1993.

Storage Tanks, Federal Version, Audit Master, Version 4.8, Pittsford, New York: Utilicom, 1993.

Water Quality, Federal Version, Audit Master, Version 4.8, Pittsford, New York: Utilicom, 1993.

\subsection{Publications}

K. M. Adams, L. E. Jensen, and D. J. Caruso, Lockheed Idaho Technologies Company, Project Control System Description, Revision 0, November 14, 1994.

Cahill, Lawrence B. and Raymond W. Kane, Environmental Audits, 6th Edition, Rockville, Maryland: Government Institutes, Inc., 1989.

Friedman, F. B., Practical Guide to Environmental Management, ELI Monograph: Environmental Law Institute, 1990.

R. S. Greenberg and C. A. Unger, "TQM and the Cost of Environmental Quality," in Environmental TQM, second edition, J. Willig, ed., New York, NY: McGraw Hill, 1994.

Miller, G., Chairman, Oversight Hearing Before the Committee on Interior and Insular Affairs, House of Representatives, One Hundred Second Congress Second Session on Release of Radioactively Contaminated Waste from Department of Energy Complexes to Civilian Incinerators, Serial No. 10235, Washington, D.C.: U. S. Government Printing Office, 1992.

Smith, A. C., "Continuous Improvement Through Environmental Auditing", in Environmental TQM, second edition, J. Willig, ed., New York, NY: McGraw Hill, 1994. 
Wells, R.P., M. N. Hochman, S. D. Hochman, and P. A. O'Connell, "Measuring Environmental Success", in Environmental TQM, second edition, J. Willig, ed., New York, NY: McGraw Hill, 1994. 


\section{Appendix A}

Abbreviations and Acronyms 


$$
\text { A-2 }
$$




\section{Appendix A}

\section{Abbreviations and Acronyms}

\begin{tabular}{|c|c|}
\hline AEA & Atomic Energy Act \\
\hline ANL-W & Argonne National Laboratory - West \\
\hline ANSI & American National Standards Institute \\
\hline ASTM & American Society for Testing and Materials \\
\hline B\&W & Babcock and Wilcox \\
\hline BIF & Boiler or Industrial Furnace \\
\hline BLM & United States Department of the Interior, Bureau of Land Management \\
\hline CAA & Clean Air Act \\
\hline CBD & Commerce Business Daily \\
\hline $\mathrm{CD}$ & Certificate of Destruction/Disposal \\
\hline CEG & Conditionally Exempt Small-Quantity Generator \\
\hline CERCLA & Comprehensive Environmental Response, Compensation, and Liability Act \\
\hline CFR & Code of Federal Regulations \\
\hline $\mathrm{CO}$ & Colorado \\
\hline CPAF & Cost Plus Award Fee \\
\hline CRTK & Community Right-to-Know \\
\hline CWA & Clean Water Act \\
\hline CWM & Chemical Waste Management, Inc. \\
\hline D\&B & Dun and Bradstreet \\
\hline DEAR & Department of Energy Acquisition Requirement \\
\hline DOE & United States Department of Energy \\
\hline DOE-HQ & United States Department of Energy - Headquarters \\
\hline DOE-ID & United States Department of Energy, Idaho Operations Office \\
\hline DOS & Disk Operating System \\
\hline DOT & United States Department of Transportation \\
\hline DRMO & Defense Reutilization and Marketing Office \\
\hline EA & environmental assessment \\
\hline EG\&G & EG\&G, Inc. \\
\hline EG\&G - EMI & EG\&G Energy Measurements, Inc. \\
\hline EG\&G Idaho & EG\&G Idaho, Inc. \\
\hline EG\&G Mound & EG\&G Mound Applied Technologies, Inc. \\
\hline EG\&G Rocky Flats & EG\&G Rocky Flats, Inc. \\
\hline EIS & environmental impact statement \\
\hline EM & Environmental Management \\
\hline ENSCO & Environmental Services Company \\
\hline EPA & (United States) Environmental Protection Agency \\
\hline EPCRA & Emergency Planning and Community Right-to-know Act \\
\hline EPD & Environmental Protection Department \\
\hline
\end{tabular}




$\begin{array}{ll}\text { ES\&H } & \text { environment, safety, and health } \\ \text { ESH\&Q } & \text { environment, safety, health, and quality } \\ \text { ETS } & \text { Fnironmental Technical Support } \\ \text { F } & \text { Fahrenheit } \\ \text { FAR } & \text { Federal Acquisition Requirement } \\ \text { FOIA } & \text { Freedom of Information Act } \\ \text { FR } & \text { Federal Register } \\ \text { FTE } & \text { full-time equivalent } \\ \text { FY } & \text { fiscal year } \\ \text { G\&A } & \text { general and administrative } \\ \text { GOCO } & \text { government-owned contractor-operated } \\ \text { HazCom } & \text { Hazard Communication } \\ \text { HAZWOPER } & \text { hazardous waste operator } \\ \text { HCS } & \text { Hazard Communication Standard } \\ \text { HDPE } & \text { high density polyethylene } \\ \text { HMTA } & \text { Hazardous Materials Transportation Act } \\ \text { HSWA } & \text { Hazardous and Solid Waste Act } \\ \text { HWHO } & \text { Hazardous Waste Handling Operations } \\ \text { HWM } & \text { hazardous waste management } \\ \text { HWSF } & \text { Hazardous Waste Storage Facility } \\ \text { ICPP } & \text { Idaho Chemical Processing Plant } \\ \text { ID } & \text { Idaho } \\ \text { INEL } & \text { Idaho National Engineering Laboratory } \\ \text { IRC } & \text { INEL Research Center } \\ \text { K } & \text { thousand } \\ \text { LDR } & \text { Land Disposal Restriction } \\ \text { LEPC } & \text { Local Emergency Planning Committee } \\ \text { Lockheed Idaho } & \text { Lockheed Idaho Technologies Company } \\ \text { LTU } & \text { Land Treatment Unit } \\ \text { LUST } & \text { leaking underground storage tank } \\ \text { M-K } & \text { Morrison Knudsen Company } \\ \text { M\&O } & \text { management and operating } \\ \text { MOU } & \text { memorandum of understanding } \\ \text { MSDS } & \text { Material Safety Data Sheet } \\ \text { MSHA } & \text { Mine Safety and Health Act } \\ \text { MTS } & \text { National Environmental Policy Act } \\ \text { NEPA } & \text { Notice of Deficiency } \\ \text { NESHAPs } & \\ \text { NOD } & \end{array}$




\begin{tabular}{|c|c|}
\hline NON & Notice of Noncompliance \\
\hline NOV & Notice of Violation \\
\hline $\mathrm{NOV} / \mathrm{CO}$ & Notice of Violation and Order for Compliance \\
\hline NPDES & National Pollutant Discharge Elimination System \\
\hline NQA & Nuclear Quality Assurance \\
\hline NRC & National Response Center \\
\hline NRC & Nuclear Regulatory Commission \\
\hline NRF & Naval Reactors Facility \\
\hline NTS & Nevada Test Site \\
\hline NV & Nevada \\
\hline $\mathrm{OH}$ & Ohio \\
\hline ORNL & Oak Ridge National Laboratory \\
\hline OSHA & Occupational Safety and Health Act \\
\hline PCB & polychlorinated biphenyl \\
\hline PMP & project management plan \\
\hline PPE & personal protective equipment \\
\hline ppm & parts per million \\
\hline QA & quality assurance \\
\hline QAMS & quality assurance managers \\
\hline $\mathrm{QC}$ & quality control \\
\hline RCRA & Resource Conservation and Recovery Act \\
\hline REECo & Reynolds Electrical and Engineering Company, Inc. \\
\hline RFA & RCRA Facility Assessment \\
\hline RFETS & Rocky Flats Environmental Technology Site \\
\hline RFI & RCRA Facility Investigation \\
\hline RFP & request for proposal \\
\hline RFQ & request for quotation \\
\hline ROD & Record of Decision \\
\hline Rollins & Rollins Environmental Services, Inc. \\
\hline RWO & Regulated Waste Operations \\
\hline SAA & satellite accumulation area \\
\hline SARA & Superfund Amendments and Reauthorization Act \\
\hline SCBA & self-contained breathing apparatus \\
\hline SDWA & Safe Drinking Water Act \\
\hline SEC & United States Security and Exchange Commission \\
\hline SERC & State Emergency Response Commission \\
\hline SMC & Special Manufacturing Complex \\
\hline SOW & statement of work \\
\hline SWMU & Solid Waste Management Unit \\
\hline T\&Cs & terms and conditior \\
\hline TBA & task baseline agreement \\
\hline
\end{tabular}


TCLP

TQM

TSA

TSCA

TSD

TSDF

USC

USDOE

EPA

USPCI

UST

VOC

WBS

WCB

WGI

WINCO

WP

WROC

WROC-TP
Toxicity Characteristic Leaching Procedure

Total Quality Management

Transportation Safety Act

Toxic Substances Control Act

treatment, storage, and disposal

treatment, storage, and disposal facility

United States Code

United States Department of Energy

United States Environmental Protection Agency

United States Pollution Control, Inc.

underground storage tank

volatile organic compound

work breakdown structure

Willow Creek Building

waste generator interface

Westinghouse Idaho Nuclear Company

work package

Waste Reduction Operations Complex

Waste Reduction Operations Complex-Technical Programs 


\section{Appendix B}

Consolidated Request for Proposal 


$$
\text { B-2 }
$$




\section{Appendix B}

\section{Consolidated Request for Proposal}

This appendix contains an abbreviated version of the consolidated request for proposal (RFP) issued by the EG\&G M\&O contractors in 1993 for hazardous waste transportation/treatment/disposal. The RFP contained a description of the purpose of the request, instructions for proposal submission, conditions for award of the subcontract, and applicable conditions. The following RFP forms and supporting documents are reproduced:

\section{Request for Proposal}

Pricing requirements applicable to all EG\&G M\&O price proposal attachments (Attachment 0).

M\&O services and hazardous waste treatment/disposal SOWs and pricing submittal forms for EG\&G Idaho and EG\&G Rocky Flats (Attachments 2 - 5 and 22 - 25) only. The M\&O services and hazardous waste treatment/disposal SOWs and pricing submittal forms for REECo and the EG\&G EMI sites were identical in format to the EG\&G Idaho forms.

Representation and certifications (Enclosure 1)

A sample small business and small disadvantage business subcontracting plan (Enclosure 2)

EG\&G Idaho Standard Terms and Conditions for Purchase Orders and Subcontracts (Enclosure 3)

A copy of the Service Contract Act of 1965, as amended (Enclosure 4)

Wage determination No. 86-0889 (Revision 12) dated August 7, 1992 (Enclosure 5)

Sample fixed price per unit master task requirement subcontract (Enclosure 6)

Proposal submittal form (Enclosure 7) also called the mandatory go/no-go form 
B-4 


\section{EG\&G IDAHO, INC.}

\section{REOUEST FOR PROPOSAL (RFP)}

SUBJECT: HAZARDOUS WASTE TRANSPORT/ TREATMENT/DISPOSAL SERVICES

EG\&G IDAHO NO: C93-170250/C93-170251

PROCUREMENT AGENT: J.R. BRAUN Th

TELEPHONE NO. (208) 526-1631

TELECOPY NO. (208) 526-7744

DATE: DECEMBER 17, 1992 


\section{REQUEST FOR PROPOSAL}

EG\&G Idaho, Inc., a Management and Operating (M\&O) Contractor for the U. S. Department of Energy (DOE) at the Idaho National Engineering Laboratory (INEL), is seeking firms which can provide Hazardous Waste Transportation, Treatment, and Disposal services for multiple EG\&G M\&O Contractors 1ocated in different geographical areas in the United States. The successful Subcontractors and lower-tier Subcontractors must possess-permits to accept wastes regulated by the Resource Conservation and Recovery Act (RCRA), the Toxic Substance Control Act (TSCA), and wastes generated from response activities under the Comprehensive Environmental Response, Compensation and Liability Act (CERCLA). The successful Subcontractors shall provide the services described in Attachments 0 through 25.

EG\&G Idaho, Inc., anticipates award of two firm-fixed-price-per-unit Master Task Requirement Subcontracts for an initial three year period starting on date of award. EG\&G Idaho shall have the unilateral option to extend the Subcontracts for a maximum of two, one year periods at the firm-fixed-priceper-unit prices quoted by the Subcontractor. The Subcontracts will be utilized by five (5) EG\&G M\&O Contractors. The five EG\&G M\&O's and their locations are identified below:

1. EG\&G Idaho, Inc. (EG\&G Idaho), Idaho Falls, Idaho facilities and the INEL facilities located approximately 50 miles West of Idaho Falls, Idaho

2. EG\&G Energy Measurement Inc. (EG\&G/EM)
3. EG\&G Rocky Flats, Inc. (EG\&G RF)
A. Rocky Flats Plant, Colorado
B. Broomfield, Colorado
C. Denver, Colorado
D. Oxnard, Cal ifornia

A. North Las Vegas Operations, Las Vegas, Nevada

B. Woburn Cathode Ray Tube Operations, Woburn, Massachusetts

C. Santa Barbara Operations, Santa Barbara, California

D. Special Technologies Laboratory, Goleta, California

E. Amador Valley Operations, Pleasanton, California

F. Kirtland Operations, Albuquerque, New Mexico

4. EG\&G Mound Applied Technologies (EG\&G Mound), Miamisburg, Ohio

5. Reynolds Electrical \& Engineering Co, Inc. (REECo), Las Vegas, Nevada

EG\&G Idaho, anticipates selecting Subcontractors that use their own facilities to provide all services required under the Subcontracts. However, EG\&G Idaho may consider joint-venture proposals under the conditions specified in Item 3 of Enclosure 7. Proposals that involve firms acting as brokers for any portion of this work will not be considered. 
PRE-PROPOSAL CONFERENCE/RECEIPT NOTIFICATION:

A pre-proposal conference will be held, and attendance by a minimum of one person but no more than 3 persons, representing the firm submitting a proposal is requested. EG\&G Idaho, will not be responsible for information missed by not attending the pre-proposal conference. There will be an EG\&G Idaho presentation followed by a question-and-answer session. The conference will begin at 8:00 AM Tocal time, on Friday, January 15, 1993, at the Palace Station, 2411 West Sahara Avenue, Las Vegas, Nevada, 89102, telephone 800-544-2411.

A11 potential offerors are requested to provide written notification to Mr. John R. Braun, Subcontract Administrator, no later than 4:30 p.m., Friday, January 8,1993 , if they 1 an to attend the pre-proposal conference. The telefax number is (208) 526-7743.

Questions can be submitted in writing to Mr. Braun prior to the pre-proposal conference by January 12, 1993. Questions arising during the pre-proposal conference which cannot be answered at that time will be answered in writing and distributed to all firms represented at the pre-proposal conference.

Upon the conclusion of the pre-proposal conference, al1 potential offerors are requested to notify EG\&G Idaho, whether or not they intend to provide a proposal. Such notification shall be provided by telegram, telecopy, or Tetter to Mr. Braun, by 4:30 p.m. Friday, January 22, 1993.

If said notification is not received, EG\&G Idaho, will assume a proposal is not forthcoming and will not direct any further correspondence, including addenda, to the nonresponding proposer. Proposers may request copies of correspondence and addenda any time prior to the proposal due date of Friday, February 5, 1993. However, extension of the proposal due date shall be at the sole discretion of EG\&G Idaho.

A. THE FOLLOWING DOCUMENTS ARE HEREBY INCORPORATED AS PART OF THIS REQUEST

FOR PROPOSAL AND ENCLOSED:

1. Pricing Requirements Applicable To A11 EG\&G M\&0 Price Proposal Attachments (Attachment 0)

2. M\&O Hazardous Waste Treatment/Disposal Scopes of Work (SOW) (Attachments 1, 6, 11, 16, and 21)

3. M\&O Scopes of Work and Price Proposals (Attachments 2, 3, 4, 5, 7, $8,9,10,12,13,14,15,17,18,19,20,22,23,24$, and 25)

4. Representations and Certifications (Enclosure 1)

5. Sample Smal1 Business and Smal1 Disadvantaged Business Subcontracting P1an (Enclosure 2)

6. EG\&G Idaho Form 183 (Revision 3-91) Standard Terms and Conditions for Purchase Orders and Subcontracts. (Enclosure 3)

7. Service Contract Act of 1965 , as amended. (Enclosure 4)

8. Wage Determination No. 86-0889 (Rev. 12) dated 8/7/92. (Enclosure 5) 
9. Sample Fixed Price Per Unit Master Task Requirement Subcontract. (Enclosure 6)

10 Proposal Submittal Form (Enclosure 7) Mandatory Go/No-Go Requirements

11. Draft - Rocky Flats Plant Health \& Safety Plan (Enclosure 8)

12. EG\&G Mound Service Contract Safety Provisions (Enclosure 9)

13. EG\&G Idaho Environmental, Safety and Health Requirements for Subcontractors (Enclosure 10)

14. EG\&G Rocky Flats - Oxnard Facility General Safety \& Security Rules - for Contractors \& Subcontractors (Enclosure 11)

C. PROPOSAL SUBMITTAL REQUIREMENTS:

PROPOSALS MUST BE SUBMITTED IN ACCORDANCE WITH THE REQUIREMENTS

HEREIN, SCOPES OF WORK, AND APPLICABLE DOCUMENTS OF THIS REQUEST FOR PROPOSAL, and must include:

1. Six complete sets of your technical and price proposals.

2. A technical proposal consisting of a completed "Proposal Submittal Form" (Enclosure 7) Mandatory Go/No-Go Requirements.

3. A price proposal containing annual firm-fixed-price-per-unit prices quoted for each year for the initial three-year period, and the two one-year optional periods (see Attachments 2, 3, 4, 5, 7, $8,9,10,12,13,14,15,17,18,19,20,22,23,24$, and 25, "Scopes of Work and Price Proposals"), for all five EG\&G M\&O's. Each individual item must be priced including those items showing no quantities.

4. A completed "REPRESENTATIONS AND CERTIFICATIONS" form (Enclosure 1).

5. A completed Subcontracting PTan in accordance with the "Sample Sma11 Business and Sma11 Disadvantaged Business Subcontracting Plan" (Enclosure 2), is required to be submitted with the proposal if the total price quoted for five years exceeds $\$ 500,000.00$, and the offeror is a large business.

6. AlI offerors are required to provide EG\&G Idaho, with their proposal, an accurate 7 isting of all 1abor categories required to perform the Subcontract for submittal to the Department of Labor for current wage determinations in accordance with the Service Contract Act. Counties and States where the work will be performed shall also be included. 
7. The offeror and any lower-tier Subcontractors shall possess adequate financial capability to fulfill the capital requirements of the subject procurement. The offeror and its lower-tier Subcontractors shall submit 10K reports or income statements and balance sheets, if $10 \mathrm{~K}$ reports are not applicable to the firm, for the previous three years. This information shall be submitted with offeror's proposal.

8. PROPOSALS FOR THE WORK SET FORTH IN THE ATTACHED WORKSCOPE (AND APPLICABLE DOCUMENTS THERETO) WILL BE RECEIVED UNTIL CLOSE OF BUSINESS 4:30 p.m. MST, Friday, February 5, 1993, at the office of EG\&G Idaho, Inc., Idaho Falls, Idaho. Prospective offerors are advised that proposal opening will not be public.

The outer sealed envelope containing the technical proposal and sealed price proposal should be marked, "Hazardous Waste Transport/ Treatment/Disposal Proposal No. M\&O-I" and be addressed as follows:

EG\&G Idaho, Inc.

1955 Fremont Avenue

P. 0. Box 1625

Idaho Falls, ID 83415-2082

Attention: John R. Braun

Subcontract Administrator

FAX - (208) 526-7743

\section{AWARD:}

This procurement will be awarded to the responsive, responsible offeror(s) meeting the mandatory Go/No-Go Criteria requirements, submitting the lowest total price, and passing the site verification assessment, as follows:

1. Mandatory Go/No-Go Criteria

The offeror's proposal must meet all of the mandatory Go/No-Go Criteria, see Enclosure 7. The proposal must address each of the mandatory requirements on a point-by-point basis and be very clear and precise. A proposal that does not meet all the mandatory Go/No-Go Criteria requirements will be considered non-responsive.

2. Price

Prices proposed for all five EG\&G M\&O Contractors for the anticipated five year period, Attachments $2,3,4,5,7,8,9,10$, $12,13,14,15,17,18,19,20,22,23,24$, and 25 are required. The Five-year grand total price of each offeror will be used for the price evaluation. Failure to submit a completed price proposal will result in disqualification. 


\section{Site Verification Assessment}

Site verification assessments will be conducted on the two technically responsive, lowest priced offerors, and any lower-tier Subcontractors. The site verification assessment includes a thorough review of the offeror, including verification of al1 the requirements of the Request for Proposal. Failure to pass the assessments will result in disqualification and the next lowest offeror(s) will then be assessed. This process will be used until such time as two offeror(s) are completely acceptable.

\section{E. TASK ORDERS/RELEASES:}

The Subcontracts will be Fixed-Price-Per-Unit Master Task Requirement Subcontracts which will define the Subcontract terms and conditions applicable to the Subcontractors and EG\&G M\&O Contractor's. Each EG\&G M\&O shall issue individual Task Orders, specific to their sites, against the Master Task Requirement Subcontracts and reserve the absolute right to determine which Subcontract to use at any time. Subcontract releases will then be issued against each Task Order by the EG\&G M\&O for the transport/treatment/disposal services required. Task orders are the vehicle through which an estimated price ceiling amount is established for a specific period of time. Releases generated against the Task Order authorize funding for the specific work to be performed for each M\&O Contractor. Task Orders will also add mutual7y agreed upon terms and conditions that are unique to that EG\&G M\&O, in addition to the terms and conditions of the Master Task Requirement Subcontract. More than one Task Order may be issued during the initial term and optional terms of the Master Task Requirement Subcontract.

Pricing will be in accordance with the firm-fixed-price-per-unit prices quoted for the five year period in this Request for Proposal (RFP). Invoices shall be directed to the specific EG\&G M\&O for which the services were performed. A11 invoices sha11 include Task Order number :and Task Order Release number.

\section{F. SERVICE CONTRACT:}

This solicitation involves work covered under the Service Contract Act of 1965, as amended (Enclosure 4). Subcontractor service employees and lower tier Subcontractor service employees performing work under the resulting Subcontracts shall be paid not less than the minimum monetary wages for their job classification as provided by a U.S. Department of Labor wage determination for their specific work location. It is anticipated that Subcontractor service employees for this work may include: Laborer, Forklift Operator, Truck Driver (1 ight), Truck Driver (medium), Truck Driver (heavy), Truck Driver (tractor-trailer), Shipping Packer, Shipper and Receiver, Computer Operator I, Key Entry Operator I. 
The U.S. Department of Labor Wage Determination Minimum Wage Rates (Enclosure 5), effective August 7, 1992, for the above listed job classes, are provided below. Note that the rates shown are based on Idaho counties statewide and can be used as a general guide, but actual rates may vary depending on the geographical location.

\begin{tabular}{|c|c|c|c|}
\hline Employee & $\begin{array}{l}\text { Minimum } \\
\text { Hourly Rate }\end{array}$ & & Health and Welfare \\
\hline $\begin{array}{l}\text { Laborer } \\
\text { Forkl ift Operator } \\
\text { Truck Driver (Light) } \\
\text { Truck Driver (Medium) } \\
\text { Truck Driver (Heavy) }\end{array}$ & $\begin{array}{r}\$ 7.97 \\
9.03 \\
8.04 \\
9.55 \\
10.03\end{array}$ & + & $\begin{array}{r}\$ 0.83 \\
.83 \\
.83 \\
.83 \\
.83\end{array}$ \\
\hline $\begin{array}{l}\text { ruck Driver (Tractor-Trailer } \\
\text { hipping Packer } \\
\text { ipper and Receiver } \\
\text { omputer Operation I } \\
\text { ay Entry Operator I }\end{array}$ & $\begin{array}{r}10.41 \\
9.45 \\
9.03 \\
7.27 \\
5.80\end{array}$ & 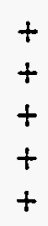 & $\begin{array}{l}.83 \\
.83 \\
.83 \\
.83 \\
.83\end{array}$ \\
\hline
\end{tabular}

NOTE: Additional benefits required by the Labor Wage Determination must be included in the hourly rate.

Upon award of a Subcontract and the determination of the geographical work locations, revised/updated wage determinations will be sought by EG\&G Idaho, through the Department of Labor and provided to the successfut Subcontractors. It is anticipated that any new wage determinations can be provided approximately 90 days from date of award. The most current rates shall prevail and apply retroactive to the date of award. EG\&G Idaho, will not provide compensation for any retroactive payments as a result of a current wage determination(s) for Subcontractor employees.

G. APPLICABLE CONDITIONS:

1. EG\&G Idaho, Inc.'s Standard Terms and Conditions (referenced in Section A. above) shall apply to the Subcontract. In addition, the EG\&G M\&O specific Environmental, Safety, and Health Requirements (ES\&H) for Subcontractors (Enclosures 8, 9, 10, and 11) shall apply to all Task Orders issued under the Subcontract for all work conducted at any EG\&G M\&O facility by the Subcontractor.

2. Upon award, the successful Subcontractors shall submit an Environmental, Safety and Health PI an for EG\&G Energy Measurements, Inc. (EG\&G/EM) and Reynolds Electrical \& Engineering Co. Inc. (REECo), for approval.

3. All requirements and conditions of the Subcontract, and task orders issued against the Subcontract, shall flow down and apply to lower-tier Subcontractors. 
4. The right is reserved by EG\&G Idaho, to reject any and all proposals and to disregard minor irregularities in proposals received. Offerors are advised that, although negotiations or discussions may follow receipt of proposals, award may be made without negotiations or discussions on proposals received and proposals should be submitted initially on the most favorable terms of price, technical exceptions, completeness, and the foregoing criteria. EG\&G Idaho, al so reserves the right to request clarifications or to conduct discussions with all offerors within a competitive range as determined by EG\&G Idaho, Inc.

5. The right is reserved by EG\&G Idaho, to revise or amend this Request for Proposal prior to the date set for receiving proposals. Such revisions and amendments, if any, will be announced by addenda to this Request for Proposal. Copies of such addenda will be furnished to all known prospective offerors, subject to limitations in the pre-proposal conference/receipt of notification section. If the revisions or amendments are of a nature which require material changes in proposals, the date set for receiving proposals may be modified by a length of time which, in the opinion of EG\&G Idaho, will enable prospective offerors to revise their proposals. In such cases, the addenda will include an announcement of the new date for receiving proposals.

Offerors submitting proposals must indicate in their proposal receipt of addenda (by number) issued subsequent to the original Request for Proposal.

6. Initial proposals must be received by EG\&G Idaho, on the date and time cited herein. However, EG\&G Idaho, reserves the right to consider a later initial proposal if deemed to be in the best interest of EG\&G Idaho.

7. Proposals may be withdrawn or modified upon written or telegraphic request received from offerors prior to the time fixed for opening of proposals.

8. Proposals must be in accordance with all conditions specified herein. Any proposals accompanied by terms and conditions essentially different from this solicitation, the applicable Subcontract form or referenced documents, may be considered nonresponsive and rejected.

9. Should offerors find discrepancies or omissions in any of the documents or information furnished, or have doubts concerning their meaning or interpretation, they should immediately notify the EG\&G Idaho's Subcontract Administrator identified herein and obtain the proper clarification (prior to submission of proposal) to avoid rejection of their proposal. 
10. Each offeror is required to identify any proprietary data provided with the proposal or contemplated to be used during performance of a Subcontract.

11. All proposal information received is held in the strictest of confidence and never divulged or discussed freety or disseminated beyond the members of the EG\&G M\&O Contractors (as defined on page 1) and evaluation team, or other than required by their respective prime contracts with the DOE. However, inasmuch as EG\&G M\&O's are prime Management and Operating Contractors for the U.S.

Department of Energy, they are subject to the mandates of the Freedom of Information Act. Therefore, all items of your proposal considered to be confidential or proprietary must be marked "proprietary."

12. EG\&G Idaho, is a wholly-owned subsidiary of EG\&G, Inc., but was organized for the sole purpose of functioning as a M\&O Contractor for the DOE Field Office Idaho (DOE-ID). EG\&G Idaho, Inc. is not allowed to submit proposals in response to non-DOE-ID requests for competitive proposals or quotes. EG\&G Idaho, and EG\&G M\&O's are not permitted to divulge to other EG\&G affiliates proprietary information received from those offerors submitting proposals in response to EG\&G Idaho, Inc.'s request for proposals or quotes without the consent of the Subcontractor.

13. Offerors are advised that, prior to award of a Subcontract, this solicitation may be amended to incorporate appropriate Subcontract provisions implementing the M\&O Contractor Accountability Rules as published by the DOE in 56 Federal Register 28099. These rules are applicable to 7 arge businesses as defined in the Federal Small Business Act and provide for an exemption for small business.

14. EG\&G Idaho, wiTl not return the proposals in response to this RFP to the unsuccessful offerors unless it is stated in the proposal that your company would like its proposal returned. If so stated, EG\&G Idaho, will ship the proposal to your company collect.

Otherwise, EG\&G Idaho, will retain or destroy the proposals at its discretion.

15. This RFP does not commit EG\&G Idaho, to pay any costs incurred in connection with any proposal or to procure.or Subcontract for any item or services.

16. Offerors should carefully examine this RFP and fuTly inform themselves as to all conditions and matters which can in any way affect the work or the price. 


\section{ATTACHMENT 1}

HAZARDOUS WASTE TREATMENT/DISPOSAL SCOPE OF WORK

1. EG\&G Rocky Flats, Inc. (EG\&G RF), a prime M\&O contractor for the U. S. Department of Energy (DOE), is seeking a firm to provide hazardous waste transportation, treatment and disposal services to EG\&G RF. This scope includes waste transportation, treatment, and disposal services for locations at Rocky Flats Plant and other EG\&G RF facilities in Broomfield and Denver, Colorado, and the Oxnard Facility located in Oxnard, California. The Subcontractor shall provide the services described in Attachments 1 through 5.

Attachment 2 lists RCRA solid and hazardous and TSCA regulated waste streams currently generated by EG\&G RF operations. EG\&G RF reserves its right to determine the quantity, if any, of each waste stream listed in Attachment 2 that shall be included in this subcontract. Additional waste streams may be added subject only to Subcontractor's permits and licenses and negotiation of unit pricing for each added waste stream. Pricing of added waste streams shall be comparable to the pricing for similar waste streams listed in Attachment 2.

2. The Subcontractor shall treat and/or dispose of at least $50 \%$ of the annual waste shipments at their own facilities or a subsidiary thereof unless granted prior written approval on a case-by-case basis from EG\&G RF to subcontract more than $50 \%$ of the total waste volume. The total number of facilities utilized under this subcontract shall not exceed ten unless approved by EG\&G RF prior to disposal. If more than one company is involved in the work performance, only one firm shall act as the Subcontractor. The Subcontractor shall obtain separate written approvals from EG\&G RF for each firm to which it desires to subcontract or dispose any portion of this subcontract, prior to involving each firm in work performance.

3. The Subcontractor shall be responsible for administering all of the transactions of the subcontract, including invoicing, and to interact solely with EG\&G RF. EG\&G RF will pay invoices from only the Subcontractor.

4. All materials submitted to the Subcontractor shall be completely treated, stored and disposed of within the continental United States.

5. The Subcontractor shall be responsible for the cost of all testing and documentation required beyond EG\&G RF's responsibilities which shall be: 1) EG\&G RF shall provide profile data for each waste stream according to the regulatory requirements specified by 40 CFR $262.11,40$ CFR 264.13 , and/or 40 CFR 265.13 , as applicable, and 2) EG\&G RF shall make payment to the Subcontractor for sample analysis according to Attachment 3 . The testing and documentation referenced in this requirement shall include present and future regulatory and Subcontractor requirements for testing and documentation. 
c. A tracking method describing how the waste streams will be accounted for, from the point of acceptance to the point of final disposition, that can cross reference by the container number of the contracting facility. Waste streams may be shipped by the Subcontractor, or may be shipped by a common carrier approved by EG\&G RF.

d. The packaging and transportation of material qualifying as hazardous material under 49 CFR must be in accordance with 49 CFR Parts 100 through 177 and 383 through 399 . EG\&G RF retains the right to audit functions and files pertaining to packaging and transportation.

e. The analytical results from final treatment of the Land Disposal Restriction (LDR) waste, referenced by container number of the contracting facility, documenting that the waste after treatment are at or below approved treatment levels.

10. The Subcontractor shall supply certificates of destruction/disposal for each waste stream manifested to their Temporary Storage Disposal Facility (TSDF) by their company to another company within $\mathbf{3 0}$ days of destruction/disposal. The certificates of destruction/disposal shall include: the manifest number; facility waste acceptance approval number relating to the waste stream that was disposed of (for subcontracted items, these numbers shall be provided for each facility until final disposition); the EPA waste codes for the waste stream; the weight/volume, and container numbers(s) of the waste stream destroyed/disposed of; the name, owner and address of the disposal facility; and the signature of a responsible company official.

11. The Subcontractor shall maintain the appropriate insurance policies and coverages as specified by federal, state, and local regulations and provide evidence thereof.

12. Transfer of hazardous waste title and responsibility to the Subcontractor follows subcontract award and inventory transfer. This includes, but is not limited to, the responsibilities associated with environmental regulations. This transfer of title and responsibility will be handled in a manner acceptable to standard industry and government practices and policies.

13. EG\&G RF and/or its designee shall have the right to inspect the facilities, records, and operations of the Subcontractor and lower-tier Subcontractors. These inspections shall be conducted at such time and in such manner as deemed appropriate by all involved parties.

14. The subcontractor shall notify EG\&G RF in writing and by phone if any discrepancies are found between profile data and acceptance sampling of the waste when it is received at the disposal or treatment facility. If this occurs then the profile may be amended by faxed letter or the waste will be immediately returned to EG\&G RF or a new profile can be established with mutual consent of both parties. 
8. The Subcontractor shall provide, upon request, all required environmental permits and authorizations including, but not limited to, the following:

a. Air quality permits

b. Water discharge permits, e.g., National Pollutant Discharge Elimination System (NPDES)

c. RCRA Part A and/or Part B permits (or applications, if the permits have not yet been approved)

d. Authority to accept CERCLA remediation wastes

e. Authority to accept TSCA wastes, and

f. Other permits required by state or local agencies.

Except as otherwise directed by EG\&G RF, the successful Subcontractor shall provide evidence of all necessary permits, authorizations, or licenses. The successful Subcontractor shall provide copies of permit amendments within 20 days of amendment receipt. The Subcontractor shall abide by all applicable laws, regulations, and ordinances of the United States and the state and political subdivision where the work shall be performed.

9. The Subcontractor shall provide documentation by which the required hazardous waste transportation, treatment and disposal services shall be performed. The documentation shall include, but not be limited to, the following:

a. Regulation compliance procedures

b. Method of accountability reporting for waste streams including applicable certificates; e.g., certificates of destruction and disposal, EPA biennial reports and state annual reports. 


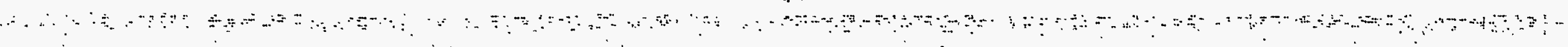

EG\&G Rocky Flats, Inc.

Attachment 2, Page 2 of 12

SPECIAL INSTRUCTIONS FOR COMPLETING ATTACHMENT 2 - 5

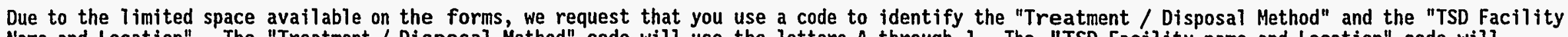
Name and Location". The "Treatment / Disposal Method" code will use the letters A through J. The "TSD Facility name and Location" code will

use the numbers 1 through 15. Please enter the Treatment / disposal methods and the TSD Facility Name and Location in the spaces provided below.

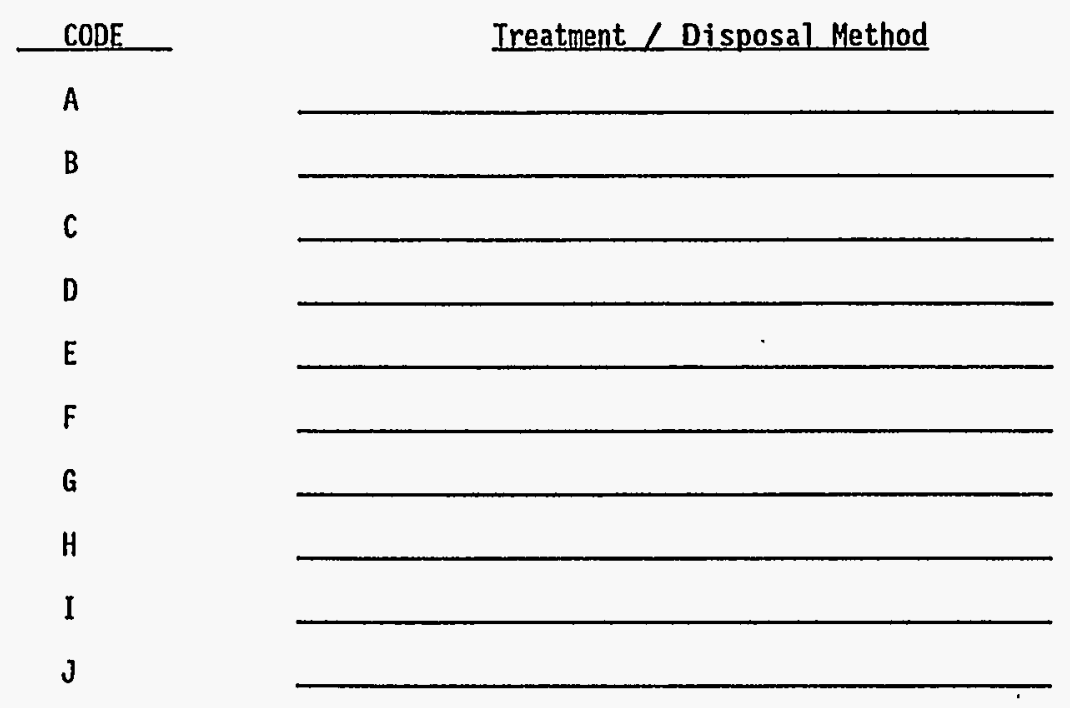

\begin{tabular}{c} 
CODE \\
\hline 1 \\
2 \\
3 \\
4 \\
5 \\
6 \\
7 \\
8 \\
9 \\
10 \\
11 \\
12 \\
13 \\
14 \\
15
\end{tabular}

ISD Facility Name and Location 


\section{EG\&G Rocky Flats, Inc.}

ATTACHMENT 2 - WASTE DISPOSAL

SCOPE OF WORK AND PRICE PROPOSAL

\section{SCOPE OF WORK}

The Subcontractor shall provide treatment and disposal services for the RCRA solid hazardous wastes, TSCA wastes, and CERCLA remediation and non-regulated wastes generated by EG\&G RF. Following is a list of waste streams currently generated by EG\&G RF. The Subcontractor shall accept wastes "as is" with no pre-treatment necessary by EG\&G RF e.g., solidification. The Subcontractor shall be required to accept waste packed or overpacked in 2 through 90-gallon drums, as well as bulk shipments. EG\&G RF will drain all free flowing PCB liquids from each transformer prior to shipment. The Subcontractor shall provide waste treatment and disposal services on both a scheduled and emergency basis. The Subcontractor may be required for emergencies to provide disposal services within 7 calendar days. It is anticipated that one shipment of waste will be made to the Subcontractor every 20 to 90 days, although this is not guaranteed or implied. EG\&G RF is assigned four EPA identification numbers: C07890010526, COTO00644195, COD983792185, and CA9890090401.

The Subcontractor shall meet or exceed the Land Disposal Restriction (LDR) treatment standards found in 40 CFR 268, and shall minimize the waste volume. Upon final treatment of waste streams, the Subcontractor will supply EG\&G RF with analytical results for wastes after treatment and before disposal. The Subcontractor or its subcontractors may be required to accept, for treatment and/or disposal, CERCLA wastes generated from sites undergoing remediation. The permitted facility shall accept the CERCLA remediation wastes arriving without an EPA waste code number and shall comply with the most current CERCLA Off-Site Policy.

If a waste stream is approved for multiple waste codes, the Subcontractor shall be required to accept documentation from EG\&G RF which specifies only the waste codes that apply to each shipment of the waste stream. The Subcontractor shall allow EG\&G RF, with prior Subcontractor approval, to add new chemicals to each approved waste stream if the contents and treatment are compatible.

If and when this service is requested, the attached unit prices shall apply. The quantities and waste streams shown are estimated annual requirements and are in no way guaranteed or implied. Additional waste streams may be added subject only to facility permits and licenses and negotiation of unit pricing for each added waste stream. Pricing of added waste streams, including wastes having a " $\mathrm{K}$ " EPA waste code, shall be comparable to the pricing for similar waste streams included in the following list.

\section{TRANSPORTATION:}

1. The Subcontractor shall provide the contractor with notice of any traffic violations received within 20 days of receipt.

2. The Subcontractor will provide the EG\&G RF Traffic Department the records and training qualifications of any driver and/or handler upon receipt.

\section{INSTRUCTIONS FOR COMPLETING ATTACHED PRICE PROPOSAL:}

Quote unit prices in all three columns of drum sizes for every waste stream, even if zero quantity is listed for any waste stream.

Comply with Attachment O, Pricing Requirements, of this Request for Proposal. 
EG\&G Rocky Fiats, Inc.

Attachment 2, Page 4 of 12

\begin{tabular}{|c|c|c|c|c|c|c|c|c|c|c|c|c|c|c|c|c|c|c|c|c|c|c|}
\hline \multirow{2}{*}{$\begin{array}{l}\text { TTER } \\
\text { Ho. } \\
\text { Ho. }\end{array}$} & \multirow{2}{*}{$\begin{array}{c}\text { EPA } \\
\text { COOES }\end{array}$} & \multirow[t]{2}{*}{ DESCRIPTIOH } & \multicolumn{6}{|c|}{ NUMBER OF DRUMS } & \multicolumn{6}{|c|}{ DISPPSAL UNIT PRICE \&Y DRUW SIZE } & \multicolumn{6}{|c|}{ EXTENDED TOTLL PRICE } & \multirow{2}{*}{ 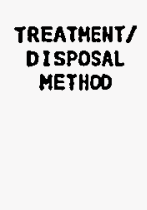 } & \multirow{2}{*}{$\begin{array}{l}\text { TSD FACLITYY NAME } \\
\text { AND LOCATIOOH }\end{array}$} \\
\hline & & & $\begin{array}{l}1-5 \\
\text { GAML. } \\
\text { DRNM }\end{array}$ & $\begin{array}{l}\text { G.-10 } \\
\text { aAL } \\
\text { ORRUM }\end{array}$ & $\begin{array}{l}11-15 \\
\text { Gat } \\
\text { ORUM }\end{array}$ & $\begin{array}{l}\text { GAL } \\
\text { GAL } \\
\text { ORRY }\end{array}$ & $\begin{array}{l}30 \\
\text { GQL. } \\
\text { DRRM }\end{array}$ & $\begin{array}{l}55 \\
\text { GALL } \\
\text { DRRW }\end{array}$ & $\begin{array}{l}10.5 \\
\text { GAL. } \\
\text { ORRM }\end{array}$ & 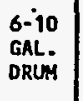 & $\begin{array}{l}\text { 11-15 } \\
\text { GAL } \\
\text { DRUM }\end{array}$ & $\begin{array}{l}20 \\
\text { Gat. } \\
\text { ORRM }\end{array}$ & $\begin{array}{l}30 \\
\text { GRL } \\
\text { DRRM }\end{array}$ & $\begin{array}{l}55 \\
\text { chat. } \\
\text { DRRMA }\end{array}$ & $\begin{array}{l}1-5 \\
\text { GaL } \\
\text { DRRU }\end{array}$ & $\begin{array}{l}\text { S.10 } \\
\text { GALL } \\
\text { DRRW }\end{array}$ & $\begin{array}{l}\substack{11-15 \\
\text { GALL } \\
\text { ORRW }} \\
-\end{array}$ & $\begin{array}{l}20 \\
\text { GALL } \\
\text { ORRU }\end{array}$ & 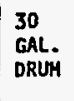 & $\begin{array}{l}55 \\
\text { CAL. } \\
\text { ORRYH }\end{array}$ & & \\
\hline 1 & 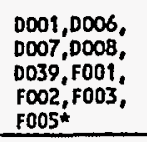 & 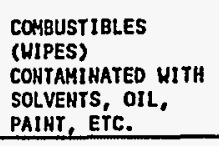 & & & & & & 105 & & & & & & & & & & & & & & \\
\hline 2 & 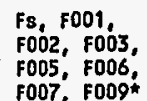 & 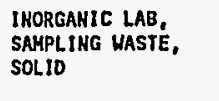 & & & & & & 3 & & & & & & & & & & & & & & \\
\hline 3 & 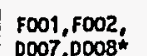 & HACHENE COOLANTS & & & & & & 20 & & & & & & & & & & & & & & \\
\hline 4 & 0008 & $\begin{array}{l}\text { IHORGAMIC SOLID } \\
\text { LAED RESTIUSE }\end{array}$ & & & & & & 8 & & & & & & & & & & & & & & \\
\hline 5 & 0009 & $\begin{array}{l}\text { CRUSHED } \\
\text { FUORESERT Q BLASS }\end{array}$ & & & & & & 42 & & & & & & & & & & & & & & \\
\hline 6 & 0009 & 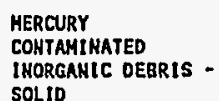 & & & & & & 11 & & & & & & & & & & & & & & \\
\hline 7 & 0009 & 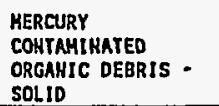 & & & & & & 1 & & & & & & & & & & & & & & \\
\hline 8 & 0009 & 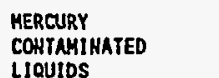 & & & & & & 2 & & & & & & & & & & & & & & \\
\hline
\end{tabular}

*Items denoted with an asterisk are wastes that may contain any or all of the specified waste codes.

+Hay or may not contain D003.

PAGE TOTAL 


\begin{tabular}{|c|c|c|c|c|c|c|c|c|c|c|c|c|c|c|c|c|c|c|c|c|c|c|}
\hline \multirow{2}{*}{$\begin{array}{l}\text { ITEM } \\
\text { NO. }\end{array}$} & \multirow{2}{*}{$\begin{array}{l}\text { EPA } \\
\text { COOES }\end{array}$} & \multirow{2}{*}{ DESCRIPTION } & \multicolumn{6}{|c|}{ RUMBER OF DRLAMS } & \multicolumn{6}{|c|}{ DISPOSAL UHIT PRICE BY ORUM SIZE } & \multicolumn{6}{|c|}{ EXTERDED TOTAL PRICE } & \multirow{2}{*}{$\begin{array}{c}\text { TREATHEATI } \\
\text { DISPPSALL } \\
\text { METHOO }\end{array}$} & \multirow{2}{*}{$\begin{array}{l}\text { TSD FACILITY } \\
\text { MAME ANO } \\
\text { LOCATION }\end{array}$} \\
\hline & & & $\begin{array}{l}1-5 \\
\text { GALL. } \\
\text { DRUM }\end{array}$ & $\begin{array}{l}\text { 6-10 } \\
\text { GALLM } \\
\text { DRLM }\end{array}$ & $\begin{array}{l}11-15 \\
\text { GALL } \\
\text { DRUM }\end{array}$ & $\begin{array}{l}20 \\
\text { GAL. } \\
\text { ORUM }\end{array}$ & $\begin{array}{l}30 \\
\text { GAkL } \\
\text { ofuY }\end{array}$ & $\begin{array}{l}55 \\
\text { GALL } \\
\text { oRUM }\end{array}$ & $\begin{array}{l}1-5 \\
\text { GAL } \\
\text { ORUM }\end{array}$ & $\begin{array}{l}6.90 \\
\text { GAL. } \\
\text { DRUM }\end{array}$ & $\begin{array}{l}11-15 \\
\text { GALL } \\
\text { DRUH }\end{array}$ & $\begin{array}{l}20 \\
\text { GQL. } \\
\text { ORUM }\end{array}$ & $\begin{array}{l}30 \\
\text { GAL } \\
\text { DRUM }\end{array}$ & $\begin{array}{l}55 \\
\text { GA } \\
\text { DRUM }\end{array}$ & $\begin{array}{l}1-5 \\
\text { GAL. } \\
\text { ORUM }\end{array}$ & $\begin{array}{l}6-10 \\
\text { GAL: } \\
\text { ORUM }\end{array}$ & $\begin{array}{l}11-15 \\
\text { GALL } \\
\text { DRUM }\end{array}$ & $\begin{array}{l}20 \\
\text { GQL. } \\
\text { ORLA }\end{array}$ & $\begin{array}{l}30 \\
\text { GAL. } \\
\text { ORLM }\end{array}$ & $\begin{array}{l}55 \\
\text { GAL. } \\
\text { DRUM }\end{array}$ & & \\
\hline 1 & 0001 & FLAMHABLE GAS & & & & & 1 & & & & & & & & & & & & & & & \\
\hline 2 & 0002 & CORROSIVE LIOUID & & & & & 4 & & & & & & & & & & & & & & & \\
\hline 3 & 0007 & $\begin{array}{c}\text { roxic LLOUID } \\
\text { W/CHROHIUH } \\
\end{array}$ & & & & & 2 & 6 & & & & & & & & & & & & & & \\
\hline 4 & 0007 & $\begin{array}{l}\text { TOXIC SOLLD } \\
\text { H/CHROMIUH } \\
\end{array}$ & & & & & & 5 & & & & & & & & & & & & & & \\
\hline 5 & $0007 \& 0008$ & $\begin{array}{l}\text { TOXIC SOLLD } \\
\text { W/CRROHIUM \& LEAD }\end{array}$ & & & & & 8 & & & & & & & & & & & & & & & \\
\hline 6 & $0007 \& 0008$ & $\begin{array}{l}\text { TOXIC LIOUID } \\
\text { H/CHROMIUYY \& LEAD }\end{array}$ & & & & & & 2 & & & & & & & & & & & & & & \\
\hline 7 & 0008 & $\begin{array}{l}\text { TOXIC LIQUID } \\
\text { H/LEAD }\end{array}$ & & & & & & 4 & & & & & & & & & & & & & & \\
\hline 8 & & PETROLEUM OIL & & & & & 1 & 2 & & & & & & & & & & & & & & \\
\hline
\end{tabular}




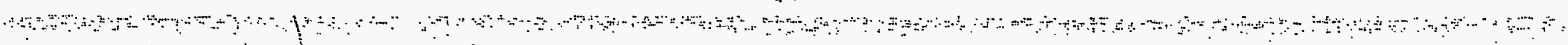

EG\&G Rocky Flats, Inc.

Attachment 2, Page 6 of 12

\begin{tabular}{|c|c|c|c|c|c|c|c|c|c|c|c|c|c|c|c|c|c|c|c|c|c|c|}
\hline \multirow{2}{*}{$\begin{array}{l}\text { ITEM } \\
\text { NO. }\end{array}$} & \multirow{2}{*}{$\begin{array}{l}\text { EPA } \\
\text { COOES }\end{array}$} & \multirow[t]{2}{*}{ DEsCRIPIION } & \multicolumn{6}{|c|}{ NUHBER OF DRUMS } & \multicolumn{6}{|c|}{ DISPOSAL UNIT PRICE GY DRUM SIZE } & \multicolumn{6}{|c|}{ EXTENDED TOTAL PRICE } & \multirow{2}{*}{$\begin{array}{c}\text { TREATHENTI } \\
\text { DOISPOSAL } \\
\text { METHOO }\end{array}$} & \multirow{2}{*}{$\begin{array}{l}\text { TSD FACILITY MAME } \\
\text { AND LOCATION }\end{array}$} \\
\hline & & & $\begin{array}{l}1-5 \\
\text { GAL. } \\
\text { DRUM }\end{array}$ & $\begin{array}{l}\text { 6-10 } \\
\text { GAL. } \\
\text { DRUM }\end{array}$ & $\begin{array}{l}11 \cdot 15 \\
\text { GAL: } \\
\text { DRUM }\end{array}$ & $\begin{array}{l}20 \\
\text { GAL. } \\
\text { DRLW }\end{array}$ & $\begin{array}{l}30 \\
\text { GGL. } \\
\text { DRUH }\end{array}$ & $\begin{array}{l}55 \\
\text { GAL. } \\
\text { DRUS }\end{array}$ & $\begin{array}{l}1-5 \\
\text { GA. } \\
\text { DRWH }\end{array}$ & $\begin{array}{l}\text { G-10 } \\
\text { GAL } \\
\text { ORLM }\end{array}$ & $\begin{array}{l}11-15 \\
\text { GAL } \\
\text { DRLM }\end{array}$ & $\begin{array}{l}20 \\
\text { GRL. } \\
\text { ORLMH }\end{array}$ & $\begin{array}{l}30 \\
\text { GRL. } \\
\text { DRRMA }\end{array}$ & $\begin{array}{l}55 \\
\text { GRL. } \\
\text { ORLM }\end{array}$ & $\begin{array}{l}9.5 \\
\text { GAL. } \\
\text { DRUA }\end{array}$ & $\begin{array}{l}6-10 \\
\text { GAL. } \\
\text { DRUH }\end{array}$ & $\begin{array}{l}111-15 \\
\text { GRL. } \\
\text { DRUM }\end{array}$ & $\begin{array}{l}20 \\
\text { GAL. } \\
\text { DRUM }\end{array}$ & $\begin{array}{l}30 \\
\text { GAL. } \\
\text { DRUM }\end{array}$ & $\begin{array}{l}55 \\
\text { GALL } \\
\text { DRUA }\end{array}$ & & \\
\hline 21 & 0002 & CAUSTIC SOLUTIONS & & & & & & 1 & & & & & & & & & & & & & & \\
\hline 22 & Fo03 & $\begin{array}{l}\text { INORGANIC SAMPLIHG } \\
\& \text { LAB HASTE, } \\
\text { LIOUID }\end{array}$ & & & & & & 1 & & & & & & & & & & & & & & \\
\hline 23 & 0003 & SMOKE GREMADES & & & & & & 4 & & & & & & & & & & & & & & \\
\hline 24 & 0003 & TEAR GAS GREMADES & & & & & & 15 & & & & & & & & & & & & & & \\
\hline 25 & F002 & FOAM COMPOKEHTS & & & & & & 15 & & & & & & & & & & & & & & \\
\hline 26 & $\begin{array}{l}\text { poo1, } \\
\text { Fo02, }\end{array}$ & IGNITABLE SOLVENTS & & & & & & 9 & & & & & & & & & & & & & & \\
\hline 27 & $\begin{array}{l}\text { Do01, } \\
\text { F002, } 0018,\end{array}$ & GARAGE SOLVEHTS & & & & & & 6 & & & & & & & & & & & & & & \\
\hline 28 & $\begin{array}{l}\text { Fo01, F002, } \\
\text { F003, F005* }\end{array}$ & CLEANING SOLVEHTS & & & & & & 3 & & & & & & & & & & & & & & \\
\hline 29 & 0001 & $\begin{array}{l}\text { TONER, PETROLEUM } \\
\text { DISTILLATES } \\
\end{array}$ & & & & & & 2 & & & & & & & & & & & & & & \\
\hline 30 & $\begin{array}{l}0001, \mathrm{~F} \\
\mathrm{~F} 0002^{\mathrm{x}}\end{array}$ & CRAMKCASE OIL & & & & & & 80 & & & & & & & & & & & & & & \\
\hline 31 & 0009 & GASOLIRE, HATER & & & & & & 7 & & & & & & & & & & & & & & \\
\hline 32 & 0003 & MAGKESIUM CHIPS & & & & & & 3 & & & & & & & & & & & & & & \\
\hline 33 & 0001 & IITAMIUM CHIPS & & & & & & 1 & & & & & & & & & & & & & $\cdot$ & \\
\hline 34 & Foor & $\begin{array}{l}\text { SOLVERT } \\
\text { CONTAMINATED METAL }\end{array}$ & & & & & & 1 & & & & & & & & & & & & & & \\
\hline
\end{tabular}

"I tems denoted with on asterisk are wastes that may contain any or all of the specified waste codes.

t May or may not contain Do03.

PAGE TOTAL 
EGRG Rocky Flats, Inc.

Attechment 2, Page 5 of 12

\begin{tabular}{|c|c|c|c|c|c|c|c|c|c|c|c|c|c|c|c|c|c|c|c|c|c|c|}
\hline \multirow{2}{*}{$\begin{array}{l}\text { ITEM } \\
\text { HO. }\end{array}$} & \multirow{2}{*}{$\begin{array}{c}\text { EPA } \\
\text { COOES }\end{array}$} & \multirow[t]{2}{*}{ DESCRIPTION } & \multicolumn{6}{|c|}{ RUHBER OF DRLHS } & \multicolumn{6}{|c|}{ DISPOSAL UNIT PRICE QY DRUM SIZE } & \multicolumn{6}{|c|}{ EXTENDED TOTAL. PRICE } & \multirow{2}{*}{$\begin{array}{l}\text { TREATHENT/ } \\
\text { DISPOSAL } \\
\text { METHOO }\end{array}$} & \multirow{2}{*}{$\begin{array}{l}\text { ISD FACILITY NAME } \\
\text { AND LOCATION }\end{array}$} \\
\hline & & & $\begin{array}{l}1.5 \\
\text { GAL. } \\
\text { ORUH }\end{array}$ & $\begin{array}{l}6-10 \\
\text { GAL. } \\
\text { DRUM }\end{array}$ & $\begin{array}{l}11-15 \\
\text { GAL. } \\
\text { DRUM }\end{array}$ & $\begin{array}{l}20 \\
\text { GAL. } \\
\text { ORUM }\end{array}$ & $\begin{array}{l}30 \\
\text { GAL. } \\
\text { DRUA }\end{array}$ & $\begin{array}{l}55 \\
\text { GAL. } \\
\text { DRUH }\end{array}$ & $\begin{array}{l}1-5 \\
\text { GAL. } \\
\text { DRUM }\end{array}$ & $\begin{array}{l}6-10 \\
\text { GAL. } \\
\text { DRUM }\end{array}$ & $\begin{array}{l}11-15 \\
\text { GAL. } \\
\text { DRUA }\end{array}$ & $\begin{array}{l}20 \\
\text { GAL. } \\
\text { DRUH }\end{array}$ & $\begin{array}{l}30 \\
\text { GAL. } \\
\text { DRUH }\end{array}$ & $\begin{array}{l}55 \\
\text { GAL. } \\
\text { DRUM }\end{array}$ & $\begin{array}{l}1-5 \\
\text { GAL. } \\
\text { DRUM }\end{array}$ & $\begin{array}{l}6-10 \\
\text { GAL. } \\
\text { DRUS }\end{array}$ & $\begin{array}{l}11-15 \\
\text { GAL.: } \\
\text { DRUM }\end{array}$ & $\begin{array}{l}20 \\
\text { GAL. } \\
\text { ORUM }\end{array}$ & $\begin{array}{l}30 \\
\text { GAL. } \\
\text { DRUH }\end{array}$ & $\begin{array}{l}55 \\
\text { GAL. } \\
\text { DRUM }\end{array}$ & & \\
\hline 9 & 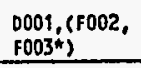 & $\begin{array}{l}\text { PAIHT, THINMER, } \\
\text { SLUDGE }\end{array}$ & & & & & & 37 & & & & & & & & & & & & & & \\
\hline 10 & 0008 & $\begin{array}{l}\text { BATTERIES, GELL } \\
\text { CELLL, LEAD ACID }\end{array}$ & & & & & & 18 & & & & & & & & & & & & & & \\
\hline 11 & 0006 & $\begin{array}{l}\text { BATTERIES, HICAD, } \\
\text { ALCAD }\end{array}$ & & & & & & 3 & & & & & & & & & & & & & & \\
\hline 12 & 0001,0007 & $\begin{array}{l}\text { CHROAIC ACID, } \\
\text { SOLID }\end{array}$ & & & & & & 5 & & & & & & & & & & & & & & \\
\hline 13 & $0003, F 009$ & CYANIDE SOLUTION & & & & & & 3 & & & & & & & & & & & & & & \\
\hline 14 & F001, $\mathrm{F}^{2} \mathrm{2}^{\star}$ & $\begin{array}{l}\text { OIL FILTERS, CRUSH } \\
\text { GRIHOER }\end{array}$ & & & & & & 5 & & & & & & & & & & & & & & \\
\hline 15 & D007 & $\begin{array}{l}\text { OIL FILTERS, } \\
\text { CRAAKCASE }\end{array}$ & & & & & & 4 & & & & & & & & & & & & & & \\
\hline 16 & 0007 & PAINT FILTERS & & & & & & 5 & & & & & & & & & & & & & & . \\
\hline 17 & $\begin{array}{l}0006, \\
0000 \% \\
0008,0018 \%\end{array}$ & $\begin{array}{l}\text { PETROLEUY SPILL } \\
\text { RESIDUES, SOLID } \\
\end{array}$ & & & & & & 51 & & & & & & & & & & & & & & \\
\hline 18 & $\begin{array}{l}\text { D001, } \\
\text { (D007, } \\
\text { D008, D006, } \\
\text { D018*) }\end{array}$ & $\begin{array}{l}\text { GASOLIAE SPILL } \\
\text { RESIDUES, SOLID }\end{array}$ & & & & & & 14 & & & & & & & & & & & & & & \\
\hline 19 & D001, 0007 & $\begin{array}{l}\text { ELECTROCHEMICAL } \\
\text { HILLING SLUDGE }\end{array}$ & & & & & & 2 & & & & & & & & & & & & & & \\
\hline 20 & 0002 & ACID SOLUTIOHS & & & & & & 3 & & & & & & & & & & & & & & \\
\hline
\end{tabular}

*I tems denoted with an asterisk are wastes that may contain ony or all of the specified waste codes.

+ May or may not contaín D003.

PAGE TOTAL 
EG\&G Rocky Flats, Inc.

Attachment 2, Page 8 of 12

\begin{tabular}{|c|c|c|c|c|c|c|c|}
\hline $\begin{array}{l}\text { ITEH } \\
\text { NO. }\end{array}$ & DESCRIPTION & QUANTITY & UNIT & UNIT PRICE & EXTENDED OVERALL PRICE & TREATMENT/DISPOSAL METHDO & $\begin{array}{l}\text { TSD FACRLLTY } \\
\text { MAKE AHD LOCATIOH }\end{array}$ \\
\hline 45 & EULK SOLLDS - LOR & - MOTE ? & & & & & \\
\hline 46 & 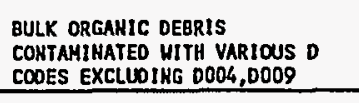 & - NOTE 1 & & & & & \\
\hline 47 & 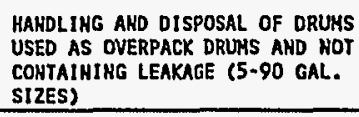 & & & & & & \\
\hline 48 & 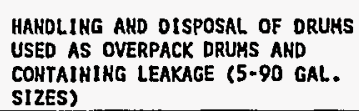 & & & & & & \\
\hline
\end{tabular}

NOTE 1 - pricing for bulk shipments in excess of 1 ton shatl be negotiated on a case-by-case basis. 
EG\&G Rocky Flats, Inc.

Attachment 2, Page 7 of 12

\begin{tabular}{|c|c|c|c|c|c|c|c|c|c|c|c|c|c|c|c|c|c|c|c|c|c|c|}
\hline \multirow{2}{*}{$\begin{array}{l}\text { ITEM } \\
\text { NO. }\end{array}$} & \multirow{2}{*}{$\begin{array}{l}\text { EPA } \\
\text { COOES }\end{array}$} & \multirow[t]{2}{*}{ DESCRIPTIOH } & \multicolumn{6}{|c|}{ HUMBER OF DRUMS } & \multicolumn{6}{|c|}{ DISPOSAL UNIT PRICE BY DRUM SIZE } & \multicolumn{6}{|c|}{ EXTENDED TOTAL PRICE } & \multirow{2}{*}{$\begin{array}{c}\text { TREATMENT/ } \\
\text { DISPOSAL } \\
\text { METHOD }\end{array}$} & \multirow{2}{*}{$\begin{array}{l}\text { TSO FACILITY HAME } \\
\text { AHD LOCATIOH }\end{array}$} \\
\hline & & & $\begin{array}{l}1-5 \\
\text { GAL. } \\
\text { DRUY }\end{array}$ & $\begin{array}{l}\text { 6-10 } \\
\text { GAL. } \\
\text { DRUM }\end{array}$ & $\begin{array}{l}11-15 \\
\text { GAL. } \\
\text { DRUY }\end{array}$ & $\begin{array}{l}20 \\
\text { GAL. } \\
\text { DRUH }\end{array}$ & $\begin{array}{l}30 \\
\text { GAL. } \\
\text { DRUM }\end{array}$ & $\begin{array}{l}55 \\
\text { GAL. } \\
\text { DRUM }\end{array}$ & $\begin{array}{l}1.5 \\
\text { GAL. } \\
\text { DRUH }\end{array}$ & $\begin{array}{l}\text { 6-10 } \\
\text { GAL. } \\
\text { DRUM }\end{array}$ & $\begin{array}{l}11-15 \\
\text { GAL. } \\
\text { DRUA }\end{array}$ & $\begin{array}{l}20 \\
\text { CAL. } \\
\text { DRUM }\end{array}$ & $\begin{array}{l}30 \\
\text { GAL.: } \\
\text { DRUM }\end{array}$ & $\begin{array}{l}55 \\
\text { GAL. } \\
\text { DRUN }\end{array}$ & $\begin{array}{l}1.5 \\
\text { GAL. } \\
\text { ORUM }\end{array}$ & $\begin{array}{l}\text { 6-10 } \\
\text { GAL. } \\
\text { DRUA }\end{array}$ & $\begin{array}{l}11-15 \\
\text { GAL. } \\
\text { ORUMY }\end{array}$ & $\begin{array}{l}20 \\
\text { GAL. } \\
\text { DRUM }\end{array}$ & $\begin{array}{l}30 \\
\text { GAL. } \\
\text { DRUM }\end{array}$ & $\begin{array}{l}55 \\
\text { GAL. } \\
\text { DRUY }\end{array}$ & & \\
\hline 35 & D006, D011* & $\begin{array}{l}\text { INORGAMIC SOL.10 } \\
\text { RESIDUES }\end{array}$ & & & & & & 9 & & & & & & & & & & & & & & \\
\hline 36 & $\begin{array}{l}\text { D004, } 0002, \\
\text { F002, } \\
\text { F005, }\end{array}$ & $\begin{array}{l}\text { SCINTILLATIOH } \\
\text { COCKTAIL }\end{array}$ & & & & & & 5 & & & & & & & & & & & & & & \\
\hline 37 & & ASBESTOS & & & & & & 6 & & & & & & & & & & & & & & \\
\hline 38 & & $\begin{array}{l}\text { PCB DIELECTRIC } \\
\text { FLUID }\end{array}$ & & & & & & 10 & & & & & & & & & & & & & & \\
\hline 39 & & $\begin{array}{l}\text { PCB COHTAHIHATED } \\
\text { HATER, FLUID }\end{array}$ & & & & & & 1 & & & & & & & & & & & & & & \\
\hline 40 & & $\begin{array}{l}\text { PCB IHORGAIHIC } \\
\text { SOLID DEBRIS }\end{array}$ & & & & & & 7 & & & & & & & & & & & & . & & \\
\hline 41 & & $\begin{array}{l}\text { PCB CAPACITORS, } \\
\text { BALLASTS }\end{array}$ & & & & & & 3 & & & & & & & & & & & & & & \\
\hline 42 & & $\begin{array}{l}\text { NOH-REGULATED } \\
\text { LIOUIDS }\end{array}$ & & & & & & 457 & & & & & & & & & & & & & & \\
\hline 43 & & $\begin{array}{l}\text { NOH-REGULATED } \\
\text { SOLIDS, HISC }\end{array}$ & & & & & & 15 & & & & & & & & & & & & & & \\
\hline 44 & & $\begin{array}{l}\text { TEAR GAS } \\
\text { EXTINGUISHERS }\end{array}$ & & & & & & 1 & & & & & & & & & & & & & & \\
\hline
\end{tabular}


EG\&G Rocky Flats, Inc.

Attachment 2, Page 10 of 12

\begin{tabular}{|c|c|c|c|c|c|c|c|c|c|c|c|c|c|c|c|c|c|c|c|c|}
\hline \multirow[t]{2}{*}{$\begin{array}{l}\text { ITEH } \\
\text { HO. }\end{array}$} & \multirow{2}{*}{ CODES EPA } & \multirow{2}{*}{$\begin{array}{l}\frac{\text { DISPOSAL OF }}{\text { LAB PACKS }} \\
\text { LA }\end{array}$} & \multicolumn{5}{|c|}{$\begin{array}{l}\text { NUMBER OF ORUMS } \\
\text { LAB PACKS }\end{array}$} & \multicolumn{5}{|c|}{$\begin{array}{c}\text { UWIT PRICE BY DRUM SIZE } \\
\text { LAB PACKS }\end{array}$} & \multicolumn{5}{|c|}{$\begin{array}{c}\text { EXTENDED PRICE BY DRUM SIZE } \\
\text { LAB PACKS }\end{array}$} & \multirow{2}{*}{$\begin{array}{l}\text { TOTAL PRICE } \\
\text { FOR ALL } \\
\text { DRUM SIZES }\end{array}$} & \multirow[t]{2}{*}{$\begin{array}{c}\text { TREATMENT / } \\
\text { DISPOSAL METHOD }\end{array}$} & \multirow{2}{*}{$\begin{array}{l}\text { TSD FACILITY } \\
\text { MAME AND } \\
\text { LOCATION }\end{array}$} \\
\hline & & & $\begin{array}{l}1-5 \\
\text { GAL. } \\
\text { DRUH }\end{array}$ & $\begin{array}{l}\text { 6-10 } \\
\text { GAL. } \\
\text { DRUH }\end{array}$ & $\begin{array}{l}11- \\
20 \\
\text { GAL. } \\
\text { DRUM }\end{array}$ & $\begin{array}{l}2 \mathrm{I}-30 \\
\text { GAL. } \\
\text { DRUA }\end{array}$ & $\begin{array}{l}31- \\
55 \\
\text { GAL. } \\
\text { DRUM }\end{array}$ & $\begin{array}{l}1-5 \\
\text { GAL. } \\
\text { DRUM }\end{array}$ & $\begin{array}{l}6-10 \\
\text { GAL. } \\
\text { DRUH }\end{array}$ & $\begin{array}{l}11-20 \\
\text { GAL. } \\
\text { DRUM }\end{array}$ & $\begin{array}{l}21-30 \\
\text { GAL. } \\
\text { DRUH }\end{array}$ & $\begin{array}{l}31-55 \\
\text { GAL. } \\
\text { DRUA }\end{array}$ & $\begin{array}{l}1-5 \\
\text { GAL. } \\
\text { ORUM }\end{array}$ & $\begin{array}{l}\text { 6-10 } \\
\text { GAL. } \\
\text { DRUM }\end{array}$ & $\begin{array}{l}11-20 \\
\text { GAL. } \\
\text { DRUM }\end{array}$ & $\begin{array}{l}21-30 \\
\text { GAL. } \\
\text { DRUA }\end{array}$ & $\begin{array}{l}31-55 \\
\text { GAL. } \\
\text { DRUM }\end{array}$ & & & \\
\hline 201 & 0001 & $\begin{array}{l}\text { MISC LAB PACKS, } \\
\text { EX CHEHS, LIQUID }\end{array}$ & & & & & 15 & & & & & & & & & & & & & \\
\hline 202 & D002 & $\begin{array}{l}\text { MISC LAB PACKS, } \\
\text { EX CHEHS, LIQUIO } \\
\end{array}$ & & & & & 4 & & & & & & & & & & & & & \\
\hline 203 & Ps \& Us* & $\begin{array}{l}\text { MISC LAB PACKS, } \\
\text { EX CHEHS, LIQUID }\end{array}$ & & & & & 2 & & & & & & & & & & & & & \\
\hline 204 & D004-D011* & $\begin{array}{l}\text { MISC LAB PACKS, } \\
\text { EX CHEHS, LIQUIO }\end{array}$ & & & & & 1 & & & & & & & & & & & & & \\
\hline 205 & $\begin{array}{l}\text { Do01. (F001. } \\
\text { F002. F003. } \\
\text { F005*) }\end{array}$ & $\begin{array}{l}\text { MISC LAB PACKS, } \\
\text { EX CHEHS. LIQUID }\end{array}$ & & & & & 2 & & & & & & & & & & & & & \\
\hline 206 & 0001,0002 & $\begin{array}{l}\text { MISC LAB PACKS, } \\
\text { EX CHEMS, LIOUID }\end{array}$ & & & & & 1 & & & & & & & & & & & & & \\
\hline 207 & $\begin{array}{l}\text { Do01, (0004- } \\
\text { D011, Fs, Ps, \& } \\
\text { Us*) }\end{array}$ & $\begin{array}{l}\text { MISC LAB PACKS, } \\
\text { EX CHEHS, LIQUID }\end{array}$ & & & & & 2 & & & & & & & & & & & & & \\
\hline 208 & $\begin{array}{l}\text { Fo01, F002, } \\
\text { F003, F005* }\end{array}$ & $\begin{array}{l}\text { MISC LAB PACKS, } \\
\text { EX CHEMS, LIQUID }\end{array}$ & & & & & 1 & & & & & & & & & & & & & \\
\hline 209 & $\begin{array}{l}0002,(0004- \\
\left.0011^{*}\right)\end{array}$ & $\begin{array}{l}\text { HISC LAB PACKS, } \\
\text { EX CHEHS, LIQUID }\end{array}$ & & & & & 1 & & & & & & & & & & & & & \\
\hline 210 & D001 & $\begin{array}{l}\text { MISC LAB PACKS. } \\
\text { EX CHEES, SOLID } \\
\end{array}$ & & & & & 2 & & & & & & & & & & & & & \\
\hline 211 & 0003 & $\begin{array}{l}\text { HISC LAB PACKS, } \\
\text { EX CHEHS, SOLID }\end{array}$ & & & & & 1 & & & & & & & & & & & & & \\
\hline
\end{tabular}

"Itens denoted with an asterisk are wastes that may contain any or all of the specifled waste codes.

thay or may not conta in D003.

PAGE TOTAL 
EG\&G Rocky Flats, Inc.

Attachment 2, Page 9 of 12

\begin{tabular}{|c|c|c|c|c|c|c|c|c|c|c|c|c|c|c|c|c|c|c|c|c|c|c|}
\hline \multirow{2}{*}{$\begin{array}{l}\text { meM } \\
\text { No. }\end{array}$} & \multirow[t]{2}{*}{$\begin{array}{l}\text { EPA } \\
\text { CODES }\end{array}$} & \multirow[t]{2}{*}{ DESCrAPION } & \multicolumn{6}{|c|}{ TOTNL WEXSHT OF MATERAL IN NOLOSPAMS } & \multicolumn{6}{|c|}{$\begin{array}{l}\text { DISPOSN PFICE PER WLOOORAM } \\
\text { IN SHIPPENT WEGAHT }\end{array}$} & \multicolumn{6}{|c|}{ EXTENDED TOTAL PAICE } & \multirow{2}{*}{$\begin{array}{l}\text { TREATMENTI } \\
\text { OISPOSNL } \\
\text { METHOO }\end{array}$} & \multirow{2}{*}{$\begin{array}{l}\text { TSD FACIUTY } \\
\text { MMMEANO } \\
\text { LOCATON }\end{array}$} \\
\hline & & & $\begin{array}{l}100 \\
\text { KO. }\end{array}$ & $\begin{array}{l}100.900 \\
\kappa Q .\end{array}$ & $\begin{array}{l}200 \\
209 \\
\text { Ka. }\end{array}$ & 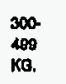 & $\begin{array}{l}500 . \\
1000 \\
\text { KG. }\end{array}$ & $\begin{array}{l}\text { OVEA } \\
\text { 1000 } \\
K Q .\end{array}$ & $\begin{array}{l}1 \oplus 0 \\
\text { KG. }\end{array}$ & $\begin{array}{l}100 . \\
100 \\
\mathrm{Ko} .\end{array}$ & $\begin{array}{l}200- \\
209 \\
k a .\end{array}$ & $\begin{array}{l}300 . \\
409 \\
\mathrm{~kg}\end{array}$ & $\begin{array}{l}800- \\
1000 \\
\mathrm{Ka} .\end{array}$ & $\begin{array}{l}\text { OVEA } \\
\text { 1000 } \\
\text { KG. }\end{array}$ & $\begin{array}{l}8.09 \\
k G .\end{array}$ & $\begin{array}{l}100 . \\
100 \\
k \times 0\end{array}$ & $\begin{array}{l}200- \\
280 \\
\text { Ko. }\end{array}$ & $\begin{array}{l}300 . \\
208 \\
k 8 .\end{array}$ & $\begin{array}{l}500 . \\
1000 \\
K G .\end{array}$ & $\begin{array}{l}\text { ONER } \\
\text { 1000 } \\
\text { KG. }\end{array}$ & & \\
\hline 48 & PCB & 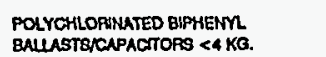 & & $100 \mathrm{~kg}$. & & & & & & & & & & & & & & & & & & \\
\hline so & PeB & 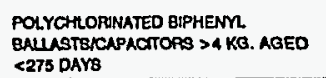 & & $100 \mathrm{~kg}$ & & & & & & & & & & & & & & & & & & \\
\hline 51 & PCA & 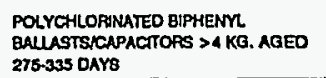 & & & & & & & & & & & & & & & & & & & & \\
\hline$\$ 2$ & PCB & 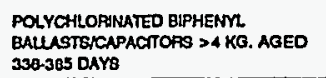 & & & & & & & & & & & & & & & & & & & & \\
\hline 33 & $\mathrm{PCO}$ & 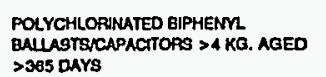 & & & & & & & & & & & & & & & & & & & & \\
\hline s4 & PCB & $\begin{array}{l}\text { DFWNEED PCB XFMER }<500 \text { PPM AGEO } \\
<275 \text { DAYS }\end{array}$ & & & & $300 \mathrm{~kg}$. & & & & & & & & & & & & & & & & \\
\hline ss & PCB & $\begin{array}{l}\text { DPWWNEO PCB XFHER \& } 300 \text { PPT AGED } \\
273-335 \text { DAYS }\end{array}$ & & & & & & & & & & & & & & & & & & & & \\
\hline 30 & $P C B$ & $\begin{array}{l}\text { DPQUNED PCB XFMEA <300 PPM AQED } \\
\text { 336.305 DAYS }\end{array}$ & & & & & & & & & & & & & & & & & & & ' & \\
\hline 87 & PCO & 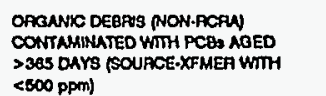 & & & & & & & & & & & & & & & & & & & & \\
\hline
\end{tabular}

*Items denoted with an asterisk are wastes that may contain any or all of the specified waste codes.

thay or may not contoin D003. 
$\therefore=y_{y}$

EG\&G Rocky Flats, Inc.

Attachment 2, Page 12 of 12

DISPOSAL OF LECTURE CTLINOERS

\begin{tabular}{|c|c|c|c|c|c|c|c|c|c|c|c|c|c|}
\hline \multirow{2}{*}{$\begin{array}{l}\text { חEM } \\
\text { No. }\end{array}$} & \multirow[t]{2}{*}{ DESCRIPTON } & \multicolumn{3}{|c|}{ OUNMTIY OF CYUNDERS } & \multicolumn{3}{|c|}{ UNIT PAACE OF } & \multicolumn{3}{|c|}{ TOTAL PFICE } & \multirow{2}{*}{$\begin{array}{l}\text { OVERULL } \\
\text { TOTAL PAICE } \\
\text { FOR } 3 \text { EIIIES }\end{array}$} & \multirow{2}{*}{$\begin{array}{l}\text { TREATMENTI } \\
\text { OLSPOSNL } \\
\text { METHOD }\end{array}$} & \multirow{2}{*}{$\begin{array}{l}\text { TSD FAGTUT } \\
\text { NANE AND } \\
\text { LOCATONON }\end{array}$} \\
\hline & & BMUL SZIE & MED. S1ZE & LAGE SITE & SMALL SIZE & MED. SIZE & UAAE BLZE & SMUL SIIE & MED. SIIE & LAFGE SIZE & & & \\
\hline 303 & FLAMMUBLESANONFUMMMBLLES - CDINDER & & & & & & & & & & & & \\
\hline 302 & POISONS - CYUNDER & & & & & & & & & & & & \\
\hline 303 & CORROSWES - CTUNOER & & & & & & & & & & & & \\
\hline 304 & FREOWS - CUUNDER & & & & & & & & & & & & \\
\hline 305 & SIUNESPPYAOPHOAKCS . CTUNDER & & & & & . & & & & & & & \\
\hline 300 & TOXOS - CYINDER & & & & & & & & & & & & \\
\hline 307 & OXOIZERS - CYUNDER & & & & & & & & & & & & \\
\hline 300 & ACETMENE - CYUNDER & & & & & & & & & & & & \\
\hline
\end{tabular}

NOTE: Pricing for lecture cylinders assumes that cyl fnder and valve are in good and working condition.

TOtAL PRICE YEAR 1 - (PAGES 3 - 13)

TOTAL PRICE - YEAR 2

inCLUDing

TOTAL PRICE - YEAR 3

JHCLUDIHG

TOTAL. PRICE - YEAR 4

IHCLUDING

TOIAL PRICE - YEAR 5

IHCLUDikg

$*$ ESCALATION*
$*$ ESCALATIOH*
$*$ ESCALATIOH*
$*$ ESCALATIOH*

*For year 2 through 5 , the quoted escalation percentage, if any, shall determine the total price as well as the price of individual items numbers 1 through 308 listed. The escalation percentage, if any, for each year shall be applied to the prior year's price to calculate the price for each year. 
EG\&G Rocky Flats, Inc.

Attachment 2, Page 11 of 12

\begin{tabular}{|c|c|c|c|c|c|c|c|c|c|c|c|c|c|c|c|c|c|c|c|c|}
\hline \multirow{2}{*}{$\begin{array}{l}\text { ITEM } \\
\text { NO. }\end{array}$} & \multirow{2}{*}{ CODES EPA } & \multirow{2}{*}{$\begin{array}{l}\text { QISPOSAL OF } \\
\text { LAB PACKS }\end{array}$} & \multicolumn{5}{|c|}{$\begin{array}{l}\text { NUMBER OF DRUHS } \\
\text { LAB PACKS }\end{array}$} & \multicolumn{5}{|c|}{$\begin{array}{l}\text { UNIT PRICE BY DRUH SIZE } \\
\text { LAB PACKS }\end{array}$} & \multicolumn{5}{|c|}{$\begin{array}{c}\text { EXTENDED PRICE BY DRUM SIZE } \\
\text { LAB PACKS }\end{array}$} & \multirow{2}{*}{$\begin{array}{l}\text { TOTAL PRICE } \\
\text { FOR ALL } \\
\text { ORUM SIZES } \\
\end{array}$} & \multirow[t]{2}{*}{$\begin{array}{c}\text { TREATMENT / } \\
\text { DISPOSAL METHOD }\end{array}$} & \multirow{2}{*}{$\begin{array}{l}\text { TSD FACILITY } \\
\text { NAME AND } \\
\text { LOCATION } \\
\end{array}$} \\
\hline & & & $\begin{array}{l}1-5 \\
\text { GAL. } \\
\text { DRUM }\end{array}$ & $\begin{array}{l}6-10 \\
\text { GAL. } \\
\text { DRUH }\end{array}$ & $\begin{array}{l}11- \\
20 \\
\text { GAL. } \\
\text { ORUM } \\
\end{array}$ & $\begin{array}{l}21-30 \\
\text { GAL. } \\
\text { DRUM }\end{array}$ & $\begin{array}{l}31- \\
55 \\
\text { GAL. } \\
\text { DRUH } \\
\end{array}$ & $\begin{array}{l}1-5 \\
\text { GAL. } \\
\text { DRUH }\end{array}$ & $\begin{array}{l}6-10 \\
\text { GAL. } \\
\text { DRUH }\end{array}$ & $\begin{array}{l}11-20 \\
\text { GAL. } \\
\text { DRUM }\end{array}$ & $\begin{array}{l}21-30 \\
\text { GAL. } \\
\text { DRUM }\end{array}$ & $\begin{array}{l}31-55 \\
\text { GAL. } \\
\text { DRUH }\end{array}$ & $\begin{array}{l}\text { I-5 } \\
\text { GAL. } \\
\text { DRUM }\end{array}$ & $\begin{array}{l}6-10 \\
\text { GAL. } \\
\text { DRUM }\end{array}$ & $\begin{array}{l}11-20 \\
\text { GAL. } \\
\text { DRUH }\end{array}$ & $\begin{array}{l}21-30 \\
\text { GAL. } \\
\text { DRUY }\end{array}$ & $\begin{array}{l}31-55 \\
\text { GAL. } \\
\text { ORUM }\end{array}$ & & & \\
\hline 212 & $0004-0011^{*}$ & $\begin{array}{l}\text { MISC LAB PACKS, } \\
\text { EX CHEMS, SOLID } \\
\end{array}$ & & & & & 1 & & & & & & & & & & & & & \\
\hline 213 & $\begin{array}{l}0001 .(0004- \\
0011 . \text { Ps \& Us*) }\end{array}$ & $\begin{array}{l}\text { HISC LAB PACKS, } \\
\text { EX CHEMS, SOLID } \\
\end{array}$ & & & & & 1 & & & & & & & & & & & & & \\
\hline 214 & 0004-D011, Fs* & $\begin{array}{l}\text { MISC LAB PACKS, } \\
\text { EX CHEHS. SOLID } \\
\end{array}$ & & & & & 1 & & & & & & & & & & & & & \\
\hline 215 & Ps \& Us* & $\begin{array}{l}\text { MISC LAB PACKS, } \\
\text { EX CHEHS, SOLIO } \\
\end{array}$ & & & & & 1 & & & & & & & & & & & & & \\
\hline 216 & 0001 & $\begin{array}{l}\text { AEROSOL CANS. } \\
\text { FLAMMABLE }\end{array}$ & & & & & 2 & & & & & & & & & & & & & \\
\hline 217 & $\begin{array}{l}\mathrm{F} 001, \mathrm{FOO2}, \\
\mathrm{F}^{0} 05^{\star}\end{array}$ & $\begin{array}{l}\text { AEROSOL CANS, } \\
\text { SOLVEHTS } \\
\end{array}$ & & & & & 2 & & & & & & & & & & & & & \\
\hline 218 & 0001 & ALUMINUM MITRATE & & & & & 4 & & & & & & & & & & & & & \\
\hline 219 & vo80 & $\begin{array}{l}\text { METHYLENE } \\
\text { CHLORIDE }\end{array}$ & & & & & 1 & & & & & & & & & & & & & \\
\hline 220 & 0002 & GLOBRITE 405 & & & & & 1 & & & & & & & & & & & & & \\
\hline
\end{tabular}




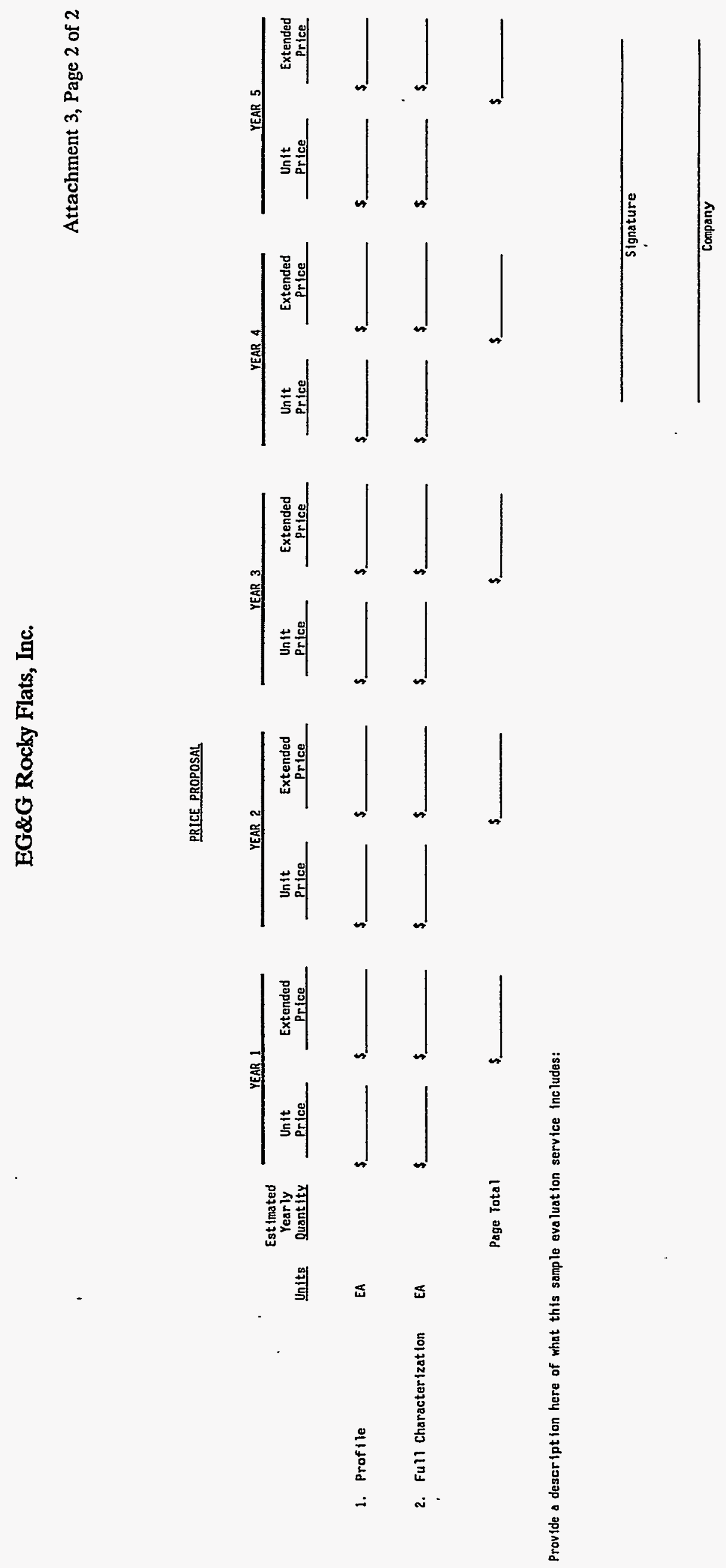




\section{EG\&G Rocky Flats, Inc.}

\section{ATTACHMENT 3 - SAMPLE EVALUATION}

\section{SCOPE OF WORK AND PRICE PROPOSAL}

\section{SCOPE OF WORK}

The Subcontractor may be required to provide sample evaluation for the purpose of preshipment verification of hazardous waste. The evaluation process shall include all tasks necessary to provide approval or denial for waste streams up to and including some characterizations.

The Subcontractor may be required to provide trained personnel to perform sampling operations work at the Rocky Flats Plant (RFP). The Subcontractor shall travel to EG\&G RF and properly sample and package for transport to an EPA approved lab for analysis.

The Subcontractor, on a normal basis, shall evaluate waste streams for approval or denial within 45 calendar days of receipt from EG\&G RF of the profile data and representative sample.

In the case of an emergency or compliance issue the subcontractor shall evaluate waste streams for approval or denial within 7 calendar days of receipt of the waste stream data sheet (and waste stream sample) from EG\&G Rocky Flats, Inc.

If and when this service is requested, the attached unit prices shall apply. The quantities and waste streams shown are estimated annual requirements and are in no way guaranteed or implied.

\section{INSTRUCTIONS FOR COMPLETING ATTACHED PRICE PROPOSAL}

Comply with Attachment O, Pricing Requirements, of this Request for Proposal. 
4. Subcontractor shall follow all EG\&G RF Integrated Work Coritrol Packages rules and instructions while at the facilities.

5. The Subcontractor shall provide EG\&G with any special requirements of individual waste disposal sites and/or lab pack wastes. The Subcontractor shall ensure that drums are labeled as required by RCRA and DOT regulations. Subcontractor shall be responsible for citations and fines levied due to its negligence in packaging, labeling, and marking, etc.

6. The packing operations shall be conducted in a manner which minimizes the possibility of container breakage or spills. In case of container breakage or spills by the Subcontractor, the Subcontractor is responsible for the costs incurred by EG\&G RF for clean up and disposal of waste generated. In addition, if any leaks, spills, fires, explosions, or other undesirable effects of a chemical release results from the activities of the Subcontractor, the Subcontractor is responsible for remediation costs incurred by EG\&G RF.

7. If PCB wastes are involved, the Subcontractor shall handle, pack, and/or label the wastes as required by TSCA, RCRA, and applicable state and local regulations. The Subcontractor shall ensure that the EG\&G RF receives a Certificate of Destruction for the PCB wastes within specified time limits in TSCA regulations.

8. The Subcontractor shall assist EG\&G RF, if requested, with the handling and loading of drums of waste.

\section{Self Lab Pack Operations:}

1. The Subcontractor shall be required to accept for disposal drums which are lab packed by EG\&G RF with off-site direction provided by the Subcontractor. The Subcontractor shall determine and provide prior acceptance approval for each lab pack item based on generator waste characterizations and MSDSs, if appropriate, provided by EG\&G RF.

2. The Subcontractor shall provide packing lists and a list of shipping names to EG\&G RF within 21 calendar days of receipt of the generator waste characterizations and MSDSs, if appropriate. The Subcontractor shall not include on the packing lists lab pack items that it does not approve. EG\&G RF shall pack and manifest each lab pack drum by following the provided packing lists and shipping names.

3. All of the other requirements listed in this Attachment 4 shall also apply to the Subcontractor for self lab pack operations. 


\section{ATTACHMENT 4 - LAB PACK}

\section{SCOPE OF WORK AND PRICE PROPOSAL}

\section{SCOPE OF WORK}

The Subcontractor may be required to provide trained personnel to perform lab pack work at EG\&G RF. The Subcontractor shall travel to EG\&G RF to properly classify and package, for transport to a disposal facility, excess laboratory chemicals, lecture cylinders, and process waste as identified in Attachment 2. The Subcontractor shall set up classification and packaging stations at various locations throughout EG\&G RF. Subcontractor may be required to perform Lab Packing services at EG\&G RF facilities at Oxnard, CA and Rocky Flats Plant, Denver, and Broomfield, CO. Lab packs are priced in Attachment 2.

The Subcontractor shall provide lab packing services on both a scheduled and emergency basis. The Subcontractor may be required to provide lab pack personnel within 20 calendar days of EG\&G RF's request and, for emergencies, within 7 calendar days of request.

Subcontractor personnel shall provide all technical expertise for the lab packing, categorization of waste streams, packing material and preparation of documents necessary for shipping.

The Subcontractor shall collect costs separately for work at each lab pack location, and provide separate line items on invoices.

\section{Lab Pack Operations:}

1. Approval, packing and transportation shall be completed by the Subcontractor within 65 days of EG\&G RF initial request for service.

2. The Subcontractor shall give prior acceptance approval for each waste stream based on generator waste characterizations and MSDSs, if appropriate, provided by EG\&G RF. Subcontractor shall not have the option of rejecting any contents of any drums that are packed in accordance with the packing list approved by the Subcontractor. The Subcontractor shall reimburse EG\&G RF for any costs incurred as a result of Subcontractor rejection of waste that it has approved for shipment.

3. Subcontractor shall base the packing lists on the compatibility of the wastes and not on drum size. However, drum size may be as large as 85 -gallons. Subcontractor shall not have the option to limit drum sizes. 
EG\&G Rocky Flats, Inc.

\section{Additional Requirements:}

The Subcontractor will be reimbursed for meals and lodging while in travel status in accordance with FAR 31.205-46 or Contractor waivers thereof approved prior to travel. (Copies of FAR 31-205-46 and Waivers are available on request.) For the purposes of this agreement, daily meal and lodging reimbursements will be made as follows:

$\begin{array}{lcc} & \text { Meals } & \text { Lodging } \\ \text { Denver, CO } & \$ 34.00 & \$ 74.00 \\ \text { Golden, CO } & \$ 34.00 & \$ 74.00 \\ \text { Oxnard, CA } & \$ 34.00 & \$ 100.00 \\ \text { Broomfield, CO } & \$ 34.00 & \$ 61.00\end{array}$

Miscellaneous matèrials used in providing lab pack services will be reimbursed at actual expenses.

Labor costs will be computed by multiplying the appropriate hourly rate quoted in Attachment 4 by the number of direct labor hours actually expended at the work site in performance of the work scope. Billable labor hours shall begin when Subcontractor personnel arrive at EG\&G RF facilities and end upon departure, excluding 1/2 hour for lunch. Invoices must not include travel time, including travel to and from the EG\&G RF facilities.

All labor will be performed based on five eight-hour days, unless otherwise requested by EG\&G RF.

Subcontractor personnel shall comply with Environmental, Safety and Health Requirements for Subcontractors (Enclosure 8, Draft - Rocky Flats Plant Health \& Safety Plan and Enclosure 11, EG\&G Rocky Flats-Oxnard Facility General Safety \& Security Rules for Contractors \& Subcontractors) while located at EG\&G RF facilities. Personnel shall not eat, drink, smoke, or chew gum or tobacco in the work areas.

All Subcontractor personnel that work at EG\&G RF locations shall be required to be U.S. citizens.

If and when this service is requested, the attached unit prices shall apply. The attached list shows estimated annual quantities of services the Subcontractor may be required to provide. The quantities are in no way guaranteed or implied.

INSTRUCTIONS FOR COMPLETING ATTACHED PRICE PROPOSAL:

Comply with Attachment O, Pricing Requirements, of this Request for Proposal. 


\section{EG\&G Rocky Flats, Inc.}

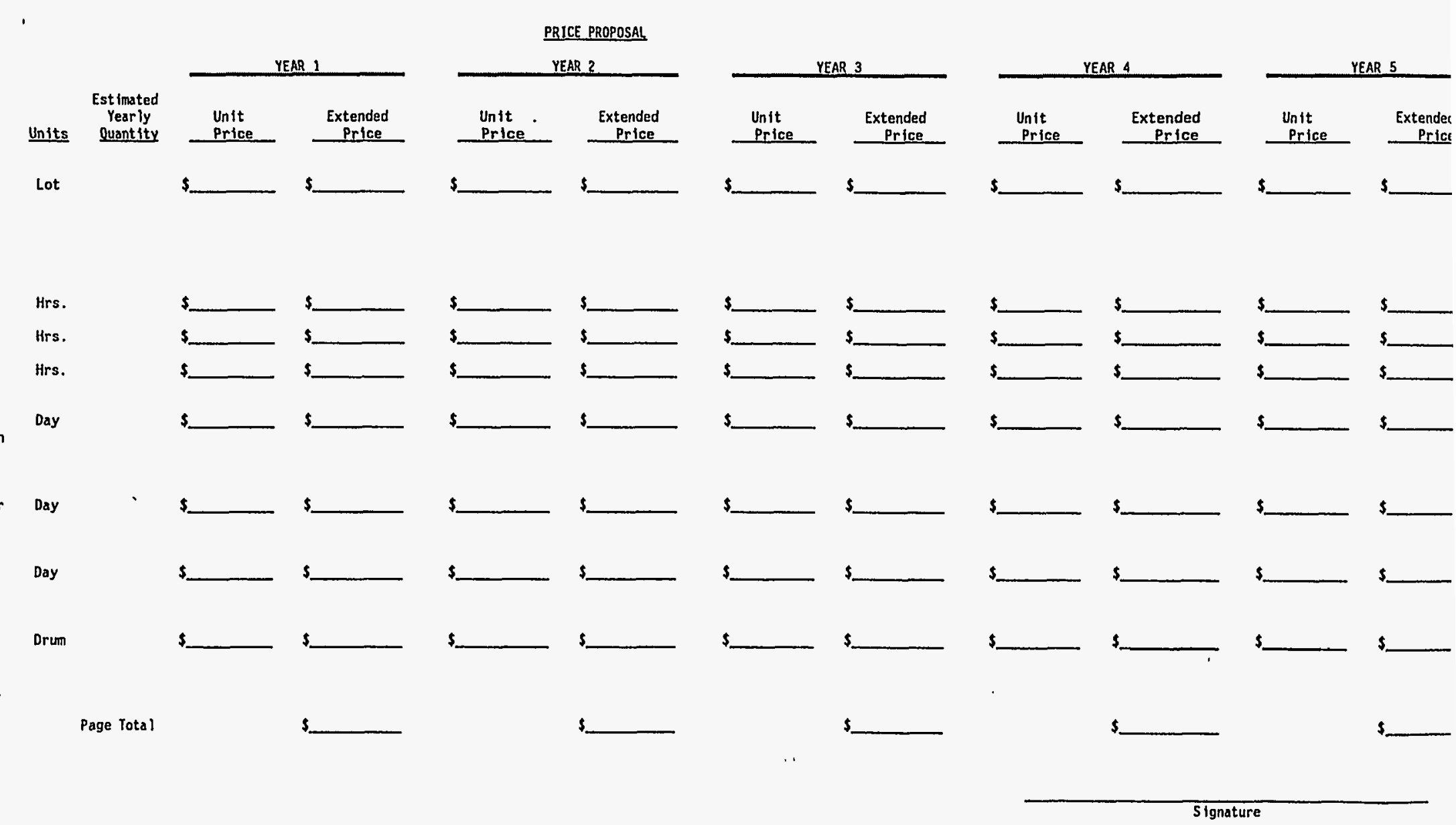




\section{PRICE PROPOSAL}

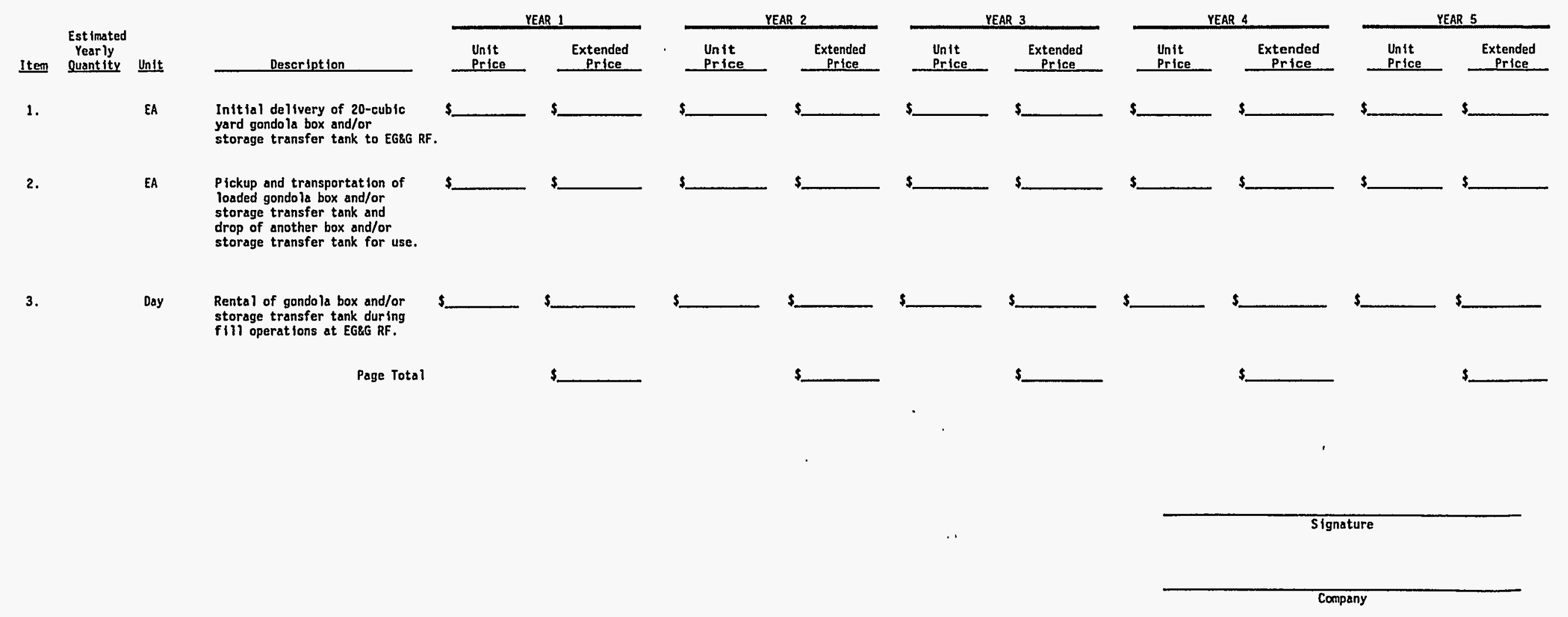


EG\&G Rocky Flats, Inc.

Attachment 5, Page 1 of 2

\section{ATTACHMENT 5 - GONDOLA BOXES/AND OR STORAGE TRANSFER TANKS}

SCOPE OF WORK AND PRICE PROPOSAL

\section{SCOPE OF WORK}

The Subcontractor may be required to provide gondola boxes, tote tanks, or other containers to facilitate the acumulation and disposal of bulk wastes from EG\&G RF facilities. After the intitial delivery of the box(s), tank(s), or other bulk accumulation container(s) to the facility, the Subcontractor, upon request, shall pick up the container full of hazardous waste to be shipped and replace it with an equivalent empty container, or shall pump or otherwise pickup the contents of the full container.

\section{INSTRUCTIONS FOR COMPLETING ATTACHED PRICE PROPOSAL:}

Comply with Attachment $\mathrm{O}$, Pricing Requirements, of this Request for Proposal. 


\section{ATTACHMENT O}

\section{PRICING REQUIREMENTS APPLICABLE TO ALL EG\&G M\&O PRICE PROPOSAL ATTACHMENTS}

1. The pricing quoted by the offeror in Attachments 2, 3, 4, 5, 7, 8, 9, 10,12,13,14, 15, 17, 18, 19, 20, 22, 23, 24, and 25, shall be valid until subcontract awards (anticipated by August 2, 1993. Upon awards, the successful Subcontractors prices quoted shall remain fixed for the term of the subcontract.

2. Quantities and waste streams shown in Attachments 2, 3, 4, 5, 7, 8, 9, 10,12,13,14,15,17, 18, 19, 20, 22, 23, 24, and 25 are estimated annual requirements. EG\&G M\&O's assume no liability if the actual requirements under the Subcontract do not equal or are grossly disproportionate to the estimates set forth herein. The Subcontractor will not be entitled to any equitable adjustment or additional compensation if the actual quantities do not meet the estimates. EG\&G M\&O's are only obligated to order their actual requirements within the scope of the Subcontract.

There is no guarantee that the quantity of waste or the number of Task Orders issued will be substantialiy equal between Subcontractors. Furthermore, EG\&G M\&O's assume no liability for any degree of variation in quantity. The estimates shown herein are based on data provided by each EG\&G M\&O. The Subcontractor assumes all risk in relying on the quantity estimates to set proposal prices.

Payment to the Subcontractor shall be made for actual quantities based on the firm-fixed unit prices provided by the Subcontractor in Attachments $2,3,4,5,7,8,9,10,12,13,14$, $15,17,18,19,20,22,23,24$, and 25 .

3. The firm-fixed unit prices provided by the offerors in Attachments $2,3,4,5,7,8,9,10,12,13,14,15,17,18,19,20,22,23,24$, and 25 shall include offerors responsibility for al testing and documentation required beyond EG\&G M\&O's responsibilities. EG\&G M\&O's responsibilities include: 1) EG\&G M\&O's shall provide profile data for each waste stream according to regulatory requirements specified by $40 \mathrm{CFR} 262.11,40 \mathrm{CFR} 264.13$, and/or $40 \mathrm{CFR} 265.13$, as applicable, and 2) EG\&G M\&O's shall make payment to the Subcontractor for sample analysis according to Attachments $3,8,13,18$, and 23.

4. The prices quoted by the successful Subcontractor in Attachments 2,7,12, 17, and 22 shall apply to the specified disposal methods for each waste stream, unless a regulatory change requires a change in the disposal method specified in Attachments $2,7,12,17$, and 22 . In that event, pricing will be negotiated by the EG\&G M\&O.

5. The prices quoted by the offerors in Attachments $2,3,4,5,7,8,9,10,12,13,14,15,17,18,19,20,22,23,24$, and 25 shall be inclusive of all applicable taxes and all transportation/freight costs. 
c. Resource Conservation and Recovery Act (RCRA)

d. Superfund Amendments and Reauthorization Act (SARA)

e. Comprehensive Environmental Response, Compensation, and Liability Act (CERCLA)

f. Toxic Substance Control Act (TSCA),

g. Occupational, Safety and Health Act (OSHA), particularly 29 CFR $\$ 1910.120$ (Hazardous Waste Operations and Emergency Response) and 1910.1000 (Hazard Communications) and/or Mine Safety and Health Act (MSHA)

h. Hazardous Materials Transportation Act (HMTA)

i. State and local environmental, safety and health regulations and statutes enacted in the state of residence of each Subcontractor facility doing business.

7. The Subcontractor shall provide EG\&G Idaho, within 20 days of violation notice, any and all DOT, environmental, OSHA, and governmental agency Notices of Violation received by all the facilities involved in providing services under this subcontract. In addition, this requirement shall apply through final disposition to all facilities to which waste is subcontracted.

8. The Subcontractor shall provide, upon request, all required environmental permits and authorizations including, but not limited to, the following:

a. Air quality permits

b. Water discharge permits, e.g., National Pollutant Discharge Elimination System (NPDES)

c. RCRA Part A and/or Part B permits (or applications, if the permits have not yet been approved)

d. Authority to accept CERCLA remediation wastes

e. Authority to accept TSCA wastes, and

f. Other permits required by state or local agencies.

Except as otherwise directed by EG\&G Idaho, the successful Subcontractor shall provide evidence of all necessary permits, authorizations, or licenses. The successful Subcontractor shall provide copies of permit amendments within 20 days of amendment receipt. The Subcontractor shall abide by all applicable laws, regulations, and ordinances of the United States and the state and political subdivision where the work shall be performed. 
EG\&G Idaho, Inc.

Attachment 21, Page 1 of 3

\section{ATTACHMENT 21}

HAZARDOUS WASTE TREATMENTIDISPOSAL

SCOPE OF WORK

1. EG\&G Idaho, Inc. (EG\&G Idaho), a prime M\&O contractor for the U. S. Department of Energy (DOE-ID), is seeking a firm to provide hazardous waste transportation, treatment and disposal services to the Idaho National Engineering Laboratory (INEL). The Subcontractor shall provide the services described in Attachments 21 through 25.

Attachment 22 lists RCRA solid and hazardous and TSCA regulated waste streams currently generated by INEL operations. EG\&G Idaho reserves its right to determine the quantity, if any, of each waste stream listed in Attachment 22 that shall be included in this subcontract. Additional waste streams may be added subject only to Subcontractor's permits and licenses and negotiation of unit pricing for each added waste stream. Pricing of added waste streams shall be comparable to the pricing for similar waste streams listed in Attachment 22 .

The Subcontractor shall treat and/or dispose of at least $50 \%$ of the annual waste shipments at their own facilities unless granted prior written approval on a case-by-case basis from EG\&G Idaho to subcontract more than $50 \%$ of the total waste volume. The total number of facilities utilized under this subcontract shall not exceed ten unless approved by EG\&G Idaho prior to disposal. If more than one company is involved in the work performance, only one firm shall act as the Subcontractor. The Subcontractor shall obtain separate written approvals from EG\&G ldaho for each firm to which it desires to subcontract or dispose any portion of this subcontract, prior to involving each firm in work performance.

3. The Subcontractor shall be responsible for administering all of the transactions of the subcontract, including invoicing, and to interact solely with EG\&G Idaho. EG\&G Idaho will pay invoices from only the Subcontractor.

4. All materials submitted to the Subcontractor shall be completely treated, stored and disposed of within the continental United States.

5. The Subcontractor shall be responsible for the cost of all testing and documentation required beyond EG\&G Idaho's responsibillties which shall be: 1) EG\&G Idaho shall provide profile data for each waste stream acoording to the regulatory requirements specified by 40 CFR 262.11, 40 CFR 264.13, and/or 40 CFR 265.13, as applicable, and 2) EG\&G Idaho shall make payment to the Subcontractor for sample analysis according to Attachment 23. The testing and documentation referenced in this requirement shall include present and future regulatory and Subcontractor requirements for testing and documentation.

6. Disposal of any materials residual to the waste treatment/disposal process shall be in accordance with all applicable environmental, safety, and health statutes and regulations. The Subcontractor shall conduct operations in an environmentally safe and sound manner and in compliance with the applicable environmental, safety, and health statutes, regulations, and standards. Specifically, these include, but are not limited to, amended regulatory requirements promulgated under the:

a. Clean Water Act (CWA)

b. Clean Air Act (CAA) 
9. The Subcontractor shall provide documentation by which the required hazardous waste transportation, treatment and disposal services shall be performed. The documentation shall include, but not be limited to, the following:

a. Regulation compliance procedures

b. Method of accountability reporting for waste streams including applicable certificates; e.g., certificates of destruction and disposal, EPA biennial reports and state annual reports.

c. A tracking method describing how the waste streams will be accounted for from the point of acceptance to the point of final disposition. Waste streams may be shipped by the Subcontractor, or may be shipped by a common carrier approved by EG\&G Idaho.

d. The packaging and transportation of material qualifying as hazardous material under 49 CFR must be in accordance with 49 CFR Parts 100 through 177 and 383 through 399. EG\&G Idaho retains the right to audit functions and files pertaining to packaging and transportation.

10. The Subcontractor shall supply certificates of destruction/disposal for each waste stream manifested to their TSDF by their company to another company within 30 days of

destruction/disposal. The certificates of destruction/disposal shall include: the manifest number; facility waste acceptance approval number relating to the waste stream that was disposed of (for subcontracted items, these numbers shall be provided for each facility until final disposition); the EPA waste codes for the waste stream; the weight/volume of the waste stream destroyed/disposed of; the name, owner and address of the disposal facility; and the signature of a responsible company official.

11. The Subcontractor shall maintain the appropriate insurance policies and coverages as specified by federal, state, and local regulations and provide evidence thereof.

12. Transfer of hazardous waste title and responsibility to the Subcontractor follows subcontract award and inventory transfer. This includes, but is not limited to, the responsibilities associated with environmental regulations. This transfer of title and responsibility will be handled in a manner acceptable to standard industry and government practices and policies.

13. EG\&G Idaho and/or its designee shall have the right to inspect the facilities, records, and operations of the Subcontractor and lower-tier Subcontractors. These inspections shall be conducted at such time and in such manner as deemed appropriate by all involved parties. 


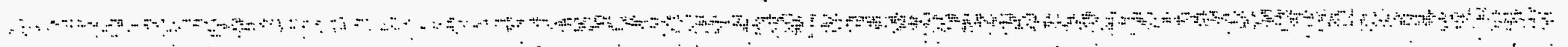

EG\&G Idaho, Inc.

Attachment 22, Page 2 of 39

The Subcontractor shall provide transportation service within seven calendar days of request by EG\&G Idaho.

Shipments shall be F.O.B. origin. Transfer of title for each shipment shall occur when the loaded transporter vehicle leaves the INEL facilities. The Subcontractor shall be responsible for compliance with environmental, safety and health regulations for each shipment starting at the time of vehicle loading.

The Subcontractor will coordinate with EG\&G Idaho Traffic Management. The Subcontractor shall acquire the necessary permits.

If and when this service is requested, the attached unit prices shall apply. The quantities and waste streams shown are estimated annual requirements and are in no way guaranteed or implied. INSTRUCTIONS FOR COMPLETING ATTACHED PRICE PROPOSAL:

Quote unit prices in all three columns of drum sizes for every waste stream, even if zero quantity is listed for any waste stream.

Comply with Attachment O., Pricing Requirements, of this Request for Proposal. 


\section{EG\&G Idaho, Inc.}

\section{SCOPE OF WORK}

The Subcontractor shall provide treatment and disposal services for the RCRA solid and hazardous wastes, TSCA wastes, and CERCLA remediation wastes generated by the INEL. Following is a list of waste streams currently generated by the INEL. The Subcontractor shall accept wastes "as is" with no pre-treatment necessary by EG\&G Idaho, e.g., solidification. The Subcontractor shall be required to accept waste packed or overpacked in 2 through 90 -gallon drums, as well as bulk shipments. EG\&G Idaho will drain all free flowing PCB liquids from each transformer prior to shipment. It is anticipated that one shipment of waste will be made to the Subcontractor every 20 to 90 days, although this is not guaranteed or implied. EG\&G Idaho is presently assigned the following EPA identification numbers: INEL-ID 4890008952, U.S. DOE - INEL Research Center-ID6890190089, and U.S. DOE INEL Willow Creek BIdg.-ID9890000103.

The Subcontractor shall meet or exceed the Land Disposal Restriction (LDR) treatment standards found in 40 CFR 268, and shall minimize the waste volume. The Subcontractor or its subcontractors may be required to accept, for treatment and/or disposal, CERCLA wastes generated from sites undergoing remediation. The permitted facility shall accept the CERCLA remediation wastes arriving without an EPA waste code number and shall comply with the most current CERCLA Off-Site Policy.

If a waste stream is approved for multiple waste codes, the Subcontractor shall be required to accept documentation from EG\&G which specifies only the waste codes that apply to each shipment of the waste stream. The Subcontractor shall allow EG\&G, with prior Subcontractor approval, to add new chemicals to each approved waste stream if the contents and treatment are compatible.

If and when this service is requested, the attached unit prices shall apply. The quantities and waste streams shown are estimated annual requirements and are in no way guaranteed or implied. Additional waste streams may be added subject only to facility permits and licenses and negotiation of unit pricing for each added waste stream. Pricing of added waste streams, including wastes having a "K" EPA waste code, shall be comparable to the pricing for similar waste streams included in the following list.

\section{TRANSPORTATION}

The Subcontractor shall be responsible for transportation from the INEL and locations in Idaho Falls, Idaho to their disposal site or other disposal areas as necessary to provide for proper handling of all hazardous wastes. The INEL is located 50 miles west of Idaho Falls, Idaho. The Subcontractor shall provide trucks which must be capable of hauling in one load a minimum of 85 drums that are 55-gallon size. 


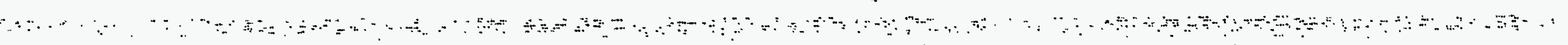

EGRG IDAHO, INC.

Atactiment 22, Page 40130

\begin{tabular}{|c|c|c|c|c|c|c|c|c|c|c|c|c|c|c|c|c|c|c|c|c|c|c|}
\hline \multirow{2}{*}{$\begin{array}{l}\text { ITEM } \\
\text { NO. }\end{array}$} & \multirow{2}{*}{$\begin{array}{l}\text { EPA } \\
\text { COOES }\end{array}$} & \multirow[t]{2}{*}{ DESCRIPTION } & \multicolumn{6}{|c|}{ NUMBER OF DRUMS } & \multicolumn{6}{|c|}{ DISPOSAL UNIT PRICE BY DRUM SIZE } & \multicolumn{6}{|c|}{ EXTENDED TOTAL PRICE } & \multirow{2}{*}{$\begin{array}{c}\text { TREATHEETI/ } \\
\text { DISPSOSAL } \\
\text { METHOO }\end{array}$} & \multirow{2}{*}{$\begin{array}{l}\text { TSO FACILITY } \\
\text { NAME ANO } \\
\text { LOCATIOH }\end{array}$} \\
\hline & & & $\begin{array}{l}1-5 \\
\text { GAL. } \\
\text { ORUM }\end{array}$ & $\begin{array}{l}6-10 \\
\text { GAL. } \\
\text { DRUK }\end{array}$ & $\begin{array}{l}11-15 \\
\text { GAL } \\
\text { DRUH }\end{array}$ & $\begin{array}{l}20 \\
\text { GALL } \\
\text { DRUM }\end{array}$ & $\begin{array}{l}30 \\
\text { GRL. } \\
\text { DRUM }\end{array}$ & $\begin{array}{l}55 \\
\text { GAL } \\
\text { DRUM }\end{array}$ & $\begin{array}{l}1-5 \\
\text { GAL } \\
\text { DRUM }\end{array}$ & $\begin{array}{l}6-10 \\
\text { GAL. } \\
\text { DRUM }\end{array}$ & $\begin{array}{l}11-15 \\
\text { GALL } \\
\text { ORUM }\end{array}$ & $\begin{array}{l}20 \\
\text { GAL. } \\
\text { DRUM }\end{array}$ & $\begin{array}{l}30 \\
\text { GAL } \\
\text { DRUM }\end{array}$ & $\begin{array}{l}55 \\
\text { GAL. } \\
\text { DRUM }\end{array}$ & $\begin{array}{l}1-5 \\
\text { GAL. } \\
\text { DRUH }\end{array}$ & $\begin{array}{l}\text { 6-10 } \\
\text { GAL. } \\
\text { ORUM }\end{array}$ & $\begin{array}{l}11-15 \\
\text { GAL } \\
\text { ORUM }\end{array}$ & $\begin{array}{l}20 \\
\text { GAL: } \\
\text { DRUM }\end{array}$ & $\begin{array}{l}30 \\
\text { GALL } \\
\text { DRUM }\end{array}$ & $\begin{array}{l}55 \\
\text { GRL. } \\
\text { DRUM }\end{array}$ & & \\
\hline 1 & $\begin{array}{l}\text { Do05-D008*, } \\
010=0011^{*}\end{array}$ & $\begin{array}{l}\text { MEUTRAL SOLIDS } \\
\text { HITH D HETALS }\end{array}$ & & & & & & 7 & & & & & & & & & & & & & & \\
\hline 2 & & CORROSIVE SOLIDS & & & & & & 9 & & & & & & & & & & & & & & \\
\hline 3 & $\begin{array}{l}\text { D002, (0004- } \\
0011)^{*}\end{array}$ & $\begin{array}{l}\text { ACID LIOUIDS UITH } \\
\text { D MERALS (WEEK } \\
\text { ACIO SOLUYIONS) }\end{array}$ & & & & & & 19 & & & & & & & & & & & & & & \\
\hline 4 & $\begin{array}{l}\text { D002, } 0005, \\
\text { Do07,0008, } \\
0010,0011)^{*} \\
0\end{array}$ & $\begin{array}{l}\text { ACID LAQUiDS HITH } \\
\text { D METALS (UEAK } \\
\text { ACID SOLUTIOWS) } \\
\end{array}$ & & & & & & 3 & & & & & & & & & & & & & & \\
\hline 5 & $\begin{array}{l}0002, \\
(0005-0008 \\
0010,0011)^{*}\end{array}$ & $\begin{array}{l}\text { ACID LIOUIDS UITH } \\
\text { D MEEALS (WEAK } \\
\text { ACID SOLUTIOHS) }\end{array}$ & & & & & & 24 & & & & & & & & & & & & & & \\
\hline 6 & $\begin{array}{l}0002, \\
(0004-0008, \\
0010,0011)^{*}\end{array}$ & $\begin{array}{l}\text { ACID LLOUIDS WITH } \\
\text { D METALS (WEAK } \\
\text { ACID SOLUTIOHS) }\end{array}$ & & & & & & 8 & & & & & & & & & & & & & & \\
\hline 7 & $\begin{array}{l}0002, \\
(0005-0011)^{*}\end{array}$ & $\begin{array}{l}\text { ACID LLOUIDS UITH } \\
\text { D METALS (LEAK } \\
\text { ACID SOLUTIOHS) } \\
\end{array}$ & & & & & & 9 & & & & & & & & & & & & & & \\
\hline 8 & $(0004-0011)^{*}$ & $\begin{array}{l}\text { MEUTRAL LIOUIDS } \\
\text { WITH D METALS } \\
\text { (LIOUIDS AND } \\
\text { SLOUGES) }\end{array}$ & & & & & & 1 & & & & & & & & & & & & & & \\
\hline
\end{tabular}

"Items denoted with an asterisk are wastes that may contain any or all of the specified waste codes.

+ Hay or may not contain Dooz. 
EG\&G Idaho, Inc.

Attachment 22, Page 3 of 39

SPECIAL INSTRUCTIONS FOR COMPLETING ATTACHMENT $22-25$

Due to the limited apace available on the forms, we request that you use a code to identify the "Treatment / Disposal Method" and the "TSD Facility Name and Location". The "Treatment / Disposal Method" code will use the letters A through J. The "TSD Facility name and Location" code wilT use the numbers 1 through 15: Please enter the Treatment / disposal methods and the TSD Facility Name and Location in the spaces provided below.

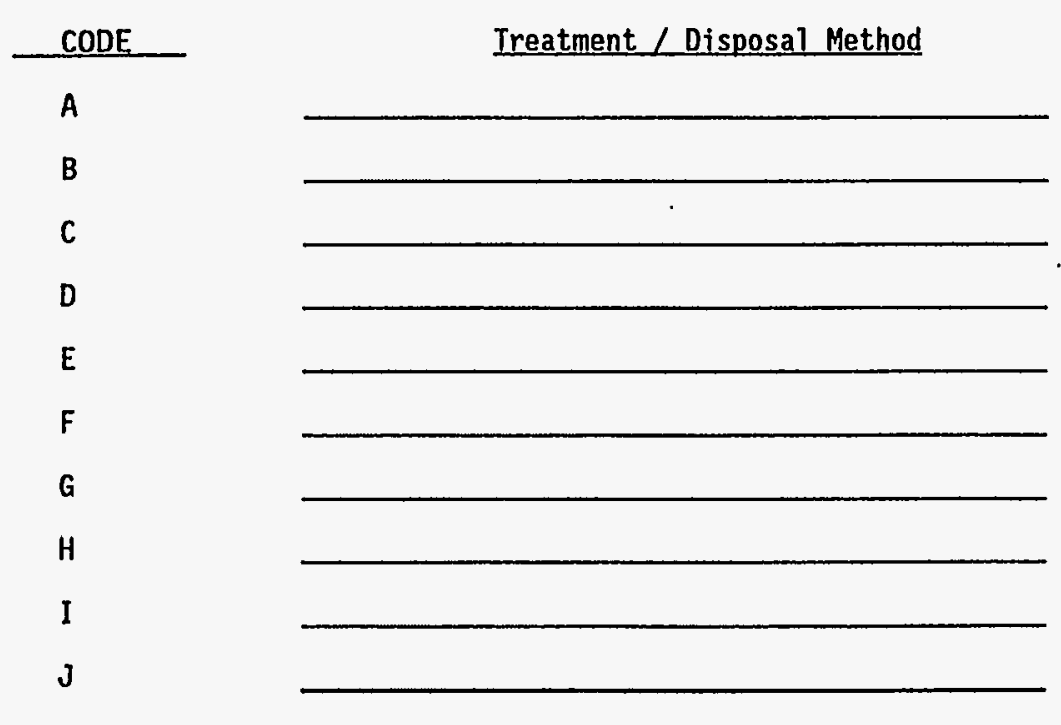

\begin{tabular}{c} 
CODE \\
\hline 1 \\
2 \\
3 \\
4 \\
5 \\
6 \\
7 \\
8 \\
9 \\
10 \\
11 \\
12 \\
13 \\
14 \\
15
\end{tabular}

TSD Facility Name and Location 


\begin{tabular}{|c|c|c|c|c|c|c|c|c|c|c|c|c|c|c|c|c|c|c|c|c|c|c|}
\hline \multirow{2}{*}{$\begin{array}{c}\text { ITEM } \\
\text { RO. }\end{array}$} & \multirow{2}{*}{$\begin{array}{c}\text { EPA } \\
\text { COOES }\end{array}$} & \multirow[t]{2}{*}{ DESCRIPIIOW } & \multicolumn{6}{|c|}{ MUHBER OF DRUNS } & \multicolumn{6}{|c|}{ DISPOSAL UNIT PRICE BY DRUM SIZE } & \multicolumn{6}{|c|}{ EXTERDED TOTAL PRICE } & \multirow{2}{*}{$\begin{array}{l}\text { TREATMENT/ } \\
\text { DISPOSAL } \\
\text { METHOD }\end{array}$} & \multirow{2}{*}{$\begin{array}{l}\text { TSD FACILITY } \\
\text { HAME AND } \\
\text { LOCATIOH }\end{array}$} \\
\hline & & & $\begin{array}{l}1-5 \\
\text { GAL. } \\
\text { DRUM }\end{array}$ & $\begin{array}{l}\text { 6-10 } \\
\text { GALL } \\
\text { DRUM }\end{array}$ & $\begin{array}{l}11-15 \\
\text { GRL. } \\
\text { DRUH }\end{array}$ & $\begin{array}{l}20 \\
\text { GAL. } \\
\text { DRLN }\end{array}$ & $\begin{array}{l}30 \\
\text { GRL. } \\
\text { ORLM }\end{array}$ & $\begin{array}{l}55 \\
\text { GRL } \\
\text { DRUM }\end{array}$ & $\begin{array}{l}1-5 \\
\text { GALL. } \\
\text { DRUM }\end{array}$ & $\begin{array}{l}6-10 \\
\text { GA. } \\
\text { ORLYM }\end{array}$ & $\begin{array}{l}11-15 \\
\text { GRL. } \\
\text { ORUM }\end{array}$ & $\begin{array}{l}20 \\
\text { GAL. } \\
\text { ORUM }\end{array}$ & $\begin{array}{l}30 \\
\text { GALL } \\
\text { DRUM }\end{array}$ & $\begin{array}{l}55 \\
\text { GALL } \\
\text { ORLM }\end{array}$ & $\begin{array}{l}1-5 \\
\text { GAL. } \\
\text { DRLA }\end{array}$ & $\begin{array}{l}\text { O-10 } \\
\text { GAL. } \\
\text { DRUM }\end{array}$ & $\begin{array}{l}19 \cdot 15 \\
\text { GALL: } \\
\text { DRUM }\end{array}$ & $\begin{array}{l}20 \\
\text { GRLL } \\
\text { DRUM }\end{array}$ & $\begin{array}{l}30 \\
\text { GAL. } \\
\text { DRUYH }\end{array}$ & \begin{tabular}{|l|}
55 \\
GRL. \\
DRUM
\end{tabular} & & \\
\hline 15 & $\begin{array}{l}\text { D002, (D005- } \\
\text { D00,8,0010, } \\
\text { D011)* }\end{array}$ & $\begin{array}{l}\text { CAUSTIC LIQUIDS } \\
\text { WIYH D METALS } \\
\text { (WEAK CAUSTIC } \\
\text { SOLUTIONS) } \\
\end{array}$ & & & & & & & & & & & & & & & & & & & & \\
\hline 16 & $\begin{array}{l}\text { D002, (0004- } \\
\text { Do08,p010, } \\
\text { D011)* }\end{array}$ & $\begin{array}{l}\text { CAUSTIC LIQUIDS } \\
\text { WITH D METALS } \\
\text { (GEAR COUSTIC } \\
\text { SOLUUIINS) } \\
\end{array}$ & & & & & & & & & & & & & & & & & & & & \\
\hline 17 & $\begin{array}{l}0002(0005- \\
0011)^{\star}\end{array}$ & $\begin{array}{l}\text { CAUSTIC LIQUUIDS } \\
\text { WITH O METALLS } \\
\text { (WEAK CAUSTIC } \\
\text { SOLUTIONS) } \\
\end{array}$ & & & & & & & & & & & & & & & & & & & & \\
\hline 18 & $\begin{array}{l}0002,(0004- \\
0011)^{*} \\
\text { (F001-F005)* }\end{array}$ & $\begin{array}{l}\text { ACID LIOUIDS WITH } \\
\text { D REIALS AND F } \\
\text { SOLVEHTS (UEAK } \\
\text { ACID SOLUT IONS) }\end{array}$ & & & & & & & & & & & & & & & & & & & & \\
\hline 19 & $\begin{array}{l}\text { D002, (D005, } \\
0007,0008, \\
0010,0011 ; \% ; \\
\text { (F001-F005); }\end{array}$ & $\begin{array}{l}\text { ACID LIQUIDS WITH } \\
\text { D KETALS AND F } \\
\text { SOLVEHTS (UEAK } \\
\text { ACIO SOLUTIOHS) }\end{array}$ & & & & & & & & & & & & & & & & & & & & \\
\hline 20 & $\begin{array}{l}\text { D002, (D005- } \\
\text { D008, D010 } \\
\text { D011)*(F001- } \\
\text { F005)* }\end{array}$ & $\begin{array}{l}\text { ACID LIQUUDS UITH } \\
\text { D KEILS AKD F } \\
\text { SOLVEHTS (WEAK } \\
\text { ACID SOLUTIONS) }\end{array}$ & & & & & & & & & & & & & & & & & & & & \\
\hline
\end{tabular}


EGEG IDAHO, INC.

Artactment 2a, Pago 50230

\begin{tabular}{|c|c|c|c|c|c|c|c|c|c|c|c|c|c|c|c|c|c|c|c|c|c|c|}
\hline \multirow{2}{*}{$\begin{array}{c}\text { ITEK } \\
\text { HOO. }\end{array}$} & \multirow{2}{*}{$\begin{array}{c}\text { EPA } \\
\text { COOES }\end{array}$} & \multirow[t]{2}{*}{ DEscription } & \multicolumn{6}{|c|}{ RUMBER OF DRMMS } & \multicolumn{6}{|c|}{ DISPOSAL URIT PRRCE BY DRUH SIZE } & \multicolumn{6}{|c|}{ EXTERDEO TOTAL PRICE } & \multirow{2}{*}{ 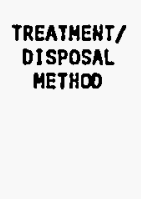 } & \multirow{2}{*}{ 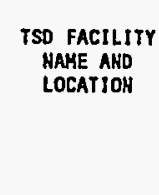 } \\
\hline & & & 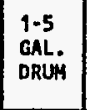 & $\begin{array}{l}\text { 6-10 } \\
\text { GALL } \\
\text { DRRM }\end{array}$ & $\begin{array}{l}\text { 11-15 } \\
\text { GGL: } \\
\text { ORLM }\end{array}$ & 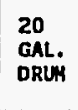 & $\begin{array}{l}30 \\
\text { GRL } \\
\text { ORRM }\end{array}$ & $\begin{array}{l}55 \\
\text { GAL } \\
\text { ORRMM }\end{array}$ & 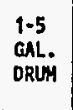 & 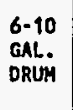 & 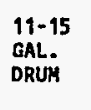 & $\begin{array}{l}20 \\
\text { GAL. } \\
\text { ORRUM }\end{array}$ & $\begin{array}{l}30 \\
\text { GoL. } \\
\text { ORRUM }\end{array}$ & $\begin{array}{l}55 \\
\text { Gak } \\
\text { DRRH }\end{array}$ & 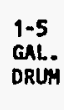 & 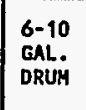 & $\begin{array}{l}11-15 \\
\text { GAL. } \\
\text { DRUM }\end{array}$ & \begin{tabular}{|l|}
$\begin{array}{l}20 \\
\text { GaL. } \\
\text { DRUMM }\end{array}$ \\
\end{tabular} & $\begin{array}{l}30 \\
\text { SGL. } \\
\text { GRLM } \\
\text { ORUM }\end{array}$ & $\begin{array}{l}55 \\
\text { GRL. } \\
\text { ORLUM }\end{array}$ & & \\
\hline 9 & 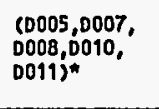 & 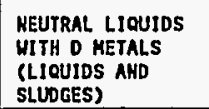 & & & & & & 7 & & & & & & & & & & & & & & \\
\hline 10 & 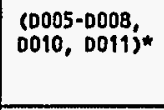 & 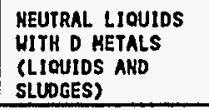 & & & & & & 87 & & & & & & & & & & & & & & \\
\hline 11 & 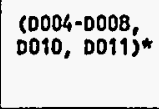 & 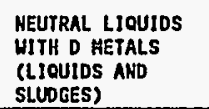 & & & & & & 3 & & & & & & & & & & & & & & \\
\hline 12 & $(0005-0011)^{*}$ & 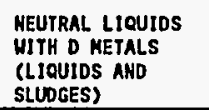 & & & & & & 12 & & & & & & & & & & & & & & \\
\hline 13 & $\begin{array}{l}\text { Door, } 0004- \\
\text { Do11i)* }\end{array}$ & 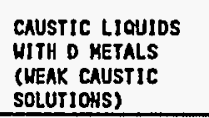 & & & & & & & & & & & & & & & & & & & & \\
\hline 14 & 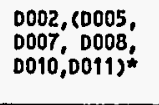 & 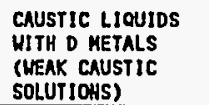 & & & & & & 3 & & & & & & & & & & & & & & \\
\hline
\end{tabular}

"I tems denoted wlth an asterisk are wastes that may contain any or all of the specified waste codes.

Hay or may not contain 0003 . 


\begin{tabular}{|c|c|c|c|c|c|c|c|c|c|c|c|c|c|c|c|c|c|c|c|c|c|c|}
\hline & & & & & & & & & & & & & & $\varepsilon$ & & & & & & 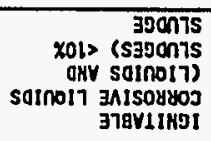 & $2000^{\prime} 1000$ & $2 \varepsilon$ \\
\hline & & & & & & & & & & & & & & & & & & & & 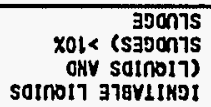 & 1000 & เ£ \\
\hline & & & & & & & & & & & & & & 26 & & & & & & 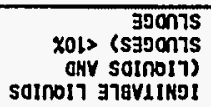 & 1000 & oE \\
\hline & & & & & & & & & & & & & & of & & & & & & 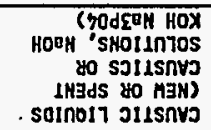 & 2000 & 62 \\
\hline & & & & & & & & & & & & & & 9 & & & & & & 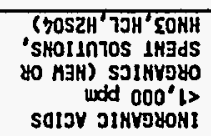 & 2000 & 82 \\
\hline & & & & & & & & & & & & & & 8 & & & & & & $\begin{array}{l}\text { Salnoth } \\
\text { ojIVnogy KOA }\end{array}$ & & $\angle 2$ \\
\hline \multirow[b]{2}{*}{$\begin{array}{l}\text { NoIIVDOT } \\
\text { GNV JWVH } \\
\text { ALI7IJV」 OSL }\end{array}$} & \multirow[b]{2}{*}{$\begin{array}{c}\text { OOHLIN } \\
\text { IVSOdSIO } \\
\text { /IHEMIVIYL }\end{array}$} & $\begin{array}{l}\text { Hnyo } \\
\text { "7vo } \\
\text { SS }\end{array}$ & $\begin{array}{c}\text { Hnyo } \\
\text {-7vg } \\
\text { or }\end{array}$ & $\begin{array}{c}\text { knyo } \\
\text {-7vg } \\
\text { 0z }\end{array}$ & $\begin{array}{r}\text { sกyo } \\
\text { stwo } \\
\text { sl- }-6\end{array}$ & $\begin{array}{l}\text { Whyo } \\
\text {-7vo } \\
\text { ot-9 }\end{array}$ & $\begin{array}{c}\text { knyo } \\
\cdot 7 \mathrm{Vg} \\
5-1\end{array}$ & $\begin{array}{l}\text { Mnyo } \\
\text {-7Vפ } \\
\text { SS }\end{array}$ & $\begin{array}{l}\text { Hnyo } \\
\text { "7vg } \\
\text { o\& }\end{array}$ & $\begin{array}{l}\text { Hnyo } \\
\cdot 7 \mathrm{VI} \\
02\end{array}$ & $\begin{array}{r}\text { Hnya } \\
\text { slivg } \\
\text { sl- }\end{array}$ & $\begin{array}{l}\text { whyo } \\
-7 V 0 \\
0 L-9\end{array}$ & $\begin{array}{c}\text { snyo } \\
7 \times 9 \\
5-1\end{array}$ & $\begin{array}{l}\text { myะo } \\
\text {-7vg } \\
\text { SS }\end{array}$ & $\begin{array}{l}\text { Wnyo } \\
\text {-7wo } \\
\text { OE }\end{array}$ & $\begin{array}{l}\text { Mnyo } \\
\text { "7vo } \\
\text { oz }\end{array}$ & $\begin{array}{c}\text { Mnyo } \\
\text { sl- } \\
\text { sl-1l }\end{array}$ & $\begin{array}{l}\text { wnyo } \\
\text {-7vo } \\
01-9\end{array}$ & $\begin{array}{l}\text { moyo } \\
\cdot 790 \\
s-1\end{array}$ & & & \\
\hline & & \multicolumn{6}{|c|}{ 301Yd TY101 OJ0HE1XJ } & \multicolumn{6}{|c|}{ gzts mya d8 эolyd likn jusodsio } & \multicolumn{6}{|c|}{ 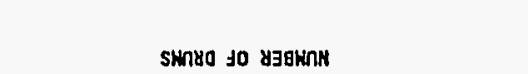 } & NOLLdI\&JS 30 & $\underset{\mathbf{V d y}}{\mathrm{SJ}}$ & $\begin{array}{l}\text { OOH } \\
\text { Hall }\end{array}$ \\
\hline
\end{tabular}




\begin{tabular}{|c|c|c|c|c|c|c|c|c|c|c|c|c|c|c|c|c|c|c|c|c|c|c|}
\hline \multirow{2}{*}{$\begin{array}{l}\text { ITEH } \\
\text { NO. }\end{array}$} & \multirow{2}{*}{$\begin{array}{c}\text { EPA } \\
\text { COOES }\end{array}$} & \multirow[t]{2}{*}{ DESCRIPTIOH } & \multicolumn{6}{|c|}{ NUMBER OF DRUHS } & \multicolumn{6}{|c|}{ DISPOSAL UNIT PRICE BY DRUM SIZE } & \multicolumn{6}{|c|}{ EXTENDED TOTAL PRICE } & \multirow{2}{*}{$\begin{array}{c}\text { TREATHEHTI } \\
\text { DISPOSAL } \\
\text { METHDO }\end{array}$} & \multirow{2}{*}{$\begin{array}{l}\text { TSD FACILITY } \\
\text { MAHE AND } \\
\text { LOCATIOH }\end{array}$} \\
\hline & & & $\begin{array}{l}\text { T-5 } \\
\text { GAL. } \\
\text { DRLA }\end{array}$ & $\begin{array}{l}\text { 6-10 } \\
\text { GAL. } \\
\text { DRUAH }\end{array}$ & $\begin{array}{l}11-15 \\
\text { GAL. } \\
\text { DRUM }\end{array}$ & $\begin{array}{l}20 \\
\text { GNL. } \\
\text { DRUA }\end{array}$ & $\begin{array}{l}30 \\
\text { GAL. } \\
\text { DRLH }\end{array}$ & $\begin{array}{l}55 \\
\text { GAL. } \\
\text { ORUM }\end{array}$ & $\begin{array}{l}1-5 \\
\text { GAL. } \\
\text { DRUN }\end{array}$ & $\begin{array}{l}\text { 6-10 } \\
\text { GAL.: } \\
\text { DRUM }\end{array}$ & $\begin{array}{l}19-15 \\
\text { GAL. } \\
\text { DRUM }\end{array}$ & $\begin{array}{l}20 \\
\text { GAL. } \\
\text { DRUH }\end{array}$ & $\begin{array}{l}30 \\
\text { GAL. } \\
\text { ORUM }\end{array}$ & $\begin{array}{l}55 \\
\text { GAL. } \\
\text { DRUK }\end{array}$ & $\begin{array}{l}1-5 \\
\text { GAL. } \\
\text { DRUM }\end{array}$ & $\begin{array}{l}\text { 6-10 } \\
\text { GAL. } \\
\text { ORUM }\end{array}$ & $\begin{array}{l}11-15 \\
\text { GAL.: } \\
\text { DRUM }\end{array}$ & $\begin{array}{l}20 \\
\text { GAL. } \\
\text { ORLS }\end{array}$ & $\begin{array}{l}30 \\
\text { GRL. } \\
\text { DRLN }\end{array}$ & $\begin{array}{l}55 \\
\text { GAL. } \\
\text { DRUM }\end{array}$ & & \\
\hline 21 & $\begin{array}{l}\text { D002, (0004- } \\
0008,0010 ; \\
0011)^{\star}(F 001- \\
F 005)^{\star}\end{array}$ & $\begin{array}{l}\text { ACID LIOUIDS WITH } \\
\text { O RETALS AND F } \\
\text { SOLVEHTS (HEAK } \\
\text { ACID SOLUTIOHS) }\end{array}$ & & & & & & & & & & & & & & & & & & & & \\
\hline 22 & $\begin{array}{l}\text { Do02, } \\
\text { D0005- } \\
\text { D011)* (F001- } \\
\text { F005)** }\end{array}$ & $\begin{array}{l}\text { ACIO LHOUIDS HITH } \\
\text { D MEEALS AND F } \\
\text { SOLVEHTS (WEAK } \\
\text { ACID SOLUTIOHS) }\end{array}$ & & & & & & & & & & & & & & & & & & & & \\
\hline 23 & $\begin{array}{l}\text { D002, } 00005, \\
0007,0008 ; \\
0010,0011 ; \%, \\
F 001-F 005) ; \\
(0018-0043)^{*}\end{array}$ & $\begin{array}{l}\text { ACID LIOUIDS WITH } \\
\text { D HETALS AHO F } \\
\text { SOLVEHTS (WEAK } \\
\text { ACID SOLUTIOKS) }\end{array}$ & & & & & & & & & & & & & & & & & & & & \\
\hline 24 & 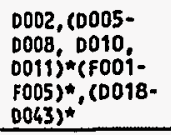 & $\begin{array}{l}\text { ACID LIOUIDS WITH } \\
\text { D METALS, F } \\
\text { SOLVENTS AHD TC } \\
\text { ORGAHICS (WEAK } \\
\text { ACID SOLUIIOHS) } \\
\end{array}$ & & & & & & & & & & & & & & & & & & 1 & & \\
\hline 25 & 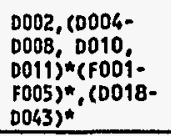 & $\begin{array}{l}\text { ACID LIOUIDS WITH } \\
\text { D HETALS, F } \\
\text { SOLVENTS AHD TC } \\
\text { ORGANICS (WEAK } \\
\text { ACIO SOLUTIOKS) } \\
\end{array}$ & & & & & & & & & & & & & & & & & & & & \\
\hline 26 & $\begin{array}{l}\text { D002, (0005- } \\
\text { D011); (F001- } \\
\text { F005)*, (D018- } \\
\text { D043)** }\end{array}$ & $\begin{array}{l}\text { ACID LIOUIDS WITH } \\
\text { D HETAL, F } \\
\text { SOLVENTS AND TC } \\
\text { ORGANICS (WEAK } \\
\text { ACID SOLUTIOHS) }\end{array}$ & & & & & & & & & & & & & & & & & & & & \\
\hline
\end{tabular}


a

EG\&G IDAHO, INC.

Attechnort 22, Pase 100 Or 30

\begin{tabular}{|c|c|c|c|c|c|c|c|c|c|c|c|c|c|c|c|c|c|c|c|c|c|c|}
\hline \multirow{2}{*}{$\begin{array}{c}\text { ITEM } \\
\text { RO. }\end{array}$} & \multirow{2}{*}{$\begin{array}{l}\text { EPA } \\
\text { COOES }\end{array}$} & \multirow[t]{2}{*}{ DESCRIPTIOH } & \multicolumn{6}{|c|}{ NUMBER OF DRUMS } & \multicolumn{6}{|c|}{ DISPOSAL UNIT PRICE BY DRUM SIZE } & \multicolumn{6}{|c|}{ EXTENOED TOTAL PRICE } & \multirow{2}{*}{$\begin{array}{c}\text { TREATMEETI } \\
\text { DISPOSAL } \\
\text { METHOO }\end{array}$} & \multirow{2}{*}{$\begin{array}{l}\text { TSO FACILLTY } \\
\text { RAAE AND } \\
\text { LOCATIOH }\end{array}$} \\
\hline & & & $\begin{array}{l}1.5 \\
\text { GAL. } \\
\text { DRUM }\end{array}$ & $\begin{array}{l}6-10 \\
\text { GAL. } \\
\text { DRUM }\end{array}$ & $\begin{array}{l}11-15 \\
\text { GAL } \\
\text { DRUM }\end{array}$ & $\begin{array}{l}20 \\
\text { GAL. } \\
\text { DRUY }\end{array}$ & $\begin{array}{l}30 \\
\text { GAL } \\
\text { ORUM }\end{array}$ & $\begin{array}{l}55 \\
\text { GA. } \\
\text { DRUM }\end{array}$ & $\begin{array}{l}1.5 \\
\text { GALL } \\
\text { DRUM }\end{array}$ & $\begin{array}{l}\text { 6-10 } \\
\text { GAL } \\
\text { DRLW }\end{array}$ & $\begin{array}{l}19-15 \\
\text { GRL. } \\
\text { ORUM }\end{array}$ & $\begin{array}{l}20 \\
\text { GALL } \\
\text { ORUH }\end{array}$ & $\begin{array}{l}30 \\
\text { GAL. } \\
\text { ORUS }\end{array}$ & $\begin{array}{l}55 \\
\text { GAL } \\
\text { DRQM }\end{array}$ & $\begin{array}{l}1-5 \\
\text { GALL. } \\
\text { DRUM }\end{array}$ & $\begin{array}{l}6-10 \\
\text { GAL. } \\
\text { ORLUN }\end{array}$ & $\begin{array}{l}11-15 \\
\text { GA. } \\
\text { DRUM }\end{array}$ & $\begin{array}{l}20 \\
\text { GALL } \\
\text { DRUM }\end{array}$ & $\begin{array}{l}30 \\
\text { GAl. } \\
\text { ORUM }\end{array}$ & $\begin{array}{l}55 \\
\text { GA. } \\
\text { ORLM }\end{array}$ & & \\
\hline 41 & $\begin{array}{l}\text { D009, } 0004- \\
0008,004 \text {, } \\
\text { Do11\%* }\end{array}$ & $\begin{array}{l}\text { IGHITABLE LLOUIDS } \\
\text { MITH D RETALS } \\
>10 X \text { SLLOGE }\end{array}$ & & & & & & & & & & & & & & & & & & & & \\
\hline 42 & $\begin{array}{l}\text { Do01;;0005- } \\
\text { Do1ij* }\end{array}$ & $\begin{array}{l}\text { IGHITASLE LIOUIDS } \\
\text { HITH O METALS } \\
\text { SIOZ SLUDGE }\end{array}$ & & & & & & & & & & & & & & & & & & & & \\
\hline 43 & $\begin{array}{l}\text { Do01; (D0005- } \\
\text { Do11i)* }\end{array}$ & 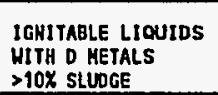 & & & & & & & & & & & & & & & & & & & & \\
\hline 44 & $\begin{array}{l}\text { Do01,(F001- } \\
\text { F005)** }\end{array}$ & $\begin{array}{l}\text { IGYITAGLE LLOUIDS } \\
\text { MITH F SOLVEHTS } \\
\text { STOX SLLOGE }\end{array}$ & & & & & & 44 & & & & & & & & & & & & & & \\
\hline 45 & $\begin{array}{l}\text { Do01, (F001- } \\
\text { F005); }\end{array}$ & 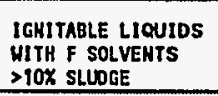 & & & & & & 19 & & & & & & & & & & & & & & \\
\hline 46 & $\begin{array}{l}\text { D001, (F001- } \\
\text { F005)*, (D018- } \\
\text { D043) }\end{array}$ & $\begin{array}{l}\text { IGHITABLE LIOUIDS } \\
\text { WITH F SOLVEHTS } \\
\text { AND TC ORGAHICS } \\
\text { <10X SL UODGE } \\
\end{array}$ & & & & & & 4 & & & & & & & & & & & & & & \\
\hline 47 & 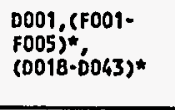 & $\begin{array}{l}\text { IGHITABLE LIOUIDS } \\
\text { MITH } F \text { SOLVENTS } \\
\text { AHD TC ORGAHICS } \\
>10 X \text { SL LOOGE }\end{array}$ & & & & & & 2 & & & & & & & & & & & & & & \\
\hline
\end{tabular}

*Items denoted with an esterisk ore wastes that may contain any or all of the specified waste codes.

thay or may not contain D003.

PAGE TOTAL 
EGEG IDAHO, INC.

\begin{tabular}{|c|c|c|c|c|c|c|c|c|c|c|c|c|c|c|c|c|c|c|c|c|c|c|}
\hline \multirow{2}{*}{$\begin{array}{l}\text { ITEM } \\
\text { MO. }\end{array}$} & \multirow{2}{*}{$\begin{array}{c}\text { EPA } \\
\text { COOES }\end{array}$} & \multirow{2}{*}{ DESCRIPTION } & \multicolumn{6}{|c|}{ RUMBER OF DRUMS } & \multicolumn{6}{|c|}{ DISPOSAL UNIT PRICE BY DRLM SIZE } & \multicolumn{6}{|c|}{ EXTENDED TOTAL PRICE } & \multirow{2}{*}{$\begin{array}{c}\text { TREATHENTI } \\
\text { DISPOSAL } \\
\text { METHOO }\end{array}$} & \multirow{2}{*}{$\begin{array}{l}\text { TSO FACILITY } \\
\text { MAMEAHD } \\
\text { LOCATIOH }\end{array}$} \\
\hline & & & $\begin{array}{l}1.5 \\
\text { GAL. } \\
\text { DRUH }\end{array}$ & $\begin{array}{l}6-10 \\
\text { GL.. } \\
\text { DRLAM }\end{array}$ & $\begin{array}{l}11-15 \\
\text { GAL: } \\
\text { DRUM }\end{array}$ & $\begin{array}{l}20 \\
\text { GAL. } \\
\text { ORUH }\end{array}$ & $\begin{array}{l}30 \\
\text { GAL. } \\
\text { ORUM }\end{array}$ & $\begin{array}{l}55 \\
\text { GALL. } \\
\text { DRUW }\end{array}$ & $\begin{array}{l}1-5 \\
\text { GALL. } \\
\text { DRUM }\end{array}$ & $\begin{array}{l}\text { 6-10 } \\
\text { GL. } \\
\text { ORLH }\end{array}$ & $\begin{array}{l}11-15 \\
\text { GR. } \\
\text { DRLW }\end{array}$ & $\begin{array}{l}20 \\
\text { GAL. } \\
\text { ORUM }\end{array}$ & $\begin{array}{l}30 \\
\text { GAL. } \\
\text { ORUM }\end{array}$ & $\begin{array}{l}55 \\
\text { GQL. } \\
\text { DRUM }\end{array}$ & $\begin{array}{l}1.5 \\
\text { GA. } \\
\text { DRUM }\end{array}$ & $\begin{array}{l}6-10 \\
\text { GAL. } \\
\text { DRUM }\end{array}$ & $\begin{array}{l}19-15 \\
\text { GAL.: } \\
\text { DRUM }\end{array}$ & $\begin{array}{l}20 \\
\text { GLL. } \\
\text { ORUM }\end{array}$ & $\begin{array}{l}30 \\
\text { GAL. } \\
\text { DRLY }\end{array}$ & $\begin{array}{l}55 \\
\text { GRL. } \\
\text { DRUM }\end{array}$ & & \\
\hline 33 & 0001,0002 & 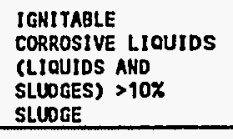 & & & & & & & & & & & & & & & & & & & & \\
\hline 34 & D0011) & $\begin{array}{l}\text { IGHTTABLE LIOUIDS } \\
\text { WIIT DLEETALS } \\
\text { S10\% SLUOGE }\end{array}$ & & & & & & 6 & & & & & & & & & & & & & & \\
\hline 35 & $\begin{array}{l}\text { D001, } \\
\text { D011 jo004- }\end{array}$ & $\begin{array}{l}\text { IGKITABLE L LQUIDS } \\
\text { WITH B RETALS } \\
>10 \% \text { SLUDGE } \\
\end{array}$ & & & & & & & & & & & & & & & & & & & & \\
\hline 36 & $\begin{array}{l}0001,(D 005, \\
D 007,, 0008, \\
D 010,0011)^{\prime} \\
00 \%\end{array}$ & $\begin{array}{l}\text { IGHTTABLE LLOUIDS } \\
\text { WITH O O HETALS } \\
<10 \% \text { SLUDGE } \\
\end{array}$ & & & & & & & & & & & & & & & & & & & & \\
\hline 37 & $\begin{array}{l}\text { Do01, (D005, } \\
\text { D007,,0008, } \\
\text { D010,0011;* }\end{array}$ & $\begin{array}{l}\text { IGHITAGLE LIOUIDS } \\
\text { HITH O METALS } \\
\text { >10X SLLOGE } \\
\end{array}$ & & & & & & 1 & & & & & & & & & & & & & & \\
\hline 38 & $\begin{array}{l}\text { Do01, (D005- } \\
\text { D008; } 0010, \\
\text { D011)* }\end{array}$ & $\begin{array}{l}\text { IGMITABLE LLQUIDS } \\
\text { WITH D METALS } \\
\text { STOX SLUDGE } \\
\end{array}$ & & & & & & 1 & & & & & & & & & & & & & & \\
\hline 39 & 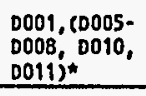 & $\begin{array}{l}\text { IGHITABLE LIOUIDS } \\
\text { WITH O METALS } \\
>\text { PIOX SLOOOEE } \\
\end{array}$ & & & & & & & & & & & & & & & & & & & & \\
\hline 40 & 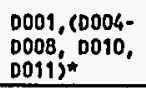 & $\begin{array}{l}\text { IOWITABLE LIQUIDS } \\
\text { WITH D HETALS } \\
\text { STOX SLUDGE }\end{array}$ & & & & & & 1 & & & & & & & & & & & & & & \\
\hline
\end{tabular}


, n.

EGEG IDAHO, INC.

Aluchmont 22, Page 120130

\begin{tabular}{|c|c|c|c|c|c|c|c|c|c|c|c|c|c|c|c|c|c|c|c|c|c|c|}
\hline \multirow{2}{*}{$\begin{array}{l}\text { ITEM } \\
\text { NO. }\end{array}$} & \multirow{2}{*}{$\underset{\text { CPPA }}{\text { CDOES }}$} & \multirow[t]{2}{*}{ DESCRIPTION } & \multicolumn{6}{|c|}{ NLMBER OF ORUHS } & \multicolumn{6}{|c|}{ DISPOSAL UNIT PRICE BY DRUW SIZE } & \multicolumn{6}{|c|}{ EXTENDED TOTAL PRICE } & \multirow{2}{*}{$\begin{array}{c}\text { TREATHEHII } \\
\text { DISPOSALI } \\
\text { METHOD }\end{array}$} & \multirow{2}{*}{$\begin{array}{l}\text { TSD FACLILTY } \\
\text { TAME AND } \\
\text { LOCATIOH }\end{array}$} \\
\hline & & & $\begin{array}{l}19-5 \\
\text { GAL. } \\
\text { DRRW }\end{array}$ & $\begin{array}{l}6-10 \\
\text { GAL. } \\
\text { DRUM }\end{array}$ & $\begin{array}{l}11-15 \\
\text { GRL. } \\
\text { DRUM }\end{array}$ & $\begin{array}{l}20 \\
\text { GAL. } \\
\text { DRLYH }\end{array}$ & $\begin{array}{l}30 \\
\text { GRL. } \\
\text { DRUM }\end{array}$ & $\begin{array}{l}55 \\
\text { GAL. } \\
\text { DRLW }\end{array}$ & $\begin{array}{l}1-5 \\
\text { GA. } \\
\text { DRUK }\end{array}$ & $\begin{array}{l}\text { 6-10 } \\
\text { GAL. } \\
\text { ORUM }\end{array}$ & $\begin{array}{l}11-15 \\
\text { GAL } \\
\text { DRUS }\end{array}$ & $\begin{array}{l}20 \\
\text { GAL. } \\
\text { ORUM }\end{array}$ & $\begin{array}{l}30 \\
\text { GALL } \\
\text { DRUA }\end{array}$ & $\begin{array}{l}55 \\
\text { GNL. } \\
\text { DRUH }\end{array}$ & $\begin{array}{l}1-5 \\
\text { GALL. } \\
\text { ORUM }\end{array}$ & $\begin{array}{l}\text { 6-10 } \\
\text { GAL. } \\
\text { DRUN }\end{array}$ & $\begin{array}{l}19-15 \\
\text { GRLO } \\
\text { DRUM }\end{array}$ & $\begin{array}{l}20 \\
\text { GAL. } \\
\text { DRUW }\end{array}$ & $\begin{array}{l}30 \\
\text { GAL. } \\
\text { DRUA }\end{array}$ & $\begin{array}{l}\text { SS } \\
\text { GAL. } \\
\text { DRUM }\end{array}$ & & \\
\hline 54 & $\begin{array}{l}\text { D001, (D005- } \\
\text { D011)* (F001- } \\
\text { F005)* }\end{array}$ & $\begin{array}{l}\text { IGHITABLE LIQUIDS } \\
\text { WITH D METALS AND } \\
\text { F SOLVEETS \& } \\
\text { SLOXGE }\end{array}$ & & & & & & & & & & & & & & & & & & & & \\
\hline 55 & $\begin{array}{l}0001,(0005- \\
0011) *(5001 . \\
\text { p005)** }\end{array}$ & $\begin{array}{l}\text { IGNITABLLE LIQUIDS } \\
\text { UITH D METALS AHD } \\
\text { F SOLVEHTS > } \\
\text { SLUDEE }\end{array}$ & & & & & & & & & & & & & & & & & & & & \\
\hline 56 & 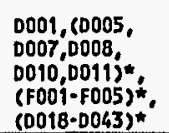 & 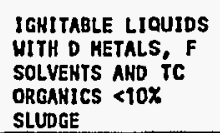 & & & & & & 17 & & & & & & & & & & & & & & \\
\hline 57 & 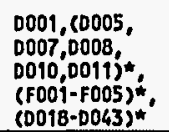 & 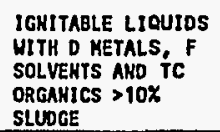 & & & & & & 5 & & & & & & & & & & & & & & \\
\hline 58 & 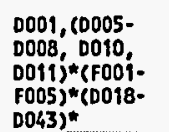 & 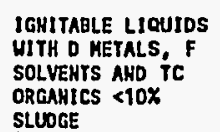 & & & & & & & & & & & & & & & & & & & & \\
\hline 59 & 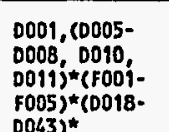 & 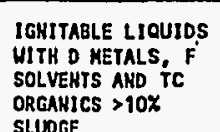 & & & & & & & & & & & & & & & & & & & & \\
\hline
\end{tabular}

*Items denoted with an asterisk are wastes that may contain any or all of the specified waste codes.

t May or may not contain D003. 
EG\&G IDAHO, INC.

Atthechment 22, Page 11030

\begin{tabular}{|c|c|c|c|c|c|c|c|c|c|c|c|c|c|c|c|c|c|c|c|c|c|c|}
\hline \multirow{2}{*}{$\begin{array}{l}\text { ITEH } \\
\text { HO. }\end{array}$} & \multirow{2}{*}{$\begin{array}{c}\text { EPA } \\
\text { CDOES }\end{array}$} & \multirow[t]{2}{*}{ DESCRIPIION } & \multicolumn{6}{|c|}{ HUMBER OF ORUMS } & \multicolumn{6}{|c|}{ DISPOSAL UNIT PRICE BY DRUM SIZE } & \multicolumn{6}{|c|}{ EXTERDED TOTAL PRICE } & \multirow{2}{*}{$\begin{array}{l}\text { TREATMENT/ } \\
\text { DISPOSAL } \\
\text { METHOO }\end{array}$} & \multirow{2}{*}{$\begin{array}{l}\text { TSD FACILITY } \\
\text { HAME AHD } \\
\text { LOCATIOH }\end{array}$} \\
\hline & & & $\begin{array}{l}1-5 \\
\text { GAL. } \\
\text { DRUS }\end{array}$ & $\begin{array}{l}6-10 \\
\text { GAL. } \\
\text { DRLM }\end{array}$ & $\begin{array}{l}11-15 \\
\text { GA.. } \\
\text { DRUM }\end{array}$ & $\begin{array}{l}20 \\
\text { GAL. } \\
\text { DRLH }\end{array}$ & $\begin{array}{l}30 \\
\text { GAL. } \\
\text { DRUM }\end{array}$ & $\begin{array}{l}5 S \\
\text { GNL. } \\
\text { DRLAM }\end{array}$ & $\begin{array}{l}9-5 \\
\text { GNL. } \\
\text { ORUMA }\end{array}$ & $\begin{array}{l}6-10 \\
\text { GAL. } \\
\text { DRUH }\end{array}$ & $\begin{array}{l}11-15 \\
\text { GAL. } \\
\text { ORLAM }\end{array}$ & $\begin{array}{l}20 \\
\text { GAL. } \\
\text { DRUH }\end{array}$ & $\begin{array}{l}30 \\
\text { GALL: } \\
\text { DRLM }\end{array}$ & $\begin{array}{l}55 \\
\text { GAL. } \\
\text { DRUH }\end{array}$ & $\begin{array}{l}1-5 \\
\text { GAL. } \\
\text { DRUM }\end{array}$ & $\begin{array}{l}6.10 \\
\text { GAL. } \\
\text { DRUH }\end{array}$ & $\begin{array}{l}119-15 \\
\text { GAL. } \\
\text { ORUM }\end{array}$ & $\begin{array}{l}20 \\
\text { GAL. } \\
\text { DRUM }\end{array}$ & $\begin{array}{l}30 \\
\text { GAL. } \\
\text { DRUH }\end{array}$ & $\begin{array}{l}55 \\
\text { GAL. } \\
\text { DRLA }\end{array}$ & & \\
\hline 48 & $\begin{array}{l}\text { D001, (D005, } \\
\text { D007,0008, } \\
0010,0011)^{\star} \\
(F 001-8005)^{\star} \\
\end{array}$ & $\begin{array}{l}\text { IGHITABLE LIOUIDS } \\
\text { HITH F SOLVEHTS } \\
\text { AND TC ORGAHICS } \\
\text { STOX SLUDGE } \\
\end{array}$ & & & & & & 7 & & & & & & & & & & & & & & \\
\hline 49 & $\begin{array}{l}\text { D001, (D005, } \\
\text { D007,0008, } \\
00010,0011)^{*} \\
(F 001-F 005)^{*} \\
\end{array}$ & $\begin{array}{l}\text { IGHITABLE LIQUIDS } \\
\text { UITH F SOLVEHIS } \\
\text { AND TC ORGAHICS } \\
\text { > IO\% SLUDGE } \\
\end{array}$ & & & & & & 8 & & & & & & & & & & & & & & \\
\hline 50 & 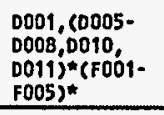 & $\begin{array}{l}\text { IGNITABLE LIQUIDS } \\
\text { WITH D METALS AHD } \\
\text { F SOLVERTS < } 10 X \\
\text { SLUDGE } \\
\end{array}$ & & & & & & & & & & & & & & & & & & & & \\
\hline 51 & 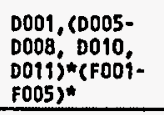 & $\begin{array}{l}\text { IGNITABLE LIQUIDS } \\
\text { WITH D RETALS AHD } \\
\text { F SOLVENTS > IOX } \\
\text { SLUDOE }\end{array}$ & & & & & & & & & & & & & & & & & & & & \\
\hline 52 & 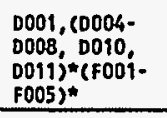 & 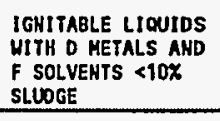 & & & & & & & & & & & & & & & & & & ' & & \\
\hline 53 & 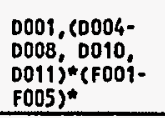 & $\begin{array}{l}\text { IGWITABLE LIOUIDS } \\
\text { GITH D MEIALS AHD } \\
\text { F SOLVENTS >10X } \\
\text { SLUDGE }\end{array}$ & & & & & & & & & & & & & & & & & & & & \\
\hline
\end{tabular}

*I tems denoted with an asterisk are wastes that may contain any or all of the specified uaste codes.

t May or may not contain D003. 
ary

EGLG IDAHO, INC.

Atrachmont 22, PAso 14 O130

\begin{tabular}{|c|c|c|c|c|c|c|c|c|c|c|c|c|c|c|c|c|c|c|c|c|c|c|}
\hline \multirow[t]{2}{*}{$\begin{array}{c}\text { ITEK } \\
\text { HO. }\end{array}$} & \multirow[t]{2}{*}{$\begin{array}{l}\text { EPA } \\
\text { COOES }\end{array}$} & \multirow[t]{2}{*}{ DESCRIPTION } & \multicolumn{6}{|c|}{ MUMBER OF DRLWS } & \multicolumn{6}{|c|}{ DISPOSAL UNIT PRICE BY DRUM SIZE } & \multicolumn{6}{|c|}{ EXTERDED TOTAL PRICE } & \multirow{2}{*}{$\begin{array}{c}\text { TREATMEHTI } \\
\text { OISPOSAL } \\
\text { METHOO }\end{array}$} & \multirow{2}{*}{$\begin{array}{l}\text { TSD FACLLITY } \\
\text { MAME AND } \\
\text { LOCATION }\end{array}$} \\
\hline & & & $\begin{array}{l}1-5 \\
\text { GAL. } \\
\text { DRUM }\end{array}$ & $\begin{array}{l}\text { 6-10 } \\
\text { GAL. } \\
\text { DRLY }\end{array}$ & $\begin{array}{l}\text { 11-15 } \\
\text { GAL: } \\
\text { DRLM }\end{array}$ & $\begin{array}{l}20 \\
\text { GL. } \\
\text { DRLM }\end{array}$ & $\begin{array}{l}30 \\
\text { GQL. } \\
\text { DRUM }\end{array}$ & $\begin{array}{l}55 \\
\text { GRL. } \\
\text { ORLM }\end{array}$ & $\begin{array}{l}7-5 \\
\text { GR. } \\
\text { DRUM }\end{array}$ & $\begin{array}{l}6-10 \\
\text { GAL. } \\
\text { GRUH }\end{array}$ & $\begin{array}{l}11-15 \\
\text { GaL } \\
\text { DRUY }\end{array}$ & $\begin{array}{l}20 \\
\text { GAL. } \\
\text { ORLWH }\end{array}$ & $\begin{array}{l}30 \\
\text { GRL. } \\
\text { DRUM }\end{array}$ & $\begin{array}{l}55 \\
\text { GAL. } \\
\text { DRLH }\end{array}$ & $\begin{array}{l}9-5 \\
\text { GLL. } \\
\text { DRUH }\end{array}$ & $\begin{array}{l}6-10 \\
\text { GAL. } \\
\text { DRUM }\end{array}$ & $\begin{array}{l}\text { 11-15 } \\
\text { GALU } \\
\text { DRUM }\end{array}$ & $\begin{array}{l}20 \\
\text { GAL. } \\
\text { ORUM }\end{array}$ & $\begin{array}{l}30 \\
\text { GAL. } \\
\text { DRUM }\end{array}$ & $\begin{array}{l}55 \\
\text { SGAL. } \\
\text { GRLM } \\
\text { DRUM }\end{array}$ & & \\
\hline 66 & 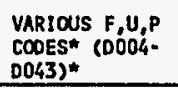 & INORGAMIC DEBRIS & & & & & & & & & & & & & & & & & & & & \\
\hline 67 & 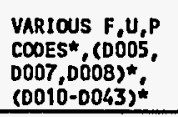 & INORGAHIC DEBRIS & & & & & & & & & & & & & & & & & & & & \\
\hline 68 & 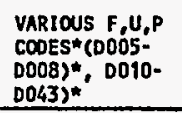 & INORGAMIC DEERIS & & & & & & & & & & & & & & & & & & & & \\
\hline 69 & 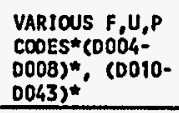 & IMORGANIC, DEBRIS & & & & & & & & & & & & & & & & & & & & \\
\hline 70 & 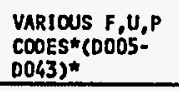 & IHORCANIC DEgRIS & & & & & & & & & & & & & & & & & & & & \\
\hline 71 & $(0004-D 011) *$ & $\begin{array}{l}\text { INORGANIC DEBRIS } \\
\text { HITH D HETALS } \\
\end{array}$ & & & & & & & & & & & & & & & & & & & & \\
\hline 72 & $\begin{array}{l}\text { S0005, D007, } \\
0008,0010, \\
0011)^{*}\end{array}$ & $\begin{array}{l}\text { INORGAHIC DEBRIS } \\
\text { WITH D RETALS }\end{array}$ & & & & & & 3 & & & & & & & & & & & & & & \\
\hline 73 & $\begin{array}{l}\text { Co005-D008, } \\
\text { Do15, D011)* }\end{array}$ & $\begin{array}{l}\text { IMORGAMIC DEBRIS } \\
\text { MITH D METALS }\end{array}$ & & & & & & & & & & & & & & & & & & & & \\
\hline
\end{tabular}

"I tens denoted with an osterisk are wastes that may contain any or all of the specified waste codes.

+Hay or may not contain D003.

PAGE YOTAL 
EGEG IDAHO, INC.

Atrachment 22, Page is O 39

\begin{tabular}{|c|c|c|c|c|c|c|c|c|c|c|c|c|c|c|c|c|c|c|c|c|c|c|}
\hline \multirow{2}{*}{$\begin{array}{l}\text { ITEM } \\
\text { HO. }\end{array}$} & \multirow{2}{*}{$\begin{array}{l}\text { EPA } \\
\text { CODES }\end{array}$} & \multirow[t]{2}{*}{ DESCRIPTION } & \multicolumn{6}{|c|}{ RUMBER OF DRUHS } & \multicolumn{6}{|c|}{ DISPOSAL UNIT PRICE BY DRUM SIZE } & \multicolumn{6}{|c|}{ EXIEHDED TOTAL PRICE } & \multirow{2}{*}{$\begin{array}{c}\text { TREATMEHT/ } \\
\text { DISPOSAL. } \\
\text { METHOD }\end{array}$} & \multirow{2}{*}{$\begin{array}{l}\text { TSD FACILITY } \\
\text { HAME AHO } \\
\text { LOCATIOH }\end{array}$} \\
\hline & & & $\begin{array}{l}1-5 \\
\text { GAL. } \\
\text { DRUA }\end{array}$ & $\begin{array}{l}6.10 \\
\text { GAL. } \\
\text { DRUH }\end{array}$ & $\begin{array}{l}11-15 \\
\text { GRL. } \\
\text { DRUH }\end{array}$ & $\begin{array}{l}20 \\
\text { GAL. } \\
\text { DRUH }\end{array}$ & $\begin{array}{l}30 \\
\text { GAL. } \\
\text { DRUM }\end{array}$ & $\begin{array}{l}55 \\
\text { GAL. } \\
\text { DRUH }\end{array}$ & $\begin{array}{l}1-5 \\
\text { GAL. } \\
\text { ORLM }\end{array}$ & $\begin{array}{l}6.10 \\
\text { GAL. } \\
\text { DRUY }\end{array}$ & $\begin{array}{l}11-15 \\
\text { GAL.: } \\
\text { DRUM }\end{array}$ & $\begin{array}{l}20 \\
\text { GAL. } \\
\text { DRUY }\end{array}$ & $\begin{array}{l}30 \\
\text { GAL. } \\
\text { DRUMY }\end{array}$ & $\begin{array}{l}55 \\
\text { GAL. } \\
\text { ORUH }\end{array}$ & $\begin{array}{l}1-5 \\
\text { GAL. } \\
\text { DRUMA }\end{array}$ & $\begin{array}{l}6-10 \\
\text { GAL. } \\
\text { DRUA }\end{array}$ & $\begin{array}{l}11-15 \\
\text { GAL. } \\
\text { DRUA }\end{array}$ & $\begin{array}{l}20 \\
\text { GAL. } \\
\text { DRUH }\end{array}$ & $\begin{array}{l}30 \\
\text { GAL. } \\
\text { ORUMY }\end{array}$ & $\begin{array}{l}55 \\
\text { GAL. } \\
\text { DRUM }\end{array}$ & & \\
\hline 60 & 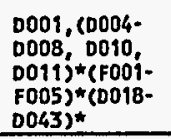 & $\begin{array}{l}\text { IGHITABLE LIQUIDS } \\
\text { WITH D METALS, F } \\
\text { SOLVEHTS AND IC } \\
\text { ORGANICS S10X } \\
\text { SLUDGE } \\
\end{array}$ & & & & & & 1 & & & & & & & & & & & & & & \\
\hline 61 & 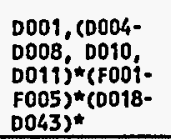 & $\begin{array}{l}\text { IGHITABLE LIOUIDS } \\
\text { WIIH D METALS, } F \\
\text { SOLVEHTS AND TC } \\
\text { ORGANICS >10\% } \\
\text { SLUDGE } \\
\end{array}$ & & & & & & 5 & & & & & & & & & & & & & & \\
\hline 62 & $\begin{array}{l}\text { D001, (D005- } \\
\text { D011)* (F001- } \\
\text { F005)*(D018- } \\
\text { D043)* }\end{array}$ & $\begin{array}{l}\text { IGNITABLE LMOUIDS } \\
\text { WIH D MEEALS, F } \\
\text { SOLVENTS AND TC } \\
\text { ORGANICS \&10\% } \\
\text { SLUDGE }\end{array}$ & & & & & & 1 & & & & & & & & & & & & & & \\
\hline 63 & $\begin{array}{l}\text { D001, (D005- } \\
\text { D011)* (F001- } \\
\text { F005)*(D018- } \\
\text { D043)* }\end{array}$ & $\begin{array}{l}\text { IGNITABLE LIOUIDS } \\
\text { WITH D RETALS, F } \\
\text { SOLVEHIS AHD IC } \\
\text { ORGANICS >10X } \\
\text { SLLDGE }\end{array}$ & & & & & & & & & & & & & & & & & & ' & & \\
\hline 64 & $\begin{array}{l}\text { VARIOUS } P, U, F, F \\
\text { COOES* (DO12- } \\
\text { D043)* }\end{array}$ & $\begin{array}{l}\text { NOH-IGNITABLE } \\
\text { ORGANICS LIOUIDS }\end{array}$ & & & & & & 9 & & & & & & & & & & & & & & \\
\hline 65 & $\begin{array}{l}\text { VARIOUS F,U,P } \\
\text { COOES* (DO12- } \\
\text { DO43)* }\end{array}$ & IMORGAKIC DEBRIS & & & & & & & & & & & & & & & & & & & & \\
\hline
\end{tabular}

-Itens denoted with an asterisk are wastes that may contain any or all of the specified waste codes.

thay or moy not contain D003. 
$=0$ r

EGRG IDAHO, INC.

\begin{tabular}{|c|c|c|c|c|c|c|c|c|c|c|c|c|c|c|c|c|c|c|c|c|c|c|}
\hline \multirow{2}{*}{$\begin{array}{l}\text { TTEM } \\
\text { MO. }\end{array}$} & \multirow{2}{*}{$\begin{array}{c}\text { EPA } \\
\text { COOES }\end{array}$} & \multirow[t]{2}{*}{ DESCRIPTION } & \multicolumn{6}{|c|}{ MUMBER OF DRUWS } & \multicolumn{6}{|c|}{ DISPOSAL UKIT PRICE BY DRUM SIZE } & \multicolumn{6}{|c|}{ EXTENOED TOTAL PRICE } & \multirow{2}{*}{$\begin{array}{c}\text { TREATHEETI } \\
\text { DAISPESAL } \\
\text { HETHOO }\end{array}$} & \multirow{2}{*}{$\begin{array}{l}\text { TSO FACILITY } \\
\text { MAME AHO } \\
\text { LOCATIOH }\end{array}$} \\
\hline & & & $\begin{array}{l}1.5 \\
\text { GAL. } \\
\text { DRUM }\end{array}$ & $\begin{array}{l}\text { 6-10 } \\
\text { GAL. } \\
\text { DRUM }\end{array}$ & $\begin{array}{l}11-15 \\
\text { GALL } \\
\text { DRUH }\end{array}$ & $\begin{array}{l}20 \\
\text { aAL. } \\
\text { DRUW }\end{array}$ & $\begin{array}{l}30 \\
\text { GALL. } \\
\text { ORRUH }\end{array}$ & $\begin{array}{l}55 \\
\text { GAL } \\
\text { DRUM }\end{array}$ & $\begin{array}{l}1-5 \\
\text { GAL. } \\
\text { ORUM }\end{array}$ & $\begin{array}{l}6.10 \\
\text { GAL. } \\
\text { DRUA }\end{array}$ & $\begin{array}{l}11-15 \\
\text { GALL } \\
\text { DRUM }\end{array}$ & $\begin{array}{l}20 \\
\text { GALL } \\
\text { DRUN }\end{array}$ & \begin{tabular}{|l|}
30 \\
GALL \\
DRUH
\end{tabular} & $\begin{array}{l}55 \\
\text { GALLM } \\
\text { DRUM }\end{array}$ & $\begin{array}{l}1.5 \\
\text { GAR. } \\
\text { ORUW }\end{array}$ & $\begin{array}{l}6-10 \\
\text { GAL. } \\
\text { ORUH }\end{array}$ & $\begin{array}{l}11-15 \\
\text { GRL. } \\
\text { DRUM }\end{array}$ & $\begin{array}{l}20 \\
\text { GALL. } \\
\text { DRUM }\end{array}$ & $\begin{array}{l}30 \\
\text { GRL. } \\
\text { DRUM }\end{array}$ & $\begin{array}{l}55 \\
\text { GAL. } \\
\text { ORUM }\end{array}$ & & \\
\hline 89 & 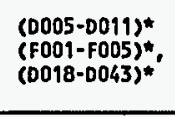 & 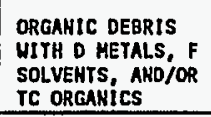 & & & & & & & & & & & & & & & & & & & & \\
\hline 82 & D004-0011* & $\begin{array}{l}\text { ORGCANLC DEBRIS } \\
\text { MITH D METRLS }\end{array}$ & & & & & & & & & & & & & & & & & & & & \\
\hline 83 & 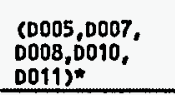 & $\begin{array}{l}\text { ORGAHIC DEERIS } \\
\text { HITH D METALS }\end{array}$ & & & & & & 38 & & & & & & & & & & & & & & \\
\hline 84 & $\begin{array}{l}\begin{array}{l}(10005-0008, \\
0010, \\
0011)^{*}\end{array} \\
\end{array}$ & $\begin{array}{l}\text { ORGGHIC DEBRIS } \\
\text { HITH D METALS } \\
\end{array}$ & & & & & & 41 & & & & & & & & & & & & & & \\
\hline es & $\begin{array}{l}(0004-0008, \\
0010,0011)^{*} \\
\end{array}$ & $\begin{array}{l}\text { OREANIC DEERIS } \\
\text { MITH D DEETALS }\end{array}$ & & & & & & 26 & & & & & & & & & & & & & & \\
\hline 86 & $(0005-0011)^{*}$ & $\begin{array}{l}\text { ORGAMIC DERRIS } \\
\text { HITHIC METALS } \\
\end{array}$ & & & & & & 11 & & & & & & & & & & & & & & \\
\hline 87 & $\begin{array}{l}\text { VARTOUS U,P } \\
\text { CDOES* (DODT- } \\
\text { D043)* }\end{array}$ & ORGAMIC DEBRIS & & & & & & 8 & & & & & & & & & & & & & & \\
\hline 88 & 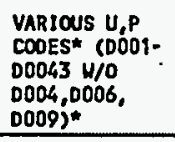 & ORGANIC DERRIS & & & & & & 1 & & & & & & & & & & & & & & \\
\hline
\end{tabular}

-Items denoted with on asterisk are westes that may contain any or all of the specified waste codes.

+ May or may not contain Do03. 
EG\&G IDAHO, INC.

Attechnert 22, Page is O1 39

\begin{tabular}{|c|c|c|c|c|c|c|c|c|c|c|c|c|c|c|c|c|c|c|c|c|c|c|}
\hline \multirow{2}{*}{$\begin{array}{c}\text { ITEM } \\
\text { RO. }\end{array}$} & \multirow{2}{*}{$\begin{array}{l}\text { EPA } \\
\text { COOES }\end{array}$} & \multirow[t]{2}{*}{ DESCRIPTION } & \multicolumn{6}{|c|}{ MUMBER OF DRUMS } & \multicolumn{6}{|c|}{ DISPOSAL UNIT PRICE GY DRUM SIZE } & \multicolumn{6}{|c|}{ EXTENDED TOTAL PRICE } & \multirow{2}{*}{$\begin{array}{c}\text { TREATMEATI } \\
\text { DISPOSAL } \\
\text { METHOO }\end{array}$} & \multirow{2}{*}{$\begin{array}{l}\text { TSO FACILITY } \\
\text { HAME AHO } \\
\text { LOCATION }\end{array}$} \\
\hline & & & $\begin{array}{l}9-5 \\
\text { GAL. } \\
\text { DRUH }\end{array}$ & $\begin{array}{l}\text { 6-10 } \\
\text { GAL: } \\
\text { DRUM }\end{array}$ & $\begin{array}{l}\text { Ii- } 95 \\
\text { GLL. } \\
\text { DRUMA }\end{array}$ & $\begin{array}{l}20 \\
\text { GAL. } \\
\text { DRUM }\end{array}$ & $\begin{array}{l}30 \\
\text { GRL. } \\
\text { DRLUM }\end{array}$ & $\begin{array}{l}55 \\
\text { GAL. } \\
\text { DRLM }\end{array}$ & $\begin{array}{l}1.5 \\
\text { GA. } \\
\text { DRUMY }\end{array}$ & $\begin{array}{l}6-10 \\
\text { GA. } \\
\text { DRUH }\end{array}$ & $\begin{array}{l}11-15 \\
\text { GAL } \\
\text { DRUH }\end{array}$ & $\begin{array}{l}20 \\
\text { GAL. } \\
\text { DRUM }\end{array}$ & $\begin{array}{l}30 \\
\text { GRL. } \\
\text { DRUH }\end{array}$ & $\begin{array}{l}55 \\
\text { GRL. } \\
\text { DRUM }\end{array}$ & $\begin{array}{l}1-5 \\
\text { GAL. } \\
\text { DRUM }\end{array}$ & $\begin{array}{l}6-10 \\
\text { GAL. } \\
\text { DRUM }\end{array}$ & $\begin{array}{l}11-15 \\
\text { GRL. } \\
\text { DRUM }\end{array}$ & $\begin{array}{l}20 \\
\text { GAL. } \\
\text { ORRM }\end{array}$ & $\begin{array}{l}30 \\
\text { GAL. } \\
\text { DRUM }\end{array}$ & $\begin{array}{l}55 \\
\text { GAL. } \\
\text { DRUM }\end{array}$ & & \\
\hline 74 & 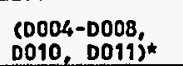 & $\begin{array}{l}\text { IRORGANIC DEERIS } \\
\text { UITH D METALS }\end{array}$ & & & & & & & & & & & & & & & & & & & & \\
\hline 75 & $(D 005-D 011)^{*}$ & $\begin{array}{l}\text { INORGANIC DEBRIS } \\
\text { MITH D METALS }\end{array}$ & & & & & & & & & & & & & & & & & & & & \\
\hline 76 & $\begin{array}{l}\text { VARIOUS F,P,U, } \\
\text { AND/OR } \\
D D 01,0012- \\
D 043 \pi\end{array}$ & ORGAHIC DEBRIS & & & & & & 34 & & & & & & & & & & & & & & \\
\hline$\pi$ & 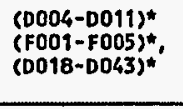 & 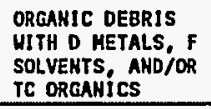 & & & & & & 1 & & & & & & & & & & & & & & \\
\hline 78 & 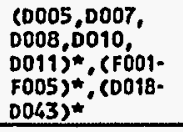 & 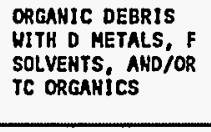 & & & & & & 5 & & & & & & & & & & & & 4 & & \\
\hline 79 & 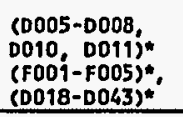 & 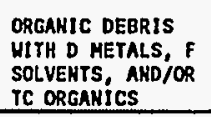 & & & & & & & & & & & & & & & & & & & & \\
\hline 80 & 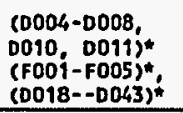 & 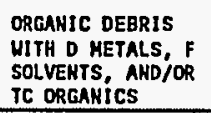 & & & & & & 5 & & & & & & & & & & & & & & \\
\hline
\end{tabular}

"I tems denoted with an asterisk are wastes that may contain any or all of the specified waste codes.

4 Moy or may not contain 0003 . 
$\because 4$

EGSG IDAHO, INC.

\begin{tabular}{|c|c|c|c|c|c|c|c|c|c|c|c|c|c|c|c|c|c|c|c|c|c|c|}
\hline \multirow{2}{*}{$\begin{array}{l}\text { ITEK } \\
\text { HO. }\end{array}$} & \multirow{2}{*}{$\begin{array}{l}\text { EPA } \\
\text { COOES }\end{array}$} & \multirow[t]{2}{*}{ DESCRIPTION } & \multicolumn{6}{|c|}{ RUMBER OF DRUMS } & \multicolumn{6}{|c|}{ DISPOSAL UNIT PRICE BY DRUM SIZE } & \multicolumn{6}{|c|}{ EXTENOED TOTAL PRICE } & \multirow{2}{*}{$\begin{array}{c}\text { TREATHENTI } \\
\text { DISPOSAL } \\
\text { METHOO }\end{array}$} & \multirow{2}{*}{$\begin{array}{l}\text { TSO FACILITY } \\
\text { NAME AND } \\
\text { LOCATION }\end{array}$} \\
\hline & & & $\begin{array}{l}1-5 \\
\text { GALL } \\
\text { DRUM }\end{array}$ & $\begin{array}{l}\text { 6-10 } \\
\text { GAL. } \\
\text { DRUW }\end{array}$ & $\begin{array}{l}19-15 \\
\text { GAL } \\
\text { DRUM }\end{array}$ & $\begin{array}{l}20 \\
\text { GNL } \\
\text { ORUH }\end{array}$ & $\begin{array}{l}30 \\
\text { GL. } \\
\text { ORLM }\end{array}$ & $\begin{array}{l}55 \\
\text { GALL } \\
\text { ORUH }\end{array}$ & $\begin{array}{l}1-5 \\
\text { GALL } \\
\text { DRUM }\end{array}$ & $\begin{array}{l}\text { O-10 } \\
\text { GALL } \\
\text { DRUM }\end{array}$ & $\begin{array}{l}19-15 \\
\text { GR. } \\
\text { ORLW }\end{array}$ & $\begin{array}{l}20 \\
\text { GRL. } \\
\text { ORUH }\end{array}$ & $\begin{array}{l}30 \\
\text { GAL. } \\
\text { DRUW }\end{array}$ & $\begin{array}{l}55 \\
\text { GAL. } \\
\text { DRLM }\end{array}$ & $\begin{array}{l}1-5 \\
\text { GRL. } \\
\text { DRUM }\end{array}$ & $\begin{array}{l}\text { G-10 } \\
\text { GALU. } \\
\text { DRUA }\end{array}$ & $\begin{array}{l}11-15 \\
\text { GAL } \\
\text { ORUM }\end{array}$ & $\begin{array}{l}20 \\
\text { GAL } \\
\text { ORUMY } \\
\text { ORU }\end{array}$ & $\begin{array}{l}30 \\
\text { GRL. } \\
\text { DRLM }\end{array}$ & $\begin{array}{l}55 \\
\text { GRL } \\
\text { DRUM }\end{array}$ & & \\
\hline 97 & $\begin{array}{l}0001,0003+ \\
(0004-0011)^{*}\end{array}$ & $\begin{array}{l}\text { SOLID OXIDIZER } \\
\text { HITH D HETALS }\end{array}$ & & & & & & & & & & & & & & & & & & & & \\
\hline 98 & $\begin{array}{l}0001,0003+, \\
60005,00007, \\
0008,0010, \\
0011)^{*}\end{array}$ & $\begin{array}{l}\text { SOLID OXIDIZER } \\
\text { WITH D METALS }\end{array}$ & & & & & & & & & & & & & & & & & & & & \\
\hline 99 & $\begin{array}{l}0001,0003+ \\
(0005-0008, \\
0010,0011)^{*}\end{array}$ & $\begin{array}{l}\text { SOLID OXIDIZER } \\
\text { UITH D METALS }\end{array}$ & & & & & & & & & & & & & & & & & & & & \\
\hline 100 & $\begin{array}{l}0001,0003+ \\
00004-0008, \\
0010,0011)_{*} \\
0.00\end{array}$ & $\begin{array}{l}\text { SOLID OXIDIZER } \\
\text { WITH D METALS }\end{array}$ & & & & & & & & & & & & & & & & & & & & \\
\hline 101 & $\begin{array}{l}0001,0003+ \\
(0005-0011)^{*}\end{array}$ & $\begin{array}{l}\text { SOLID OXIDIZER } \\
\text { UITH D METALS } \\
\end{array}$ & & & & & & 1 & & & & & & & & & & & & & & \\
\hline 102 & $0001,0003+$ & SOL1D OXIDIZER & & & & & & & & & & & & & & & & & & & & \\
\hline 103 & & AsBestos & & & & & & 1 & & & & & & & & & & & & & & \\
\hline 104 & 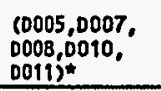 & $\begin{array}{l}\text { ASBESTOS UITH D } \\
\text { METALS }\end{array}$ & & & & & & & & & & & & & & & & & & & & \\
\hline 105 & $\begin{array}{l}(0005-D 008, \\
0010,0011)^{*}\end{array}$ & $\begin{array}{l}\text { ASBESTOS MITH D . } \\
\text { MEIALS }\end{array}$ & & & & & & 4 & & & & & & & & & & & & & & \\
\hline 106 & $\begin{array}{l}\text { (D0004-D008, } \\
\text { Do10, D011j* }\end{array}$ & $\begin{array}{l}\text { ASBESSTOS WITH DE } \\
\text { METALS }\end{array}$ & & & & & & & & & & & & & & & & & & & & \\
\hline
\end{tabular}

"I tems denoted with an asterisk ore wastes that may contoin any or all of the specified waste codes.

thay or may not contein D003. 
EGSG IDAHO, INC.

Attechment 22, Papo 17 or 30

\begin{tabular}{|c|c|c|c|c|c|c|c|c|c|c|c|c|c|c|c|c|c|c|c|c|c|c|}
\hline \multirow{2}{*}{$\begin{array}{l}\text { ITEM } \\
\text { Ho. }\end{array}$} & \multirow{2}{*}{$\begin{array}{l}\text { EPA } \\
\text { COOES }\end{array}$} & \multirow[t]{2}{*}{ DESCRIPTION } & \multicolumn{6}{|c|}{ NUMBER OF ORUMS } & \multicolumn{6}{|c|}{ DISPOSAL UNIT PRICE BY DRUM SIZE } & \multicolumn{6}{|c|}{ EXTENDED tOTAL PRICE } & \multirow{2}{*}{$\begin{array}{c}\text { TREATHEET/ } \\
\text { OISPOSAL } \\
\text { METHOO }\end{array}$} & \multirow{2}{*}{$\begin{array}{l}\text { TSO FACILITY } \\
\text { HAAE AHD } \\
\text { LOCATIOH }\end{array}$} \\
\hline & & & $\begin{array}{l}1-5 \\
\text { GA. } \\
\text { ORLYM }\end{array}$ & $\begin{array}{l}6-10 \\
\text { GAL. } \\
\text { ORUM }\end{array}$ & $\begin{array}{l}19-15 \\
\text { GALL } \\
\text { DRUM }\end{array}$ & $\begin{array}{l}20 \\
\text { GAL. } \\
\text { DRUY }\end{array}$ & $\begin{array}{l}30 \\
\text { GAL } \\
\text { ORUM }\end{array}$ & $\begin{array}{l}55 \\
\text { GAL. } \\
\text { DRUM }\end{array}$ & $\begin{array}{l}1-5 \\
\text { GA. } \\
\text { ORLUH }\end{array}$ & $\begin{array}{l}6-10 \\
\text { GAL. } \\
\text { DRUM }\end{array}$ & $\begin{array}{l}11-15 \\
\text { GALU } \\
\text { DRUM }\end{array}$ & $\begin{array}{l}20 \\
\text { GAL. } \\
\text { ORUM }\end{array}$ & $\begin{array}{l}30 \\
\text { GRL. } \\
\text { DRUMH }\end{array}$ & $\begin{array}{l}\text { SS } \\
\text { GAL. } \\
\text { DRUM }\end{array}$ & $\begin{array}{l}1-5 \\
\text { GAL. } \\
\text { ORRMA }\end{array}$ & $\begin{array}{l}6-10 \\
\text { GAL. } \\
\text { DRUM }\end{array}$ & $\begin{array}{l}11-15 \\
\text { GRL. } \\
\text { DRUM }\end{array}$ & $\begin{array}{l}20 \\
\text { GAL. } \\
\text { ORUS }\end{array}$ & $\begin{array}{l}30 \\
\text { GRL. } \\
\text { ORLM }\end{array}$ & \begin{tabular}{|l|}
55 \\
GAL. \\
DRIM
\end{tabular} & & \\
\hline 89 & 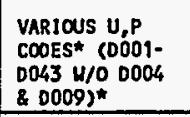 & OREAMIC DEBRIS & & & & & & & & & & & & & & & & & & & & \\
\hline 90 & 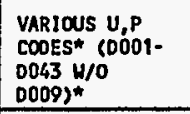 & ORGAHIC DEBRIS & & & & & & & & & & & & & & & & & & & & \\
\hline 91 & 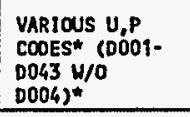 & ORGANIC DEBRIS. & & & & & & & & & & & & & & & & & & & & \\
\hline 92 & 0009 & $\begin{array}{l}\text { KERCURY } \\
\text { COHTAMIHATED } \\
\text { ORGAMIC DEQRIS }\end{array}$ & & & & & & 1 & & & & & & & & & & & & & & \\
\hline 93 & 0009 & $\begin{array}{l}\text { MERCURY } \\
\text { COWHATHATTED } \\
\text { IHORGANIC DEBRIS }\end{array}$ & & & & & & 2 & & & & & & & & & & & & & & \\
\hline 94 & $0001,0002,0005$ & 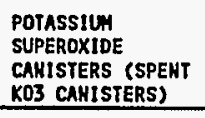 & & & & & & 15 & & & & & & & & & & & & & & \\
\hline 95 & 0003 & REACTIVE CYAHIDE & & & & & & & & & & & & & & & & & & & & \\
\hline 96 & 0003 & REACTIVE SULFIDE & & & & & & & & & & & & & & & & & & & & \\
\hline
\end{tabular}

"I tens denoted with an esterisk are wastes that may contain any or all of the specified waste codes.

+ May or may not contain D003.

PAGE TOTAL 
EG\&G IDAHO, INC.

Alechmort 22, Page 100130

\begin{tabular}{|c|c|c|c|c|c|c|c|c|c|c|c|c|c|c|c|c|c|c|c|c|c|c|}
\hline \multirow{2}{*}{$\begin{array}{l}\text { ITEH } \\
\text { HO. }\end{array}$} & \multirow{2}{*}{$\begin{array}{l}\text { EPA } \\
\text { COOES }\end{array}$} & \multirow[t]{2}{*}{ DESCRIPTION } & \multicolumn{6}{|c|}{ RUMBER OF DRUMS } & \multicolumn{6}{|c|}{ DISPOSAL UXIT PRICE BY DRUM SIZE } & \multicolumn{6}{|c|}{ EXTENOED TOTAL PRICE } & \multirow{2}{*}{$\begin{array}{l}\text { TREATHEHYI } \\
\text { DISPOSAL } \\
\text { METHOO }\end{array}$} & \multirow{2}{*}{$\begin{array}{l}\text { TSO FACLLITY } \\
\text { NAME AND } \\
\text { LOCATIOH }\end{array}$} \\
\hline & & & $\begin{array}{l}1.5 \\
\text { GALL. } \\
\text { DRUM }\end{array}$ & $\begin{array}{l}6-10 \\
\text { GAL: } \\
\text { ORLW }\end{array}$ & $\begin{array}{l}11-15 \\
\text { GALL } \\
\text { ORUM }\end{array}$ & $\begin{array}{l}20 \\
\text { GRL. } \\
\text { ORUM }\end{array}$ & $\begin{array}{l}30 \\
\text { GALL } \\
\text { DRUM }\end{array}$ & $\begin{array}{l}55 \\
\text { GAL } \\
\text { DRUM }\end{array}$ & $\begin{array}{l}1-5 \\
\text { GALL } \\
\text { ORUM }\end{array}$ & $\begin{array}{l}\text { 6-10 } \\
\text { GALL } \\
\text { DRRM }\end{array}$ & $\begin{array}{l}11-15 \\
\text { GLL. } \\
\text { ORLWM }\end{array}$ & $\begin{array}{l}20 \\
\text { GALL } \\
\text { DRUH }\end{array}$ & $\begin{array}{l}30 \\
\text { GRL } \\
\text { ORUM }\end{array}$ & $\begin{array}{l}\text { 55 } \\
\text { GALL } \\
\text { ORUM }\end{array}$ & $\begin{array}{l}1-5 \\
\text { GAL. } \\
\text { ORRUM }\end{array}$ & $\begin{array}{l}6-10 \\
\text { GAL. } \\
\text { ORUM }\end{array}$ & $\begin{array}{l}11-15 \\
\text { GALL } \\
\text { DRLM }\end{array}$ & $\begin{array}{l}20 \\
\text { GL. } \\
\text { ORUM }\end{array}$ & $\begin{array}{l}30 \\
\text { GAL. } \\
\text { ORLUM }\end{array}$ & $\begin{array}{l}55 \\
\text { GLL. } \\
\text { DRLM }\end{array}$ & & \\
\hline 107 & (D005-0011)* & $\begin{array}{l}\text { ASEESTOS WITH D } \\
\text { METALS }\end{array}$ & & & & & & 3 & & & & & & & & & & & & & & \\
\hline 108 & $D 001,0003$ & LITHIOM BATtERY & & & & & & & & & & & & & & & & & & & & \\
\hline 109 & & $\begin{array}{l}\text { ALKALINE } \\
\text { BATTERIES }\end{array}$ & & & & & & 12 & & & & & & & & & & & & & & \\
\hline 110 & 0006 & HICAD BATTERIES & & & & & & 8 & & & & & & & & & & & & & & \\
\hline$m$ & $D 001,0003$ & AEROSOL CAMS & & & & & & 3 & & & & & & & & & & & & & & \\
\hline 112 & $D 001,0003$ & $\begin{array}{l}\text { AEROSOL CANS - } \\
\text { VARIOUS FLAKAABLE } \\
\text { GAS }\end{array}$ & & & & & & 3 & & & & & & & & & & & & & & \\
\hline 113 & $\begin{array}{l}\text { DOO1,D003, } \\
\text { VARIOUS U } \\
\text { COOES } \\
\end{array}$ & AEROSOL CANS & & & & & & 3 & & & & & & & & & & & & & & \\
\hline 114 & 0002,0007 & CrH204 & & & & & & & & & & & & & & & & & & ' & & \\
\hline 115 & F032 & $\begin{array}{l}\text { PCP CONTAMIHATED } \\
\text { LIQUIDS - COHIIAIH } \\
\text { NO ISOMERS OF } \\
\text { DIOXINS }\end{array}$ & & & & & & 1 & & & & & & & & & & & & & & \\
\hline
\end{tabular}

*I tems denoted with an astorlsk ore wastes that may contain any or all of the specified waste codes.

thay or may not contoin D003. 
EG\&G IDAHO, INC.

\begin{tabular}{|c|c|c|c|c|c|c|c|c|c|c|c|c|c|c|c|c|c|c|c|c|c|c|}
\hline \multirow{2}{*}{$\begin{array}{l}\text { ITEH } \\
\text { HO. }\end{array}$} & \multirow{2}{*}{$\begin{array}{l}\text { EPA } \\
\text { COOES }\end{array}$} & \multirow[t]{2}{*}{ DESCRIPTION } & \multicolumn{6}{|c|}{ NUMBER OF DRUHS } & \multicolumn{6}{|c|}{ DISPOSAL UKIT PRICE BY DRUM SIZE } & \multicolumn{6}{|c|}{ EXTEKDED TOTAL PRICE } & \multirow{2}{*}{$\begin{array}{c}\text { TREATKEHYI } \\
\text { DISPOSAL } \\
\text { METHOD }\end{array}$} & \multirow{2}{*}{$\begin{array}{l}\text { TSO FACILITY } \\
\text { MAME AND } \\
\text { LOCATIOH }\end{array}$} \\
\hline & & & $\begin{array}{l}1-5 \\
\text { GRL. } \\
\text { GRUM }\end{array}$ & $\begin{array}{l}6-10 \\
\text { GAL } \\
\text { DRUM }\end{array}$ & $\begin{array}{l}11-15 \\
\text { GLL } \\
\text { DRUM }\end{array}$ & $\begin{array}{l}20 \\
\text { GAL. } \\
\text { DRLM }\end{array}$ & $\begin{array}{l}30 \\
\text { GRL } \\
\text { ORUH }\end{array}$ & $\begin{array}{l}55 \\
\text { GR.L } \\
\text { DRLM }\end{array}$ & $\begin{array}{l}9-5 \\
\text { GAR. } \\
\text { DRUM }\end{array}$ & $\begin{array}{l}6.10 \\
\text { GAL. } \\
\text { GRUM }\end{array}$ & $\begin{array}{l}11-15 \\
\text { GR. } \\
\text { ORUMY }\end{array}$ & $\begin{array}{l}20 \\
\text { GAL. } \\
\text { DRUM }\end{array}$ & $\begin{array}{l}30 \\
\text { GRL } \\
\text { DRUM }\end{array}$ & $\begin{array}{l}55 \\
\text { GRL } \\
\text { ORUM }\end{array}$ & $\left|\begin{array}{c}1-5 \\
\text { GRL. } \\
\text { DRLM }\end{array}\right|$ & $\begin{array}{l}6-10 \\
\text { GAL. } \\
\text { ORUM }\end{array}$ & $\begin{array}{l}19-15 \\
\text { GAL } \\
\text { ORUM }\end{array}$ & $\begin{array}{l}20 \\
\text { GRL. } \\
\text { DRUM }\end{array}$ & $\begin{array}{l}30 \\
\text { GAL } \\
\text { ORUM }\end{array}$ & $\begin{array}{l}55 \\
\text { GALL. } \\
\text { DRUM }\end{array}$ & & \\
\hline 130 & PCB. & $\begin{array}{l}\text { DRAIMED PCB XFMER } \\
\text { OIL } 50-500 \mathrm{pPM} \\
\text { AGED }>365 \text { DAYS } \\
\end{array}$ & & & & & & & & & & & & & & & & & & & & \\
\hline 131 & PCB & $\begin{array}{l}\text { DRAITHED PCB XFNER } \\
\text { O1L >500 PPPA AGED } \\
<275 \text { DAYS } \\
\end{array}$ & & & & & & & & & & & & & & & & & & & & \\
\hline 132 & PCB & $\begin{array}{l}\text { ORAINED PCB XFHER } \\
\text { OIL } 3500 \text { Ppon AGED } \\
275-335 \text { DAYS } \\
\end{array}$ & & & & & & & & & & & & & & & & & & & & \\
\hline 133 & PCB & $\begin{array}{l}\text { ORAINED PCE XFMER } \\
\text { OOIL }>500 \text { ppm AGED } \\
336-365 \text { DAYS }\end{array}$ & & & & & & & & & & & & & & & & & & & & \\
\hline 134 & PCB & $\begin{array}{l}\text { DRAINED PCB XFHER } \\
\text { OIL }>500 \text { pppm AGED } \\
>365 \text { DAYS } \\
\end{array}$ & & & & & & & & & & & & & & & & & & & & \\
\hline 135 & РСв & $\begin{array}{l}\text { PCB CONTAMIHATED } \\
\text { WATER AGED <2RT } \\
\text { DAYS (SOURCE- } \\
\text { XFMER <500 pPpm) } \\
\end{array}$ & & & & & & & & & & & & & & & & & & & & \\
\hline 136 & PCB & $\begin{array}{l}\text { PCB COHTAMIHATED } \\
\text { HATER AGED <275 } \\
\text { DAYS (SOURCE- } \\
\text { XFMER >500 PPA). }\end{array}$ & & & & & & & & & & & & & & & & & & & . & \\
\hline
\end{tabular}


EGRG IDAHO, INC.

Aftuchmont 22, Page 21 of 30

\begin{tabular}{|c|c|c|c|c|c|c|c|c|c|c|c|c|c|c|c|c|c|c|c|c|c|c|}
\hline \multirow{2}{*}{$\begin{array}{l}\text { ITEK } \\
\text { HO. }\end{array}$} & \multirow{2}{*}{$\underset{\text { CPPA }}{\text { ECOES }}$} & \multirow{2}{*}{ DESCRIPTION } & \multicolumn{6}{|c|}{ RUMBER OF DRUMS } & \multicolumn{6}{|c|}{ DISPOSAL UNIT PRICE GY DRUM SIZE } & \multicolumn{6}{|c|}{ EXTERDED tOTAL PRICE } & \multirow{2}{*}{$\begin{array}{c}\text { TREASHENTI } \\
\text { DISPOSAL } \\
\text { METHOO }\end{array}$} & \multirow{2}{*}{$\begin{array}{l}\text { TSO FACLLIITY } \\
\text { TAAMEAAD } \\
\text { LOCATIOH }\end{array}$} \\
\hline & & & $\begin{array}{l}1-5 \\
\text { GAL. } \\
\text { ORLA }\end{array}$ & $\begin{array}{l}\text { 6-10 } \\
\text { GAL. } \\
\text { DRLM }\end{array}$ & $\begin{array}{l}11-15 \\
\text { GALLM } \\
\text { ORUM }\end{array}$ & \begin{tabular}{|l}
20 \\
GAL. \\
ORLM
\end{tabular} & $\begin{array}{l}30 \\
\text { GAL. } \\
\text { DRUA }\end{array}$ & $\begin{array}{l}55 \\
\text { GALL } \\
\text { DRLM }\end{array}$ & $\begin{array}{l}1-5 \\
\text { GAL. } \\
\text { DRUM }\end{array}$ & $\begin{array}{l}\text { 6-10 } \\
\text { GAL. } \\
\text { DRUM }\end{array}$ & $\begin{array}{l}11-15 \\
\text { GRL. } \\
\text { DRUM }\end{array}$ & $\begin{array}{l}20 \\
\text { GAL. } \\
\text { DRUY }\end{array}$ & $\begin{array}{l}30 \\
\text { GAL. } \\
\text { DRUM }\end{array}$ & $\begin{array}{l}55 \\
\text { GAL. } \\
\text { DRUM }\end{array}$ & $\begin{array}{l}1.5 \\
\text { GAL. } \\
\text { DRUM }\end{array}$ & $\begin{array}{l}6-10 \\
\text { GAL. } \\
\text { DRLM }\end{array}$ & $\begin{array}{l}11-15 \\
\text { GRL. } \\
\text { DRUM }\end{array}$ & $\begin{array}{l}20 \\
\text { GAL. } \\
\text { ORUM }\end{array}$ & $\begin{array}{l}30 \\
\text { GAL. } \\
\text { ORUM }\end{array}$ & $\begin{array}{l}55 \\
\text { GALL } \\
\text { ORUM }\end{array}$ & & \\
\hline 122 & $\begin{array}{l}0001,0004- \\
00111^{2}=0005 * \\
\text { Fo01-F005* }\end{array}$ & 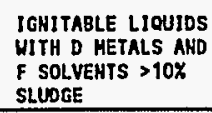 & & & & & & 2 & & & & & & & & & & & & & & \\
\hline 123 & PCB & 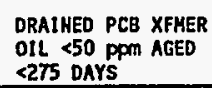 & & & & & & 1 & & & & & & & & & & & & & & \\
\hline 124 & PCB & 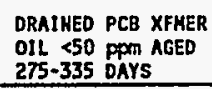 & & & & & & & & & & & & & & & & & & & & \\
\hline 125 & PCB & 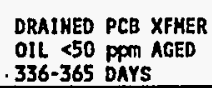 & & & & & & & & & & & & & & & & & & & & \\
\hline 126 & PCB & 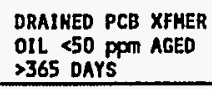 & & & & & & & & & & & & & & & & & & & & \\
\hline 127 & PCB & 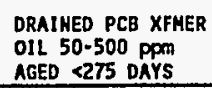 & & & & & & 1 & & & & & & & & & & & & & & \\
\hline 128 & PCB & 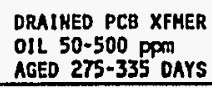 & & & & & & & & & & & & & & & & & & & & \\
\hline 129 & PCB & 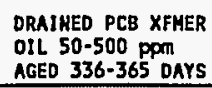 & & & & & & & & & & & & & & & & & & & & \\
\hline
\end{tabular}

-I tems denoted with an asterisk are wastes that may contain any or all of the specified waste codes.

+ May or moy not contaín D003.

PAGE TOTAL 

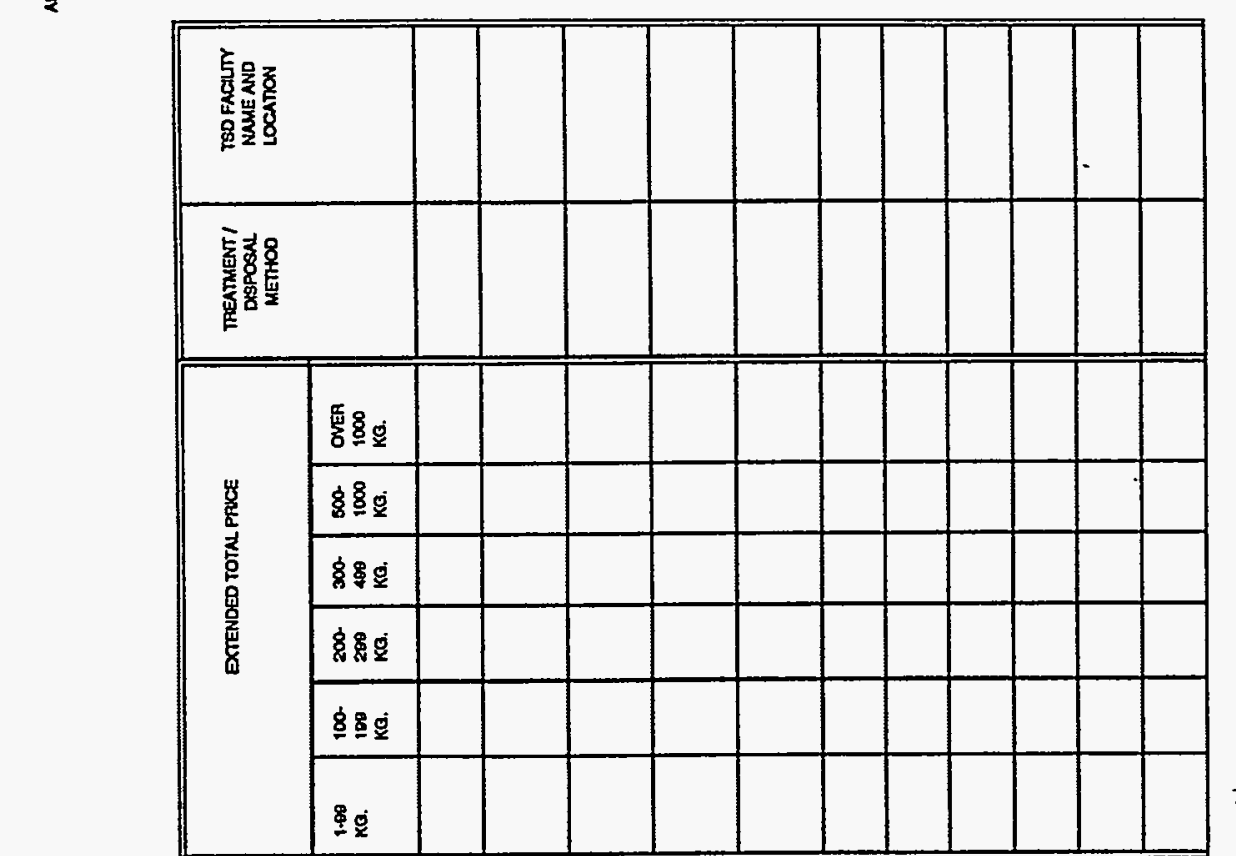

\begin{tabular}{|c|c|c|c|c|c|c|c|c|c|c|c|c|}
\hline \multirow{6}{*}{ 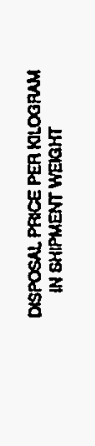 } & 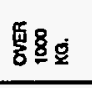 & & & & & & & & & & & \\
\hline & 88 & & & & & & & & & & & \\
\hline & 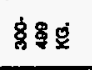 & & & & & & & & & & & \\
\hline & 유. కీ & & & & & & & & & & & \\
\hline & 888 & & & & & & & & & & & \\
\hline & $\$ 8$ & & & & & & & & & & & \\
\hline \multirow{6}{*}{ 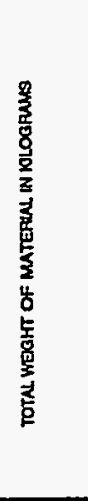 } & 58 & & & & & & & & & & & \\
\hline & 88 & & & & & & & & & & & \\
\hline & $88^{\circ}$ & & & & & & $\begin{array}{l}8 \\
8 \\
\end{array}$ & & & & & \\
\hline & 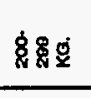 & & & & & & & & & & & \\
\hline & $\begin{array}{l}8 \\
8 \\
\end{array}$ & $\begin{array}{l}8 \\
8\end{array}$ & si & & & & & & & & & \\
\hline & $\$$ & & & & & & & & & & & \\
\hline 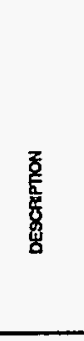 & & 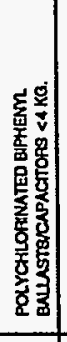 & 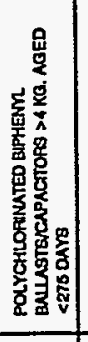 & 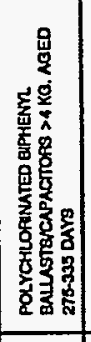 & 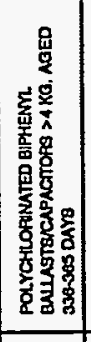 & 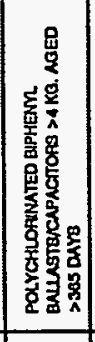 & 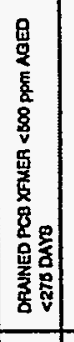 & 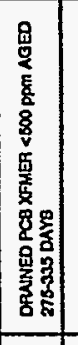 & 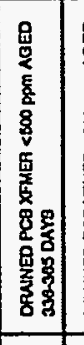 & 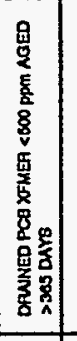 & 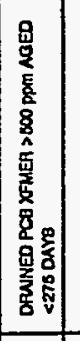 & 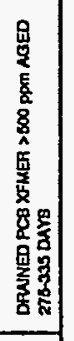 \\
\hline 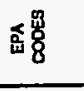 & & 8 & 8 & 8 & 8 & 8 & 8 & 8 & 8 & 8 & 8 & 8 \\
\hline 胥定 & & $\equiv$ & $q$ & $?$ & \pm & 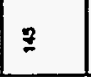 & & $\Xi$ & 9 & 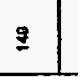 & $\underline{8}$ & $\overline{5}$ \\
\hline
\end{tabular}


EGRG IDAHO, INC.

Atachmont 22, Page 23 O1 39

\begin{tabular}{|c|c|c|c|c|c|c|c|}
\hline $\begin{array}{l}\text { ITEM } \\
\text { HO. }\end{array}$ & DESCRIPTION & OUANTITY & UAIT & UNIT PRICE & EXTERDED OVERALL PRICE & TREATMENT/DISPOSAL METHDO & $\begin{array}{l}\text { TSD FACILLTY } \\
\text { RAME AND LOCATIOH }\end{array}$ \\
\hline 137 & BULK SOLIDS - HOH LDR & & & & & & \\
\hline 138 & $\begin{array}{l}\text { BULK ORGANIC DEBRIS } \\
\text { CONTANIMATED MITH VARIOUS D } \\
\text { COOES EXCLUDING DO04, DO09 }\end{array}$ & & & & & & \\
\hline 139 & $\begin{array}{l}\text { HAKOLLING AND DISPOSAR OF DRUMS } \\
\text { USED AS OVERPACK DRLNS AND HOT } \\
\text { CONTAIHIHG LEAKAGE (5-90 GAL. } \\
\text { SIZES) }\end{array}$ & & & & & & \\
\hline 140 & $\begin{array}{l}\text { HANDLLIHG AND DISPOSAL OF DRUMS } \\
\text { USED AS OVERPACK DRLMS AND } \\
\text { CONTAINING LEAKAGE (5-90 GRL. } \\
\text { SIZES) }\end{array}$ & & & & & & \\
\hline
\end{tabular}

NOTE 1 - Pricing for bulk shipnents in excess of 1 ton shall be negotiated on a case-by-case basis. 
Hor

EGRG IDAHO, INC.

\begin{tabular}{|c|c|c|c|c|c|c|c|c|c|c|c|c|c|c|c|c|c|c|c|c|c|c|}
\hline \multirow{2}{*}{ 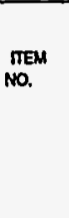 } & \multirow[t]{2}{*}{$\begin{array}{l}\text { ERA } \\
\text { cooss }\end{array}$} & \multirow[t]{2}{*}{ Descarentar } & \multicolumn{6}{|c|}{ 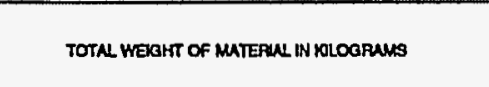 } & \multicolumn{6}{|c|}{ 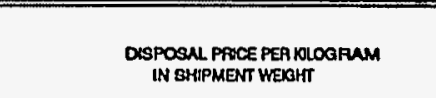 } & \multicolumn{6}{|c|}{ DRENDED TOTN PACE } & \multirow{2}{*}{ 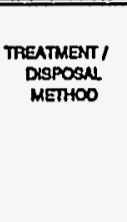 } & \multirow{2}{*}{ 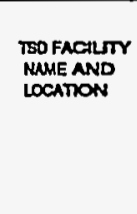 } \\
\hline & & & $\begin{array}{l}109 \\
\mathrm{ka}\end{array}$ & 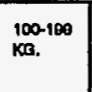 & 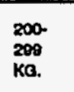 & 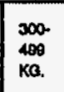 & \begin{tabular}{|l|}
$\begin{array}{c}500 \\
100 \\
k 0 .\end{array}$ \\
$k \times 0$
\end{tabular} & 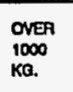 & $\begin{array}{l}1.00 \\
\text { אa. }\end{array}$ & 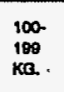 & 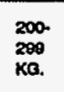 & \begin{tabular}{|l|}
500 \\
soo \\
ka.
\end{tabular} & 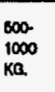 & $\begin{array}{l}\text { oven } \\
\substack{1000 \\
\text { Ka: }}\end{array}$ & 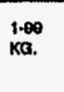 & \begin{tabular}{|l|l}
1000 \\
and \\
$k \mathrm{ka}$
\end{tabular} & 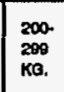 & 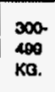 & \begin{tabular}{|l}
500 \\
1000 \\
$k 0$.
\end{tabular} & 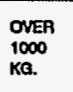 & & \\
\hline 100 & PCB & 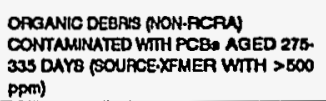 & & & & & & & & & & & & & & & & & & & & \\
\hline 184 & $\mathrm{PCB}$ & 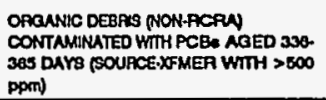 & & & & & & & & & & & & & & & & & & & & \\
\hline 185 & PCB & 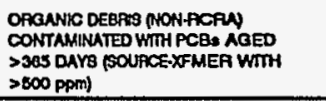 & & & & & & & & & & & & & & & & & & & & \\
\hline 100 & PCs & 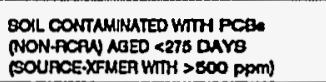 & & $100 \mathrm{~kg}$ & & & & & & & & & & & & & & & & & & \\
\hline 107 & PCs & 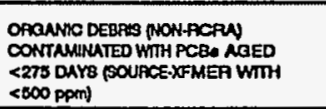 & & & & & & & & & & & & & & & & & & & & \\
\hline 100 & pess & 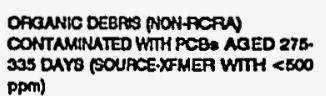 & & & & & & & & & & & & & & & & & & & & \\
\hline $1 \infty$ & Pes & 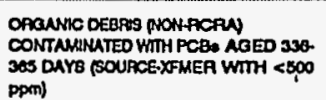 & & & & & & & & & & & & & & & & & & & & \\
\hline
\end{tabular}

*Iterns denoted with an asterisk are wastes that may contain any or all of the specified waste codes.

thay or may not contain D003. 

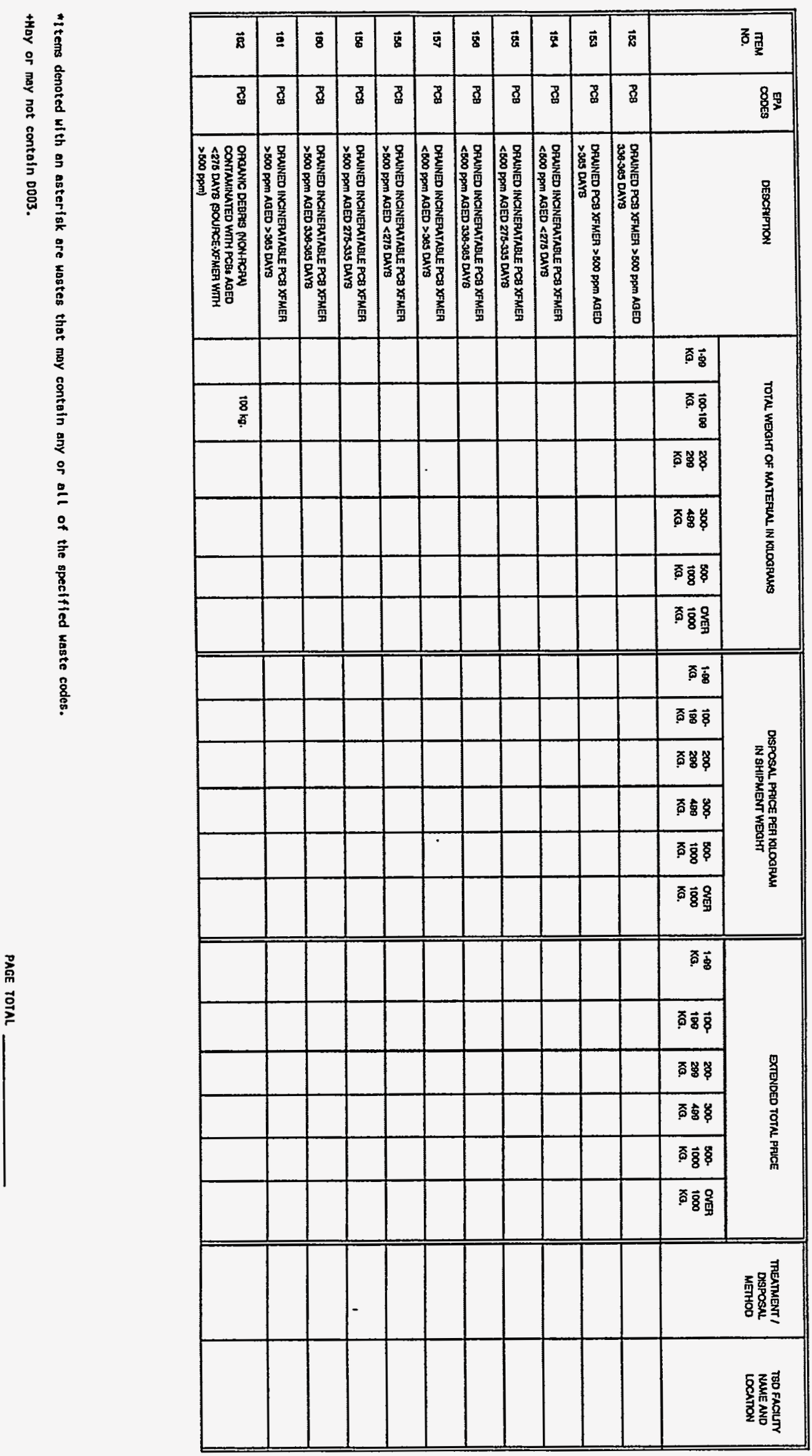
$\because 49 \mathrm{a}$

EGEG IDAHO, INC.

Ateschmont 2, Pase 280130

\begin{tabular}{|c|c|c|c|c|c|c|c|c|c|c|c|c|c|c|c|c|c|c|c|c|}
\hline \multirow[t]{2}{*}{$\begin{array}{l}\text { ITEM } \\
\text { No. }\end{array}$} & \multirow[t]{2}{*}{ EPA CODES } & \multirow[t]{2}{*}{$\begin{array}{l}\text { DISPOSAL OF } \\
\text { LAB PACKS }\end{array}$} & \multicolumn{5}{|c|}{$\begin{array}{l}\text { RUMEER OF ORUMS } \\
\text { LAB PACKS }\end{array}$} & \multicolumn{5}{|c|}{$\begin{array}{l}\text { UNIT PRICE BY DRUY SIZE } \\
\text { LAB PACKS } \\
\end{array}$} & \multicolumn{5}{|c|}{$\begin{array}{l}\text { EXTENDED PRICE BY DRUM SIZZ } \\
\text { LAB PACKS }\end{array}$} & \multirow[t]{2}{*}{$\begin{array}{l}\text { TOTAL PRICE } \\
\text { FOR ALL } \\
\text { ORUM SIZES } \\
\end{array}$} & \multirow[t]{2}{*}{$\begin{array}{c}\text { TREATMENT / } \\
\text { DISPOSAL METKOD }\end{array}$} & \multirow[t]{2}{*}{$\begin{array}{l}\text { TSO FACILITY } \\
\text { NAME AAO } \\
\text { LOCAIION } \\
\end{array}$} \\
\hline & & & $\begin{array}{l}1-5 \\
\text { GAL. } \\
\text { DRUH }\end{array}$ & $\begin{array}{l}6-10 \\
\text { GRL. } \\
\text { DRUH }\end{array}$ & $\begin{array}{l}\text { 11-20 } \\
\text { GAL } \\
\text { DRUM }\end{array}$ & $\begin{array}{l}21-30 \\
\text { GAL. } \\
\text { DRUM }\end{array}$ & $\begin{array}{l}31- \\
55 \\
\text { GAL. } \\
\text { DRUM }\end{array}$ & $\begin{array}{l}1-5 \\
\text { GAL. } \\
\text { ORUM }\end{array}$ & $\begin{array}{l}6-10 \\
\text { GAL. } \\
\text { ORUM }\end{array}$ & $\begin{array}{l}111-20 \\
\text { GAL. } \\
\text { ORUM }\end{array}$ & $\begin{array}{l}21-30 \\
\text { GAL. } \\
\text { ORUM }\end{array}$ & $\begin{array}{l}31-55 \\
\text { GRLL } \\
\text { ORUM }\end{array}$ & $\begin{array}{l}1-5 \\
\text { GAL. } \\
\text { DRUM }\end{array}$ & $\begin{array}{l}\text { 6-10 } \\
\text { GAL. } \\
\text { ORUM }\end{array}$ & $\begin{array}{l}11-20 \\
\text { GAL. } \\
\text { DRUM }\end{array}$ & $\begin{array}{l}21-30 \\
\text { GAL } \\
\text { ORUM }\end{array}$ & $\begin{array}{l}31-55 \\
\text { GAL } \\
\text { ORUM }\end{array}$ & & & \\
\hline 201 & $\begin{array}{l}0002,(0004- \\
0011)^{\star} \\
x^{*}\end{array}$ & $\begin{array}{l}\text { ACID LIQUIDS WITH } \\
\text { D METALS (MEAK } \\
\text { ACID SOLUTIOHS) } \\
\end{array}$ & & & & 5 & 5 & & & & & & & & & & & & & \\
\hline 202 & $\begin{array}{l}0002,0005, \\
0007,0008, \\
0010,0011)^{*}\end{array}$ & $\begin{array}{l}\text { ACID LIQUIDS WITH } \\
\text { D METALS (WEAK } \\
\text { ACID SOLUTIOHS) } \\
\end{array}$ & 2 & & & & & & & & & & & & & & & & & \\
\hline 203 & $\begin{array}{l}\text { Do02, (D005- } \\
\text { Do08, D0010. } \\
\text { Do11)* }\end{array}$ & $\begin{array}{l}\text { ACID LIQUTDS UITH } \\
\text { D METALS (WEAK } \\
\text { ACID SOLUTIOHS) }\end{array}$ & 10 & & & & & & & & & & & & & & & & & \\
\hline 204 & $\begin{array}{l}0002,(0004- \\
0008,0010 . \\
0011)^{\star}\end{array}$ & $\begin{array}{l}\text { ACID LLQUUDS WITH } \\
\text { O METALS (WEER } \\
\text { ACID SOLUTIOHS) } \\
\end{array}$ & & & & & & & & & & & & & & & & & & \\
\hline 205 & $\begin{array}{l}\text { D002, (D005- } \\
\text { D011)** }\end{array}$ & $\begin{array}{l}\text { ACID LIQUIDS HITH } \\
\text { O HETALS (MEAK } \\
\text { ACIO SOLUTIONS) } \\
\end{array}$ & & & & & & & & & & & & & & & & & & \\
\hline 206 & $(0004-0011)^{*}$ & $\begin{array}{l}\text { MEUTRRL LIOUIDS } \\
\text { MITHA OHETALS } \\
\text { (LIOUUDS AHD } \\
\text { SLUOGES) } \\
\end{array}$ & 1 & & & & & & & & & & & & & & & & & \\
\hline 207 & 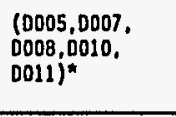 & $\begin{array}{l}\text { MEUTRAL LIOUIDS } \\
\text { MUTH D HETALS } \\
\text { (LLQUDS AAD } \\
\text { SLUDGES) } \\
\end{array}$ & 1 & & 1 & & & & & & & & & & & & & & . & \\
\hline 208 & $\begin{array}{l}\text { (0005-D008; } \\
\text { D010,0011) }\end{array}$ & $\begin{array}{l}\text { MEUTRAL LIOUIDS } \\
\text { UYTH O METILS } \\
\text { (LIQUIDS AND } \\
\text { SLUDGES) }\end{array}$ & & & & & & & & & & & & & & & & & & \\
\hline 209 & $\begin{array}{l}\text { (0004-0008; } \\
0010,0011)^{*}\end{array}$ & $\begin{array}{l}\text { MEUTRAL LIOUIDS } \\
\text { HITH D RETALS } \\
\text { (LLQUIDS AND } \\
\text { SLUOGES) }\end{array}$ & 1 & & & & & & & & & & & & & & & & & \\
\hline
\end{tabular}

*Items denoted with an asterisk are wastes that may conta in any or all of the specified waste codes.

thay or may not conta in 0003.

PAGE TOTAL 


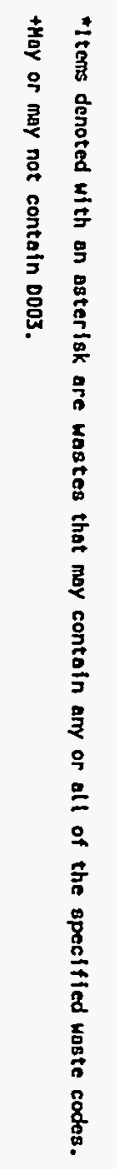

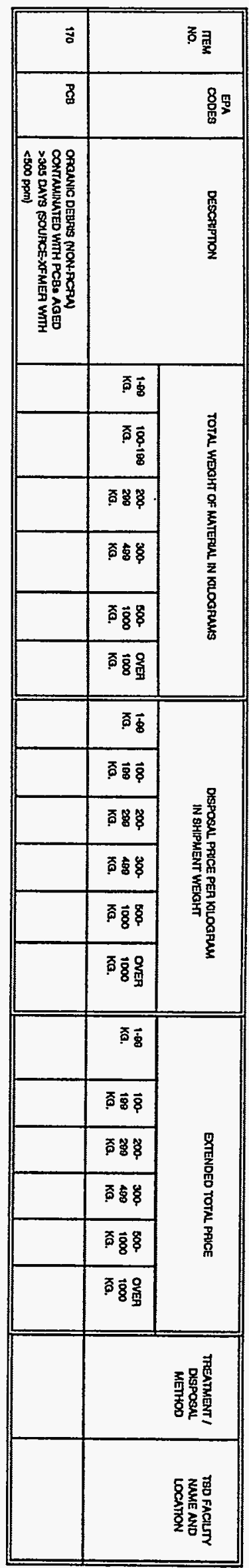

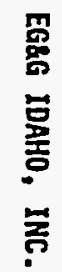

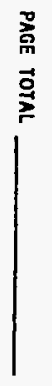



EGRG IDAHO, INC.

Attachmont 22, Pape za of 30

\begin{tabular}{|c|c|c|c|c|c|c|c|c|c|c|c|c|c|c|c|c|c|c|c|c|}
\hline \multirow[t]{2}{*}{$\begin{array}{c}\text { ITEM } \\
\text { HO. }\end{array}$} & \multirow[t]{2}{*}{ EPA CODES } & \multirow{2}{*}{$\frac{\text { DISPOSAL OF }}{\text { LAB PACKS }}$} & \multicolumn{5}{|c|}{$\begin{array}{l}\text { NUMBER OF DRUMS } \\
\text { LAB PACKS }\end{array}$} & \multicolumn{5}{|c|}{$\begin{array}{c}\text { UHIT PRICE BY DRUM SIZE } \\
\text { LAB PACKS }\end{array}$} & \multicolumn{5}{|c|}{$\begin{array}{c}\text { EXTENDED PRICE BY DRUM SIZE } \\
\text { LAB PACKS }\end{array}$} & \multirow{2}{*}{$\begin{array}{l}\text { TOTAL PRICE } \\
\text { FOR ALL } \\
\text { FRUM SIZES } \\
\end{array}$} & \multirow[t]{2}{*}{$\begin{array}{c}\text { TREATMEHT / } \\
\text { DISPOSAL METHOD }\end{array}$} & \multirow{2}{*}{$\begin{array}{l}\text { TSD FACILITY } \\
\text { MAME AND } \\
\text { LOCATIOH } \\
\end{array}$} \\
\hline & & & $\begin{array}{l}1-5 \\
\text { GAL. } \\
\text { ORUH }\end{array}$ & $\begin{array}{l}6-10 \\
\text { GAL. } \\
\text { ORUH }\end{array}$ & $\begin{array}{l}11-20 \\
\text { GAL } \\
\text { ORUM }\end{array}$ & $\begin{array}{l}21-30 \\
\text { GAL. } \\
\text { ORUM }\end{array}$ & $\begin{array}{l}31- \\
55 \\
\text { GAL. } \\
\text { ORUH }\end{array}$ & $\begin{array}{l}1-5 \\
\text { GALU } \\
\text { ORUM }\end{array}$ & $\begin{array}{l}6-10 \\
\text { GAL. } \\
\text { ORUM }\end{array}$ & $\begin{array}{l}11-20 \\
\text { GAL.: } \\
\text { DRUM }\end{array}$ & $\begin{array}{l}21-30 \\
\text { GAL } \\
\text { ORUH }\end{array}$ & $\begin{array}{l}31-55 \\
\text { GALL } \\
\text { ORUM }\end{array}$ & $\begin{array}{l}1-5 \\
\text { GAL. } \\
\text { ORUM }\end{array}$ & $\begin{array}{l}6-10 \\
\text { GAL. } \\
\text { DRUM }\end{array}$ & $\begin{array}{l}11-20 \\
\text { GAL. } \\
\text { DRUM }\end{array}$ & $\begin{array}{l}21-30 \\
\text { GAL } \\
\text { ORUM }\end{array}$ & $\begin{array}{l}31-55 \\
\text { GALU } \\
\text { DRUM }\end{array}$ & & & \\
\hline 210 & $(0005-0011)^{*}$ & $\begin{array}{l}\text { MEUTRAL LIQUIDS } \\
\text { WITH D METALS } \\
\text { (LIOUIDS AND } \\
\text { SLUGGES) }\end{array}$ & 1 & & 1 & & & & & & & & & & & & & & & \\
\hline 211 & $\begin{array}{l}\text { D002,(D004- } \\
\text { D011)* }\end{array}$ & $\begin{array}{l}\text { CAUSTIC LIOUIOS } \\
\text { IITH D METALS } \\
\text { (HEAK CAUSTIC } \\
\text { SOLUTIOHST } \\
\end{array}$ & & & & 5 & 10 & & & & & & & & & & & & & . \\
\hline 212 & $\begin{array}{l}\text { D002,(0005, } \\
\text { D007,0008; } \\
0010,0011 \text {; * }\end{array}$ & $\begin{array}{l}\text { CAUSTIC LIQUIDS } \\
\text { VITH D METALS } \\
\text { (WEAK CAUSTIC } \\
\text { SOLUTIONS) } \\
\end{array}$ & 1 & & 1 & 1 & & & & & & & & & & & & & & \\
\hline 213 & $\begin{array}{l}\text { Door., (D005- } \\
\text { D008,p010. } \\
\text { D011)* }\end{array}$ & $\begin{array}{l}\text { CAUSTIC LIOUIDS } \\
\text { WITH D METALS } \\
\text { (MEAC CAUSTIC } \\
\text { SOLUTIONS) } \\
\end{array}$ & & & & & & & & & & & & & & & & & & \\
\hline 214 & $\begin{array}{l}\text { Do02, (D0004- } \\
\text { Do08, } 0010 . \\
\text { Do11)** }\end{array}$ & $\begin{array}{l}\text { CAUSTIC LIQUIDS } \\
\text { WITH D MEALAS } \\
\text { (WEAK CAUSYIC } \\
\text { SOLUTIONS) }\end{array}$ & & & & & & & & & & & & & & & & & & \\
\hline 215 & $\begin{array}{l}0002 \\
(0005-0011)^{\star}\end{array}$ & $\begin{array}{l}\text { CAUSTIC LIOUIDS } \\
\text { WHIH D METALS } \\
\text { (MEAC CAUSTIC } \\
\text { SOLUIIONS) } \\
\end{array}$ & & . & & & & & & & & & & & & & & & & \\
\hline 216 & 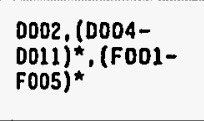 & $\begin{array}{l}\text { ACID LIQUIDS UITH } \\
\text { O HEEALS AND F } \\
\text { SOLVENTS (WEAK } \\
\text { ACID SOLUTIONS) }\end{array}$ & & & & & & & & & & & & & & & & & & \\
\hline
\end{tabular}


EG\&G IDAHO, INC.

\begin{tabular}{|c|c|c|c|c|c|c|c|c|c|c|c|c|c|c|c|c|c|c|c|c|}
\hline \multirow[t]{2}{*}{$\begin{array}{l}\text { ITEM } \\
\text { No. }\end{array}$} & \multirow[t]{2}{*}{ EPA CODES } & \multirow[t]{2}{*}{$\begin{array}{l}\text { DISPOSAL OF } \\
\text { LAB PACKS }\end{array}$} & \multicolumn{5}{|c|}{$\begin{array}{l}\text { MUMBER OF ORUMS } \\
\text { LAB PACKS }\end{array}$} & \multicolumn{5}{|c|}{$\begin{array}{c}\text { UNIT PRICE BY DRUY SIZE } \\
\text { IAB PACKS }\end{array}$} & \multicolumn{5}{|c|}{$\begin{array}{l}\text { EXTENDED PRICE BY ORUM SIZE } \\
\text { LAB PACKS }\end{array}$} & \multirow[t]{2}{*}{$\begin{array}{l}\text { TOTAL PRICE } \\
\text { FOR ALIL } \\
\text { ORUH SIZES } \\
\end{array}$} & \multirow[t]{2}{*}{$\begin{array}{c}\text { TREATHENT / } \\
\text { DISPOSAL METHOD }\end{array}$} & \multirow[t]{2}{*}{$\begin{array}{l}\text { TSO FACLLITY } \\
\text { MAME AND } \\
\text { LOCATIOH } \\
\end{array}$} \\
\hline & & & $\begin{array}{l}1-5 \\
\text { GAL. } \\
\text { ORUH }\end{array}$ & $\begin{array}{l}\text { 6-10 } \\
\text { GAL. } \\
\text { ORUM }\end{array}$ & $\begin{array}{l}11-20 \\
\text { GAL. } \\
\text { DRUH }\end{array}$ & $\begin{array}{l}21-30 \\
\text { GAL } \\
\text { DRUM }\end{array}$ & $\begin{array}{l}31- \\
55 \\
\text { GAL. } \\
\text { DRUM }\end{array}$ & $\begin{array}{l}1-5 \\
\text { GAL. } \\
\text { ORUM }\end{array}$ & $\begin{array}{l}\text { 6-10 } \\
\text { GAL. } \\
\text { ORUM }\end{array}$ & $\begin{array}{l}\text { 11-20 } \\
\text { GALL } \\
\text { DRUM }\end{array}$ & $\begin{array}{l}21-30 \\
\text { GALL } \\
\text { DRUH }\end{array}$ & $\begin{array}{l}31-55 \\
\text { GAL. } \\
\text { ORUM }\end{array}$ & $\begin{array}{l}1-5 \\
\text { GAL. } \\
\text { DRUM }\end{array}$ & $\begin{array}{l}\text { G-10 } \\
\text { GA. } \\
\text { ORUH }\end{array}$ & \begin{tabular}{|l}
$11-20$ \\
GALO \\
ORUM
\end{tabular} & $\begin{array}{l}21-30 \\
\text { GAL.M } \\
\text { DRUM }\end{array}$ & $\begin{array}{l}31-55 \\
\text { GALL } \\
\text { DRUM }\end{array}$ & & & \\
\hline 231 & 0001,0002 & $\begin{array}{l}\text { IGNITABLE } \\
\text { CORROSIVE LIQUIDS } \\
\text { (LIQUIDS AND } \\
\text { SLUDGES) >10\% } \\
\text { SLUDGE }\end{array}$ & & & & & & & & & & & & & & & & & & \\
\hline 232 & $\begin{array}{l}\text { D001. } \\
(0004-D 011)^{*}\end{array}$ & $\begin{array}{l}\text { IGHITALLE LIDUIDS } \\
\text { WITH O R HETALS } \\
\leq 10 \% \text { SLUOGE } \\
\end{array}$ & & & & & & & & & & & & & & & & & & \\
\hline 233 & $\begin{array}{l}0001 . \\
(0004-0011)^{*}\end{array}$ & $\begin{array}{l}\text { IGNITABLE LIQUIDS } \\
\text { HIIH D METALS } \\
>10 \% \text { SLUDGE }\end{array}$ & & & & & & & & & & & & & & & & & & \\
\hline 234 & $\begin{array}{l}0001,(0005, \\
0007,0008, \\
0010,0011)^{*}\end{array}$ & $\begin{array}{l}\text { IGHITABLE LIQUIDS } \\
\text { WITH O HETALS } \\
<0 \% \text { SLUDGE }\end{array}$ & 1 & & & & & & & & & & & & & & & & & \\
\hline 235 & 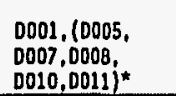 & $\begin{array}{l}\text { IGHITABLE LIQUIDS } \\
\text { MIIH D RETALLS } \\
\rightarrow 10 \% \text { SLUOGE }\end{array}$ & & & & & & & & & & & & & & & & & & \\
\hline 236 & $\begin{array}{l}0001,(10005- \\
\text { Do08.,0010. } \\
\text { D011) }\end{array}$ & $\begin{array}{l}\text { IGHITABLE LIQUIDS } \\
\text { WIIH D REETALS } \\
\leq 10 \% \text { SLUDGE }\end{array}$ & & & & & & & & & & & & & & & & & & \\
\hline 237 & $\begin{array}{l}0001,(0005- \\
0000,0010 . \\
0011)^{*}\end{array}$ & $\begin{array}{l}\text { IGHITAGLE LIQUIDS } \\
\text { WITH O H HETALS } \\
\rightarrow 10 \% \text { SLUOGE }\end{array}$ & & & & & & & & & & & & & & & & & . & \\
\hline 238 & $\begin{array}{l}\text { Do01. (10004- } \\
\text { Do000.00010. } \\
\text { D011) }\end{array}$ & $\begin{array}{l}\text { IGMITABLE LIQUIDS } \\
\text { WIIH D METEAL } \\
\text { <10\% SLUDGE }\end{array}$ & & & & & & & & & & & & & & & & & & \\
\hline 239 & 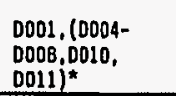 & $\begin{array}{l}\text { IGHITABLE LIQUIDS } \\
\text { WHIH D P HETALL } \\
\rightarrow 10 \% \text { SLUOGE }\end{array}$ & & & & & & & & & & & & & & & & & & \\
\hline
\end{tabular}

"Itens denoted with an asterisk are wastes that may contain any or all of the specif led waste codes.

thay or may not contain D003.

PAGE TOTAL 
EG\&G IDAHO, INC.

\begin{tabular}{|c|c|c|c|c|c|c|c|c|c|c|c|c|c|c|c|c|c|c|c|c|}
\hline \multirow[t]{2}{*}{$\begin{array}{l}\text { ITEM } \\
\text { SO. }\end{array}$} & \multirow[t]{2}{*}{ EPA CODES } & \multirow[t]{2}{*}{$\begin{array}{l}\frac{\text { DISPOSAL OF }}{\text { LAB PACKS }} \\
\end{array}$} & \multicolumn{5}{|c|}{$\begin{array}{l}\text { RUMBER OF DRUMS } \\
\text { LAB PACKS }\end{array}$} & \multicolumn{5}{|c|}{$\begin{array}{l}\text { UHIT PRICE BY DRUH SIZE } \\
\text { LAB PACKS }\end{array}$} & \multicolumn{5}{|c|}{$\begin{array}{l}\text { EXTEHDED PRICE BY DRUM SIZE } \\
\text { LAB PACKS }\end{array}$} & \multirow{2}{*}{$\begin{array}{l}\text { TOTAL PRICE } \\
\text { FRR ALL } \\
\text { FRUH SIZES } \\
\end{array}$} & \multirow[t]{2}{*}{$\begin{array}{c}\text { TREATMERT I } \\
\text { OISPOSAL METHOD }\end{array}$} & \multirow[t]{2}{*}{$\begin{array}{l}\text { TSO FACILITY } \\
\text { MAAE ANO } \\
\text { LOCATION } \\
\end{array}$} \\
\hline & & & $\begin{array}{l}1-5 \\
\text { GAL. } \\
\text { DRUM }\end{array}$ & $\begin{array}{l}6-10 \\
\text { GAL. } \\
\text { ORUM }\end{array}$ & $\begin{array}{l}11-20 \\
\text { GAL } \\
\text { ORUM }\end{array}$ & $\begin{array}{l}21-30 \\
\text { GAL } \\
\text { ORUM }\end{array}$ & $\begin{array}{l}31- \\
55 \\
\text { GAL. } \\
\text { DRUM }\end{array}$ & $\begin{array}{l}1-5 \\
\text { GAL. } \\
\text { ORUM }\end{array}$ & $\begin{array}{l}6-10 \\
\text { GAL: } \\
\text { ORUM }\end{array}$ & $\begin{array}{l}11-20 \\
\text { GA. } \\
\text { ORUM }\end{array}$ & $\begin{array}{l}21-30 \\
\text { GAL. } \\
\text { ORLM }\end{array}$ & $\begin{array}{l}31-55 \\
\text { GAL. } \\
\text { ORUH }\end{array}$ & $\begin{array}{l}1-5 \\
\text { GAL. } \\
\text { DRUM }\end{array}$ & $\begin{array}{l}6-10 \\
\text { GALU } \\
\text { DRUM }\end{array}$ & $\begin{array}{l}11-20 \\
\text { GAL } \\
\text { ORUM }\end{array}$ & $\begin{array}{l}21-30 \\
\text { GAL. } \\
\text { DRUM }\end{array}$ & $\begin{array}{l}31-55 \\
\text { GAL. } \\
\text { DRUM }\end{array}$ & & & \\
\hline 224 & 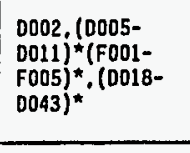 & $\begin{array}{l}\text { ACIO LIQUIDS UITH } \\
\text { D METALS, F } \\
\text { SOLVEHTS AHO TC } \\
\text { ORGANICS (MEAK } \\
\text { ACIO SOLUTIOHS) } \\
\end{array}$ & & & & & & & & & & & & & & & & & & \\
\hline 225 & 0001,0003 & LITHIUH BATTERY & 1 & & & & & & & & & & & & & & & & & \\
\hline 226 & 0002 & 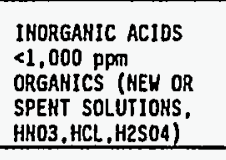 & & & & & & & & & & & & & & & & & & \\
\hline 227 & 0002 & 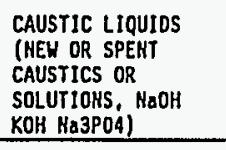 & & & & & & & & & & & & & & & & & & \\
\hline 228 & 0001 & $\begin{array}{l}\text { IGHITABLE LLQUIDS } \\
\text { (LIOUIDS AND } \\
\text { SLUDGES < }<10 X \\
\text { SLUDGE } \\
\end{array}$ & 7 & 10 & & & & & & & & & & & & & & & & \\
\hline 229 & 0001 & $\begin{array}{l}\text { IGHITAQLE LIQUIDS } \\
\text { (LIQUIDS ARD } \\
\text { SLUOGES) >10X } \\
\text { SLUOGE } \\
\end{array}$ & & & & & & & & & & & & & & & & & & \\
\hline 230 & 0001,0002 & $\begin{array}{l}\text { IGHITABLE } \\
\text { CORROSIVE LIOUIOS } \\
\text { (LIOUIDS AND } \\
\text { SLUDGES) C10\% } \\
\text { SLUDGE } \\
\end{array}$ & 1 & 1 & & & & & & & & & & & & & & & & \\
\hline
\end{tabular}

*Items denoted with an asterisk ore wastes that may conta in any or all of the specified waste codes.

Hay or may not conta in 0003 .

PAGE TOTAL 
$\therefore$ a

EGRG IDAHO, INC.

emechment 20, Pago se or

\begin{tabular}{|c|c|c|c|c|c|c|c|c|c|c|c|c|c|c|c|c|c|c|c|c|}
\hline \multirow[t]{2}{*}{$\begin{array}{l}\text { ITEH } \\
\text { NO. }\end{array}$} & \multirow[t]{2}{*}{ EPA CODES } & \multirow[t]{2}{*}{$\begin{array}{l}\text { DISPOSAL OF } \\
\text { LAB PACKS }\end{array}$} & \multicolumn{5}{|c|}{$\begin{array}{l}\text { NUMBER OF DRUHS } \\
\text { LAB PACKS }\end{array}$} & \multicolumn{5}{|c|}{$\begin{array}{l}\text { UNIT PRICE BY DRUH SIZE } \\
\text { LAB PACKS }\end{array}$} & \multicolumn{5}{|c|}{$\begin{array}{l}\text { EXTENDED PRICE BY ORUM SIZE } \\
\text { LAB PACKS }\end{array}$} & \multirow[t]{2}{*}{$\begin{array}{l}\text { TOTAL PRICE } \\
\text { FOR ALL } \\
\text { DRUM SIZES }\end{array}$} & \multirow[t]{2}{*}{$\begin{array}{c}\text { TREATHEET I } \\
\text { DISPOSAL METHOD }\end{array}$} & \multirow[t]{2}{*}{$\begin{array}{l}\text { TSD FACILITY } \\
\text { NAHE AND } \\
\text { LOCATIOH } \\
\end{array}$} \\
\hline & & & $\begin{array}{l}1-5 \\
\text { GAL } \\
\text { ORUM }\end{array}$ & $\begin{array}{l}\text { G-10 } \\
\text { GAL. } \\
\text { DRUM }\end{array}$ & $\begin{array}{l}11-20 \\
\text { GAL. } \\
\text { ORUM }\end{array}$ & $\begin{array}{l}21-30 \\
\text { GALL } \\
\text { DRUM }\end{array}$ & $\begin{array}{l}31- \\
55 \\
\text { GAL. } \\
\text { DRUM }\end{array}$ & $\begin{array}{l}1-5 \\
\text { GAL. } \\
\text { ORVH }\end{array}$ & $\begin{array}{l}\text { 6-10 } \\
\text { GAL. } \\
\text { DRUM }\end{array}$ & $\begin{array}{l}\text { I1-20 } \\
\text { GAL. } \\
\text { DRUM }\end{array}$ & $\begin{array}{l}21-30 \\
\text { GALO } \\
\text { ORUM }\end{array}$ & $\begin{array}{l}31-55 \\
\text { GAL } \\
\text { DRUM }\end{array}$ & $\begin{array}{l}1-5 \\
\text { GAL. } \\
\text { DRUM }\end{array}$ & $\begin{array}{l}6-10 \\
\text { GAL. } \\
\text { ORUH }\end{array}$ & $\begin{array}{l}11-20 \\
\text { GAL. } \\
\text { DRUM }\end{array}$ & $\begin{array}{l}21-30 \\
\text { GAL } \\
\text { ORUM }\end{array}$ & $\begin{array}{l}31-55 \\
\text { GAL.: } \\
\text { DRUYM }\end{array}$ & & & \\
\hline 248 & $\begin{array}{l}\text { Do01, (0005- } \\
0008,0010, \\
\text { D011)*(Fo01- } \\
\text { Fo05)* }\end{array}$ & $\begin{array}{l}\text { IGWITABLE LIQUIDS } \\
\text { WITH D METALS AND } \\
\text { F SOLVENTS <10\% } \\
\text { SLUDGE }\end{array}$ & 1 & & 3 & & & & & & & & & & & & & & & \\
\hline 249 & $\begin{array}{l}0001 .(0005- \\
000080010 . \\
0011)^{*}(F 001- \\
\text { F005)* }\end{array}$ & $\begin{array}{l}\text { IGNITAQLE LIQUIDS } \\
\text { HITH D METALS AND } \\
\text { F SOLVENTS }>10 \% \\
\text { SLUDGE }\end{array}$ & & & & & & & & & & & & & & & & & & \\
\hline 250 & $\begin{array}{l}0001,(0004- \\
0000,0010, \\
0011)^{*}(F 001- \\
F 005)^{*}\end{array}$ & $\begin{array}{l}\text { IGHITABLE LIQUIDS } \\
\text { WITH D METALS ANO } \\
\text { F SOLVENTS <10\% } \\
\text { SLUDGE }\end{array}$ & & & & & & & & & & & & & & & & & & \\
\hline 251 & $\begin{array}{l}0001,(0004-0008, \\
001010^{*} \\
0011)^{*}(F 001- \\
F 005)^{*}\end{array}$ & $\begin{array}{l}\text { IGHITABLE LIQUIDS } \\
\text { UITH O HETALS AND } \\
\text { F SOLVENTS >10\% } \\
\text { SLUDGE } \\
\end{array}$ & & & & & & & & & & & & & & & & & & \\
\hline 252 & $\begin{array}{l}0001, \text {, (0005- } \\
0011)^{*} \text { (F001- } \\
\text { Fo055) }\end{array}$ & $\begin{array}{l}\text { IGHITABLE LIQUIDS } \\
\text { WITH D METALS AAD } \\
\text { F SOLVEHTS <10X } \\
\text { SLUDGE }\end{array}$ & & & & & & & & & & & & & & & & & & \\
\hline 253 & $\begin{array}{l}\text { Do01,(D005- } \\
\text { D011): (F001- } \\
\text { F005)** }\end{array}$ & $\begin{array}{l}\text { IGHTTABLE LIQUIDS } \\
\text { UITH O METALS AND } \\
\text { F SOLVERTS >10X } \\
\text { SLUDGE } \\
\end{array}$ & & & & & & & & & & & & & & & & & & \\
\hline 254 & $\begin{array}{l}\text { Do01,(0005. } \\
0007,0008, \\
0010,0011)^{*} \\
(F 001-F 005)^{\star} \\
(0018-0043)^{*}\end{array}$ & $\begin{array}{l}\text { IGMITABLE LIQUIDS } \\
\text { 'UITH D HETALS, F } \\
\text { SOLVEHTS AHD TC } \\
\text { ORGAHICS <10\% } \\
\text { SLUDGE }\end{array}$ & & & 1 & & & & & & & & & & & & & & & \\
\hline
\end{tabular}

"Items denoted with an asterisk are wastes that may contain any or all of the speciffed waste codes.

+May or may not conta in D003.

PAGE TOTAL 
EGEG IDAHO, INC.

\begin{tabular}{|c|c|c|c|c|c|c|c|c|c|c|c|c|c|c|c|c|c|c|c|c|}
\hline \multirow{2}{*}{$\begin{array}{l}\text { ITEM } \\
\text { NO. }\end{array}$} & \multirow[t]{2}{*}{ EPA CODES } & \multirow{2}{*}{$\begin{array}{l}\text { DISPOSAL OF } \\
\text { LAB PACKS }\end{array}$} & \multicolumn{5}{|c|}{$\begin{array}{l}\text { NUMBER OF DRUMS } \\
\text { LAB PACKS }\end{array}$} & \multicolumn{5}{|c|}{$\begin{array}{c}\text { UHIT PRICE BY ORUM SIZE } \\
\text { LAB PACKS }\end{array}$} & \multicolumn{5}{|c|}{$\begin{array}{c}\text { EXTENDED PRICE BY ORUM SIZE } \\
\text { LAB PACKS }\end{array}$} & \multirow{2}{*}{$\begin{array}{l}\text { TOTAL PRICE } \\
\text { FOR ALL } \\
\text { ORUM SIZES } \\
\end{array}$} & \multirow[t]{2}{*}{$\begin{array}{c}\text { TREATMENT / } \\
\text { DISPOSAL METHOD }\end{array}$} & \multirow{2}{*}{$\begin{array}{l}\text { TSD FACILITY } \\
\text { MAME AND } \\
\text { LOCATION }\end{array}$} \\
\hline & & & $\begin{array}{l}1-5 \\
\text { GAL. } \\
\text { DRUH }\end{array}$ & $\begin{array}{l}6-10 \\
\text { GAL. } \\
\text { ORUM }\end{array}$ & $\begin{array}{l}11-20 \\
\text { GAL. } \\
\text { ORUM }\end{array}$ & $\begin{array}{l}21-30 \\
\text { GAL. } \\
\text { DRUY }\end{array}$ & $\begin{array}{l}31- \\
55 \\
\text { GAL. } \\
\text { DRUM }\end{array}$ & $\begin{array}{l}1-5 \\
\text { GAL. } \\
\text { DRUH }\end{array}$ & $\begin{array}{l}\text { 6-10 } \\
\text { GAL. } \\
\text { ORUS }\end{array}$ & $\begin{array}{l}11-20 \\
\text { GAL. } \\
\text { ORUM }\end{array}$ & $\begin{array}{l}21-30 \\
\text { GAL. } \\
\text { ORUH }\end{array}$ & $\begin{array}{l}31-55 \\
\text { GAL. } \\
\text { DRUM }\end{array}$ & $\begin{array}{l}1-5 \\
\text { GAL. } \\
\text { DRUM }\end{array}$ & $\begin{array}{l}\text { 6-10 } \\
\text { GAL. } \\
\text { DRUH }\end{array}$ & $\begin{array}{l}11-20 \\
\text { GAL. } \\
\text { DRUM }\end{array}$ & $\begin{array}{l}21-30 \\
\text { GAL. } \\
\text { DRUM }\end{array}$ & $\begin{array}{l}31-55 \\
\text { GAL. } \\
\text { DRUH }\end{array}$ & & & \\
\hline 240 & D011) & $\begin{array}{l}\text { IGNITABLE LIQUIOS } \\
\text { UITH D HETALS } \\
<10 \% \text { SLUDGE } \\
\end{array}$ & & & & & & & & & & & & & & & & & & \\
\hline 241 & $\begin{array}{l}0001 \text { (10005- } \\
\text { Do11)* }\end{array}$ & $\begin{array}{l}\text { IGHITABLE LIQUIDS } \\
\text { WITH D METALS } \\
\rightarrow 10 \% \text { SLUDGE } \\
\end{array}$ & & & & & & & & & & & & & & & & & & \\
\hline 242 & $\begin{array}{l}0001 \text { (F001- } \\
\text { F005)* }\end{array}$ & $\begin{array}{l}\text { IGHITABLE LIQUIDS } \\
\text { HITH F SOLVEHTS } \\
\text { <10\% SLUDGE } \\
\end{array}$ & & & 1 & & & & & & & & & & & & & & & \\
\hline 243 & $\begin{array}{l}\text { D001, (F001- } \\
F 005)^{*}\end{array}$ & $\begin{array}{l}\text { IGNITABLE LIQUIDS } \\
\text { WITH F SOLVENTS } \\
>10 \% \text { SLUDGE }\end{array}$ & & & & & & & & & & & & & & & & & & \\
\hline 244 & $\begin{array}{l}\text { D001, (F001- } \\
\text { f005)*, (D018- } \\
\text { D043) }\end{array}$ & $\begin{array}{l}\text { IGNITABLE LIQUIDS } \\
\text { WITH F SOLVENTS } \\
\text { AND TC ORGANICS } \\
\text { <10\% SLUDGE } \\
\end{array}$ & & & & & 1 & & & & & & & & & & & & & \\
\hline 245 & 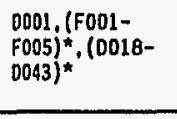 & $\begin{array}{l}\text { IGHITABLE LIQUIDS } \\
\text { WITH F SOLVENTS } \\
\text { AHD TC ORGAHICS } \\
\text { >1OX SLLUOGE } \\
\end{array}$ & & & & & & & & & & & & & & & & & & \\
\hline 246 & $\begin{array}{l}0001,(0005, \\
0007,0008, \\
0010,0011)^{*} \\
\text { (F001-F005) }\end{array}$ & $\begin{array}{l}\text { IGHITABLE LIQUIDS } \\
\text { WITH F SOLVENTS } \\
\text { AND TC ORGANICS } \\
<10 \% \text { SLUDGE } \\
\end{array}$ & & & & & & & & & & & & & & & & & & \\
\hline 247 & $\begin{array}{l}0001,(0005, \\
0007,0008, \\
0010,0011)^{\star} \\
(F 001-F 005)^{*}\end{array}$ & $\begin{array}{l}\text { IGNITABLE LIQUIDS } \\
\text { MITH F SOLVENTS } \\
\text { AND TC ORGANICS } \\
\text { >10X SLUDGE }\end{array}$ & & & & & & & & & & & & & & & & & & \\
\hline
\end{tabular}


$\because 7 x+4$

EG\&G IDAHO, INC.

Attechmont za, Page 30 or 30

\begin{tabular}{|c|c|c|c|c|c|c|c|c|c|c|c|c|c|c|c|c|c|c|c|c|}
\hline \multirow[t]{2}{*}{$\begin{array}{l}\text { ITEH } \\
\text { NO. }\end{array}$} & \multirow[t]{2}{*}{ EPA CODES } & \multirow[t]{2}{*}{$\begin{array}{l}\frac{\text { DISPDSAL OF }}{\text { LAB PACKS }} \\
\end{array}$} & \multicolumn{5}{|c|}{$\begin{array}{l}\text { RUMBER OF DRUMS } \\
\text { LAB PACKS }\end{array}$} & \multicolumn{5}{|c|}{$\begin{array}{c}\text { UNIT PRICE BY DRUM SIZE } \\
\text { LAB PACKS } \\
\end{array}$} & \multicolumn{5}{|c|}{$\begin{array}{l}\text { EXTENDED PRICE BY DRUM SIZE } \\
\text { LAB PACKS }\end{array}$} & \multirow[t]{2}{*}{$\begin{array}{c}\text { TOTAL PRICE } \\
\text { FOR ALL } \\
\text { DRUM SIZES } \\
\end{array}$} & \multirow[t]{2}{*}{$\begin{array}{l}\text { TREATHENT / } \\
\text { DISPOSAL METHOD }\end{array}$} & \multirow{2}{*}{$\begin{array}{l}\text { TSD FACILITY } \\
\text { MAME AND } \\
\text { LOCATYON } \\
\end{array}$} \\
\hline & & & $\begin{array}{l}1-5 \\
\text { GAL } \\
\text { ORUM }\end{array}$ & $\begin{array}{l}6-10 \\
\text { GAL. } \\
\text { DRUM }\end{array}$ & $\begin{array}{l}11-20 \\
\text { GAL } \\
\text { DRUM }\end{array}$ & $\begin{array}{l}21-30 \\
\text { GAL: } \\
\text { ORUH }\end{array}$ & $\begin{array}{l}31- \\
55 \\
\text { GAL. } \\
\text { ORUM } \\
\end{array}$ & $\begin{array}{l}1-5 \\
\text { GAL. } \\
\text { DRUH }\end{array}$ & $\begin{array}{l}6-10 \\
\text { GAL. } \\
\text { ORUM }\end{array}$ & $\begin{array}{l}11-20 \\
\text { GA. } \\
\text { GRUM }\end{array}$ & $\begin{array}{l}21-30 \\
\text { GA. } \\
\text { GRUH }\end{array}$ & $\begin{array}{l}31-55 \\
\text { GRL } \\
\text { DRUH }\end{array}$ & $\begin{array}{l}1-5 \\
\text { GAL. } \\
\text { ORUH }\end{array}$ & $\begin{array}{l}\text { 6-10 } \\
\text { GAL: } \\
\text { DRUM }\end{array}$ & $\begin{array}{l}11-20 \\
\text { GAL } \\
\text { ORUY }\end{array}$ & $\begin{array}{l}21-30 \\
\text { GAL. } \\
\text { DRUH }\end{array}$ & $\begin{array}{l}31-55 \\
\text { GAL } \\
\text { ORLAM }\end{array}$ & & & \\
\hline 261 & 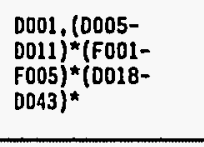 & $\begin{array}{l}\text { IGHITABLE LIQUIDS } \\
\text { UITH D HETALS, F } \\
\text { SOLVENTS AHD IC } \\
\text { ORGANICS >10\% } \\
\text { SLUDGE } \\
\end{array}$ & & & & & & & & & & & & & & & & & & \\
\hline 262 & $\begin{array}{l}\text { VARIOUS P,U,F } \\
\text { CODES } \\
(0012-D 043)^{\star}\end{array}$ & $\begin{array}{l}\text { NON-IGNITABLE } \\
\text { ORGANICS LIQUIDS }\end{array}$ & 9 & & 11 & 1 & & & & & & & & & & & & & & \\
\hline 263 & D003 & REACTIVE CYAMIDE & 1 & & 1 & 1 & & & & & & & & & & & & & & \\
\hline 264 & 0003 & REACTIVE SULFIDE & 1 & & & & & & & & & & & & & & & & & \\
\hline 265 & 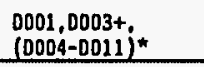 & $\begin{array}{l}\text { SOLID OXIDIZER } \\
\text { VITH D METALS } \\
\end{array}$ & 1 & & & & & & & & & & & & & & & & & \\
\hline 266 & $\begin{array}{l}0001,0003+. \\
00005,0007 \\
0008.0010 .0011)^{*}\end{array}$ & $\begin{array}{l}\text { SOLID DXIOIZER } \\
\text { WITH O METALS }\end{array}$ & 8 & & 2 & & & & & & & & & & & & & & & \\
\hline 267 & $\begin{array}{l}0001,0003+ \\
(0005-0008, \\
0010,0011)^{*}\end{array}$ & $\begin{array}{l}\text { SOLID OXIDIZER } \\
\text { WITH D HETALS }\end{array}$ & & 1 & 1 & 1 & & & & & & & & & & & & & & \\
\hline 268 & $\begin{array}{l}0001.0003+ \\
(0004-0008 \\
0010.0011)^{*}\end{array}$ & $\begin{array}{l}\text { SOLLD OXIDIZER } \\
\text { WITH D HETALS, }\end{array}$ & & & & & & & & & & & & & & & ' & & & \\
\hline 269 & $\begin{array}{l}0001,0003+ \\
(0005-0011)^{*}\end{array}$ & $\begin{array}{l}\text { SOLID OXIDIZER } \\
\text { WITH O METALS }\end{array}$ & 2 & 2 & 1 & & & & & & & & & & & & & & & \\
\hline 270 & $0001,0003+$ & SOLID OXIDIZER & 8 & & 2 & & & & & & & & & & & & & & & \\
\hline 271 & & CORROSIVE SOLIDS & 5 & & & & & & & & & & & & & & & & & \\
\hline
\end{tabular}

"Items denoted with an asterisk are wastes that may contain any or all of the specified waste codes.

+Hay or may not conta in D003.

PAGE TOTAL 
EG\&G IDAHO, INC.

Attuchment 22, Pape as of as

\begin{tabular}{|c|c|c|c|c|c|c|c|c|c|c|c|c|c|c|c|c|c|c|c|c|}
\hline \multirow[t]{2}{*}{$\begin{array}{l}\text { ITEA } \\
\text { HO. }\end{array}$} & \multirow[t]{2}{*}{ EPA CODES } & \multirow[t]{2}{*}{ 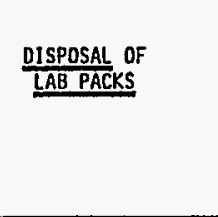 } & \multicolumn{5}{|c|}{$\begin{array}{l}\text { RUMEER OF DRUYS } \\
\text { LAB PACKS }\end{array}$} & \multicolumn{5}{|c|}{$\begin{array}{c}\text { UNIT PRICE BY DRUM SIZE } \\
\text { LAB PACKS }\end{array}$} & \multicolumn{5}{|c|}{$\begin{array}{l}\text { EXTENOED PRICE BY DOUU SIZE } \\
\text { LAA PACKS }\end{array}$} & \multirow[t]{2}{*}{$\begin{array}{l}\text { TOTAL PRICE } \\
\text { FoR ALL } \\
\text { DRUY SIZES }\end{array}$} & \multirow[t]{2}{*}{$\begin{array}{c}\text { TREATMEET } 1 \\
\text { DISPOSAL METHOD }\end{array}$} & \multirow[t]{2}{*}{ 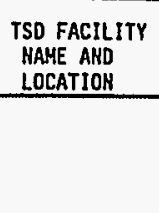 } \\
\hline & & & 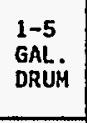 & 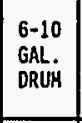 & $\begin{array}{l}\text { I1-20 } \\
\text { GEL } \\
\text { ORRUH } \\
\end{array}$ & 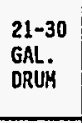 & \begin{tabular}{|l|}
$31-$ \\
55 \\
GSA \\
ORUUA \\
\end{tabular} & $\begin{array}{l}1-5 \\
\text { GAL } \\
\text { ORUH }\end{array}$ & $\begin{array}{c}6-10 \\
\text { GAL } \\
\text { DRRH } \\
\end{array}$ & 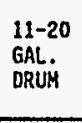 & 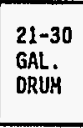 & $\begin{array}{l}31-55 \\
\text { GALL } \\
\text { ORLUH }\end{array}$ & $\begin{array}{l}1-5 \\
\text { 6-6L. } \\
\text { DRVUM }\end{array}$ & 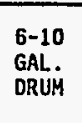 & \begin{tabular}{|l|}
$11-20$ \\
GaLL \\
oRLUH
\end{tabular} & $\begin{array}{ll}21-30 \\
\text { GA-30 } \\
\text { ORLUH }\end{array}$ & $\begin{array}{l}31-55 \\
\text { SARL } \\
\text { ORRH }\end{array}$ & & & \\
\hline 255 & 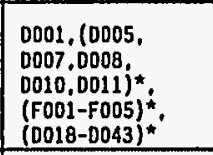 & 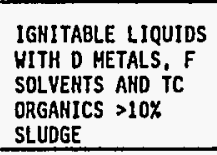 & & & & & & & & & & & & & & & & & & \\
\hline 256 & 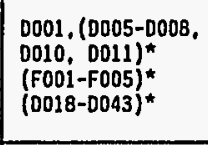 & 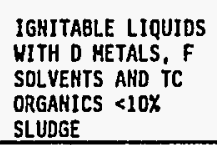 & 1 & & 2 & & & & & & & & & & & & & & & \\
\hline 257 & 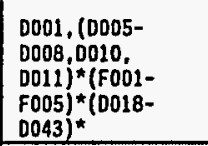 & 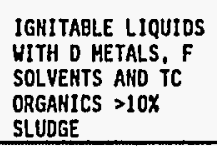 & & & & & & & & & & & & & & & & & & \\
\hline 258 & 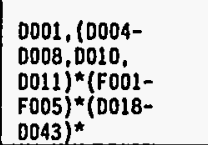 & 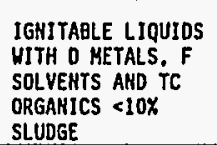 & & & & & & & & & & & & & & & & & & \\
\hline 259 & 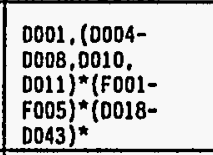 & 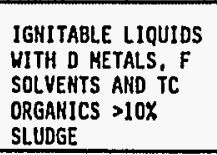 & & & & & & & & & & & & & & & & & & \\
\hline 260 & 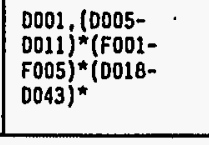 & 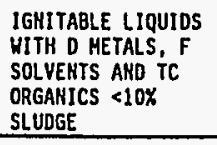 & & & & & & & & & & & & & & & & & & \\
\hline
\end{tabular}

*Items denoted with an asterisk are wastes that may contain ony or all of the specif ied waste codes.

+ May or may not contaln 0003.

PAGE TOTAL 


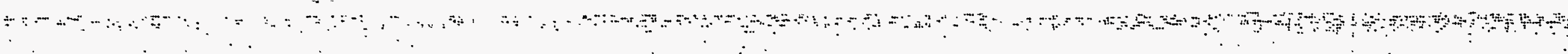

EG\&G IDAHO, INC.

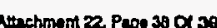

\begin{tabular}{|c|c|c|c|c|c|c|c|c|c|c|c|c|c|c|c|c|c|c|c|c|}
\hline \multirow{2}{*}{$\begin{array}{l}\text { ITEH } \\
\text { KO. }\end{array}$} & \multirow[t]{2}{*}{ EPA CODES } & \multirow{2}{*}{$\begin{array}{l}\text { DISPOSAL OF } \\
\text { LAB PACKS }\end{array}$} & \multicolumn{5}{|c|}{$\begin{array}{l}\text { NUMBER OF DRUMS } \\
\text { LAB PACKS }\end{array}$} & \multicolumn{5}{|c|}{$\begin{array}{c}\text { UNIT PRICE BY DRUM SIZE } \\
\text { LAB PACKS }\end{array}$} & \multicolumn{5}{|c|}{$\begin{array}{l}\text { EXTENDED PRICE BY DRUM SIZE } \\
\text { LAB PACKS }\end{array}$} & \multirow{2}{*}{$\begin{array}{l}\text { TOTAL PRICE } \\
\text { FOR ALL } \\
\text { DRUM SIZES }\end{array}$} & \multirow[t]{2}{*}{$\begin{array}{c}\text { TREATMENT / } \\
\text { DISPOSAL METHDD }\end{array}$} & \multirow{2}{*}{$\begin{array}{l}\text { TSD FACILITY } \\
\text { NAME AHD } \\
\text { LOCATION } \\
\end{array}$} \\
\hline & & & $\begin{array}{l}1-5 \\
\text { GAL. } \\
\text { DRUH }\end{array}$ & $\begin{array}{l}6-10 \\
\text { GAL. } \\
\text { ORUM }\end{array}$ & $\begin{array}{l}11-20 \\
\text { GAL. } \\
\text { DRUM }\end{array}$ & $\begin{array}{l}21-30 \\
\text { GAL. } \\
\text { DRUA }\end{array}$ & $\begin{array}{l}31- \\
55 \\
\text { GAL. } \\
\text { ORUH }\end{array}$ & $\begin{array}{l}1-5 \\
\text { GAL. } \\
\text { DRUH }\end{array}$ & $\begin{array}{l}\text { 6-10 } \\
\text { GAL. } \\
\text { ORUH }\end{array}$ & $\begin{array}{l}11-20 \\
\text { GAL. } \\
\text { DRUM }\end{array}$ & $\begin{array}{l}21-30 \\
\text { GAL. } \\
\text { DRUM }\end{array}$ & $\begin{array}{l}31-55 \\
\text { GAL. } \\
\text { DRUY }\end{array}$ & $\begin{array}{l}1-5 \\
\text { GAL. } \\
\text { DRUM }\end{array}$ & $\begin{array}{l}6-10 \\
\text { GAL. } \\
\text { DRUM }\end{array}$ & $\begin{array}{l}11-20 \\
\text { GAL. } \\
\text { DRUM }\end{array}$ & $\begin{array}{l}21-30 \\
\text { GAL. } \\
\text { ORUM }\end{array}$ & $\begin{array}{l}31-55 \\
\text { GAL. } \\
\text { DRUM }\end{array}$ & & & \\
\hline 286 & 0009 & $\begin{array}{l}\text { HERCURY } \\
\text { CONTAHINATED } \\
\text { IMORGANIC DEBRIS }\end{array}$ & 1 & & 2 & & & & & & & & & & & & & & & \\
\hline 287 & & $\begin{array}{l}\text { NOH-RCRA } \\
\text { REGULATED SOLIOS } \\
\end{array}$ & 1 & & 36 & & & & & & & & & & & & & & & \\
\hline 288 & & $\begin{array}{l}\text { NOH-RCRA } \\
\text { REGULATED LIQUIDS }\end{array}$ & 4 & & 23 & & 2 & & & & & & & & & & & & & \\
\hline 289 & 0001.0003 & AEROSOL CAHS & & & 1 & & & & & & & & & & & & & & & \\
\hline 290 & 0001,0003 & $\begin{array}{l}\text { AEROSOL CANS - } \\
\text { VARIOUS FLAMHABLE } \\
\text { GAS }\end{array}$ & & & 1 & & & & & & & & & & & & & & & \\
\hline 291 & $\begin{array}{l}\text { DOO1, 0003, VARIOU } \\
\text { S U CODES }\end{array}$ & AEROSOL CANS & & & 1 & & & & & & & & & & & & & & & \\
\hline
\end{tabular}


EGRG IDAHO, INC.

Attachmont 22, Pago 37 of 39

\begin{tabular}{|c|c|c|c|c|c|c|c|c|c|c|c|c|c|c|c|c|c|c|c|c|}
\hline \multirow{2}{*}{$\begin{array}{l}\text { ITEH } \\
\text { NO. }\end{array}$} & \multirow[t]{2}{*}{ EPA CODES } & \multirow{2}{*}{$\begin{array}{l}\frac{\text { DISPOSAL OF }}{\text { LAB PACKS }} \\
\end{array}$} & \multicolumn{5}{|c|}{$\begin{array}{l}\text { NUMBER OF DRUAS } \\
\text { LAB PACKS }\end{array}$} & \multicolumn{5}{|c|}{$\begin{array}{l}\text { UNIT PRICE BY ORUM SIZE } \\
\text { LAB PACKS }\end{array}$} & \multicolumn{5}{|c|}{$\begin{array}{c}\text { EXTENDED PRICE BY ORUM SIZE } \\
\text { LAB PACKS }\end{array}$} & \multirow{2}{*}{$\begin{array}{l}\text { TOTAL PRICE } \\
\text { FOR ALL } \\
\text { DRUM SIZES } \\
\end{array}$} & \multirow[t]{2}{*}{$\begin{array}{c}\text { TREATMEAT I } \\
\text { DISPOAAL METTOOD }\end{array}$} & \multirow{2}{*}{$\begin{array}{l}\text { TSO FACILITY } \\
\text { NAME AND } \\
\text { LOCATIOH } \\
\end{array}$} \\
\hline & & & $\begin{array}{l}1-5 \\
\text { GAL. } \\
\text { ORUH }\end{array}$ & $\begin{array}{l}6-10 \\
\text { GAL: } \\
\text { ORUM }\end{array}$ & $\begin{array}{l}11-20 \\
\text { GAL } \\
\text { DQUM }\end{array}$ & $\begin{array}{l}21-30 \\
\text { GAL. } \\
\text { DRUM }\end{array}$ & $\begin{array}{l}31- \\
55 \\
\text { GAL. } \\
\text { DRUM } \\
\end{array}$ & $\begin{array}{l}1-5 \\
\text { GAL } \\
\text { DRUM }\end{array}$ & $\begin{array}{l}6-10 \\
\text { GAL. } \\
\text { ORUH }\end{array}$ & $\begin{array}{l}11-20 \\
\text { GAL. } \\
\text { ORUM }\end{array}$ & $\begin{array}{l}21-30 \\
\text { GAL. } \\
\text { ORUM }\end{array}$ & $\begin{array}{l}31-55 \\
\text { GAL } \\
\text { DRUH }\end{array}$ & $\begin{array}{l}1-5 \\
\text { GAL } \\
\text { DRUM }\end{array}$ & $\begin{array}{l}6-10 \\
\text { GAL. } \\
\text { ORUM }\end{array}$ & $\begin{array}{l}11-20 \\
\text { GAL } \\
\text { DRUH }\end{array}$ & $\begin{array}{l}21-30 \\
\text { GAL. } \\
\text { ORUH }\end{array}$ & $\begin{array}{l}31-55 \\
\text { GAL } \\
\text { ORUM }\end{array}$ & & & \\
\hline 272 & $\begin{array}{l}(0005-0008 \\
0010,0011)^{\star}\end{array}$ & CORROSIVE SOLIOS & 2 & & & & & & & & & & & & & & & & & \\
\hline 273 & $\left(P^{\prime} s \& U^{\prime} s\right)^{*}$ & MEUTRAL LIOUIDS & & & & 1 & & & & & & & & & & & & & & \\
\hline 274 & 0001 & FLAMHABLE SOLIDS & 4 & & & 5 & & & & & & & & & & & & & & \\
\hline 275 & $\begin{array}{l}0001-0002,(0005- \\
0008,0010-0011)^{*}\end{array}$ & FLAAHRBLE SOLIDS & 2 & & & & & & & & & & & & & & & & & \\
\hline 276 & O001. (U CODES $)^{*}$ & FLAMYABLE SOLIDS & 1 & & & & & & & & & & & & & & & & & \\
\hline 277 & $0018-0043^{*}$ & FLAMHABLE LIQUIOS & & & & 2 & & & & & & & & & & & & & & \\
\hline 278 & F. $\left(P^{\prime} s \& U^{\prime} s\right)^{*}$ & FLAMMABLE LIQUJDS & 3 & & & 7 & & & & & & & & & & & & & & \\
\hline 279 & & $\begin{array}{l}\text { MON-IGGITABLE } \\
\text { ORGAHICS }\end{array}$ & 2 & & & 2 & & & & & & & & & & & & & & \\
\hline 280 & $\begin{array}{l}(0005-0008 \\
0010-0043)^{\star}\end{array}$ & $\begin{array}{l}\text { MOY-IGMITABLE } \\
\text { ORGAMICS }\end{array}$ & 2 & & & 1 & & & & & & & & & & & & 1 & & \\
\hline 281 & 0001 & OXIO1ZER LIOUIDS & 3 & & & & & & & & & & & & & & & & & \\
\hline 282 & $\begin{array}{l}\text { (D005-D008, } \\
0010-0011)^{*}\end{array}$ & $\begin{array}{l}\text { MEUTRAL SOLIOS } \\
\text { (HOH-DEBRIS) }\end{array}$ & 10 & & & 15 & & & & & & & & & & & & & & \\
\hline 283 & $(P ' s \& U ' s)^{*}$ & $\begin{array}{l}\text { MEUTRAL SOLIDS } \\
\text { (HOH-DEBRIS) }\end{array}$ & 5 & & & & & & & & & & & & & & & & & \\
\hline 284 & $(0004-0011)^{\star}$ & $\begin{array}{l}\text { NEUTRAL SOLIOS } \\
\text { (HOY-DEQRIS) }\end{array}$ & 5 & & & & & & & & & & & & & & & & & \\
\hline 285 & $\begin{array}{l}(0004-0011)^{*} \\
(F 001-F 005) * \\
(D 018-0043)^{*}\end{array}$ & $\begin{array}{l}\text { ORGAHIC DEBRIS } \\
\text { UITH D METALS. F } \\
\text { SOLVENTS AND/OR } \\
\text { TC ORGAAICS } \\
\end{array}$ & 1 & & & & & & & & & & & & & & & & & \\
\hline
\end{tabular}

- "Items denoted with an asterisk are wastes that may contain any or all of the specif led waste codes.

+May or may not conta in 0003 . 



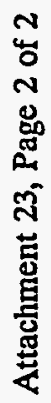
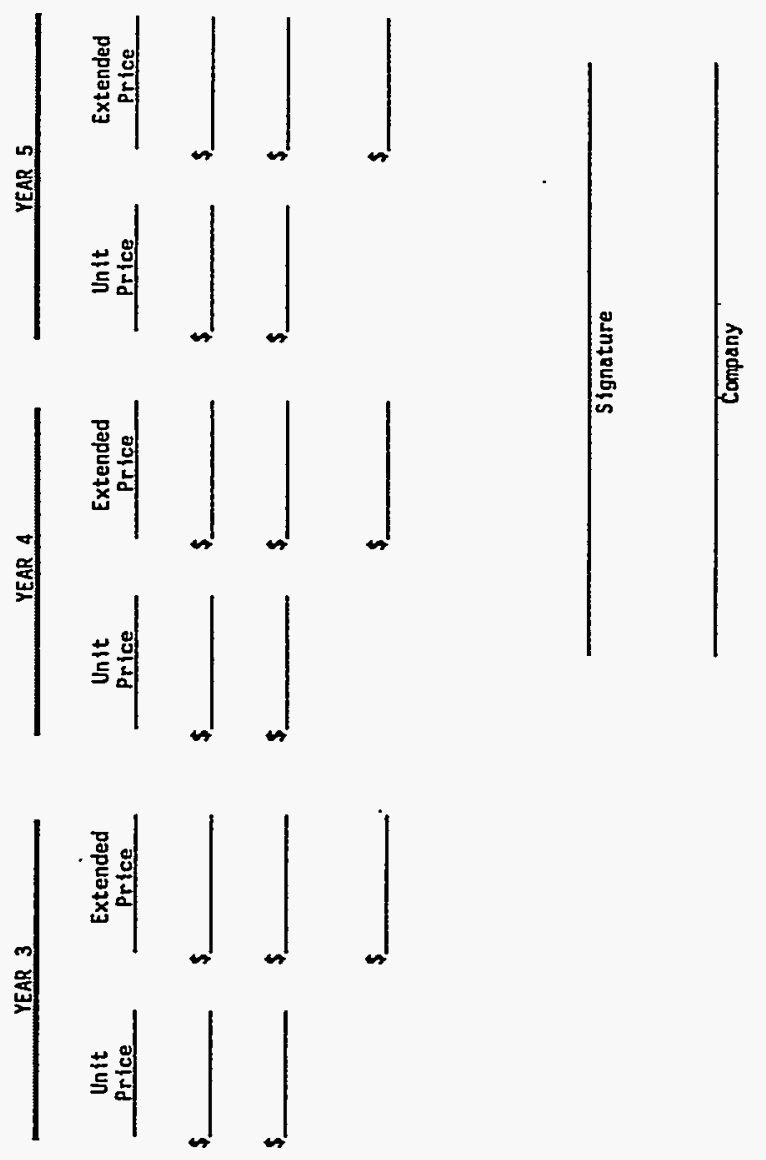

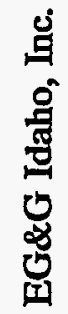
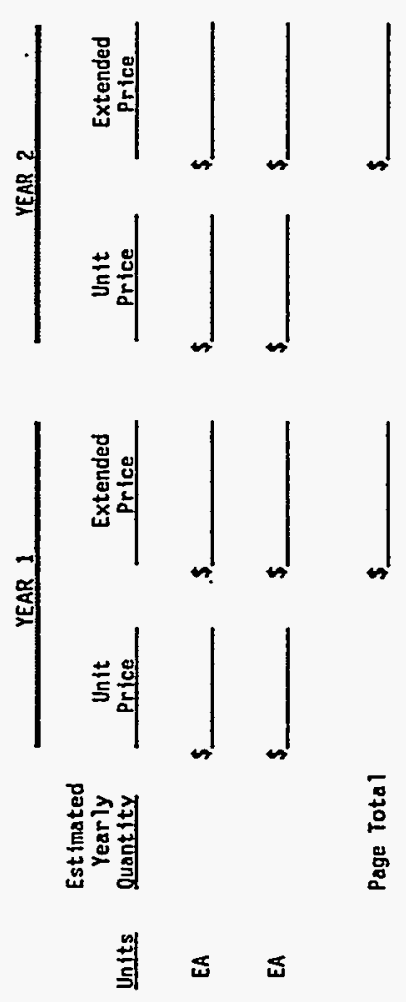

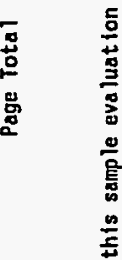

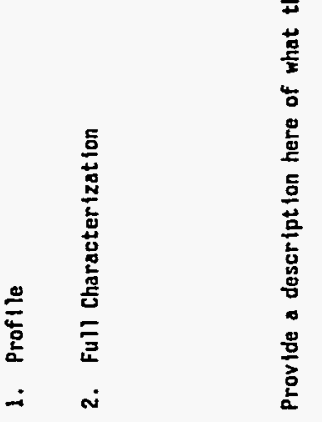


EG\&G Idaho, Inc.

Attachment 23, Page 1 of 2

ATTACHMENT 23 - SAMPLE EVALUATION

SCOPE OF WORK AND PRICE PROPOSAL

\section{SCOPE OF WORK}

The Subcontractor may be required to provide sample evaluation for the purpose of preshipment verification of hazardous waste. The evaluation process shall include all tasks necessary to provide approval or denial for waste streams. It is estimated that $80 \%$ of the waste streams will be one-time occurrences, rather than recurring waste streams.

The Subcontractor shall evaluate waste streams for approval or denial within 45 calendar days of receipt from EG\&G Idaho of the profile data and representative sample.

If and when this service is requested, the attached unit prices shall apply. The quantities and waste streams shown are estimated annual requirements and are in no way guaranteed or implied.

\section{INSTRUCTIONS FOR COMPLETING ATTACHED PRICE PROPOSAL:}

Comply with Attachment O, Pricing Requirements, of this Request for Proposal. 
and

EG\&G Idaho, Inc.

Attachment 24, Page 2 of 4

4. The Subcontractor shall provide EG\&G with any special requirements of individual waste disposal sites and/or lab pack wastes. The Subcontractor shall ensure that drums are labeled as required by RCRA and DOT regulations. Subcontractor shall be responsible for citations and fines levied due to its negligence in packaging, labeling, and marking, etc.

5. The packing operations shall be conducted in a manner which minimizes the possibility of container breakage or spills. In case of container breakage or spills by the Subcontractor, the Subcontractor is responsible for the costs incurred by the INEL for cleanup and disposal of waste generated. In addition, if any leaks, spills, fires, explosions, or other undesirable effects of a chemical release results from the activities of the Subcontractor, the Subcontractor is responsible for remediation costs incurred by the INEL.

6. If PCB wastes are involved, the Subcontractor shall handle, pack, and/or label the wastes as required by TSCA, RCRA, and applicabie state and local regulations. Arrange for the shipment and disposal of PCB wastes. Ensure that the INEL receives a Certificate of Destruction for the PCB wastes.

7. The Subcontractor shall assist EG\&G, if requested, with the handling and loading of drums of waste.

\section{Self Lab Pack Operations:}

1. The Subcontractor shall be required to accept for disposal drums which are lab packed by EG\&G Idaho with off-site direction provided by the Subcontractor. The Subcontractor shall determine and provide prior acceptance approval for each lab pack item based on generator waste characterizations and MSDSs, if appropriate, provided by EG\&G Idaho.

2. The Subcontractor shall provide packing lists and a list of shipping names to EG\&G Idaho within 21 calendar days of receipt of the generator waste characterizations and MSDSs, if appropriate. The Subcontractor shall not include on the packing lists lab pack items that it does not approve. EG\&G Idaho shall pack and manifest each lab pack drum by following the provided packing lists and shipping names.

3. All of the other requirements listed in this Attachment 24 shall also apply to the Subcontractor for self lab pack operations. 
EG\&G Idaho, Inc.

Attachment 24, Page 1 of 4

\section{ATTACHMENT 24 - LAB PACK}

\section{SCOPE OF WORK AND PRICE PROPOSAL}

\section{SCOPE OF WORK}

The Subcontractor may be required to provide trained personnel to perform lab pack work at the INEL. The Subcontractor shall travel to the INEL to properly classify and package, for transport to a disposal facility, excess laboratory chemicals, lecture cylinders, and process waste as identified in Attachment 22 . The Subcontractor shall set up classification and packaging stations at various locations throughout the INEL. Present plans call for approximately four different locations that may require lab pack services, with one in Idaho Falls, Idaho and the others at the INEL as dictated by the actual waste generated. Lab packs are priced in Attachment 22.

The Subcontractor shall provide lab packing services on both a scheduled and emergency basis. The Subcontractor may be required to provide lab pack personnel within 20 calendar days of EG\&G Idaho's request and, for emergencies, within 7 calendar days of request.

Subcontractor personnel shall provide all technical expertise for the lab packing, categorization of waste streams, and preparation of documents necessary for shipping. EG\&G Idaho will supply the drums and packing material, which may be distributed to the Subcontractor by the Central Facilities Warehouse (CFA).

The Subcontractor shall collect costs separately for work at each lab pack location, and provide separate line items on invoices.

\section{Lab Pack Operations:}

1. Approval, packing and transportation shall be completed by the Subcontractor within 65 days of EG\&G Idaho's initial request for service.

2. The Subcontractor shall give prior acceptance approval for each waste stream based on generator waste characterizations and MSDSs, if appropriate, provided by EG\&G Idaho. Subcontractor shall not have the option of rejecting any contents of any drums that are packed in accordance with the packing list approved by the Subcontractor. The Subcontractor shall reimburse the INEL for any costs incurred as a result of Subcontractor rejection of waste that it has approved for shipment.

3. Subcontractor shall base the packing lists on the compatibility of the wastes and not on drum size. However, drum size may be as large as 85-gallons. Subcontractor shall not have the option to limit drum sizes. 


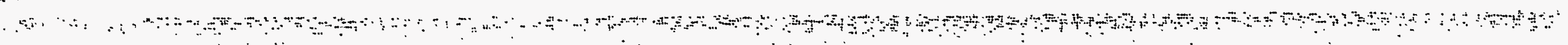

\section{EG\&G Idaho, Inc.}

1. Mobilization and Demobilization (Includes all costs prior to departing from the IMEU).
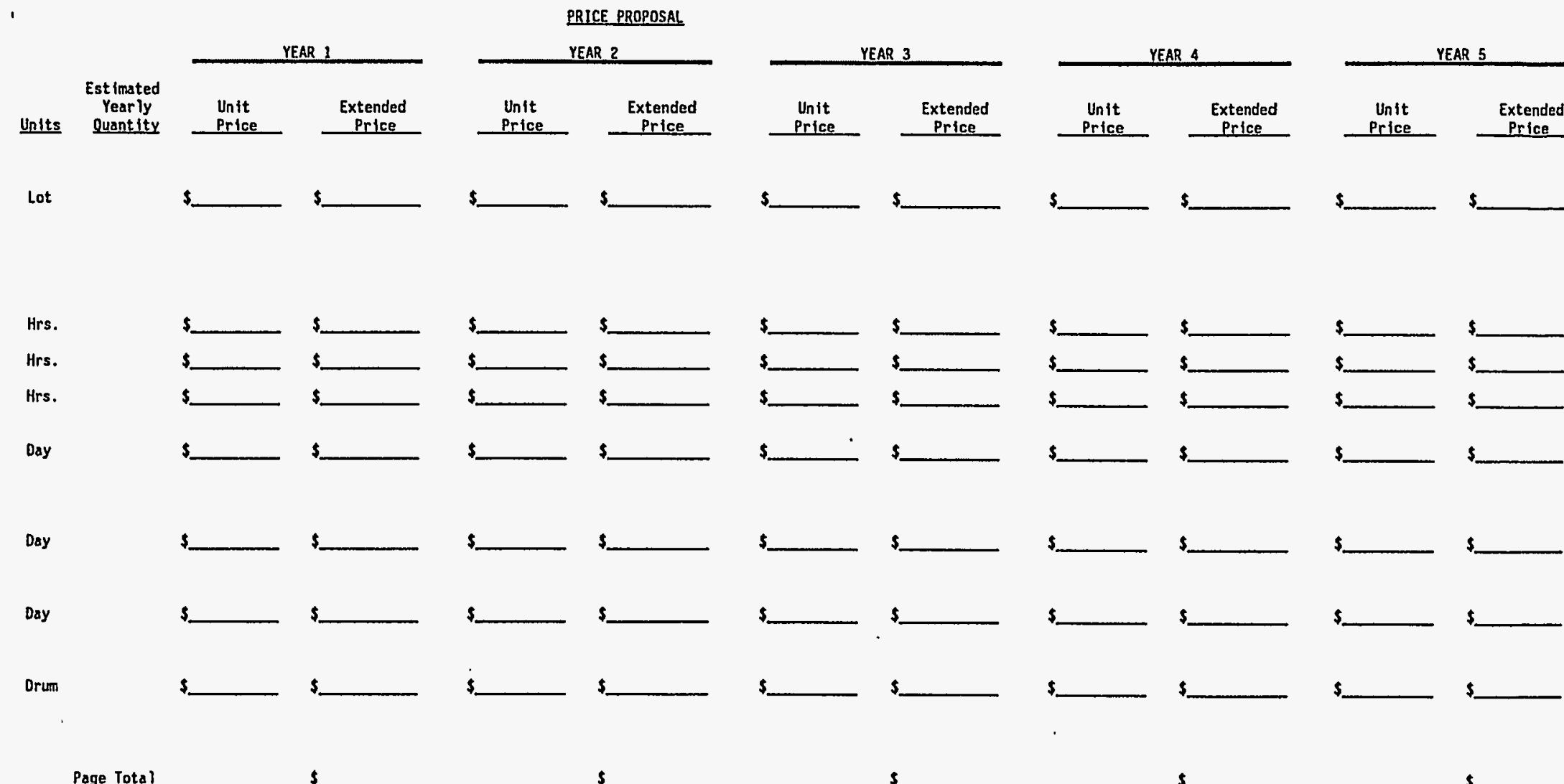

\section{Personnel Price \\ Project Kanager \\ Chemist}

Technician. 3. Personnel travel expense while
at the IHEL. (Per diem for eac person while in travel status).

4. Personnel protective safety gear for each person.

5. Support vehicle during performance of the work.

6. Provide off-site direction and packing 11sts/shlpping names

for self-lab packing (drum size
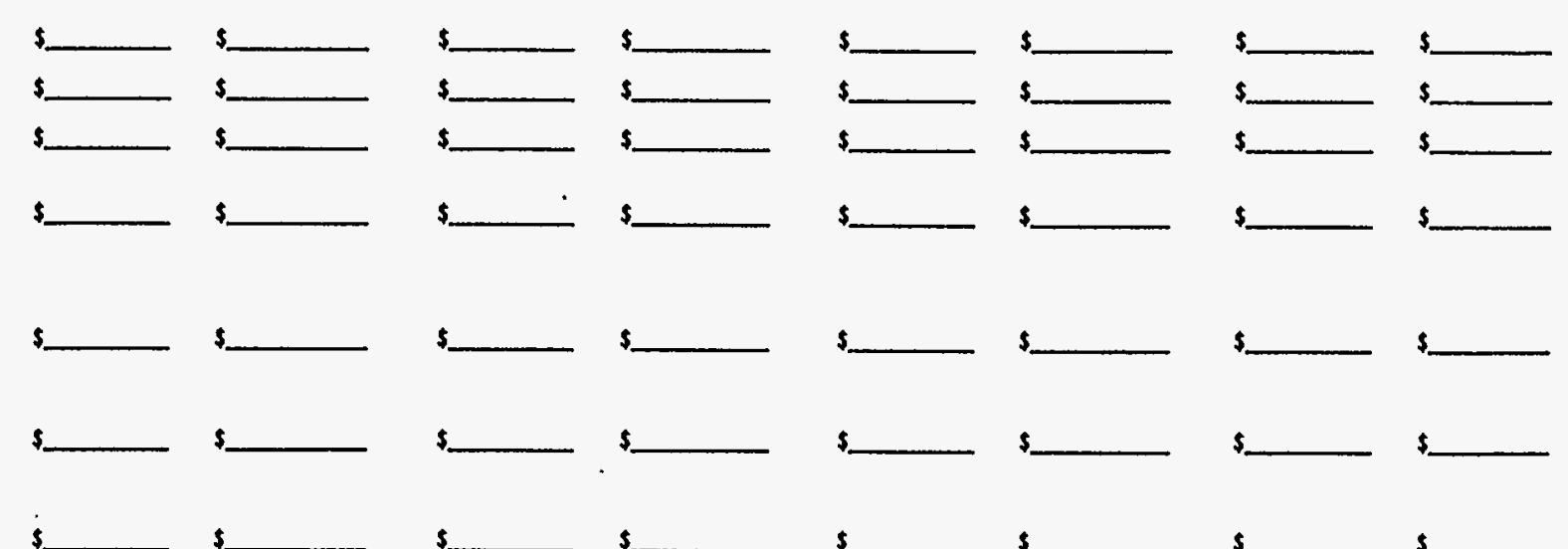

$\$$<smiles>[131IH]</smiles>

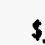

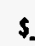

$\$$

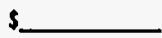
$s$

$\$$ 


\section{EG\&G Idaho, Inc.}

\section{Additional Requirements:}

The Subcontractor will be reimbursed for meals and lodging while in travel status in accordance with FAR $31.205-46$ or Contractor waivers thereof approved prior to travel. (Copies of FAR 31-205-46 and INEL Waivers are available on request.) For the purposes of this agreement, daily meal and lodging reimbursements will be made as follows:

$$
\text { Meals } \quad \text { Lodging }
$$

\section{Idaho Falls, Idaho}

\section{$\$ 40.00$}

Miscellaneous materials used in providing lab pack services will be reimbursed at actual expenses.

Labor costs will be computed by multiplying the appropriate hourly rate quoted in Attachment 24 by the number of direct labor hours actually expended at the work site in performance of the work scope. Billable labor hours shall begin when Subcontractor personnel arrive at the INEL facilities and end upon departure, excluding $1 / 2$ hour for lunch. Invoices must not include travel time, including travel to and from the INEL facilities.

All labor will be performed based on five eight-hour days, unless otherwise requested by EG\&G Idaho.

Subcontractor personnel shall comply with Environmental, Safety and Health Requirements for Subcontractors (Enclosure 4) while located at INEL facilities. Personnel shall not eat, drink, smoke, or chew gum or tobacco in the work areas.

All Subcontractor personnel that work at INEL locations shall be required to be U.S. citizens.

If and when this service is requested, the attached unit prices shall apply. The attached list shows estimated annual quantities of services the Subcontractor may be required to provide. The quantities are in no way guaranteed or implied.

\section{INSTRUCTIONS FOR COMPLETING ATTACHED PRICE PROPOSAL:}

Comply with Attachment O, Pricing Requirements, of this Request for Proposal. 


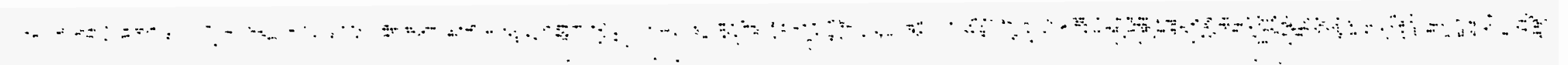

EG\&G Idaho, Inc.

\section{PRICE PBOPOSAL}

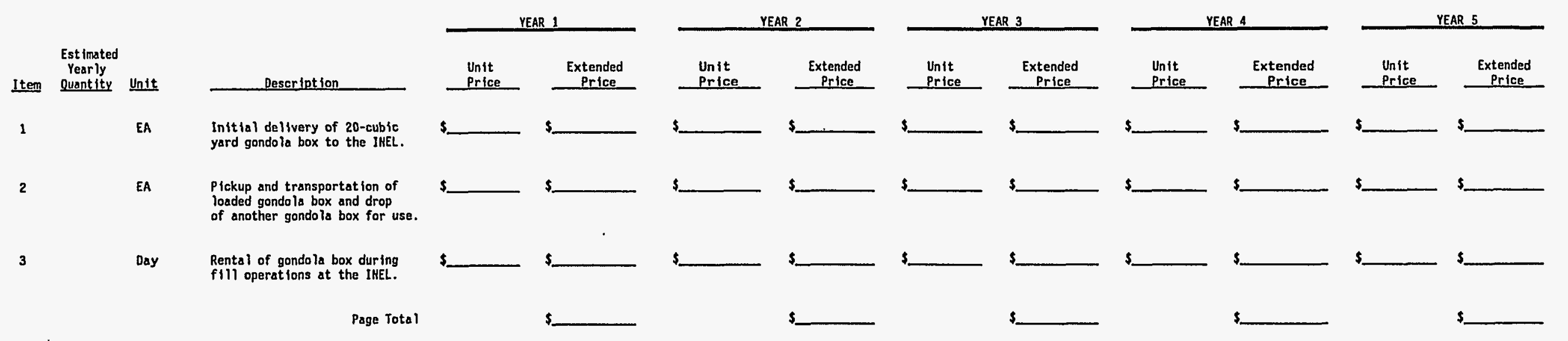

Signature 
EG\&G Idaho, Inc.

\section{ATTACHMENT 25 - GONDOLA BOXES}

\section{SCOPE OF WORK AND PRICE PROPOSAL}

\section{SCOPE OF WORK}

The Subcontractor may be required to provide gondola boxes for removal of bulk shipments from the Idaho National Engineering Laboratory (INEL). After the initial delivery of the box to the INEL, the Subcontractor, upon request, shall deliver an empty box and pickup the previous delivered box containing the hazardous waste being shipped. The filled box shall be delivered to the proposed site and properly disposed of.

If and when this service is requested, the attached unit prices, excluding disposal of the hazardous waste, shall apply. The attached lists the estimated yearly quantities of this service the Subcontractor may be required to provide. The quantities are in no way guaranteed or implied.

\section{INSTRUCTIONS FOR COMPLETING ATTACHED PRICE PROPOSAL:}

Comply with Attachment $O$, Pricing Requirements, of this Request for Proposal. 


\section{REPRESENTATIONS AND CERTIFICATIONS}

The offering organization makes the following representations and certifications as part of its offer: (Check or complete all approprlate blanks and sign and date last page.)

1. The offering organization represents that it is a regular dea ler in. manufacturer of. the supplies bid upon.

2. The offering organization represents that it operates incorporated in the State of

as an individua?, in partnership. as a corporation

3. Women-Owned Business. The offering organization represents that the firm submitting this offer is, is not, a women-owned business. A women-owned business is a business that is at least 51 percent owned by a woman or women who also control and operate the business. Control in this context means exercising the power to make policy decisions. Operate in this context means being activeiy involved in the day-to-day management. For the purposes of this definition, businesses which are publicly owned, joint stock associations, and business trusts are exempted. Exempted businesses may voluntarily represent that they are or are not women-owned if this information is available. (Approved by the Office of Management and Budget under OMB control number 3090-0075.)

4. Small and Sma 11 Disadvantaged Business Certification.

(a) The offering organization certifies that it is, is not, a small business concern as defined in accordance with Section 3 of the Small Business Act ( 15 U.S.C. 632 and SBA's rules and regulations set forth at 13 CFR 121.3-8). If an affirmative certification is made, the offering organization shall complete the certifications at paragraph (b) of this section.

(b) The offering organization certifies that it is a small business as set forth in (a) above and is, is not, owned and controlled by socially and economically disadvantaged individuals. Such a firm is defined as one: (1) which is at least 51 percent owned by one or more such individuals or, in the case of a publicly owned business, at least 51 percent of the stock is owned by such individuals; (2) whose management and daily business operations are controlled by one or more such individuals; and (3) which certifies said ownership and control is by the following: (i) United States citizens who are Black Americans, Hispanic Americans, Native Americans, Asian Pacific Americans, or other specified minorities; or (ii) any other individual found to be disadvantaged pursuant to Section $8(a)$ of the Small Business Act (15 U.S.C. 632).

5. Recovered Materials. (Applicable when specifications require the use of recovered materials by a specified percentage or maximum extent possible.) The offering organization certifies that recovered materials_will, will not. be used as required by specifications referenced in the solicitation. (Recovered materials means material which has been collected or recovered from solid waste. It includes reclaimed materials.)

The kind and percentage of materiais to be used are:

6. Contingent Fee. The offering organization represents that:

(a) : It _has, has not, employed or retained any company or person (other than a ful1-time, bona fide employee working solely for the offering organization) to solicit or secure this subcontract; and that

(b) It __has, has not, paid or agreed to pay any company or person (other than a ful1-time, bona fide employee working solely for the offering organization) any fee, commission, percentage, or brokerage fee contingent upon or resulting from the award of this subcontract; and

(c) Agrees to furnish information relating to (a) and (b) as requested by the Contractor.

(For interpretation of the representation, including the term "bona fide employee," see Code of Federal Regulations, Title 44. Subpart 1-1.5.)

7. Equal Opportunity. The offering organization represents that it _has, has not, participated in a previous contract or subcontract subject to the Equal Opportunity clause herein, or the clause originaliy contained in Section 301 of Executive Order No. 10925, or the clause contained in Section 201 of Executive Order No. 11114; that it _ has, has not, filed ail required compliance reports; and that representations indicating submission of required compliance reports, signed by proposed lower tier subcontractors, will be obtained prior to such lower tier subcontract award.

8. Buy American Certificate. The offering organization certifies that each end product, except the end products listed below, is a domestic source end product (as def ined in the clause entitled "Buy American Act"), and that components of unknown origin have been considered to have been mined, produced, or manufactured outside the United States. 
9. Country of Manufacturer. The product which the offering organization proposes to furnish is, mined, or grown in the Unite control number 3090-0061.)

manufactured, mined, or grown in the United States, the (Approved by the Office of Management and Budget under OMB

10. Parent Company and Employer Identification Number. Each offering organization shall furnish the following information by filling in the appropriate blanks: Is the offering organization owned or controlled by a parent company as described below? Yes No

[For the purpose of this offer, a parent company is defined as one that either owns or controls the activities and basic business policies of the offering organization. To own another company means the parent company must own at least a majority (more than 50 percent) of the voting rights in that company. To control another company, such ownership is not required; if another company is able to formulate, determine, or veto basic business policy decisions of the offering organization, such other company is considered the parent company of the offering organization. This control may be exercised through the use of dominant minority voting rights, use of proxy voting. contractual arrangements, or otherwise.]

If the answer to (a) above is "Yes," offering organization shall insert in the space be low the name and main office address of the parent company.

(Name)

(Address)

(c) The offering organization shall insert in the applicable space below, if it has no parent company, its own employer's ident if ication number (E.I. No.) (Federal social security number used on employer's quarterly Federal tax return, U. S. Treasury Department Form 941) or, if it has a parent company, the E.I. No. of its parent company.

Bidder's E.I. No.

Parent company's E.I. No.

11. Clean Air and Water Certification. (Applicable if the offer exceeds $\$ 100.000$, or the Contractor has determined that orders under an indefinite quantity contract in any one year will exceed $\$ 100,000$, or a facility to be used has been the subject of a conviction under the Clean Air Act [43 U.S.C. $1857 \mathrm{c}-8(\mathrm{c})(1)]$ or the Federal Water Pollution Control Act [33 U.S.C. $1319(c)]$ and is listed by the Environmental Protection Agency, or is not otherwise exempt.) The offering organization certifies as follows:

(a) Any facility to be utilized in the performance of this proposed subcontract the Environmental Protection Agency list of Violating Facilities.

has, has not, been listed on

It will promptly notify Contractor, prior to award, of the receipt of any comnunication from the Director, Office of Federal Activities. Environmental Protection Agency (EPA). indicating that any facility it proposes to use for the performance of the subcontract is under consideration to be listed on the EPA list of Violating Facilities. It will include substantially this certification. including this paragraph (c), in every nonexempt lower tier subcontract.

12. Certification of Nonsegregated Facilities. (Applicable to contracts and subcontracts exceeding $\$ 10,000$, which are not exempt from the provisions of the equal opportunity clause.) By the submission of this offer, the offering organization or subcontractor certifies that it does not maintain or provide for its employees any segregated facilities at any of its establishments, and that it does not permit its employees to perform their services at any location, under its control, where segregated facilities are maintained. It certifies further that it will not ma intain or provide for its employees any segregated facilities at any of its establishments, and that it will not permit its employees to perform their services at any location, under its control, where segregated facilities are maintained. The offering organization or subcontractor agrees that a breach of this certification is a violation of the Equal Opportunity clause in this subcontract. As used in this certification, the term "segregated facilities" means any waiting rooms, work areas, restrooms and washrooms, restaurants and other eating areas, timeclocks, locker rooms and other storage or dressing areas, parking lots, drinking fountains, recreation or entertainment areas, transportation, and housing facilities provided for employees that are segregated by explicit directive or are in fact segregated on the basis of race, color, religion, or national origin, or because of habit, local custom, or otherwise. It further agrees that (except when it has obtained identical certifications from proposed lower tier subcontractors for specific time periods) it will obtain identical certifications from proposed subcontractors prior to the award of lower tier subcontracts exceeding $\$ 10,000$, which are not exempt from the provisions of the Equal Opportunity clause; that it will retain such certifications in its files; and that it will forward the following notice to such proposed subcontractors (except when the proposed subcontractors have submitted identical certifications for specific time periods): 


\section{NOTICE TO PROSPECTIVE SUBCONTRACTORS OF REQUIREMENTS}

FOR CERTIFICATION OF NONSEGREGATED FACILITIES

A Certification of Nonsegregated Facilities must be submitted prior to the award of a subcontract exceeding $\$ 10,000$, which is not exempt from the provisions of the Equal Opportunity clause. The certification may be submitted either for each subcontract or for ail subcontracts during a period (i.e., quarterly, semiannually, or annually).

NOTE: The penalty for making faise statements is prescribed in 18 U.S.C. 1001 .

13. Certificate of Independent Price Determination.

(a) By submission of this proposal, each offering organization certifies, and in the case of a joint proposal, each party thereto certifies as to its own organization, that in connection with this procurement: (1) the prices in this proposal have been arrived at independently, without consultation, communication, or agreement for the purpose of restricting competition as to any matter relating to such prices with any other offering organization or with any competitor; (2) un less otherwise required by law, the prices quoted in this proposal have not been knowingly disclosed by the offering organization and will not knowingly be disclosed by the offering organization prior to award, directly or indirectly to any other offering organization or to any competitor; (3) no attempt has been made or will be made by the offering organization to induce any other person or firm to submit or not to submit a bid or proposal for the purpose of restricting competition.

(b) Each person signing this proposal certifies that: (1) he is the person in the offeror's organization responsible within that organization for the decision as to the prices being offered herein, and that he has not participated, and will not participate, in any action contrary to $(a)(1)$ through (a)(3) above; or (2)(i) he is not the person in the offering organization responsible within that organization for the decision as to the prices being offered herein, but that he has been authorized in writing to act as agent for the persons responsible for such decision in certifying that such persons have not participated, and will not participate, in any action contrary to (a)(1) through (a) (3) above, and as their agent does hereby so certify; and (ij) he has not participated, and will not participate, in any action contrary to (a)(1) through (a)(3) above.

(c) This certification is not applicable to a foreign bidder or offering organization submitting a proposal for a subcontract that requires performance or delivery outside the United States, its possessions, and Puerto Rico.

(d) A proposal will not be considered for award when (a)(1). (a)(3); or (b) above has been deleted or modified. When (a) (2) above has been deleted or modified, the proposal will not be considered for award unless the offering organization furnished with the proposal a signed statement that sets forth in detail the circumstances of the disclosure and Contractor determines that such disclosure was not made for the purpose of restricting competition.

14. Affirmative Action. (Applicabie only to offers of $\$ 50,000$ or more and offering organization has 50 or more employees.) The offering organization represents that it has developed and has on $f i l e \ldots$. has not developed and does not have on file $\rightarrow$ at each establishment affirmative action programs as required by the rules and regulations of the Secretary of Labor (41 CFR 60-1, 60-2), or __ it has not previously had contracts subject to the written affirmative action program requirements of the rules and regulations of the Secretary of Labor.

15. Certification of Subcontractor's Quality Program. The offering organization certifies that it has read the Standard Qua lity Requirements for Supplies (Form EG\&G-1097) and understands that such requirements are included in the subcontract; and that it does_. does not_._. maintain a quality system under which it can prepare and submit the special procedures, certifications, and reports required by that document.

NOTE: SMALL BUSINESS CONCERNS ARE WHOLLY EXEMPT FROM COST ACCOUNTING STANDARDS AND ARE NOT REQUIRED TO COMPLETE ITEMS 16 THROUGH 19 BELOH.

16. Disclosure Statement - Cost Accounting Practices and Certification. Any subcontract in excess of $\$ 100,000$ resulting from this solicitation, except

(a) When the price negotiated is based on (1) established catalog or market prices of cormercial items sold in substantial quantities to the general public, or (2) prices set by law or regulations:

(b) Subcontracts awarded to sma 11 business concerns (as defined in 1-701.1 of the Defense Acquisition Regulations or FPR 1-1.701-1); or 
shal1 be subject to the requirements of the Cost Accounting Standards Board. Any offering organization submitting a proposal, which, if accepted, will result in a subcontract subject to the requirements of the Cost Account ing Standards Board must, as a condition of contracting, submit a disclosure statement as required by regulations of the Board. The disclosure statement must be submitted as a part of the offering organization's proposal under this solicitation (see I. below), unless (1) the offeringorganization, together with all divisions, subsidiaries, and affiliates under common control, did not receive net awards exceeding the monetary exemption for disclosure as established by the Cost Accounting Standards Board (see II. below): (2) the offering organization exceeded the monetary exemption in its cost accounting period immediately preceding the cost accounting period in which this proposal was submitted, but, in accordance with the regulations of the Cost Accounting Standards Board, is not yet required to submit a disclosure statement (see III. below); or (3) the offering organization has already submitted a disclosure statement disclosing the practices used in connection with the pricing of this proposa? (see IV. below).

CAUTION: A practice disclosed in a disclosure statement shall not, by virtue of such disclosure, be deemed to be a proper, approved, or agreed-to practice for pricing proposals or accumulating and reporting subcontract performance cost data.

CHECK THE APPROPRIATE BLANK BELOW

\section{CERTIFICATE OF CONCURRENT SUBMISSION OF DISCLOSURE STATEMENT(S)}

The offering organization certifies that it has submitted, as part of its proposal under this solicitation, copies of the disclosure statement(s) as follows: (1) original and one copy to the cognizant Contracting Officer [Administrative Contracting Office, (ACO)]. see DOD Directory of Contract Administration Components (DOD 4105.59H): and (2) one copy to the cognizant contract auditor.

Date of Disclosure Statement(s)

Name(s) and Address(es) of Cognizant $A C O(s)$ Where Filed:

\section{CERTIFICATE OF MONETARY EXEMPTION}

The offering organization hereby certifies that it, together with all divisions, subsidiaries, and affiliates under conmon control, did not receive net awards of negotiated national defense prime contracts and subcontracts subject to cost accounting standards totaling more than $\$ 10$ million in its cost accounting period immediately preceding the period in which this proposal was submitted. The offering organization further certifies that if its status changes prior to an award resulting from this proposal, it will advise the Contractor immediately.

CAUTION: $\quad$ Offering organizations who submitted a disciosure statement under the filing requirements previously established by the Cost Accounting Standards Board may claim this exemption only if the dollar volume of CAS covered national defense prime contract and subcontract awards in their preceding cost accounting period did not exceed the $\$ 10$ million threshold and the amount of this award will be less than $\$ 10$ million. Such offering organizations will continue to be responsible for maintaining the disclosure statement and following the disclosed practices on CAS covered prime contracts and subcontracts awarded during the period in which a disclosure statement was required.

\section{CERTIFICATE OF INTERIM EXEMPTION}

The offering organization certifies that (1) it first exceeded the monetary exemption for disclosure, as defined in II. above, in its cost accounting period immediately preceding the cost accounting period in which this proposal was submitted, and (2) in. accordance with the regulations of the Cost Accounting Standards Board [4 CFR 351.40(b)], it is not yet requirec to submit a disclosure statement. The offering organization further certifies that if an award resulting from this proposal has not been made within 90 days after the end of that period, it wili immediately submit a revised certificate tc the Contractor, in the form specified under I. above or IV. below, as appropriate, to verify its submission of a completed disc losure statement.

CAUTION: $\quad$ Offering organizations may not claim this exemption if they are currently required to disclose because they were awarded a CAS covered national defense prime contract or subcontract of $\$ 10$ million or more in the current cost accounting period. Further, the exemption applies only in connection with proposals submitted prior to expiration of the 90-day period following the cost accounting period in which the monetary exemption was exceeded. 


\section{CERTIFICATE OF PREVIOUSLY SUBMITTED DISCLOSURE STATEMENT(S)}

The offering organization hereby certifies that the disclosure statement(s) were filed as follows:

Date of Disclosure Statement(s)

Name(s) and Address(es) of

Cognizant ACO(s) Where Filed

The offering organization further certifies that practices used in estimating costs in pricing this proposal are consistent with the cost accounting practices disclosed in the disclosure statement(s).

17. Cost Accounting Standards - Exemptions for Subcontracts of $\$ 500,000$ or Less. If this proposa 1 is expected to result in the award of a subcontract of $\$ 500,000$ or less, the offering organization shall indicate whether the exemption to the Cost Accounting Standards clause under the provisions of 4 CFR $331.30(\mathrm{~b})(7)$ is claimed. Failure to check the blank space below shall mean that the resulting subcontract is subject to the Cost Accounting Standards clause or that the offering organization elects to comply with the applicable clause.

The offering organization hereby claims an exemption from the Cost Accounting Standards clause under the provision of

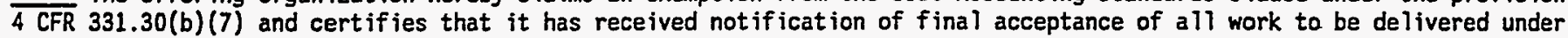
all CAS covered prime contracts or subcontracts. The offering organization further certifies it will immediately notify the Contractor in writing in the event it is awarded any other contract or subcontract containing a Cost Accounting Standards clause subsequent to the date of this certificate but prior to the date of any award resulting from this proposal.

18. Cost Accounting Standards Eligibility for Modified Contract Coverage. If the offering organization is eligible to use the modified provisions of 4 CFR Part 332. and elects to do so, it shall indicate by checking the space below. Checking the space below shall mean that the resulting subcontract is subject to the Disclosure and Consistency of Cost Accounting Practices clause in lieu of the Cost Accounting Standards clause.

The offering organization hereby claims an exemption from the Cost Accounting Standards clause under the provisions of 4 CFR 331.30 (b) (2), and certifies that it is eligible for use of the Disclosure and Consistency of Cost Accounting Practices clause because

(a) During its cost accounting period imnediately preceding the period in which this proposal was submitted, it received less than $\$ 10$ million in awards of CAS covered national defense price contracts and subcontracts, and

(b) The sum of such awards equaled less than 10 percent of its total sales during the cost accounting period.

The offering organization further certifies that if its status changes prior to an award resulting from this proposal, it will advise the Contractor immediateiy.

CAUTION: $\quad$ Offering organizations may not claim the above eligibility for modified contract coverage if this proposal is expected to result in the award of a subcontract of $\$ 10$ million or more, of if, during their current cost accounting period, they have been awarded a single CAS covered national defense prime contract or subcontract of $\$ 10$ million or more.

19. Additional Cost Accounting Standards Applicable to Existing Contracts. The offering organization shall indicate below whether award of the contemplated subcontract would, in accordance with paragraph (a)(3) of the Cost Account ing Standards clause (Part III of the EG\&G Idaho. Inc., Standard Terms and-Conditions), require a change in its established cost accounting practices affecting existing contracts and subcontracts. Yes No

NOTE: If the offering organization has checked "Yes" above, and is awarded the contemplated subcontract. it will be required to comply with the Adninistration of Cost Accounting Standards clause.

20. Smal1 Business Concerns and Smal1 Disadvantaged Business Concerns Certification. (Applicable to subcontracts over $\$ 500,000$, or, in the case of construction, over $\$ 1,000,000$.

(a) The offering organization represents that the following conditions prevail which determine whether the firm shall be required to submit a subcontracting plan for small business concerns and small business concerns owned and controlled by socially and economically disadvantaged individuals: (i) it is a small business as defined in accordance with 13 CFR. Part 121 of the SBA regulations: (ii) subcontracting possibilities are not offered with respect to this subcontract_; and ( $i$ _ii) the subcontract is not expected to exceed $\$ 1,000,000$ (if solely for construction of a public facility) or $\$ 500,000$ otherwise 

small disadvantaged businesses because it has properly executed one or more of the above representations.

21. Small Business and Small Disadvantaged Business Subcontracting Plan. (Applicable to subcontracts over $\$ 500,000$, or, in the case of construction, over $\$ 1,000,000$.)

(a) This provision does not apply to small business concerns.

(b) The term "subcontract" means any agreement (other than one involving an employer-employee relationship) entered into by a Federal Government prime contractor or subcontractor calling for supplies or services required for the performance of the original contract or subcontract.

(c) The offering organization acknowledges that it is aware of the subcontracting plan requirements in this provision and, if the subcontract offers subcontracting possibilities, agrees to negotiate a plan that includes:

(1) Percentage goa is (expressed in terms of percentage of total planned subcontracting dollars) for the utilization as lower tier subcontractors of smali business concerns and sma 11 business concerns owned and controlled by socially and economically disadvantaged individuals (for the purposes of the subcontracting plan, the Subcontractor may include all purchases that contribute to the performance of the subcontract, including a proportionate share of products, services, etc., whose costs are normally allocated as indirect or overhead costs).

As part of its establishment of percentage goa is, the apparent successful offering organization shall also include in its subcontracting plan: (i) a statement of (1) total dollars planned to be subcontracted, (2) total dollars planned to be subcontracted to small business, and (3) total dollars planned to be subcontracted to small disadvantaged business; (ii) a description of the principal product and service areas to be subcontracted and an identification of those areas where it is planned to use (1) small business subcontractors, and (2) small disadvantaged business subcontractors; (iii) a statement of the method used in developing proposed subcontracting goals for (1) small business and (2) small disadvantaged business concerns (e.g.. did the offering organization use for lower tier subcontract solicitation purposes company source lists, the small business and disadvantaged small business source ident ification system provided by the Small Business Administration's Procurement Automated Source System, the National Minority Purchasing Council Vendor Information Service, the Office of Minority Business Data Center in the Department of Commerce, and the facilities of local small business and minority associations?); and (iv) if the offering organization includes indirect and overhead costs as an element in establishing the goals in the subcontracting plan, the method used in determining the proportionate share of indirect and overhead costs incurred with (1) small business and (2) small disadvantaged bus iness subcontractors shall be explained.

(2) The name of an individual within the employ of the offering organization who will administer the subcontracting program of the offering organization and a description of the duties of such individual.

A description of the efforts the offering organization will take to ensure that small business concerns and small business concerns owned and controlled by socially and economically disadvantaged individuals will have an equitable opportunity to compete for lower tier subcontracts.

Assurances that the offering organization will include the clause entitled "Utilization of Small Business Concerns and Sma 11 Business Concerns Owned and Controlled by Socially and Economically Disadvantaged Individuals" in all subcontracts that offer further subcontracting opportunities, and will require all lower tier subcontractors (except small business concerns) that receive subcontracts in excess of $\$ 500,000$, or in the case of a subcontract for the construction of any public facility, $\$ 1,000,000$, to adopt and comply with a plan similar to the plan agreed to by the offering organization. Such assurances shall describe the offering organization's procedures for the review, approval and monitoring of compliance with such plans.

Assurances that the offering organization will submit such periodic reports and cooperate in any studies or surveys as may be required by the Department of Energy and the Small Business Administration in order to determine the extent of compliance by the offering organization with the subcontracting plan.

A recitation of the types of records the offering organization will maintain to demonstrate procedures that have been adopted to comply with the requirements and goals set forth in the plan, including the establishment of source lists of small business concerns and small business concerns owned and controlled by socially and economically disadvantaged individuals; and efforts to identify and award lower tier subcontracts to such small business concerns. The records shall include at least the following (these records may be maintained on a plant-wide or company-wide basis unless otherwise indicated): (i) small and disadvantaged business source lists. guides, and other data identifying small and small disadvantaged business vendors; ( $i i$ ) organizations contacted for small and disadvantaged business sources; ( $i$ i $i$ ) on a contract-by-contract basis, records on all lower tier subcontract solicitations over $\$ 100,000$ indicat ing on each solicitation (1) whether small business was solicited and, if not. why not; (2) whether small disadvantaged business was solicited and, if not. why not: and (3) reasons for the failure of solicited small business or small disadvantaged business to receive the subcontract award; (iv) records to support other outreach efforts, such as (1) contacts with minority and small business trade associations (2) 
contacts with small business development organizations, and (3) attendance at small and minority business procurement conferences and trade fairs; ( $v$ ) records to support internal activities to guide and encourage buyers, such as (1) workshops, seminars, training programs, etc.. and (2) monitoring activities to evaluate compliance; and $(v i)$ on a contract-by-contract basis, records to support award data submitted to the Contractor to include name and address of lower tier subcontractors.

(d) The offering organization understands that:

(1) No subcontract will be awarded unless and until an acceptable plan is negotiated with the Contractor, and such plan will be incorporated into the subcontract as a material part thereof.

(2) An acceptable plan must, in the determination of the Contractor, provide the maximum practicable opportunity for small business concerns and small business concerns owned and controlled by socially and economically disadvantaged persons to participate in the performance of the subcontract.

(3) If a subcontracting plan acceptable to the Contractor is not negotiated within the time limits prescribed by the Contractor, and such failure arises out of causes within the control and with the fault or negligence of the offering organization, the offering organization shall be ineligible for an award. The Contractor shall notify the subcontractor in writing of the reasons for determining a subcontracting plan to be unacceptable. Such notice shall be given early enough in the negotiation process to allow the subcontractor to modify the plan within the time limits prescribed.

(4) Prior compliance of the offering organization with other such subcontracting plans under previous contracts will be considered by the Contractor in determining the responsibility of the offering organization for award of the subcontract.

(5) It is the offering organization's responsibility to develop a satisfactory subcontracting plan with respect to both small business concerns and small business concerns owned and controlled by socially and economically disadvantaged individuals, and each such aspect of the offering organization's plan will be judged independent of the other.

(6) The offering organization will submit, as required by the Contractor, subcontracting reports in accordance with the instructions thereon, and as further directed by the Contractor. Lower tier subcontractors will also submit these reports to the Contractor, or as otherwise directed, with a copy to the subcontractor's designated small and disadvantaged business liaison.

(6) The offering organization will submit, as required by the Contractor, subcontracting reports in accordance with the instructions thereon, and as further directed by the Contractor. Lower tier subcontractors will also submit these reports to the Contractor. or as otherwise directed, with a copy to the subcontractor's designated small and disadvantaged business liaison.

(e) The failure of the subcontractor or any lower tier subcontractor to comply in good faith with (i) the clause entitled "Utilization of Small Business Concerns and Small Business Concerns Owned and Controlled by Socially and Economically Disadvantaged Individuals," or (ii) an approved plan required by this Sma 11 Business and Sma 11 Disadvantaged Business Subcontracting Plan provision, will be a material breach of such subcontract.

Commercial Products. If a commercial product (defined below) is offered, the required subcontract ing plan may relate to the company's production generally (both for comercial and noncormercial products). rather than solely to the item being procured under the subcontract. In such cases, the subcontractor shall be required to submit one company-wide, annual plan to be reviewed for approval by the first agency with which it enters into a prime contract (which requires a subcontracting plan) during the fiscal year, or by another agency, satisfactory to the Contractor. The approved plan will remain in effect for the company's entire fiscal year for all of the company's or division's commercial products.

The term "commercial products" means products in regular production, sold in substantial quantities to the general public and/or industry at established market or catalog prices. A product that, in the opinion of the Contractor. differs only insignificantly from the subcontractor's commercial product may be regarded for the purpose of this clause as a commercial product.

22. Equal Opportunity Compliance. (Applicable to proposals exceeding $\$ 1,000,000$.) The offering organization represents that

(a) A full compliance review of the offering organization's employment practices has has not been conducted by an agency of the Federal Government.

(b) If a full compliance review has been conducted by an agency of the Federal Government, the most recent compliance review was conducted on

by 
(c) The proposed lower tier subcontractors that will be awarded subcontracts of $\$ 1,000,000$ or more are:

Any offering organization and its known lower tier subcontractors that will be awarded subcontracts of $\$ 1,000,000$ or more will be subject to full preaward equal opportunity reviews before the award of the subcontract for the purpose of determining whether the offering organization and its lower tier subcontractors are able to comply with the provisions of the Equal Opportunity clause.

23. Insurance Information Required.

(a) What is the vendor's fire insurance rate? c/\$100 value/year.

(b) What is the vendor's business interruption insurance rate? $c / \$ 100$ gross earnings/year.

(c) Who is the insurance company?

(d) Name, address, and phone number of insurance agent or broker:

24. In consideration for the like agreement of other offering organizations, the undersigned offering organization agrees to hold this proposal (offer) open for acceptance for a minimum of ninety (90) days, or until written notice of rejection or acceptance thereof.

25. Lobbying Activities (Applicable if the Subcontract or the Subcontract as modified exceeds or could exceed $\$ 100,000$.

(a) The definitions and prohibitions contained in the c.lause, at FAR 52.203-12, Limitation on Payments to Influence Certain Federal Transactions, included in this solicitation, are hereby incorporated by reference in paragraph (b) of this certification.

(b) The offering organization hereby certifies that as of December 23, 1989, that to the best of his or her knowledge and belief, that:

(1) No Federal appropriated funds have been paid or will be paid to any person for influencing or attempting to influence an officer or employee of any agency, a Member of Congress, an officer or employee of Congress, or an employee of a Member of Congress on his or her behalf in connection with the awarding of any Federal contract. the making of any Federal grant, the making of any Federal loan, the entering into of any cooperative agreement, and the extension, continuation, renewal, amendment or modification of any Federa 1 contract, grant, loan, or cooperative agreement;

(2) If any funds other than Federa) appropriated funds (including profit or fee received under a covered Federal transaction) have been paid, or will be paid, to any person for influencing or attempting to influence an officer or employee of any agency, a Member of Congress, an officer or employee of Congress on his or her behalf in connection with this solicitation, the offeror shall complete and submit, with its offer, OMB Standard Form LLL, Disclosure Lobbying Activities, to the Contracting Officer; and

He or she will include the language of this certification in all subcontract awards at any tier and require that all recipients of subcontract awards in excess of $\$ 100,000$ shall certify and disclose accordingly.

(c) Submission of this certification and disclosure is a prerequisite for making or entering into this contract imposed by Section 1352. Title 31. United States Code. Any person who makes an expenditure prohibited under this provision or who fails to file or amend the disclosure form to be filed or amended by this provision, shall be subject to a civil penalty of not less than $\$ 10,000$, and not more than $\$ 100,000$, for each such failure.

NOTE: If the offering organization is a corporation, indicate the state of incorporation, under signature, and if a partnership, give full names of all partners.

COMPANY

By.

Title 


\section{SAMPLE \\ SMALL BUSINESS AND SMALL DISADVANTAGED BUSINESS SUBCONTRACTING PLAN}

Date:

Contractor:

Address:

Subcontract Number:

Item/Service:
October 8, 1992

YOUR COMPANY NAME

COMPANY ADDRESS

Subcontract Number

(DESCRIPTION OF SERVICES OR ITEMS TO BE PROVIDED)

Subcontract Total: Dollar Value to be subcontracted

The following, together with any attachments, is hereby submitted as a subcontracting plan to satisfy the applicable requirements of Public Law 95-507 as implemented by FAR 52.219-9 and DEAR 952.219-9:

1. The total estimated dollars to be subcontracted is (Dollar Amount). The following dollar values and percentage goals expressed in terms of a percentage of total planned subcontracting dollars are applicable to the subcontract cited above:

GOALS

Large Business

Small Business

Small Disadvantaged Business

Women Owned Business

Labor Surplus Area Business
AMOUNT

$\$ 000,000$

$\$ 000,000$

$\$ 00,000$

$\$ 00,000$

$\$ 00,000$

\section{PERCENTAGE}

$00.0 \%$

$00.0 \%$

$0.0 \%$

$0.0 \%$

$0.0 \%$

2. The principal products and/or services to be subcontracted under the subcontract and the type of businesses utilized are shown on Attachment 1.

3. The following method was used in developing the subcontract goals:

a. The work scope for this subcontract was reviewed to establish potential materials and services which could be subcontracted.

b. From the total estimate of potential subcontracted items, a list of those items which were candidates for small businesses was established.

c. From the total estimate of potential subcontracted items to small business, a list of those items which could be subcontracted to small disadvantaged businesses, women owned businesses and labor surplus area businesses was established. 


\section{Page -2- Sample Subcontract Plan}

4. The following individual will administer the subcontracting program:

\section{NAME}

TITLE

\section{ADDRESS}

Phone: $(000) 000-0000$

This individual's specific duties, as they relate to the subcontracting plan, are as follows:

a. Oversees compliance with the content of this plan.

b. Ensures that all subcontracts placed contain the latest provisions regarding small business and small disadvantages business subcontracting and that the requirements of FAR 52.219-9 as implemented by this plan are being fulfilled by the subcontractors.

c. Performs periodic audits of subtier subcontracting plans to measure progress of goals and monitors attainment of goals under this subcontracting plan.

d. Submits Standard Form SF-294, Subcontracting Report for Individual Contracts as requested.

e. Participates in procuring, planning and selection of potential sources to ensure that small business and small disadvantaged business concerns are offered every opportunity to participate in the program.

f. Coordinates and participates with the Small Business Administration, small business utilization specialist, and other groups to locate capable firms.

g. Ensures inclusion of small business, small disadvantaged business or women owned business concerns in all solicitations.

h. Removes statements, clauses, etc., from solicitations which may tend to prohibit small business, small disadvantaged business and women owned business concerns' participation.

i. Maintains records of small business, small disadvantaged business and women owned business concerns' programs.

j. Provide records and reports and fully cooperates in all studies and surveys as may be required by the customer or Government regulations.

k. Attends or arranges for attendance at Business Opportunity Workshops, Minority Enterprise Seminars, Trade Fairs, etc.

1. Conducts or arranges for conduct of motivational training for purchasing personnel pursuant to the intent of Public Law 95-507

5. The following outreach efforts will be taken to ensure that small and small disadvantaged business concerns will have an equitable opportunity to compete for subcontracts. Efforts will be made as follows as a minimum:

a. Distribution of company policies and procedures which implement the requirements of FAR 52.219-9.

b. Assignment by name of specific individuals to carry out the requirements of the policies and procedures.

c. Periodic review of progress made with regard to goals established by individual subcontracting plans.

d. Training and motivation of personnel to ensure their complete support of the plan.

e. Provision of technical and management assistance to small business and small disadvantaged business concerns to ensure complete understanding of requirements. 
f. Provision of clear-cut and realistic technical specifications and delivery schedules to encourage maximum participation.

g. Consideration of all available small business and small disadvantaged business concerns during the make/buy process.

h. Allowing special consideration to small and small disadvantaged business firms by preparing solicitations, allowing adequate time for preparation of bids, arranging specifications and delivery schedules of facilitate the participation of such firms.

i. Where additional bidders as required, the following publications will be used to search for capable firms:

1. Minority Business Enterprise, published by the Defense Logistics Agency.

2. Trv Us, National Business Campaign, 1201 12th Avenue N, Minneapolis, MN 55411.

3. The Regional Minority Purchasing Council's listings.

4. The Woman-owned Business directory.

5. National Minority Council mailing list.

j. An outreach effort will be made to solicit the assistance of local, state, and federal offices, trade and manufacturing associations and labor organizations in identifying qualified firms.

k. Every effort will be made by Mr. John P. Anybody, California, Regional Service Supervisor to attend small, small disadvantaged and women-owned business procurement conferences, workshops, and trade fairs that are available in their specific regions during the term of this subcontract. Such as:

a. Pittsburgh Minority Trade Fair - February, 1991

b. Annual Alcoa Minority Business Conference - April, 1991

c. "Minority Business Opportunity Day IX" - sponsored by the Portland Federal Executive Boards Minority Business Opportunity Committee and the Northwest Regional Minority Purchasing Council. - June, 1991.

d. Seattle Area Procurement Conference: - sponsored by the Chamber of Commerce, Small Business Development Center, Western Washington Council of Governments and the University of Washington. - August, 1991.

e. Tucson Area Procurement Conference sponsored by the Greater Tucson Chamber of Commerce, SCORE, South Arizona Planning and Development Association. - September, 1990.

f. Texas Trade Fair and Business Outlook Conference" - October, 1990.

g. Houston Region Small and Small Disadvantaged Business Conferencen - November, 1990.

6. Subcontractor agrees that the Clause FAR 52.219-8 entitled "Utilization of Small Business Concerns and Small Disadvantaged Business Concerns (Jun 1985)" will be included in all subcontracts which offer further subcontracting opportunities, and that all subcontractors except small business concerns who receive subcontracts in excess of \$500,000 will include Clause DEAR 952.219-9 entitled "Small Business and Small Disadvantaged Business Subcontracting Plan (Apr 1984)" and those subcontractors will be required to adopt and comply with subcontracting plans similar to this one. Such plans will be reviewed by comparing them with the provisions of Public Law 95-507, and assuring that all minimum requirements of an acceptable subcontracting plan have been satisfied. The acceptability of percentage goals shall be determined on a case-by-case basis depending on the supplies/services involved, the availability of potential small and small disadvantaged subcontracts, and prior experience. Once approved and implemented, plans will be monitored through the submission of periodic reports, and/or, as time and availability of funds permit, periodic visits to subcontractor's facilities to review applicable records and subcontracting program progress. 


\section{Page -4 Sample Subcontract Plan}

7. Subcontractor agrees to comply with "Labor Surplus Area, Subcontracting Program," FAR 20.302, and "Subcontracting Opportunities for Women-Owned Business," FAR 19.902.

8. A Standard Form 294, "Subcontracting Report for Individual Contracts, "will be submitted on a semi-annual basis and upon contract completion in accordance with DOE procedures as stated in Clause DEAR 952.219-9 as follows:

1st Report = October $1-$ March 31 (Reports due by April 10th)

2nd Report $=$ April 1 - September 30 (Reports due by Sept. 20th)

Final report due 25 days after expiration of contract or current budget period.

The Standard Form 294 shall indicate in the remarks block the number and dollar amount of awards made to labor surplus area and woman-owned business concerns. The remarks block shall also include (a) the period of performance (b) the current one year period being reported. Boxes 13,14, 15, 16 of the SF 294 will correspond to the current one-year period.

9. Subcontractor will cooperate in any studies or surveys that may be required by the customer or Government regulations.

10. The following types of records to document compliance with this Subcontracting Plan will be maintained:

a. Source lists of qualified small and small disadvantaged and women-owned business firms.

b. Correspondence and invitations to small, small disadvantaged, and women-owned business firms to submit bids.

c. Documentation of reasons why particular firms contacted did or did not meet our bidding requirements.

d. Standard Form 294 will be maintained and updated on a quarterly basis.

e. Lists of corporate minority suppliers.

f. Records on solicitations over $\$ 100,000$ on a subcontract-by-subcontract basis whether or not small, small disadvantaged or women-owned businesses were solicited; if not, why not; and if they offered on the subcontract why they failed to get the award.

g. Lists of organizations contacted for small, small disadvantaged, and women-owned businesses.

h. Records to support other outreach efforts, e.g., contacts with agencies, trade associates, etc. 
ENCLOSURE 03

PAGE 1 OF 28

STC-EG\&G-183

(Rev. 6-91)

EG\&G IDAHO, INC.

STANDARD TERMS AND CONDITIONS

FOR

PURCHASE ORDERS AND SUBCONTRACTS

Issued June, 1991 
ENCLOSURE 03

PAGE 2 OF 28

CONTENTS

ARTICLE

TITLE

PAGE NO.

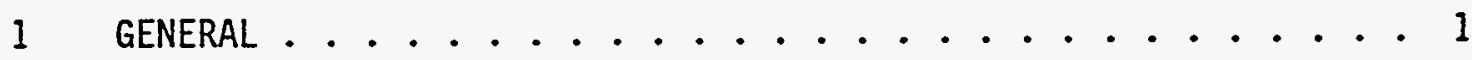

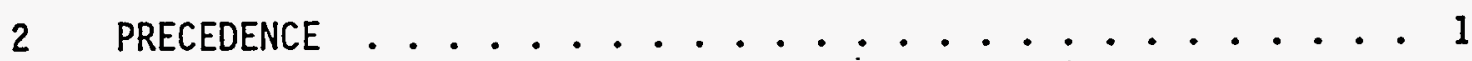

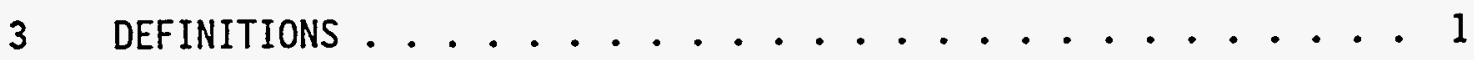

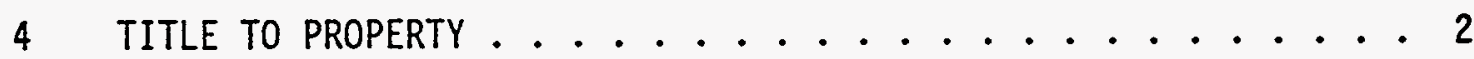

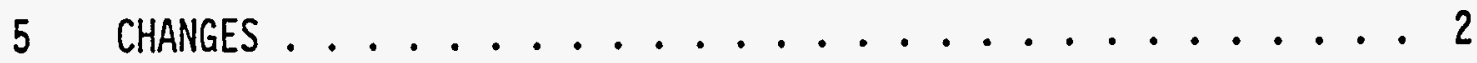

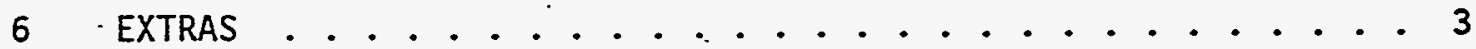

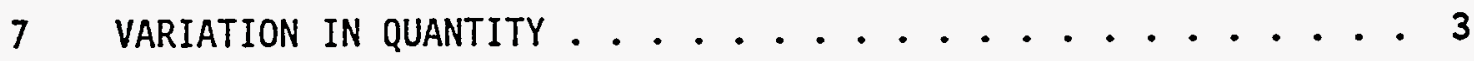

8 SUBSTITUTIONS AND UNAUTHORIZED CHANGES ......... 3

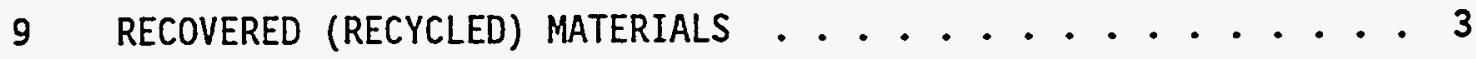

10 MATERIALS AND WORKMANSHIP ............. 3

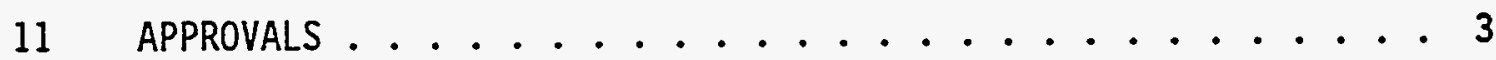

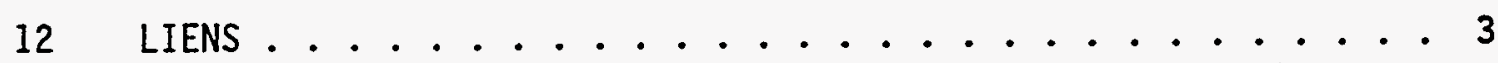

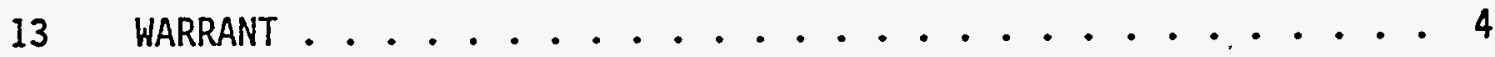

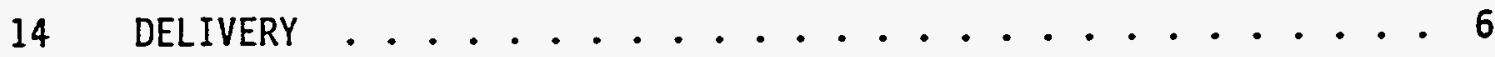

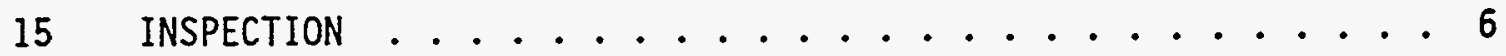

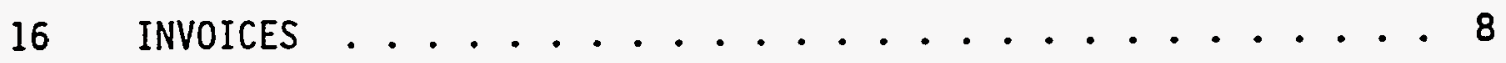

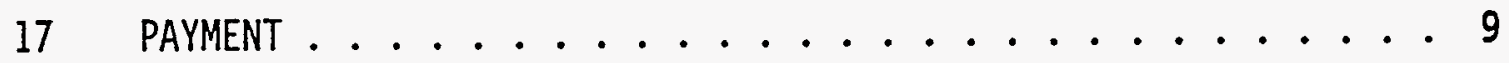

18 ENGINEERING AND OPERATIONS DATA REQUIREMENTS ....... 9

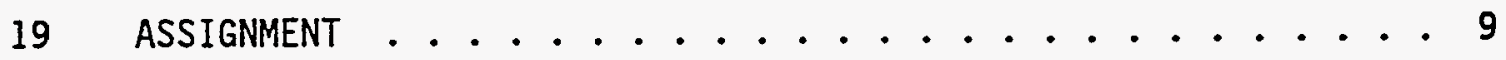

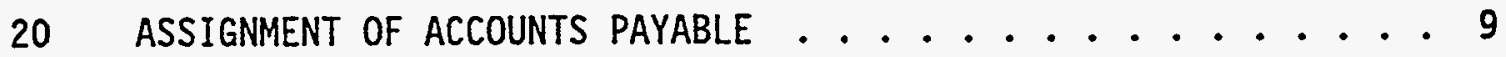

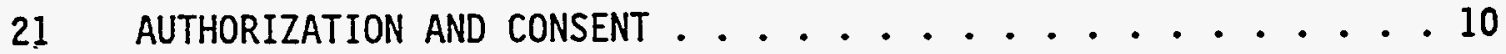

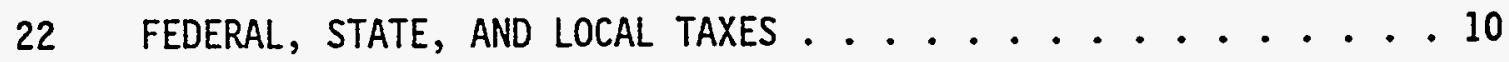

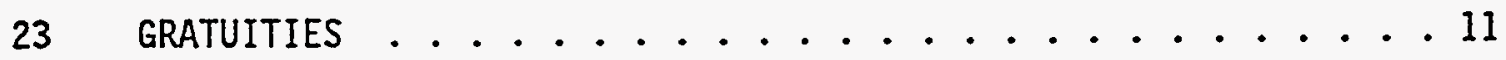


ENCLOSURE 03

PAGE 3 OF 28

CONTENTS

ARTICLE

TITLE

PAGE NO.

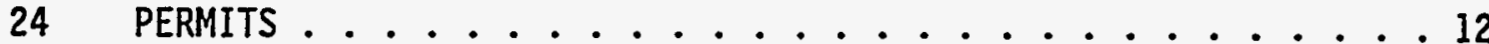

25 PRICING OF ADJUSTMENTS . . . . . . . . . . . . 12

26 REPRESENTATION CONCERNING NUCLEAR HAZARDS INDEMNITY . . . . 12

27 WORKMEN'S COMPENSATION COVERAGE AND INDEMNITY . . . . . . . 12

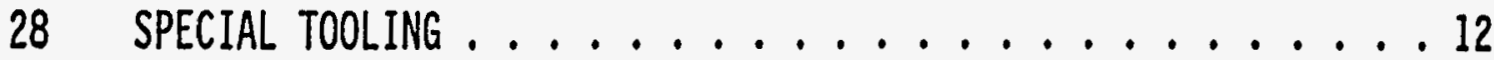

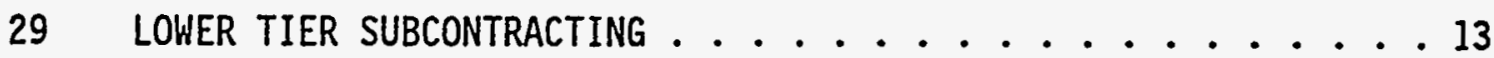

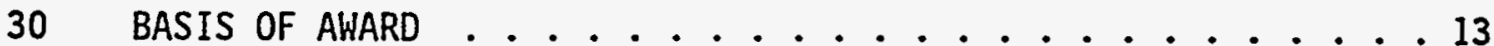

31 NOTICE AND ASSISTANCE REGARDING PATENT AND

COPYRIGHT INFRINGEMENT . . . . . . . . . . . . . 13

32 PUBLIC RELEASE OF INFORMATION . . . . . . . . . . 14

33 REPORTING OF ROYALTIES ................ 14

34 SUSPENSION OF DELIVERIES OR SERVICE . . . . . . . . . 14

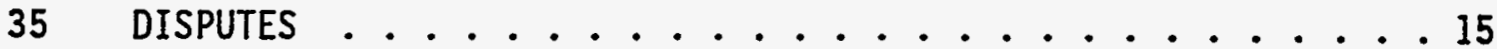

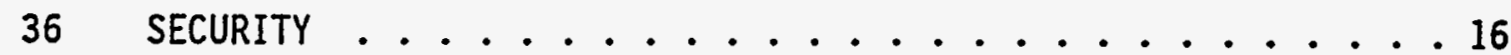

37 ORGANIZATIONAL CONFLICTS OF INTEREST - GENERAL . . . . . 17

38 PRESERVATION OF INDIVIDUAL OCCUPATIONAL RADIATION

EXPOSURE RECORDS .................. 17

39 SUBSTANCE ABUSE POLICY ..................... 18

40 HAZARDOUS MATERIALS BROUGHT BY SUBCONTRACTOR

ONTO THE INEL . . . . . . . . . . . . . . . . . . 19

41 INSURANCE FOR LOSS IN TRANSIT . . . . . . . . . . 19

42 OCCURRENCE NOTIFICATION AND REPORTING BY SUBCONTRACTOR.. .19

43 ENVIRONMENTAL, SAFETY AND HEALTH . . . . . . . . . . 20

44 ARTICLES INCORPORATED BY REFERENCE

ADDENDUM 1, 2 AND 3 


\title{
EG\&G IDAHO, INC. STANDARD TERMS AND CONDITIONS
}

\author{
FOR PURCHASE ORDERS AND SUBCONTRACTS
}

\section{GENERAL}

This subcontract (which term shall be deemed to include related plans, drawings, specifications, standards, and other documents) contains the entire agreement of the parties, and no modification, alteration, waiver or other provisions which are inconsistent with or in addition to the provisions of this subcontract shall have any force or effect unless the same shall be accepted in writing by the Contractor. The standard terms and conditions for this subcontract shall prevai1 notwithstanding any variance with the terms and conditions that may be submitted or proposed by the Subcontractor, Subcontractor's commencement of work or shipment of goods shall be deemed to be an acceptance of the Contractor's standard terms and conditions, and no modifications thereto will be of any effect except by the written acknowledgment of the Contractor. Failure of the Contractor or the Government to enforce any of their rights hereunder shall not constitute a waiver of such rights or of any other rights under this subcontract.

\section{PRECEDENCE}

(a) In the event of an inconsistency between the several documents in this subcontract, the order of precedence shall be: (1) the subcontract, as amended, including these terms and conditions, (2) applicable specifications, (3) applicable drawings, and (4) applicable standards.

(b) Anything mentioned in the specifications and not shown on the drawings, or shown on the drawings and not mentioned in the specifications, shall be of like effect as if shown or mentioned in both.

(c) In the event of an inconsistency between provisions of this subcontract, the inconsistency shall be resolved by giving precedence as follows: (1) schedule, (2) statement of work, (3) the general provisions, (4) other provisions of the subcontract, whether incorporated by reference or otherwise, (5) Subcontractor's technical proposal, if incorporated in the subcontract by reference or otherwise.

\section{DEFINITIONS}

As used throughout this subcontract and except where otherwise indicated, the following terms shall have the meaning set forth below:

(a) The term "Subcontractor" shall mean the supplier or vendor of the materials, supplies or services covered by this subcontract;

(b) The term "Contractor" shall mean EG\&G Idaho, Inc., or its duTy authorized representative or representatives;

(c) The term "lower tier subcontractor" means any party entering into an agreement with the Subcontractor or any lower tier subcontractor for the furnishing of supplies or services required for performance of this subcontract; 
(d) The term "Government" shall mean the United States of America or any duly authorized representative thereof;

(e) The term "DOE" means. the U. S. Department of Energy; and

(f) The term "Contracting Officer" means Manager of the DOE Idaho Operations Office or his duly authorized representative.

\section{TITLE TO PROPERTY}

It is understood and agreed that this subcontract is entered into by the Contractor for and on behalf of the Government; that title to all supplies furnished hereunder by the subcontractor shall pass directly from the Subcontractor to the Government as purchaser, at the point of delivery; that the Contractor is authorized to and will make payment hereunder from Government funds advanced and agreed to be advanced to it by DOE and not from its own assets and administer this subcontract in other respects for DOE unless otherwise specifically provided for herein; that administration of this subcontract may be transferred from the Contractor to DOE or its designee, and in case of such transfer and notice thereof to the Subcontractor, the Contractor shall have no further responsibilities hereunder; and that nothing herein shall preclude liability of the Government for any payment properly due hereunder if for any reasons such payment is not made by the contractor from such Government funds.

\section{CHANGES}

The Contractor may at any time, by written order, and without notice to the sureties, make changes, within the general scope of this subcontract, in any one or more of the following:

(a) Drawings, designs, or specifications, where the supplies to be furnished are to be specially manufactured for the contractor in accordance therewith;

(b) Method of shipment or packing; and

(c) Place of delivery.

If any such change causes an increase or decrease in the cost of, or the time required for, the performance of any part of the work under this subcontract, whether changed or not changed by any such order, an equitable adjustment shal1 be made in the subcontract price or delivery schedule or both, and the subcontract shall be modified in writing accordingly. Any claim by the Subcontractor for adjustment under this clause must be asserted within 30 days from the date of receipt by the Subcontractor of the notification of change provided, however, that the contractor, if it decides that the facts justify such action, may receive and act upon any such claim asserted at any time prior to final payment under this subcontract. Where the cost of property made obsolete or excess as a result of a change is included in the Subcontractor's claim for adjustment, the Contractor shai1 have the right to prescribe the manner of disposition of such property. Failure to agree to any adjustment shall be a dispute within the meaning of the clause of this subcontract entitled "Disputes." However, nothing in this clause shall excuse the Subcontractor from proceeding with the subcontract as changed. 


\section{6. $\underline{\text { EXTRAS }}$}

Except as otherwise provided in this subcontract, no payment for extras shall be made unless such extras and the price therefor have been authorized in writing by the Contractor.

7. VARIATION IN QUANTITY

No variation in the quantity of any item called for by this subcontract will be accepted unless such variation has been caused by conditions of loading, shipping, or packing, or allowances in manufacturing processes, and then only to the extent, if any, specified elsewhere in this subcontract.

8. SUBSTITUTIONS AND UNAUTHORIZED CHANGES

(a) Subcontractor shall not substitute other materials or accessories for those specified in the subcontract without written consent of the Contractor.

(b) No changes to this subcontract are authorized unless made by the authorized subcontract administrator, buyer, or his superior and substantiated by a formal, written change order. Changes made by the Subcontractor, unless authorized by change notice, shall be made at the sole risk of Subcontractor, there being no financial recourse against the Contractor.

9. RECOVERED (RECYCLED) MATERIALS

The Subcontractor shall use Recovered (Recycled) Materials in the performance of work under this subcontract to the maximum extent practicable without jeopardizing the intended use of the item(s) being delivered.

10. MATERIALS AND WORKMANSHIP

Unless otherwise specifically approved by the Contractor, all equipment, materials, and articles incorporated in the work covered by this subcontract are to be new and of the most suitable grade of their respective kinds for the purpose intended, and 277 workmanship shall be performed in a skillful and workmanlike manner consistent with the specifications, drawings, stated requirements, and other applicable criteria of this subcontract.

11. APPROVALS

The granting of approvals by the Contractor or design, work drawings, specifications, reports, and any other data submitted by Subcontractor under provisions of the subcontract or specifications shall not affect or relieve Subcontractor from such responsibility as Subcontractor otherwise has with respect to adequacy or correctness of the design, working drawings, specifications, reports, and all other data submitted or used by the Subcontractor in performance of work under this subcontract.

12. LIENS

Subcontractor agrees to deliver to the contractor the articles covered by this subcontract free and clear of all liens and encumbrances. 


\section{WARRANTIES}

(a) Orders under $\$ 10,000$

The Subcontractor hereby agrees to cover all equipment and/or work and each item thereof by warranties (including warranties against faulty workmanship and materials) which are in no event less favorable as to - items covered, length and type of warranty, than those warranties generally established in the trade or industry for the type of equipment or work involved hereunder.

(b) Orders over $\$ 10,000$

(1) In addition to his obligations under other provisions of this subcontract (including those concerning inspection and acceptance), Subcontractor warrants against defects in material and workmanship, and that the items furnished under this subcontract will be manufactured in accordance with the subcontract requirements and if Subcontractor is responsible for design, the design will meet all design requirements set forth in this subcontract. The term of this warranty is for a period of three years after delivery or for a period of one year after the date first placed in use, whichever first expires. Standard commercial components of items furnished under this warranty are for a one year period after delivery.

(2) The Contractor shall give Subcontractor notice of any defect or lack of conformity with subcontract requirements within a reasonable time after discovery. Subcontractor shall promptly thereafter (without cost to the Contractor) either correct or replace such defective or nonconforming item or component thereof, and correct or replace all appropriate drawings, procedures and manuals, or if the Contractor does not require correction or replacement of the defective or nonconforming item or component thereof, Subcontractor, within a reasonable time after the notice shail repay such portion of the subcontract price of the item as is equitable under the circumstances. If Subcontractor fails to proceed with reasonable promptness to make any corrections or replacement in accordance with the provisions of this clause, the Contractor reserves the right to cause such correction or replacement to be made and Subcontractor agrees to reimburse the Contractor for the cost incurred thereby. Unless otherwise agreed, correction or replacement of defective or nonconforming items or components thereof shall be performed subject to and in accordance with the provisions of this subcontract. The Contractor has the right to require Subcontractor to correct in place any defective or nonconforming item or component thereof delivered under this subcontract or to return such item or component to Subcontractor for correction in which case Subcontractor shall be responsible for packing and packaging charges and shipping cost (to and from Subcontractor's plant) for item or component returned for correction. In exercising this right, the Contractor will notify Subcontractor which alternative it proposes to take. In this connection the Contractor will be reasonable in making its election in terms of its and the Government's time requirements, the relative economics of each course, and the particular circumstances at the time of election, giving due regard to any reasonable requests of 
Subcontractor. In the event that Subcontractor is required to correct in place, Subcontractor sha71 not be responsible for removal or reinstallation of the items or structural parts not furnished by Subcontractor under this subcontract. Subcontractor shall not be required to incur costs for such correction in place in excess of an amount equal to the total price of this subcontract. In the event that any defective item is returned by the Contractor to Subcontractor's plant for correction, the Contractor shall be responsible for removing the defective item from the system and Subcontractor shall upon completion of correction, make delivery as directed by the Contractor, but shall not be obligated to incur costs in excess of the total price of this subcontract, plus shipping (to and from Subcontractor's plant) and packing and packaging charges, nor shall Subcontractor be responsible for any cost of reinstallation. However, Subcontractor shall not be responsible for shipping costs outside the continental limits of the United States.

(3) The warranty with respect to a corrected or replaced item, items or components thereof, shall be subject to the same terms as the warranty provided for in paragraph (a). The original warranty for other than the corrected or replaced item, items or components thereof, shall continue until the expiration of the period prescribed in paragraph (a) plus a period equal to the time elapsed between the discovery of the defect and correction or replacement of the defective item, items or components thereof.

(4) Defective or nonconforming items or components thereof which Subcontractor is required to correct or replace in accordance with the provisions of this clause may be contaminated with radioactivity. Should the level of radioactivity of items or components thereof be sufficient to create by itself a "radiation area" (as defined in 10 CFR Section 20.202 in effect on the date of this subcontract), Subcontractor sha11 nevertheless prompt7y correct or replace such items or components as directed by the Contractor. In the event Subcontractor's cost of correction or replacement is increased solely by reason of the level of radioactivity of any such item or components thereof which exceeds the level specified in the definition of "radiation areas," an equitable adjustment shall be made, and such adjustment shall be agreed to in writing. If the Contractor, with respect to any such items or components thereof having a level of radioactivity sufficient to create by itself a "radiation area," elects, as provided in paragraph (b) above, to require payment of an equitable portion of the subcontract price, the parties shall not consider the estimated additional costs of correcting such item or component incurred solely by reason of radioactivity specified in the definition of "radiation area." Failure to agree to an equitable adjustment in price or a reasonable price for a replacement item as provided for herein shall be a dispute within the meaning of the clause of this subcontract entitled "Disputes." 
(5) Approval of designs, drawings, samples, test results, procedures, processes, or schedules by the Contractor and/or the Government shall not in any way limit or diminish Subcontractor's warranties hereunder.

\section{DELIVERY}

Delivery shall be made as specified and strictly in accordance with the delivery requirements of this subcontract. Subcontractor shall furnish sufficient labor and management forces, plant and equipment, and shall work such hours, including night shifts, overtime, weekend and holiday work, as may be necessary to assure compliance with the significant components of the approved manufacturing schedule and established subcontract delivery requirements and dates, or any duly authorized extensions thereof, at no increase in the price of this subcontract. If the Subcontractor's significant components or deliveries fail to comply with such requirements, the Contractor may direct in writing that the Subcontractor perform such night shifts, overtime, weekend and holiday work as the Contractor deems necessary to ensure the earliest possible recovery to the approved manufacturing schedule or contractual delivery schedule of the material or services; the Subcontractor agrees to comply with any such directive, when issued, including the payment of any difference between the method of shipping specified in this subcontract and premium transportation rates, at no additional compensation, unless the delay in delivery arises out of causes beyond the control and without the fault or negligence of the Subcontractor within the meaning of the clause thereof entitled "Termination for Default--Damages for Delay."

15. INSPECTION

(a) Subcontractor shall provide and maintain a quality assurance system capable of controlling supplies covered by this subcontract.

(b) All work (throughout this clause, this term includes--without limitation--design review, raw materials, procedures and processes, components, intermediate assemblies, and end products) shall be subject to inspection, examination, and test by the contractor and/or the Government or its designee(s) to the extent practicable at all times and places including the period of manufacture, and in any event prior to acceptance. Subcontractor is responsible for and shall, upon the Contractor's reasonable request and without interference with the work, furnish evidence of compliance with ali requirements of the subcontract. Inspection and test by the Contractor and/or the Government or its designee(s) of any work, or approval of designs, drawings, samples, test results, procedures, processes or schedules by the Contractor and/or the Government or its designee(s) does not relieve Subcontractor from any responsibility to meet the subcontract requirements.

(c) In case any material is defective in material or workmanship or otherwise not in conformity with the requirements of this subcontract, the Contractor and/or the Government or its designee(s) shall have the right to reject it (with or without instructions as to its disposition), or require correction. Material which has been rejected or required to be corrected shall be removed, or if permitted or required by the 
Contractor, corrected in place by and at the expense of Subcontractor, promptly after notice and shall not thereafter be tendered for acceptance unless the former rejection or requirement of correction is disclosed. Costs of packaging and shipment of defective material (to and from Subcontractor's plant) for correction shall be at the expense of the Subcontractor. If Subcontractor fails promptly to remove such material which is required to be removed, or promptly to replace or correct such work as specified by the Contractor, the Contractor may either: subcontract or otherwise replace or correct such material and charge to Subcontractor the cost occasioned thereby, or (2) terminate this subcontract for default as provided in the clause entitled "Termination for Default--Damages for Delay." Unless Subcontractor corrects or replaces such material within the delivery schedule, the Contractor may require the delivery of such material at a reduction in price which is equitable under the circumstances. Failure to agree to such reduction in price shall be a dispute within the meaning of the clause of this subcontract entitled "Disputes."

(d) If any inspection or test is made by the Contractor and/or the Government or its designee(s) on the premises of Subcontractor or a lower tier subcontractor, Subcontractor without additional charge shal1 provide a11 reasonable facilities including inspection tools, gauges, and equipment and shall additionally provide assistance for the safety and convenience of the Contractor and/or the Government or its designee(s) inspector in the performance of their duties. If the Contractor and/or the Government or its designee( $s$ ) inspection or test is made at a point other than the premises of Subcontractor or a lower tier subcontractor, it shall be at the expense of the Contractor except as otherwise provided in this subcontract--provided that, in case of rejection, the Contractor shall not be 1 iable for any reduction in value of samples used in connection with such inspection or test.

(e) A11 inspections and tests by the Contractor and/or the Government or its designee(s) shall be performed in such a manner as not to unduly delay the work. The contractor reserves the right to charge to the Subcontractor any additional cost of the Contractor and/or the Government or its designee(s) inspection and test when work is not ready at the time such inspection and test is requested by Subcontractor or when reinspection or retest is necessitated by prior rejection.

(f) Acceptance or rejection of the work shall be made as promptly as practicable after delivery, except as otherwise provided in this subcontract; but fai7ure to inspect and accept or reject work shall neither relieve Subcontractor from responsibility of such work as is not in accordance with the subcontract requirements nor impose liability upon the Contractor therefor.

(g). The inspection and test by the Contractor and/or the Government or its designee(s) of any work hereof does not relieve the Subcontractor from any responsibility regarding defects or other failures to meet the subcontract requirements which may be discovered prior to acceptance. Except as otherwise provided in this subcontract, acceptance shall be conclusive except as regards latent defects, fraud or such gross mistakes as amount to fraud. 
(h) Subcontractor shall provide and maintain (and require its lower tier subcontractors to provide and maintain) an inspection and quality control system acceptable to the Contractor covering the work hereunder. Records of all inspection and quality control work by Subcontractor (and his lower tier subcontractors) shall be kept complete and available to the Contractor and/or the Government or its designee(s) during the performance of this subcontract and for such longer period as may be specified el sewhere in this subcontract.

(i) No inspector can change the drawings and/or specifications or bind the Contractor in any way contractually. All changes affecting the subcontract must be in writing from an authorized representative of the Contractor's Procurement Division.

(j) The Contractor and the Government assume no contractual obligation to perform any inspection and test for the benefit of the subcontractor unless specifically set forth el sewhere in the subcontract.

(k) Final acceptance of materials, services, and equipment under this subcontract occurs at the time of authorization for final payment by the Contractor's representative designated to administer this subcontract.

\section{INVOICES}

Subcontractor shall submit invoices for monies due under this subcontract. Subcontractor's lower tier suppliers and subcontractor's invoices will not be honored. Subcontractor sha71 submit his invoices in duplicate. Each invoice MUST BE COMPLETE in the following particulars OR IT HILL BE RETURNED FOR CORRECTION without prejudice to the Contractor for the discount period.

(a) Invoice shall be for one order ONLY and must show the Contractor subcontract number.

(b) Each invoices item must conform to the subcontract and shal1 be identified against the subcontract number. Where "as equal" substitutions are furnished and accepted by the contractor, the invoiced item shall be identified as furnished and referenced against the subcontract item number.

(c) Billing Units: (a) UNIT PRICE must conform to subcontract, (2) QUANTITIES must conform to packing slip(s) compatible to unit price, (3) DESCRIPTION must conform to subcontract. Components shipped separately and invoiced will not be honored uniess the subcontract is supplemented to identify and subdivide the original subcontract item.

(d) Invoices for services performed at or materials shipped to other than Idaho National Engineering Laboratory, Idaho, must state where the services were performed or the materials were shipped.

(e) Transportation charges for the Contractor's account must be detailed separately on all invoices. Supporting bill of lading showing weight of each shipment together with the three copies of the original paid freight bill must be attached. Supporting documents for parcel post charges will not be required. 
(f) Invoices shall be mailed to: EG\&G Idaho, Inc., Accounts Payable Section, P. 0. Box 1625, Idaho Falls, Idaho 83415.

17. PAYMENTS

The Subcontractor shall be paid, upon the submission of proper invoices or vouchers, the prices stipulated herein for supplies delivered and accepted or services rendered and accepted, less deductions, if any, as herein provided.

(a) Discount. Where discounts are offered, the discount period will be computed from the latest date on which ail the following conditions are met: (1) acceptance of material, (2) receipt and approval of ALL Vendor Data, (3) receipt of properiy executed invoice. Payment is deemed to be made for purpose of earning the discount on the date of mailing of the Contractor check.

(b) Partial Deliveries. Payments will be made on partial deliveries when warranted and provided such payments are contemplated and authorized by this subcontract.

(c) Payment Withheld--Vendor Data. On subcontracts which require the submittal of vendor data, if such data, or any part thereof, is not delivered within the time specified by this subcontract or is deficient upon delivery, the Contractor may, until such data is delivered or deficiencies are corrected, withhold payments (not to exceed $20 \%$ of subcontract price) to the Subcontractor to assure prompt delivery of required vendor data.

18. ENGINEERING AND OPERATIONS DATA REQUIREMENT

(a) Engineering and Operations data normally required must be furnished by the supplier. For the purpose of this provision, Engineering and Operations data are defined but not totally restricted to the following: data required by the subcontract in support of design, performance, and materials traceability. Materials procured and/or fabricated involve the submission for approval by the supplier of the following types of documents: (Engineering) operation and performance data, design drawings, wiring diagrams, motor data, stress analyses, flow calculations, special process data, etc.; (Operations) maintenance and operations manuals, repair procedures, parts lists, etc.

(b) Engineering and Operations data requirements for this subcontract in addition to the above are attached.

19. ASSIGNMENT

Neither this subcontract nor any interest therein nor claim thereunder shall be assigned or transferred by the Subcontractor, except as expressiy authorized in writing by the Contractor. This subcontract may be assigned by the Contractor to the Government or to DOE's designee(s). 


\section{ASSIGNMENT OF ACCOUNTS PAYABLE}

Subcontractor may assign with the Contractor's approval claims for monies due or to become due hereunder to a bank, trust company, or other financial institution including any Federal lending agency. Any such assignment. shall cover all amounts payable under this subcontract and not already paid, and shall not be made to more than one party, except that any such assignment may be made to one party, as agent or trustee to two or more parties participating in such financing. Payments to an assignee of any monies due or to become due hereunder shall be subject to setoff or recoupment for any present or future claim or claims which the Contractor may have against Subcontractor arising under this and other subcontracts. Subcontractor shall supply the Contractor immediately with two copies of any such assignment and shail indicate on each invoice to whom payment is to be made.

21. AUTHORIZATION AND CONSENT

The Government hereby gives its authorization and consent (without prejudice to any rights of indemnification) for all use and manufacture in the performance of this subcontract or any part hereof or any amendment hereto or any lower tier subcontract hereunder of any invention described in and covered by a patent of the United States

(a) embodied in the structure or composition of any article the deliver of which is accepted by the Government under this subcontract, or

(b) utilized in the machinery, tools, or methods the use of which necessarily results from compliance by the Subcontractor to the using lower tier subcontractor with (1) specifications or written provisions now or hereafter forming a part of this subcontract, or (2) specific written instructions given by the Contractor directing the manner of performance.

The entire liability to the Government and the Contractor for infringement of a : patent of the United States shall be determined solely by the provisions of the indemnity clause, if any, included in this subcontract or any lower tier subcontract hereunder, and the Government assumes liability for all other infringement to the extent of the authorization and consent hereinabove granted.

22. FEDERAL, STATE, AND LOCAL TAXES

(a). Except as may be otherwise provided in this subcontract, the subcontract prices include all applicabie Federal, State, and 1ocal taxes and duties. (THE CONTRACTOR IS EXEMPT UNDER IDAHO LAW FROM THE PAYMENT OF CERTAIN IDAHO SALES TAXES AND IS AUTHORIZED BY AGREEMENT WITH THE STATE OF IDAHO DEPARTMENT OF REVENUE AND TAXATION TO PAY DIRECTLY. TO THE STATE OF IDAHO ANY SALES AND USE TAXES OWING ON PURCHASES OF TANGIBLE PERSONAL PROPERTY. THEREFORE, THE SUBCONTRACT PRICE SHOULD NOT INCLUDE IDAHO SALES OR USE TAXES. ALL OTHER APPLICABLE FEDERAL, STATE AND LOCAL TAXES AND DUTIES SHOULD BE INCLUDED.)

(b). Nevertheless, if a statute, court decision, written ruling, or regulation takes effect after the subcontract date and results in the Subcontractor being required to pay any tax, duty, interest or penalty which would not otherwise have been payable on the transactions or property covered by this subcontract, the subcontract price shal7 be increased by the amount 
of such tax, duty, rate increase, interest or penalty if the Subcontractor warrants in writing that the subcontract price does not include any contingency for the same and if liability for such tax, rate increase, interest or penalty was not incurred through the Subcontractor's fault, negligence or failure to follow the instructions of the Contractor.

(c) If a statute, court decision, written ruling, or regulation takes effect after the subcontract date and results in the Subcontractor being relieved of any tax, duty, rate increase or penalty related to the transaction or property covered by this subcontract, or in the refund or drawback of any portion thereof, the subcontract price shall be decreased by the amount of such relief, refund or drawback. If the Contractor has already paid the amount of such tax, duty, rate increase or penalty, the same shall be repaid by the Subcontractor to the Contractor, including any interest received from the Government by the Subcontractor incident to such relief, refund or drawback.

(d) The contract price shall be decreased by the amount of any tax or duty, or any portion thereof, that was included in the contract price and that the Subcontractor is required to pay or bear, or for which no refund or other relief is obtained, through the Subcontractor's fault, negligence, or failure to follow the instructions of the Contractor.

(e) No adjustment shall be made in the contract price under this clause unless the amount of the adjustment exceeds $\$ 100$.

(f) As used in subparagraphs (b) through (e) above, the term "subcontract date" means the date set for the bid opening, or if this is a negotiated subcontract, the date of this subcontract. As to additional supplies or services procured by modification to this subcontract, the term "subcontract date" means the date of such modification.

(g) The Subcontractor shall promptly notify the Contractor of all tax matters which may reasonably be expected to result in either an increase or decrease in the subcontract price, and shall take action with respect thereto as directed by the Contractor.

(h) Except as otherwise provided in this subcontract, upon request of the Subcontractor, without further liability, the Contractor shall furnish evidence appropriate to establish an exemption from any tax when (1) the Subcontractor warrants in writing that such exemption applies to a tax excluded from the subcontract price, and (2) a reasonable basis exists to sustain such an exemption. In addition, the Contractor may furnish evidence to establish an exemption from any tax that may, pursuant to this clause, give rise to either an increase or decrease in the subcontract price. Except as otherwise provided in this subcontract, evidence appropriate to establish exemption from duties will be furnished only at the discretion of the Contractor.

\section{GRATUITIES}

The Government and the Contractor prohibit their employees from using their official position for personal financial gain, or from accepting any personal advantage from anyone under circumstances which might reasonably be interpreted as an attempt to influence the recipients in the conduct of their official 
ENCLOSURE 03

PAGE 15 OF 28

duties. Subcontractor or his employees shall not, under circumstances which might reasonably be interpreted as an attempt to influence the recipients in the conduct of their duties, extend any gratuity or special favor to employees of the Government or the Contractor and shall not accept any gratuity or special favor from individuals or organizations with whom Subcontractor is doing business, or proposing to do business, in accomplishing work under this subcontract. This subcontract is subject to the provisions of 41 U.S.C. 51-54 prohibiting the kickback of fees, money, or other valuables in public contracting.

24. PERMITS

Except as otherwise directed by the Contractor, the Subcontractor shal1 procure all necessary permits or licenses and abide by all applicable laws, regulations, and ordinances of the United States and of the State, territory, and political subdivision in which the work under this subcontract is performed.

25. PRICING OF ADJUSTMENTS

When costs are a factor in any determination of a subcontract price adjustment pursuant to the "Changes" clause or any other provision of this subcontract, such costs shall be in accordance with the subcontract cost principles and procedures in Part 31 of the Federal Acquisition Regulations as supplemented or modified by the DOE Procurement Regulations Part 931 in effect on the date of this subcontract.

26. REPRESENTATION CONCERNING NUCLEAR HAZARDS INDEMNITY

The Contractor represents that there is included in its prime contract with DOE an indemnity agreement, entered into by DOE under the authority of Section 170 of the Atomic Energy Act of 1954, as amended by Pub7ic Law 85-256 (the "Price-Anderson Act"), a copy of which may be obtained from the Contractor that, under said agreement, DOE has agreed to indemnify the Contractor and other persons indemnified, including the Subcontractor, against claims for public :liability (as defined in said Act arising out of or in connection with the contractual activity; that the indemnity applies to covered nuclear incidents which ( $i$ ) take place at a "contract location" (which term, as defined in the indemnity agreement, does not include the location of the Subcontractor's plant and facilities); or (ii) arise out of or in the course of transportation of source, special nuclear or by-product material to or from a "contract location," or (iii) involve items produced or delivered under the prime contract. The obligation of DOE to indemnify is subject to the conditions stated in the indemnity agreement.

27. WORKER'S COMPENSATION COVERAGE AND INDEMNITY

For all subcontract work performed in the State of Idaho, Subcontractor agrees to cover its employees performing such work by applicable Workers' Compensation Insurance and Subcontractor will furnish proof of such coverage upon Contractor's written request. Subcontractor will indemnify and hold harmless Contractor and its officers, agents, employees, and the Department of Energy for any costs, expenses, claims, Tosses, damages, causes of action, whether in tort or otherwise, and reasonable attorneys' fees (incurred under the terms of this indemnity or in enforcing this provision) arising from death or injury occurring as a result of the acts or omissions of Subcontractor or its agents or employees. Subcontractor specifically waives its limitation of liability under Idaho 
Workers' Compensation Law, Idaho Code 72-209(2), with regard to this indemnification. This indemnification does not apply to death or injury that occurs solely as a result of Contractor's negligence or liability arising from a nuclear incident.

\section{SPECIAL TOOLING}

Except as may be otherwise provided for in this subcontract, jigs, dies, fixtures, molds, patterns, special gauges, special test equipment, and other items of special tooling shall be furnished by and at the expense of Subcontractor. Special tooling shall be kept in good condition by Subcontractor and when necessary shall be replaced by Subcontractor without expense to the Contractor. Tit7e to special tooling, furnished by and at the expense of the Subcontractor, shall remain with the Subcontractor. Subcontractor shall hold special tooling for one year after completion of the subcontract when requested in writing by the Contractor, and the Contractor may, at any time, within one year after completion of this subcontract, reimburse Subcontractor for the cost of part or all special tooling, and upon payment therefor shall become the owner and entitied to possession.

Where the cost of the special tooling is included in the price of the subcontract, title to the special tooling shall remain with the contractor. At the completion of the subcontract, Subcontractor shall prepare a 1ist of tooling and request in writing the Contractor's disposition instructions. Upon disposition instructions from the Contractor, the Subcontractor shall dispose of the equipment at the expense of the Contractor. The net proceeds of any such disposal shall be credited to the subcontract price or shall be paid to the Contractor.

All directions or communications issued pursuant to this article shall be in writing.

\section{LOWER TIER SUBCONTRACTING}

Subcontractor shall not subcontract all or substantially all work on any article to be supplied under this subcontract without prior written approval of the Contractor. Any changes of proposed lower tier subcontractors after award, shall be furnished to the Contractor in writing prior to their award in order that the Contractor may determine the competency of the lower tier subcontractor. This provision shall not apply to purchases of standard commercial articles or raw materials. Subcontractor shall promptiy forward to the Contractor, $P$. 0 . Box 1625, Idaho Fa71s, Idaho 83415-2083, Attn: Supp 7ier Data Control, three unpriced copies of its purchase order to lower tier subcontractors on a71 purchases of material or equipment entered into for the manufacture of products herein ordered. 
30. BASIS OF AWARD

Where award of this subcontract has been made pursuant to a proposal (other than the low offeror) on the basis of earlier delivery and the successful offeror, with knowledge of the basis of this award, does not meet its subcontract delivery date or dates, there will be deducted from the payments otherwise due under this subcontract a proportionate amount of the difference between the low offer and the supplier's offer, based on the ratio between the number of days delay in making delivery and the difference in the time stated in the supplier's offer and the low offer.

\section{NOTICE AND ASSISTANCE REGARDING PATENT AND COPYRIGHT INFRINGEMENT}

(a) The Subcontractor shall report to the Contractor, promptly and in reasonable written detail, each notice or claim of patent or copyright infringement based on the performance of this subcontract of which Subcontractor has knowledge.

(b) In the event of any claim or suit against the Contractor or the Government on account of any a lleged patent or copyright infringement arising out of the performance of this subcontract or out of the use of any supplies furnished or work or services performed hereunder, Subcontractor shall furnish to the Contractor or the Government upon request all evidence and information in possession of Subcontractor pertaining to such suit or claim. Such evidence and information shall be furnished at the expense of the Government except in those cases in which Subcontractor has agreed to indemnify the Contractor and the Government.

(c) This clause shall be included in all lower tier subcontracts and purchase orders.

32. PUBLIC RELEASE OF INFORMATION

Information, data, photographs, sketches, advertising, etc., relating to the work under this subcontract, which Subcontractor desires to release or publish, shall be submitted to the contractor for approval eight weeks prior to the desired release date. As part of the approval request, subcontractor shall identify the specific media to be used as well as other pertinent details of the proposed release. All releases, regardless of tier or supplier, must have the prior approval of the Contractor. Subcontractor shall include all provisions of this clause including this sentence in all lower tier subcontracts under this subcontract.

33. REPORTING OF ROYALTIES

If this subcontract is in an amount which exceeds $\$ 10,000$ and if any royalty payments are directly involved in the subcontract or are reflected in the subcontract price to the Contractor, the Subcontractor agrees to report in writing to the DOE Patent Counsel (with notification by Patent Counsel to the Contractor) during the performance of this subcontract and prior to its completion or final settlement, the amount of any royalties or other payments paid or to be paid by it directly to others in connection with the performance of this subcontract together with the names and addresses of 1 icensors to whom such payments are made and ejther the patent numbers involved or such other 
information as will permit identification of the patents or other basis on which the royalties are to be paid. The approval of DOE of any individual payments or royalties shall not stop the Contractor or the Government at any time from contesting the enforceability, validity, or scope of, or title to, any patent under which a royalty or payments are made.

34. SUSPENSION OF DELIVERIES OR SERVICE

(a) EG\&G Idaho may order the Subcontractor in writing to suspend, delay, or interrupt delivery of materials and all or any part of the work for such period of time as it may determine to be appropriate for the convenience of EG\&G Idaho. Upon the expiration of the period of suspension or the prior receipt of an order to resume operations, Subcontractor shall promptly proceed with the work.

(b) If the performance of all or any part of the work is, for an unreasonable period of time, suspended, delayed, or interrupted by an act of EG\&G Idaho in the administration of this subcontract, or by EG\&G Idaho's failure to act within the time specified in this subcontract (or if no time is specified, within a reasonable time), an adjustment shall be made in the time for performance of this subcontract and for any increase in the cost of performance of this subcontract (excluding profit) necessarily caused by such unreasonable suspension, delay, or interruption, and the subcontract modified in writing accordingly. However, no adjustment shall be made under this clause for any suspension, delay, or interruption to the extent (1) that performance would have been so suspended, delayed, or interrupted by any other cause, including the fault or negligence of the Subcontractor, or (2) for which an equitable adjustment is provided or excluded under any other provision of this subcontract.

(c) No claim under this clause shall be allowed (1) for any costs incurred more than 20 days before the Subcontractor sha71 have notified EG\&G Idaho in writing of the act or failure to act involved (but this requirement shall not apply as to a claim resulting from a suspension order); and (2) unless the claim, in an amount stated, is asserted in writing as soon as practicable after the termination of such suspension, delay, or interruption, but no later than the date of final payment under the subcontract. No part of any claim based on the provisions of this clause shall be allowed if not supported by adequate evidence showing that the cost would not have been incurred but for a delay within the provisions of this clause.

\section{DISPUTES}

(a) The parties agree that the appropriate forum for resolution of any dispute of claim pertaining to this subcontract shall be a court of competent jurisdiction as follows:

(1) Subject to paragraph A.2. of this clause, any such Titigation shall be brought and prosecuted exclusively in Federal District Court; with venue in the United States District Court for the District of Idaho in Pocatel10, Idaho. 
(2) Provided, however, that in the event that the requirements for jurisdiction in any Federal District Court are not present, such litigation shali be brought in the District Court of the Seventh Judicial District of the State of Idaho, in and for the County of Bonneville, with venue in the District Court of the Seventh Judicial District for the District of Idaho in Idaho Falls, Idaho.

(b) - Any substantive issue of law in such dispute, claim, or litigation shall be determined in accordance with the body of law applicable to procurement of goods and services by the Federal Government. Nothing in this clause shail grant to the Subcontractor by implication any statutory rights or remedies not expressiy set forth in this subcontract.

(c) There shall be no interruption in the prosecution of the work, and the Subcontractor shall proceed diligentiy with the performance of this subcontract pending final resolution of any dispute, claim, or litigation arising under or related to this subcontract between the parties hereto or between the Subcontractor and subtier subcontractors or supplies.

(d) The Contract Disputes Act of 1978 (41 U.S.C. Sections 601-613) shall not apply to this subcontract; provided, however, that nothing in this clause shall prohibit Contractor, in its sole discretion, from sponsoring a claim of the Subcontractor for resolution under the provisions of its prime contract with DOE. In the event that Contractor so sponsors a claim at the request of the Subcontractor, the Subcontractor shall be bound by the decision of the cognizant DOE contracting officer to the same extent and in the same manner as the Contractor.

36. SECURITY

(a) Subcontractor's Duty to Safequard Restricted Data, Formerly Restricted Data, and Other Classified Information. The Subcontractor shall, in accordance with DOE's security regulations and requirements, be responsible for safeguarding restricted data, formerly restricted data, and other classified information and protecting against sabotage, espionage, loss, and theft, the classified documents and material in the Subcontractor's possession in connection with the performance of work under this subcontract. Except as otherwise expressly provided in this subcontract, the Subcontractor shall, upon completion or termination of this subcontract, transmit to the Contractor any classified matter in the possession of the Subcontractor or any person under the Subcontractor's control in connection with performance of this subcontract. If retention by the Subcontractor of any classified matter is required after the completion or termination of the subcontract and such retention is approved by the Contractor, the Subcontractor will complete a certificate of possession to be furnished to the Contractor specifying the classified matter to be retained. The certification shall identify the items and types or categories of matter retained, the conditions governing the retention of the matter, and the period of retention, if known. If retention is approved by the Contractor, the security provisions of this subcontract will continue to be applicable to the matter retained. 
(b) Regulations. The Subcontractor agrees to conform to alT security regulations and requirements of the Contractor and DOE. No non-U. S. citizen employee shall be assigned to work at DOE's Idaho National Engineering Laboratory in Idaho or other DOE-ID controlled facilities in Idaho Falls, without approval of the Contractor obtained in advance.

(c) Definition of Restricted Data. The term "Restricted Data," as used in this clause, means all data concerning (i) design, manufacture, or utilization of atomic weapons; (ii) the production of special nuclear material; or (iii) the use of special nuclear material in the production of energy, but shatl not include data declassified or removed from the Restricted Data category pursuant to Section 142 of the Atomic Energy Act of 1954 , as amended.

(d) Definition of Formerly Restricted Data. The term "Formerly Restricted Data," as used in this clause, means a71 data removed from the Restricted Data category under Section 142d of the Atomic Energy Act of 1954, as amended.

(e) Security Clearance of Personnel. The Subcontractor shal1 not permit any individual to have access to restricted data, formerly restricted data, or other classified information, except in accordance with the Atomic Energy Act of 1954, as amended, and DOE's regulations or requirements applicable to the particular type or category of classified information to which access is required.

(f) Criminal Liability. It is understood that disclosure of restricted data, formerly restricted data, or other classified information, relating to the work or services ordered hereunder to any person not entitled to receive it, or failure to safeguard any restricted data, formerly restricted data, or any other classified matter that may come to the Subcontractor or any person under the Subcontractor's control in connection with work under this subcontract, may subject the Subcontractor, its agents, employees, or lower tier subcontractors to criminal liability under the laws of the United States. (See the Atomic Energy Act of 1954, as amended, 42 U.S.C. 2100 et seq.; 18 U.S.C. Sections 793 and 794; and Executive Order No. 11652 , as amended.)

(g) Subcontracts and Purchase Orders. Except as otherwise authorized in writing by the Contractor, the Subcontractor shall insert provisions similar to the foregoing in a17 lower tier subcontracts and purchase orders under this subcontract.

37. ORGANIZATIONAL CONFLICTS OF INTEREST - GENERAL

(The following clause is applicable when the subcontract work involves (1) evaluation services or activities; (2) technical consulting and management support services and professional services; (3) research and development; and (4) other contractual situations where special organizational conflicts of interest provisions are noted in the solicitation and included in the resulting subcontract.) 
(a) The Subcontractor warrants that, to the best of its knowledge and belief, and except as otherwise disclosed, there are no relevant facts which could give rise to organizational conflicts of interest, as defined in DEAR 909.570-3 or that the Subcontractor has disclosed all relevant information.

(b) The Subcontractor agrees that, if after award, an organizational conflict - of interest with respect to this subcontract is discovered, an immediate and full disclosure in writing shall be made to the Contractor which shal1 include a description of the action which the Subcontractor has taken or proposes to take to avoid or mitigate such conflicts. The Contractor may, however, terminate the subcontract for its convenience if it deems such termination to be in the best interests of the Government.

(c) In the event that the Subcontractor was aware of an organizational conflict of interest prior to the award of this subcontract and did not disclose the conflict to the Contractor, the Contractor may terminate the subcontract for default.

(d) The provisions of this clause shall be included in all lower tier subcontracts for work to be performed similar to the services provided by the Subcontractor and the terms "subcontract, "Subcontractor," and "Contractor" modified appropriately to preserve the Contractor and the Government's rights.

38. PRESERVATION OF INDIVIDUAL OCCUPATIONAL RADIATION EXPOSURE RECORDS

(This article is applicable if Subcontractor employees are required to perform work in facilities where potential radiation exposure exists.)

Individual occupational radiation exposure records generated in the performance of work under this subcontract shall be subject to inspection by DOE and shal1 be preserved by the Subcontractor until disposal is authorized by DOE or at the : option of the Subcontractor delivered to DOE upon completion or termination of this subcontract. If the Subcontractor exercises the foregoing option, title to such records shall vest in DOE upon delivery.

39. SUBSTANCE ABUSE POLICY

(This article is applicable only if the work hereunder is being performed at Contractor operated facilities, or if the work requires a security clearance.)

The Subcontractor shall not utilize for the performance of work under this subcontract employees who use, possess, or sell illegal substances. Additionally, the Subcontractor will not allow in the workplace those employees whose use of legal substances adversely affects work productivity or safety.

DEFINITIONS:

"Illegal substances" are controlled substances listed in 21 USC 812 which are not legally obtainable or those which are obtained illegally.

"Legal substances" include: 1) controlled substances that are prescribed or administered by a licensed physician; 2) over-the-counter drugs purchased legalty; and 3) alcoholic beverages. 
"Drug Screen or Drug Testing" means Taboratory screening for illegal substances in the urine, normally performed by EG\&G Idaho Medical, using cutoff levels preselected by Medical in accordance with appropriate standards.

\section{PROCEDURE:}

It is pointed out that the granting, suspension, denial and reinstatement of a security clearance is determined exclusively by the Department of Energy (DOE). In accordance with DOE Security requirements and the Contractor's company policy, derogatory information will include reports of Subcontractor personnel granted facility access who are arrested and/or convicted for off-the-job illegal drug and/or alcohol related offenses, including driving under the influence.

In addition, the Contractor may require a screening test:

- of any Subcontractor employee upon reasonable suspicion of specific illegal substance usage;

- of any Subcontractor employee upon reasonable suspicion of abuse of legal substances;

- of any Subcontractor employee directly involved in an accident or incident resulting in personal injury, death or property damage.

A screening test for alcohol shall not be ordered by the Contractor solely on the basis of smelling alcohol on a Subcontractor employee's breath unless it is associated with on-the-job aberrant behavior or poor work performance. Subcontractor employees requested to submit to a screening test upon reasonable suspicion will be escorted to EG\&G Idaho Medical or other appropriate facility for a test. Consent by Subcontractor employees to submit to a screening test in accordance with this policy is a condition of their continued performance of work under this subcontract. Subcontractor employees who refuse to be tested must surrender their identification badge and will be suspended from further work performance under this subcontract. If the screening test for illegal drugs is positive, the employee will relinquish his/her identification badge and will be suspended until confirmation of the test results are obtained. If the positive results are confirmed, the employee will be permanently suspended from work performance under this subcontract.

If the screening test is for alcohol, and the corresponding blood alcohol level is 0.10 percent or above, the employee is presumed to be under the influence and must therefore leave work without his/her badge and will not be returned for work under this subcontract.

40. HAZARDOUS MATERIALS BROUGHT BY SUBCONTRACTOR ONTO THE IDAHO NATIONAL ENGINEERING LABORATORY (INEL)

(Resource Conservation and Recovery Act (RCRA) and SARA Title III reporting requirements)

For all work to be performed at the INEL, Subcontractor shall comply with all environmental laws, including the requirements of the Resource Conservation and Recovery Act, 42 USC Sections 6901 et seq. Pursuant to the Superfund Amendments 
and Reauthorization Act of 1986 (P.L. 99-499) Subcontractor shall be responsible for reporting to the subcontract administrator/buyer all hazardous chemicals brought onto the INEL site.

41. INSURANCE FOR LOSS IN TRANSIT

Contractor will not accept price adders for the cost of providing insurance against risk of loss in transit. If the subcontractor chooses to insure its risk of loss in transit the cost of same must be included in the subcontract price. The contractor is self-insured as to its risk of loss in transit and there is no authorization to the subcontractor to procure any insurance against that risk for the account of the contractor.

42. OCCURRENCE NOTIFICATION AND REPORTING BY SUBCONTRACTOR

(This article is applicable when Subcontractor personnel are at Contractoroperated facilities.)

Subcontractor personnel shall immediately (not to exceed one hour) notify the Contractor technical representative (as designated in the subcontract or purchase order) of any event or condition which comes to their attention. An event or condition is defined as follows:

Event. A real-time occurrence (e.g., pipe break, valve failure, loss of power, etc.)

Condition. Any as-found state, whether or not resulting from an event, which may have adverse safety, health, quality assurance, security, operational or environmental implications. A condition is more programmatic in nature, for example, an error in analysis or calculation; an anomaly associated with design or performance; or, an item indicating a weakness in the management process.

If there is confusion as to whether an event or condition should be reported, the :Subcontractor shali report in accordance with the requirements herein.

43. ENVIRONMENTAL, SAFETY AND HEALTH

The contractor shall take all reasonable precautions in the performance of the work under this contract to protect the safety and health of employees and of members of the public and shall comply with all applicable safety and health regulations and requirements (including reporting requirements) of DOE. The contracting officer shall notify the contractor, in writing, of any noncomp 7 iance with the provisions of the clause and the corrective action to be taken. After receipt of such notice, the contractor shall immediately take corrective action. The contractor shall submit a management program and implementation $\mathrm{plan}$ to the contracting officer for review and approval within 30 days after the date of award of this contract. In the event that the contractor fails to comply with said regulations or requirements of DOE, the contracting officer may, without prejudice to any other legal or contractual rights of DOE, issue an order stopping all or any part of the work; thereafter, a start order for resumption of the work may be issued at the discretion of the contracting officer. The contractor shall make no claim for an extension of time or for compensation or damages by reason of, or in connection with, such work stoppage. 
44. ARTICLES INCORPORATED BY REFERENCE

The work covered by this Purchase Order or Subcontract relates to a prime contract with the United States Government and is within the jurisdiction of the U. S. Department of Energy. Unless otherwise indicated below, the following terms and designations shali apply in each of the Government clauses identified herein:

(a) "Contractor" means seller.

(b) "Subcontractor" means seller's subcontractor.

(c) "Contract" means the order.

(d) "Contracting Officer" means EG\&G Idaho's Subcontract Administrator or Buyer.

(e) "Government" means EG\&G Idaho, Inc.

The following Federal Acquisition Regulations (FAR) clauses and Department of Energy Acquisition Regulations (DEAR) clauses are. incorporated herein by reference:

1. Stopwork and Shutdown Authority,

2. Termination for Convenience, FAR 52.249-1 (<\$100K), FAR 52.249-2 (> \$100K)

3. Termination for Default, FAR 52.249-8

4. Preference for U. S. Flag Air Carriers, FAR 52.247-63

5. Walsh-Healey Public Contracts Act, FAR 52.222-20

6. Government Property, FAR 52.245-2

7. Government Property, FAR 52.245-4 (< \$50K)

8. Classification, DEAR 952.204-70

9. Rights in Technical Data, DEAR 952.227-75

10. Buy American Act - Supplies, FAR 52.225-3 as amended by DEAR 970-5203-3

11. Convict Labor, FAR 52.222-3

12. Officials Not to Benefit, FAR 52.203-1

13. Priorities, Allocations, and Allotments, FAR 52.212-8

14. Required Source for Jewel Bearings, FAR 52.208-1

15. Clean Air and Water, FAR 52.223-2 $(\$ 100,000)$ 
16. Hazardous Material Identification and Material Safety Data, FAR $52.223-3$

17. Notice of Labor Disputes, DEAR 970.5204-30

18. Patent Indemnity, FAR 52.227-3

19. Progress Payments, FAR 52.232-16 - This article is not applicable unless progress payments are specifically cited as available in the solicitation and specifically cited as applicable in the subcontract or purchase order.

20. Contract Work Hours and Safety Standards Act - Overtime Compensation, FAR $\underline{52.222-4}$

21. Examination of Records by the Comptroller General, FAR 52.215-1 as amended by DEAR $970.5203-2(\$ 10,000)$

22. Price Reduction for Defective Cost or Pricing Data, FAR 52.215-22

*23. Audit--Negotiation, FAR 52.215-2 $(\$ 10,000)$

24. Subcontractor Cost or Pricing Data, DEAR 970.5204-24

*25. Cost Accounting Standards, FAR 52.230-3 $(\$ 100,000)$

*26. Disclosure and Consistency of Cost Accounting Practices, FAR 52.230-5 $(\$ 100,000)$

27. Administration of Cost Accounting Standards, FAR 52.230-4

28. Covenant Against Contingent Fees, FAR 52.203-5 as amended by DEAR 970.5203-1

29. Affirmative Action for Handicapped Workers, FAR 52.222-36

*30. Affirmative Action for Special Disabled and Vietnam Era Veterans, FAR $\underline{52.222-35}(\$ 10,000)$

31. Equal Opportunity, FAR 52.222-26 as amended by DEAR 922.8

32. Utilization of Smal1 Business Concerns and Sma17 Business Concerns Owned and Controlled by Socially and Economically Disadvantaged Individuals, FAR $\underline{52.219-8}$

33. Utilization of Concerns in Labor Surplus Areas, FAR 52.220-3

34. Utilization of Women-Owned Sma11 Businesses, FAR 52.219-13

*35. Labor Surp7us Area Subcontracting Program, FAR 52.220-4 $(\$ 500,000)$ 
*36. Sma11 Business and Small Disadvantaged Business Subcontracting Plan, FAR 52.219-9 $(\$ 500,000)$

37. Subcontracts, FAR 52.244-1 $(\$ 500,000)$

38. Anti-Kickback Procedures, FAR 52.203-7

39. Waiver of Facilities Capital Cost of Money, FAR 52.215-31

40. Limitation on Payments to Influence Certain Federal Transactions (Jan 1990), FAR 52.203.12 $(\$ 100,000)$

41. Radiation Protection and Nuclear Critica7ity, DEAR 952.223-72

42. Employment Reports on Special Disable Veterans and Veterans of the Vietnam Era, FAR 52.222-37 $(\$ 10,000)$.

*Note: Clause is applicable if order exceeds the amount indicated. 
ENCLOSURE 03

PAGE 27 OF 28

\author{
ADDENDUM NO. 1 \\ TO THE EG\&G IDAHO, INC. \\ STANDARD TERMS AND CONDITIONS FOR \\ PURCHASE ORDERS AND SUBCONTRACTS \\ (STC-EG\&G-183, Rev. 3-91)
}

1. The following is to be incorporated:

STOP-WORK AND SHUTDOWN AUTHORITY

A. Definitions:

1. Shutdown - The cessation of facility operations for environment, safety, health, or other related reasons by the direction of the Contractor Representative or his designees.

2. Stop-Work - The suspension of a specific activity or activities by the Contractor Representative or his designees based on the determination or observation of conditions that present an imminent risk of harm to the life or health of the workers, the public, or the environment.

B. Authority: As contemplated by the clause of this subcontract entitled "Safety and Health (Government Owned or Leased) (Apr. 1984)", cl ause incorporated by reference, DEAR 970.5204-2, the Contractor Representative or his designees may at any time during the performance of this subcontract shutdown facility operations or stop-work on specific activities of the Subcontractor.

C. The Subcontractor shall insert a clause, modified appropriately to substitute Subcontractor representatives for the Contractor Representative or his designees, in all sub-subcontracts containing the above-cited "Safety and Health" article.

2. The following replaces in its entirety Article 27 - WORKMEN'S COMPENSATION COVERAGE AND INDEMNITY:

\title{
WORKER'S COMPENSATION COVERAGE AND INDEMNITY
}

For a.11 subcontract work performed in the State of Idaho, Subcontractor agrees to cover its employees performing such work by applicable Workers' Compensation Insurance and Subcontractor will furnish proof of such coverage upon Contractor's written request. Subcontractor will indemnify and hold harmless Contractor and its officers, agents, employees, and the Department of Energy for any costs, expenses, claims, losses, damages, causes of action, whether in tort or otherwise, and reasonable attorneys' fees (incurred under the terms of this indemnity or in enforcing this provision) arising from death or injury occurring as a result of the acts or omissions of Subcontractor or its agents or employees. Subcontractor specifically waives its limitation of liability under Idaho Horkers' Compensation Law, Idaho Code 72-209(2), with regard to this indemnification. This indemnification does not apply to death or injury that occurs solely as a result of Contractor's negligence or liability arising from a nuclear incident. 
ENCLOSURE 03

PAGE 28 OF 28

\section{ADDENDUM NO. 2}

1. To be incorporated into Article 43 - ARTICLES INCORPORATED BY REFERENCE:

Employment Reports on Special Disabled Veterans and Veterans of the Vietnam Era, FAR 52.222-37 $(\$ 10,000)$.

2. The following article will no longer be incorporated by reference and is applicable as follows:

\section{ENVIRONMENT, SAFETY AND HEALTH}

(This article is applicable when Subcontractor personnel are at Government-owned and Contractor-operated facilities.)

The Subcontractor shall take all reasonable precautions in the performance of the work under this subcontract to protect the safety and health of employees and of members of the public and shall comply with all applicable safety and health regulations and requirements (including reporting requirements) of DOE. The Contractor shall notify the subcontractor, in writing, of any noncompliance with the provisions of the clause and the corrective action to be taken. After receipt of such notice, the Subcontractor shall immediately take corrective action. The Subcontractor shall submit a management program and implementation plan to the Contractor for review and approval within 30 days after the date of award of this contract if required by the contractor. In the event that the Subcontractor fails to comply with said regulations or requirements of $D O E$, the Contractor may, without prejudice to any other legal or contractual rights of the Contractor, issue an order stopping all or any part of the work; thereafter, a start order for resumption of the work may be issued at the discretion of the Contractor. The Subcontractor shall make no claim for an extension of time or for compensation or damages by reason of, or in connection with, such work stoppage (DEAR 970.5204-2).

ADDENDUM NO. 3

SUPERFUND AMENDMENTS AND REAUTHORIZATION ACT (SARA) - REPORTING HAZARDOUS SUBSTANCES

(This article is applicable when Subcontractor uses or transports SARA reportable chemicals on the INEL site or any associated Idaho Falls facilities.)

The Subcontractor shall prepare and submit to the Contractor a report each quarter (the first Monday of January, Apri1, July and October) for SARA reportable chemicals used or transported on the INEL site or at any associated Idaho Falls facilities. The required reporting is 1 imited to those SARA reportable hazardous chemicals within the definition found at 29 CFR 1910.1200. Specific lists for Extremely Hazardous Substances can be found in the Appendices of 40 CFR Part 355 and in 40 CFR 372 for toxic chemicals. Specific exemptions from these reporting requirements for chemicals and substances listed or defined can be found in 40 CFR 370 . The report is to be provided on the appropriate form that can be obtained from the Contractor's Subcontract Administrator upon request. 
ENCLOSURE 04

PAGE 1 OF 8

February 25, 1985

\section{SERVICE CONTRACT ACT OF 1965, AS AMENDED}

This subcontract is subject to the Service Contract Act of 1965, as amended (41 U.S.C. 351, et seq.) and is subject to the following provisions and to all other applicable provisions of the Act and regulations of the Secretary of Labor issued thereunder (29 CFR Part 4).

\section{A Compensation}

Each service employee employed in the performance of this subcontract by the Subcontractor or any lower tier subcontractor shall be paid not less than the minimum monetary wages and shall be furnished fringe benefits in accordance with the wages and fringe benefits determined by the Secretary of Labor or authorized representative, as specified in any wage determination attached to this subcontract.

B. Unclassified Workers and Conforming Procedure

1. If there is such a wage determination attached to this subcontract, the Contractor shall require that any class of service employee which is not listed therein and which is to be employed under the subcontract (i.e., the work to be performed is not performed by any classification listed in the wage determination) be classified by the Subcontractor so as to provide a reasonable relationship (i.e., appropriate level of skill comparison) between such unlisted classifications and the classifications listed in the wage determination. Such conformed class of employees shall be paid the monetary wages and furnished the fringe benefits as are determined pursuant to the procedures in this section.

2. Such conforming procedure shall be initiated by the Subcontractor prior to the performance of subcontract work by such unlisted class of employee. A written report of the proposed conforming action, including information regarding the agreement or disagreement of the authorized representative of the employees involved or, where there is no authorized representative, the employees themselves, shall be submitted by the Subcontractor to the Contractor no later than $\mathbf{3 0}$ days after such unlisted class of employees performs any subcontract work. The Contractor shall review the proposed action and promptly submit a report of the action, together with its recommendation and all pertinent information including the position of the Subcontractor and the employees, to the Wage and Hour Division, Employment Standards Administration, U. S. Department of Labor, for review. The Wage and Hour Division will approve, modify, or disapprove the action or rend final determination in the event of disagreement within 30 days of receipt or will notify the Contractor within $\mathbf{3 0}$ days of receipt that additional time is necessary.

3. The final determination of the conformance action by the Wage and Hour Division shall be transmitted to the Contractor who will promptly notify the Subcontractor of the action taken. Each affected employee shall be furnished by the Subcontractor with a written copy of such determination or it shall be posted as a part of the wage determination. 
4. The process of establishing wage and fringe benefit rates that bear a reasonable relationship to those listed in a wage determination cannot be reduced to any single formula. The approach used may vary from wage determination to wage determination depending on the circumstances. Standard wage and salary administration practices which rank various job classifications by pay grade pursuant to point schemes or ether job factors may, for example, be relied upon. Guidance may also be obtained from the way different jobs are rated under Federal pay systems (Federal Wage Board Pay System and the General Schedule) or from other wage determinations issued in the same locality. Basic to the establishment of any conformable wage rate(s) is the concept that a pay relationship should be maintained between job classifications based on the skill required and the duties performed.

5. In the case of a subcontract modification, an exercise of an option or extension of an existing subcontract, or in any other case where a subcontractor succeeds a subcontract under which the classification in question was previously conformed pursuant to this section, a new conformed wage rate and fringe benefits may be assigned to such conformed classification by indexing (i.e., adjusting) the previous conformed rate and fringe benefits by an amount equal to the average (mean) percentage increase (or decrease, where appropriate) between the wages and fringe benefits specified for all classifications to be used on the subcontract which are listed in the current wage determination, and those specified for the corresponding classifications in the previousiy applicable wage determination. Where conforming actions are accomplished in accordance with this paragraph prior to the performance of subcontract work by the unlisted class of employees, the Subcontractor shall advise the Contractor of the action taken but the other procedures in paragraph B.2. of this section need not be followed.

6. No employee engaged in performing work on this subcontract shall in any event be paid less than the currently applicable minimum wage specified under section $6(a)(1)$ of the Fair Labor Standards Act of 1938, as amended.

7. The wage rate and fringe benefits finally determined pursuant to paragraphs B.1 and 2 of this section shall be paid to all employees performing in the classification from the first day on which subcontract work is performed by them in the classification. Failure to pay such unlisted employees the compensation agreed upon by the interested parties and/or finally determined by the Wage and Hour Division retroactive to the date such class of employees commenced subcontract work shall be a violation of the Act and this subcontract.

8. Upon discovery of failure to comply with paragraphs B.1 through 7 of this section, the Wage and Hour Division shall make a final determination of conformed classification, wage rate, and/or fringe benefits which shall be retroactive to the date such class of employees commenced subcontract work.

\section{Adjustment of Wages and Benefits for Subcontracts Extending Over One Year}

If, as authorized pursuant to section 4(d) of the Service Contract Act of 1965 as amended, the term of this subcontract is more than one year, the minimum monetary wages and fringe benefits required to be paid or furnished thereunder to service employees shall be subject to adjustment after one year and not less often than once every two years, pursuant to wage determinations to be issued by the Wage and Hour Division, Employment Standards Administration of the Department of Labor as provided in such Act. 
D. Making Equivalent or Differential Payments in Lieu of Fringe Benefits

The Subcontractor or lower tier subcontractor may discharge the obligation to furnish fringe benefits specified in the attachment or determined conformably thereto by furnishing any equivalent combination of bona fide fringe benefits, or by making equivalent or differential payments in cash in accordance with the applicable rules set forth in Subpart D of 29 CFR Part 4, and not otherwise.

E. Minimum Wage

In the absence of a minimum wage attachment for this subcontract, neither the Subcontractor nor any lower tier subcontractor under this subcontract shall pay any person performing work under the subcontract (regardless of whether they are service employees) less than the minimum wage specified in section 6(a)(1) of the Fair Labor Standards Act of 1938. Nothing in this provision shall relieve the Subcontractor or any lower tier subcontractor of any other obligation under law or contract for the payment of a higher wage to any employee.

F. Obligations Attributable to Collective Bargaining Agreements of Predecessor Contracts

If this subcontract succeeds a contract subject to the Service Contract Act of 1965 as amended, under which substantially the same services were furnished in the same locality and service employees were paid wages and fringe benefits provided for in a collective bargaining agreement, in the absence of the minimum wage attachment for this subcontract setting forth such collectively bargained wage rates and fringe benefits, neither the Subcontractor nor any lower tier subcontractor under this subcontract shall pay any service employee performing any of the subcontract work (regardless of whether or not such employee was employed under the predecessor contract), less than the wages and fringe benefits provided for in such collective bargaining agreements, to which such employee would have been entitled if employed under the predecessor contract, including accrued wages and fringe benefits and any prospective increases in wages and fringe benefits provided for under such agreement. No Subcontractor or lower tier subcontractor under this subcontract may be relieved of the foregoing obligation unless the limitations of section 4.lb(b) of 29 CFR Part 4 apply or unless the Secretary of Labor or his authorized representative finds, after a hearing as provided in section 4.10 of 29 CFR Part 4 that the wages and/or fringe benefits provided for in such agreement are substantially at variance with those which prevail for services of a character similar in the locality, or determines, as provided in section 4.11 of 29 CFR Part 4, that the collective bargaining agreement applicable to service employees employed under the predecessor contract was not entered into as a result of arm's length negotiations. Where it is found in accordance with the review procedures provided in 29 CFR 4.10 and/or 4.11 and Parts 6 and 8 that some or all of the wages and/or fringe benefits contained in a predecessor contractor's collective bargaining agreement are substantially at variance with those which prevail for services of a character similar in the locality, and/or that the collective bargaining agreement applicable to service employees employed under the predecessor contract was not entered into as a result of arm's length negotiations, the Department will issue a new or revised wage determination setting forth the applicable wage rates and fringe benefits. Such determination shall be made part of the subcontract or lower tier subcontract, in accordance with the decision of the Administrator, the Administrative Law Judge, or the Board of Service Contract Appeals, as the case may be, irrespective of whether such issuance occurs prior to or after the award of a subcontract or lower tier subcontract. 53 Comp. Gen. 401 (1973). In the case of a wage determination issued solely as a result of a finding of substantial variance, such determination shall be effective as of the date of the final administrative decision. 


\section{G. Notification to Employee}

The Subcontractor and any lower tier subcontractor under this subcontract shall notify each service employee commencing work on this subcontract of the minimum monetary wage and any fringe benefits required to be paid pursuant to this subcontract, or shall post the wage determination attached to this subcontract. The poster provided by the Department of Labor (Publication WH 1313) shall be posted in a prominent and accessible place at the worksite. Failure to comply with this requirement, is a violation of $2(a)(4)$ of the Act and of this subcontract.

H. Safe and Sanitary Working Conditions

The Subcontractor or lower tier subcontractor shall not permit any part of the services called for by this subcontract to be performed in buildings or surroundings or under working conditions provided by or under the control or supervision of the Subcontractor or lower tier subcontractor which are unsanitary or hazardous or dangerous to the health or safety of service employees engaged to furnish these services, and the Subcontractor or lower tier subcontractor shall comply with the safety and health standards applied under 29 CFR Part 1925.

\section{I. $\quad \underline{\text { Records }}$}

The Subcontractor and each lower tier subcontractor performing work subject to the Act shall make and maintain for three years from the completion of the work records containing the information specified in this paragraph I.1. through 6 . for each employee subject to the Act and shall make them available for inspection and transcription by authorized representatives of the Wage and Hour Division, Employment Standards Administration of the U. S. Department of Labor:

1. Name and address and social security number of each employee;

2. The correct work classification or classifications, rate or rates of monetary wages paid and fringe benefits provided, rate or rates of fringe benefit payments in lieu thereof, and total daily and weekly compensation of each employee;

3. The number of daily and weekly hours so worked by each employee;

4. Any deductions, rebates, or refunds from the total daily or weekly compensation of each employee;

5. A list of monetary wages and fringe benefits for those classes of service employees not included in the wage determination attached to this subcontract but for which such wage rates or fringe benefits have been determined by the interested parties or by the Administrator or authorized representative pursuant to the labor standards clause in paragraph $B$ of this clause. A copy of the report required by the clause in paragraph B.2. of this clause shall be deemed to be such a list; and

6. Any list of the predecessor contractor's employees which had been furnished to the Subcontractor pursuant to paragraph $Q$. of this clause.

The Subcontractor shall also make available a copy of this subcontract for inspection or transcription by authorized representatives of the Wage and Hour Division. 
Failure to make and maintain or to make available such records for inspection and transcription shall be a violation of the regulations and this subcontract, and in the case of failure to produce such records, the Contractor, upon direction of the Department of Labor and notification of the Subcontractor, shall take action to cause suspension of any further payment or advance of funds until such violation ceases.

J. Interviews with Employees

The Subcontractor shall permit authorized representatives of the Wage and Hour Division to conduct interviews with employees at the worksite during normal working hours.

K. Withholding Wages

The Subcontractor shall unconditionally pay to each employee subject to the Act all wages due free and clear and without subsequent deduction (except as otherwise provided by law or regulations, 29 CFR Part 4), rebate, or kickback on any account. Such payments shall be made no later than one pay period following the end of the regular pay period in which such wages were earned or accrued. A pay period under this Act may not be of any duration longer than semi-monthly.

L. Withholding Payments to Subcontractor and Termination of Subcontract

The Contractor shall withhold or cause to be withheld from the Subcontractor under this subcontract, and the DOE Contracting Officer may withhold or cause to be withheld from the Subcontractor under this subcontract or any other Government contract with the Subcontractor, such sums as an appropriate official of the Department of Labor requests or such sums as the Contractor decides may be necessary to pay underpaid employees employed by the Subcontractor or lower tier subcontractor. In the event of failure to pay any employees subject to the Act all or part of the wages or fringe benefits due under the Act, Contractor may, after authorization or by direction of the Department of Labor and written notification to the Subcontractor, take action to cause suspension of any further payment or advance of funds until such violations have ceased. Additionally, any failure to comply with the requirements of these clauses relating to the Service Contract Act of 1965, may be grounds for termination of the right to proceed with the subcontract work. In such event, Contractor may enter into other subcontracts or arrangements for completion of the work, charging the Subcontractor in default with any additional cost.

\section{Lower Tier Subcontracts}

The Subcontractor agrees to insert these clauses in this section relating to the Service Contract Act of 1965 in all lower tier subcontracts subject to the Act. The term "Subcontractor" as used in these clauses in any lower tier subcontract shall be deemed to refer to the lower tier subcontractor.

N. Definition of Service Employee

As used in this clause, the term "service employee" means any person engaged in the performance of this subcontract other than any person employed in a bona fide executive, administrative, or professional capacity, as those terms are defined in Part 541 of Title 29, CFR, as of July 30, 1976, and any subsequent revision of those regulations. The term "service employee" includes all such persons regardless of any contractual relationship that may be alleged to exist between a contractor or subcontractor and such persons. 


\section{O. Comparable Rates}

The following statement is included in subcontracts pursuant to section 2(a)(5) of the Act and is for informational purposes only:

The following classes of service employees expected to be employed under the subcontract would be subject, if employed by the Department of Energy, to the provisions of 5 U.S.C. 5341 or 5 U.S.C. 5332 and would, if so employed, be paid not less than the following rates of wages and fringe benefits:

Employee Class

\section{Monetary Wage -}

Fringe Benefits

\section{P. Collective Bargaining Agreements}

If wages to be paid or fringe benefits to be furnished any service employees employed by the Subcontractor or any lower tier subcontractor under the subcontract are provided for in a collective bargaining agreement which is or will be effective during any period in which the subcontract is being performed, the Subcontractor shall report such fact to the Contractor, together with full information as to the application and accrual of such wages and fringe benefits, including any prospective increases, to service employees engaged in work on the subcontract, and a copy of the collective bargaining agreement. Such report shall be made upon commencing performance of the subcontract, in the case of collective bargaining agreements effective at such time, and in the case of such agreements or provisions or amendments thereof effective at a later time during the period of subcontract performance, such agreements shall be reported promptly, after negotiation thereof.

Q. Vacation and Other Benefit Provisions of Predecessor or Successor Contracts

Not less than ten days prior to completion of any contract being performed at a Federal facility where service employees may be retained in the performance of the succeeding subcontract and subject to a wage determination which contains vacation or other benefit provisions based upon length of service with a contractor (predecessor) or successor (section 4.173 of Regulations, 29 CFR Part 4), the incumbent contractor shall furnish to the Contractor a certified list of the names of all service employees on the contractor's or subcontractor's payroll during the last month of contract performance. Such list shall also contain anniversary dates of employment on the contract either with the current or predecessor contractors of each such service employee. The Contractor shall turn over such list to the successor subcontractor at the commencement of the succeeding subcontract.

\section{R. Rulings, Interpretations, Certification, Ineligible Firms, and Penalties}

1. Rulings and interpretations of the Service Contract Act of 1965 as amended, are contained in Regulations, 29 CFR Part 4. 
2. By entering into this subcontract, the Subcontractor (and officials thereof) certifies that neither it (nor he or she) nor any person or firm who has a substantial interest in the Subcontractor's firm is a person or firm ineligible to be awarded Government contracts by virtue of the sanctions imposed pursuant to section 5 of the Act.

3. No part of this subcontract shall be subcontracted to any person or firm ineligible for award of a Government contract pursuant to section 5 of the Act.

4. The penalty for making false statements is prescribed in the U. S. Criminal Code, 18 U.S.C. 1001 .

S. Apprentices, Student-Learners, Handicapped Persons, and Sheltered Workshops

Notwithstanding any of the clauses in paragraphs A through Q. of this section relating to the Service Contract Act of 1965, the following employees may be employed in accordance with the following variations, tolerances, and exemptions, which the Secretary of Labor, pursuant to section $4(\mathrm{~b})$ of the Act prior to its amendment by Pub. L. 92-473, found to be necessary and proper in the public interest or to avoid serious impairment of the conduct of Government business:

1. Apprentices, student-learners, and workers whose earning capacity is impaired by age, physical, or mental deficiency or injury may be employed at wages lower than the minimum wages otherwise required by section 2(a)(1) or 2(b)(1) of the Service Contract Act without diminishing any fringe benefits or cash payments in lieu thereof required under section 2(a)(2) of that Act, in accordance with the conditions and procedures prescribed for the employment of apprentices, student-learners, handicapped persons, and handicapped clients of sheltered workshops under section 14 of the Fair Labor Standards Act of 1938, in the regulations issued by the Administrator (29 CFR Parts 520, 521, 524 and 525.)

2. The Administrator will issue certificates under the Service Contract Act for the employment of apprentices, student-learners, handicapped persons, or handicapped clients of sheltered workshops not subject to the Fair Labor Standards Act of 1938, or subject to different minimum rates of pay under the two acts, authorizing appropriate rates of minimum wages (but without changing requirements concerning fringe benefits or supplementary cash payments in lieu thereof), applying procedures prescribed by the applicable regulations issued under the Fair Labor Standards Act of 1938 (29 CFR Parts 520, 521, 524 and 525).

3. The Administrator will also withdraw, annul, or cancel such certificates in accordance with the regulations in Parts 525 and 528 of Title 29 of the CFR.

4. Apprentices will be permitted to work at less than the predetermined rate for the work they perform when they are employed and individually registered in a bona fide apprenticeship program registered with a State Apprenticeship Agency which is recognized by the U. S. Department of Labor, or if no such recognized agency exists in a State, under a program registered with the Bureau of Apprenticeship and Training, Employment and Training Administration, U. S. Department of Labor. Any employee who is not registered as an apprentice in an approved program shall be paid the wage rate and fringe benefits contained in the applicable wage determination for the journeyman classification of work actually performed. The wage rates paid apprentices shall not be less than the wage rate for their level of progress set forth in the registered program, expressed as the appropriate percentage 
of the journeyman's rate contained in the applicable wage determination. The allowable ratio of apprentices to journeymen employed on the subcontract work in any craft classification shall not be greater than the ratio permitted to the Subcontractor as to his entire work force under the registered program.

\section{T. Tips as Wages}

An employee engaged in an occupation in which he or she customarily and regularly receives more than $\$ 30$ a month in tips may have the amount of tips credited by the employer against the minimum wage required by section 2(a)(1) or section 2(b)(1) of the Act in accordance with section 3(m) of the Fair Labor Standards Act and Regulations, 29 CFR Part 531: Provided, however, That the amount of such credit may not exceed $\$ 1.24$ per hour beginning January 1, 1980, and $\$ 1.34$ per hour after December 31, 1980. To utilize this proviso:

1. The employer must inform tipped employees about this tip credit allowance before the credit is utilized;

2. The employees must be allowed to retain all tips (individually or through a pooling arrangement and regardless of whether the employer elects to take a credit for tips received);

3. The employer must be able to show by records that the employee received at least the applicable Service Contract Act minimum wage through the combination of direct wages and tip credit; and

4. The use of such tip credit must have been permitted under any predecessor collective bargaining agreement applicable by virtue of section $4(\mathrm{c})$ of the Act.

U. Disputes Concerning Labor Standards

Disputes arising out of the labor standards provisions of this subcontract shall not be subject to the general disputes clause of this subcontract. Such disputes shall be resolved in accordance with the procedures of the Department of Labor set forth in 29 CFR Parts 4, 6, and 8. Disputes within the meaning of this clause include disputes between the Subcontractor (or any of its lower tier subcontractors) and the Contractor, the DOE, the U. S. Department of Labor, or the employees or their representatives. 


\section{U.S. DEPARTMENT OF LABOR EMPLOYMENT STANDARDS ADMINISTRÄTTION WAGE AND HOUR DIVISION WASHINGTON, D.C. 20210 \\ REGISTER OF WAGE DETERMINATIONS UNDER THE SERVICE CONTRACT ACT by direction of the Secretary of Labor}

$\begin{array}{ll}\text { Alan L. Moss } & \text { Division } \\ \text { Director } & \text { Wage Determinations }\end{array}$

\begin{tabular}{|c|c|c|c|c|}
\hline \multirow[b]{2}{*}{ LOCALITY } & \multicolumn{3}{|c|}{ State: Idaho } & \\
\hline & \multicolumn{4}{|c|}{ Area: ID COUNTIES: STATEWIDE } \\
\hline \multicolumn{4}{|c|}{ Wage Determination No: $86-0889$ (Rev. 12) } & 92 \\
\hline \multirow{2}{*}{$\begin{array}{l}\text { Minimum } \\
\text { Hourly } \\
\text { Wage }\end{array}$} & \multicolumn{3}{|c|}{ Fringe Benefit Payments } & \\
\hline & $\begin{array}{l}\text { Health \& } \\
\text { Welfare }\end{array}$ & Vacation & Holiday & Other \\
\hline
\end{tabular}

Class of Service Employees

Furniture Maintenance and Repair, Machine Tool Operations and Repair Occupations, Material Handling and Packing Occupations, Mechanics and Maintenance and Repair Occupations, Transportation and Mobile Equipment Operations Occupations, and Plant and Systems Operation Occupations:

$\begin{array}{ll}\text { 1. } & \text { Material Coordinator } \\ \text { 2. } & \text { Order Filler } \\ \text { 3. } & \text { Tool \& Parts Attendant } \\ \text { 4. } & \text { Warehouseman } \\ \text { 5. } & \text { Electrostatic Spray Painter } \\ \text { 6. } & \text { Furniture Refinisher } \\ \text { 7. } & \text { Furniture Refinisher, Helper } \\ \text { 8. } & \text { Upholsterer } \\ \text { 9. } & \text { Laborer } \\ \text { 10. } & \text { Machine-Tool Operator (Toolroom) } \\ \text { 11. } & \text { Fuel Distribution System Operator } \\ \text { 12. } & \text { Material Handling Laborer } \\ \text { 13. } & \text { Power Truck Operator (other than Forklift) } \\ \text { 14. } & \text { Forklift Operator }\end{array}$


ENCLOSURE 05

Page 2 of 11

\section{U.S. DEPARTMENT OF LABOR EMPLOYMENT STANDARDS ADMINISTRATION \\ WAGE AND HOUR DIVISION \\ WASHINGTON, D.C. 20210 \\ REGISTER OF WAGE DETERMINATIONS UNDER THE SERVICE CONTRACT ACT \\ by direction of the Secretary of Labor}

\begin{tabular}{ll}
$\begin{array}{l}\text { Alan L. Moss } \\
\text { Director }\end{array}$ & $\begin{array}{l}\text { Division } \\
\text { Wage Determinations }\end{array}$ \\
\hline \multicolumn{2}{c}{ Class of Service Employees } \\
\hline
\end{tabular}

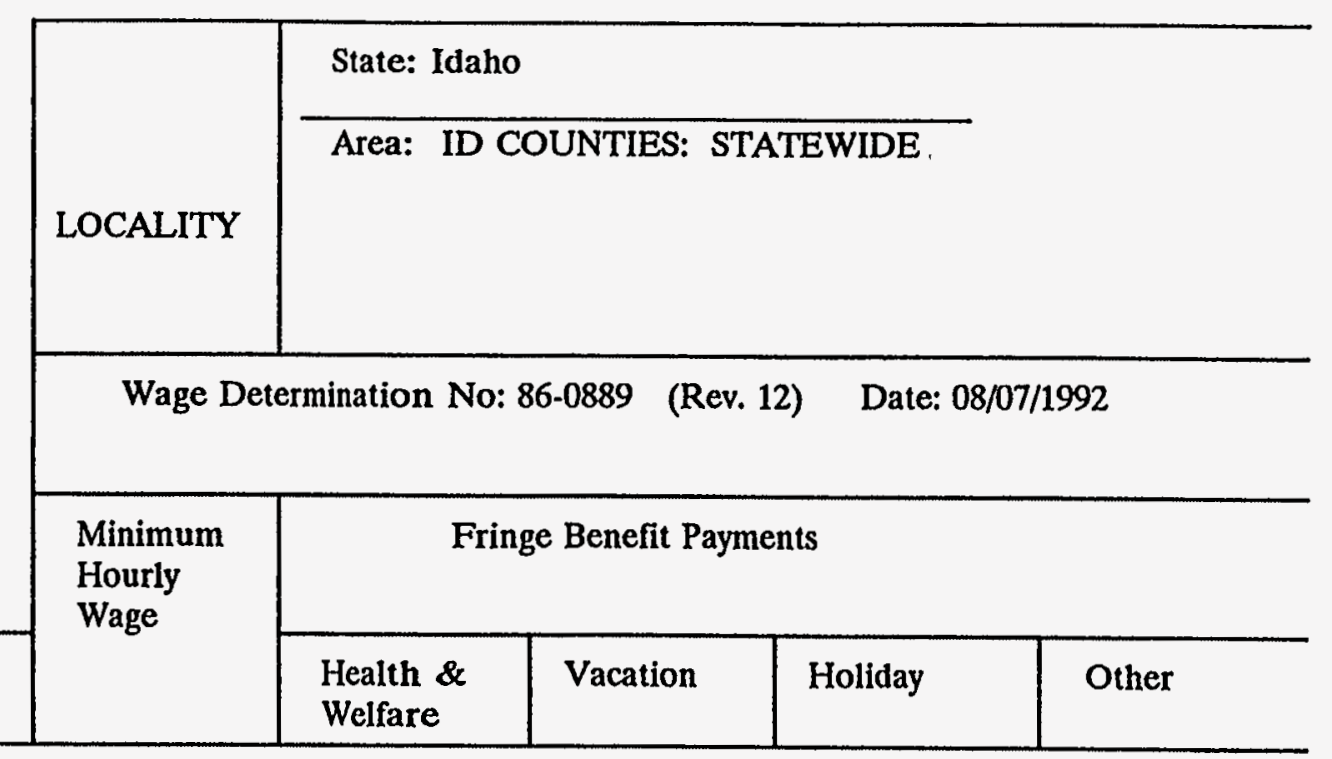

$\begin{array}{llc}\text { 15. } & \text { Shipper and Receiver } & \$ 9.03 \\ \text { 16. } & \text { Shipper } & \$ 9.03 \\ \text { 17. } & \text { Receiver } & \$ 9.03 \\ \text { 18. } & \text { Shipping Packer } & \$ 9.45 \\ \text { 19. } & \text { Aircraft Mechanic } & \$ 12.19 \\ \text { 20. } & \text { Aircraft Mechanic Helper } & \$ 9.03 \\ \text { 21. } & \text { Aircraft Servicer } & \$ 9.90 \\ \text { 22. } & \text { Aircraft Worker } & \$ 10.32 \\ \text { 23. } & \text { Appliance Mechanic } & \$ 10.34 \\ \text { 24. } & \text { Audiovisual Equipment Mechanic } & \$ 12.10 \\ \text { 25. } & \text { Bicycle Repairer } & \$ 9.05 \\ \text { 26. } & \text { Carpenter, Maintenance } & \$ 10.75 \\ \text { 27. } & \text { Carpet Layer } & \$ 10.32 \\ \text { 28. } & \text { Electrician, Maintenance } & \$ 12.19 \\ \text { 29. } & \text { Electronics Mechanic } & \$ 12.10 \\ \text { 30. } & \text { Electronics Worker } & \$ 10.34 \\ \text { 31. } & \text { Fabric Worker } & \$ 9.05 \\ \text { 32. } & \text { Fire Alarm System Mechanic } & \$ 12.19 \\ \text { 33. } & \text { Fire Extinguisher Repairman } & \$ 9.90 \\ \text { 34. } & \text { Fuel Distribution System Mechanic } & \$ 12.19\end{array}$


U.S. DEPARTMENT OF LABOR

EMPLOYMENT STANDARDS ADMINISTRÄTION

WAGE AND HOUR DIVISION

WASHINGTON, D.C. 20210

REGISTER OF WAGE DETERMINATIONS UNDER THE SERVICE CONTRACT ACT

by direction of the Secretary of Labor

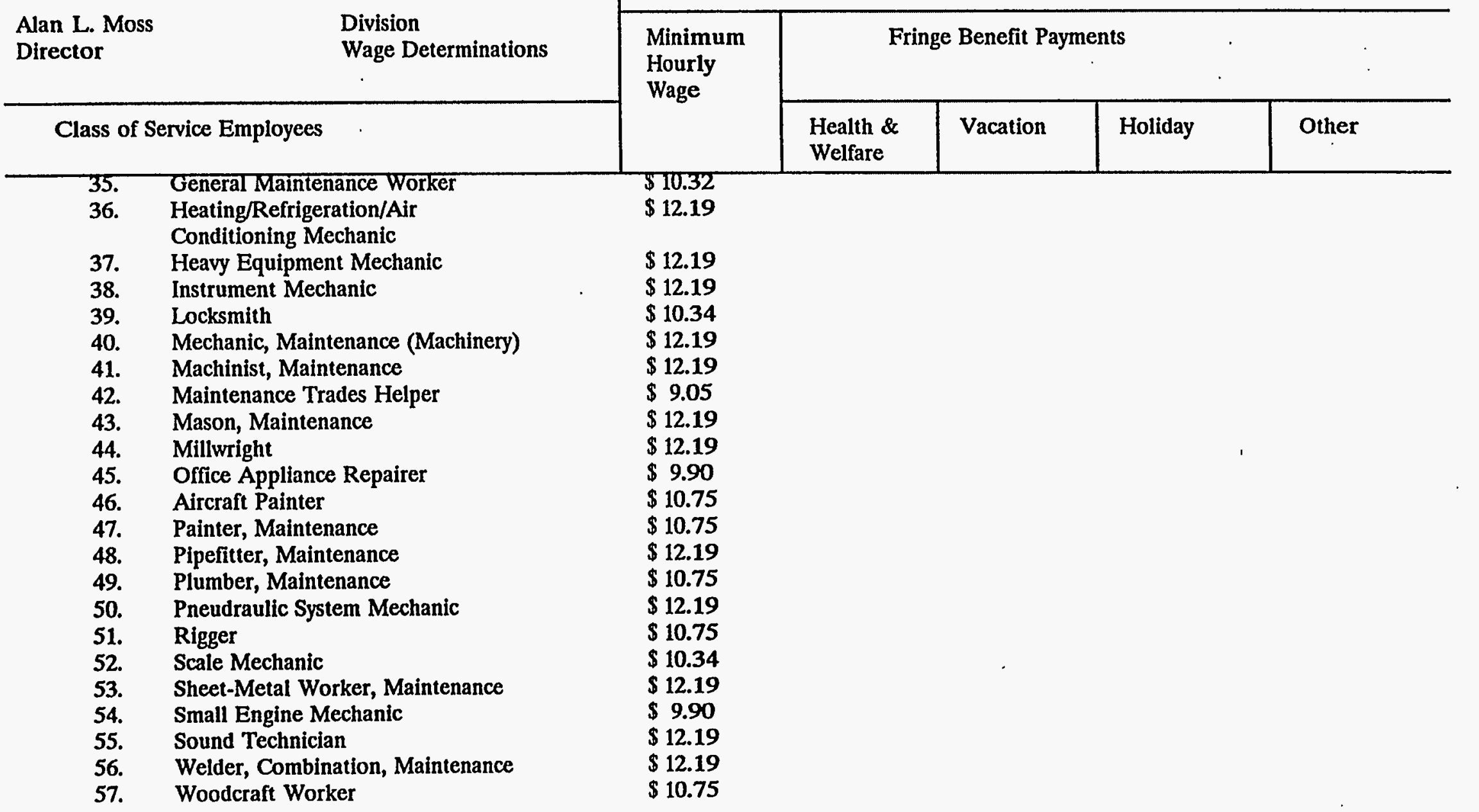

State: Idaho

Area: ID COUNTIES: STATEWIDE

LOCALITY

Wage Determination No: 86-0889 (Rev. 12) Date: 08/07/1992

$\$ 12.19$

12.19

9.90

10.75

9.90

$\$ 10.75$ 
ENCLOSURE 05

Page 4 of 11

U.S. DEPARTMENT OF LABOR EMPLOYMENT STANDARDS ADMINISTRATION WAGE AND HOUR DIVISION WASHINGTON, D.C. 20210

REGISTER OF WAGE DETERMINATIONS UNDER THE SERVICE CONTRACT ACT by direction of the Secretary of Labor

Alan L. Moss

Director

Division

Wage Determinations

\begin{tabular}{|c|c|c|c|c|}
\hline \multirow[b]{2}{*}{ LOCALITY } & \multicolumn{4}{|c|}{ State: Idaho } \\
\hline & \multicolumn{4}{|c|}{ Area: ID COUNTIES: STATEWIDE } \\
\hline \multicolumn{4}{|c|}{ Wage Determination No: $86-0889$ (Rev. 12) } & 92 \\
\hline \multirow{2}{*}{$\begin{array}{l}\text { Minimum } \\
\text { Hourly } \\
\text { Wage }\end{array}$} & \multicolumn{4}{|c|}{ Fringe Benefit Payments } \\
\hline & $\begin{array}{l}\text { Health \& } \\
\text { Welfare }\end{array}$ & Vacation & Holiday & Other \\
\hline
\end{tabular}

Class of Service Employees
$\$ 10.34$
$\$ 10.75$
$\$ 10.75$
$\$ 12.19$
$\$ 10.75$
$\$ 12.19$
$\$ 8.04$
$\$ 9.55$
$\$ 10.03$
$\$ 10.41$
$\$ 12.62$
$\$ 12.19$
$\$ 12.19$
$\$ 12.19$ 
U.S. DEPARTMENT OF LABOR

EMPLOYMENT STANDARDS ADMINISTR'ATION

WAGE AND HOUR DIVISION

WASHINGTON, D.C. 20210

REGISTER OF WAGE DETERMINATIONS UNDER

THE SERVICE CONTRACT ACT

by direction of the Secretary of Labor

\section{Alan L. Moss}

Director
Division

Wage Determinations

\begin{tabular}{|l|l}
\hline \multirow{2}{*}{ LOCALITY } & State: Idaho \\
\cline { 2 - 2 } & Area: ID COUNTIES: STATEWIDE \\
\hline
\end{tabular}

Wage Determination No: 86-0889 (Rev. 12) Date: 08/07/1992

Class of Service Employees

\begin{tabular}{|l|l|l|l|l|}
\hline $\begin{array}{l}\text { Minimum } \\
\text { Hourly } \\
\text { Wage }\end{array}$ & \multicolumn{3}{|c}{ Fringe Benefit Payments } \\
\cline { 2 - 4 } & $\begin{array}{l}\text { Health \& } \\
\text { Welfare }\end{array}$ & Vacation & Holiday & Other \\
\hline
\end{tabular}

1 / HEALTH \& WELFARE: $\$ 0.83$ per hour or $\$ 33.30$ per week or $\$ 143.86$ per month.

21 VACATION: 2 weeks paid vacation after 1 year of service with a contractor or successor; 3 weeks after 5 years; 4 weeks after 15 years. Length os service includes the whole span of continuous service with the present (successor) contractor, wherever employed, and with the predecessor contractor in the performance of similar work at the same Federal facility. (Reg. 4.173)

$3 /$ HOLIDAYS; 9 paid holidays per year: New Year's Day, Washington's Birthday, Memorial Day, Independence Day. Labor Day, Columbus Day, Veterans' Day, Thanksgiving Day, and Christmas Day. (A contractor may substitute for any of the named holidays another day off with pay in accordance with a plan communicated to the employees involved.) 
NOTE: The contracting officer shall require that any class of service employee which is not listed herein and which is to be employed under the contract (i.e., the work to be performed is not purformed by any classification listed in the wage determination), be classified by the contractor so as to provide a reasonable relationship (i.e., appropriate level of skill comparison) between such unlisted classification and the classifications listed in the wage determination. Such confirmed classes of employees shall be paid the monetary wages and furnished the fringe benefits as are determined. Such conforming procedures shall be initiated by the contractor prior to the performance of contract work by such unlisted class(es) of employees. A written report of the proposed conforming action, including information regarding the agreement or disagreement of the authorized representative of the employees involved or, where there is no authorized representative, the employees themselves, shall be submitted by the contractor to the contracting officer no later than $\mathbf{3 0}$ days after such unlisted class(es) of employees performs and any contract work. The contracting officer shall review the proposed action and promptly submit a report of the action, together with the agency's recommendation and all pertinent information including the position of the contractor and the employees, to the Wage and Hour Division, Employment Standards Administration, U.S. Department of Labor, for review. (See section 4.6 (b) (2) of Regulations 29 CFR 4)

UNIFORM ALLOWANCE: If Employees are required to ware uniforms in the performance of this contract (either by the terms of the Government contract, by the employer, by the state of local law, etc.), the cost of furnishing such uniforms and maintaining (by laundering or dry cleaning) such uniforms is an expanse that may not be borne by an employee where such cost reduces the hourly rate below that required by the wage determination. The Department of Labor will accept payment in accordance with the following standards as compliance:

The contractor or subcontractor is required to furnish all employees with an adequate number of uniforms without cost or to reimburse employees for the actual cost of the uniforms. In addition, where uniform cleaning and maintenance is made the responsibility of the employees, all contractors and subcontractors subject to the wage determination shall (in the absence of a bona fide collective bargaining agreement providing for a different amount, or the furnishing of contrary affirmative proof as to the actual cost), reimburse all employees for such cleaning and maintenance at a rate of $\$ 3.80$ a week (or 76 cents a day); and effective April 1, 1991, the note shall be $\$ 4.25$ per week (or $\$ .85$ cents per day). However, in those instances where the uniforms furnished are made of "wash and wear" materials, may be routinely washed and dried with other personal garments, and do not require any special treatment such as dry cleaning, daily washing, or commercial laundering in order to meet the cleanliness or appearance standards set by the terms of the Government contract, by the contractor, by law, or by the nature of the work, there is no requirement that employees by reimbursed for uniform maintenance costs.

NOTE: The duties of employees under job titles listed are those described in the Service Contract Act Directory of Occupations, Second Edition, July 1986, unless otherwise indicated. See also 29 CFR Part 4 Section 4.152. 


\section{******************** OCCUPATIONS NOT INCLUDED IN THE SCA DIRECTORY OF OCCUPATIONS}

\section{AIRCRAFT INSPECTOR}

Requires the inspection of work accomplished on the aircraft except for electronic. This includes maintenance and repair of fixed and rotary wing aircraft systems, except for avionics, airframes, components and assemblies to ensure that work has satisfactory been accomplished. Aircrafts worked on include a variety of models, are single and multi-engine types and have reciprocating or jet engines. Works under the supervision of Chief of Quality Control. Must be a journeyman.

\section{Lineman}

This occupation includes jobs that involve installing, maintaining, and repairing aerial and underground communications lines and auxiliary equipment such as conduits, insulators, and poles. The work does not require completing line connections.

\section{TELEPHONE MECHANIC}

Responsible for telephone installation, removal, relocation, problem resolution, and cable maintenance and repair. Specifically, the telephone mechanic handles circuit testing, analyses results, repairs and modifies circuits and equipment in a step by step, $\mathrm{XY}$, all relay and/or Electronic Switch system. Locates electrical, electronic, and mechanical failures in telephone schematic drawings, computer printouts, and troubletickets. Repairs equipment by replacing defective parts and such by procedures as setting clearances, adjusting spring tensions, wipers, relay contacts, and other interrelated mechanisms. Installs or rearranges equipment frames and shelves, and such equipment as line finders, switch banks, selectors, connectors, repeaters, peg counters, restricting post cams, and various interrelated trunk circuits. performs traffic study analysis and office grading. Installs approved modifications and makes suggestions for improvements. Resolves complex problems between exchange, both government and commercial. May direct, instruct, and assist lower level employees with their overall assignments. Performs other duties as assigned.

\section{CABLE SPLICER}

Installs maintains, repairs, and modifies cable systems. Uses engineered drawings, statements of work, and technical manuals to determine requirements for maintaining underground, buried, and aerial cable systems. Prepares and installs distribution equipment. Terminates tip cables on main distribution frames. Installs, maintains, and repairs dry air compressors and continuous flow and static pressurization systems. Ensures techniques, materials, and accomplishments are according to technical standards, and specifications and engineered directives. Locates, repairs, and/or replaces splice cases. performs pneumatic troubleshooting to locate faulty splice cases and pressure component assemblies, using resistance measurements and pressure gradients. Repairs pressure component assemblies and adjusts pressure contractors. Determines course of signal deterioration in voice and data circuits over cable by using test equipment. Interprets compressor meter readings and adjusts controls. Troubleshoots pneumatic and electrical malfunctions in cable air-dryer compressors. 
ENCLOSURE 05

Page 8 of 11

U.S. DEPARTMENT OF LABOR

EMPLOYMENT STANDARDS ADMINISTRATION

WAGE AND HOUR DIVISION

.WASHINGTON, D.C. 20210

\section{REGISTER OF WAGE DETERMINATIONS UNDER THE SERVICE CONTRACT ACT}

by direction of the Secretary of Labor

\begin{tabular}{ll|l|l|l|l}
\multicolumn{1}{c|}{$\begin{array}{l}\text { Alan L. Moss } \\
\text { Director }\end{array}$} & $\begin{array}{l}\text { Division } \\
\text { Wage Determinations }\end{array}$ & $\begin{array}{l}\text { Minimum } \\
\text { Hourly } \\
\text { Wage }\end{array}$ & \multicolumn{3}{|c}{ Fringe Benefit Payments } \\
\cline { 4 - 6 } Class of Service Employees & & $\begin{array}{l}\text { Health \& } \\
\text { Welfare }\end{array}$ & Vacation & Holiday & Other \\
\hline
\end{tabular}

Automatic Data Processing Occupations, Information and Arts Occupations, Library and Archive Occupations, and Technical Occupations:

$\begin{array}{llr}\text { 1. } & \text { Computer Data Librarian } & \$ 7.27 \\ \text { 2. } & \text { Computer Operator I } & \$ 7.27 \\ \text { 3. } & \text { Computer Operator II } & \$ 9.82 \\ \text { 4. } & \text { Computer Operator III } & \$ 11.49 \\ \text { 5. } & \text { Computer Operator IV } & \$ 14.04 \\ \text { 6. } & \text { Computer Programmer I 1 / } & \$ 8.76 \\ \text { 7. } & \text { Computer Programmer II 1/ } & \$ 10.66 \\ \text { 8. } & \text { Computer Programmer III 1 } & \$ 12.88 \\ \text { 9. } & \text { Computer Programmer IV 1/ } & \$ 15.58 \\ \text { 10. } & \text { Computer Systems Analyst I 1/ } & \$ 10.94 \\ \text { 11. } & \text { Computer Systems Analyst II 1/ } & \$ 12.76 \\ \text { 12. } & \text { Computer Systems Analyst III 1/ } & \$ 15.24 \\ \text { 13. } & \text { Computer Systems Analyst IV 1/ } & \$ 18.28 \\ \text { 14. } & \text { Key Entry Operator I } & \$ 5.80 \\ \text { 15. } & \text { Key Entry Operator II } & \$ 6.34 \\ \text { 16. } & \text { Peripheral Equipment Operator } & \$ 6.86 \\ \text { 17. } & \text { Exhibits Specialist I } & \$ 8.66 \\ \text { 18. } & \text { Exhibits Specialist II } & \$ 11.06 \\ \text { 19. } & \text { Exhibits Specialist III } & \$ 12.39 \\ \text { 20. } & \text { IIlustrator I } & \$ 8.66\end{array}$

State: Idaho

Area: ID COUNTIES: STATEWIDE

LOCALITY

Wage Determination No: 86-0889 (Rev. 12) Date: 08/07/1992

7.27

9.82

11.49

10.66

12.88

12.76

15.24

6.34

11.06

$\$ 8.66$ 
U.S. DEPARTMENT OF LABOR

EMPLOYMENT STANDARDS ADMINISTRATION

WAGE AND HOUR DIVISION

WASHINGTON, D.C. 20210

REGISTER OF WAGE DETERMINATIONS UNDER THE SERVICE CONTRACT ACT by direction of the Secretary of Labor

Alan L. Moss
Director

Alan L. M
Director

Division

Wage Determinations

Class of Service Employees

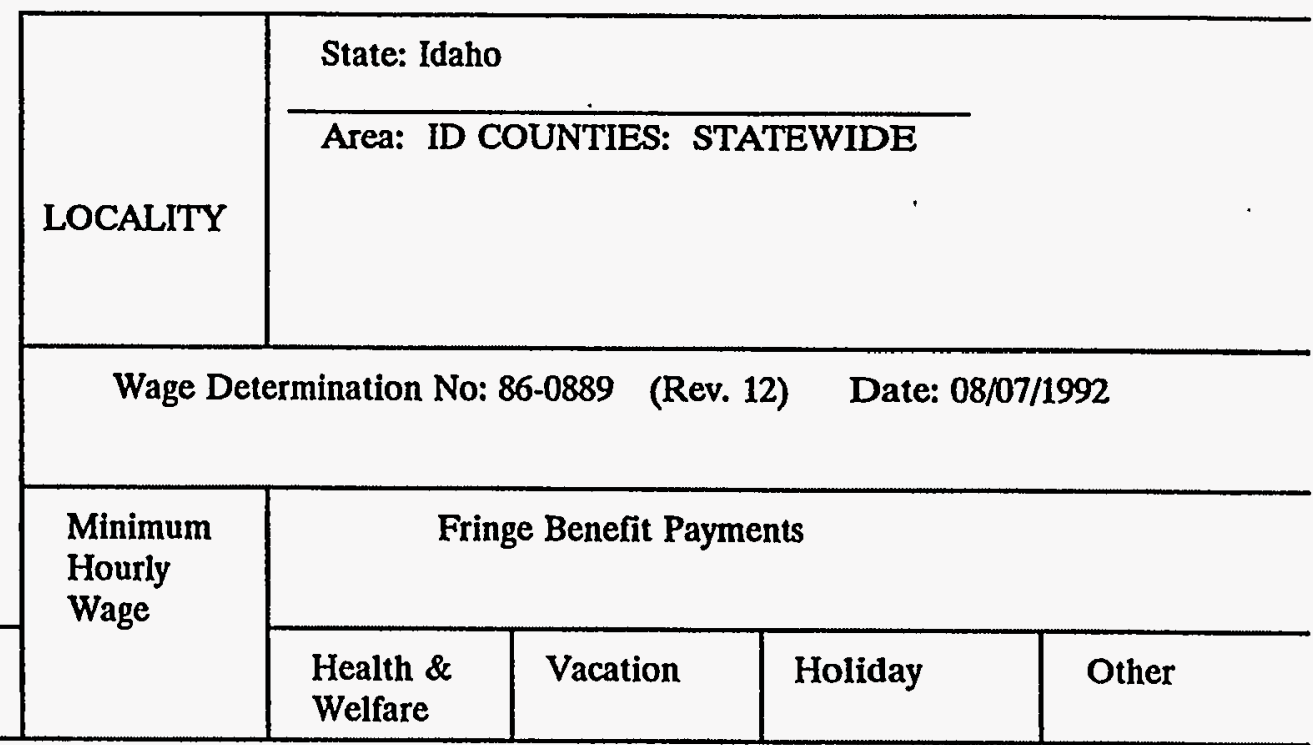

21. Illustrator II

$\$ 11.06$

22. Illustrator III

$\$ 12.39$

Photographer I

$\$ 8.66$

24. Photographer II

$\$ 11.06$

Photographer III

$\$ 12.39$

$\$ 8.34$

$\$ 10.14$

Librarian

$\$ 7.38$

$\$ 8.66$

$\$ 11.06$

$\$ 12.39$

$\$ 9.15$

$\$ 12.04$

$\$ 7.28$

$\$ 7.96$

$\$ 8.66$

$\$ 11.06$

$\$ 12.39$

$\$ 8.34$

$\$ 12.04$

$\begin{array}{ll}\text { 41. Technician III } 5 / & \$ 14.24 \\ \text { 42. Instructor } & \$ 8.34\end{array}$

$\begin{array}{lr}\text { Technician II 5 / } & \$ 12.04 \\ \text { Technician III } 5 / & \$ 14.24 \\ \text { Instructor } & \$ 8.34\end{array}$


ENCLOSURE 05

Page 10 of 11

\section{U.S. DEPARTMENT OF LABOR EMPLOYMENT STANDARDS ADMINISTRATION \\ WAGE AND HOUR DIVISION \\ WASHINGTON, D.C. 20210 \\ REGISTER OF WAGE DETERMINATIONS UNDER THE SERVICE CONTRACT ACT \\ by direction of the Secretary of Labor}

Alan L. Moss
Director

Alan L. Mo
Director

Division

Wage Determinations

\begin{tabular}{|c|c|c|c|c|}
\hline \multirow[b]{2}{*}{ LOCALITY } & \multicolumn{4}{|c|}{ State: Idaho } \\
\hline & \multicolumn{4}{|c|}{ Area: ID COUNTIES: STATEWIDE } \\
\hline \multicolumn{5}{|c|}{ Wage Determination No: $86-0889$ (Rev. 12) } \\
\hline \multirow{2}{*}{$\begin{array}{l}\text { Minimum } \\
\text { Hourly } \\
\text { Wage }\end{array}$} & \multicolumn{4}{|c|}{ Fringe Benefit Payments } \\
\hline & $\begin{array}{l}\text { Health \& } \\
\text { Welfare }\end{array}$ & Vacation & Holiday & Other \\
\hline
\end{tabular}

Class of Service Employees

Fringe benefits applicable to all classes of service employees engaged in contract performances:

21

3 /

$4 /$

$1 /$ Does not apply to employees employed in a bona fide executive, administrative, or professional capacity as defined and delineated in 29 CFR 541. (See 29 CFR 4.156)

21 HEALTH \& WELFARE: $\$ 0.83$ per hour or $\$ 33.20$ per week or $\$ 143.86$ per month.

$3 /$ VACATION: 2 weeks paid vacation after 1 year of service with a contractor or successor; 3 weeks after 5 years; 4 weeks after 15 years. Length os service includes the whole span of continuous service with the present (successor) contractor, wherever employed, and with the predecessor contractor in the performance of similar work at the same Federal facility. (Reg. 4.173)

4 / HOLIDAYS; 9 paid holidays per year: New Year's Day, Washington's Birthday, Memorial Day, Independence Day. Labor Day, Columbus Day, Veterans' Day, Thanksgiving Day, and Christmas Day. (A contractor may substitute for any of the named holidays another day off with pay in accordance with a plan communicated to the employees involved.)

5 / The Technician classification includes all of the following: Electronics, Electromechanical, Environmental, Instrumentation, Mathematical, Mechanical, and Photo-Optics. 
NOTE: The contracting officer shall require that any class of service employee which is not listed herein and which is to be employed under the contract (i.e., the work to be performed is not performed by any classification listed in the wage determination), be classified by the contractor so as to provide a reasonable relationship (i.e., appropriate level of skill comparison) between such unlisted classification and the classifications listed in the wage determination. Such confirmed classes of employees shall be paid the monetary wages and furnished the fringe benefits as are determined. Such conforming procedures shall be initiated by the contractor prior to the performance of contract work by such unlisted class(es) of employees. A written report of the proposed conforming action, including information regarding the agreement or disagreement of the authorized representative of the employees involved or, where there is no authorized representative, the employees themselves, shall be submitted by the contractor to the contracting officer no later than $\mathbf{3 0}$ days after such unlisted class(es) of employees performs and any contract work. The contracting officer shall review the proposed action and promptly submit a report of the action, together with the agency's recommendation and all pertinent information including the position of the contractor and the employees, to the Wage and Hour Division, Employment Standards Administration, U.S. Department of Labor, for review. (See section 4.6 (b) (2) of Regulations 29 CFR 4)

UNIFORM ALLOWANCE: If Employees are required to ware uniforms in the performance of this contract (either by the terms of the Government contract, by the employer, by the state of local law, etc.), the cost of furnishing such uniforms and maintaining (by laundering or dry cleaning) such uniforms is an expanse that may not be borne by an employee where such cost reduces the hourly rate below that required by the wage determination. The Department of Labor will accept payment in accordance with the following standards as compliance:

The contractor or subcontractor is required to furnish all employees with an adequate number of uniforms without cost or to reimburse employees for the actual cost of the uniforms. In addition, where uniform cleaning and maintenance is made the responsibility of the employees, all contractors and subcontractors subject to the wage determination shall (in the absence of a bona fide collective bargaining agreement providing for a different amount, or the furnishing of contrary affirmative proof as to the actual cost), reimburse all employees for such cleaning and maintenance at a rate of $\$ 3.80$ a week (or 76 cents a day); and effective April 1, 1991, the note shall be $\$ 4.25$ per week (or $\$ .85$ cents per day). However, in those instances where the uniforms furnished are made of "wash and wear" materials, may be routinely washed and dried with other personal garments, and do not require any special treatment such as dry cleaning, daily washing, or commercial laundering in order to meet the cleanliness or appearance standards set by the terms of the Government contract, by the contractor, by law, or by the nature of the work, there is no requirement that employees by reimbursed for uniform maintenance costs.

NOTE: The duties of employees under job titles listed are those described in the Service Contract Act Directory of Occupations, Second Edition, July 1986, unless otherwise indicated. See also 29 CFR Part 4 Section 4.152. 
Enclosure 06

Page 1 of 7

\author{
SUBCONTRACT NO. (ISSUED \\ PURSUANT- TO CONTRACT NO. \\ DE-AC07-76ID01570 BETWEEN U.S. \\ DEPARTMENT OF ENERGY AND EG\&G \\ IDAHO, INC.)
}

SAMPLE

MASTER TASK

FIRM-FIXED-PRICE-PER-UNIT MASTER TASK REQUIREMENTS SUBCONTRACT

BETWEEN

EG\&G IDAHO, INC.

AND 
INTRODUCTION................................ 1

1. DEFINITIONS................................ 1

2. SCOPE OF WORK............................... 2

3. PERIOD OF PERFORMANCE $\ldots \ldots \ldots \ldots \ldots \ldots \ldots \ldots \ldots \ldots \ldots \ldots \ldots \ldots \ldots \ldots$

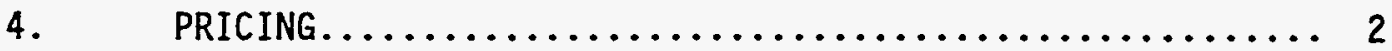

5. WORK AUTHORIZATION............................. 2

6. PAYMENT AND TERMS $\ldots \ldots \ldots \ldots \ldots \ldots \ldots \ldots \ldots \ldots \ldots \ldots \ldots \ldots \ldots \ldots$

7. REVIEW AND APPROVAL OF PROCEDURES................ 3

8. SUBCONTRACTOR'S ADMINISTRATION................. 3

9. CONTRACTOR'S ADMINISTRATION................... 4

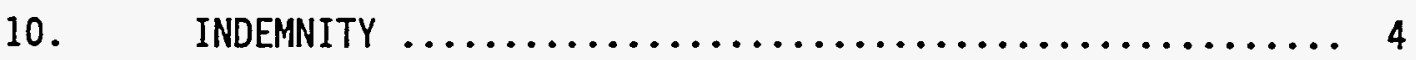

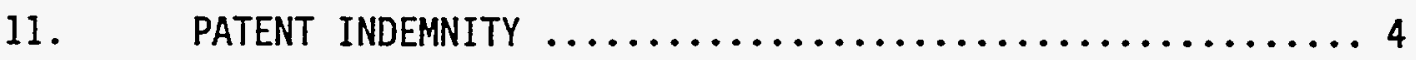

12. STANDARD TERMS AND CONDITIONS.................. 5

13. ENVIRONMENTAL, SAFETY, AND HEALTH
REQUIREMENTS FOR SUBCONTRACTORS $\ldots \ldots \ldots \ldots \ldots \ldots \ldots \ldots$

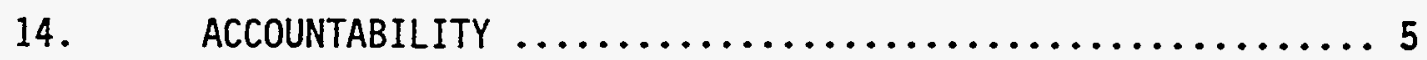

SIGNATURES.............................. 5

APPENDIX A - SERVICE CONTRACT ACT OF 1965, AS AMENDED

APPENDIX B - SUBCONTRACTING PLAN 


\author{
SUBCONTRACT NO. \\ BETWEEN \\ EG\&G IDAHO, INC. \\ AND
}

THIS SUBCONTRACT, effective by and between EG\&G IDAHO, INC., a corporation organized and existing under the laws of the State of Idaho, with its principal office at Idaho Falls, Idaho, (hereinafter called the "Contractor"), acting under Contract No. DE-ACO7-76ID01570 with the United States Government (hereinafter called the "Government") represented by the Idaho Operations Office of the Department of Energy (hereinafter called "DOE"), and (hereinafter called "Subcontractor").

WHEREAS, Contractor has heretofore entered into Contract No. DE-AC07-761D01570 (hereinafter sometimes referred to as the "Prime Contract"), dated October 1, 1976, with DOE for the management and operation by Contractor of certain. specified facilities at DOE's Idaho National Engineering Laboratory (INEL) in Southeastern Idaho; and

WHEREAS, Subcontractor is willing to perform certain work hereinafter described in accordance with the provisions of this subcontract on a fixed price basis; and

WHEREAS, Contractor finds that Subcontractor is qualified to perform the work, all relevant factors considered, and that such performance will be in furtherance of the Prime Contract;

NOW, THEREFORE, the parties hereto agree, as follows:

ARTICLE 1 - DEFINITIONS

As used throughout this Subcontract, the following terms shall have the meaning set forth below:

A. : $\quad$ The term "DOE" means the United States Department of Energy.

B. The term "INEL" means DOE's Idaho National Engineering Laboratory in Southeastern Idaho.

C. The term "EG\&G M\&O" means EG\&G Management and Operating Contractor.

D. The term "Contracting Officer" means the Manager of the Idaho Operations Office of DOE and includes his successors or any duTy authorized representative thereof.

E. The term "Contractor" means EG\&G Idaho, Inc., or any duTy authorized representative thereof.

F. The term "Subcontractor" means or any duty - authorized representative thereof. 
ARTICLE 2 - SCOPE OF WORK

This is a Requirements Subcontract. The Subcontractor sha71, upon receipt of written order from any of the five (5) EG\&G M\&O's, provide any or all of the services described in the Scopes of Work (Attachments -1 through 25). The five M\&O's and their locations are identified below:

1. EG\&G Idaho, Inc., Idaho Falls, Idaho facilities and the INEL facilities located approximately 50 miles West of Idaho Falls, Idaho.

2. EG\&G Energy Measurement, Inc. (EG\&G/EM)
A. North Las Vegas Operations, Las Vegas, Nevada
B. Woburn Cathode Ray Tube Operations, Hoburn Massachusetts
C. Santa Barbara Operations, Santa Barbara, California
D. Special Technologies Laboratory, Goleta, California
D. Amador Valley Operations, Pleasanton, California
E. Kirtland Operations, Albuquerque, New Mexico

3. EG\&G Rocky Flats, Inc. (EG\&G RF)
A. Rocky Flats Plant, Colorado
B. Broomfield, Colorado
C. Denver, Colorado
D. Oxnard, California

4. EG\&G Mound Applied Technologies, Miamisburg, Ohio

5. Reynolds Electrical \& Engineering Co., Inc. (REECo), Las Vegas, Nevada

\section{ARTICLE 3 - PERIOD OF PERFORMANCE}

The period of performance of this Subcontract shall be for three years beginning on date of award. EG\&G Idaho reserves the right to award up to two additional one-year optional periods of performance at the firm-fixed-unit prices listed in the Pricing Schedules, Attachments $23,4,5,7,8,9,10$, $12,13,14,15,17,18,19,20,22,23,24$, and 25.

Completion of the work, including all supporting data, shall be delivered to EG\&G Idaho, as specified in the Scopes of Work.

\section{ARTICLE 4 - PRICING}

Based on the Price Summary, Enclosure 7, the total ceiling price of this Subcontract is

The firm-fixed unit prices 1 isted in the Pricing Schedules, Attachments $23,4,5,7,8,9,10,12,13,14,15,17,18,19$, $20,22,23,24$, and 25, shall apply if and when services are performed by the Subcontractor. In the event EG\&G Idaho exercises 
the renewal options to extend the period of performance under this Subcontract for years, 4 and 5 , the pricing listed for each year in Attachments $23,4,5,7,8,9,10,12,13,14,15,17,18,19$, $20,22,23,24$, and 25 shall apply.

(c) The firm-fixed unit prices listed in Attachments 2 3, 4, 5, 7, 8, $9,10,12,13,14,15,17,18,19,20,22,23,24$, and 25 shal1 include Subcontractor responsibility for all testing and documentation required beyond EG\&G $M \& O^{\prime} s$ responsibilities which shal1 be: 1) EG\&G M\&O shall provide profile data for each waste stream according to regulatory requirements specified by 40 CFR 262.11 , 40 CFR 264.13, and/or 40 CFR 265.13, as applicable, and 2) EG\&G M\&O shall make payment to the Subcontractor for sample analysis according to Attachments $3,8,13,18$, and 23 .

(d) The firm-fixed unit prices 1isted in Attachments 2, 7, 12, 17, and 22 shall apply for all disposal methods for each waste stream, unless a reguiatory change not identified above requires a change in the disposal method specified in Attachments 2, 7, 12, 17, and 22 by the Subcontractor.

(e) The firm-fixed unit prices listed in Attachments $23,4,5,7,8$, $9,10,12,13,14,15,17,18,19,20,22,23,24$, and 25 shali be inclusive of all applicable taxes and all transportation/freight costs.

\section{ARTICLE 5 - HORK AUTHORIZATION}

Work shall be ordered and authorized by the issuance of written subcontract releases by EG\&G M\&O's. Al1 releases will be subject to the terms and conditions of the Subcontract.

\section{ART:ICLE 6 - PAYMENT AND TERMS}

Payment shall be made to the Subcontractor by $\mathrm{MQO}^{\prime}$ 's for services rendered under each subcontract release and in accordance with the terms and conditions stated in this Subcontract. Partial payments, after performance of each release, will be made on net 30 terms.

Quantities and waste streams shown in the Pricing Schedules, Attachments 2 3, $4,5,7,8,9,10,12,13,14,15,17,18,19,20,22,23,24$, and 25 , are estimated annual requirements and are in no way guaranteed or imp 7 ied.

Payment to the successful Subcontractor shall be made for actual quantities based on the firm-fixed unit prices provided by the Subcontractor in Attachments $23,4,5,7,8,9,10,12,13,14,15,17,18,19,20,22,23$, 24 , and 25 . The actual required quantity of services may be higher or lower, or none at a77. 
ENCLOSURE 06

PAGE 6 OF 7

\section{ARTICLE 7 - REVIEH AND APPROVAL OF PROCEDURES}

The action of Contractor in reviewing and/or approving Subcontractor's sampling, analytical, safety, treatment and/or disposal procedures shall not affect or relieve Subcontractor from such responsibility as subcontractor otherwise has with respect to the adequacy or correctness of such procedures used by the Subcontractor in the performance of work under this Subcontract.

\section{ARTICLE 8 - SUBCONTRACTOR'S ADMINISTRATION}

The Subcontractor agrees that will have overall technical direction of the work to be performed by the Subcontractor and that he will be available at all reasonable times in connection therewith. Any change in this assignment must have prior approval of the Contractor.

\section{ARTICLE 9 - CONTRACTOR'S ADMINISTRATION}

A.

UnTess the Subcontractor is otherwise notified in writing, the Contractor's responsibilities under this Subcontract shall be administered by the Manager, Environmental \& Waste Management Acquisitions and/or his/her authorized representative who, for the purpose of this Subcontract is John R. Braun, Subcontract Administrator.

\section{ARTICLE 10 - INDEMNITY}

The Subcontractor shall indemnify the Contractor and the Government of the United States and the officers, agents and employees of each of the foregoing and hold them harmless from and against all loss, damage, expense and Tiability resulting from injury to or death of any person and loss of or damage to property, or claims of such injury, death, loss or damage resulting from the negligent acts or omissions of the Subcontractor, his lower tier subcontractors, agents, servants or employees. The Subcontractor sha11, on request of any of the above-named indemnities, defend each party making such request in any suit asserting a claim covered by this indemnity. The Subcontractor shall pay any cost which may be incurred by any of the above-named indemnities in enforcing this indemnity.

\section{ARTICLE 11 - PATENT INDEMNITY}

The Subcontractor shall indemnify the Contractor and the Government and its officers, agents and employees against liability, including costs, for infringement of any U.S. Letters Patent (except U.S. Letters Patent issued upon an application which is now or may hereafter be kept secret or otherwise withheld from issue by order of the Government) resulting from the Subcontractor's: (i) furnishing or supplying standard parts or components which have been sold or offered for sale to the public on the commercial open market; or (ii) utilizing its normal practices or methods which normally are or have been used in providing goods and services in the commercial open market, in the performance of the subcontract; or (iii) utilizing any parts, components, practices or methods to the extent which the Subcontractor has secured indemnification from liability. The foregoing indemnity shall not 
apply unless the Subcontractor shall have been informed as soon as practicable by the Contractor or the Government of the suit or action alleging such infringement, and shall have been given such opportunity as is afforded by applicable laws, rules or regulations to participate in the defense thereof; and further, such indemnity shall not apply to a claimed infringement which is settled without the consent of the Subcontractor, unless required by final decree of a court of competent jurisdiction or to an infringement resulting from addition to or change in such supplies or components furnished or construction work performed for which addition or change was made subsequent to delivery or performance by the Subcontractor.

\section{ARTICLE 12 - STANDARD TERMS AND CONDITIONS}

EG\&G Idaho, Inc., Standard Terms and Conditions for Purchase Orders and Subcontracts (issued March 1991) apply hereto, as applicable.

\section{ARTICLE 13 - ENVIRONMENTAL, SAFETY, AND HEALTH REQUIREMENTS FOR SUBCONTRACTORS}

M\&O specific Environmenta7, Safety and Health Requirements (ES\&H) for Subcontractors, shall apply to all Task Orders issued under the subcontract for all work conducted at any M\&O facility by the Subcontractor. Upon award the successfull Subcontractors shal1 submit an Environmental, Safety and Health Plan, with their proposal, for EG\&G Energy Measurements, Inc. (EG\&G/EM) and Reynolds Electrical and Engineering Co. Inc. (REECo), for approva?.

\section{ARTICLE 14 - ACCOUNTABILITY}

EG\&G Idaho, Inc. and the Subcontractor are entering into this agreement with the understanding that DOE policy with regard to the Accountability Rules, 56 FR 280099 (June 19, 1991), is expected to be incorporated, as required, into this Subcontract. The parties agree to implement the Accountability Rule in the Subcontract, and to negotiate, in good faith, an appropriate upward or downward price adjustment as appropriate.

IN WITNESS WHEREOF, EG\&G Idaho, Inc., and the Subcontractor have caused this subcontract to be executed effective on the day and year first above written intending to be legally bound thereby.

EG\&G IDAHO, INC.

By

Title
By

\section{Title}


PROPOSAL SUBMITTAL FORM

REQUEST FOR PROPOSAL NOP.

\section{Proposing Firm's Data:}

Name:

Address:

Telephone No.:

FAX No.:

Personnel Contact:

The answers to this Enclosure 7 shall comprise the offeror's technical proposal. Failure to respond to each item herein will result in proposal disqualification. In addition, any offeror which does not respond in the affirmative to items 1 through 18 below sha17 be considered nonresponsive to the Request for Proposal.

\section{GO/NO-GO CRITERIA}

The offeror may submit comments for any of the following 18 GO/NO-GO Criteria if the comments serve to clarify the answers. Several items request additional information for clarification, as we17. Provide responses on separate pages which specify the item number shown below to which you are responding. In the event the offeror proposes to subcontract to other lower-tier Subcontractos for any portion of this work, provide this requested information, items 1-18, for both your firm and lower-tier Subcontractor on seperate sets of responses.

YES NO

1. The pricing quoted by the offeror in Attachments $2-5,7-10$, $12-15,17-20$, and $22-25$ shall be valid until subcontract awards, anticipated by August 2, 1993 . Upon awards, the successful Subcontractors prices quoted shall remain fixed for the term of the subcontract.

2. Offeror owns facilities (under common parent-company ownership) that have the capacity to provide $100 \%$ of the services specified in Attachments $1,2,6,7,11,12,16,17,21$, and 22 for a minimum of $50 \%$ of the waste codes identified in Attachment 2, 7, 12, 17, and 22 irrespective of volume, for five (5) years. 
3. If facilities not owned by the offeror are proposed, as subcontractors, to handle the remaining, less than $50 \%$ of the waste codes specified above, the offeror certifies that it and its subcontractors own facilities to provide all of the services required by Attachments 1 through 25 for $100 \%$ of the waste streams 7 isted in Attachment 2, 7, 12, 17, and 22.

\section{NOTE THE FOLLOWING:}

Brokers shall not be involved in this subcontract. A broker is defined as a firm which acts as an agent in securing the services of other firms for performing any portion of this subcontract.

No more than ten (10) facilities shall be used for waste disposal without written approval from EG\&G Idaho prior to disposal. If more than one company is involved in the offer, only one will be identified as the Subcontractor. The Subcontractor shall be responsible for administering all of the transactions of the disposal subcontract, including invoicing, and to interact solely with EG\&G M\&O's.

4. Offeror certifies that all materials shipped from EG\&G M\&O's shall be completely treated, stored and disposed of within the continental United States.

5. Offeror certifies that its pricing quoted in Attachments 2 - 5, $7-10,12-15,17-20$, and $22-25$ shal1 include Subcontractor responsibility for all testing and documentation required beyond the EG\&G M\&O's responsibilities which are defined in the attached Scopes of Work (SOWs). (See Attachments 1, 6, 11, 16, and 21.)

6. Offeror certifies that it shall evaluate waste streams for approval or denial as follows:

within 45 calendar days for EG\&G Idaho, EG\&G Mound, EG\&G RF;

within 30 calendar days for REECO; and

within 15 calendar days for EG\&G/EM

of receipt from the EG\&G M\&O of the profile data and representative sample.

Describe on a separate sheet, the process for ensuring that this condition can be met for each M\&O. 
7. Offeror specifies that it shall have the capacity and ability to handle the estimated quantities shown in Attachments 2 - 5, $7-10,12-15,17-20$, and $22-25$ within applicable federal, state, and local regulations and statutes immediately starting on date of award.

8. Offeror certifies that it shall have the ability starting August 2, 1993, to meet or exceed the Land Disposal Restriction (LDR) treatment standards found in 40 CFR 268 and have the ability to minimize waste volume.

9. Offeror certifies that it and its lower-tier Cubcontractors shall submit to pre-award and post-award on-site inspections by EG\&G Idaho, Inc. and/or its designee, and provide requested information related to the requirements of this Request for Proposal and associated documents.

10. Offeror certifies that it or its subcontractors shall accept, and has authority to accept, for treatment and/or disposal, CERCLA wastes generated from sites undergoing remediation.

Identify facilities with this approval on a separate sheet of paper.

11. Offeror certifies that the permitted facility shall accept CERCLA remediation wastes without an EPA waste code number and shall comply with the most current CERCLA Off-Site Policy.

12. Offeror certifies that it shall provide EG\&G Idaho, Inc. and M\&Os, within 20 days of violation notice, any and all DOT, environmental, OSHA, and governmental Notices of Violation received by ail of the facilities involved in providing services under the Subcontract.

13. Offeror certifies that it and its subcontractors shall provide all services identified in the attached Scopes of Work (SOW) for each of the M\&Os as follows:

EG\&G RF (Attachments 1-5)

EG\&G Mound (Attachments 6-10)

EG\&G/EM (Attachments 11-15)

REECo (Attachments 16-20)

EG\&G Idaho (Attachments 21-25)

14. Offeror certifies that it has the capability to provide trained personnel to perform 1 ab pack work at the EG\&G M\&O facilities within the scope of Attachments 4, 9, 14, 19, and 24 . 
YES NO

15. Offeror certifies that it shall provide 1 ab packing services on both a scheduled and emergency basis for each of the M\&O's within the following time periods:

$\begin{array}{lll} & \text { Scheduled } & \text { Emergency } \\ \text { EG\&G RF } & 20 \text { calendar days } & 7 \text { calendar days } \\ \text { EG\&G Mound } & 20 \text { calendar days } & 7 \text { calendar days } \\ \text { EG\&G/EM } & 14 \text { calendar days } & 5 \text { calendar days } \\ \text { REECo } & 25 \text { calendar days } & 7 \text { calendar days } \\ \text { EG\&G Idaho } & 20 \text { calendar days } & 7 \text { calendar days }\end{array}$

Describe on a separate sheet, the process for ensuring that these conditions can be met for each M\&O.

16. Offeror certifies that it shall commit to completing the approval, packing, and transportation of lab packs within the following time frames:

For EG\&G RF, EG\&G Mound, EG\&G/EM, and EG\&G Idaho: 65 days

For REECo: 50 days

of the initial request for service.

17. Offeror shall provide packing lists and list of shipping names to the EG\&G M\&O's within the following time frames:

For EG\&G RF, EG\&G Mound, EG\&G/EM, EG\&G Idaho: 21 calendar days

For REECo: 14 calendar days (or 10 working days)

of the receipt of the generator waste characterization or MSDS for lab packed wastes.

Describe on a separate sheet, the process for ensuring that this condition can be met for each M\&O.

18. Offeror certifies that it has the capability to provide gondola boxes and associated services as specified in Attachments, 5 , $10,15,20$, and 25 of the RFP.

\section{NARRATIVE RESPONSES}

Provide responses on separate pages which specify the item number shown below to which you are responding, e.g., Item 19. If you intend to subcontract to other firms any portion of this subcontract, provide the requested information for both your firm and the subcontractors in separate sets of responses for each firm. 
19. Describe programs which ensure compliance for you and each of the subcontractors with the applicable environmental, safety, and health statutes, regulations, and standards, specifically, but not limited to amended regulatory requirements promulgated under the:
a. Clean Water Act (CHA)
b. Clean Air Act (CAA)
c. Resource Conservation and Recovery Act (RCRA)
d. Superfund Amendments and Reauthorization Act (SARA)
e. Comprehensive Environmenta] Response, Compensation and Liability Act (CERCLA)
f. Toxic Substance Control Act (TSCA)
g. Occupational Safety and Health Act (OSHA), particularly 29 CFR $\S \S$ 1910.120 (Hazardous Haste Operations and Emergency Response) and 1910.1000 (Hazard Communication), and/or Mine Safety and Health Act (MSHA).

h. Hazardous Materials Transportation Act (HMTA)

i. State and 1ocal environmental, safety, and health statutes enacted in the state of residence of each facility doing business.

20. Identify all required environmental, safety, health and transportation permits or authorizations including, but not limited to, the following for you and your lower-tier Subcontractors. Be prepared to provide copies of these doucments in accordance with the requirements in Phase III, Basis for Award.

a. Environmental:

1. Environmental Protection Agency (EPA) Identification Numbers

2. Air permits, e.g., Permits to Construct, Air Quality Management District permits

3. Hater discharge permits, e.g., National Pollutant Discharge Elimination System (NPDES), Publicly Owned Treatment Horks (POTW), etc.

4. RCRA Part A and/or Part B permits (or applications if permits have not yet been approved)

PLEASE NOTE: Submittal of copies of the Part B Permit Applications will not be required for this portion of the evaluation, but may be requested during the pre-award assessment.

5. CERCLA Off-Site Policy approval

6. TSCA storage/disposat approval

7. EPA laboratory certification 


\section{Groundwater monitoring permits}

b. Safety and Health:

1. Standard Industrial Classification (SIC) code(s).

c. Transporter:

1. Interstate Commerce Commission (ICC) or Department of Transportation (DOT) registration numbers

2. EPA Identification numbers

3. Proof of Financial Responsibility (insurance)

d. Other permits required by federal, state or local agencies.

21. Describe the following methods you and the subcontractors will use in performance of this subcontract:

a. Regulatory compliance procedures

b. Method of accountability reporting for waste streams including applicable certificates; e. g., certificates of destruction and disposal, EPA biennial report, and State annual report.

c. A tracking method describing how the waste streams will be accounted $\mathrm{fl}_{\mathrm{f}}$ from the point of acceptance to the point of final disposition.

d. Laboratory quality assurance/quality control ( $Q A / Q C)$ procedures.

22. Identify the insurance policies and coverage that you and each of the subcontractors have as specified by federal, state, and local regulations. Provide copies of the certifications.

23. Provide a description of all the physical locations that you list on Attachment 2, 7, 12, 17, and 22 where treatment, storage and disposal activities will occur for this work. This description shall include the nam of the facility and its owner, shipping address, and the facility status, ie corporate headquarters, plant, subsidiary, etc.

24. Identify which portions of the subcontract you intend to subcontract to othe firms. Specify which subcontractor will perform which service described in Attachments 1 through 25 . The list shall include the subcontractor's name a owner, and the subcontractor's facility name and location to be used for thi subcontract.

25. Completely describe the abilities and methods that you and your lower-tier Subcontractors will use to perform the Scopes of Work shown in Attachments 1 through 25.

26. Provide Security and Exchange Commission (SEC) 10K reports, or income statements and balance sheets only if 10K reports are not applicable to the firm, for the previous three years for you and each of the subcontractors. the subcontractor is a subsidiary of another company, provide the SEC IOKs $f$ the parent, as well as the subsidiary. 
ENCLOSURE 07

PAGE 7 OF 8

27. Complete Page 8 of this Enclosure 7. Page 8 is a summary of your pricing quoted in Attachments $2-5,7-10,12-15,17-20$, and $22-25$. This cost summary will be used by EG\&G Idaho to determine the low offeror for the fiveyear period, and to establish the total ceiling price of the Master Task Requirements Subcontract.

Signature and Tit7e

Company

Date 


\section{PRICE SUMMARY}

TOTAL PRICES FROM

YEAR 4

YEAR 5

ATTACHMENT 2, 7 ,

12,17 , and 22

HASTE DISPOSAL

ATTACHMENT $3,8,13$,

18 , and 23

SAMPLE EVALUATION

ATTACHMENT 4, 9, 14 ,

19 , and 24

LAB PACKS

ATTACHMENT 5, 10, 15,

20 , and 25

GONDOLA BOXES AND/OR

STORAGE TANKS

GRAND TOTAL
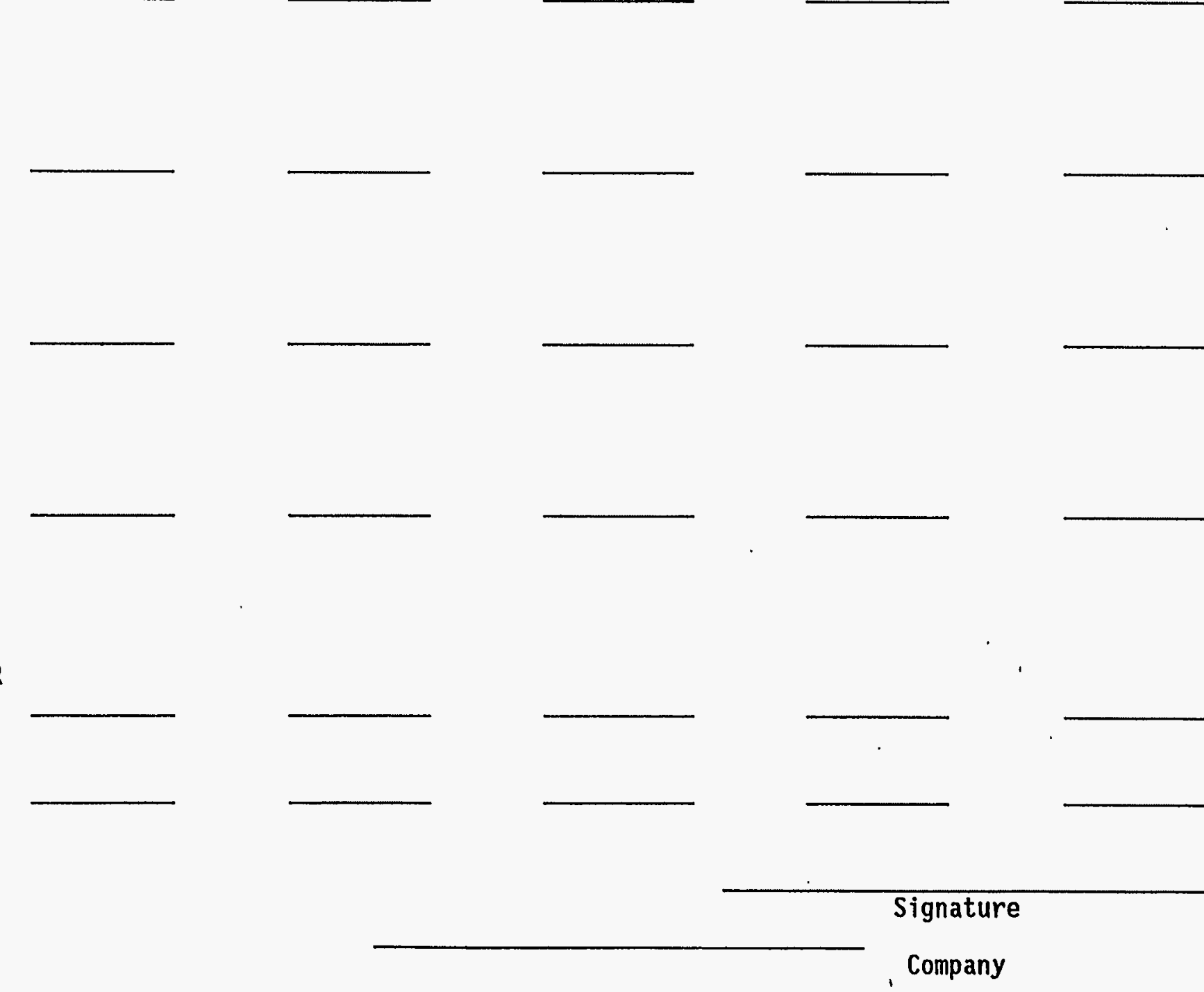


\section{Appendix C}

ESH\&Q Liability Assessment Team Training Program Contents 
C-2 


\section{Appendix C}

\section{ESH\&Q Liability Assessment Team Training Program Contents}

A copy of the Student Guide for ESH\&Q Liability Assessments for Off-Site Facilities is contained in this appendix. This was the training prepared and conducted by EG\&G Idaho which was designed to prepare experienced DOE-complex auditors as qualified assessment team members for the commercial TSDF assessments. 
C-4 


\section{STUDENT GUIDE FOR \\ ESH\&Q LIABILITY ASSESSMENTS FOR OFF-SITE FACILITIES}

January 1993 


\section{STUDENT GUIDE FOR \\ ESH\&Q LIABILITY ASSESSMENTS FOR OFF-SITE FACILITIES}

\section{OVERVIEW}

\section{OUTLINE OF ACTIVITIES}

Day 1

Introduction

Overview

Scope

Documentation--Forms \& Checklists

Day 2

Documentation--Forms and Checklists Overview of Assessment Report

Preparation for an On-Site Assessment
Day 3 .

Conduct of the On-Site Assessment Assessment Report

Day 4

Assessment Report

Post Assessment Procedures

Day 5

Audit Master ${ }^{\text {TM }}$

Wrapup 


\section{PROGRAM OF INSTRUCTION FOR ESH\&Q LIABILITY ASSESSMENTS FOR OFF-SITE FACILITIES}

TERMINAI OBJECTIVE:

ENABLING OBJECTIVES

REFERENCES: EG\&G Idaho, Inc Standard Practice (SP), "Qualification \& Certification of Environmental Oversight Audit Personnel", \#4, dated September 28, 1990.

EG\&G Idaho, Inc. SP, Environmental Oversight Program External Audit Procedure, \#6, dated March 1, 1990, Section 4.0 "Procedures for Environmental Audits and Risk Assessments of Off-Site Facilities"

Audit Master User's Guide and Reference Manual, Version 4.7, June 1992, Utilicom, Pittsford, NY. 
METHOD OF

INSTRUCTION: Lecture; Lab; Class Participation

DURATION: $\quad 40$ hours

PREREQUISITES: Personnel attending the training must have the following minimum qualifications and prerequisite skills:

1. Certified ESH\&Q auditor, lead preferable.

2. Must have conducted at least two ESH\&Q audits within the last year (on-site surveillances are acceptable).

3. Must have expertise in at least 6 "areas of expertise" shown in Table 1.

4. Must have attended a 40-hour OSHA (hazwoper) class and a current 8-hour OSHA refresher.

5. Must be respirator certified--half-face, full-face, and SCBA.

6. Must have attended hazard communication training.

7. Must know the difference between commercial ESH\&Q requirements and those specific to DOE and nuclear facilities.

8. Must own basic safety equipment--steel-toed boots or shoes and safety glasses. If wearing prescription glasses, they must have safety frames/lenses with side shields. If wearing contact lenses, safety glasses must also be worn.

9. Must be proficient in the use of WordPerfect software.

In addition to these prerequisites, attendees must bring a computer loaded with Audit Master ${ }^{\mathrm{TM}}$ to the training class. 
TABLE 1

AREAS OF EXPERTISE

\begin{tabular}{|c|c|c|}
\hline Environmental Area & Legislation & Regulations \\
\hline Air Quality & $\mathrm{CAA}$ & 40 CFR $50-52,60,61,124$ \\
\hline $\begin{array}{l}\text { Solid and Hazardous } \\
\text { Waste especially the } \\
\text { following requirements: } \\
\text { generator, interim status } \\
\text { and permitted TSDF, } \\
\text { recycling, permit } \\
\text { applications, LDR, BIF }\end{array}$ & RCRA, HSWA, CERCLA & $\begin{array}{l}40 \text { CFR 24, } 124,148,257- \\
258,260-272,280-281\end{array}$ \\
\hline $\begin{array}{l}\text { Spill Prevention and } \\
\text { Control }\end{array}$ & $\begin{array}{l}\text { CWA, RCRA, CERCLA, } \\
\text { SARA }\end{array}$ & $\begin{array}{l}40 \text { CFR 110, 112, 117, } \\
300,302\end{array}$ \\
\hline $\begin{array}{l}\text { Storage Tanks (above and } \\
\text { under ground) }\end{array}$ & RCRA, HSWA & 40 CFR $280-281$ \\
\hline Toxic Substances Control & TSCA & $\begin{array}{l}40 \text { CFR } 717,761-762,796- \\
798\end{array}$ \\
\hline Water Quality & CWA, SDWA, RCRA & $\begin{array}{l}40 \text { CFR } 110,112,116-117, \\
121-125,130-131,136, \\
141-148,260,264-265,311 \text {, } \\
400-699 \\
43 \text { CFR } 11\end{array}$ \\
\hline $\begin{array}{l}\text { Community Right-to- } \\
\text { Know/Chemical Risk }\end{array}$ & SARA II, III & $\begin{array}{l}40 \text { CFR } 302,350,355, \\
370,372,373\end{array}$ \\
\hline Remediable Actions & RCRA, CERCLA, CWA & $\begin{array}{l}40 \text { CFR 24, 300, 302, } 373 \\
43 \text { CFR } 11\end{array}$ \\
\hline $\begin{array}{l}\text { Hazardous Materials } \\
\text { Transportation }\end{array}$ & TSA & $\begin{array}{l}10 \text { CFR } 30,50,71,110 \\
49 \text { CFR 101, 171-180, 300, } \\
340,390\end{array}$ \\
\hline $\begin{array}{l}\text { Hazard Communication } \\
\text { and Hazardous Worker }\end{array}$ & OSHA & 29 CFR 1910 \\
\hline Occupational Medicine & OSHA & 29 CFR 1910 \\
\hline
\end{tabular}




\begin{tabular}{||l|l|l||}
\hline Environmental Area & Legislation & Regulations \\
\hline Quality Assurance & CWA, CAA, RCRA, & 40 CFR 50, 53, 61, 122, \\
& CERCLA, TSCA & $129,130,136,143,240-$ \\
& & $241,260-280,300,402$, \\
& & $710,717,792$ \\
& & EPA, QAMS-005-80, \\
& EPA, QAMS-001/80, \\
& & EPA-SW-846, EPQ-600/2- \\
& & $80-018$, EPA Contract Lab \\
& & Program. \\
\hline
\end{tabular}




\section{RESPONSIBILITY}

To ensure that the Department of Energy (DOE) and/or an M\&O Contractor is not put at risk by a potential subcontractor, an environmental, safety, health, and quality (ESH\&Q) and financial liability assessment must be conducted.

The Comprehensive Environmental Response and Liability Act (CERCLA) and the Superfund Amendments and Reauthorization Act (SARA) assign strict joint and severe liability to all responsible parties for release of hazardous substances to the environment. Responsible parties can include Treatment, Storage or Disposal Facility (TSDF) owners and operators, recycling facility owners and operators (recyclers), past owners and operators of TSDF's or recycling facilities, transporters, and persons contracting for disposal or recycling. Therefore, $\mathrm{M \& O}$ contractors who generate hazardous waste and contract for disposal or generate recyclable hazardous materials and contract for recycling, could be held liable for all or part of the cost of remedial cleanup if the off-site TSDF or recycler lacks the capacity to pay for clean up. It is the intent of the assessment to ensure that $\mathrm{M} \& O$ contractors dispose of hazardous waste or recyclable hazardous materials only at off-site facilities that will not create a remedial action site for which $M \& O$ contractors may be held liable.

In addition, DOE Order $5480.1 \mathrm{~B}$ requires that in the selection of contractors, the DOE facilities ensure the ability of offerors to meet ES\&H requirements. It also requires that the DOE operations assure that applicable ESH\&QA requirements are included in the contracts. 


\section{SCOPE DEFINITION}

A complete external audit of the off-site facility will consist of pre-assessment, on-site assessment, post-assessment, risk assessment, and financial evaluations. The comprehensiveness of an external assessment may be modified and adjusted by the External Liability Assessment Team Leader with concurrence from the ETS Manager. Factors that could influence the scope of the assessment include: .type of hazardous waste or hazardous material to be sent, amount of waste or material to be sent, time period under which the M\&O Contractor will be doing business with the off-site facility, etc. The scope of the assessment may also be adjusted at any point during the evaluation, based on information gathered during the procedure.

The external liability assessment will examine compliance with regulations established by:

Clean Air Act (CAA)

Clean Water Act (CWA)

Comprehensive Environmental Response

Compensation, and Liability Act (CERCLA)

Resource Conservation and Recovery Act (RCRA)

Safe Drinking Water Act (SDWA)

Superfund Amendment and Reauthorization Act (SARA)

Toxic Substances Control Act (TSCA)

Occupational Safety \& Health Act (OSHA)

Any applicable regulations established by State and local legislation.

A complete external liability assessment will include the following:

a. On-site review of the TSDF or recycling facility operation

b. Examination of facility plans and construction

c. Examination of all applicable permits.

d. Examination of facility records

e. Review of where the wastes or recyclable materials go, cradle to grave

f. U. S. Environmental Protection Agency (EPA), State, and local regulatory observations of the facility

g. Opinions of other businesses that use the facility

h. Review of other parties that take title of the waste or materials 
i. Review of transporters

j. Review of certificates of destruction or disposal

k. Review of M\&O Contractor contract for adequacy

1. Opinion of the community in which the facility is located

m. Financial condition of the facility/parent and ability to pay for cleanup and potential lawsuits. 


\section{DOCUMENTATION}

The following documentation shall be generated and/or maintained for each external liability assessment or risk analysis performed: facility file, the external liability assessment chronology log (Figure 1), the regulatory contact checklist (Figure 2), the memo of conversation (Figure 3 ) and/or memo to file (Figure 4), and the formal assessment or risk analysis report. Electronic and or hard copies of these forms will be provided with this guide.

\section{Facility Files}

A formal file must be created and maintained for each facility being evaluated. These files shall contain all correspondence, notes, completed assessment checklists, copies of permits and contracts, completed external liability assessment chronology log (Figure 1), regulatory contact checklist (Figure 2), risk assessment, external liability assessment report, and any other information that was collected and used during the facility evaluation. The contents of the files must be able to withstand a regulatory and/or quality audit.

\section{External Liability Assessment Chronology Log}

The external liability assessment chronology log is used to track activities and statuses associated with the conduct of the external environmental assessment of a potential, or active, vendor doing business with the M\&O Contractor. This form is started when a decision is made to investigate a potential vendor as part of the RFP or RFQ process. It must be kept in the facility files at all times. It is filled out as follows:

a. The PAGE _ OF _ field contains the current page number and total number of pages. The total number of pages for the log is added when the file is closed.

b. The COMPANY NAME field contains the name of the company whose activities are being tracked.

c. The DATE field contains the date the activity or status occurred. If more than one activity is entered for a date, this date need not be re-entered.

d. The empty column next to the DATE field is an action item field. When an action item is assigned, this column remains empty until the action is complete. At that time a check mark $(\mathcal{})$ is placed in the column.

e. The STATUS AND ACTION TTEMS field contains descriptions of the activities surrounding the external liability assessment of the facility in question. 
Figure 1. External Liability Assessment Chronology Log.

$\mathrm{EG \& G}$ Idaho, Inc.

Page _ of _

External Liability Assessment CHRONOLOGY LOG

Company Name

\begin{tabular}{|l|l|l||}
\hline DATE & & \\
\hline & & \\
\hline & & \\
\hline & & \\
\hline & & \\
\hline & & \\
\hline & & \\
\hline & & \\
\hline & & \\
\hline & & \\
\hline & & \\
\hline & & \\
\hline & & \\
\hline & & \\
\hline & & \\
\hline
\end{tabular}




\section{Regulatory Contact Checklist}

The regulatory contact checklist is used to ensure that each regulatory agency and the local officials are contacted about the operations of the facility in question. The matrix is completed as follows:

a. The COMPANY NAME field contains the name of the company of interest.

b. In the AGENCY column, the EPA Region number, the name of the State, County, City, and Agencies must be added. If other agencies are contacted, they must be listed on the lines below Others.

c. For each vertical column such as PERMITS, CERCLA INVOLVEMENT, etc., the date that this subject was discussed with the regulators must be entered. If the subject was not applicable, such as discussing CERCLA INVOLVEMENT with the local Chamber of Commerce, an N/A must be entered in the column.

d. The RECOMMENDATIONS/MMPRESSIONS/COMMENTS column is used to record any significant comments expressed by the authorities or the auditor. Detailed records of the conversations must still be recorded as a Memo of Conversation or Memo to File, as previously described. 
Figure 2. Regulatory Contact Checklist.

REGULATORY CONTACT CHECKLIST .

Company Name

\begin{tabular}{||l|l|l|l|l|l|l|l||}
\hline \hline Agency & $\begin{array}{l}\text { Permit } \\
\text { Status }\end{array}$ & $\begin{array}{l}\text { CERCLA } \\
\text { In- } \\
\text { volvement }\end{array}$ & $\begin{array}{l}\text { Existing } \\
\text { Contamina- } \\
\text { tion }\end{array}$ & $\begin{array}{l}\text { Compliance } \\
\text { Problems }\end{array}$ & $\begin{array}{l}\text { Inspection } \\
\text { Results }\end{array}$ & $\begin{array}{l}\text { Financial } \\
\text { Compliance }\end{array}$ & $\begin{array}{l}\text { Recommendations/Impressions } \\
\text { Comments }\end{array}$ \\
\hline $\begin{array}{l}\text { EPA Region_- } \\
\text { RCRA }\end{array}$ & & & & & & & \\
\hline $\begin{array}{l}\text { EPA Region_- } \\
\text { Air }\end{array}$ & & & & & & & \\
\hline $\begin{array}{l}\text { EPA Region_- } \\
\text { Water }\end{array}$ & & & & & & & \\
\hline $\begin{array}{l}\text { State: } \\
\text { RCRA }\end{array}$ & & & & & & & \\
\hline $\begin{array}{l}\text { State: } \\
\text { Air }\end{array}$ & & & & & & & \\
\hline $\begin{array}{l}\text { State: } \\
\text { Water }\end{array}$ & & & & & & & \\
\hline $\begin{array}{l}\text { County: } \\
\text { Agency Name:- }\end{array}$
\end{tabular}




\begin{tabular}{|c|c|c|c|c|c|c|c|}
\hline Agency & $\begin{array}{l}\text { Permit } \\
\text { Status }\end{array}$ & $\begin{array}{l}\text { CERCLA } \\
\text { ln- } \\
\text { volvement }\end{array}$ & $\begin{array}{l}\text { Existing } \\
\text { Contamina- } \\
\text { iion }\end{array}$ & $\begin{array}{l}\text { Compliance } \\
\text { Problems }\end{array}$ & $\begin{array}{l}\text { Inspection } \\
\text { Results }\end{array}$ & $\begin{array}{l}\text { Financial } \\
\text { Compliance }\end{array}$ & $\begin{array}{l}\text { Recommendations/Impressions } \\
\text { Comments }\end{array}$ \\
\hline $\begin{array}{l}\text { Better Business } \\
\text { Bureau }\end{array}$ & . & & & & & & \\
\hline \multicolumn{8}{|l|}{ Others: } \\
\hline & & & & & & & \\
\hline & & & & & & & \\
\hline & & & & & & & \\
\hline & & . & & & & & \\
\hline & & & & & & & \\
\hline & & & & & & & \\
\hline & & & & & & & \\
\hline & & . & & & & & \\
\hline
\end{tabular}




\section{Telephone Conversations}

All telephone conversations which are held regarding the facility under evaluation must be documented using a Memo of Conversation form (Figure 3) or memo to file form (Figure 4). The forms must be typed or written in black indelible ink. These memos must be kept as a record in the facility file. The Memo of Conversation Form can be used to document any conversation, although it was designed to document phone conversations. The form information on the form may be typed or hand written in indelible black ink. The form is completed as follows:

a. The PERSON CALLING identifies the person placing the call or recording the meeting.

b. The DATE field contains the month, day, and year that the phone call or meeting took place.

c. The REPRESENTING ORG. field contains the name of the organization the caller represents.

d. The TIME field contains the time, as well as noting morning or afternoon, the conversation took place.

e. The PERSON CALLED is the individual, or individuals, contacted.

f. The PHONE NUMBER field contains the phone number, including area code, of the person called.

g. The REPRESENTING CO. field contains the name of the company the person called represents.

h. The CITY field contains the name of the city in which the representing company and person called reside.

i. The SUBJECT fields contain descriptions of the subjects discussed during the phone call or meeting.

j. The DISTRIBUTION fields contain a listing of the people or files which received copies of this memo of conversation.

k. The SIGNATURE field must be signed, in black indelible ink, by the person named in the PERSON CALLING field. 
Figure 3. EG\&G Idaho Memo of Conversation Form.

EG\&G Idaho, Inc.

FORM EG\&G-561

(Rev. 05/88)

\section{MEMO OF CONVERSATION}

PERSON CALLING:

DATE:

REPRESENTING ORG:

TIME: _ AM: _ PH: -

PERSON CALLED:

PHONE NUMBER:

REPRESENTING CO:

CITY:

SUBJECT 1:

2:

3:

DISTRIBUTION a:

$b$ :

c:

d:

e:

f:

SIGNATURE: 


\section{Memo to File}

The memo to file form is used to record phone calls or meetings in more detail than can be done on the Memo of Conversation form or the external liability assessment chronology log. This form shall be used to record the pre-assessment contacts and information gathering. It may be typed or hand-written. It is filled out as follows:

a. The DATE field is the date the memo to file was generated. -The date is upper case if typed, or underlined if written.

b. The SUBJECT field describes the subject of the memo, such as External Liability Assessment OF ABC COMPANY. The subject is upper case if typed and underlined if written.

c. The FIRM CONTACTED is the company or regulatory agency contacted. This is the full mailing address and telephone number.

d. The PERSON CONTACTED is the individual, or individuals, with whom the assessor spoke.

e. The PURPOSE is an indented paragraph describing the purpose of the call or meeting.

f. The next section of the memo to file contains the record of the phone call or meeting. This information should be recorded in enough detail that it can be used as corroborating evidence.

g. SIGNATURE and DATE fields at the bottom of the form should be signed and dated the day the memo to file was completed. The signature and date must be in black indelible ink, even if the form is typed. 
Figure 4. Memo to File Form.

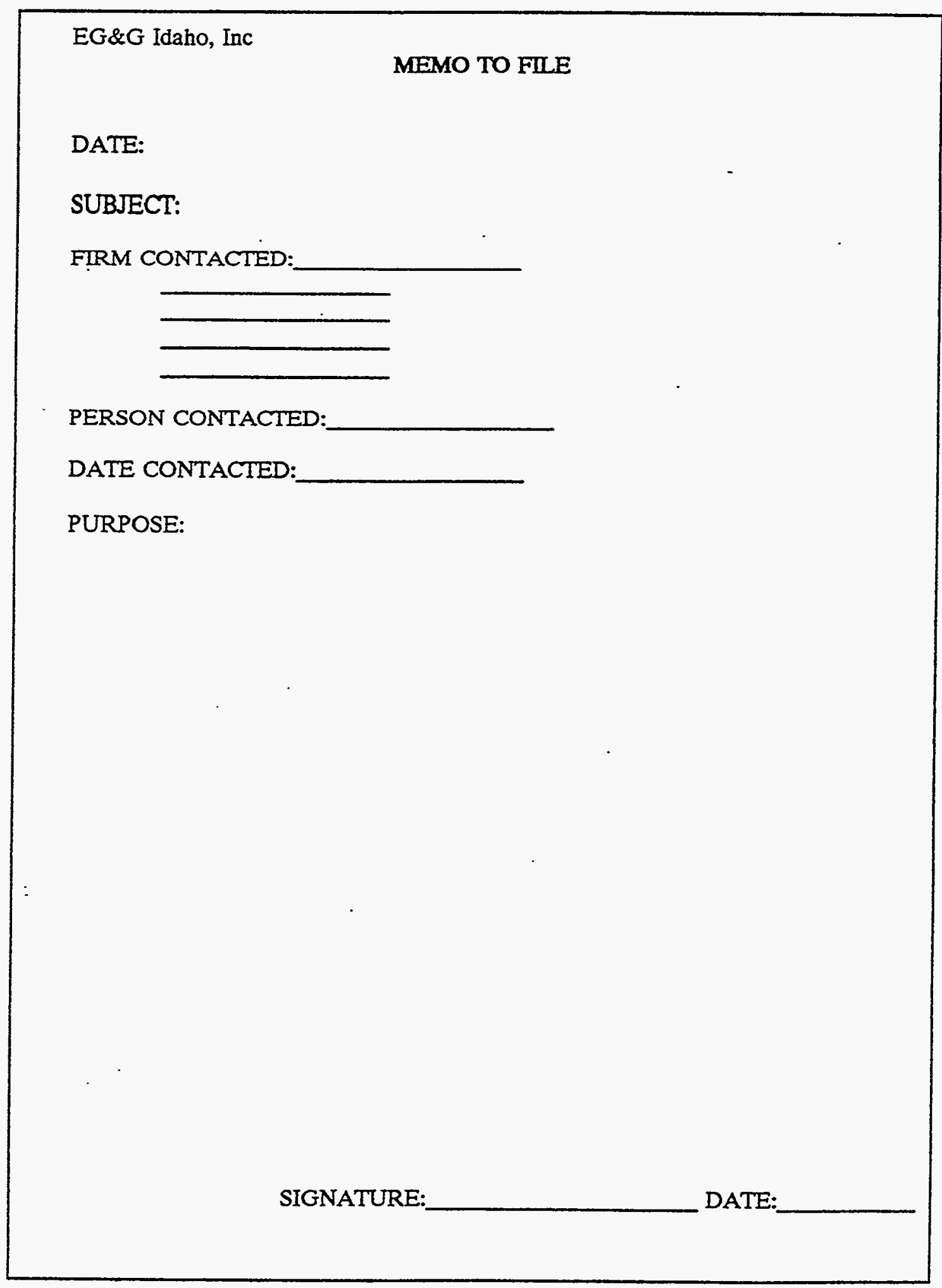




\section{RISK EVALUATION QUESTIONS}

When you are conducting a pre- or post-assessment, the following checklist of questions is helpful to determine and evaluate the potential risk and level of that risk.

\section{Regulatory}

- Do engineering design and operational controls for each on-site technology meet the letter and spirit of existing and pending regulations?

- Are management practices such as training, inspections, waste analysis, and record keeping implemented to reduce risks or just to meet regulatory paperwork requirements?

- Is the company name on the RCRA Part A or B permit application the same as the facility name, not the parent company?

- Does the RCRA Part A or B permit application clearly distinguish actual conditions from those that are planned?

- Does the facility have a pattern of permit violations, regulatory enforcement action, or pending litigation?

\section{Operations and Environmental Setting}

- Does the facility currently or historically handle large quantities of highly toxic, carcinogenic, unstable, and environmentally mobile wastes?

- Does the design and operation of the technologies used to store, treat, or dispose of the waste limit the potential for human exposure and environmental contamination?

- Does the environmental setting of the facility limit the potential for waste to travel to groundwater or surface water in the event of an engineering failure?

- Is the facility responsible for any existing environmental contamination? If yes, have remedial efforts been implemented and/or are they effective?

- Are surface and groundwater supplies used for drinking, irrigation, agriculture, and are they susceptible to contamination from the facility?

- Does a significant population exist, which can either be affected by groundwater contamination or by the consequences of a fire, spill, or explosion? 


\section{Financial}

- Does the facility have an insurance policy that meets or exceeds the minimum sudden and nonsudden insurance requirements?

- Does the closure/post-closure cost estimate represent a worst-case closure scenario?

- Are closure and corrective action financial assurance mechanisms adequately funded to cover maximum potential costs?

- Do the facility owners or its parent have adequate financial resources to rapidly respond to environmental incidents?

- Are the facility owners or parents involved at any listed or nominated Superfund sites, or other litigation that could significantly impact its ability to respond to on-site needs or problems?

- Does the facility accept hazardous wastes or recyclable hazardous materials from a large percentage of Fortune 500 companies? 


\section{PRE-ASSESSMENT REVIEW PROCEDURES}

The pre-assessment review consists of information gathering and is conducted using the telephone, mail, or electronic data base systems. The purpose of the pre-assessment review is to determine if:

a. In the case of a Treatment, Storage, or Disposal Facility (TSDF), the TSDF waste management processes are compatible with wastes generated:

b. In the case of a recycler, the materials or RCRA recyclable materials are being recycled in accordance with the regulations and the facility properly disposes of any waste it generates.

c. The facility has had serious environmental, regulatory, financial, or legal problems which can be identified using the sources described as follows.

If a complete assessment has been conducted recently and a report is available, it should be requested and evaluated before proceeding with the pre-assessment. If the report information is inadequate or unavailable, the pre-assessment should continue. The External Liability Assessment Team Lead shall make this decision with the concurrence of the Environmental Technical Support (ETS) Manager.

\section{LEXIS/NEXIS}

A LEXIS/NEXIS search should be conducted to identify any situations such as adverse publicity, criminal proceedings, and/or major environmental problems which could have a detrimental impact on any arrangements that the M\&O Contractor might make with the facility. LEXIS/NEXIS are electronic search programs that access a computer database containing information of interest primarily to the legal profession. The EG\&G Legal Department has access to this program and can perform the searches or assist the assessor with the searches.

\section{Dun and Bradstreet}

Dun and Bradstreet search should be conducted to collect the following information about a company:

Financial condition

Company rating and trends.

Net assets

Balance sheet information

Company history. 
The financial condition of the facility of interest may be collected and evaluated by the M\&O Contractor's Financial Services or Procurement Groups. Dun and Bradstreet is a financial publication which evaluates companies on an annual basis. The M\&O Contractor Technical Library and the local library do maintain subscriptions to this publication.

\section{Regulatory Contacts}

a. Regulatory contacts include, but are not limited to: the EPA, State regulators, e.g., the State water commission, and local regulators, e.g., city or county sanitation districts. A list of EPA and State regulatory agencies for RCRA, air, and water issues are provided in Figure 4.

Each regulatory agency should be contacted in order to obtain or verify the following information:
(1) Permit status
(2) CERCLA involvement
(3) Existing contamination
(4) Compliance problems
(5) Inspection results
(6) Financial compliance
(7) Recommendations

b. Written Freedom of Information Act requests may also be needed. If necessary, a charging system may have to be established in order to cover the costs of processing requests for information from the agency. These activities must be approved by the ETS Manager.

c. In addition to the regulatory agencies, the assessor should contact city and/or county officials, local fire departments, the local chamber of commerce and the Better Business Bureau in order to obtain opinions they might have concerning the conduct of operations and community opinions of the facility of interest.

\section{TSDF or Recycler Contact}

a. The TSDF or recycler should be contacted directly in order to collect the following information:

(1) Site history and CERCLA involvement

(2) Existing contamination

(3) Ownership

(4) Services and operations

(5) Waste streams, or recyclable materials, accepted and not accepted 
(6) Permit status, including RCRA, air, and water

(7) Financial information

(8) Insurance information

(9) References

(10) Other businesses that use and/or have assessed the TSDF

(11) Regulatory compliance status

(12) Assessment coordination procedures, only if a decision has been made to conduct an on-site assessment.

b. Care should be taken to ensure that knowledgeable personnel, such as compliance officers, are contacted in order to guarantee that this information is factual and accurate. Sales representatives may be used as first contacts in order to collect background information about the facility, operations, and names of additional personnel to contact. All information should be verified with cognizant personnel.

\section{Other Businesses That Use TSDF Contacts}

Contact businesses that have conducted a risk assessment or compliance evaluation of the facility. Discuss their opinions of the facility and ask to receive the results of any risk assessments or evaluations they have conducted of the TSDF or recycler.

\section{Contract Reviews}

The M\&O Contractor contract, Request for Proposal (RFP), or Request for Quotation (RFQ) with the TSDF or recycler should be reviewed for adequacy. The following points should be noted:

1. Non-assignability clause

2. Return of completed manifest before payment

3. Certificates of destruction/treatment before payment

4. Hold harmless, indemnification, contribution clauses

5. Reviewed by company attorney.

After a review of all of the above information, a determination should be made as to whether an on-site assessment is necessary or if sufficient information has been obtained in order to complete an assessment report. If a determination is made by the External Liability Assessment Team Leader, with the concurrence of the ETS Manager, or designee, that sufficient information has been acquired, a risk evaluation and assessment report shall be completed. The following pages are the instructions and format for the 
evaluation and the subsequent report. It is extremely important to become familiar with the report format and content to ensure assessment accuracy and completeness.

How to use the Audit Master ${ }^{\mathrm{TM}}$ software will be discussed later. 


\section{ON-SITE ASSESSMENT PROCEDURES}

The purpose of an on-site assessment is to examine the facility history, capabilities, operations, and general site acceptability.

\section{PREPARATION FOR AN ON-SITE ASSESSMENT}

a. Establish assessment date and assessment schedule with the TSDF contact and confirm in writing.

b. Make arrangements with TSDF contact to have the following information mailed ahead for review before the site visit. This information should also be available for on-site review:

(1). Information on site history, pre-RCRA/TSCA waste disposal

(2) Consent agreements and responses to Notices of Violations

(3) All permits and corrective action plans

(4) Surface water, air, and groundwater monitoring data for the last three years.

(5) Closure/post-closure plans, cost estimates and basis, and financial mechanism documentation

(6) Current Certificate of Insurance for Sudden and Nonsudden Incident, and a copy of policy

(7) Independently assessed financial statements for the past 3 years

(8) Involvement in any Superfund sites or related active or pending environmental litigation

(9) Information on assignees to which waste is transferred

(10) Certificates of destruction or disposal

(11) Facility construction plans

(12) Emergency/contingency plans

(13) Manifests, bills of lading, records, reports, and notices

(14) Hazardous waste minimization plan

(15) Personnel training records

(16) Land use permits or documentation

c. Determine what wastes have been shipped from your M\&O Contractor to this facility. Make copies of shipping manifest. If a large number of manifests are involved, make a random selection to be utilized during the on-site evaluation.

d. Determine whether the state or states in which the facility of interest is located have primacy in any areas of environmental protection. If the state has primacy in any area, review the implementing regulations and prepare a checklist to address compliance with these regulations. States with/without primacy can be found in $40 C F R 272$. 


\section{CONDUCT OF THE ON-SITE ASSESSMENT}

a. Checklists will be used during the conduct of the on-site assessment. These checklists must include all applicable Federal regulations and, where the State has primacy, applicable State regulations. The checklists may be prepared ahead of time, or if a computer program such as Audit Master ${ }^{\mathrm{TM}}$ is used, during the on-site inspection. If the Audit Master ${ }^{\mathrm{TM}}$ is not used, commercially available, or specially developed checklists may be used. However, these checklists must be reviewed and approved by the External Liability Assessment Team Leader before the on-site inspection.

b. Tour facility and operations in the sequence specified below utilizing checklists for the specific type of facility:
(1). Waste arrival
(2) Waste storage
(3) Waste analysis and verification procedures
(4) Manifest verification
(5) Inspection of each unit
(6) Residues management
(7) Transportation into and out of facility

c. Interview facility representatives to assess managements understanding of the facility, regulations, and company's risk assessment procedures. Management to be interviewed include the laboratory manager, facility manager, and environmental coordinator.

d. Review the RCRA Part A or B permit application, air emissions permits, water permits, and any other permit required by the State and local regulatory agencies and compare requirements to conditions observed during the tour.

e. Review the following:

(1) Consent Order Agreements and responses to notices of Violation

(2) Monitoring data for the last 3 years

(3) Closure/post-closure plans and provisions for complying with financial requirements for closure/post-closure

(4) Copy of Insurance for Sudden and Nonsudden incidents and general liability provisions

(5) Financial assessments for the last 3 years

(6) Documentation of involvement in any Superfund sites or related activities or pending environmental litigation

(7) Facility construction plans 
(8) Other assignees to which the waste is transferred, final disposition of waste, and certificates of disposal or destruction documents

(9) Emergency/contingency plans

(10) Manifests, Bills of Lading, records, reports, and notices

(11) Plans for hazardous waste minimization and statement on manifests

(12) Personnel training records

(13) Land use permits or documentation

(14) Inspection records, including storage areas, loading and unloading areas, and equipment.

f. Evaluate their tracking system. This can be done by following the processing on one of the M\&O Contractor shipments through from arrival to final disposition. Check all internal records. 


\section{ASSESSMENT REPORT CONTENTS AND ORGANIZATION}

The external liability assessment and risk assessment reports shall be prepared. All information gathered during the assessment should be consulted and compiled. The report shall conform to EG\&G Idaho documentation standards. The following outline should be used for the organizational structure of the report:

1. Introduction
a. Purpose of assessment/facility assessed.
b. Name and affiliation of assessor.
c. Date of assessment.

2. Facility/Hazardous Waste Operation Identification
a. Facility name and location.
b. Name and address of facility owner.
c. Facility RCRA identification number.
d. Facility type (brief description of the operation).

3. Background and History
a. Site history and ownership.
b. Current and past use by the generator.
c. Current and historical methods for residue disposal.

4. Description of the Assessment
a. Operations toured.
b. Facility personnel contacted.
c. Regulatory agencies contacted.
d. Other.

5. Facility Setting
a. Pathway analysis - Groundwater.
b. Pathway analysis - Surface water.
c. Pathway analysis - Air.
d. Receptor analysis - Populations and environments at risk. 
6. Technical Data and Analysis

a. Site description.

b. Wastes description - Analytical requirements, types, quantities, sources.

c. Wastes management - Technical adequacy of operational units.

d. Regulatory compliance/violations history - Observed and reported.

e. Environmental incidents - Observed and reported.

f. Facility management attitudes - Training, record keeping, preparedness and prevention, monitoring programs, and occupational safety.

7. Financial Strength

a. Insurance.

b. Closure and post-closure care.

c. Financial assurance.

d. History and experience of owners.

e. Capacity of the company.

f. Capital.

g. Current financial condition.

8. Risk Assessment and Summary of Pertinent Information

a. Public health risks.

b. Environmental risks.

c. Financial risk.

d. Summary of other risks-related information: violations history, pending litigation, environmental incidents, and management attitudes.

e.- Rating of facility, based on risks and comparison to other similar operations.

The following pages contain examples of the title page and table of contents for the external liability assessment and risk assessment report. 
EGG-ESQ-

Month year

INFORMAL REPORT

ES\&H LIABILITY ASSESSMENT REPORT

OF

FACILITY NAME

CITY, STATE

AUTHORS 


\section{ES\&H LIABILITY ASSESSMENT REPORT}

OF

FACILITY NAME

CITY, STATE

Authors, Company Affiliations

Publ ished 199

EG\&G Idaho, Inc.

Idaho Falls, ID 83415

Prepared for the

U. S. Department of Energy

Idaho Operations office

Under DOE Contract No. DE-ACO7-76ID01570 


\section{CONTENTS}

1. INTRODUCTION

1.1. Purpose.

1.2. Scope.:.

1.3. Content

1.4. Disclaimer

2. FACILITY/HAZARDOUS WASTE OPERATION IDENTIFICATION

2.1. Facil ity Name and Location.

2.2. Name and Address of the Facility Owner

2.3. Facility Identification Number.

2.4. Facility Type.

3. BACKGROUND AND HISTORY.

3.1. Site History and Ownership.

3.2. Current and Past Use by the Generator.

3.3. Current and Historical Methods for Residue Disposal..........

4. DESCRIPTION OF THE ASSESSMENT.

4.1. Operations Toured.

4.1.1. Treatment Facilities.

4.1.2. Storage Facilities.

4.1.3. Disposal Facilities.

4.1.4. Laboratory Facilities.

4.1.5. Transportation Facilities.

4.2. Facility Personnel Contacted.

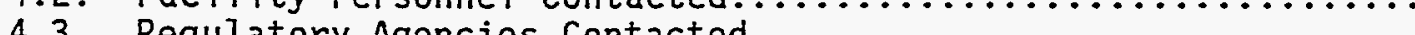

4.3.1. Region \# EPA.

4.3.2. State of +++ .

4.3.3. ++ County.

4.4.4. Other Agencies.

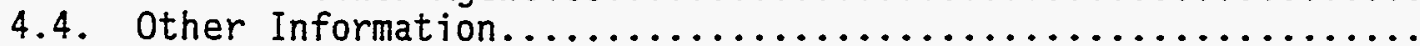

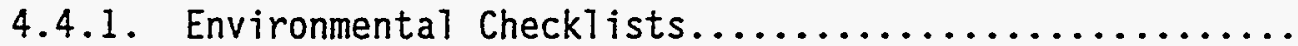

4.4.2. Document Review...

4.4.3. Permits.

4.4.4. Site Inspection.

5. FACILITY SETTING.

5.1. Pathway Analysis - Groundwater

5.1.1. Background.

5.1.2. Facility Location and Analysis.

5.2. Pathway Analysis - Surface Water...

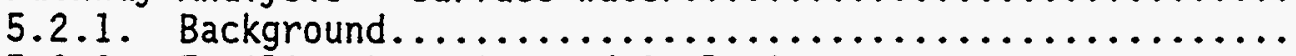

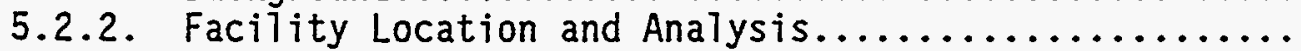

5.3. Pathway Analysis - Air

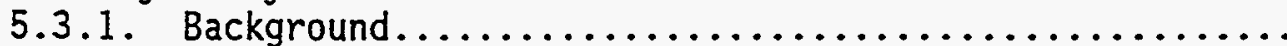

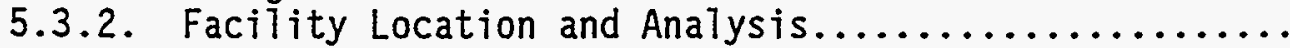

5.4. Receptor Analysis - Populations and Environments at Risk.....

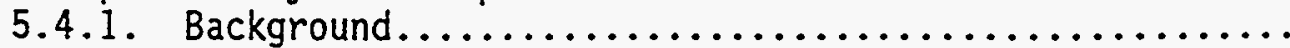

5.4.2. Facility Location and Analysis 
6. TECHNICAL DATA AND ANALYSIS.

6.1. Site Description.

General Operations.

6.1.2. Treatment Facilities.

6.1.3: Storage Facilities.

6.1.4. Disposal Facilities.

6.1.5. Laboratory Facilties.

6.1.6. Security.

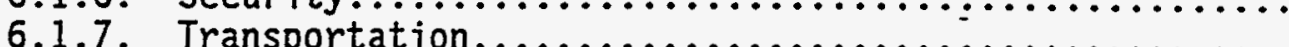

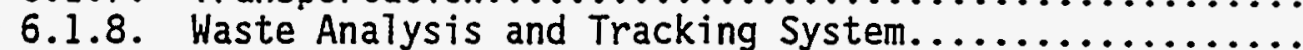

6.2. Waste Description..................................

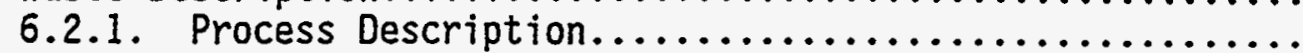

6.2.2. INEL Observations/Impressions...................

6.3. Waste Management....................................

6.3.1. Process Description.

6.3.2. INEL Observations/Impressions.

6.4. ReguTatory Compliance/Violations History

6.4.1. Violations History....

6.4.2. INEL Observations/Impressions.

6.4.3. RCRA Remediation/Corrective Actions.

6.4.4. CERCLA Remediation/Corrective Actions.

6.6.5. Pending Litigation...

6.6.6. Involvement in "Superfund" Sites.

6.5. Environmenta] Incidents...

6.6.1. Summary of Incidents

6.6.2. INEL Observatidents.............................

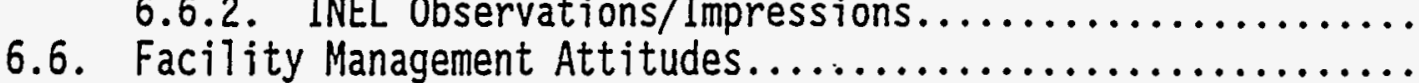

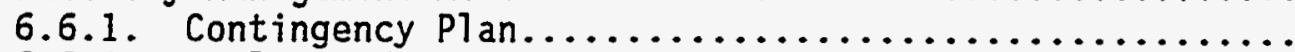

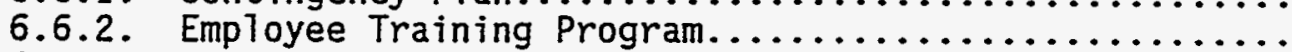

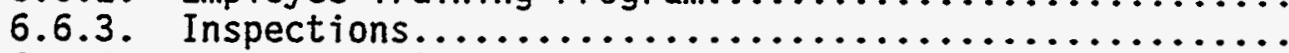

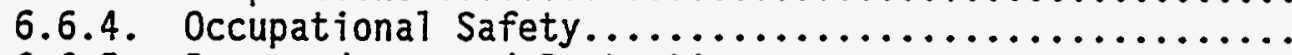

6.6.5. Preparedness and Prevention...

6.7. Document Review.

6.7.1. RCRA Part A/B Permit Application..

6.7.2. RCRA Part B Permit.

6.7.3. Annua7 Hazardous Waste/Bienniaj Report

6.7.4. Closure/Post-Closure Plan.

6.7.5. Emergency Response/Contingency Plan...

6.7.6. Facility Construction Plan

6.7.7. Hazardous Haste Manifests...

6.7.8. Operations Record.

6.7.9. SARA Reports.

6.7 .10 . Sample Analys is Plan.

6.7.11. Waste Analysis Plan.

6.7.12. Waste Minimization Plan.

6.7.13. Groundwater Monitoring P1 an.

6.7.14. Wastewater Monitoring Reports

6.7.15. TSCA Storage/Disposal Approvai

6.7.16. CERCLA Off-Site Policy Approval. 
6.8. Environmental Monitoring Programs...

6.8.1. Air Monitoring.

6.8.2. Groundwater Monitoring.

7. FINANCIAL STRENGTH.

7.1. Insurance.

7.2. Closure and Post-Closure Care.

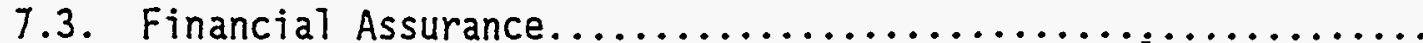

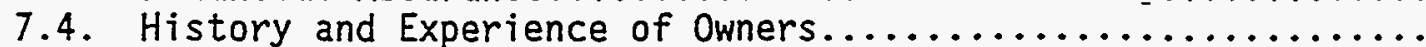

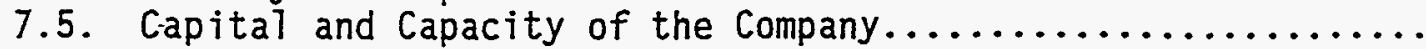

8. RISK ASSESSMENT AND SUMMARY OF PERTINENT INFORMATION..............

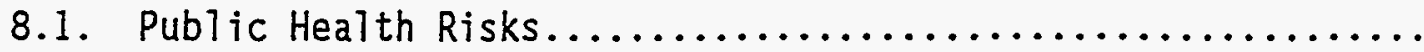

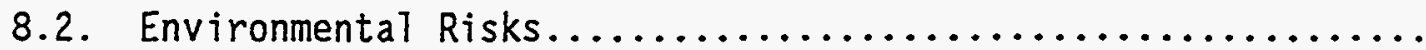

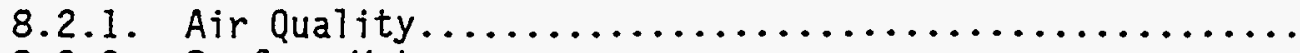

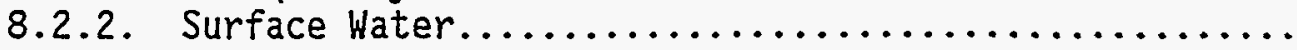

8.2.3. Groundwater.

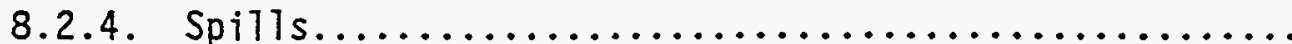

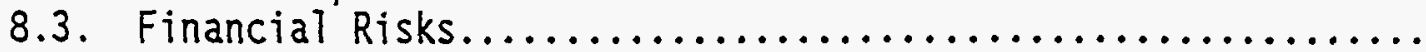

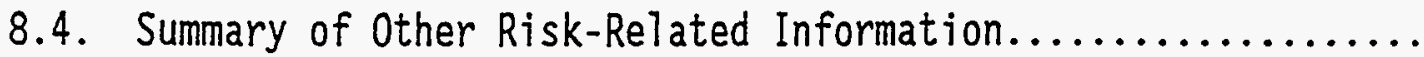

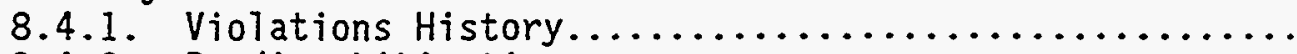

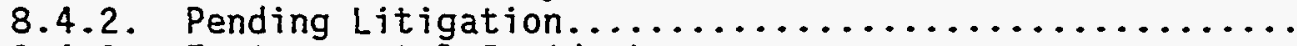

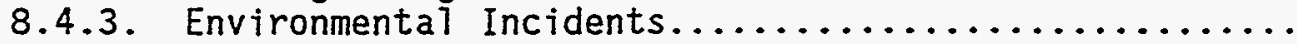

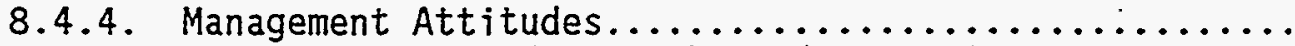

8.5. Rating of Facility, Based on Risks and Comparison to Other

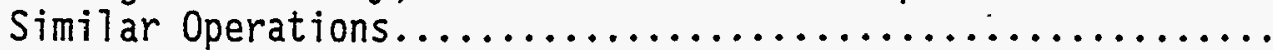

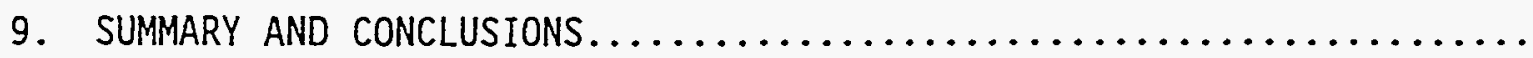

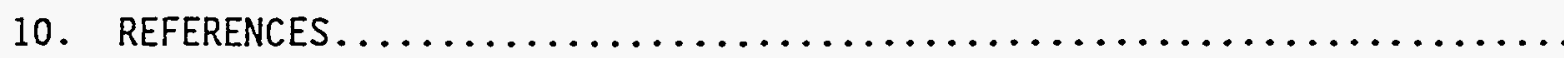

FIGURES

1. Facility location map.

2. — Facility Site PTan...

\section{TABLES}

1. Liability Assessment Participants...........................

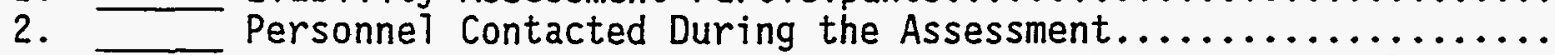

3. Documents and Information Reviewed Concerning the Facility....

\section{APPENDICES}

A. Abbreviations and Acronyms... 


\section{POST-ASSESSMENT PROCEDURES}

1. Prepare a TSDF Risk Evaluation described earlier in this guide.

2. Prepare an assessment report using format described earlier in this guide.

3. Ensure that the facility file is complete. 


\section{REFERENCE MATERIAL}

Additional reference material is provided for your convenience. EG\&G Idaho, Inc. will also provide electronic copy of the forms and boilerplate report.

The remainder of the training will utilize the Audit Master ${ }^{\mathrm{TM}}$ User's Guide and Reference Manual. 


\section{Appendix D}

ESH\&Q and Financial Liability Assessment Report Contents 
D-2 


\section{Appendix D}

\section{ESH\&Q and Financial Liability Assessment Report Contents}

This section contains a copy of the ESH\&Q and Financial Liability Assessment Report boiler plate used for the consolidated liability assessment reports. Each assessment team participant received a copy of the boiler plate and was instructed to insert their impressions/observations, regulatory contact observations, and processes information into the form. Process descriptions were generally reproduced verbatim from TSDF documents. If a state had not adopted the federal statutory regulations by reference, the state regulatory citations were inserted along with the federal regulatory citations. Sections were added to, commented out, or deleted from the report format depending upon the nature of the TSDF being assessed. 
EGG-ESQ-

\title{
ESH\&Q Liability Assessment Report of Facility Name, City, State-
}

\author{
N. J. Fix \\ E. H. Baker" \\ J. A. Ciuccib \\ R. J. Kieffer ${ }^{c}$ \\ R. J. Molter ${ }^{b}$ \\ D. E. Trump ${ }^{d}$ \\ G. D. Whitea
}

Published _ 1994

\section{Idaho National Engineering Laboratory \\ EG\&G Idaho, Inc. \\ Idaho Falls, Idaho 83415}

\author{
Prepared for the \\ U.S. Department of Energy \\ Under Contract Nos. DE-AC07-76ID01570 \\ DE-AC34-90RS62349, DE-AC08-89NV10630, DE-AC08-93NV11265, \\ and DE-AC04-88DP43495
}

a. EG\&G Energy Measurements, Inc., Las Vegas, NV 89125

b. EG\&G Rocky Flats, Inc., Golden, CO 80402

c. EG\&G Mound Applied Technologies, Inc., Miamisburg, OH 45343

d. Reynolds Electrical and Engineering Company, Inc., Las Vegas, NV 89193 
ABSTRACT 
CONTENTS

\section{FIGURES}

TABLES 


\section{ESH\&Q Liability Assessment Report of Facility Name, City, State}

\section{INTRODUCTION}

\subsection{Purpose}

The Comprehensive Environmental Response, Compensation, and Liability Act (CERCLA) and the Superfund Amendments and Reauthorization Act (SARA) assign joint and several liability to all responsible parties for releases of hazardous substances into the environment. Responsible parties can include treatment, storage, and disposal facility (TSDF) owners and operators, past owners and operators, transporters, and persons contracting or arranging for disposal. Therefore, the United States Department of Energy (DOE) and its Management and Operating (M\&O) contractors which generate and contract for the disposal of hazardous waste could be liable for all or part of the cost of remedial clean up if the offsite TSDF lacks the capacity to pay for clean up. In order to reduce the potential liability inherent in dealing with an offsite contractor, which is not under the direct control of a DOE M\&O contractor, EG\&G Idaho, Inc. (EG\&G Idaho) has set up an environmental, safety, health, and quality (ESH\&Q) liability assessment program with the purpose of evaluating potential and current offsite contractors with respect to environmental compliance. This program has been adopted by EG\&G, Inc. (EG\&G) DOE Services corporate division for its other DOE M\&O contracts. It is believed that this evaluation process will provide a clearer picture of the risks associated with a contractor which will aid the EG\&G M\&O contractors in making the best decisions with regard to selection of an offsite contractor.

This report describes the results of the 1993 ESH\&Q liability assessment of , a permitted Resource Conservation and Recovery Act (RCRA) and Tocix Substances Control Act (TSCA) TSDF located in - This assessment was conducted as part of the evaluation process for the EG\&G Idaho request for proposal (RFP) to transport, treat, recycle, and/or dispose of hazardous waste.

: has not, as yet, been used by the EG\&G M\&O contractors for hazardous waste treatment and/or disposal. The company was listed as a subcontractor by one of the vendors who submitted proposals in response to an RFP (No. C93-170250/C93-170251) issued by EG\&G Idaho for this purpose.

\subsection{Scope}

An ESH\&Q and financial liability assessment was conducted of the facility. The liability assessment consisted of pre-assessment, on-site inspection, post-assessment, financial evaluations, a risk assessment of the facilities, and this report. The liability assessment process uses observations of the facility at a single point in time. Based on these observations, the probability of future environmental problems is projected. In addition, the risk of DOE or EG\&G M\&O contractor liability, should a problem occur is included in the risk assessment. The liability assessment is not intended to evaluate whether a facility is, or is not, in actual compliance with environmental, safety, and/or health laws or regulations.

The ESH\&Q liability assessment examined compliance with regulations promulgated by the Clean Air Act (CAA), Clean Water Act (CWA), Comprehensive Environmental Response, Compensation, and 
Liability Act (CERCLA), Hazardous Materials Transportation Act (HMTA), Hazardous and Solid Waste Act (HSWA), Mine Safety and Health Act (MSHA), Occupational Safety and Health Act (OSHA), Resource Conservation and Recovery Act (RCRA), Safe Drinking Water Act (SDWA), Superfund Amendment and Reauthorization Act (SARA), Toxic Substances Control Act (TSCA), Nuclear Regulatory Commission (NRC) requirements, and applicable regulations promulgated by the State of and local legislation.

The ESH\&Q and financial liability assessment included the following:

- On-site review of the RCRA and PCB TSD facilities operations,

- Examination of facility plans and construction,

- Examination of all applicable permits,

- Examination of facility records,

- Review of where the waste materials went, cradle to grave,

- United States Environmental Protection Agency (EPA), State of , and local County) regulatory observations of the facilities,

- Opinions of other businesses that use the facilities,

- Review of other parties that take title of the waste or materials,

- Review of transporters,

- Review of certificates of destruction or disposal,

- Review of the EG\&G contract for adequacy,

- Opinion of the communities near which the facilities are located, and

- Financial condition of the facilities/parent and ability to pay for potential cleanup and lawsuits.

The ESH\&Q liability assessment was conducted as part of the environmental oversight function of the EG\&G Idaho Environmental Technical Support Unit (ETS) to support the Department of Energy Idaho Operations Office (DOE-ID). The on-site portion of the assessment was conducted on 1993. On-site evaluation assistance was also provided by EG\&G Energy Measurements, Inc.; EG\&G - Rocky Flats,Inc.; EG\&G - Mound Applied Technologies, Inc.; and Reynolds Electrical and Engineering Company, Inc., a wholly owned EG\&G subsidiary. Table 1 lists the participants and their affiliations. Funding support was provided by the U. S. DOE contracts DE-AC07-76ID01570, DE-AC34-90RS62349, DE-AC08-89NV10630, DE-AC08-93NV11265, and DE-AC04-88DP43495. 
Table 1. EG\&G liability assessment participants at

\begin{tabular}{||c|c|}
\hline Name of participant & Company affiliation \\
\hline & \\
\hline & \\
\hline & \\
\hline & \\
\hline
\end{tabular}

\subsection{Content}

Section 1 contains the introduction and a description of the scope of this report. Section 2 identifies the facilities. Section 3 contains the background and history of the site operations. Section 4 describes the scope of the assessment. Section 5 presents pathway analyses of potential air and water contamination. Section 6 provides detailed analyses of data obtained for the assessment. Section 7 contains a financial analysis of , including information about insurance coverage and closure care estimates. Section 8 summarizes the risks associated with - Section 9 contains the summary and conclusions of the report. Section 10 contains a list of references used in this report. Appendix A contains a list of abbreviations and acronyms used in this report. Appendix B contains a summary of regulatory violations. Appendix C presents 's responses to this assessment.

The format of this report is designed to standardize data and observations required for a liability assessment of a TSDF. Regulatory citations will include both RCRA permitted and interim status requirements. In the case of the safety and health requirements, both the OSHA and MSHA regulations will be cited. The dual citation is due to the fact that cement kiln operations are regulated by MSHA rather than OSHA. However, the OSHA requirements are applicable for hazardous waste operations. OSHA is cited for consistency, and where applicable, the appropriate MSHA requirements will be cited.

\subsection{Disclaimer}

The conclusions and recommendations contained in this report are based on facility background information, evaluations of information and documents from regulatory authority files and interviews with regulatory agencies and facility personnel, and an inspection of the facility all of which occurred during the period of , 1994. The report represents a snap shot in time of the operations of the _ _ facility. The purpose of this report was to identify potential ESH\&Q and financial risks associated with the prospect of the EG\&G operated DOE facilities using the facility for the (treatment, storage, disposal, recycling, transportation, bulking) of hazardous wastes. Nothing in this report should be construed to be a statement on TEK's actual compliance or lack of compliance with any law, regulation, or requirement. 
This page intentionally left blank 


\section{FACILITY/HAZARDOUS WASTE OPERATION IDENTIFICATION}

\subsection{Facility Name and Location}

Facility name and location, street address, phone number, and mailing address, if different. Include legal description, e.g., township, range, etc.

The ___ Facility encompasses approximately _ acres located The facility is bordered

The name and mailing address of the facility is:

Company name

Address

Phone number

The physical address of the facility is:

Company name

Address

Phone number

The ___ Facility consists of _ tracts of land which are described by metes and bounds. The legal descriptions are as follows:

\subsection{Name and Location of Facility Owner}

Name and location of the parent, or subsidiary company that owns the facility under review. Include street address and mailing address, if different.

The Facility is owned by which has its corporate headquarters located at:

Company name

Address

Phone number

\subsection{Facility Identification Number}

All permit numbers and identification numbers. Add additional identification sources and numbers if needed.

The ___ Facility has the following identification and permit numbers:

EPA Identification Number:

Part A Permit:

Part B Permit:

NPDES Permit: 
Publicly Owned Treatment Works:

Radioactive Materials License:

Air Pollution Control Agency:

CERCLA off-site waste approval:

Commercial PCB Storage Permit:

Conditional Use Permit:

Wastewater Discharge Permit:

Standard Industrial Classification Code:

\subsection{Facility Type}

Brief description of type of facility and operations. 


\section{BACKGROUND AND HISTORY}

\subsection{Site History and Ownership}

Detailed history of the actual site, including previous uses, e.g., agricultural, refinery, etc. Detailed ownership: who owned and when. How ownerships changed.

\subsection{Current and Past Use by the Generator}

How did the Generator, e.g., BEI, RES(TX), use the facility in the past, how are they using it now.

\subsection{Current and Historical Methods for Residue Disposal}

How did the generator dispose of residuals in the past, what are they doing with it now, e.g., RES(TX) on site landfills for incinerator ash. 
This page intentionally left blank 


\section{DESCRIPTION OF THE ASSESSMENT}

The liability assessment consisted of a preliminary written request for ESH\&Q information about the company and its facilities, discussions with the appropriate regulatory and municipal agencies, and database searches for financial and legal information. After these activities were complete and deemed acceptable, arrangements were made with the management at operations, and discuss the activities in detail. to visit the facility, tour the

The following subsections briefly describe the preliminary assessment and on-site inspection. Detailed descriptions of the operations can be found in Section 6 of this document.

\subsection{Operations Toured}

Briefly describe the types of operations under each of the subsections. Note: Definitions of treatment, storage, and disposal are RCRA/TSCA definitions. Therefore, check your processes, e.g., incineration is treatment.

\subsubsection{Treatment Facilities}

\subsubsection{Storage Facilities}

\subsubsection{Disposal Facilities}

\subsubsection{Laboratory Facilities}

\subsubsection{Transportation Facilities}

\subsection{Facility Personnel Contacted}

The personnel listed in Table 2 were contacted during the onsite inspection of the facility.

Table 2. personnel interviewed by the EG\&G Assessment Team.

\begin{tabular}{||c|c|}
\hline Name & Position \\
\hline & \\
\hline & \\
\hline & \\
\hline & \\
\hline & \\
\hline & \\
\hline
\end{tabular}




\subsection{Regulatory Agencies Contacted}

Summarize the observations received from discussing the facility's operations and compliance status with the regulatory agencies. Add sections as necessary.

4.3.1 U. S. EPA, Region

4.3.1.1 Air and Toxics Division.

4.3.1.1.1 Air Branch-

4.3.1.1.2 Toxics/Pesticides Branch-

4.3.1.2 Environmental Services Division.

4.3. 1.2.1 Emergency Planning and Response Branch-

4.3.1.2.2 Environmental Monitoring/Compliance Branch-

4.3.1.3 Waste Management Division.

4.3.1.3.1 Program Support Branch-

4.3.1.3.2 RCRA Branch-

4.3. 1.3.3 Superfund Branch-

4.3.1.4 Water Management Division.

4.3. 1.4.1 Drinking Water Branch-

4.3. 1.4.2 Groundwater Protection-

4.3.1.4.3 Water Compliance Branch-

4.3. 1.4.4 Criminal Investigation Division-

4.3.2 State of

4.3.2.1 Emergency Response Commission.

4.3.2.2 Health and Environment Department.

4.3.2.2.1 Air Quality/Radiation Division-

4.3.2.2.2 Environmental Division- 


\section{3:2.2.3 Water Bureau-}

\subsection{UST/LUST-}

\subsubsection{Industrial Commission.}

\subsection{3_ County}

\subsubsection{Other Agencies}

\subsubsection{1_Better Business Bureau.}

\subsubsection{2 _ Chamber of Commerce.}

\section{4:3.4.3 __ Fire Department.}

\subsubsection{4___ Publicly Owned Treatment Works.}

\subsection{Other Information}

\subsubsection{Environmental Checklists}

Environmental audit checklists were used for part of the facility appraisal. These checklists tested compliance with regulations promulgated by the U. S. EPA. The checklists used were generated by the Audit Master $^{\mathrm{TX}}$ environmental audit checklist, which is a commercially available computer software program that generates facility specific audit checklists. (See Section 10 for references.) The Audit Master $^{\text {Th }}$ checklists concerning solid and hazardous waste (RCRA, HSWA, CERCLA), water quality (CWA, SDWA), air quality (CAA), and EPCRA [Emergency Planning and Community Right-to-Know Act] (SARA II, III), Industrial Hygiene, Hazardous Materials Transportation (HMTA), Occupational Medicine, Personnel Safety (OSHA), PCB management (TSCA), storage tank programs (RCRA, HSWA), and spill prevention (CWA, RCRA, SARA, CERCLA) were generated on site during the interviews with facility representatives. These checklists are kept as part of the assessment record. Additional checklists were used to address quality assurance and remedial actions.

\subsubsection{Document Review}

The documents and information listed in Table 3 were reviewed before and/or during the site inspection and at the facility.

\subsubsection{Permits}

Briefly describe whether or not had permits, and what the status is on each. What are the permit conditions. If not applicable, state this. If there are more permits that those listed. Add sections. Compliance with permit conditions occurs in Section 6. 
Table 3. Documents and information reviewed concerning the

Facility.

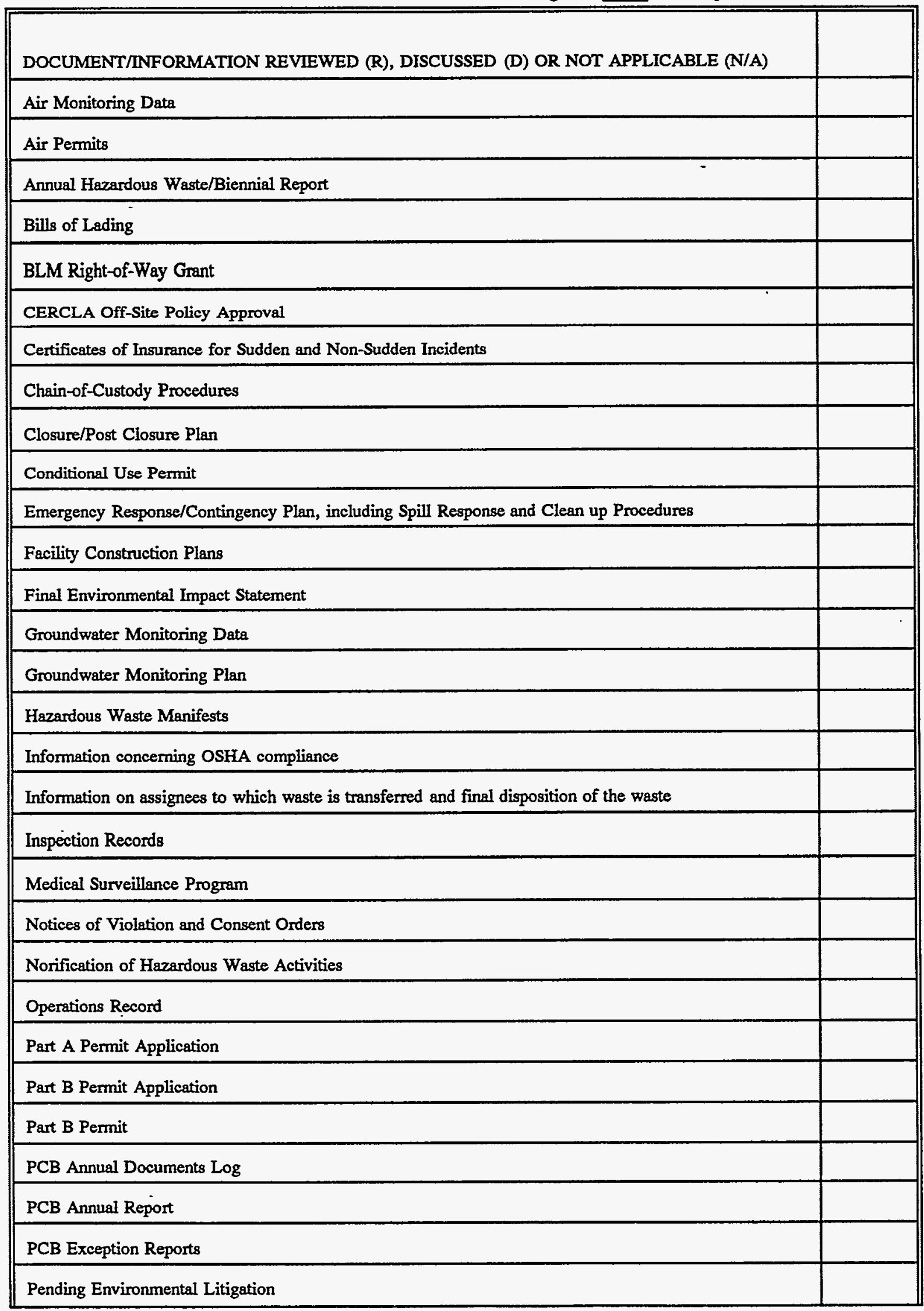




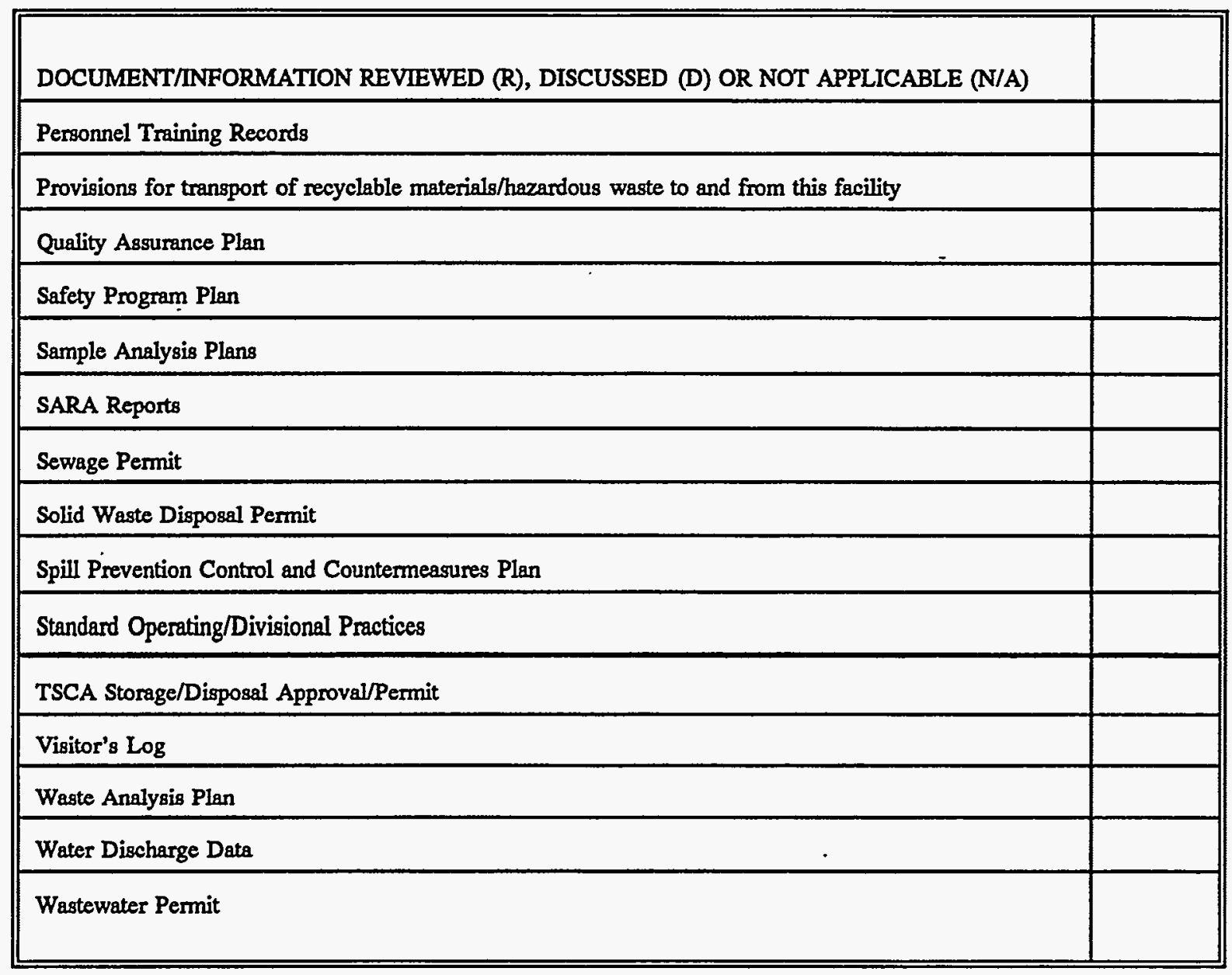

\subsubsection{RCRA Part A/B Permit.}

\subsubsection{TSCA Storage/Disposal Approval.}

\subsubsection{Conditional Use Permit.}

\subsubsection{BLM Right-of-Way Grant.}

\subsubsection{Air Permit.}

\subsubsection{Groundwater Monitoring Permit.}

\subsubsection{Wastewater Permit.}

\subsubsection{CERCLA Off-Site Policy Approval.}

\subsubsection{Radioactive Materials License.}

\subsubsection{Solid Waste Disposal Permit.}




\subsubsection{Site Inspection}

The EG\&G Assessment Team conducted a site inspection of the Facilities. The purpose of the inspection was to observe and compare the operations of the facilities with their documentation and permit conditions. The site inspection consisted of documentation reviews, process flows, and operational observations. Photographs were taken of various operations. Copies of relevant photographs are included in this report. All of the photographs are kept as part of the assessment record. 


\section{FACILITY SETTING}

The following sections contain pathway analyses of potential groundwater, surface water, and air contamination, and a receptor analysis of potential populations and environments that could be at risk from activities conducted at the facility. The purpose of a pathway analysis is to determine potential paths that pollutants could take which would significantly degrade the quality of a natural resource. The receptor analysis uses information from the pathway analysis and determines the potential risk to neighboring populations from a release of pollutants at the facility in question.

Sources of information for this section include: RCRA Facility Investigations, Corrective Action Plans, Groundwater and Air monitoring plans.

\subsection{Pathway Analysis - Groundwater}

\subsubsection{Background}

Describe geology, hydrology, geomorphology, topography of the area. Information can be obtained from general facility standards in Part B application and RFI's.

\subsubsection{Facility Location and Analysis}

Describe the facility's location with respect to background information. Analyze the data with respect to potential for contamination.

\subsection{Pathway Analysis - Surface Water}

\subsubsection{Background}

Describe geomorphology, topography, climatology (rainfall, storm patterns).

\subsubsection{Facility Location and Analysis}

Describe the facility's location with respect to background information. Analyze the data with respect to potential for contamination.

\subsection{Pathway Analysis - Air}

\subsubsection{Background}

Describe climatology (wind patterns, storm tracks). Add wind rose.

\subsubsection{Facility Location and Analysis}

Describe the facility's location with respect to background information. Analyze the data with respect to potential for contamination. 


\subsection{Receptor Analysis - Populations and Environments at Risk}

\subsubsection{Background}

Describe sensitive environments, including wildlife refuges, schools, residential areas, etc.

\subsubsection{Facility Location and Analysis}

Describe the facility's location with respect to background information. Analyze the data with respect to potential for contamination and/or environmental damage. 


\section{TECHNICAL DATA AND ANALYSIS}

This section describes the facilities inspected and documents reviewed in detail. The facility processes and documents were evaluated against regulatory requirements and RCRA Part B permit conditions. For this inspection the Federal regulations, particularly 40 CFR $\S \S 262,264$ and 265, were used in lieu of the State of Solid and Hazardous Waste regulations. The State of regulations are very nearly the same as the Federal regulations, except that the State is-more stringent with respect to - The State regulators stated that using the Federal regulations was a valid comparison for this type of assessment. However, the state regulations have been cited for completeness in the report.

The process descriptions in this section were reproduced verbatim from the facility's RCRA Part B Permit Application and RCRA/HSWA Part B Permit.

\subsection{Site Description}

\subsubsection{General Operations}

Describe in great detail. Definitions are RCRA/TSCA regulatory. Described the processesfor each and your impressions based on what you saw, what you read. Add subsections for treatment, storage, etc. as necessary. For example, add a subsection for each type of treatment, if one does not already exist. Write not applicable for those section which are not present, e.g., landfill cells. Separate TSCA from RCRA descriptions.

\subsubsection{Treatment Facilities}

Treatment, as defined by RCRA means any method, technique, or process, including neutralization, designed to change the physical, chemical, or biological character or composition of any hazardous waste so as to neutralize such waste, or so as to recover energy or material resources from the waste, or so as to render such waste non-hazardous, or less hazardous; safer to transport, store, or dispose of; or amenable for recovery, amenable for storage, or reduced in volume (40 CFR § 260.10).

\subsubsection{Stabilization.}

\subsection{Process Description-}

\subsection{EG\&G Assessment Team Observations/Impressions-}

\subsubsection{Neutralization System.}

\subsection{Process Description-}

\subsection{EG\&G Assessment Team Observations/Impressions-}

6.1.2.3 Land Treatment Units. 40 CFR $\S \S 264$, Subpart M and 265, Subpart M state that an owner or operator who wishes to treat or dispose of hazardous waste in a land treatment unit must 
establish a land treatment program that is designed to ensure that the hazardous constituents placed in or on the treatment zone are degraded, transformed, or immobilized within the treatment zone.

\subsection{Process Description-}

\subsection{EG\&G Assessment Team Observations/Impressions-}

6. 1.2.4 Incineration. An incinerator is defined by RCRA as any enclosed device that: (1) uses controlled flame combustion and neither meets the criteria for classification as a boiler, sludge dryer, or carbon regeneration unit, nor is listed as an industrial furnace; or (2) meets the definition of infrared incinerator or plasma arc incinerator (40 CFR $\S 260.10$ ).

Requirements for the permitting and operation of hazardous waste incinerators are specified in 40 CFR $\S \S 264$, Subpart O; 265, Subpart O; and 270.19. Specific requirements for operation of hazardous waste incinerators are delineated in the RCRA Part B Permit Application, Section Part B Permit, Section _and RCRA/HSWA

\subsection{Process Description-}

\subsection{EG\&G Assessment Team Observations/Impressions-}

\section{1.2.4 Fuel Blending.}

\subsection{Process Description-}

\subsection{EG\&G Assessment Team Observations/Impressions-}

6.1.2.6 Industrial Furnace. An industrial furnace is defined by RCRA as including "any of the following enclosed devices that are integral components of manufacturing processes and that use thermal treatment to accomplish recovery of materials or energy:

(1) Cement kilns

(2) Lime kilns

(3) Aggregate kilns

(4) .Phosphate kilns

(5) Coke ovens

(6) Blast furnaces

(7) Smelting, melting, and refining furnaces (including pyrometallurgical devices such as cupolas, reverberator furnces, sintering maching roasters, and foundry furnaces)

(8) Titanium dioxide chloride process oxidation reactors 
(9) Methane reforming furnaces

(10) Pulping liquor recovery furnaces

(11) Combustion devices used in the recovery of sulfur values from spent sulfuric acid

(12) Halogen acid furnaces (HAFs) for the production of acid from halogenated hazardous waste generated by chemcial production facilities where the furnace is located on the site of a chemical procuction facility, the acid product has a halogen acid contennt of at least $3 \%$, the acid procut is used in a manufacturing process, and, except for hazardous waste burned as fuel, hazardous waste fed to the furnace has a minimum halogen content of $20 \%$ as-generated.

(13) Such other devices as the Administrator may, after notice and comment, add to this list on the basis of one or more of the following factors:

(i) The design and use of the device primarily to accomplish recovery of material products;

(ii) The use of the device to burn or reduce raw materials to make a material product;

(iii) The use of the device to burn or reduce secondary materials as effective substitutes for raw materials, in processes using raw materials as principal feedstocks;

(iv) The use of the device to burn or reduce secondary materials as ingredients in an industrial process to make a material product;

(v) The use of the device in common industrial practice to produce a material product; and

(vi) Other factors, as appropriate" (40 CFR $\S 260.10$ ).

\subsection{Process Description-}

\subsection{EG\&G Assessment Team Observations/Impressions-}

\subsubsection{Storage Facilities}

6.1.3.1 Tanks. Requirements for the construction, use, and maintenance of tanks and tank systems used for the storage and treatment of hazardous wastes are specified in 40 CFR $\S 264$, Subpart J and 265, Subpart J. Specific requirements for operation of hazardous waste tank storage are delineated in the RCRA Part B Permit Application, Section and RCRA Part B Permit, Module

\subsection{Process Description-}

\subsection{EG\&G Assessment Team Observations/Impressions-}

6.1.3.2 Containers. The use and management of containers is regulated by 40 CFR $\$ \S 264$, Subpart I and 265, Subpart I. Specific requirements for operation of hazardous waste container storage areas are delineated in the RCRA Part B Permit Application, Section and RCRA Part B Permit, 
Module . This section will describe the use and management of containers as part of the treatment, storage, and disposal of hazardous wastes received in containers at the facility. Use and management of containers of hazardous waste generated by the 90 day accumulation areas, is discussed in Section 6.3 of this document.

\subsection{Process Description- \\ 6.1.3.2.2 EG\&G Assessment Team Observations/Impressions-}

6.1.3.3 Surface Impoundment. Requirements for the construction, use, and maintenance of surface impoundments used for the storage and treatment of hazardous wastes are specified in 40 CFR $\S \S 264$, Subpart K and 265, Subpart K. Specific requirements for construction, maintenance, and operation of a hazardous waste surface impoundment are delineated in the RCRA Part B Permit Application, Section and the Part B Permit, Section

\subsection{Process Description-}

\subsection{EG\&G Assessment Team Observations/Impressions-}

\subsubsection{Disposal Facilities}

6.1.4.1 RCRA Landfill Cells. Requirements for the construction, use, and maintenance of landfill cells used for the disposal of hazardous wastes are specified in 40 CFR §§ 264, Subpart $N$ and 265, Subpart N. Specific requirements for construction, maintenance, operation, and closure of a hazardous waste landfill are delineated in the RCRA Part B Permit Application, Section and the RCRA Part B Permit, Module

6.1.4.1.1 Process Description-The following subsections contain descriptions of the construction of the RCRA landfill cells. Those subsections are followed by the EG\&G observations and impressions of the landfill operations.

\subsection{RCRA Cell Number One-}

\subsection{RCRA Cell Number Two-}

6.1.4.1.1.3 RCRA Cell Number Three-

6.1.4.1.1.4 RCRA Cell Number Four-

6.1.4.1.1.5 RCRA Cell Number Five-

6.1.4.1.1.6 Additional RCRA Cells-

6.1.4.1.2 EG\&G Assessment Team Observations/Impressions- 
6.1.4.2 Industrial Waste Landfill Cells. Requirements for the construction, use, and maintenance of industrial waste landfill cells are specified in 40 CFR $\S 257$. Specific requirements for construction, maintenance, operation, and closure of a hazardous waste landfill are delineated in the RCRA Part B Permit Application, Section and the RCRA Part B Permit, Module

6.1.4.2.1. Process Description-The following subsections contain descriptions of the construction of the industrial waste landfill cells. Those subsections are followed by the EG\&G observations and impressions of the landfill operations.

\subsection{Industrial Cell One-}

6.1.4.2.1.2 Industrial Cell Two-

6.1.4.2.1.3 Industrial Cell Three-

6.1.4.2.2 EG\&G Assessment Team Observations/Impressions-

\subsubsection{Laboratory Operations}

\subsubsection{Process Description.}

\subsection{Chain-of-Custody-}

6.1.5.1.2 Quality Assurance/Quality Control-

6.1.5.1.3 Testing Methods/Procedures-

\subsubsection{EG\&G Assessment Team Observations/Impressions.}

\subsection{Chain-of-Custody-}

\section{1.5.2.2 Quality Assurance/Quality Control-}

\subsection{Testing Methods/Procedures-}

\subsubsection{Security}

The RCRA regulations promulgated at 40 CFR $\S 264.14$ and 265.14 state that "The owner or operator must prevent the unknowing entry, and minimize the possibility for the unauthorized entry, of persons, or livestock onto the active portion of his facility...." The facility must have a 24-hour surveillance system which continuously monitors and controls entry onto the active portion or the facility; or an artificial or natural barrier, which completely surrounds the active portion of the facility. The facility must have a means to control entry, at all times, through gates or other entrances to the facility. It must also have a sign with the legend, "Danger -- Unauthorized Personnel Keep Out" which must be posted at each entrance to the active portion of the facility, and at other locations, in sufficient numbers 
to be seen from any approach to this active portion. The legend must be written in English and in any other language prominent in the area surrounding the facility.

\subsubsection{Process Description.}

\subsubsection{EG\&G Assessment Team Observations/Impressions.}

\subsubsection{Transportation}

Describe compliance with applicable RCRA, TSCA, DOT, ICC, and State transportation regulations.

\subsubsection{Process Description.}

6.1.7.1.1 Driver's Training/Certification-

6.1.7.1.2 Inspections-

6.1.7.1.3 Load Verification and Placarding-

6.1.7.1.4 Manifest System and Recordkeeping-

6.1.7.1.5 Permits-

6.1.7.1.6 Spill Prevention and Cleanup Procedures-

6.1.7.1.7 Insurance-

6.1.7.1.8 Truck Wash-

6.1.7.2 EG\&G Assessment Team Observations/Impressions.

6.1.7.2.1 Driver's Training/Certification-

6.1 7.2.2 Inspections-

6. 1.7.2.3 Load Verification and Placarding-

6.1 7.2.4 Manifest System and Recordkeeping-

6.1 7.2.5 Permits-

6.1.7.2.6 Spill Prevention and Cleanup Procedures-

6.1.7.2.7 Inșurance-

6.1.7.2.8 Truck Wash- 


\subsubsection{Waste Analysis and Tracking.System}

The RCRA regulations promulgated at 40 CFR $\$ \S 264.13$ (a) and 265.13(a) requires the owner or operator of a TSDF to "obtain a detailed chemical and physical analysis of a representative sample of the wastes" which the facility will treat, store, or dispose. The waste analysis must be conducted according to a prepared WAP as according to 40 CFR $\S \S 264.13(\mathrm{~b})$ and $265.13(\mathrm{~b})$. In addition, $40 \mathrm{CFR} \S \S$ 264.73(b) and 265.73(b) require the owner or operator of a TSDF to maintain information in the facility operating record which tracks the types and quantities of wastes received, and the method(s) and date(s) of its treatment.

How is the waste analysis plan implemented. How are waste tracked from receipt to grave.

\subsubsection{Process Description.}

\section{6:1.8.2 EG\&G Assessment Team Observations/Impressions.}

\subsection{Generator Waste Description}

Describe what wastes are present including those generated by the facility. Again detail impressions of the wastes etc.

\subsubsection{Process Description}

\subsubsection{EG\&G Assessment Team Observations/Impressions}

\subsection{Generator Waste Management}

Describe the management of facility generated wastes, e.g., SAA's, 90 day areas, etc. and the management of wastes in tanks and containers. Detail impressions of the management of these materials. Compliance with permit conditions and regulations.

\subsubsection{Less Than 90 Day Accumulation}

A generator may accumulate hazardous wastes on site for 90 day or less without a permit or having interim status provided he meets the regulatory requirements specified by 40 CFR $\S 262.34(b, c)$.

\subsubsection{Process Description.}

\subsubsection{EG\&G Assessment Team Observations/Impressions.}

\subsubsection{Satellite Accumulation Areas}

A generator may accumulate as much as 55 gallons of hazardous wastes or one quart of acutely hazardous wastes as listed in 40 CFR $\$ 261.33(\mathrm{e})$ in containers at or near the point of generation where the wastes initially accumulate, which is under the control of the operator of the process generating the 
waste, without a permit or having interim status provided he meets the regulatory requirements specified by 40 CFR $\S 262.34(\mathrm{c})$.

\subsubsection{Process Description.}

\subsubsection{EG\&G Assessment Team Observations/Impressions.}

\subsection{Regulatory Compliance/Violations History}

Detail violations from NOV's. Describe RCRA or CERCLA remediation actions which the facility is involved in, onsite and superfund clean up elsewhere.

Impressions: Look for repeat violations in NOV's, compare present operations with previous violations. Look for patterns. Describe opinions of remedial efforts.

Information for this section can be obtained from LEXIS/NEXIS database queries, SEC-10K's, annual reports, NOV/CO's, RCRA Part B Permits.

\subsubsection{Violations History}

\subsubsection{Summary of Violations.}

6.4.1.2 EG\&G Assessment Team Observations/Impressions.

\subsubsection{RCRA Remediation/Corrective Actions}

\subsubsection{Description of Actions.}

6.4.2.2 EG\&G Assessment Team Observations/Impressions.

\subsubsection{CERCLA Remediation/Corrective Actions}

\subsubsection{Description of Actions.}

6.4.3.2 EG\&G Assessment Team Observations/Impressions.

\subsubsection{Pending Litigation}

\subsubsection{Description of Actions.}

6.4.4.1 EG\&G Assessment Team Observations/Impressions.

6.4.5 Involvement at "Superfund" Sites

6.4.5.1 Description of Actions. 


\subsubsection{EG\&G Assessment Team Observations/Impressions.}

\subsection{Environmental Incidents}

Describe any historical incidents, e.g., fires, reportable spills. If you saw any present problems, describe. Impressions of operations with respect to potential for incidents. Are they operating in a environmentally safe manner.

\subsubsection{Summary of Incidents}

\subsubsection{EG\&G Assessment Team Observations/Impressions}

\subsection{Facility Management Attitudes}

Describe facility operations with respect to each set of requirements. Describe impressions of the level of compliance with regulatory requirements. Add details, e.g., adequate aisle space, what is the aisle spacing: 4'? Much detail. The purpose of this section is to describe the programs and the implementation of the programs, not to review the content of the documents. That occurs in section 6.7.

\subsubsection{Contingency Plan}

The RCRA regulations promulgated at 40 CFR $\S \S 264$, Subpart D and 265, Subpart D require that the owners and operators of all hazardous waste facilities prepare and implement a contingency plan for the facility. This plan is designed to minimize hazards to human health or the environment from fires, explosions, or any unplanned sudden or non-sudden release of hazardous waste or hazardous waste constituents to the air, soil, or surface water.

\subsubsection{Process Description.}

\subsubsection{EG\&G Assessment Team Observations/Impressions.}

\subsubsection{Employee Training Program}

The RCRA regulations promulgated at $40 \mathrm{CFR} \S \S 264.16$ (a) and 265.16(a) state that "Facility personnel must complete a program of classroom instruction or on-the-job training that teaches them to perform their duties in a way that ensures the facility's compliance with the requirements of this part [ 40 CFR 264]...."

\subsubsection{Process Description.}

\subsubsection{EG\&G Assessment Team Observations/Impressions.}

\subsubsection{Inspections}

The RCRA regulations promulgated at 40 CFR $\S \S 264.15$ (a) and 265.15(a) state that "The owner or operator must inspect his facility for malfunctions and deterioration, operator errors, and discharges 
which may be causing - or may lead to - (1) releases of hazardous waste constituents to the environment . or (2) a threat to human health."

\subsubsection{Process Description.}

\subsubsection{EG\&G Assessment Team Observations/Impressions.}

\subsubsection{Occupational Safety}

The OSHA regulations promulgated at 29 CFR 1910.120(p) require that employers conducting operations at a TSDF have a safety program and a medical surveillance program.

6.6.4.1 Safety Program. Requirements for the OSHA safety program are specified in 29 CFR $\S \S 1910.120(b)$ and $1910.120(p)(1)$.

\subsection{Process Descriprion-}

\subsection{EG\&G Assessment Team Observations/Impressions-}

6.6.4.2 Medical Surveillance. Requirements for the medical surveillance program are specified in 29 CFR $\S \S 1910.120(f)$ and $1910.120(p)(3)$.

\subsection{Process Description-}

\subsection{EG\&G Assessment Team Observations/Impressions-}

\subsubsection{Preparedness and Prevention}

The RCRA regulations promulgated at 40 CFR $\S \S 264$, Subpart C and 265 , Subpart C specify requirements for the design and operation of the facility, required equipment, testing and maintenance of equipment, access to communications or alarm system, required aisle space, and arrangements with local authorities for owners and operators of all hazardous waste facilities, unless they meet the exemptions specified in 40 CFR $\$ \S 264.1$ or 265.1 . The requirements are stated and EG\&G observations of the facility and its operations are discussed as follows:

6.6.5.1 Design and Operation of Facility. 40 CFR $\$ \S 264.31$ and 265.31 state that "Facilities must be designed, constructed, maintained and operated to minimize the possibility of a fire, explosion, or any unplanned sudden or non-sudden release of hazardous waste or hazardous waste constituents to air, soil, or surface water which could threaten human health or the environment."

\subsection{Process Description-}

\subsection{EG\&G Assessment Team Observations/Impressions-}


6.6.5.2 Required Equipment. 40 CFR $\S \S 264.32$ and 265.32 state that the facilities must be equipped with the following equipment: internal communications or alarm system, telephone or two-way radio, portable fire extinguishers, and water at adequate volume and pressure.

\subsection{Process Description-}

\subsection{EG\&G Assessment Team Observations/Impressions-}

6.6.5.3 Testing and Maintenance of Equipment. $40 \mathrm{CFR} \$ \$ 264.33$ and 265.33 state that "All facility communications or alarm systems, fire protection equipment, spill control equipment, and decontamination equipment, where required, must be tested and maintained as necessary to assure its proper operation in time of emergency."

\subsection{Process Description-}

\subsection{EG\&G Assessment Team Observations/Impressions-}

6.6.5.4 Access to Communications or Alarm Systems. 40 CFR $\$ \S 264.34$ and 265.34 state that whenever hazardous waste is being poured, mixed, spread, or otherwise handled, all personnel involved in the operation must have immediate access to an internal alarm or emergency communication device,.... In addition if there is ever just one employee on the premises while the facility is operating, he must have immediate access to a device, such as a telephone,....

\subsection{Process Description-}

\subsection{EG\&G Assessment Team Observations/Impressions-}

6.6.5.5 Required Aisle Space. 40 CFR $\S \S 264.35$ and 265.35 state that "The owner or operator must maintain aisle space to allow the unobstructed movement of personnel, fire protection equipment, spill control equipment, and decontamination equipment to any area of facility operation in an emergency, unless it can be demonstrated to the Regional Administrator that aisle space is not needed for any of these purposes."

\subsection{Process Description-}

\subsection{EG\&G Assessment Team Observations/Impressions-}

6.6.5.6 Arrangements with Local Authorities. 40 CFR $\S 264.37$ and 265.37 state that the owner or operator must make arrangements with local emergency authorities and State emergency response teams to familiarize them with the layout of the TSDF, the hazardous waste handled there, and the emergency plans. In addition the owner or operator must document the arrangements or the refusal of such arrangements. The documentation must be part of the operating record.

\subsection{Process Description--}

\subsection{EG\&G Assessment Team Observations/Impressions-}




\subsection{Document Review}

Review all documents with respect to regulatory requirements. Do they meet the intent of the regulations. Are all pertinent sections with details present. Add sections as necessary for documents not listed, e.g., SPCC Plans. If a section is not applicable, state why.

\subsubsection{RCRA Part A/B Permit Application}

\subsubsection{Part A Permit Application.}

6.7.1.2 Part B Permit Application. The facility Part B Permit Application was reviewed with respect to the regulatory requirements specified in 40 CFR $\$ 270$ and 264.

6.7.1.2.1 General Requirements-40 CFR $\S 270.14$ specifies the general information requirements for a Part B Permit. This information is required for all hazardous waste management (HWM) facilities, unless 40 CFR $\S 264.1$ specifies otherwise. The following information is required:

(1) A general description of the facility.

(2) Chemical and physical analysis of the hazardous wastes to be handled at the facility.

(3) A copy of the waste analysis plan required by 40 CFR \& 264.13.

(4) A description of the security procedures and equipment required by 40 CFR $\$ 264.14$.

(5) A copy of the general inspection schedule required by 40 CFR \& 264.15(b)

(6) A justification of any request for a waiver(s) of the preparedness and prevention requirements of 40 CFR 264 Subpart C.

(7) A copy of the contingency plan required by 40 CFR 264 Subpart D.

(8) A description of the procedures, structures, or equipment used at the facility to prevent hazards.

(9) A description of prevent accidental ignition or reaction of ignitable, reactive, or incompatible wastes (40 CFR § 264.17).

(10) Traffic pattems, estimated volumes, and controls.

(11) Facility location information, including:

- Political jurisdiction

- Compliance with the seismic standard (40 CFR 264, Appendix VI)

- Identification as to whether or not the facility is located within the 100 -year flood plain

(12) An outline of both the introductory and continuing training programs.

(13) A copy of the closure plan.

(14) For hazardous waste disposal units that have been closed, documentation that notices required under 40 CFR \& 264.119 have been filed.

(15) The most recent closure cost estimate for the facility prepared in accordance with 40 CFR $\$ 264.142$ and a copy of documentation required to demonstrate financial assurance under 40 CFR \& 264.143.

(16) Where applicable, the most recent post-closure cost estimate for the facility prepared in accordance with $40 \mathrm{CFR} \&$ 264.144 plus a copy of documentation required to demonstrate financial assurance under 40 CFR \& 264.145.

(17) Where applicable, a copy of the insurance policy or other documentation which comprises compliance with 40 CFR $\$ 264.147$.

(18) Where appropriate, proof of coverage by a State financial mechanism in compliance with 40 CFR $\$ \$ 264.149$ or 264.150 .

(19) A topographic map meeting the informational requirements of 40 CFR $\$ 270.14(\mathrm{~b})(19)$, including:

- Map scale and date

- 100-year floodplain area

- Surface waters including intermittent streams

- Surrounding land use (residential, commercial, agricultural, recreational)

- Wind rose, i.e., prevailing wind speed and direction

- Orientation of the map (north arrow) 
- Legal boundaries of the HWM facility site

- Access control (fences, gates)

- Injection and withdrawal wells both on-site and off-site

- Buildings; TSD operations, or other structures

- Barriers for drainage or flood control

- Location of operational units within the HWM facility site.

The RCRA Part B Permit Application was reviewed with respect to the above specified requirements. Table 6 identifies the sections of the permit application which address each of the applicable requirements.

Table 6. Comparison of the Part B Permit Application with regulatory requirements.

\begin{tabular}{|c|c|c|c|}
\hline Regulatory requirement & Permit application section & Regulatory requirement & Permit application section \\
\hline 40 CFR 270.14(b)(1) & & 40 CFR 270.14(b)(11) & \\
\hline 40 CFR 270.14(b)(2) & & 40 CFR 270.14(b)(12) & \\
\hline 40 CFR $270.14(b)(3)$ & & 40 CFR 270.14(b)(13) & \\
\hline 40 CFR $270.14(b)(4)$ & & 40 CFR 270.14(b)(14) & \\
\hline 40 CFR 270.14(b)(5) & & 40 CFR 270.14(b)(15) & \\
\hline 40 CFR $270.14(b)(6)$ & & 40 CFR $270.14(b)(16)$ & \\
\hline 40 CFR 270.14(b)(7) & & 40 CFR 270.14(b)(17) & \\
\hline 40 CFR $270.14(b)(8)$ & & 40 CFR 270.14(b)(18) & \\
\hline 40 CFR 270.14(b)(9) & & 40 CFR 270.14(b)(19) & \\
\hline 40 CFR $270.14(b)(10)$ & & & \\
\hline
\end{tabular}

6.7.1.2.2 Groundwater Monitoring-40 CFR §270.14(c) contains additional informational requirements regarding the protection of groundwater if the facility requesting the permit contains a regulated unit, unless that unit meets the requirements of 40 CFR $\S 264.90(\mathrm{~b})$.

6.7.1.2.3 Solid Waste Management Units-40 CFR § 270.14(d) describes information requirements regarding solid waste management units (SWMUs) at a facility seeking a permit.

6.7.1.2.4 Storage in Containers - 40 CFR $\S 270.15$ specifies information that owners and operators of facilities that store containers of hazardous waste must supply in the Part B Permit Application except as otherwise provided in 40 CFR $§ 264.170$. 
6.7.1.2.5 Treatment and Storage in Tanks-40 CFR $\$ 270.16$ specifies information that owners and operators of facilities that use tanks to store or treat hazardous waste must supply in the Part B Permit Application except as otherwise provided in 40 CFR $\S 264.190$.

6.7.1.2.6 Surface Impoundment $-40 \mathrm{CFR} \S 270.17$ specifies.information that owners and operators of facilities that store, treat, or dispose of hazardous waste in surface impoundments must supply in the Part B Permit Application except as otherwise provided in 40 CFR $§ 264.1$.

6.7. 1.2.7 Waste Piles-40 CFR $\$ 270.18$ specifies information that owners and operators of facilities that store or treat hazardous waste in waste piles must supply in the Part B Permit Application except as otherwise provided in 40 CFR $\$ 264.1$.

6.7. 1.2.8 Incineration-40 CFR § 270.19 specifies information that owners and operators of facilities that incinerate hazardous waste must supply in the Part B Permit Application except as otherwise provided in 40 CFR $\$ 264.340$.

6.7.1.2.9 Land Treatment Units-40 CFR $\$ 270.20$ specifies information that owners and operators of facilities that dispose of hazardous waste in land treatment units must supply in the Part B Permit Application except as otherwise provided in 40 CFR $\S 264.1$.

6.7. 1.2.10 Landfills - 40 CFR $\$ 270.21$ specifies information that owners and operators of facilities that dispose of hazardous waste in landfills must supply in the Part B Permit Application except as otherwise provided in 40 CFR $\$ 264.1$.

6.7. 1.2.11 Drip Pads-40 CFR $\S 270.22$ specifies information that owners and operators of facilities that collect, store, or treat hazardous waste on drip pads must supply in the Part B Permit Application except as otherwise provided in 40 CFR $\S 264.1$.

6.7:1.2.12 Miscellaneous Units-40 CFR $\S 270.23$ specifies information that owners and operators of facilities that treat, store, or dispose of hazardous waste in miscellaneous units must supply in the Part B Permit Application except as otherwise provided in 40 CFR $\S 264.600$. 
6.7.1.2.13 Process Vents-40 CFR $\S 270.24$ specifies information that owners and operators of facilities that have process vents to which 40 CFR $\S 264$, Subpart AA applies must supply in the Part B Permit Application except as otherwise provided in 40 CFR $\$ 264.1$.

6.7.1.2.14 Equipment Leaks-40 CFR $\S 270.25$ specifies information that owners and operators of facilities that have equipment to which 40 CFR $\S 264$, Subpart BB applies must supply in the Part B Permit Application except as otherwise provided in 40 CFR § 264.1.

\subsubsection{RCRA Part B Permit}

\subsubsection{RCRA Part B Permit.}

\subsubsection{RCRA/HSWA Part B Permit.}

\subsubsection{Annual Hazardous Waste/Biennial Report}

The RCRA Sections 3002, 3004, and 3007, as promulgated by 40 CFR $\S \S 264.75$ and 265.75 , require owners or operators of a TSDF to prepare and submit a single copy of a biennial report to the Regional Administrator (the State of in this case) by March 1 of each even numbered year. Regulations promulgated at 40 CFR $\S 262.41$ require the same of hazardous waste generators. The purpose of the report is to provide the EPA with information that will be used to facility waste capacity studies, waste tracking, and assessment of waste minimization activities, and to support State hazardous waste programs (EPA, p. 1).

The Biennial Report was obtained from . It was the most recent report available at this time. It was submitted to the State of on 19. The report was reviewed with respect to the requirements specified in 40 CFR $\S \S \overline{262.41}, 264.75$ and 265.75 and the EPA 1989 Hazardous Waste Report Instructions and Forms.

\subsubsection{Closure/Post-Closure Plan}

The RCRA regulations promulgated at 40 CFR $\S 264$ Subpart G, Section 112 and 265 Subpart G, Section 112 require that the owner or operator of a hazardous waste management facility have a written closure plan. The approved closure plan must become a condition of any RCRA permit.

\subsubsection{Emergency Response/Contingency Plan}

The RCRA regulations promulgated at 40 CFR $\S \S 264$, Subpart D and 265, Subpart D require the owners and operators of all hazardous waste facilities to have a contingency plan for the facility. The contingency plan must be designed to minimize hazards to human health or the environment from fires, 
explosions, or any unplanned sudden or non-sudden release of hazardous waste or hazardous waste to air, soil, or surface water.

\subsubsection{Facility Construction Plans}

\subsubsection{Hazardous Waste Manifests}

The RCRA regulations promulgated at 40 CFR $\S \S 264$, Subpart E and 265, Subpart E specify the requirements for the TSDF manifest system, as well as, general record keeping and reporting. 40 CFR $\S 262$, Subpart D specifies the requirements for a generator's manifest system, as well as, general record keeping and reporting. The EG\&G Assessment Team reviewed __ manifests with respect to the requirements of 40 CFR $\S \S 262$, Subpart D; $264.71 ; 264.72 ; 265.71 ;$ and 265.72.

\subsubsection{Operations Record}

The RCRA regulations promulgated at $40 \mathrm{CFR} \S \S 264.73$ and 265.73 state that the owner or operator must keep a written operating record at his facility. The information specified by this section

must be kept as part of the operating record until closure of the facility. The only exception to the "lifetime retention" requirement is that inspection records need only be kept three years.

Where is it located, what's in it, how is it managed.

\subsubsection{SARA Reports}

The primary purpose of SARA Title III is to inform the public of the presence of toxic chemicals in their communities. The following sections describe the basic SARA reporting requirements. In every case, even though a facility may not appear to be subject to the requirements based on the qualifying criteria, the State Emergency Response Commission (SERC) may require the facility to file.

Compliance with the various SARA regulatory requirements was discussed in some detail with the facility representatives while developing the Audit Master ${ }^{\mathrm{rx}}$ checklists.

6.7.9.1 SARA Section 311 MSDS Reporting. Under 40 CFR Part 370, all employers are required to inform state and local emergency response groups, and local fire departments of their inventories of hazardous chemicals. Two major reporting requirements are imposed: material safety data sheets (MSDSs) or equivalent lists must be submitted for hazardous chemicals present above certain threshold levels, and an inventory report must be submitted for these chemicals on an annual basis.

Facilities that are subject to the MSDS requirements of OSHA's Hazard Communication Standard (HCS) must submit copies of their MSDSs, or equivalent list, to the appropriate local emergency planning committee (LEPC), SERC, and local fire department. This material must be submitted by October 17, 
1990 , or three months after a facility is required to have an MSDS under the OSHA regulations, whichever is later.

6.7.9.2. SARA Section 312 Tier I and/or Tier II Report. The hazardous chemical inventory requirements of SARA Title III Sections 311 and 312 cut across two federal programs: the HCS administered by OSHA and the Title III program administered by EPA.

Facilities that are required to submit MSDSs are also required to submit an annual inventory form containing:

- an estimate of the maximum amount of each hazardous chemical present at the facility at any one time during the previous calendar year,

- an estimate of the average daily amount of each hazardous chemical at the facility, and

- the location of these chemicals at the facility.

These inventories may be submitted on either the Tier I or Tier II Forms. The annual inventory must be submitted by March 1 for chemicals at the facility for the preceding year.

6.7.9.3 SARA 313 Form $R$ Report. Section 313 of SARA Title III requires EPA to create an annual inventory of toxic chemical emissions that occur as a result of normal business operations.

Four basic criteria are used to determine if a facility is subject to the reporting requirements:

: The facility must manufacture, import, process, or otherwise use one or more of the approximately 330 chemicals listed in 40 CFR $\$ 372.65$;

- The facility must have more than 10 full-time employees;

- The facility must have a primary SIC code between 20 and 39; and

- The quantity of chemical used, manufactured, imported or processed must exceed certain threshold levels that range from 10,000 pounds per year to 25,000 pounds per year. operates within SIC codes 29 to 39 ( ), has more than 10 employees, and uses hazardous chemicals in quantities above the threshold planning quantities.

6.7.9.4 SARA Section 302 and 304 Emergency Planning and Notification. Under the SARA regulations promulgated at 40 CFR 355, a regulated facility must notify its respective state emergency response commission, and report any releases of prescribed materials in designated quantities. 
The facility must also designate an emergency coordinator, and inform the local emergency planning committee of the designations. These notifications are to occur by specified dates.

\subsubsection{Sample Analysis Plan}

\subsubsection{Spill Prevention Control and Countermeasures Plan}

The CWA regulations promulgated at 40 CFR $\S 112$ require owners or operators of nontransportation-related on-shore and offshore facilities engaged in drilling, producing, gathering, storing, processing, refining, transferring, distributing, or consuming oil and oil products, and which, due to their location, could reasonably be expected to discharge oil in harmful quantities, as defined in 40 CFR 110 , into or upon the navigable waters of the United States or adjoining shorelines to prepare and maintain a Spill Prevention Control and Countermeasures (SPCC) Plan.

40 CFR $\S \S 112.3,264.52$ (b), and 265.52 (b) require that the owner operators of a facility for which a SPCC Plan is required maintain a copy at the plant if the facility is normally attended at least eight hours per day and make copies available to the Regional Administrator for onsite review during normal working hours. 40 CFR $\S 112.7$ provides additional guidelines for preparation and implementation of a SPCC Plan. This becomes applicable if there has been one or more spill from the facility in the last twelve months, where experience indicates there is a reasonable potential for equipment failure (such as a tank overflow, rupture, or leakage), secondary containment has failed or there is a potential of such.

The TSCA regulations promulgated at 40 CFR $\$ \S 761.65$ (c)(1)(iv) and 761.65 (c)(7)(ii) require the owner/operator of a facility that stores liquid PCB's at a concentration between 50 and 500 ppm, for disposal develop a Spill Prevention Control and Countermeasures (SPCC) Plan. The definition of "oil" for the purposes of the SPCC plan is "PCBs" and the contents of the plan must be in accordance with 40 CFR 112. 


\begin{tabular}{|c|c|c|c|}
\hline Regulatory Requirement & $\begin{array}{l}\text { SPCC Plan } \\
\text { Section }\end{array}$ & Regulatory Requirement & $\begin{array}{l}\text { SPCC Plan } \\
\text { Section }\end{array}$ \\
\hline Past Spill Occurrences 40 CFR \& 112.7(a) & & $\begin{array}{l}\text { Oil Production Facilities (Onshore) } 40 \\
\text { CFR \& 112.7(e)(5) }\end{array}$ & \\
\hline Potential Spill Occurrences 40 CFR \& 112.7(b) & & $\begin{array}{l}\text { Oil Drilling and Workover Facilities } 40 \\
\text { CFR \& 112.7(e)(6) }\end{array}$ & \\
\hline $\begin{array}{l}\text { Containment and Diversionary Structures } 40 \\
\text { CFR \& } 112.7 \text { (c) }\end{array}$ & & $\begin{array}{l}\text { Oil Drilling, Production or Workover } \\
\text { Facilities (Offshore) } 40 \text { CFR \& } \\
112.7(e)(7)\end{array}$ & \\
\hline Facility Drainage 40 CFR \& 112.7(e)(1) & & $\begin{array}{l}\text { Inspection and Records } 40 \text { CFR \& } \\
112.7(\mathrm{e})(8)\end{array}$ & \\
\hline $\begin{array}{l}\text { Bulk Storage Tanks Potentially Used for Fuels } \\
\text { and Oils } 40 \text { CFR \& } 112.7(e)(2)\end{array}$ & & Security 40 CFR \& 270.14(b)(15) & \\
\hline $\begin{array}{l}\text { Facility Transfer Operations } 40 \text { CFR \& } \\
112.7(\text { e)(3) }\end{array}$ & & $\begin{array}{l}\text { Personnel, Training and Spill Prevention } \\
\text { Procedures } 40 \text { CFR \& 112.7(e)(10) }\end{array}$ & \\
\hline $\begin{array}{l}\text { Facility Tank Truck Loading/Unloading Station } \\
40 \text { CFR \& 112.7(e)(4) }\end{array}$ & & & \\
\hline
\end{tabular}

\subsubsection{Waste Analysis Plan}

The RCRA regulations promulgated at 40 CFR $\S \S 264.13(4)$ (b) and 265.13(4)(b) require the owner/operator of a TSDF to develop and follow a written waste analysis plan which describes the procedures which he will carry out to comply with in order to obtain a detailed chemical and physical analysis of a representative sample of a waste for treatment, storage, or disposal. This plan must also be kept at the facility. The regulation then proceeds with a description of the requirements for the plan.

In addition, 40 CFR $\S 268.7$ (a)(4) requires a generator who is managing a land disposal prohibited waste in tanks, containers, or containment buildings regulated under 40 CFR $\S 262.34$, and who is treating such waste in such tanks, containers, or containment buildings to meet applicable treatment standards under 40 CFR $\S 268$, Subpart D. The generator must also develop and follow a written waste analysis plan which describes the procedures the generator will carry out to comply with the treatment standards. This plan must be kept on site in the generator's records.

\subsubsection{Waste Minimization Certification/Plan}

The RCRA regulations promulgated at $40 \mathrm{CFR} \S 264.73$ (b)(9) require the owner/operator of a TSDF to certify on at least an annual basis that they have a program in place to reduce the volume and toxicity of hazardous waste that he generates to the degree determined by the permittee to be economically practicable; and the proposed method of treatments, storage, or disposal that is the 
practicable method currently available to the permittee which minimizes the present and future threat to human health and the environment.

\subsubsection{Groundwater Monitoring Plan}

The RCRA regulations promulgated at 40 CFR $\$ \S 264$, Subpart F and 265, Subpart F require that owners and operators of solid waste management units, surface impoundments, landfills, and land treatment units comply with the monitoring requirements of the subpart. 40 CFR §§ 264.97 and 265.97 specify the general groundwater monitoring requirements.

\subsubsection{Wastewater Monitoring Reports}

\subsubsection{TSCA Storage/Disposal Approval}

\subsubsection{CERCLA Off-Site Policy Approval}

6.7.18 Radioactive Materials License

\subsection{Environmental Monitoring Programs}

Described the programs, requirements, sources.

\subsubsection{Air Monitoring}

\subsubsection{Process Description.}

6.8.1.2 EG\&G Assessment Team Observations/Impressions.

\subsubsection{Groundwater Monitoring}

\subsubsection{Process Description.}

6.8.2.2 EG\&G Assessment Team Observations/Impressions. 


\section{FINANCIAL STRENGTH}

The purpose of this section is to provide documentation verifying __ 's abilities to respond quickly to environmental, safety, and health incidents, to provide adequate financial assurances for facility closure costs, and to maintain financial assurances for any potential litigation.

\subsection{Insurance}

40 CFR §§ 264.147 and 265.147 require an owner or operator of a hazardous waste treatment, storage, or disposal facility, or a group of such facilities, to maintain liability insurance. In particular, 40 CFR $\S \S 264.147$ (a) and 265.147(a) require the owner or operator to maintain coverage for sudden accidental occurrences arising from operations of the facility or group of facilities. (A sudden accidental occurrence is defined as "an occurrence which is not continuous or repeated in nature" (40 CFR $264.140(\mathrm{~g}))$.) The owner or operator must have and maintain liability coverage for sudden accidental occurrences in the amount of at least $\$ 1$ million per occurrence with an annual aggregate of at least $\$ 2$ million, exclusive of legal defenses. The regulations specify the methods which the owner or operator may use in order to demonstrate the liability coverage.

40 CFR $\S \S 264.147(b)$ and 265.147 (b) require the owner or operator of a surface impoundment, landfill, or land treatment facility which is used to manage hazardous waste, or a group of such facilities, to maintain coverage for nonsudden accidental occurrences arising from operations of the facility or group of facilities. (A nonsudden accidental occurrence is defined as "an occurrence which takes place over time and involves continuous or repeated exposure" (40 CFR 264.140(g)).) The owner or operator must have and maintain liability coverage for nonsudden accidental occurrences in the amount of at least $\$ 3$ million per occurrence with an annual aggregate of at least $\$ 6$ million, exclusive of legal defenses. The owner or operator who must meet the requirements of this section may combine the sudden and nonsudden accidental coverages into a single per-occurrence level and combine the required annual aggregate coverage levels for sudden and nonsudden accidental coverages into a single annual level. Owners or operators who combine coverage levels must maintain liability coverage in at least $\$ 4$ million per occurrence and at least $\$ 8$ million annual aggregate. The regulations specify the methods which the owner or operator may use in order to demonstrate the liability coverage.

\section{Describe insurance coverage and provide certificate as a figure in this report.}

\subsection{Closure and Post-Closure Care}

40 CFR $\S \S 264.142$ and 265.142 require an owner or operator to have a detailed written estimate, in current dollars, for the cost of closing the facility in accordance with the requirements in $\S \$ 264.111$ through 264.115 and/or 265.111 through 265.115 and applicable closure requirements in $\$ \S 264.178$ and/or 265.178 (containers), 264.197 and/or 265.197 (tanks), 264.228 and/or 265.228 (surface impoundments), 264.258 and/or 265.258 (waste piles), 264.280 and/or 265.280 (land treatment units), 264.310 and/or 265.310 (landfills), 264.351 and/or 265.351 (incinerators), and 264.601 through 264.603 and/or 265.601 through 265.603 (miscellaneous units).

In addition the regulations (40 CFR $\$ \$ 264.142(b)$ and $265.142(b)$ ) specify that during the active life of the facility the owner or operator must adjust the closure cost estimate for inflation within 60 day 
prior to the anniversary date of the establishment of the financial instrument(s) used to comply with $\S$. 264.143 and 265.143.

Describe coverage and annual adjustments. Compare with regulatory requirements.

\subsection{Financial Assurance}

There are six different methods allowed by the RCRA rules to guarantee closure costs ( 40 CFR $\S \S$ 264.146 and/or 265.146):

- Closure Trust Fund [40 CFR $\$ \S 264.143(a)$ and/or 265.143(a)]

- Surety Bond for payment into a Trust Fund [40 CFR §§ 264.143(b) and/or 265.143(b)]

- $\quad$ Performance Surety Bond [40 CFR $\$ \$ 264.143(c)$ and/or 265.143(c)]

- Closure Letter of Credit [40 CFR $\$ \S 264.143(d)$ and/or 265.143(d)]

- Closure Insurance [40 CFR $\S \S 264.143(\mathrm{e})$ and/or 265.143(e)]

- Financial Test and/or Corporate Guarantee [40 CFR \$§ 264.143(f) and/or 265.143(f)]

Describe coverage and annual adjustments. Compare with regulatory requirements.

\subsection{History and Experience of Owners}

Describe the history of the company, its parents, and its experience in the field under consideration.

\subsection{Capacity and Capital of the Company}

This section is generally completed by financial analysts. It requires analysis of D\&B reports, SEC $10 K$, and company annual reports. This information should be compared with the closure requirements for adequacy.

Table ??. Financial Ratios for

\begin{tabular}{llll}
\hline TYPE OF RATIO & 1992 & 1991 & 1990 \\
\hline LIQUIDITY RATIOS & & & \\
Current Ratio & & ERR $^{*}$ \\
Acid Test Ratio & & & ERR $^{*}$ \\
Working Capital & $\$$ & $\$$ &
\end{tabular}

EFFICIENCY RATIOS 
Average Collection Period

Inventory Tumover $\quad$ ERR'

$\begin{array}{lc}\text { Fixed Asset Tumover } & \text { ERR* }\end{array}$

$\begin{array}{ll}\text { Total Asset Tumover } & \text { ERR }^{*}\end{array}$

LEVERAGE RATIOS

Debt Ratio

ERR*

Long-Term Debt to Total Capitulation

ERR*

Times Interest Earned

Cash Flow Overall Ratio

PROFITABILITY RATIOS

Gross Profit Margin

Operating Profit Margin

Net Profit Margin

Operating Income Return on Investment

ERR'

Retum on Total Assets

ERR

Return on Common Equity

ERR*

- $E R R=$ No data available 


\title{
8. RISK ASSESSMENT AND SUMMARY OF PERTINENT INFORMATION
}

\begin{abstract}
All off-site commercial treatment, storage, and disposal facilities will present some level of risk to a waste generator. The handling and treatment of hazardous and toxic wastes is by nature fraught with environmental, human health, and regulatory related risks. The purpose of an ESH\&Q liability assessment is to facilitate the proper management of those risks.
\end{abstract}

Evaluate risks based on information reviewed in sections 4-6.

\subsection{Public Health Risks}

\subsection{Environmental Risks}

\subsubsection{Air Quality}

\subsubsection{Surface Water}

\subsubsection{Groundwater}

8.2.4 Spills

\subsection{Financial Risks}

\subsection{Summary of Other Risk-Related Information}

\subsubsection{Violations History}

\subsubsection{Pending Litigation}


8.4.3 Environmental Incidents

8.4.4 Management Attitudes

\subsection{Rating of Facility, Based on Risks and Comparison to Other Similar Operations}




\section{SUMMARY AND CONCLUSIONS}

Summarize and make recommendations. 


\section{REFERENCES}

\subsection{Federal Statutes}

Clean Air Act (as amended) 42 U.S.C. 7401 et seq.

Clean Water Act (Federal Water Pollution Control Act) (as amended) U.S.C. $§ 1251$ et seq.

Comprehensive Environmental Response, Compensation, and Liability Act (as Amended) Title I Hazardous Substances Releases, Liability, Compensation, 42 USC $\$ 9601$ et seq.

Comprehensive Environmental Response, Compensation, and Liability Act (as Amended) Title III Miscellaneous Provisions, 42 USC $\S 9651$ et seq.

Hazardous and Solid Waste Amendments of 1984, Subtitle C, "Hazardous Waste Management,"

Hazardous Materials Safety Act of 1974, (P. L. 93-633).

Hazardous Materials Transportation Act of 1974, (49 USC 1801 et seq).

Safe Drinking Water Act as Amended (42 USC $\$ 300$ et seq.)

Toxic Substances Control Act, as Amended, 42 USC 2601 et seq.

Water Quality Act of 1987 (P. L. 100-4).

\subsection{Code of Federal Regulations}

29 CFR 1910.120, "Hazardous Waste Operations and Emergency Response," Office of the Federal Register, March 1989.

29 CFR 1910.1200, "Hazard Communication," Office of the Federal Register, March 1989.

30 CFR 11, "Respiratory Protective Devices; Tests for Permissibility; Fees," Office of the Federal Register, July 1991.

30 CFR 48, "Training and Retraining of Miners," Office of the Federal Register, July 1991.

30 CFR 56, "Safety and Health Standards-Surface Metal and Nonmetal Mines," Office of the Federal Register, July 1991.

40 CFR 50, "National Primary and Secondary Ambient Air Quality Standards," Office of the Federal Register, July 1994.

40 CFR 60, "Standards of Performance for New Stationary Sources, "Office of the Federal Register, July 1994. 
40 CFR 61, "National Emissions Standards for Hazardous Air Pollutants (NESHAPs),"Office of the Federal Register, July 1994.

40 CFR 110, "Discharge of Oil," Office of the Federal Register, July 1994.

40 CFR 112, "Oil Pollution Prevention," Office of the Federal Register, July 1994.

40 CFR 116, "Designation of Hazardous Substances," Office of the Federal Register, July 1994.

40 CFR 117, "Determination of Reportable Quantities for Hazardous Substances," Office of the Federal Register, July 1994.

40 CFR 122, "EPA Administered Permit Programs: The National Pollutant Discharge Elimination System," Office of the Federal Register, July 1994.

40 CFR 125, "Criteria and Standards for the National Pollutant Discharge Elimination System," Office of the Federal Register, July 1994.

40 CFR 136, "Guidelines Establishing Test Procedures for the Analysis of Pollutants," Office of the Federal Register, July 1994.

40 CFR 141, "National Primary Drinking Water Regulations," Office of the Federal Register, July 1994.

40 CFR 142, "National Primary Drinking Water Regulations Implementation," Office of the Federal Register, July 1994.

40 CFR 143, "National Secondary Drinking Water Regulations," Office of the Federal Register, July 1994.

40 CFR 144, "Underground Injection Control Program," Office of the Federal Register, July 1994.

40 CFR 146, "Underground Injection Control Program: Criteria and Standards," Office of the Federal Register, July 1994.

40 CFR 148, "Hazardous Waste Injection Restrictions," Office of the Federal Register, July 1994.

40 CFR 257; "Criteria for Classification of Solid Waste Disposal Facilities and Practices," Office of the Federal Register, July 1994.

40 CFR 260, "Hazardous Waste Management System - General," Office of the Federal Register, July 1994.

40 CFR 261, "Identification and Listing of Hazardous Waste," Office of the Federal Register, July 1994.

40 CFR 262, "Standards Applicable to Generators of Hazardous Waste," Office of the Federal Register, July 1994. 
40 CFR 263, "Standards Applicable to Transporters of Hazardous Waste, " Office of the Federal Register, July 1994.

40 CFR 264, "Standards for Owners and Operators of Hazardous Waste Treatment, Storage, and Disposal Facilities," Office of the Federal Register, July 1994.

40 CFR 266, "Standards for Management of Specific Hazardous Wastes and Specific Types of Hazardous Waste Management Facilities," Office of the Federal Register, July 1994.

40 CFR 268, "Land Disposal Restrictions," Office of the Federal Register, July 1994.

40 CFR 270, "EPA Administered Permit Programs: The Hazardous Waste Permit Program, " Office of the Federal Register, July 1994.

40 CFR 271, "Requirements for Authorization of State Hazardous Waste Management Programs, " Office of the Federal Register, July 1994.

40 CFR 272, "Approved State Hazardous Waste Management Programs, " Office of the Federal Register, July 1994.

40 CFR 280, "Underground Storage Tanks," Office of the Federal Register, July 1994.

40 CFR 281, "State Programs for Administering the Underground Storage Tank Programs," Office of the Federal Register, July 1994.

40 CFR 761, "Polychlorinated Biphenyls (PCBs) Manufacturing, Processing, Distribution in Commerce, and Use Prohibition," Office of the Federal Register, July 1994.

40 CFR 300, "National Oil and Hazardous Substances Pollution Contingency Plan," Office of the Federal Register, July 1994.

40 CFR 302, "Designation, Reportable Quantities, and Notification," Office of the Federal Register, July 1994.

40 CFR 355, "Emergency Planning and Notification," Office of the Federal Register, July 1994.

40 CFR 370, "Hazardous Chemical Reporting: Community Right-To-Know," Office of the Federal Register, July 1994.

40 CFR 372, "Toxic Chemical Release Reporting: Community Right-To-Know," Office of the Federal Register, July 1994.

40 CFR 401, "General Provisions," Office of the Federal Register, July 1994.

40 CFR 403, "General Pretreatment Regulations for Existing and New Sources of Pollution," Office of the Federal Register, July 1994. 
49 CFR 171, "General Information, Regulations, and Definitions," Office of the Federal Register, July 1994.

49 CFR 172, "Hazardous Materials Table, Special Provisions, Hazardous Materials Communications Requirements and Emergency Response Information," Office of the Federal Register, July 1994.

49 CFR 173, "Shippers - General Requirements for Shipments and Packagings," Office of the Federal Register, October 1994.

49 CFR 177, "Carriage by Public Highway," Office of the Federal Register, October 1994.

49 CFR 178, "Specifications for Packagings," Office of the Federal Register, October 1994.

49 CFR 180, "Continuing Qualification and Maintenance of Packagings," Office of the Federal Register, October 1994.

\subsection{Correspondence}

\subsection{Computer Software}

Air Quality, Federal Version, Audit Master, Version 4.8, Pittsford, New York: Utilicom, 1993.

EPCRA, Federal Version, Audit Master, Version 4.8, Pittsford, New York: Utilicom, 1993.

Hazardous Materials Transportation, Federal Version, Audit Master, Version 4.8, Pittsford, New York: Utilicom, 1993.

Industrial Hygiene, Federal Version, Audit Master, Version 4.8, Pittsford, New York: Utilicom, 1993.

Materials and Equipment Safety, Federal Version, Audit Master, Version 4.8, Pittsford, New York: Utilicom, 1993.

Occupational Medicine, Federal Version, Audit Master, Version 4.8, Pittsford, New York: Utilicom, 1993.

PCB Management, Federal Version, Audit Master, Version 4.8, Pittsford, New York: Utilicom, 1993.

Personnel Safety, Federal Version, Audit Master, Version 4.8, Pittsford, New York: Utilicom, 1993.

Solid and Hazardous Waste, Federal Version, Audit Master, Version 4.8, Pittsford, New York: Utilicom, 1993.

Spill Prevention, Federal Version, Audit Master, Version 4.8, Pittsford, New York: Utilicom, 1993. 
Storage Tanks, Federal Version, Audit Master, Version 4.8, Pittsford, New York: Utilicom, 1993.

Water Quality, Federal Version, Audit Master, Version 4.8, Pittsford, New York: Utilicom, 1993.

10.4 Publications

Examples:

Cahill, Lawrence B. and Raymond W. Kane, Environmental Audits, fth Edition, Rockville, Maryland: Government Institutes, Inc., 1989.

Chronic, Hakka, Roadside Geology of Utah, Missoula, Montana: Mountain Press Publishing Company, 1990.

Union Pacific Corporation, 1989 Annual Report, February 1990.

United States Securities and Exchange Commission, Union Pacific Corporation, Form 10-K, 1989.

47 
This page intentionally left blank 


\section{Appendix A}

\section{Abbreviations and Acronyms}




\section{Appendix A}

\section{Abbreviations and Acronyms}

\begin{tabular}{|c|c|}
\hline ANSI & American National Standards Institute \\
\hline ASTM & American Society for Testing and Materials \\
\hline BLM & United States Department of the Interior, Bureau of Land Management \\
\hline CAA & Clean Air Act \\
\hline $\mathrm{CE}$ & Cost estimate \\
\hline CEG & Conditionally Exempt Small Quantity Generator \\
\hline CERCLA & Comprehensive Environmental Response, Compensation, and Liability Act \\
\hline $\begin{array}{l}\text { CFR } \\
\mathrm{cm} / \mathrm{sec}\end{array}$ & $\begin{array}{l}\text { Code of Federal Regulations } \\
\text { centimeters per second }\end{array}$ \\
\hline CRTK & Community Right-to-Know \\
\hline $\mathrm{CV}$ & Current value \\
\hline CWA & Clean Water Act \\
\hline $\mathrm{D} \& \mathrm{~B}$ & Dun and Bradstreet \\
\hline DOE & United States Department of Energy \\
\hline DOE-ID & United States Department of Energy, Idaho Operations Office \\
\hline DOT & United States Department of Transportation \\
\hline EA & Environmental Assessment \\
\hline EG\&G & EG\&G Idaho, Inc. \\
\hline EIS & Environmental Impact Statement \\
\hline EPA & United States Environmental Protection Agency \\
\hline EPCRA & Emergency Planning and Community Right-to-know Act \\
\hline ES\&H & Environment, Safety, and Health \\
\hline ESH\&Q & Environment, Safety, Health, and Quality \\
\hline ETS & Environmental Technical Support \\
\hline $\mathbf{F}$ & Fahrenheit \\
\hline FOIA & Freedom of Information Act \\
\hline FR & Federal Register \\
\hline $\mathrm{HazCom}$ & Hazard Communication \\
\hline HCS & Hazard Communication Standard \\
\hline HDPE & High Density Polyethylene \\
\hline HMTA & Hazardous Materials Transportation Act \\
\hline HSWA & - Hazardous and Solid Waste Act \\
\hline HWM & Hazardous Waste Management \\
\hline INEL & Idaho National Engineering Laboratory \\
\hline
\end{tabular}


K

LEPC

LTU

LUST

M\&O

$\mathrm{mg} / 1$

MSDS

MSHA

NEPA

NESHAPS

NOD

NON

NOV

NOV/CO

NPDES

NRC

NRC

ORNL

OSHA

PCB

PPE

ppm

RCRA

RFA

RFI

RFP

RFQ

ROD

SAA

SARA

SDWA

SERC

SWMU

TAA

TCLP

TSCA

TSD

TSDF thousand

Local Emergency Planning Committee

Land Treatment Unit

Leaking Underground Storage Tank

Management and Operations

milligrams per litre

Material Safety Data Sheet

Mine Safety and Health Act

National Environmental Policy Act

National Emission Standards for Hazardous Air Pollutants

Notice of Deficiency

Notice of Noncompliance

Notice of Violation

Notice of Violation and Order for Compliance

National Pollutant Discharge Elimination System

National Response Center

Nuclear Regulatory Commission

Oak Ridge National Laboratory

Occupational Safety and Health Act

Polychlorinated Biphenyl

Personal Protective Equipment

parts per million

Resource Conservation and Recovery Act

RCRA Facility Assessment

RCRA Facility Investigation

Request for Proposal

Request for Quotation

Record of Decision

Satellite Accumulation Area

Superfund Amendments and Reauthorization Act

Safe Drinking Water Act

State Emergency Response Commission

Solid Waste Management Unit

Temporary Accumulation Area

- Toxicity Characteristic Leaching Procedure

Toxic Substances Control Act

Treatment, Storage, and Disposal

Treatment, Storage, and Disposal Facility 


$\begin{array}{ll}\text { USC } & \text { United States Code } \\ \text { UST } & \text { Underground Storage Tank } \\ \text { VOC } & \text { Volatile Organic Compound } \\ \text { Y } & \text { Year }\end{array}$


This page intentionally left blank 


\section{Appendix B}

\section{History of Regulatory Violations}


1

B-2 
Appendix B

History of Regulatory Violations 